Göttinger Beiträge zum Alten Orient Band 1

Frauke Weiershäuser

\title{
Die königlichen Frauen der III. Dynastie von Ur
}

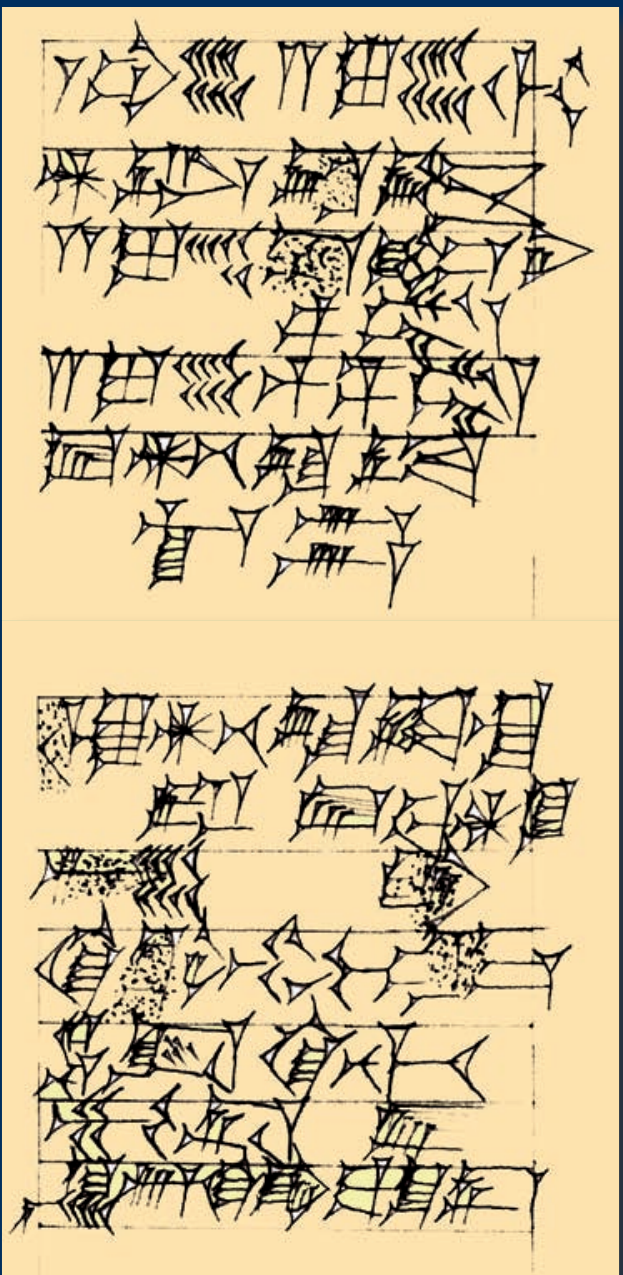

Universitätsverlag Göttingen 

Die königlichen Frauen der III. Dynastie von Ur

This work is licensed under the Creative Commons License 2.0 "by-nc-nd", allowing you to download, distribute and print the document in a few copies for private or educational use, given that the document stays unchanged and the creator is mentioned. Commercial use is not covered by the licence. 
erschienen als Band 1 in der Reihe „Göttinger Beiträge zum Alten Orient“ im Universitätsverlag Göttingen 2008

Früher unter dem Titel „Göttinger Arbeitshefte zur Altorientalischen Literatur“ 
Frauke Weiershäuser

Die königlichen Frauen der

III. Dynastie von Ur

Göttinger Beiträge

zum Alten Orient

Band 1

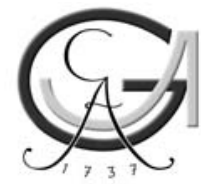

Universitätsverlag Göttingen 2008 


\section{Bibliographische Information der Deutschen Nationalbibliothek}

Die Deutsche Nationalbibliothek verzeichnet diese Publikation in der Deutschen Nationalbibliographie; detaillierte bibliographische Daten sind im Internet über $<$ http://dnb.ddb.de> abrufbar

Anschrift der Herausgeber

Prof. Dr. Brigitte Groneberg

Seminar für Altorientalistik

Georg-August-Universität Göttingen

Weender Landstr. 2

D-37073 Göttingen

Anschrift der Autorin

Frauke Weiershäuser

e-mail: fweiers@gwdg.de

Dieses Buch ist auch als freie Onlineversion über die Homepage des Verlags sowie über den OPAC der Niedersächsischen Staats- und Universitätsbibliothek (http://www.sub.uni-goettingen.de) erreichbar und darf gelesen, heruntergeladen sowie als Privatkopie ausgedruckt werden. Es gelten die Lizenzbestimmungen der Onlineversion. Es ist nicht gestattet, Kopien oder gedruckte Fassungen der freien Onlineversion zu veräußern.

Satz und Layout: Frauke Weiershäuser

Umschlaggestaltung: Margo Bargheer, Maren Büttner

Titelabbildung: Text aus dem Šulgi-simti-Archiv, Kopie Markus Hilgert. Aus: OIP 115, Text 18. Abdruck mit freundlicher Genehmigung des Oriental Institute of the University of Chicago

(C) 2008 Universitätsverlag Göttingen

http://univerlag.uni-goettingen.de

ISBN: 978-3-940344-10-6

ISSN: $1866-2595$ 
Meinen Eltern 



\section{Inhaltsverzeichnis}

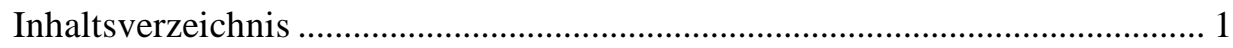

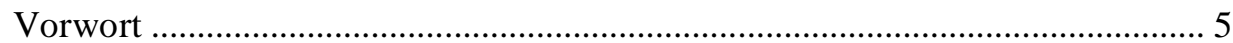

Abkürzungen ........................................................................................... 7

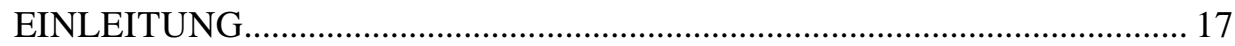

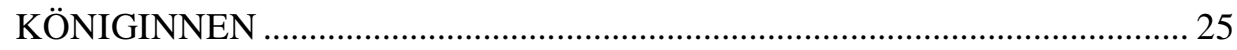

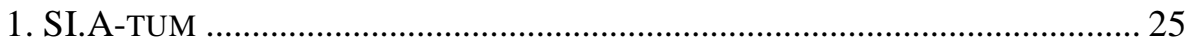

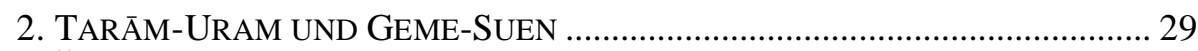

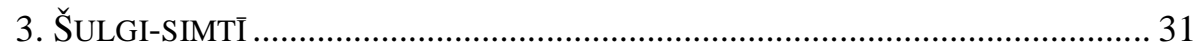

3.1. Die Einordnung des Archives ............................................................ 31

3.2. Von Geme-Suen zu Šulgi-simtī - wer war Königin? ......................... 35

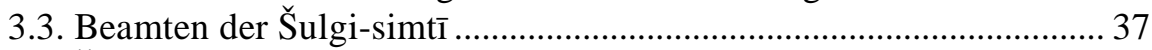

3.4. Šulgi-simtī als Empfängerin von Lieferungen (mu - D U ).................. 41

3.4.1. Was wird geliefert?........................................................................ 41

3.4.2. Wer liefert was und wann? ............................................................ 42

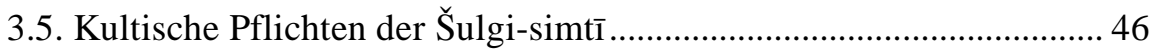

3.5.1. Enlil und Ninlil und der Kult von Nippur ..................................... 49

3.5.2. Monatliche Feiertage ...................................................................... 56

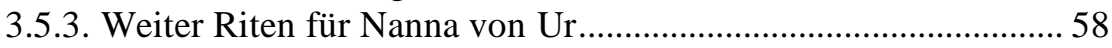

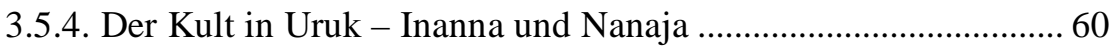

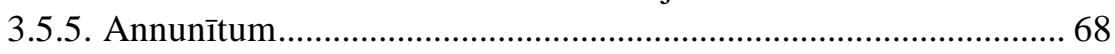

3.5.6. Riten des Bierausschenkens für andere Götter ............................. 72

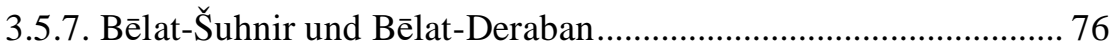

3.5.8. Elūnum und Nabrium .................................................................. 81

3.5.9. Regelmäßige Lieferungen für die persönlichen Göttinnen

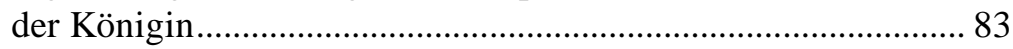

3.5.10. Verschiedene selten belegte Feste und Riten ............................. 84

3.5.11. Übersicht über jährliche Feste und Riten .................................... 91

3.6. Nicht-kultische Ausgaben im Archiv der Šulgi-simtī........................... 94

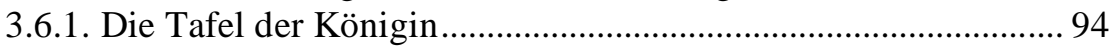

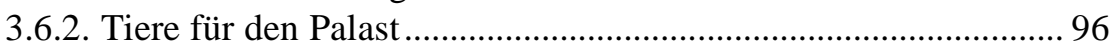

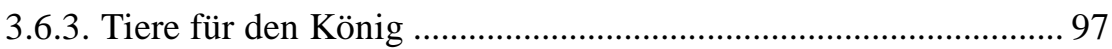

3.6.4. Bierausschenken für Angehörige des Hofes ................................ 98

3.6.5. Proviant (igi-kár) und andere Ausgaben an verschiedene

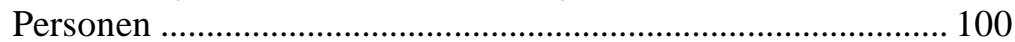

3.7. Textilproduktion für Šulgi-simtī ....................................................... 103

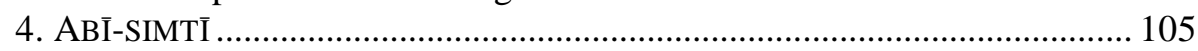

4.1. Herkunft, Amtszeit, Familie ........................................................... 105 


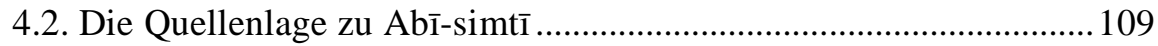

4.3. Dienerschaft/Beamten und das persönliche Umfeld der Abī-simtī.. 113

4.4. Kultische Pflichten der Abī-simtī..................................................119

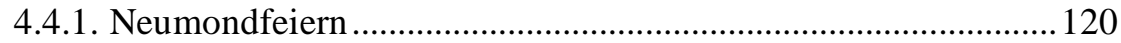

4.4.2. Der Kult der großen Göttern Enlil, Ninlil und Nanna ................ 128

4.4.3. Die syrischen Gottheiten Dagān, Išḩara und Haburītum ............ 132

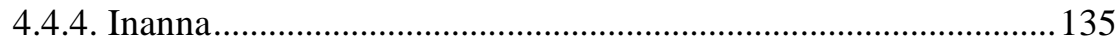

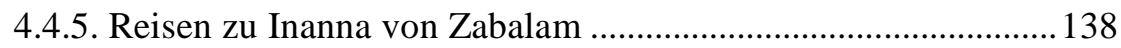

4.4.6. Der Kult verschiedener kleinerer Gottheiten................................ 143

4.4.7. Übersicht über kultische Aktivitäten der Abī-simtī..................... 145

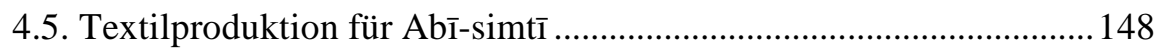

Exkurs 1: Die Mutter des Königs in Ebla ........................................... 150

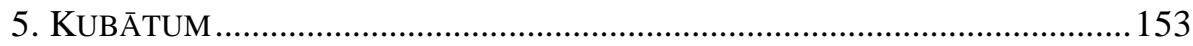

5.1. Herkunft und Familie ......................................................................... 154

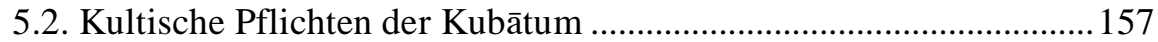

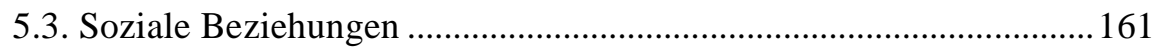

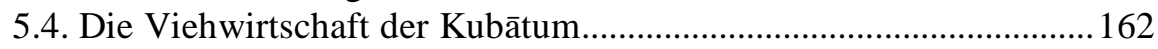

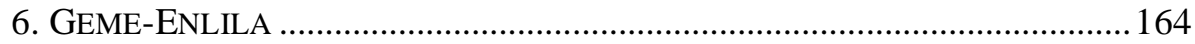

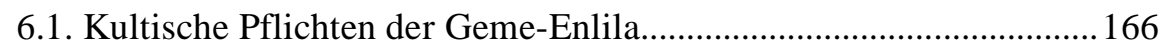

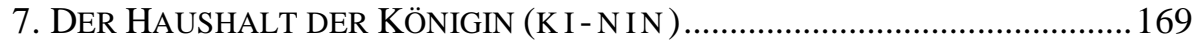

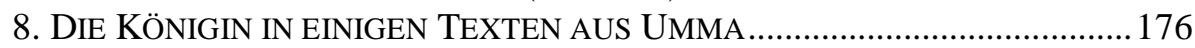

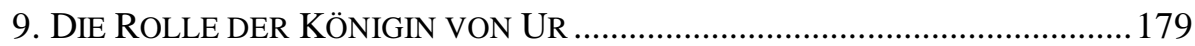

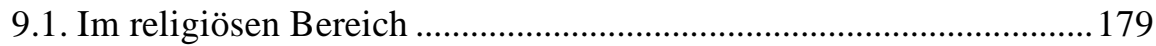

9.2. Im sozialen und wirtschaftlichen Bereich ............................................ 184

Exkurs 2: Königinnen in Ebla und Akkade ……….............................. 186

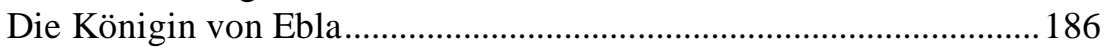

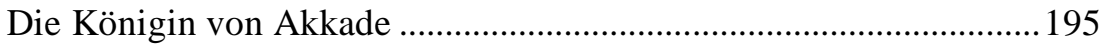

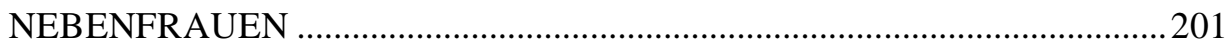

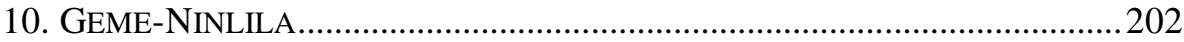

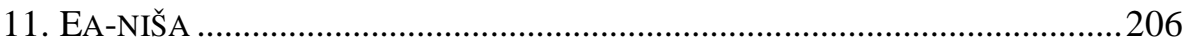

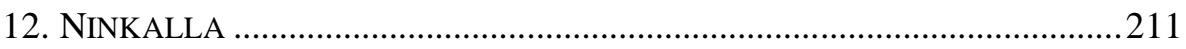

12.1. Ninkalla in Texten aus Puzriš-Dagān..............................................2213

12.2. Ninkalla in Texten aus Nippur ........................................................218

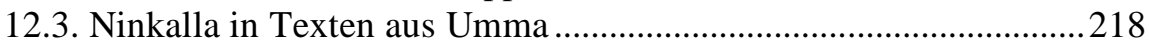

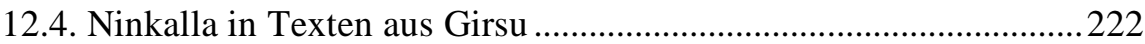

12.5. Ergebnisse der Untersuchungen zu Ninkalla..................................224

13. TI'AMAT-BĀ

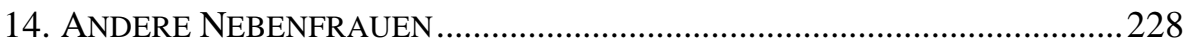

15. DIE ROLLE DER KÖNIGLICHEN NEBENFRAUEN.......................................23

16. DIE TITEL DER KÖNIGLICHEN FRAUEN: „D A M “, „N IN “ UND „,L U K U R “ 


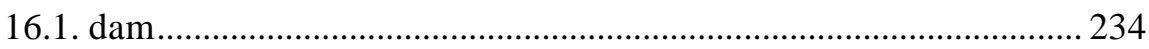

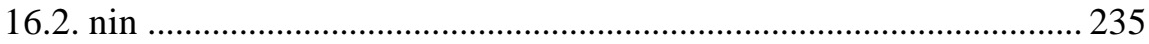

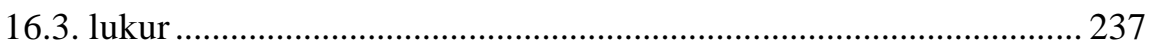

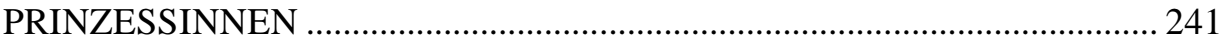

17. DIE EN-PRIESTERINNEN DES NANNA VON UR...................................... 241

Exkurs 3: Königstöchter als Priesterinnen in Ebla und Akkade ........ 245

Priesterinnen aus dem Königshaus von Ebla ..................................... 245

Priesterinnen aus dem Königshaus von Akkade ................................... 249

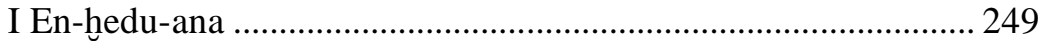

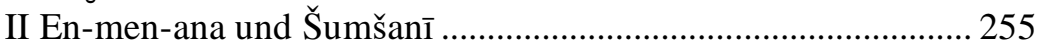

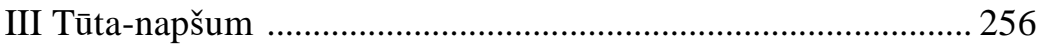

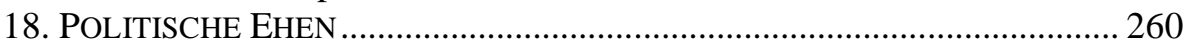

18.1. Der außenpolitische Bereich ......................................................... 261

18.2. Der innenpolitische Bereich ........................................................... 265

Exkurs 4: Politische Ehen in Ebla und Akkade................................... 266

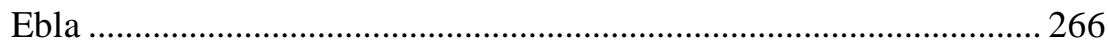

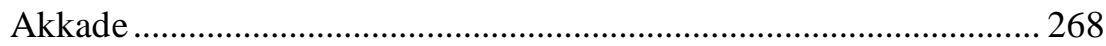

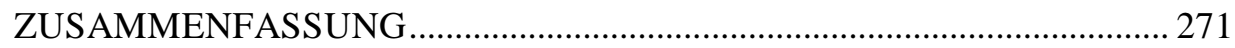

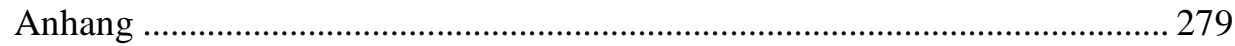

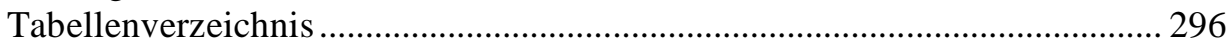

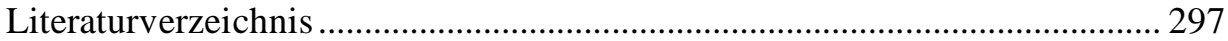

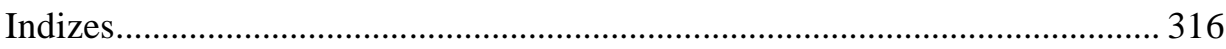





\section{Vorwort}

Die vorliegende Arbeit ist die überarbeitete Fassung meiner Dissertation, die 2004 von der Philosophischen Fakultät der Universität Göttingen angenommen wurde. Das Thema wurde angeregt von B. Groneberg, welche die Entstehung der Arbeit stets mit großem Interesse und vielen wertvollen Hinweisen begleitet hat. Ihr möchte ich an dieser Stelle ganz herzlich danken.

Während meines Studienaufenthalts in Leiden wurde ich von K. Veenhof und G. van Driel sehr freundlich aufgenommen. Auch dafür sei herzlich gedankt. Die Beschäftigung mit den Texten aus Ebla geht auf einen Vorschlag von G. van Driel zurück.

Hinweise zu einzelnen, teilweise noch unveröffentlichten Texten gaben D. Owen und K. Volk sowie M. Hilgert. D. Owen und J. Dahl stellten mir noch unpublizierte Arbeiten zur Verfügung. H. Neumann hat eine frühere Version dieser Arbeit gelesen und zahlreiche wertvolle Hinweise und Korrekturvorschläge gegeben, wofür ich ganz herzlich danke. Fragen zu Problemen des Sumerischen konnte ich mit W. Schramm diskutieren, dem ich hiermit ebenso danken möchte wie D. Shehata und K. Zand für viele hilfreiche Gespräche im Seminar für Altorientalitstik. A. Meiner und R. Körbel haben geholfen, Tippfehler zu finden.

Die Arbeit wurde gefördert durch ein Promotionsstipendium des Evangelischen Studienwerkes Villigst e.V., wofür ich mich ebenfalls bedanken möchte.

Und nicht zuletzt möchte ich an dieser Stelle von Herzen meinen Eltern danken, die mich während meines gesamten Studiums stets unterstützt haben. Ihnen ist diese Arbeit gewidmet. 



\section{Abkürzungen}

AAICAB Jean-Pierre Grégoire: Archives Administratives et Inscriptions Cunéiformes de l'Ashmolean Museum et de la Bodelein Collection d'Oxford (Paris).

AASF

ÄAT

$\mathrm{AB}$

Aegyptus

AfO

$\mathrm{AHw}$

Amherst

AMI

Amurru I

$\mathrm{AnOr}$

$\mathrm{AO}$

AOAT

AoF

AOS

ARET

ARM

ArOr

ARRIM

AS

Ashm.

ASJ

AUCT

$\mathrm{AuOr}$
Annales Academiae Scientiarum Fennicae (Helsinki).

Ägypten und Altes Testament (Wiesbaden).

Assyriologische Bibliothek (Leipzig).

Aegyptus. Rivista (italiana) di egittologia e di papirologia (Mailand).

Archiv für Orientforschung (Berlin, Graz, Horn, Wien).

W. von Soden: Akkadisches Handwörterbuch (Wiesbaden 1959-1981).

T. G. Pinches: The Amherst Tablets. Being an Account of the Babylonian Inscriptions in the Collection of The Right Lord Amherst of Hackney, F.S.A. at Didlington Hall, Norfolk. Part I. Texts of the Period Extending to and Including the Reign of Bûr-Sin. (London 1908).

Archäologische Mitteilungen aus Iran (Berlin).

Jean-Marie Durand (Hg.): Amurru I. Mari, Ébla et les Hourrites. Dix ans de travaux (Paris 1996).

Analecta Orientalia (Rom).

Tafelsignaturen des Louvre (Paris).

Alter Orient und Altes Testament. Veröffentlichungen zur Kultur und Geschichte des Alten Orients und des Alten Testaments (Münster).

Altorientalische Forschungen (Berlin).

American Oriental Series (New Haven, CT).

Archivi Reali di Ebla, Testi (Rom).

Archives Royales de Mari (Paris).

Archív Orientální (Prag).

Annual Review of the Royal Inscriptions of Mesopotamia Project (Toronto).

Amar-Suen; bei der Angabe der Regierungsjahre des Königs.

Tafelsignatur der Texte des Ashmolean-Museum (Oxford).

Acta Sumerologica (Hiroshima).

Andrews University Cuneiform Texts (Berriens Springs, MI).

Aula Orientalis (Barcelona). 
AUWE

Bab.

BagMit

Barton HLC

BBVO

BCT I

BCT II

BE

BiMes

BIN

BiOr

BJRL

BJVF

BM

BOREAS

Boson

BPOA

BPOA 1

BPOA 2

CAD

$\mathrm{CM}$

CNI Publications

Contenau, Umma

CRAI
Ausgrabungen in Uruk-Warka, Endberichte (Mainz).

Babyloniaca. Études de philologie assyro-babylonienne (Paris).

Baghdader Mitteilungen (Berlin).

G. A. Barton: Haverford Library Collection of Cuneiform

Tablets or Documents from the Temple Archives of Telloh (London, Philadelphia, PA 1909).

Berliner Beiträge zum Vorderen Orient (Berlin).

J.P. Watson: Catalogue of Cuneiform Tablets in Birmingham City Museum, vol. I: Neo-Sumerian Texts from Drehem (Warminster 1986).

J. P. Watson, W. B. Horowitz: Catalogue of Cuneiform Tablets in Birmingham City Museum, vol. II: NeoSumerian Texts from Umma and Other Sites (Warminster 1986).

The Babylonian Expedition of the University of Pennsylvania (Philadelphia, PA).

Bibliotheca Mesopotamica (Malibu, CA).

Babylonian Inscriptions in the Collection of James B. Nies, Yale University (New Haven, CT, London).

Bibliotheca Orientalis (Leiden).

Bulletin of the John Rylands Library (Manchester).

Berliner Jahrbuch für Vor- und Frühgeschichte (Berlin).

Tafelsignatur der Texte des British Museum (London).

Acta Universitatis Upsaliensis. BOREAS. Uppsala Studies in Ancient Mediterranean and Near Eastern Civilizations (Uppsala).

G. Boson: Tavolette cuneiformi sumere, degli archivi di Drehem e di Djoha, dell'ultimo dinastia di Ur (Mailand 1936).

Biblioteca des Próximo Oriente Antiguo (Madrid).

T. Ozaki, M. Sigrist: Ur III Administrative Tablets from the British Museum, Part One (Madrid 2006).

T. Ozaki, M. Sigrist: Ur III Administrative Tablets from the British Museum, Part Two (Madrid 2006).

The Assyrian Dictionary of the Oriental Institute of the University of Chicago (Chicago, IL, Glückstadt 1956-).

Cuneiform Monographs (Groningen).

Carsten Niebuhr Institute Publications (Kopenhagen).

G. Contenau: Umma sous la dynastie d'Ur. (Paris 1916).

Compte Rendu de la Rencontre Assyriologique Inter- 
nationale (verschiedene Orte).

CST

CT

CTMMA

CTNMC

DAS

DCEPHE

DCS

DPOA E-1

DV

Eames

Eblaitica

FAOS

FAOS 7

FAOS 8

FAOS 9,2

FAOS 19
T. Fish: Catalogue of Sumerian Tablets in the John Rylands Library, (Manchester 1932).

Cuneiform Texts from Babylonian Tablets in the British Museum (London).

Cuneiform Texts in the Metropolitan Museum of Art (New York, NY).

T. Jacobsen: Cuneiform Texts in the National Museum, Copenhagen, chiefly of economical contents (Leiden 1939).

B. Lafont: Documents Administratifs Sumériens provenant du Site de Tello et Conservés au Musée du Louvre. Éditions Recherche sur les Civilisations Mémoire No. 61 (Paris 1985).

J.-M. Durand: Documents cunéiformes de la IVe Section de l'École pratique des Hautes Etudes. Tome I: catalogue et copies cuneiformes (Genf, Paris 1982).

D. Charpin, J.-M. Durand: Documents cuneiformes da Strasbourg conservés à la Bibliotheque Nationale et Universitaire, Tome 1. Recherche sur les grandes civilisations. Cahier no. 4 (Paris 1981).

H. Limet: Textes Sumériens de la IIIe Dynastie d'Ur, Documents du Proche Orient Ancien - Epigraphie 1 (Brüssel 1976).

Drevnij vostok (Erewan).

A. L. Oppenheim: Catalogue of the Cuneiform Tablets of the Wilberforce Eames Babylonian Collection in The New York Public Library. Tablets of the Time of the Third Dynasty of Ur. AOS 32 (New Haven, CT 1948).

C.H. Gordon, G.A. Rendsburg (Hg.): Essays on the Ebla Archives and Eblaite Language (Winona Lake, IN).

Freiburger altorientalische Studien (Stuttgart).

I. Gelb, B. Kienast: Die Altakkadischen Königsinschriften des 3. Jahrtausends v. Chr. (Stuttgart 1990).

B. Kienast, W. Sommerfeld: Glossar zu den Altakkadischen Königsinschriften (Stuttgart 1994).

H. Steible: Die Neusumerischen Bau- und Weihinschriften Teil 2; Kommentar zu den Gudea-Statuen, Inschriften der III. Dynastie von Ur, Inschriften der IV. und „V.“ Dynastie von Uruk, Varia (Stuttgart 1991).

B. Kienast, K. Volk: Die sumerischen und akkadischen Briefe des III. Jahrtausends aus der Zeit vor der III. 
FS Astour

Dynastie von Ur (Stuttgart 1995).

G. D. Young, M. W. Chavalas, R. E. Averbeck (Hg.): Crossing Boundaries and Linking Horizons. Studies in Honour of Michael C. Astour on His 80th Birthday (Bethesda, MD 1997).

FS Cagni S. Graziani (Hg.): Studi sul Vicino Oriente Antico dedicati alla memoria di Luigi Cagni (Neapel 2000).

FS Fronzaroli P. Marrassini (Hg.): Semitic and Assyriological Studies Presented to Pelio Fronzaroli by Pupils and Colleagues (Wiesbaden 2003).

FS Haas

T. Richter, D. Prechel, J. Klinger (Hg.): Kulturgeschichten, Altorientalistische Studien für Volkert Haas zum 65. Geburtstag (Saarbrücken 2001).

FS Jones

M. A. Powell jr., R. H. Sack (Hg.): Studies in Honor of Tom B. Jones. AOAT 203 (Neukirchen-Vluyn 1979).

FS Larsen

J. G. Dercksen (Hg.): Assyria and Beyond. Studies presented to Mogens Trolle Larsen (Leiden 2004).

FS Levine

R. Chazan, W. W. Hallo, L. H. Schiffman (Hg.): Ki Baruch Hu. Ancient Near Eastern, Biblical, and Judaic Studies in Honor of Baruch A, Levine (Winona Lake, IN 1999).

FS Loretz

M. Dietrich, I. Kottsieper (Hg.): „Und Moses schrieb dies Lied auf". Studien zum Alten Testament und zum Alten Orient. Festschrift für Oswald Loretz zur Vollendung seines 70. Lebensjahres mit Beiträgen von Freunden, Schülern und Kollegen. AOAT 250 (Münster 1998).

FS Matouš

B. Hrouška, G. Komoróczy (Hg.): Festschrift Lubor Matouš (Budapest 1978).

FS Oates L. al-Gailani Werr, J. Curtis, H. Martin, A. McMahon, J. Oates, J. Reade (Hg.): On Pots and Plans. Papers on the Archaeology and History of Mesopotamia and Syria presented to David Oates in Honour of his 75th Birthday. (London 2002).

FS Oppenheim $\quad$ R. D. Biggs, J. A. Brinkman (Hg.): Studies Presented to L. A. Oppenheim. June 7, 1964 (Chicago, IL 1964).

FS Schretter R. Rollinger (Hg.): Von Sumer bis Homer. Festschrift für Manfred Schretter zum 60. Geburtstag am 25. Februar 2004. AOAT 325 (Münster 2004).

FS Sjöberg H. Behrens, D. Loding, M. T. Roth (Hg.): DUMU-E $2_{2}$ DUB-BA-A. Studies in Honor of Åke Sjöberg. OPSNKF 11 (Philadelphia, PA 1989). 
G

HANE/M

HANES

Hirose

HSAO

HUCA

IE

IRSA

IS

ITT

JANES

JAOS

JCS

JEOL

JNSL

JSOR

$\mathrm{K}$

Ktema

Kurth

MAD

MARI

MCS

MDOG

MEE

MTBM

MVN

NABU
Großvieh (in Einnahme- und Ausgabetexten).

History of the Ancient Near East/Monographs (Padua).

History of the Ancient Near East, Studies (Padua).

T. Gomi, Y. Hirose, K. Hirose: Neo-Sumerian Administrative Texts of the Hirose Collection (Potomac, MD 1990).

Heidelberger Studien zum Alten Orient (Heidelberg).

Hebrew Union College Annual (Cincinnati, MA).

Išbi-Erra von Isin; bei der Angabe der Regierungsjahre des Königs.

E. Sollberger, R. Kupper: Inscriptions royales sumériennes et akkadiennes (Paris 1971).

Ibbi-Suen; bei der Angabe der Regierungsjahre des Königs.

Inventaire des Tablettes de Tello, Conservées au Musée Imperial Ottoman (Paris 1910-1921).

Journal of the American Near Eastern Society of Columbia University (New York, NY).

Journal of the American Oriental Society (New Haven, CT).

Journal of Cuneiform Studies (verschiedene Orte).

Jaarbericht van het Vooraziatisch-Egyptisch Genootschap „Ex Oriente Lux“ (Leiden).

Journal of Northwest Semitic Languages (Stellenbosch).

Journal of the Society of Oriental Research (Toronto).

Kleinvieh (in Einnahme- und Ausgabetexten).

Civilisations de l'Orient, de la Grèce et de Rome Antiques (Straßburg).

Inventar der Kurth'schen Sammlung des Archäologischen Museums der Martin-Luther-Universität HalleWittenberg am Institut für Klassische Altertumswissenschaften.

Materials for the Assyrian Dictionary (Chicago, IL).

Mari, Annales de Recherches Interdisciplinaires (Paris).

Manchester Cuneiform Studies (Manchester).

Mitteilungen der Deutschen Orient-Gesellschaft zu Berlin (Berlin).

Materiali Epigrafici di Ebla (Neapel).

M. Sigrist: Messenger-Texts from the British Museum (Ann Arbor, MI 1990).

Materiali per il vocabilario neosumerico (Turin).

N.A.B.U. Nouvelles Assyriologiques Brèves et Utilitaires 


\begin{tabular}{|c|c|}
\hline Nakahara & $\begin{array}{l}\text { (Rouen, Paris). } \\
\text { Y. Nakahara, The Sumerian Tablets in the Imperial } \\
\text { Library of Kyoto (Tokyo 1928). }\end{array}$ \\
\hline NATN & $\begin{array}{l}\text { D. I. Owen: Neo-Sumerian Archival Texts Primarily from } \\
\text { Nippur (Winona Lake, IN 1982). }\end{array}$ \\
\hline NBC & Nies Babylonia Collection (Tafelsignatur in Yale). \\
\hline Nik. & $\begin{array}{l}\text { M. V. Nikolskij: Dokumenty chozjajstvennoj otčetnosti } \\
\text { drevnej Xaldei, iz sobranija N. P. Lichačeva. Cast' II, } \\
\text { Epoxa dinastij Agade i Epoxa dinastij Ura (Moskau } \\
\text { 1915). }\end{array}$ \\
\hline NIN & NIN- Journal of Gender Studies in Antiquity (Groningen). \\
\hline NISABA & Studi Assiriologici Messinesi (Messina 2002ff.) \\
\hline NSGU & $\begin{array}{l}\text { A. Falkenstein: Die neusumerischen Gerichtsurkunden } \\
\text { (München 1956). }\end{array}$ \\
\hline OBO & $\begin{array}{l}\text { Orbis Biblicus at Orientalis (Freiburg/Schweiz, Göttin } \\
\text { gen). }\end{array}$ \\
\hline OBO $160 / 1$ & $\begin{array}{l}\text { J. Bauer, R. K. Englund, M. Krebernik: Mesopotamien. } \\
\text { Späturuk-Zeit und Frühdynastische Zeit. Annäherungen } 1 . \\
\text { Herausgegeben von P. Attinger u. M. Wäfler (Freiburg/ } \\
\text { Schweiz, Göttingen 1998). }\end{array}$ \\
\hline OBO $160 / 3$ & $\begin{array}{l}\text { W. Sallaberger, A. Westenholz: Mesopotamien, Akkade- } \\
\text { Zeit und Ur III-Zeit, Annäherungen 3. Herausgegeben von } \\
\text { P. Attinger u. M. Wäfler (Freiburg/Schweiz, Göttingen } \\
\text { 1999). }\end{array}$ \\
\hline OIP & Oriental Institute Publications (Chicago, IL). \\
\hline OIP 115 & $\begin{array}{l}\text { M. Hilgert: Cuneiform Texts from the Ur III Period in the } \\
\text { Oriental Institute, Volume 1. Drehem Administrative } \\
\text { Documents from the Reign of Šulgi (Chicago, IL 1998). }\end{array}$ \\
\hline OIP 121 & $\begin{array}{l}\text { M. Hilgert: Cuneiform Texts from the Ur III Period in the } \\
\text { Oriental Institute, Volume 2. Drehem Administrative } \\
\text { Documents from the Reign of Amar-Suena (Chicago, IL } \\
\text { 2003). }\end{array}$ \\
\hline OLA & Orientalia Lovaniensia Analecta (Leuven). \\
\hline OMRO & $\begin{array}{l}\text { Oudeheidkundige Mededelingen uit het Rijksmuseum } \\
\text { van Oudeheden te Leiden (Leiden). }\end{array}$ \\
\hline OPSNKF & $\begin{array}{l}\text { Occasional Publications of the Samuel Noah Kramer Fund } \\
\text { (Philadelphia, PA). }\end{array}$ \\
\hline OrAn & $\begin{array}{l}\text { Oriens Antiquus. Rivista del Centro per le Antichità e la } \\
\text { Storia dell'Arte del Vicino Oriente (Rom). }\end{array}$ \\
\hline Orient & $\begin{array}{l}\text { Report of the Society for Near Eastern Studies in Japan } \\
\text { (Tokyo). }\end{array}$ \\
\hline
\end{tabular}


OrNS

OrSP

OSP II

PDT I

PDT II

16

PIOL

PP

PRAK

PTS

QdS

RA

RGTC

RIME

RIME 2

RIME 3/2

RlA

$\mathrm{RO}$

Rochester

RT

RTC

$\mathrm{S}$

SACT I
Orientalia nova series (Rom).

Orientalia series prior (Rom).

A. Westenholz: Old Sumerian and Old Akkadian Texts in Philadelphia. Part Two: The "Akkadian" Texts, the Enlilemaba Texts, and the Onion Texts, CNI Publications 3 (Kopenhagen 1987).

M. Çıg, H. Kızılyay, A. Salonen: Die Puzriš-Dagan-Texte der Istanbuler Archäologischen Museen, Teil I: Nr. 1-725, AASF B 92 (Helsinki 1954).

F. Yıldız, T. Gomi: Die Puzriš-Dagan-Texte der Istanbuler Archäologischen Museen, Teil II: Nr. 726-1379, FAOS (Stuttgart 1988).

Publications de l'Institut Orientaliste de Louvain (Leuven).

La parola del passato, rivista di studi classici (Neapel).

H. de Genouillac: Premières Recherches Archéologiques à Kich (Paris 1924/5).

Tafelsignatur der Texte des Princeton Theological Seminary.

Quaderni di Semitistica (Florenz).

Revue d'Assyriologie et d'Archéologie Orientale (Paris).

Répertoire Géographique des Textes Cunéiformes (Wiesbaden).

The Royal Inscriptions of Mesopotamia. Early Periods (Toronto).

D. R. Frayne: Sargonic and Gutian Periods (2334-2113 BC). (Toronto 1993).

D. R. Frayne: Ur III Period (2112-2004 B.C.). (Toronto 1997).

Reallexikon der Assyriologie und der Vorderasiatischen Archäologie (Berlin, Leipzig, New York, NY).

Rocznik orientalistyczny (Warschau).

M. Sigrist: Documents from Table Collections in Rochester, New York (Bethesda, MD 1991).

Recueil des travaux relatifs à la Philologie et à l'Archéologie Egyptiennes et Assyriennes (Paris).

F. Thureau-Dangin: Recueil des Tablettes Chaldéennes (Paris 1903).

Schweine (in Einnahme- und Ausgabetexten).

S. T. Kang: Sumerian and Akkadian Cuneiform Texts in the Collection of the World Heritage Museum of the University of Illinois. I: Sumerian Economic Texts from 
SACT II

SAOC

SAT

SCCNH

SCT

SDU

SEL

SET

SMS

SNATBM

SRD

SRT

STA

STD

St.Sem. NS

STTI

$\check{S}$

ŠA the Drehem Archive (Urbana 1972).

S. T. Kang: Sumerian and Akkadian Cuneiform Texts in the Collection of the World Heritage Museum of the University of Illinois. II: Sumerian Economic Texts from the Umma Archive (Urbana 1973).

Studies in Ancient Oriental Civilizations (Chicago, IL).

M. Sigrist: Sumerian Archival Texts (Bethesda, MD).

Studies on the Civilization and Culture of Nuzi and the Hurrians (Winona Lake, IN).

C.H. Gordon: Smith College Tablets. 110 Cuneiform Texts Selected from the College Collection (Northampton, MA 1952).

N. W. Forde: Neo-Sumerian Texts From South Dakota University, Luther and Union Colleges (Lawrence, SD 1987).

Studi Epigrafici e Linguistici sul Vicino Oriente antico (Rom).

T. B. Jones, J. W. Snyder: Sumerian Economic Texts from the Third Ur Dynastie. A Catalogue and Discussion of Documents from various Collections (Minneapolis, MN 1961).

Syro-Mesopotamian Studies (Malibu).

T. Gomi: Selected Neo-Sumerian Administrative Texts from the British Museum (Kujike 1990).

W. M. Nesbit: Sumerian Records from Drehem, Columbia University Oriental Studies Vol. VIII (New York, NY 1914).

E. Chiera: Sumerian Religious Texts (Upland 1924).

E. Chiara: Selected Temple Accounts from Telloh, Yokha and Drehem. Cuneiform Tablets in the Library of Princeton University (Philadelphia, PA 1921).

E. Margolis: Sumerian Temple Documents. Submitted in partial fulfilment of the requirements for the degree of Doctor of Philosophy in the faculty of Philosophy of Columbia University (New York, NY 1915).

Studi Semitici, Nuova serie (Rom).

V. Donbaz, B. R. Foster: Sargonic Texts from Telloh in the Istanbul Archaeological Museums (Philadelphia, PA 1982).

Šulgi; bei der Angabe der Regierungsjahre des Königs.

C.-F. Jean: Šumer et Akkad, contribution à l'histoire de la 
ŠS

Šulgi B

TAD

TCL

TCND

TCNY

TCS

TCTI I

TCTI 2

TÉL

TENS

TLB

TMH NF

TMH NF $1 / 2$

Toronto

Toronto II civilisation dans la Basse-Mésopotamie (Paris 1923).

Šu-Suen; bei der Angabe der Regierungsjahre des Königs.

G. R. Castellino: Two Šulgi Hymns (BC), Studi Semitici 42 (Rom 1972).

S. Langdon: Tablets from the Archives of Drehem. With a complete Account of the origin of the sumerian calendar, translation, commentary and 23 plates (Paris 1911).

Textes cunéiformes du Louvre (Paris).

A. Archi, F. Pomponio: Testi cuneiformi neo-sumerici da Drehem (Mailand 1990).

H. Sauren: Les tablettes cunéiformes de l'époque d'Ur des collections de la New York Public Library, PIOL 19 (Leuven 1978).

Texts from Cuneiform Sources (Locust Valley, NY).

B. Lafond, F. Yildiz: Tablettes cunéiformes de Tello au Musée d'Istanbul, Datant de l'époque de la IIIe Dynastie d'Ur, I (ITT II/1, 617-1038), Uitgave van het Nederlands Historisch-Archaeologisch Instituut te Istanbul 65 (Leiden 1989).

B. Lafond, F. Yildiz: Tablettes cunéiformes de Tello au Musée d'Istanbul, Datant de l'époque de la IIIe Dynastie d'Ur, II (ITT II/1, 2544-2819, 3158-4342, 4708-4713), Uitgave van het Nederlands Historisch-Archaeologisch Instituut te Istanbul 77 (Leiden 1996).

M. Lambert: Tablettes économiques de Lagash (époque de la III ${ }^{\mathrm{e}}$ dynastie d'Ur) copiées en 1900 au Musée Impérial Ottoman par Charles Virolleaud, Cahiers de la Société Asiatique XIX (Paris 1968).

M. Sigrist: Textes Économiques Néo-Sumeriens de l'Université de Syracuse (Paris 1983).

Tabulae cuneiformes a F.M.Th. de Liagre Böhl collectae (Leiden).

Texte und Materialien der Frau Professor Hilprecht Collection of Babylonian Antiquities im Eigentum der Universität Jena, Neue Folge (Berlin).

A. Pohl: Rechts- und Verwaltungsurkunden der III. Dynastie von Ur. Autographiert und mit Inventarverzeichnis und Namenlisten versehen (Leipzig 1937).

M. Sigrist: Neo-Sumerian Texts from the Royal Ontario Museum I. The Administration at Drehem (Bethesda, MD 1995).

M. Sigrist: Neo-Sumerian Texts from the Royal Ontario 
Museum II. Administrative Texts mainly from Umma (Bethesda, MD 2004).

TPTS

M. Sigrist: Tablettes du Princeton Theological Seminary. Époque d'Ur III (Philadelphia, PA 1990).

$\operatorname{TrD}$

TRU

H. de Genouillac: La trouvaille de Drehem (Paris 1911).

TUT

L. Legrain: Le temps des rois d'Ur (Paris 1912).

Tutub

G. Reisner: Tempelurkunden aus Telloh (Berlin 1901).

W. Sommerfeld: Die Texte der Akkad-Zeit 1. Das DijalaGebiet: Tutub. IMGULA 3/1 (Münster 1999).

UDT J. B. Nies: Ur Dynasty Tablets chiefly from Tello and Drehem. With Translations, Lists and Complete Indices. AB 25 (Leipzig 1919).

UET

UF

UTI Ur Excavation Texts (London).

Ugarit-Forschung. Internationales Jahrbuch für die Altertumskunde Syrien-Palästinas (Kevelaer, NeukirchenVluyn).

Die Umma-Texte aus den Archäologischen Museen zu Istanbul (Bethesda, MD).

UVB Vorläufige Berichte über die Ausgrabungen in UrukWarka (Berlin).

$\mathrm{V}$

VO

WO

Xenia

YNER

ZA

ZVO
Vögel (in Einnahme- und Ausgabetexten).

Vicino Oriente (Rom).

Welt des Orients (Wuppertal, Stuttgart, Göttingen)

W. Schuller (Hg.): Konstanzer Althistorische Vorträge und Forschungen (Konstanz).

Yale Near Eastern Researches (New Haven, CT, London). Zeitschrift für Assyriologie und Vorderasiatische Archäologie (Berlin, New York, NY).

Zapiski Vostočnogo Otdelenija Russkogo Archeologičeskago Obšcestva (St. Petersburg) 


\section{Einleitung}

Die königlichen Frauen der dritten Dynastie von Ur waren in der Vergangenheit wiederholt Gegenstand von Untersuchungen. Insbesondere die 1982 abgeschlossene Serie von Aufsätzen von Michalowski und der Beitrag von Steinkeller sind hier zu nennen. ${ }^{1}$ Seit dieser Zeit ist die Zahl der publizierten Ur III-Texte stetig gewachsen und damit auch die Zahl der bekannten Angehörigen des Königshauses, darunter inzwischen bald 100 Prinzen und Prinzessinnen ${ }^{2}$.

In dieser Arbeit liegt der Schwerpunkt auf der Rolle und Position der königlichen Gemahlinnen, der Königinnen wie der königlichen Nebenfrauen. Diese Frauen nahmen eine einflußreiche Stellung im gesellschaftlichen Leben ihrer Zeit ein, die Königinnen waren auch im Kult der großen Göttern des Landes eingebunden, und für einige dieser Frauen läßt sich sogar ein eigenes Profil der persönlichen Frömmigkeit feststellen. Anhand des umfangreichen Quellenmaterials ist insbesondere für die Königin Šulgi-simtī neben ihren Aufgaben im Kult ein weitgespanntes Netz sozialer Beziehungen zu beobachten, wie es auch für ihre Nachfolgerinnen angenommen, jedoch aufgrund der Quellenlage nicht in der gleichen Ausführlichkeit dokumentiert werden kann. Im wirtschaftlichen Bereich hatten die Frauen der Herrscher von Ur ebenfalls vielfältige Aufgaben zu erfüllen.

Neben den königlichen Gemahlinnen werden die En-Priesterinnen des Nanna von Ur besprochen, die stets aus dem Königshaus stammten und eine der bedeutendsten kultischen Ämter ihrer Zeit bekleideten. Als letzter Aspekt wird auf die Heiratspolitik der Könige von Ur eingegangen. Die Könige selber heirateten Frauen aus Regionen außerhalb ihres Herrschaftsbereiches, für ihre Töchter arrangierten sie dynastische Verbindungen zu verschiedenen Königshäusern vornehmlich im Osten des Reiches von Ur.

Michalowski, Royal Women of the Ur III Period - Part I: The Wife of Šulgi, JCS 28 (1976), S. 169-172; Royal Women of the Ur III Period - Part II: Geme-Ninlila, JCS 31 (1979), S. 171-176; Royal Women of the Ur III Period - Part III, ASJ 4 (1982), S. 129-142; Steinkeller, More on Ur III Royal Wives, ASJ 3 (1981), S. 77-92.

$2 \quad$ Sigrist, Drehem, S. 361 Anm. 41; Sallaberger, OBO 160/3 (1999), S. 185. 
In der vorliegenden Arbeit bleibt der Blick indes nicht ausschließlich auf die Frauen des Herrscherhauses von Ur gerichtet, sondern es werden auch frühere Epochen vergleichend einbezogen. In das ausgehende Frühdynastikum datieren Schriftquellen, welche erstmals in größerem Umfang Aussagen zur Situation der königlichen Frauen ermöglichen. Diese Texte stammen zum einen aus Lagaš, zum anderen aus Ebla. Letzteres nimmt geographisch innerhalb der besprochenen Gesellschaften insofern eine Sonderstellung ein, als es nicht zum Kernland Mesopotamiens, sondern zum syrischen Kulturkreis zu rechnen ist. In den historischen Epochen Mesopotamiens und Syriens bestand stets ein reger Austausch zwischen beiden Regionen, und überdies lassen sich eine Reihe von Gemeinsamkeiten in der Position der königlichen Frauen von Ebla und jener im sumerischen Kernland feststellen. Somit eröffnet die Einbeziehung des reichen Quellenmaterials aus Ebla interessante Aspekte für die Geschichte der hochgestellten Frauen jener Zeit. Die der Ur III-Zeit unmittelbar vorausgehende Akkadezeit bietet nach der derzeitigen Quellenlage nur sehr eingeschränkt Material zur Situation der Frauen des Königshauses, nur wenige Frauen des Herrscherhauses sind überhaupt namentlich bekannt, doch stammte mit Enhedu-ana, der Tochter des Dynastiegründers Sargon, eine der prominentesten Frauengestalten der mesopotamischen Geschichte aus dieser Epoche. In vier Exkursen wird die Situation der königlichen Frauen aus den Gesellschaften von Ebla und Akkade beschrieben und somit die Position der Frauen der Ur III-Zeit in einen größeren historischen Kontext gestellt. Da die frühdynastischen Texte zu den Frauen des Herrscherhauses von Lagaš wiederholt Gegenstand von Untersuchungen waren ${ }^{3}$, werden sie hier nicht gesondert besprochen, sondern erst in der Zusammenfassung vergleichend zur Situation der Ur III-Zeit betrachtet.

Die Position der Frauen aller Gesellschaftsschichten innerhalb der mesopotamischen Kulturen ist nicht erst seit der Rencontre in Paris $1986^{4}$ Gegenstand der Forschung ${ }^{5}$. Von den in jüngerer Zeit erschienenen Arbeiten zur Stellung der Frau seien hier exemplarisch die Beiträge von Stol „Women in Mesopotamia“6 und Hallo „Women“7 erwähnt. Während Stol verschiedene

3 Zuletzt u.a. Bauer, Der vorsargonische Abschnitt der mesopotamischen Geschichte, OBO 160/1, S. 532-555 und Magid, Micromanagement in the é-mi/ ${ }^{\mathrm{d} B a-u ́, ~ C R A I ~ 45 / 1 ~}$ (2001), S. 313-328.

4 J.-M. Durand (Hg.), La Femme dans la Proche Orient Antique, CRAI 33 1986, Paris 1987.

5 J. Asher-Greve, Women and Gender in Ancient Near Eastern Cultures. Bibliography 1885-2001 AD. NIN 3 (2002), S. 33-114.

6 Stol, Women in Mesopotamia. JESHO 38 (1995), S. 123-144.

7 In: Hallo, Origins (1996) S. 243-270. 
Aspekte wie die Stellung der Frau innerhalb der Familie, Eheschließung, Geburt und Erbrecht aber auch königliche Frauen sowie arbeitende Frauen der unteren Bevölkerungsschichten bespricht, geht Hallo auf die rechtliche Stellung der Frauen ein und behandelt königliche Frauen sowie den Aspekt von weiblicher Autorenschaft. Stol wie Hallo ziehen dabei Quellen aus verschiedenen Epochen heran. Mit der rechtlichen Stellung der Frau nach den Gesetzestexten befaßt sich ausführlich Lafont. ${ }^{8}$ Eine Übersicht über die Rolle und Position der königlichen Frauen unterschiedlicher Epochen gibt Melville. ${ }^{9}$ Mit den Ansätzen der Genderforschung betrachten Bahrani und Asher-Greve die bildlichen Darstellungen von Frauen in Mesopotamien, wobei sie insbesondere auf die Bildwerke des dritten Jahrtausends eingehen. ${ }^{10}$

$\mathrm{Zu}$ den Texten aus dem 1975 entdeckten Archiv von Ebla ist inzwischen eine reiche Literatur vorhanden. Eine Übersicht über die verschiedenen Textgattungen und die Forschungsgeschichte der ersten Jahre bieten Kienast und Waetzoldt, ${ }^{11}$ eine Darstellung der Geschichte von Ebla gibt Astour. ${ }^{12} \mathrm{Zu}$ den Frauen aus Ebla haben insbesondere Biga und Archi gearbeitet. ${ }^{13}$

Eine umfassende Übersicht über die Geschichte, die verschiedenen Fundorte und Archivzusammenhänge sowie über die Verwaltung der Ur III-Zeit gibt Salleberger in OBO 160/3. Dort ist auch die Bibliographie zu den publizierten Ur III-Texten, welche Sigrist und Gomi begonnen haben, fortgeführt. ${ }^{14} \mathrm{Zu}$ den königlichen Frauen sind insbesondere die Artikel von Michalowski und Steinkeller zu nennen. ${ }^{15}$ Eine besondere Stellung unter den Texten der Frauen

Siehe Lafont, Femmes, Droit et Justice dans l'Antiquité orientale. OBO 165 (1999).

Melville, Royal Women and the Exercise of Power in the Ancient Near East (2005), S. 219-228.

10 Bahrani, Women of Babylon (2001), S. 96-120. Asher-Greve, 'Golden Age' of Women? Status and Gender in Third Millenium Sumerian and Akkadian Art. OBO 220 (2006), S. 41-81. Zum Konzept von Gender in der altorientalischen Forschung siehe auch van de Mieroop, Cuneiform Texts and the Writing of History (1999), S. 138-160.

11 Kienast/Waetzoldt, Zwölf Jahre Ebla: Versuch einer Bestandsaufnahme. Eblaitica 2 (1990), S. 31-77.

12 Astour, An Outline of the History of Ebla (Part 1). Eblaitica 3 (1992), S. 3-82 und ders., A Reconstruction of the History of Ebla (Part 2). Eblaitica 4 (2002), S. 57-195.

13 Biga, Femmes de la Familie Royale d'Ebla, CRAI 33 (1987), S. 41-47; dies, Donne alla Corte di Ebla, PP 46 (1991), S. 365-377; zuletzt Archi, The Role of Women in the Society of Ebla, CRAI 47 (2002), S. 1-9.

14 Sigrist/Gomi, The Comprehensive Catalogue of Published Ur III Tablets (1991), S. 13-95; de Maaijer/Sallaberger, OBO 160/3 (1999), S. 351-363.

15 Siehe Fn. 1. Vgl. auch Kang, The Role of Women in the Drehem Texts. SACT I, S. 261-270. 
des Königshauses von Ur nehmen die Quellen aus dem Archiv der Königin Šulgi-simtī ein, das zuerst 1961 von Jones und Snyder ${ }^{16}$ dargestellt und später von Sigrist und Sallaberger ${ }^{17}$ ausführlich beschrieben wurde.

Die überwiegende Zahl der für diese Arbeit ausgewerteten Quellen sind Wirtschaftstexte, daneben bilden Siegellegenden und Weihinschriften weitere Textgruppen. Briefe sind für die Geschichte der königlichen Frauen dieser frühen Epochen kaum von Bedeutung. Nur sehr vereinzelt werden die Damen in Briefen erwähnt, Briefe von den Frauen selber oder an sie gerichtet, wie sie aus der altbabylonischen Zeit in großer Zahl bekannt sind, liegen für das dritte Jahrtausend kaum vor. Auch Bildquellen, die sich einzelnen Frauen des Königshauses sicher zuordnen lassen, sind nur in sehr begrenztem Umfang erhalten. Sie werden in die Untersuchung einbezogen, sofern der Bildinhalt Aussagen zur Rolle oder Stellung der Frau in der dargestellten Situation zuläßt. Dies ist sowohl bei der bekannten Reliefscheibe der En-hyedu-ana der Fall, als auch bei einigen Siegelbildern der Ur III-Zeit.

Der größte Teil der Ergebnisse beruht jedoch auf der Analyse von Wirtschaftsdokumenten aus der staatlichen Verwaltung. Von den bisher publizierten Texten der Ur III-Zeit beziehen sich mehr als 1000 auf Aktivitäten der königlichen Gemahlinnen. Diese Texte ermöglichen Aussagen über eine einzelne Buchung hinaus, wenn sie in möglichst umfassendem Kontext aller verfügbaren Belege zu einer Person oder einem Ereignis betrachtet werden können. Dafür wurden die Texte unter verschiedenen Fragestellungen untersucht, unter anderem den Fragen, wer wann welche Güter an eine der Damen lieferte, wann die einzelnen Frauen bestimmte Güter wie z.B. Tiere, Textilien oder Schmuckstücke an Götter oder Menschen ausgaben, welche Gottheiten die besondere Aufmerksamkeit einzelner Frauen erfuhren und mit welchen Personen die Damen in bestimmten Zusammenhängen Kontakte pflegten. So läßt sich feststellen, in welchem Zeitraum die Frauen an einzelnen Orten belegt sind und welchen Aufgaben sie jeweils nachgingen.

Die Ur III-Texte zu den königlichen Frauen kommen aus unterschiedlichen Fundorten, die größte Gruppe stammt aus Puzriš-Dagān, eine geringerer Zahl aus Ur, Umma, Girsu und Nippur. Sie enthalten in der Mehrzahl kurze Buchungsbelege über die Einnahme oder Ausgabe verschiedener Güter, wobei in der Regel der Lieferant bzw. Empfänger sowie der verantwortliche Beamte auf der Tafel vermerkt ist. Bei der Auswertung wurde nicht nur der Inhalt, sondern auch der Herkunftsort und das Datum berücksichtigt. Gerade die oft auf den Tag genaue Datierung dieser Verwaltungstexte ermöglicht es zum

16 Jones/Snyder, An Early Drehem(?) Series. SET S. 203-208.

17 Sigrist, Drehem (1992) S. 222-246, Sallaberger, Der kultische Kalender (1993), S. 1825 und ders. in OBO 160/3 (1999), S. 253-260. 
einen, bestimmte regelmäßig wiederkehrende Verpflichtungen der einzelnen königlichen Frauen zu beobachten, und zum anderen, mitunter eine Entwicklung im Tätigkeitsspektrum festzustellen. Letzteres ist insbesondere bei den beiden gut bezeugten Königinnen Šulgi-simtī und Abī-simtī möglich, da zu beiden erstens eine ausreichend große Anzahl von Einzelquellen vorhanden ist und diese zweitens aus dem Zeitraum der Epoche stammen, aus denen insgesamt eine reiche Quellenbasis vorliegt.

Der Verwendungszweck der einzelnen Güter ist nicht immer, und wenn, dann nur in knapper Form angegeben. So erhielt beispielsweise die Königin Abī-simtī regelmäßig eine größere Menge unterschiedlicher Tiere mit dem Vermerk „für ihren Neumondtag“. Dabei ist den Texten nicht zu entnehmen, ob alle Tiere den Göttern geopfert wurden - nie wird in diesem Zusammenhang der Name einer Gottheit genannt - oder ob die Tiere auch für andere Zwecke benötigt wurden.

Die Aufgaben der Frauen vor allem im Kult, aber auch in der Wirtschaft, sind anhand des reichen Materials gut nachzuvollziehen. Dabei lassen sich eine Reihe neuer Erkenntnisse zum Tätigkeitsspektrum der königlichen Gemahlinnen gewinnen, insbesondere auch zu den Unterschieden in den Aufgabenbereichen der Königinnen im Vergleich zu jenen der königlichen Nebenfrauen. Darüber hinaus lassen die Texte Aussagen über die sozialen Beziehungen der Frauen untereinander sowie zu den führenden Angehörigen der königlichen Verwaltung zu. Zuletzt kann beobachtet werden, in welchem Umfang die Frauen aus dem Königshaus über eigenes Personal verfügten und inwieweit sie mit den Beamten des Königs zusammenarbeiten konnten. Einschränkend ist dabei zu beachten, daß die überwiegende Zahl der Texte aus dieser Zeit aus dem Bereich der staatlich kontrollierten Viehwirtschaft stammt. Dagegen ist bisher vergleichsweise wenig über die großen privaten Haushalte bekannt, die mitunter von weiblichen Angehörigen des Herrscherhauses geführt werden konnten. ${ }^{18}$ Auch ist der Bereich der Viehwirtschaft in den Quellen gegenüber den Transaktionen von pflanzlichen Produkten eindeutig überrepräsentiert, was ein etwas verzerrtes Bild ergibt, jedoch in der Zufälligkeit der Fundsituation der Texte begründet ist.

Im Gegensatz zu den Texten der Ur III-Zeit stammen die Quellen aus Ebla aus nur einem Fundort, den Archiven in Palast G. ${ }^{19}$ Die Archive aus Ebla und den verschiedenen Fundorten der Ur III-Zeit sind insofern vergleichbar, als es sich in beiden Fällen um Zeugnisse aus der staatlichen Wirtschaft und

18 D. Owen bereitet eine Studie zu den Texten aus dem Haushalt der Prinzessin SimatIštarān (Garšana-Archiv) vor.

19 Zu diesen Archiven siehe Archi, Archival Record-Keeping at Ebla 2400-2350 BC (2003), S. 17-36. 
Buchhaltung handelt. Unterschiede bestehen jedoch sowohl im Themenspektrum, welches in den Eblatexten eingeschränkter ist, als auch in der Art der Aufzeichnungen. Aus Ebla sind zumeist umfangreiche Listen über die Ausgabe diverser Güter an eine Vielzahl verschiedener Personen zu unterschiedlichen Anlässen wie z.B. der Hochzeit einer Tochter des Königs oder der Geburt eines Kindes der Königin erhalten. Dagegen handelt es sich bei den Quellen der Ur III-Zeit überwiegend um kurze Einzelbuchungen zu sehr verschiedenen Anlässen.

Die Texte aus Ebla geben uns vielfältige Informationen über die Frauen der königlichen Familie sowie ihre Beziehungen zu anderen Königshäusern. Die Position einer Frau innerhalb der Hierarchie ist insbesondere anhand ihrer Stellung in den Listen der „Frauen des Königs“ über Textil-, Metall- und Lebensmittelzuweisungen, sowie am Wert der jeweiligen Güter, die sie empfing, zu erkennen. Ein weiteres wichtiges Indiz für den Rang einer Person ist ihre jeweilige Position unter den Empfängern von Totenopfern.

Unser Wissen über die Gesellschaft von Ebla wird im wesentlichen aus den Informationen rekonstruiert, welche diese Listen aus der Palastverwaltung überliefert haben. Schwierigkeiten bei der Betrachtung der Texte aus Ebla bereitet zum Teil die Tatsache, daß Frauen jeden Ranges mitunter nur als Ehefrau (d a m) bezeichnet wurden ${ }^{20}$, was ihre Identifizierung ebenso verkompliziert wie die Tatsache, daß mehrere Frauen verschiedener Generationen denselben Namen trugen ${ }^{21}$. Die interne Chronologie der Texte ist nur durch inhaltliche Vergleiche zu ermitteln, da die Texte oft nur eine Monatsangabe und kein Jahresdatum tragen, und trotz der großen Fortschritte vor allem von Archi, Biga und Pomponio in den letzten Jahren ist die genaue zeitliche Einordnung vieler Texte noch immer unsicher. ${ }^{22}$

Eine weitere Schwierigkeit ergibt sich aus der relativ kurzen Laufzeit des Archives. Die Texte umfassen gerade drei Generationen, was es unmöglich macht, allgemeingültige Aussagen zu Fragen wie der Thronfolgeregelung zu treffen, da nicht sicher ist, ob die überlieferten Beispiele die übliche Vorgehensweise widerspiegeln, oder ob es sich um Sonderfälle handelt.

20 Biga, Femmes de la Familie Royale d'Ebla, CRAI 33 (1987); Waetzoldt, Frauen (dam) in Ebla (1987).

21 Biga, Prosopographie et datation relative des Textes d'Ébla, Amurru I (1996), S. 43.

22 Tonietti, Le liste delle dam en: Cronologia interna, QdS 16 (1989); Biga/Pomponio, Elements for a Chronological Division of the Administrative Documentation of Ebla, JCS 42 (1990); Dies., Critères de rédaction comptable et chronologie relative des Textes d'Ebla, MARI 7 (1993); Archi, Chronologie relative des archives d'Ébla, Amurru I (1996), S. 11-28; Biga, Prosopographie, Amurru I (1996); Biga, The reconstruction of a relative Chronology for the Ebla texts, OrNS 72 (2003). 
Die Texte vermitteln ein umfangreiches Bild vom Leben der weiblichen Bevölkerung des Palastes. Neben den hochrangigsten Damen, der Mutter des Königs, der Königin, Prinzessinnen, die herausragende Priesterämter bekleideten, sowie zwei bis drei weiteren Damen ersten Ranges, ist stets eine Gruppe von Frauen belegt, die zusammen unter der Sammelbezeichnung dam en, Frauen des Königs, geführt wurden. Auch die Damen ersten Ranges werden unter diesen dam en summiert, wenn die Frauen gemeinsam Textil- oder Lebensmittelzuweisungen erhielten. In diesem Fall stehen sie an erster Stelle der Listen. ${ }^{23}$ Neben den Frauen des Königs lebten auch seine Töchter sowie eine große Zahl von Dienern, Köchinnen, Weberinnen, Salbenbereitern, Ammen und anderen mehr im Palast.

Es ist denkbar, jedoch bisher nicht archäologisch zu belegen, daß der Palast von Ebla über Gebäude oder Räume verfügte, die ausschließlich von Frauen genutzt wurden. ${ }^{24}$ Von einem Harem wie zur Zeit der Osmanen, wo die Frauen in völliger Abgeschlossenheit gehalten wurden, kann weder in Ebla noch in Ur die Rede sein. Vielmehr ist zu zeigen, daß die königlichen Frauen der besprochenen Gesellschaften in vielen Bereichen eigenständig und verantwortlich agieren konnten.

23 Tonietti, Le liste delle dam en, QdS 16 (1989).

24 Biga, Donne alla Corte di Ebla, PP 46 (1991), S. 286; Archi, The Role of Women in the Society of Ebla, CRAI 47 (2002), S. 3. 



\section{Königinnen}

\section{SI.A-tum}

Aus der Zeit vor dem Jahr Šulgi 30 ist die Textüberlieferung weitaus spärlicher als für die folgenden Jahrezehnte bis zur ersten Dekade der Regierungszeit Ibbi-Suens, weswegen zu den frühen Königinnen vor Šulgi-simti kaum etwas bekannt ist.

Die Mutter des Dynastiegründers Ur-Namma trug mit großer Wahrscheinlichkeit den Namen Damiqtum, denn eine Frau dieses Namens wird in zwei Texten erwähnt, in denen Lieferungen von Rohr im Zusammenhang mit dem Totenkult verbucht werden ${ }^{25}$. Da Damiqtum im Text ArOr 62, S. 240, I 870 unmittelbar nach Ur-Namma und vor dem Vater des Ur-Namma (a b- b a Ur${ }^{\mathrm{d}} \mathrm{N}$ a m ma) genannt wird, schlossen Boese und Sallaberger, daß es sich bei ihr um die Mutter des Königs gehandelt haben könnte ${ }^{26}$. Es fällt auf, daß Damiqtum vor dem Vater des Königs geführt wird und mit 180 Rohrbündeln auch eine deutlich größere Menge erhält als der nicht namentlich genannte Vater, der nur 40 Rohrbündel bekommt. Ob dies mit einer besonderen Stellung der Mutter des zukünftigen Königs bei der Regelung der Thronfolge erklärt werden kann, ist auf der Grundlage eines vereinzelten Textes nicht zu beantworten, insbesonder solange nicht bekannt ist, nach welchen Verfahren die Thronfolge in Ur geregelt wurde.

Die Frau des Ur-Namma war SI.A-tum ${ }^{27}$, wie aus dem Siegel ihres Beamten Lugal-kuzu zu ersehen ist, wo sie als da m $\mathrm{Ur}-{ }^{\mathrm{d}} \mathrm{N}$ a m m a bezeichnet wird $^{28}$. Wie Michalowski gezeigt hat, wird der Titel „dam“ nur bis zum

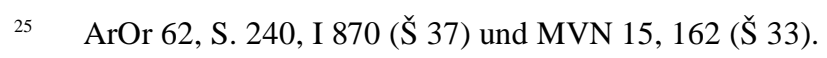

26 Boese, Sallaberger, Apil-kīn von Mari und die Könige der III. Dynastie von Ur, AoF 23 (1998), S. 29.

27 Die von Sollberger (Ladies of the Ur -III Empire, RA 61 (1967), S. 69) vorgeschlagene Lesung Watartum für SI.A-tum konnte bisher nicht bestätigt werden, weshalb hier die Schreibung SI.A-tum beibehalten wird. Vgl. Steible, FAOS 9,2, S. 196.

28 RIME 3/2.1.1.51. Dieses Siegel ist allein zweimal auf einem Tonstück abgerollt, ohne daß damit ein Text gesiegelt wäre (Sollberger, Ladies of the Ur -III Empire, RA 61 (1967), S. 69). Möglicherweise handelt es sich um eine Tonbulle als Gefäßverschluß. 
Zeitpunkt der Vergöttlichung des Königs für dessen Gemahlinnen genutzt, danach wird die Hauptfrau des Königs, die Königin, als „n in “ angesprochen, kann aber auch wie seine Nebenfrauen den Titel „l u k u r" tragen $^{29}$.

Drei Texte der Regierungszeit Šulgis verbuchen Lieferungen von Schafen und Ziegen an SI.A-tum ${ }^{30}$. Erhalten ist weiterhin eine Achatperle, die SI.A-tum der Inanna „für das Leben des Šulgi, des starken Mannes, des Königs von Ur“ stiftete $^{31}$. Es ist gut möglich, daß sich mit dieser Weihung an Inanna schon die enge Beziehung der Königinnen der dritten Dynastie von Ur zu dieser Göttin abzeichnet, die für SI.A-tums Nachfolgerinnen Šulgi-simtī und Abī-simtī gut dokumentiert ist.

Sollberger ergänzte die nach den Personennamen in Z. 8 abgebrochene Inschrift wie folgt: „SI.A-tum a [ma] t[u-d]a-ni [a mu-na-ru] 'Watartum. [the mother who bore] him, [has dedicated (this plaque) to her] ${ }^{\prime 632}$. Diese Ergänzung kann nach Kollation des Textes nicht mehr bestätigt werden, da beim derzeitigen Erhaltungszustand der Perle selbst das von Hilprecht noch deutlich gelesene, $\mathrm{ni}^{\text {' }}$ nicht mehr zu erkennen ist $\mathrm{t}^{33}$.

Steinkeller nahm an, Šulgi habe nach dem Tod der Si.A-tum einen offiziellen Kult für seine Mutter installiert, in welchem diese als Personifikation der Göttin Geštinanna, als Geštinanna-SI.A-tum, verehrt wurde ${ }^{34}$.

In dem auf das Jahr Šulgi 33 datierte Text MVN 15, 162, wird im Rahmen des Totenkultes für Ur-Namma ${ }^{35}$ nicht nur Rohr für den verstorbenen König, sondern und unter anderem auch für Damiqtum und die Göttinnen GeštinannaSI.A-tum und Geštinanna-lugal verbucht. Dies ist jedoch kein Belegt dafür, daß SI.A-tum im Jahr Š 33 bereits verstorben war, denn drei Quellen lassen darauf schließen, daß SI.A-tum in diesem Jahr noch lebte: ŠA XXXIII:1, ein Text des Šulgi-simtī-Archives aus dem Jahr Š 42, in dem Schafe als Proviant für SI.Atum ausgegeben werden; BIN III, 491 (Š 43), in dem ein Enlil-zimu lú SI.Atum ein Rind empfängt, und insbesondere der Text ArOr 62, S. 240, I 870 aus

29 Michalowski, Royal Women of the Ur III Period. Part I: The Wife of Šulgi, JCS 28 (1976), S. 169.

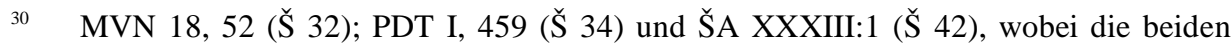
letzteren zum Šulgi-simtī-Archiv gehören.

31 Hilprecht, BE 1, 15 = RIME 3/2.1.2.66, die Perle stammt aus Nippur.

32 Sollberger, Ladies of the Ur -III Empire, RA 61 (1967), S. 69.

33 Sollberger, Ladies of the Ur -III Empire, RA 61 (1967), S. 69; Frayne, RIME 3/2.1.2.66.

34 Steinkeller, More on Ur III Royal Wives, ASJ 3 (1981), S. 77-78. Als Belege führt Steinkeller folgende Texte an: OrSP 18 KDD 24 (ŠS 2); TCL 2, 5514 (IS 2) und AUCT II, 97 (ohne Jahresdatum).

35 Boese, Sallaberger, Apil-kīn von Mari, AoF 23 (1998), S. 29. 
dem Jahr Šulgi 37. In ihm werden Rohrbündel im Rahmen des Totenkultes für Ur-Namma und seine Eltern verbucht, nicht aber für SI.A-tum. Dies ist ein deutlicher Hinweis darauf, daß SI.A-tum noch am Leben war, denn sonst wäre zu erwarten, daß auch sie in diesem Text erwähnt worden wäre. Totenopfer für Ur-Namma und „,die Königin“ (n in ) werden im Jahr Amar-Suen 5 verbucht ${ }^{36}$. Bei der Königin wird es sich hier mit großer Wahrscheinlichkeit um SI.A.-tum und nicht um Šulgi-simtī handeln, da in der vorangehenden Zeile Ur-Namma und nicht Šulgi genannt ist. Es ist also davon auszugehen, daß SI.A-tum ihren Mann um rund 40 Jahre überlebt hat.

Steinkellers Annahme, bei Si.A-tum, der Frau des Ur-Namma und Stifterin der Achatperle für Inanna, handele es sich um die Mutter Šulgis ${ }^{37}$, ist überzeugend. Nach der offiziellen Königsideologie sind die Herrscher der dritten Dynastie von Ur Kinder der Götter Lugalbanda und Ninsun ${ }^{38}$. Doch je nach Anlaß konnte ein König als „Sohn“ verschiedener Göttinnen angesprochen werden. So bezeichnet sich Šulgi auf einem goldenen Ohrring, den er der Geštinanna weiht, als ihr Sohn (du mu -ni $)^{39}$. Die Widmung stammt aus der frühen Regierungszeit Šulgis, als sein Name noch ohne das Gottesdeterminativ geschrieben wurde. Im Zusammenhang mit diesem Text sah Steinkeller die Personifikationen der Geštinanna als Geštinanna-SI.A-tum und Geštinanna-ama-lugal ${ }^{40}$ als Beleg dafür, daß Šulgi für seine Mutter SI.Atum nach deren Tod einen Kult einrichtete und sie als eine Personifikation der Geštinanna verehrt wurde ${ }^{41}$. Wie oben gezeigt wurde, stammt der erste Beleg für Geštinanna-SI.A-tum noch aus der Zeit vor dem Tod der Mutter Šulgis (MVN 15, 162). Es ist jedoch möglich, daß Šulgi die Verehrung seiner Mutter als Geštinanna im Zusammenhang mit seiner eigenen Vergöttlichung als König eingeführt hat, denn Geštinanna galt in der Ideologie des Herrscherhauses schon seit der Zeit Ur-Nammas mitunter als mythologische Mutter der Könige von $\mathrm{Ur}^{42}$. Ob es sich bei der Geštinanna-ama-lugal ${ }^{43}$ um die als Geštinanna

36 UET 3, 21. als Überbringerin ( $\mathrm{g}$ i $\mathrm{ri}_{3}$ ) der Gaben fungiert eine Dame namens Nanna-

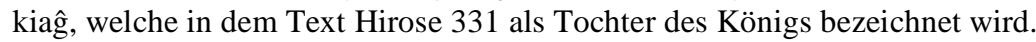

37 Steinkeller, More on Ur III Royal Wives, ASJ 3, S. 77-78.

38 Šulgi B, Z. 7; Sallaberger, Der kultische Kalender der Ur III-Zeit (1993), S. 56. Flückiger-Hawker, Urnamma of Ur in Sumerian Literary Tradition (1999), S. 86.

39 RIME 3/2.1.2.62.

40 Geštinanna.SI.A-tum: MVN 15, 162; TCL 2, 5514; OrSP 18 KDD 24; AUCT II, 97; Geštinanna-ama-lugal: SACT II, 258.

$41 \quad$ Steinkeller, More on Ur III Royal Wives, ASJ 3 (1981), S. 78.

42 Flückiger-Hawker, Urnamma of Ur in Sumerian Literary Tradition (1999), S. 86; D. Katz, The Image of the Netherworld (2003), S. 397ff zu Geštinana.

43 SACT II, 258; der Text stammt aus Umma und ist nur auf den Monat datiert. 
verehrte Königsmutter Si.A-tum handelt oder um die Göttin als Mutter eines Ur III-Königs, der nicht notwendigerweise Šulgi sein muß, ist nicht zu entscheiden ${ }^{44}$.

Auch wenn aus der Zeit Ur-Nammas keine Wirtschaftstexte überliefert sind, die Aufschluß geben könnten über die Aufgaben und Pflichten der SI.Atum, so läßt sich doch ihre prominente Stellung am Königshof in der Zeit UrNammas aus den spärlichen Quellen erahnen. In der Regierungszeit ihres Sohnes Šulgi nahm sie, die Königsmutter, anders als später Abī-simtī, zumindest in den späteren Jahren, für die wir über eine reichhaltige Quellenlage verfügen, keine erkennbar herausragende Stellung im öffentlichen Leben und im Kult war. Es bleibt Spekulation, ob das mit ihrem zu dem Zeitpunkt schon fortgeschrittenen Alter oder mit anderen Faktoren zu erklären ist.

Ein weiterer Hinweis auf ihre Bedeutung an der Seite Ur-Nammas ist ihre Erwähnung in dem literarischen Werk „Ur-Nammas Tod ${ }^{\text {“45. }}$. Hier wird in beinahe 30 Zeilen das Leid und die Trauer der Witwe des toten Königs beschrieben (Z. 166-194). Zwar wird in diesem Text immer nur von der „Frau“ des Königs (dam oder nitadam) gesprochen, ohne daß sie je namentlich genannt wäre, doch ist anzunehmen, daß es sich bei dieser Frau des Königs um SI.A-tum gehandelt hat ${ }^{46}$. Möglicherweise war sie sogar die Auftraggeberin der Komposition. Wilcke ging so weit, sie als die Verfasserin des Textes zu bezeichnen und anzunehmen, ,daß ,U(rnammas) T(od)' die Klage der verwitweten Königin um ihren toten Gemahl ist“". Kramer vermutete eher einen gelehrten Schreiber als Verfasser, der im Auftrag von Šulgi gearbeitet haben könnte ${ }^{47}$. Die Frau des Ur-Namma ist neben Abī-simtī und Kubātum ${ }^{48}$ die einzige Königin dieser Zeit, die in einem literarischen Text Erwähnung gefunden hat. Dies macht deutlich, welche prominente Position sie, die Gemahlin des Betrauerten, gehabt haben muß, denn anders ist ihre Erwähnung in einem Literaturwerk dieser Zeit kaum zu erklären. Zusammen mit der kultischen Verehrung, die sie spätestens seit dem Jahr Šulgi 33 genossen hat, unterstreicht das den hohen Rang der ersten Königin dieser Dynastie.

$44 \quad$ Vgl. Sallaberger, Der kultische Kalender (1993), S. 45 Anm. 191.

45 Zuletzt bearbeitet bei Flückiger-Hawker, Urnamma of Ur in Sumerian Literary Tradition (1999), S. 92-182; siehe dort auch zu der älteren Literatur.

46 Wilcke, Eine Schicksalsentscheidung für den toten Urnammu, CRAI 17 (1970), S. 86 Anm. 2; Michalowski, Royal Women of the Ur III Period Part I: The Wife of Šulgi, JCS 28 (1976), S. 169.

47 Wilcke, Eine Schicksalsentscheidung für den toten Urnammu, CRAI 17 (1970), S. 86; Kramer, The Death of Ur-Nammu (1991), S. 197 Anm. 5.

$48 \quad$ SRT 23. 


\section{Tarām-Uram und Geme-Suen}

Tarām-Uram war mit großer Wahrscheinlichkeit die erste Frau Šulgis. Sie war die Tochter des Apil-kīn von Mari, wie aus der altbabylonischen Abschrift einer Weihinschrift von ihr hervorgeht, in welcher sie sich als „,die Tochter des Apil-kīn, des Königs von Mari, die Schwiegertochter des Ur-Namma, des Königs von Ur" bezeichnet ${ }^{49}$. Die Tatsache, daß hier noch Ur-Namma als König von Ur genannt wird und Tarām-Uram sich selber seine Schwiegertochter (é-gi $\left.\mathrm{i}_{4}-\mathrm{a}\right)$ nennt, zeigt deutlich, daß diese Ehe vor dem Regierungsantritt Šulgis geschlossen worden ist, welcher zum Zeitpunkt der Hochzeit noch sehr jung gewesen sein muß. Neben dieser Weihinschrift ist von TarāmUram nur ein weiteres Textzeugnis erhalten, das Siegel ihres Dieners PuzurSuen $^{50}$. Wirtschaftstexte mit ihrem Namen sind derzeit nicht bekannt, was nicht weiter auffällig ist, da die Textüberlieferung für die ersten Regierungsjahre Šulgis sehr spärlich ist.

Wie Boese und Sallaberger zeigen konnten, wurde Apil-kīn von Mari bis zum Ende der Ur III-Zeit in den Totenkult der Könige der Dynastie einbezogen und steht dabei nicht nur Ur-Namma, sondern auch Amar-Suen in besonderer Weise nahe ${ }^{51}$. Diese Einbeziehung des Königs von Mari in den Totenkult der Herrscher von Ur ist kaum anders zu erklären als damit, daß Apil-kīn zu den direkten Vorfahren des Königshauses von Ur zählte. Folglich muß seine Tochter Tarām-Uram die Frau Šulgis und Mutter seines Sohnes und Nachfolgers Amar-Suen gewesen $\operatorname{sein}^{52}$.

Der Name „Tarām-Uram = Sie liebt Ur“ ist ein programmatischer Name, den die Prinzessin aus Mari bei ihrer Verheiratung nach Ur angenommen hat.

Die Verbindung zwischen dem Königshaus von Ur und dem von Mari begründete die während der gesamten Ur III-Zeit friedlichen Beziehungen zwischen den beiden Reichen, was sich zum einen im Fehlen jeglicher kriegerischer Auseinandersetzung und zum anderen in den häufigen Erwähnungen von Leuten aus Mari in den Texten des Reiches von Ur niederschlägt ${ }^{53}$.

Über das weitere Schicksal der Tarām-Uram ist nichts bekannt, weshalb man annimmt, daß sie früh verstorben ist. Da sie bei ihrer Hochzeit einen neuen Namen angenommen hat, ist es kaum vorstellbar, daß sie ein weiteres

\footnotetext{
49 RIME 3/2.1.1.52.

50 RIME 3/2.1.1.53.

51 Boese, Sallaberger, Apil-kīn von Mari, AoF 23 (1998), S. 27-28, 34.

52 ebd., S. 33-34.

53 Sallaberger, OBO 160/3 (1999), S. 160-161; Michalowski, Men from Mari, OLA 65 (1995), S. 181-188.
} 
Mal ihren Namen geändert haben sollte und dadurch in den Texten nicht mehr zu identifizieren wäre.

Die zweite Frau Šulgis war Geme-Suen. Auch von ihr sind keine Wirtschaftstexte mit ihrem Namen erhalten. Bekannt ist Geme-Suen nur durch das Siegel ihres Dieners Šu-Kūbum, das auf zwei Tafeln abgerollt ist, auf denen die Übernahme von totem Vieh durch Šu-Kūbum verzeichnet wurde ${ }^{54}$. In der Siegellegende wird Geme-Suen dam Šul-gi genannt, wobei der Name des Königs hier noch ohne das Gottesdeterminativ geschrieben wurde. Da der Titel „dam“ für die Frau des Königs nur so lange Verwendung fand, wie dieser nicht vergöttlicht wurde ${ }^{55}$, ist davon auszugehen, daß das Siegel aus der Zeit vor dem Jahr Šulgi 20 stammt. Die beiden gesiegelten Texte jedoch sind auf die Jahre Š 28 (JCS 31, S. 133) und Š 26 bzw 32 (JCS 28, S. 171) ${ }^{56}$ datiert. Da Šu-Kūbum für die Jahre Š 29 bis Š 32 als Hauptbeamter der Viehhaltung von Šulgi-simtī gilt ${ }^{57}$, werden diese beiden Texte ihrem Archiv zugerechnet ${ }^{58}$. Es ist allerdings fraglich, ob diese Zuordnung zutreffend ist.

Bei beiden Texten handelt es sich um die Annahme von totem Vieh durch Šu-Kūbum. Im Text JCS 31, S. 133 ist der liefernde Beamte Nalu ${ }^{59}$. Dieser Beamte, der in Puzriš-Dagān in der Zeit von Š 26 bis zu ŠS 6 belegt ist, erscheint sonst kaum je im Zusammenhang mit Šulgi-simtī. Diese Tatsache, wie auch das frühe Datum des Textes und das Siegel, auf welchem Šu-Kūbum sich Diener der Geme-Suen nennt, könnten dafür sprechen, daß es sich hier um eine Transaktion im Namen/im Auftrag der Geme-Suen gehandelt haben könnte. Unklar ist, ob dann auch der Text JCS 28, S. 171, aufgrund des Siegels der Geme-Suen zuzurechnen ist ${ }^{60}$. Die Zuordnung der Texte zu einer der beiden königlichen Damen nur auf der Grundlage eines Dienersiegels ist in jedem Fall nicht unproblematisch, da die Verwendung eines Siegels nicht unbedingt mit

54 JCS 28 (1976), S. 171 und JCS 31 (1979), S. 133 Nr. 1; zum Siegel siehe RIME 3/2.1.2.68.

55 Michalowski, Royal Women of the Ur III Period. Part I: The Wife of Šulgi, JCS 28 (1976), S. 170-171. Zu den Titeln der königlichen Frauen s.u. S. 234-240.

56 Bei diesem Text handelt es sich um eine Tafel mit Hülle, wobei die Tafel das Datum $\breve{S}$ 26 (zweite Zerstörung von Simurrum), die Hülle das Datum Š 32 (dritte Zerstörung von Simurrum') trägt. Diese Beobachtung ist schwer zu erklären, Michalowski nahm an, daß das spätere Datum das zutreffende und der fehlende Keil im Datum der Tafel als Schreiberfehler anzusehen sei (JCS 28 (1976), S. 170).

57 Zu dem Beamten der Königin Šulgi-simtī siehe Kap. 3.3.

58 Vgl. die Liste der Šulgi-simtī-Texte bei Sallaberger, OBO 160/3 (1999), S. 377-390.

59 Zu Nalu in den Texten aus Drehem siehe Sigrist, Drehem (1992), S. 257-259.

60 Zur Schwierigkeit der Zuordnung der frühen Texte aus dem Archiv der Šulgi-simtī siehe Kap. 3.2. 
dem Leben des in der Legende erwähnten Vorgesetzten endete.

Außer dem Siegel des Šu-Kūbum ist mit dem des Itrak-ilī möglicherweise das Siegel eines weiteren Dieners der Geme-Suen erhalten. In der Siegellegende ist der Name der Frau des Šulgi nicht vollständig erhalten, der Name des Königs ist hier mit dem Gottesdeterminativ geschrieben ${ }^{61}$.

Eine Dame namens Geme-Suen ist auf dem Siegel des Ajazimu erwähnt ${ }^{62}$. Da die mit diesem Siegel versehene Tafel aber aus dem Jahr IS 7 stammt, handelt es sich hier wohl nicht um Geme-Suen, Frau des Šulgi, sondern möglicherweise um eine spätere Prinzessin des gleichen Namens ${ }^{63}$.

Des weiteren ist das Siegel eines Ur-Enlil, $\mathrm{nu}-\mathrm{b}$ anda $\mathrm{a}_{3} \mathrm{nin}$, bekannt. Aufgrund des Datums der Tafel, auf der das Siegel abgerollt ist ${ }^{64}$, kann UrEnlil entweder als Diener der Geme-Suen oder der Šlgi-simtī angesehen werden. Da jedoch ein Ur-Enlil nicht als Diener von Šulgi-simtī bekannt ist, liegt es nahe, ihn als nu-b and $a_{3}$ der Geme-Suen zu betrachten.

\section{3. Šulgi-simtī}

\subsection{Die Einordnung des Archives}

Das bei weitem umfangreichste Quellenmaterial zu einer Königin dieser Epoche liegt zu Šulgi-simtīi ${ }^{65}$, der letzten von Šulgis Königinnen, vor. Sie war in der Zeit von ii $/ \breve{S} 28^{66}$ bis xi/Š $48^{67}$ aktiv. Kurze Zeit nach dem Tod Šulgis ist sie ebenfalls verstorben, wie Opfer an ihrem „Wassertränkort“ (ki-a-nâg) belegen. ${ }^{68}$

${ }^{61}$ RIME 3/2.1.2.68. Frayne ergänzte den Namen der Dame mit ${ }^{\top} A-m a-a t^{\top}{ }^{\mathrm{d}}$ EN.ZU. Problematisch bei dieser Ergänzung ist, daß die Namen der königlichen Haupt- und Nebenfrauen mit dem Namenselement "Dienerin des GN" stets mit dem sumerischen Terminus gé m e geschrieben werden und nicht in der akkadischen Form amat.

62 NATN 5; siehe Kutscher, From the Royal Court to Slavary in the Ur III Period, Tel Aviv 11 (1984), S. 186-187.

63 Zur erneuten Verwendung der Personennamen bedeutender Vorfahrinnen siehe S. 274.

64 MVN 3, $130(-/ i /$ Š 31).

65 Der Name dieser Königin erscheint in den Texten in den beiden Formen ${ }^{\mathrm{S}}$ Šulgi-simtī

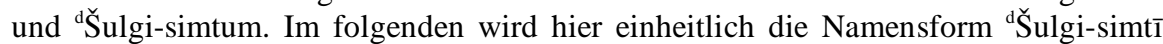
gebraucht, sofern nicht in einem zitierten Text die andere Namensform verwendet wird.

66 UET 3, 289.

67 MVN 8, 113.

68 ZVO 25, 134, 2 (22/iii/AS 1), Totenopfer für Šulgi sind erstmals belegt am 2/xi/Š 48, siehe Sallaberger OBO 160/3 (1999), S. 161-163. Zu den Orten für Libationen im 
Šulgi-simtī kam wahrscheinlich aus Ešnunna, worauf die beiden von ihr besonders verehrten Göttinnen Bēlat-Šuhnir und Bēlat-Deraban weisen, welche zum Pantheon dieser Stadt zu zählen sind ${ }^{69}$. Diese Göttinnen brachte Šulgisimtī mit nach $\mathrm{Ur}^{70}$. Mit einer dynastischen Verbindung zu Ešnunna konnte Šulgi das strategisch wichtige Dijala-Gebiet für das Reich von Ur sichern. Möglicherweise geht die besondere Stellung Ešnunnas im Abgabensystem des Reiches auf die Verbindung des Königs mit Šulgi-simtī zurück. Ešnunna, das geographisch zur Peripherie des Reiches gehörte, war wie eine Stadt des Kernlandes in das System der bala-Lieferungen eingebunden ${ }^{71}$. Bei dem Namen der späteren Königin, „Šulgi ist meine Zierde“, handelt es sich wie bei Tarām-Uram um einen mit der Eheschließung angenommenen $\mathrm{Namen}^{72}$, der die Verbundenheit mit der neuen Heimat, der neuen Familie zum Ausdruck bringen sollte.

Eine Schwester der Königin $\left(\mathrm{nin}_{9}-\mathrm{nin}\right)$ ist in zwei Texten aus Girsu zu finden, von denen einer in das Jahr $\breve{S} 36$ datiert. $^{73}$ Dieses Datum legt die Vermutung nahe, es handele sich um eine Schwester der Šulgi-simtī. Der Name dieser Schwester ist noch nicht zu ermitteln.

Šulgi-simtī konnte über eine eigene Verwaltung ihres Viehbestandes verfügen, aus dem sie vor allem die Tiere für die regelmäßig anfallenden Opfer bezog. Aber auch zu nichtkultischen Anlässen wurden Tiere aus dem Bestand der Königin abgebucht. Nur sehr wenige Texte, die Aufschluß geben über Šulgi-simtī, gehören nicht in den Zusammenhang ihres Archives ${ }^{74}$. Dieses System der getrennten Buchhaltung zu den Viehbeständen des Königs und jenen der Königin wurde nach Šulgi-simtī aufgegeben. Ihre Nachfolgerinnen waren bezüglich ihrer wirtschaftlichen Belange eingebunden in ein

Rahmen des Totenkultes für die einzelnen Angehörigen der königlichen Familie von Ur siehe Gomi, Shulgi-simti and her libation place (KI-A-NAG), Orient 12 (1976), S. 4-5.

69 Sallaberger, Der kultische Kalender (1993), S. 19.

70 Siehe S. 47.

71 Siehe Steinkeller, The Administrative and Economic Organization of the Ur III State: The Core and the Periphery, SAOC 46 (1987), S. 22 mit Anm. 12.

72 Sigrist, Drehem (1992), S. 222; Boese, Sallaberger, Apil-kīn von Mari, AoF 23 (1998), S. 25.

73 MVN 22, 140 (5/vi/-), Arbeiter für einen „Kanal der Schwester der Königin“; MVN 22, 145 (xi $\left.{ }^{\mathrm{II}} / \mathrm{S} \mathrm{S} 36\right)$ Kleinvieh für kultische Zwecke, Abbuchung bei der Schwester der Königin (zi-ga ki nin ${ }_{9}$-nin-ta).

74 Dazu zählen PDT I, 434 (dieser Text gehört zum Schuharchiv von Drehem) und der bisher nur online publizierte Text Philips 13 (http://courses.smsu.edu/mac566f/ Phillips13/phillips13.html). Seit kurzem ist die Tafel Teil der Gratianus-Stiftung, Reutlingen, K. Volk bereitet die Publikation des Textes vor. 
einheitliches System der königlichen Verwaltung.

Die zum sogenannten „Archiv der Šulgi-simtī“ gehörigen Quellen wurden erstmals 1961 von Jones und Snyder unter der Bezeichnung „An Early Drehem (?) Series" beschrieben und zusammengestellt. ${ }^{75}$ Die Texte dieses Archives, das zuerst in Esaĝdana ${ }^{76}$ und später in Puzriš-Dagān (Drehem) zu lokalisieren ist, sind von den zeitgleichen Texten der königlichen Viehverwaltung in PuzrišDagān durch die Form der Datierung, die Terminologie und die handelnden Personen deutlich zu unterscheiden. So ist das Formular der Tagesangaben kennzeichnend, es tritt außer im Šulgi-simtī-Archiv nur noch in den Texten aus dem Schatzarchiv von Puzriš-Dagān aus dem Jahr Šulgi 45 auf: iti-ta $\mathrm{u}_{4}-\mathrm{X}$ ba-ra-zal, etwa „von dem Monat sind X Tage vergangen“77. Weiterhin ist kennzeichnend, daß die Einführung des Akiti-Jahres im Reichskalender in den Jahren Š 44 bis Š 48 im Archiv der Šulgi-simtī nicht übernommen wurde ${ }^{78}$.

Das umfangreiche Textkorpus zu Šulgi-simtī gibt zum einen Aufschluß über die kultischen Aktivitäten dieser Königin, zum anderen erlaubt es jedoch auch eine Untersuchung zum sozialen Umfeld dieser Dame, und informiert damit über die Interaktionen der Angehörigen der obersten Gesellschaftsschicht im Reich von Ur III.

Die überwiegende Mehrzahl der Texte läßt sich zwei Gruppen zuordnen:

Die Einnahmetexte verbuchen Lieferungen unterschiedlicher Tiere von verschiedensten Personen. Ab der Mitte des Jahres Š $33^{79}$ haben diese Texte, von Ausnahmen abgesehen, durchgängig die Formel „PN ì-dab $b_{5} \mathrm{mu}-\mathrm{DU}$ dŠulgi-simtī - PN nahm es an, Einlieferung an Šulgi-simtī". In der Zeit vor S 33 findet sich entweder der erste Teil der Formel $\left(\mathrm{PN} \grave{\mathrm{i}}-\mathrm{dab}_{5}\right.$ ) oder der zweite Teil (mu-DU d Šulgi-simtī). Da die annehmenden Beamten in diesen Texten eindeutig der Königin zugeordnet werden können, und da sich die Amtszeiten der einzelnen Beamten genau abgrenzen lassen, stellen sie ein

75 Jones/Snyder, Sumerian Economic Texts from the Third Ur Dynastie. Zu dem Archiv zuletzt Sigrist, Drehem (1992) S. 222-246, Sallaberger, Der kultische Kalender (1993), S. 18-25 und ders. in OBO 160/3 (1999), S. 253-260. Eine Zusammenstellung der zum Archiv gehörigen Texte findet sich bei Sallaberger OBO 160/3 (1999) S. 377390. Dazu kommen die später publizierten Texte in Hilgert, OIP 115, Sigrist, SAT II, Grégoire, AAICAB 1/2, Owen, ASJ 19, S. 200 Nr. 1, Wilbanks/Biggs, NABU 1997/99, v. Dassow, JCS 52, S. 128, Veldhuis, ZA 93, S. 58 Nr. 10 und NISABA 8. Wilcke, É-saĝ-da-na Nibru ${ }^{\mathrm{ki}}$ : An Early Administrative Center of the Ur III Empire. OPSNKF 14 (1992), S. 311-324.

77 Zur Schwierigkeit der Etymologie von zal „strahlen, aufleuchten“ oder ,verfließen“ siehe Sallaberger, Der kultische Kalender (1993), S. 22 Anm. 84. Zum Kalender der Ur III-Zeit siehe Sallaberger OBO 160/3 (1999), S. 231-237, zum Kalender der Šulgi-simtī-Texte siehe ebd. S. 257.

79 Der früheste mir vorliegende Beleg ist CST 42 (v/Š 33). 
wichtiges Kriterium für die Zuordnung von Urkunden zum Archiv der Šulgisimtī dar. In den Einnahmetexten tritt Šulgi-simtī, wenn sie erwähnt wird, immer mit ihrem Namen auf, nie wird sie nur mit dem Titel genannt.

Die zweite große Gruppe von Texten umfaßt die Verbuchung von Ausgaben. Diverse Tiere werden für unterschiedliche kultische oder profane Zwecke zur Verfügung gestellt. Diese Texte sind durch die Formel ,zi - g a PN - abgebucht bei PN“ gekennzeichnet. Der Name der Königin erscheint nur in einigen wenigen Ausnahmefällen. Hier treten die schon aus den Einlieferungstexten bekannten Beamten in der Funktion der ausgebenden Person auf, womit sich diese Texte dem Archiv der Königin zuordnen lassen. Ein weiteres Kriterium für die Zuordnung von Ausgabetexten zum Archiv sind die Namen der mit Opfertieren versorgten Gottheiten. Hier sind insbesondere die beiden Göttinnen Bēlat-Šuhnir und Bēlat-Deraban, die persönlichen Göttinnen der Šulgi-simtī, sowie die Göttinnen Annunītum und Ulmašītum zu nennen.

Eine besondere Gruppe innerhalb der Ausgabentexte sind jene Urkunden, in denen die Königin nicht mit ihrem Namen, wohl aber mit dem Titel „Königin/Herrin“ (nin) erscheint. Hierbei werden entweder Lieferungen für die Tafel der Königin verbucht $\left(n \hat{1} \hat{g}-g u_{7} \text { nin-ĝá-šè }\right)^{80}$, oder die Königin tritt bei Opfern an die Götter selber als Überbringerin auf ( $\left(\hat{\mathrm{g}}\right.$ i ri $\left.{ }_{3} \mathrm{nin}-\hat{\mathrm{g} a ́}\right)$.

Bei der überwältigenden Mehrzahl der Texte aus dem Archiv der Šlgisimtī geht es um die Einnahme oder Ausgabe von Tieren zu unterschiedlichen Zwecken. Doch eine kleine Textgruppe gibt Einblick in die Aktivitäten der Königin in der Textilproduktion. Dieser in Mesopotamien bedeutsame Wirtschaftszweig fand schon in Ebla die besondere Aufmerksamkeit der königlichen Frauen ${ }^{81}$. Abī-simtī, die Amtsnachfolgerin von Šulgi-simtī war, wie zu zeigen sein wird, in diesem Wirtschaftsbereich ebenfalls sehr aktiv.

Auffällig ist das weitgehende Aussetzen der Texte zu Šulgi-simtī im letzten Regierungsjahr Šulgis. Der König ist mit großer Wahrscheinlichkeit am 2/xi/ $\breve{S} 48$ verstorben $^{82}$, am folgenden Tag wurden Tiere aus dem Bestand des Königs an Šulgi-simtī überwiesen ${ }^{83}$. Totenopfer für Šulgi-simtī sind im Monat iii/AS 1 belegt, die Königin ist also kurz nach dem König gestorben. Während für die Jahre Š 30 bis Š 47 eine umfangreiche Dokumentation zu den Einnahmen und Ausgaben der Königin vorliegt, fehlen diese fast vollständig für das Jahr Š 48. Der letzte bisher bekannte Einnahmetext datiert auf den

\footnotetext{
80 Siehe dazu Kap. 3.6.1. S. 94f.

81 Siehe Exkurs 2 S. 194f.

82 Sallaberger, OBO 160/3 (1999), S. 161-162.

83 MVN 8, 113.
} 
5/xi/ $/{ }^{5} 47^{84}$, die letzte Ausgabe für nicht-kultische Zwecke erfolgte kurz danach, am 19/xi/ $/ \check{S} 47^{85}$, die letzte Ausgabe für den Kult ist verbucht am 10/ii//̌ $48^{86}$. Danach setzt die Dokumentation, von einer Wollieferung abgesehen ${ }^{87}$, bis zum Tod Šulgis aus. Möglicherweise ist der Text UDT 116 (12/xii/ ̌ 48), wo 4 Schafe für den Wassertränkort des Šulgi sowie 1 Schaf für das é-uz-ga im Namen der Königin (mu nin-šè) verbucht werden, noch auf Šulgi-simtī zu beziehen, es könnte jedoch auch der erste Tetxt sein, der ihre Nachfolgerin Abī-simtī als Königin nennt. Es stellt sich die Frage, was in den 9 Monaten, für die die Dokumentation über die Aktivitäten Šulgi-simtīs fehlt, geschehen ist.

\subsection{Von Geme-Suen zu Šulgi-simtī - wer war Königin?}

Schwierigkeiten bestehen noch bei der Frage, ab wann Šulgi-simtī die Position einer Königin einnahm und ab wann sie selbständig die heute mit ihrem Namen verbundenen Transaktionen führte und veranlaßte. Erstmals in den Urkunden erwähnt wird Šulgi-simtī im Monat ii/ ̌ 28 in einem Text aus Ur, wo es um das Gewicht einer Bronzeschale für Šulgi-simtī geht ${ }^{88}$. Die letzte Urkunde, die mit dem Siegel des Šu-Kūbum gesiegelt ist, auf dem er sich als Diener der GemeSuen bezeichnet, stammt aus dem Jahr Š $32^{89}$. Aus eben diesem Jahr stammt

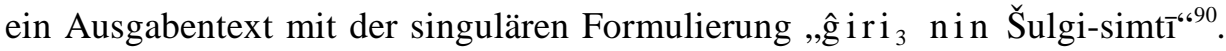
Nur in diesem einen Text erscheint die Königin mit Titel und Namen, danach wird immer nur eines von beiden genannt. Dies ließ schon Sallaberger vermuten, daß es in diesem Jahr zu einem Wechsel an der Spitze der königlichen Frauen am Hof von Ur gekommen sein könnte, und daß es unmittelbar nach dem Amtswechsel noch nötig war, die neue Königin mit Titel und Namen zu bezeichnen ${ }^{91}$. Für diese Annahme spricht, daß ein ähnliches Phänomen auch in Ebla zu beobachten ist, wo die Königin in den Wirtschaftstexten ausschließlich mit dem Titel genannt wird. ${ }^{92}$ Nur unmittelbar nach ihrem Amtsantritt werden Name und Titel festgehalten, um jedem in der Verwaltung deutlich zu machen, wer sich hinter dem Titel der Königin - maliktum in Ebla, nin in Ur -

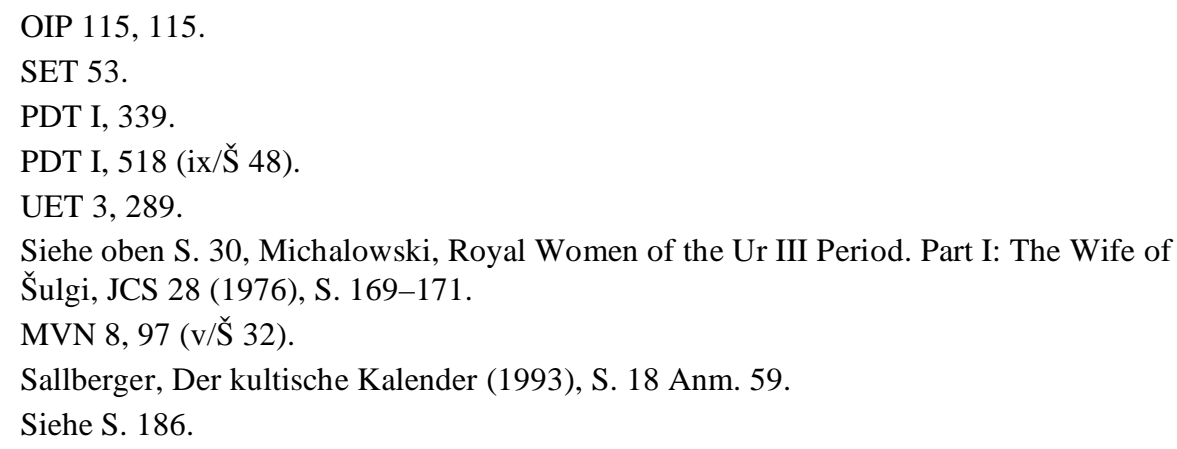


verbirgt.

Für die Annahme eines Amtswechsels im Jahr Š 32 können auch die frühen Einlieferungstexte, die dem Šulgi-simtî-Archiv zugerechnet werden und die alle mit der Person des Beamten Šu-Kūbum verbunden sind, sprechen. Vier Texte aus den Jahren Š 29 bis Š 31 verbuchen mu-DU-Lieferungen, welche von ihm angenommen werden. ${ }^{93}$ Unter den Lieferanten sind einige, die auch in späteren Jahren an Šulgi-simtī liefern wie Teșīn-Mama und Ama-bara, sodaß hier kein Wechsel festgestellt werden kann. Allerdings ändert sich mit dem Jahr Š 32 leicht das Formular der mu-DU-Texte. Allen vier eben zitierten Texten ist die Formulierung „Šu-Kübum ì- da $b_{5}$ “" gemein, ohne daß der Name einer Dienstherrin mit aufträte. Ab dem Jahr Š 32 findet sich das Formular

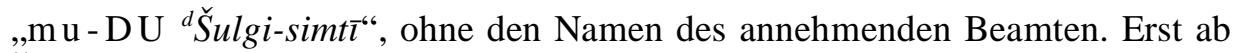
Š 33 und unter dem Beamten Bēlītṭāb wird das Formular einheitlich „PN ì $\mathrm{dab}_{5} \mathrm{mu}-\mathrm{DU}{ }^{d} \breve{S} u l g i-\operatorname{simtit} "$.

Schwieriger ist es dagegen mit den Ausgabetexten dieser Zeit, bei denen Šu-Kūbum als abbuchender Beamter auftritt. Die Zuweisung dieser Texte zum Archiv der Šulgi-simtī erfolgte bei den Texten des Beamten Šu-Kūbum über Bēlat-Šuhnir und Bēlat-Deraban, die persönlichen Göttinnen der Königin. Für diese beiden Göttinnen werden ab dem Jahr Š 29 Opfer verbucht ${ }^{94}$. In zwei Fällen erscheint neben dem ausgebenden Beamten Šu-Kūbum auch die Königin als Überbringerin der Opfer (ĝiri ${ }_{3}$ nin-ĝá) $)^{95}$. Bei dem früheren dieser beiden Texte werden Bēlat-Šuhnir und Bēlat-Deraban beopfert, in dem anderen Fall handelt es sich um Opfer an die für Šulgi-simtī untypischen Götter Enki, Gula und Nin-GIŠ-KÉŠ-a. Ob diese Gottheiten möglicherweise von Geme-Suen besonders verehrt wurden, ist aufgrund fehlender Quellen zu jener Dame nicht zu entscheiden. Will man diese Texte der Amtszeit Geme-Suens zuweisen, so erscheint es befremdlich, daß die persönlichen Göttinnen der dann zu postulierenden königlichen Nebenfrau Šulgi-simtī so prominent in den Texten erscheinen, während keine Hinweise auf die Gottheiten zu finden sind, welche von Geme-Suen bevorzugt verehrt worden sein könnten. Dieses Problem kann zum derzeitigen Zeitpunkt noch nicht befriedigend gelöst werden.

Dennoch soll folgender Versuch einer Rekonstruktion der Ereignisse versucht werden:

Šulgi-simti kam im Jahr Š 28 infolge einer dynastischen Ehe des Königs nach Ur. Dort war zu dieser Zeit Geme-Suen Hauptfrau und Königin. In ihren

93 OIP 115, 16 (xi/Š 29); MVN 3, 117 (i/Š 31); OIP 115, 17 (iv/Š 31) und BIN III, 360 (iv/Š 31).

94 Zuerst OIP 115, 18 (vi/Š 29) Opfer an Allatum, Bēlat-Šuhnir und Bēlat-Deraban.

$95 \quad$ PDT II, 1314 (x/Š 29) und PDT II, 1363 (viii/Š 31). 
Diensten stand Šu-Kūbum, der für die Viehwirtschaft der Königin verantwortlich war. In den Jahren Š 28 bis Š 32 gelang es Šulgi-simtī, ihre Position am Hof zu sichern, wobei die Versorgung ihrer persönlichen Göttinnen aus dem Bestand der Königin Geme-Suen bestritten wurde, welche zumindest einmal den neuen, fremden Gottheiten selber Opfer darbrachte ${ }^{96}$. Möglicherweise erkrankte Geme-Suen gegen Ende des Jahres Š 31, worauf Opfer an die Heilgöttin Gula und den Gott Enki deuten könnten ${ }^{97}$. Ab der Mitte des Jahres Š 32 übernahm dann Šulgi-simtī die Position der Königin. Von diesem Zeitpunkt ändert sich das Formular der Texte wie oben dargelegt, und Šulgisimtī ist nun nicht mehr nur im Bereich des privaten Kultes tätig, sondern engagiert sich ebenso im Kult der großen Göttern des Landes. Ab dem Jahr Š 32 treten die Gottheiten Inanna, Nanna, Enlil und Ninlil (neben verschiedenen anderen) als Empfänger von Opfern seitens der Šulgi-simtī auf.

Wenn diese Rekonstruktion zutreffend sein sollte, so hieße das, daß man die spätere Königin gut vier Jahre bevor sie dieses Amt übernahm am Hof von Ur nachweisen kann, und daß hier der Aufstieg einer ausländischen Prinzessin von der Nebenfrau des Königs zu seiner Hauptfrau zu beobachten wäre. Darüber hinaus ließe sich die sonst nicht zu belegende Vermutung Sallabergers, Šulgi-simtī habe die Tätigkeiten der Geme-Suen übernommen ${ }^{98}$, bestätigen, denn dann wäre zwar nicht für den Bereich des Kultes der großen Göttern, wohl aber für das gesamte System von Einnahme (mu-DU) und Ausgabe (zi-ga) in der Haushaltsführung der Königinnen zur Zeit des Šulgi eine Kontinuität zu beobachten.

\subsection{Beamten der Š Sulgi-simtī}

Die Amtszeiten der Hauptbeamten des Achives sind deutlich voneinander abgegrenzt. Es war stets nur ein Beamter für die Einnahme des Viehs verantwortlich, welcher dann auch für den größten Teil der Ausgabeurkunden zeichnete. Daher bieten die Namen der Beamten eine sichere Grundlage für die Zuweisung eines Textes zum Archiv der Königin. Folgende Amtszeiten lassen sich nach der derzeitigen Quellenlage für die einzelnen Beamten feststellen ${ }^{99}$ :

\footnotetext{
$96 \quad$ PDT II, 1314 (x/Š 29).

$97 \quad$ PDT II, 1363 (viii/Š 31).

98 Sallaberger, Der kultische Kalender (1993), S. 18.

99 Vgl. Sigrist, Drehem (1992), S. 226; Sallaberger, Der kultische Kalender (1993) S. 21.
} 
Königinnen

\begin{tabular}{|c|c|c|}
\hline & derzeit erster Beleg & derzeit letzter Beleg \\
\hline Šu-Kūbum $^{100}$ & vi/Š 29 (TLB III, 12) & i/Š 32 (TLB III, 94) \\
\hline Bēlī-tāb & v/Š 33 (CST 42) & vi/Š 37 (MVN 3, 153) \\
\hline Apilia & ix/Š 37 (TPTS 9) & 11/x/ŠS 41 (OIP 115, 65) \\
\hline Apilatum & 26/xi/Š 41 (TCND 52) & vi/Š 45 (PDT II, 982) \\
\hline Ur-Lugal-edenka & 11/vii/Š 45 (MVN 18, 72) & 28/iv/Š 47 (CST 173) \\
\hline Šulgi-ilī & iv/Š 47 (TCND 24) & 4/iv/AS 1 (PDT II, 1215) \\
\hline
\end{tabular}

Tabelle 1: Hauptbeamten der Šulgi-simtī

Bei den drei Beamten Bēlī-tāa, Apilia und Apilatum betrug die Amtszeit jeweils gut dreieinhalb bis vier Jahre. Ob es sich hier möglicherweise um eine regelmäßige Amtsperiode von vier Jahren handelt oder ob diese Zeitspannen der Tätigkeit zufällig sind, läßt sich nicht entscheiden, zumal bei den Hauptbeamten des Zentralarchives von Puzriš-Dagān keine turnusmäßigen Wechsel im Amt festzustellen sind. Šulgi-ilī, der letzte Beamte der Viehverwaltung der Šulgi-simtī überführte nach dem Tod der Königin die letzten Tiere in die königliche Zentralverwaltung, wo sie vom dortigen Hauptbeamten Nasa übernommen wurden ${ }^{101}$.

Es fällt auf, daß diese Hauptbeamten der Königin ihre letzten Abrechnungen und die Rückerstattung von Vieh an Šulgi-simtī erst lange nach dem Ende ihrer Amtszeit abschlossen. So hat Bēlīțāa erst gut sechs Jahre später die letzten Tiere an die Königin zurückgegeben ${ }^{102}$. Apilatum erstattete die fehlenden Tiere im Jahr Š 46 zurück, wie die Annahme eines Schafes als rückerstattete Restschuld (lá-ì su-ga) durch Ur-Lugal-edenka, den amtierenden Verwalter der Königin, zeigt ${ }^{103}$. Nach einer Bilanz über die Zeit von vi/Š 44 bis viii/Š 46 wurde für Apilatum ein Fehlbestand von einem Rind und insgesamt 94 Tauben verzeichnet ${ }^{104}$, doch noch im selben Monat werden diese Tiere geliefert und als vorhanden (in- $\mathrm{d} a-\hat{g}$ ál) verbucht ${ }^{105}$.

Šu-Kūbum trägt auf dem Siegel, auf welchem er sich Diener der GemeSuen nennt, die Amtsbezeichnung „Bote“ (rá-gaba) ${ }^{106}$. Im Jahr Š 38, also

\footnotetext{
100 Šu-Kūbum wird hier mit geführt, da er in jedem Fall im Dienst einer Königin stand, unabhängig davon, ob dies nun Geme-Suen oder Šulgi-simtī war.

101 PDT II, 1215.

102 MVN 18, 144 (xii/Š 43).

103 BIN III, 310 (iv/Š 46).

$104 \quad$ MVN 13, 649.

105 CST 129 (viii/Š 46).

106 RIME 3/2.1.2.67.
} 
nach seiner Amtszeit als Hauptbeamter der Königin, erscheint er einmal im Kontext von mu-DU-Lieferungen an Šulgi-simtī als Aufseher (ugula) mit der Amtsbezeichnung „Viehverwalter“ $\left(\mathrm{ku} \mathrm{s}_{7}\right)^{107}$. Beli-țāb, Apilatum und Šulgi-ilī tragen die Amtsbezeichnung „Viehmäster“ (kurušda) ${ }^{108}$. Ur-Lugaledenka bezeichnet sich auf seinem Siegel als „Schreiber“ (dub-sar) ${ }^{109}$. In einem Text erscheint Šulgi-ilī als „Bote“ $\left(\mathrm{rá}-\mathrm{g} a \mathrm{ba}\right.$ ) ${ }^{110}$, allerdings handelt es sich hier um Vieh als mu - DU -Lieferung für den König, welches von Šulgi-ilī, einem Beamten der Königin, angenommen worden war. Möglicherweise trägt die Urkunde deshalb den singulären Vermerk "Siegel der Šulgi-simtum“ (kišib ${ }^{d} \breve{S} u l$-gi-sí-im-tum), da die 80 Schafe und Ziegen eigentlich von der falschen Administration in Empfang genommen worden waren und später in die königliche Viehverwaltung überführt werden mußten. Die Königin selbst bestätigte dabei die Richtigkeit des Vorgangs, ihr Hauptbeamter war als Bote für die Verwaltung des Königs tätig. Ein ähnlicher Vorgang ist in TCND 23 (vii/Š 46) dokumentiert, wo Šulgi-simtī 120 Stück Kleinvieh als Lieferung für den König (mu - DU lug al) von Narām-ilīi ${ }^{111}$ annahm (ì - dab ${ }_{5}$ ).

Außerhalb ihrer Amtszeit als Hauptverantwortliche für die Tierbestände der Königin treten diese Beamten noch vereinzelt in den Texten des Šulgi-simtīArchives auf, entweder als Beamten in der Funktion des Überbringers ( $\left(\hat{\mathrm{ir}} \mathrm{i}_{3}\right.$ ) oder des Bevollmächtigten (maški m) oder aber als Lieferanten von Tieren im Rahmen der mu - DU-Lieferungen.

Neben den Hauptbeamten sind noch weitere Funktionäre der Königin direkt zuzuordnen. In den Jahren $\breve{S} 30$ bis Š $36^{112}$ ist Ahima als Ausgabebeamter tätig.

107 MVN 18, 42; zu ku š ${ }_{7}$ als hoher Funktionär, verantwortlich für das Vieh des Hofes, siehe Sigrist, Drehem (1992) S. 187. Der Vorschlag von Beal statt kuš $\check{7}_{7}$ eher šǔš zu lesen (NABU 1992/48), ist wiederholt diskutiert worden. Vgl. dazu Cavigneaux, NABU 1992/103; Foxvog, Cuneiform Tablets in California Private Collections, ASJ 15 (1993), S. 72; De Maaijer, B. Ur III-Texts (Nos. 2-15), JEOL 33 (1995), S. 117; Such-Gutiérrez, Beiträge zum Pantheon von Nippur im 3. Jahrtausend (2003), Teil I S. 73, mit weiterer Literatur. In dieser Arbeit wird die Lesung kuš $\check{5}_{7}$ beibehalten, da die Lesung šùš, wie Visicato/Westenholz (some Unpublished Sale Contracts from Fara, GS Cagni, S. 1112) ausgeführt haben, derzeit nur in lexikalischen Texten aus späteren Epochen belegt ist.

Das Siegel des Bēlī-țāb (RIME 3/2.1.2.71) findet sich auch auf der Hüllentafel MVN $18,144$.

109 RIME 3/2.1.2.70, das Siegel befindet sich auf der Tafel PDT I, 530.

110 TPTS 37 (x/Š 48).

111 Zu Narām-ilī, der bis Š 43 Hauptbeamte der königlichen Viehverwaltung, danach dem neuen Hauptbeamten Nasa unterstellt war, siehe Sigrist, Drehem (1992), S. 259-260 und 265-267.

112 Der früheste Text ist SDU $9=$ MVN 15, 57 (vi , ix/Š 30), der letzte Text ist CST 41 
Auch er trägt, wie der Großteil der Hauptbeamten der Königin, die Amtsbezeichnung „Viehmäster“ (kurušda). Nur in einem Fall ist er in annehmender Funktion zu finden, als er in Ur Schafe als Bala-Lieferung des Ensi von Girsu entgegennimmt ${ }^{13}$. Möglicherweise läßt sich im Falle von Ahima der berufliche Aufstieg eines Beamten im Dienste der Šulgi-simtī nachvollziehen: Ahima tritt erstmals auf als abbuchender Beamter im Jahre Š 30, in einer Zeit also, als Šu-Kūbum noch als Hauptbeamter der Königin tätig war. Šu-Kūbum ist bei dieser Transaktion in der Funktion des Überbringers ( $\left.\hat{g}_{i} \mathrm{ri}_{3}\right)$ tätig. Gegenstand der Transaktion sind Schafe für die Göttinnen BēlatSuhnir und Bēlat-Deraban, die persönlichen Göttinnen der Šulgi-simtī. In der Folgezeit erscheint Ahima bei der Buchung von Tierkadavern, die in einem Fall von ihm an den Walker geliefert werden, wobei jedoch die Abbuchung von Šu-Kūbum getätigt wird ${ }^{114}$. Erst nachdem Šulgi-simtī die Position der Königin übernommen hatte, was wahrscheinlich in der ersten Häfte des Jahres $\breve{S} 32$ geschehen war ${ }^{115}$, war Ahima verstärkt bei Opfern für Bēlat-Šuhnir und Bēlat-Deraban tätig. Bēlī-țāb ist in den Jahren Š 32 bis Š 36 im Bereich des Kultes vor allem in Uruk zu finden, wohingegen Ahima offenbar besonders für den Kult der persönlichen Göttinnen der Königin verantwortlich war, welche ihren Kultplatz wohl in Ur gehabt haben.

Zwischen Š 45 und $\breve{S} 48^{116}$ arbeitete Kalam-ḩenagi als Ausgabebeamter. Er ist insbesondere mit Buchungen in Uruk verbunden ${ }^{117}$, was zu der Annahme führt, Šulgi-simtī habe dort eine Zweigstelle ihres Viehhofes unterhalten, um die Tiere für den lokalen Kult vor Ort zur Verfügung zu halten und sie nicht zu jedem Anlaß aus Puzriš-Dagān nach Uruk treiben zu müssen.

Auch der Schreiber Halili, dessen Siegel sich auf einer Tafel über die Lieferung von Teilen der Dattelpalme findet ${ }^{118}$, stand im Dienst der Šulgi-simtī. Diese von Halili angenommene Lieferung erfolgte über Barbarlia, welcher eng mit der Königin verbunden war, zum einen als Lieferant von Tieren und als Überbringer $\left(\mathrm{g}_{\mathrm{iri}}{ }_{3}\right)$ von Opfergaben der Königin ${ }^{119}$. Neben Halili wird ein

$$
\text { (v/Š 36). }
$$

113 Toronto 59 (x/Š 35). Zum Bala-System siehe T. Sharlach, Provincial Taxation and the Ur III State (2004).

114 TCNY 163. $\mathrm{Zu} \mathrm{azlag}$ = Walker siehe Waetzoldt, Untersuchungen zur Neusumerischen Textilindustrie (1972), S. 153.

115 Siehe oben S. 36-40.

116 Der früheste Text ist PDT I, 370 (15/ii/ ̌ك 45), der letzte Text ist PDT I, 339 (10/ii/Š 48).

117 Sallaberger, Der kultische Kalender (1993), S. $22+$ Anm. 82.

118 OIP 115,460 (viii/ ̌ 35$)$.

119 Barbarlia als Lieferant von Tieren: OIP 115, 35 (iv/Š 38); TCNY 105 (-/v/Š 38); 
Baqri als Mann der Šulgi-simtī (lú ${ }^{d} \breve{S} u l$-gi-sí-im-ti) bezeichnet ${ }^{120}$, doch tritt dieser sonst in keinem weiteren Text aus dem Archiv der Königin auf. Es ist anzunahmen, daß Baqri zu den untergeordneten Personen in der Verwaltung von Puzrišs-Dagān gehörte.

\section{4. Šulgi-simtī als Empfängerin von Lieferungen (mu-DU ${ }^{121}$ )}

\subsubsection{Was wird geliefert?}

Ein großer Teil der Urkunden aus dem Archiv der Šulgi-simtī verbucht die Lieferung von Schafen, Ziegen, Rindern sowie ab dem Jahr Š 38 von Geflügel und ab S 39 auch von Schweinen ${ }^{122}$ durch Einzelpersonen. Im Vergleich zum Hauptarchiv von Puzriš-Dagān fällt auf, daß keine Wildtiere wie Gazellen verbucht werden, ausländische Haustierrassen wie Šimaški-Schafe treten gar nicht auf oder werden nicht eigens vermerkt. Lediglich Fettschwanzschafe finden sich in seltenen Fällen unter den an die Königin gelieferten Tieren. Die Qualitätsbezeichnungen der Tiere sind bei Šulgi-simtī eingeschränkter als im Hauptarchiv. Es wird lediglich zum Teil die Art der Fütterung angegeben (niga = mit Gerste gefüttert/gemästet, ú = mit Gras gefüttert/Weidevieh). Daneben finden sich die beiden Qualitätsangaben $\mathrm{gu}_{4}$ e-ús-sa und niga sá- $d u_{11}{ }^{123}$.

Die Anzahl der überbrachten Tiere beläuft sich selten auf mehr als 10 Stück pro Lieferung, wobei bei der gleichzeitigen Lieferung von Groß- und Kleinvieh häufig das Verhältnis von einem Stück Großvieh (Rinder) zu 10 Stück Kleinvieh (Schafe und Ziegen) zu beobachten ist. Dieses Lieferverhältnis ist in der Ur III-Zeit auch in anderen Zusammenhängen zu beobachten, so zum Beispiel bei der Übersendung von Vieh aus der Peripherie des Reiches ${ }^{124}$.

TCNY 235 (vii/ك̌ 38); MVN 3, 161 (iii/Š 39); AUCT I, 952 (6/iv/ك̌ 39); OIP 115, 38 (29(iv/Š 39); BCT II, 246 (8/vi/Š 41); SET, 7 (24/ii/Š 42).

Als Überbringer von Opfern: DCEPHE 306 (-/xi/Š 29); OIP 115, 19 (-/vii/Š 30); OIP 115, 26 (-/ii/Š 34); Hirose, 12 (-/vi/Š 34); RA 19, 192 Nr. 4 (vii/Š 34).

120 AUCT I, 695 (-/iv/-).

${ }^{121}$ Das Zeichen DU ist möglicherweise $\mathrm{ku}_{\mathrm{x}} \mathrm{zu}$ lesen, siehe Krecher, $\mathrm{DU}=\mathrm{ku}_{\mathrm{x}}(-\hat{\mathrm{r}})$,,eintreten“, „hineinbringen“, ZA 77 (1987), S. 7-21; Steible, FAOS 9/2 S. 83-84; Sallaberger, ZA 84 (1994), S. 307-308. Dagegen argumentierte Bauer, ZA 94 (2004), S. 16f. In dieser Arbeit wird die Schreibweise DU beibehalten.

122 Boson 358 (iv/Š 38) erstmals Lieferung von Vögeln; TCND 32 (i/Š 39) erste belegte Lieferung von Schweinen.

123 Zu dieser Qualitätsangabe siehe Kent Hillard, niga sá-du ${ }_{11}$ as a Fattening Grade in Ur III Textes, ZA 85 (1995), S. 8-18 und ders. "While my article“ NABU 1995, 79.

124 Sallaberger, OBO 160/3 (1999), S. 196-199, 257. 
An Schweinen werden vorwiegend Ferkel geliefert, die entweder der Rasse šah ği š-gi (Röhrichtschwein) ${ }^{125}$ oder der Rasse šah iri (Hausschwein) angehören. Diese Tiere werden nicht den Göttern geopfert, sondern sind für die königliche Tafel bestimmt oder werden an bestimmte Einzelpersonen ausgegeben.

Bei den Vögeln, die der Königin geliefert werden, handelt es sich um zwei verschiedene Taubenrassen ( $\mathrm{ir}_{7}{ }^{\mathrm{mu} \text { š n }}=$ Wildtauben, $\mathrm{tu}^{-\mathrm{gur}_{4}}{ }^{\mathrm{mu} \text { šen }}=$ Haus? Tauben), sowie um Enten (uz/uz-tur). Häufig werden auch junge Enten (amar-sag-uz-tur) geliefert. Diese Tiere sind im wesentlichen für die königliche Tafel bestimmt, nur selten werden sie in kultischem Kontext verwendet, nie jedoch explizit einer Gottheit geopfert ${ }^{126}$.

Neben den Texten, die Einnahmen von Vieh und Ausgaben für bestimmte Verwendungszwecke verbuchen, geben einige Urkunden einen kleinen Einblick in die interne Verwaltung der Viehbestände der Königin. So z.B. bei der Abbuchung von Tierkadavern $\left(\mathrm{ad}_{6}\right)^{127}$, der Überstellung von mehr als 200 Schweinen an das Nagabtum ${ }^{128}$ oder der Annahme von Ferkeln für den Viehbestand der Königin ${ }^{129}$. In einem Fall tritt die Königin selber als Lieferantin von Lämmern aus ihrem Viehbestand auf. ${ }^{130}$

\subsubsection{Wer liefert was und wann?}

Von den rund 200 verschiedenen Lieferanten, die in den bisher publizierten Texten des Šulti-simtī-Archives auftreten, sind gut 20\% in mehr als zwei Fällen als Lieferanten der Königin belegt. Nur 10\% aller Personen sind regelmäßig und über einen längeren Zeitraum in dieser Form mit der Königin verbunden und treten fünfmal oder häufiger als Quelle für mu-DU-Lieferungen in Erscheinung. Bei einem Viertel der Lieferanten handelt es sich sicher um Frauen ${ }^{131}$. Dabei fällt auf, daß diese Frauen in der Regel nicht selber mit ihrem Namen genannt werden, sondern als Mutter, Frau, Schwester oder Tochter

125 Vgl. v.d. Mieroop, Reed in the Old Babylonian Texts from Ur, BSA 6 (1992), S. 149.

Zu der Tafel der Königin siehe Kap 3.6.1. S. 94f. Nur ein Text verbucht die Ausgabe von Geflügel für s i s k u r ${ }_{2}$-Riten, siehe dazu S. 89.

127 OIP $115,28(-/ \mathrm{ii} / \mathrm{S} 34)$.

128 OIP $115,132(-/ \mathrm{iii} / \mathrm{S}$ 46).

129 TCND $73(1 / x i i / \check{S} 41)$. In den Bereich der internen Verwaltung gehört auch das Tafelkorbetikett ASJ 4, S. 65 Nr. 5 (x/Š 43-xii/Š 44).

130 TCND $208(24 / \mathrm{v} / \mathrm{S}$ 43).

131 Aufgrund der Schwierigkeit, sumerische und oft auch akkadische Personennamen als männlich oder weiblich zu erkennen, wurden hier nur die Personen gezählt, die eindeutig als Frau, Schwester oder Mutter einer anderen Person benannt sind, oder die aus sicherem Kontext als weiblich bekannt sind. 
eines anderen gekennzeichnet werden. Nur selten finden sich Personenangaben wie „Rubātum, Frau des Nuida ${ }^{132 ، .}$. Offensichtlich herrscht auch hier das Prinzip, daß eine Person, so sie nicht allein mit dem Namen genannt wird, über das jeweils ranghöchste Familienmitglied bezeichnet wird ${ }^{133}$.

Wiederholt treten Angehörige des Königshauses als Liefernde auf, darunter der König selbst sowie verschiedene Prinzen und Prinzessinnen wie Šarrum-ilī, Šu-Eštar, Nabium und Teșīn-Mama. Die Kinder des Königs gehören häufiger als andere Angehörige der Verwaltung zu denen, die regelmäßig und über viele Jahre die Königin beliefern. Eine besondere Beziehung bestand offensichtlich zwischen der Königin und folgenden Personen: den Prinzen Puzur-Eštar und Ur-niĝar sowie der Prinzessin Teșinn-Mama, außerdem Ninliltum-imdi und Niridaĝal. All diese sind der Šulgi-simtī praktisch über ihre gesamte Amtszeit verbunden und sind oft häufiger als einmal jährlich als Quelle für mu-DULieferungen genannt ${ }^{134}$. Mit Ausnahme des Nir-idaĝal erhalten alle Vieh aus dem Bestand der Königin zurück. Dies legt die Vermutung nahe, daß es sich auch bei Ninliltum-imdi und Nir-idaĝal um Königskinder gehandelt haben könnte, selbst wenn sich dieser Verdacht bisher nicht durch Siegellegenden bestätigen läßt.

Im Falle des Prinzen Ur-nighar setzt sich die Verbundenheit mit der Königin auch noch in der folgenden Generation fort. Er selbst, seine Frau, der Sohn Šuruš-kēn und eine Tochter stehen über viele Jahre mit dem Haushalt der Königin in Beziehung.

lugal (wohl Šulgi)

Ur-niĝar: Š 32 (BIN V, 11) - Š 44 (SET 8) $\infty$ d a m Ur-niĝar: Š 33 (CST 42) - Š 36 (MVN 18, 2)

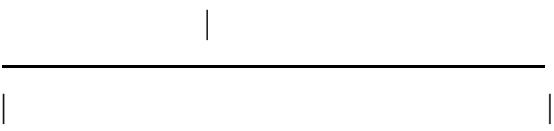

SUHUUŠ-kēn: Š 38 (TCND 31) - Š 46 (MVN 18, 11) d u mu - mu n u s Ur-niĝar: Š 38 (Boson 358)

Da bisher keine Prosopographie für das Reich von Ur III vorliegt, stellt sich bei häufig auftretenden Personennamen immer die Frage, ob es sich um eine Person oder um mehrere Personen gleichen Namens handelt. Ein Ur-niĝar (Ur$\mathrm{ni}_{9}$-gar) ist sehr häufig zu finden und wird auf vielen Siegeln als Vater prominenter Personen der Ur III-Administration genannt, darunter auch einige,

\footnotetext{
132 OIP 115, 42 (25/xi/Š 39).

133 Siehe S. 274.

134 Siehe Anhang 1, Tabelle 18: mu - D U -Lieferanten der Šulgi-simtī.
} 
die im Zusammenhang mit den königlichen Damen zu finden sind. Zu diesen gehören Irĝu, der sehr häufig in der Funktion des Bevollmächtigten (m a ški m) bei Abī-simtī auftritt und Lu-duga, welcher unter Šu-Suen in Umma arbeitete $^{135}$. Jedoch finden sich auch ein Irĝu, Sohn des Šara-zame ${ }^{136}$, und für Ur-nighar lassen sich auf den Siegeln verschiedene Filiationen finden ${ }^{137}$. Eine weitere Schwierigkeit besteht in der Schreibung des Namens Ur-niĝar. Die bei weitem häufigste Form ist Ur-ni ${ }_{9}$-gar, seltener tritt die Form Ur-ni ${ }_{9}$ auf, wobei zu fragen ist, ob es sich dabei um eine Kurzform des Namens handelt oder um eine andere Person. So wird die Form Ur-ni ${ }_{9}$ in den mu-DU-Texten zu Šulgisimtī nur bei Buchungen des Beamten Apilatum verwendet, wobei dieser mitunter auch Ur-ni ${ }_{9}$-gar schreibt. Geht man davon aus, daß es sich um eine Lang- und eine Kurzform desselben Namens handelt, so kommen im Familienschema für die Ehefrau als Lieferantin der Königin noch zwei Belege aus den Jahren Š 44 hinzu $^{138}$. Ein ähnliches Problem stellt sich bei der Person des Šuruš-kēn bzw. SUHUŠ-kēn, welcher unter Šulgi und unter Amar-Suen mit den Königinnen in Beziehung steht. Hier findet sich die syllabische Schreibung Šu-ru-uš-ki-in neben der logographischen SUHUŠ-ki-in, was vermuten läßt, daß es sich hier um dieselbe Person handelt ${ }^{139}$.

Ein weiteres Beispiel für eine der Königin eng verbundene Familie ist die des Inim-Šara. Dieser liefert zwar nicht selber an Šulgi-simtī, seine Söhne, insbesondere Šara-kam und dessen Frau sind jedoch in der Zeit von $\breve{S} 40$ bis Š 46 mehrfach als mu - DU -Lieferanten belegt. Möglicherweise handelt es sich bei der Schwiegertochter (é-gi $i_{4}$-a) des Inim-Šara, welche im Jahr Š 40 Enten abgibt $^{140}$, um die gleiche Person, die von $\breve{S} 43$ bis $\breve{S} 46$ als Frau des Šara-kam (d a m ${ }^{\mathrm{S}}$ Šára-kam) auftritt ${ }^{141}$. Es ist denkbar, daß die aus den Šulgi-simtī-Texten bekannte Persönlichkeit Šara-kam identisch ist mit dem späteren Ensi von

135 Siegel des Irĝu, Sohn von Ur-niĝar u.a. SAT II, 312, 405, 667. Siegel des Lú-duga, Sohn von Ur-nighar u.a. SAT II, 389 und 633. Irĝu und Lú-duga sind wohl eher als Söhne des Ur-nighar aus der Familie des GIRINI von Umma anzusehen, siehe Dahl, The quest for eternity, FS Larsen (2004), S. 121-125.

136 UTI VI, 3674.

137 dumu-lugal in BIN V, 11; dumu Lugal-duga in SAT II, 1098; dumu Șil-lí[...] šabra $\mathrm{n}$ in in UDT 27. Letzte Lesung gegen die Kopie nach Sigrist, Catalogue of the Babylonian Collections at Yale 3, NBC 27.

138 YOS 18, 6 (ii/Šs 44) und RA 19, 192 Nr. 7 (iii/Š 44).

139 Vgl. Hilgert, OIP 115, Index of Personal Names, allerdings ist auch ein Šu-ru-uš-ki-in, Sohn des Am-NI-NI bekannt (Hilgert, OIP 121, 588 (ix/AS 5).

140 CST 51

141 OIP 115, 74 (ix/Š 43); Hirose 22 (xii/ŠS 43); Orient 16, 6 (xi/Š 44); JCS 29, S. 117 Nr. $1(\mathrm{i} / \mathrm{S}$ 46). 
Girsu unter Amar-Suen ${ }^{142}$.

$\mathrm{Zu}$ den Personen, die nur ein- oder zweimal Vieh an die Königin geben, gehören die Angehörigen der Verwaltung der Šulgi-simtī sowie möglicherweise Abbasaga und Urkununna, welche später unter Amar-Suen zu den Spitzenbeamten der königlichen Verwaltung gehören und damit auch eng mit der Königin Abī-simtī zusammenarbeiten ${ }^{143}$. Auffallenderweise hatte Sulgisimtī kaum jemals wirtschaftliche Beziehungen zu den obersten Angehörigen der königlichen Verwaltung wie Enlila, Nalu, oder Narām-ilī, und auch zu Urkununna bestanden nach Š 38 keine Beziehung mehr ${ }^{144}$. Dies zeigt deutlich, daß zur Zeit Šulgi-simtīs der Haushalt und die gesamte Verwaltung der Königin von der des Königs nicht nur administrativ, sondern auch personell getrennt war. Möglicherweise wurde von den Angehörigen der Oberschicht des Reiches erwartet, daß sie zumindest einmal Abgaben an die Königin leisteten. Dies könnte die große Zahl derer erklären, die nur ein- oder zweimal als Lieferanten auftreten. Die Beziehungen von später besonders prominenten Personen zu Šulgi-simtī, wie Šara-kam, Abbasaga und Urkununna geben Anlaß zu der Vermutung, daß der gesellschaftliche Aufstieg in der Hierarchie des Reiches von Ur nicht allein über den König geschah, sondern daß die Königin möglicherweise Einfluß hatte auf wichtige gesellschaftliche Entscheidungen.

Wie das System der mu - DU -Lieferungen an die Königin organisiert war, welche Persönlichkeit bestimmte, wer wann welche Tiere zu geben hatte, ist derzeit nicht zu sagen. Allerdings kann man beobachten, daß es keinen bevorzugten Zeitraum oder Monat für diese Lieferungen gab. Es hat offenbar ein System gegeben, das eine gleichmäßige Versorgung mit Tieren gewährleistete, da dies sowohl für die Versorgung des Haushaltes der Königin wie für die regelmäßigen Opfer an die Götter notwendig war. Bei den Personen, die regelmäßig Tiere bereitstellten, ist allerdings eine Tendenz zu beobachten, entweder bevorzugt Kleinvieh oder aber Vögel zu liefern, zudem erfolgten die Lieferungen in bestimmten Monaten. So überbringt Barbarlia ${ }^{145}$ mit einer Ausnahme nur Vögel und tut dies in den Monaten 3 bis 7, Teșīn-Mama dagegen stellte bevorzugt Kleinvieh zur Verfügung, zumeist in den Monaten 9 bis 2. Ein Sonderfall ist der Vogelfänger Bagum, welcher, wie nach der

142 Sallaberger, OBO 160/3 /1999), S. 192; de Maaijer, Land Tenure in Ur III Lagaš (1998), S. 53.

143 Abbasaga eventuell in RT 37, 130 Nr. 1 (ix/Š 44), der Text wurde 1915 nur in Transliteration publiziert, in der Umschrift steht [Ab]-ba-sag. Urkununna erscheint im Jahr Š 38 als Lieferant von Kleinvieh an die Königin (SACT I, 55). Hier ist auffällig, $\mathrm{daß}$ der Name Ur- ${ }^{\mathrm{d}}$ kù-nun-na geschrieben ist anstatt des sonst üblichen Ur-kù-nun-na.

144 Zu den Spitzenfunktionären unter Šulgi siehe Sigrist, Drehem (1992), S. 247-272.

$145 \quad$ Zu Barbarlia siehe S. 40. 
Berufsbezeichnung zu erwarten ist, fast ausschließlich Vögel abgibt, wobei dies vor allem in den Monaten 6 bis 10 geschieht. Der einzige Text, in dem Bagum Kleinvieh liefert, ist NABU 1997/99, und hier fungiert er eher als Überbringer/Bote, da die Tiere aus dem Palast (é - g a l-ta) bzw. einem Tempel (é - è š) stammen.

Zusammenfassend läßt sich sagen, daß die Königin über eine personell wie administrativ getrennte Verwaltung verfügte. Anhand der Personen, die die Königin mit Tieren beliefern, lassen sich die Beziehungen rekonstruieren, die sie $\mathrm{zu}$ den verschiedenen Angehörigen des Königshauses und den verschiedenen Funktionären des Reiches unterhielt. Auffallend ist der fehlende Kontakt zur Spitze der königlichen Beamten in Puzriš-Dagān. Diese leisteten keinen Beitrag zu den mu-DU-Lieferungen an Šulgi-simtī und erhalten auch keine Tiere aus den Beständen der Königin.

\subsection{Kultische Pflichten der Šulgi-simtī}

Die kultischen Verpflichtungen Šulgi-simtīs sind, soweit es sich um die Tieropfer handelt, durch die Texte ihres Archives aus Puzriš-Dagān gut dokumentiert. Dagegen sind kaum Belege über unblutige Opfer zu finden. Dies bedeutet sicher nicht, daß es nur wenige unblutige Opfer gegeben hat, es handelt sich lediglich um den Zufall der Überlieferung, daß die Texte zur Viehwirtschaft aus den Archiven des Königs und der Königin so zahlreich erhalten sind. ${ }^{146}$

Bis zum Jahr Š 39 sind die Texte aus dem Archiv der Šulgi-simtī noch nicht mit dem Tagesdatum versehen, was eine genaue Einordnung kultischer Handlungen im Ablauf des Monats schwierig macht. Eine Zuordnung der früheren Texte in einen bestimmten Kontext ist oft nur über den Vergleich mit späteren, auf den Tag genau datierten Texten möglich.

Die Fülle des Materials gibt Antworten auf die Frage, zu welchem Anlaß bestimmten Gottheiten Opfer dargebracht wurden, doch über den Ablauf der Rituale im einzelnen sind wir nicht unterrichtet. Nur in seltenen Fällen ist anhand der Formulierung der Urkunden das grobe Schema eines mehrtägigen Festablaufes erkennbar. Dann sind die einzelnen Eintragungen über die gelieferten Tiere und den Verwendungszweck unterteilt durch die Formulierung „1. Tag, 2. Tag, 3. Tag usw.“. Was genau nach dem Ende der Kulthandlung mit den geopferten Tieren geschah, ist ebenfalls nicht bekannt. In seltenen Fällen ist belegt, daß das Fleisch der Tiere an das Tempelpersonal und

146 Vgl. Sallaberger, Der kultische Kalender (1993), S. 27. Unblutige Opfer seitens der Königin sind selten belegt, so z.B. PDT I, 430 (ii/Š 45), wo unter anderem Datteln, Sesamöl und Käse anläßlich eines Annunītum-Festes versprengt werden. 
die Inhaber verschiedener Pfründe verteilt wurde. ${ }^{147}$

Betrachtet man die von der Königin besonders verehrten Gottheiten, so fällt auf, daß es sich in erster Linie um weibliche Gottheiten handelt. Dies könnte, wie schon die Häufung weiblicher Lieferanten von Tieren, ein weiterer Hinweis auf eine deutliche Trennung der Lebenswelten von König und Königin sein. Dem entspricht die Beobachtung, daß sich wie schon in den Einnahmetexten auch bei den Ausgaben der Königin für den profanen Bereich häufig Frauen als Empfängerinnen finden. ${ }^{148}$

Bei vielen Kulten handelt es sich um zyklisch wiederkehrende Feste, die häufig im Zusammenhang mit einem der monatlichen Feiertage, dem Neulichttag, dem 7. oder dem 15. Tag des Monats begangen wurden. Zum 21. Tag eines Monats wurden keine besonderen Riten abgehalten. Neben diesen zyklischen Festen finden sich einzelne Feiern, welche nur selten belegt sind. Hier stellt sich die Frage, ob es sich bei letzteren ebenfalls um eigentlich regelmäßige Feste handelt, für die die Überlieferungssituation nur fragmentarischer ist, oder ob diese Feste tatsächlich nur zu besonderen Ereignissen begangen wurden. Sollte letzteres zutreffen, wäre es interessant zu erfahren, aus welchem Anlaß diese Feiern begangen wurden, doch ist eine Korrelierung der Kulthandlung mit anderen Ereignissen aus dem politischen oder gesellschaftlichen Leben bisher nicht möglich, da unser Wissen über derartige „Tagesgeschehnisse“ derzeit noch zu gering ist.

Neben den großen Götternn des Landes, Enlil, der die Königswürde verlieh, und seiner Gemahlin Ninlil, dem Mondgott Nanna, Gott der Reichshauptstadt Ur, und Inanna, der Göttin von Uruk, kümmerte sich Šulgisimtī intensiv um den Kult verschiedener Göttinnen, die sie aus ihrer Heimat mitgebracht hatte. Hier sind zuerst Bēlat-Šuhnir und Bēlat-Deraban ${ }^{149} \mathrm{zu}$ nennen, welche in der Zeit nach Šulgi-simtī im Kult des Reiches von Ur kaum noch eine Rolle spielten ${ }^{150}$. Die Göttin Allatum, die bei Šulgi-simtī in verschiedenen kultischen Kontexten beopfert wird, stammt ebenfalls aus der Gegend von Ešnunna, aus Zimudar ${ }^{151}$. Auch Annunītum und die ihr verbundene

147 Sallaberger, Der kultische Kalender (1993), S. 313-314; v.d. Mieroop, Rezension zu Sallaberger, Kult. Kalender, BiOr 52 (1995), S. 718.

148 Siehe Kap. 3.6.5. S. 100-103.

149 Sallaberger, Der kultische Kalender (1993) S. 19; Such-Gutiérrez, Beiträge zum Pantheon von Nippur im 3. Jahrtausend (2003), Teil I S. 322f.

150 Babati, Bruder der Abī-simtī, führt auf seinem Siegel, das ihm von Šu-Suen verliehen wurde, den Titel „Šabra der Herrinnen (n i n ) Bēlat-Šuhnir und Bēlat-Deraban“ (RIME 3/2.1.4.32 und 33). Dies zeigt, daß der Kult dieser beiden Göttinnen nicht gänzlich in Vergessenheit geraten war.

151 Michalowski, Royal Women - Part III, ASJ 4 (1982), S. 132; Such-Gutiérrez, Beiträge 
Ulmašĩtum, die Annunītum ihres Tempels É-Ulmaš in Akkade, gehören zu den bevorzugten Göttinnen der Königin. Annunītum war eine Ištargestalt mit dem Aspekt der kriegerischen Göttin. Ihr Kult war seit der Akkadezeit für die Könige von großer Bedeutung ${ }^{152}$. Eine weitere dem Kreis der Inanna nahestehende und von der Königin verehrte Göttin war Nanaja, wie Inanna eine Tochter des Himmelsgottes An. Des weiteren sind die Liebesgöttin Išhara und die Gottheit Allagula zu nennen. Bei letzterer ist nicht einmal bekannt, ob es sich um eine Göttin oder einen Gott handelt. ${ }^{153}$

Regelmäßig wurde die Göttin Ninsun, nach der Königsideologie die göttliche Mutter der Könige von Ur, von Šulgi-simtī mit Opfern bedacht ${ }^{154}$. Dagegen findet Lugalbanda, der göttliche Vater der Könige, keine Erwähnung in den Texten der Königin. Der König versorgte seinerseits beide göttlichen Elternteile mit Opfergaben. ${ }^{155}$ Auffallend selten erhielt Ningal, die Gemahlin des Mondgottes, Opfer von der Königin, allerdings ist diese Göttin im Kult des Reiches von Ur eher von untergeordneter Bedeutung. ${ }^{156}$

Daneben finden sich noch verschiedene andere Gottheiten, die bei bestimmten Gelegenheiten Opfer von der Königin erhielten, worauf im folgenden näher eingegangen werden wird.

Eine wirkliche Trennung von „persönlichem“ und „offiziellem“ Kult ist nicht möglich, da die Opfer der Königin wie die des Königs dem ganzen Land zum Segen gereichen sollten. ${ }^{157}$ Auf die zentrale, und aus moderner Sicht leicht

zum Pantheon von Nippur im 3. Jahrtausend (2003), Teil I S. 311-313.

152 Zu den beiden Göttinnen siehe Sallaberger, Der kultische Kalender (1993), S. 198 und Westenholz, OBO 160/3 (1999) S. 31. Zu Annunītum siehe auch Selz, Five Divine Ladies: Thoughts on Inanna(k), Ištar, In(n)in(a), Annunītum, and Anat, and the Origin of the Title "Queen of Heaven", NIN 1 (2000), S. 34-35.

153 Siehe zu Allagula Sallaberger, Der kultische Kalender (1993), S. 45 Anm. 192. SuchGutiérrez, Beiträge zum Pantheon von Nippur im 3. Jahrtausend (2003), vertritt die Auffassung, bei Allagula handele es sich um eine männliche Gottheit, S. $225 \mathrm{f}$.

154 Z.B. in den Texten MVN 18, 61 (v/ŠS 37); OIP 115, 61 (18/x/Š 40), PDT I, 414 (30/x/Š 46), DCEPHE 299 (20/ix/Š 47) und TRU 286 (23/ix/[ ]). In der Inschrift der Šuqurtum, lukur des Šulgi, wird in der Fluchformel die Göttin Ninsun als persönliche Göttin der Stifterin genannt, Lugalbanda als „mein König“ bezeichnet (RIME 3/2.1.2.85). Dies zeigt die enge Bindung der Frauen des Königshauses zu dieser Göttin. Zu Ninsun als Mutter der neusumerischen Könige siehe Wilcke, Artikel „Ninsun“, R1A 9 (2001), S. 503 § 4.5.

155 Siehe Sallaberger, Der kultische Kalender (1993), Tab. 9 und 32.

156 Sallaberger, Der kultische Kalender (1993), S. 203. Die beiden Belege für Opfer der Šulgi-simtī an Ningal sind PDT I, 645 (12/v/Š 45) und MVN 18, 73 (13/ix/S 45). Beide Texte verbuchen Opfer in Zusammenhang mit monatlichen Feiertagen.

157 Sallaberger, OBO 160/3 (1999), S. 258. 
zu unterschätzende Bedeutung des Kultes für das Königtum der Ur III-Zeit hat Sallaberger hingewiesen. „Denn den Göttern ist alles irdische Leben und Sterben zu verdanken, der Herrscher nimmt es stellvertretend für sein Land entgegen: den Göttern gegenüber hat sich denn auch der Herrscher als Vertreter seines Reiches $\mathrm{zu}$ verantworten, sie $\mathrm{zu}$ ehren und $\mathrm{zu}$ versorgen stellt seine

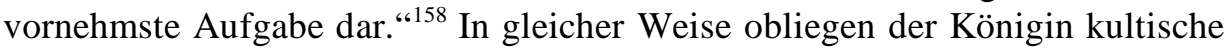
Verpflichtungen. Die angemessene Verehrung der Götter ist damit im Selbstverständnis der Zeit eine staatstragende und den Staat erhaltende Aufgabe, an der die Königin ihren Anteil hat.

Im folgenden sollen die einzelnen kultischen Pflichten der Königin, soweit sie nach den Ausgabetexten ihres Archives rekonstruiert werden können, vorgestellt werden. Dabei werden der Kult der von Šulgi-simtī mitgebrachten Göttinnen und die von ihr in Ur eingeführten akkadischen Feste wie das Elūnum-Fest oder das Nabrium-Fest getrennt vom Kult der großen Götter des Landes, Nanna, Inanna, Enlil und Ninlil betrachtet, da diese Kulte und Feste, anders als die Verehrung der großen Götter des Landes, nicht von ihren Nachfolgerinnen fortgesetzt wurden. Damit läßt sich eine Unterscheidung machen zwischen dem Staatskult und dem Kult der persönlichen Göttinnen der Königin, auch wenn letzterer natürlich ebenso dem Wohlergehen des Landes diente, da das Wohlwollen der Göttinnen für die Königin sich segensreich für das ganze Land auswirken sollte.

\subsubsection{Enlil und Ninlil und der Kult von Nippur}

Nippur war in dieser Zeit eines der wichtigsten Kultzentren des Landes. Eine Vielzahl von Gottheiten wurde in dieser Stadt verehrt, doch Enlil war der bedeutendste Gott dieser Stadt. Er gehörte zu den Göttern, die nach der Vorstellung der Zeit das Königtum verliehen und die Herrschaft eines Königs legitimierten $^{159}$, weswegen man der Unterstützung und dem Schutz dieses Gottes für den König große Bedeutung zumaß. Aus diesem Grund wurde der Tempel des Enlil und seiner Gemahlin Ninlil von allen Königen der dritten Dynastie von Ur regelmäßig und reichhaltig mit Opfergaben versorgt, und auch die Königinnen kümmerten sich um den Kult dieser wichtigen Gottheiten.

Ab dem Jahr Šulgi 36 sind Opfer der Šulgi-simtī für Enlil und Ninlil belegt. Dabei wird fast immer beiden Göttern ein bis drei Stück Kleinvieh dargebracht. Nur in zwei Fällen versorgte die Königin Ninlil, ohne gleichzeitig Enlil ein

158 Sallaberger, Königtum und Kult in der Hauptstadt Ur unter den Herrschern ihrer III. Dynastie (21 Jh.) (1999), S. 255.

159 Vgl. Sallaberger, Nippur als religiöses Zentrum Mesopotamiens (1997). 
Opfer zu bringen ${ }^{160}$. In den meisten Fällen wird Ninlil in den Texten der Königin vor Enlil genannt, und sie erhielt mitunter auch umfangreichere Gaben. Bei den Opfern des Königs steht dagegen immer Enlil als Empfänger vor Ninlil. ${ }^{161}$ Auch hier läßt sich wieder die weibliche Lebenswelt beobachten: Die Frauen des Reiches liefern Tiere an die Königin, welche diese zuerst an die Gemahlin des obersten Gottes und erst danach an den Gott selber weitergibt.

Häufiger als in anderen kultischen Kontexten tritt die Königin bei den Opfern in Nippur selber als Überbringerin der Gaben auf ( $\hat{g}_{i r i} i_{3}$ nin-gá). Verfolgt man die Daten der Texte, so zeigt sich, daß Šulgi-simtī sich etwa alle drei bis sechs Monate in Nippur aufgehalten hat. Die Königin hatte also regelmäßige Verpflichtungen in einem der wichtigsten religiösen Zentren des Reiches, die sie ab dem Jahr Š 35 konsequent befolgte. Möglicherweise nahm sie diese Verpflichtungen schon früher war, doch dafür fehlt bislang die Dokumentation.

Die meisten der Feiern in Nippur werden im Zusammenhang mit den monatlichen Feiern zum 7. ${ }^{162}$ oder zum $15 .{ }^{163}$ Tag begangen. Neben Enlil und Ninlil erhalten in diesem Zusammenhang auch die Gottheiten Allagula, Allatum und Ninĝagia ${ }^{164}$ die Gabe von einem Stück Kleinvieh. ${ }^{165}$ Ab dem Jahr Š 37 erhält Ninlil meist 3, Enlil 2 Stück Kleinvieh. Hier zeigt sich die besondere Aufmerksamkeit der Königin für die Göttin, welche vor ihrem göttlichen Gemahl aufgeführt wird und auch umfangreichere Gaben erhält. Meist werden die zu diesen Tagen vollzogenen Riten als sisku $\mathrm{r}_{2}$ bezeichnet, selten als è š ès. Welche Bedeutung diese beiden Termini genau haben und wie sie sich unterscheiden, ist nicht bekannt. ${ }^{166}$ Die Verwendung der beiden Begriffe ist je nach Ort und Archivzusammenhang unterschiedlich, im Šulgi-simtī-Archiv bezeichnet èš-èš immer einen monatlichen Feiertag, kann aber in diesem

160 Tel Aviv I, 56 (5/viii/Š 40) und Rochester 22 (10/i/ك̌ 48).

161 Sallaberger, Der kultische Kalender (1993), S. 46.

162 ASJ 9, S. 316 Nr. 6 (-/iii/Š36); CST 44 (-/v/Š 37); Tel Aviv I, 56 (4,5/viii/Š 40); MVN 3,178 (5/ix/Š 40); OIP 115, 63 (4/i/ ̌S 41); DCEPHE 293 (-/ii/ŠS 41); MVN 18, 68 (4/ii/Š 41); SACT I, 133 (5/iv/Š 41); MVN 18, 71 (4, 5/x/ŠS 43); BIN III, 366 (5/iii/Š 45); TLB III, 13 (5/viii/Š46); Bab 7, Pl. XIX Nr. 4 (7/xi/Š 46).

163 SAT II, 153 (-/x/Š 36); OrSP 18, 21 (14/iii/Š 42); PDT I, 370 (-/ii/Š 45); PDT I, 645 (14/v/Š 45).

164 Zur Verehrung der Ningagia in Nippur siehe Such-Gutiérrez, Beiträge zum Pantheon von Nippur im 3. Jahrtausend (2003), Teil I S. 270-273.

$165 \mathrm{Zu}$ den Opfern zum 7. und 15. Tag in Nippur siehe bei Sallaberger, Der kultische Kalender (1993), Tab. 4.

166 Zu siskur ${ }_{2}$ siehe Limet, Le Sacrifice siskur, OLA 55 (1993), S. 243-255; Sallaberger, Der kultische Kalender (1993), S 41-42. 
Kontext mit s is ku r ${ }_{2}$ frei wechseln. ${ }^{167}$

Anders als bei den Festen in Uruk und Ur, bei denen die Königin häufig auch ihren persönlichen Göttinnen Bēlat-Šuhnir und Bēlat-Deraban opfert, werden diese beiden Göttinnen bei den Feierlichkeiten in Nippur nicht erwähnt $^{168}$. Dies ist damit zu erklären, daß Bēlat-Šuhnir und Bēlat-Deraban ihren Tempel in Ur hatten. Für den Kult in Nippur waren diese persönlichen Göttinnen Šulgi-simtīs ohne Bedeutung, in dieser Stadt vollzog die Königin Riten im Rahmen des offiziellen Kultes, während sie in der Haupt- und Residenzstadt Ur neben dem offiziellen Kult auch jenen ihrer persönlichen Gottheiten pflegen konnte.

Für das Ende des Jahres Š 46 sind umfangreichere kultische Aktivitäten der Königin in Nippur belegt, als es sonst der Fall ist. Gleich viermal werden in den Monaten xi und xii Opfergaben für Ninlil und Enlil sowie für einige andere Gottheiten aus dem Bestand der Königin abgebucht ${ }^{169}$. Die Ausgaben beginnen mit Opfern zum 7. Tag an Enlil, Ninlil und Ninhursaĝ, eine Göttin, die sonst selten bei Šulgi-simtī erwähnt wird ${ }^{170}$, stets jedoch im Zusammenhang mit besonderen Festen. Am 9. Tag werden Enlil und Ninlil je 2 Stück Kleinvieh für Klageriten (ér siskur ${ }_{2}$ ) dargebracht, nachdem am Vortag Inanna, Ninurta und Nuska Gaben erhalten haben. Die Königin fungiert bei diesem wie auch dem Opfer am 15. Tag, bei dem nochmals 2 Stück Kleinvieh für Ninlil und Enlil geopfert werden, als Überbringerin ( $\hat{g}$ iri ${ }_{3}$ nin-ĝ́á) ${ }^{171}$. Zum Ende des folgenden Monats werden wiederum mehrere Stück Kleinvieh für Enlil und Ninlil sowie nun auch für Inanna bei s is kur $\mathrm{r}_{2}$-Riten dargebracht ${ }^{172}$. Ob diese Häufung der Gaben in einem Monat an Ninlil und Enlil ein Sonderfall ist, oder

167 Sallaberger, Der kultische Kalender (1993), S. 41. Ein Beispiel für diesen Wechsel sind die Texte CST 44 (v/Š 37) und MVN 18, 68 (4/ii/Š 41), beide verbuchen Ausgaben für Opfer der Königin zum 7. Tag in Nippur, die beopferten Gottheiten sind dieselben, in CST 44 werden die Ausgaben für è š-è š-Feiern verzeichnet, in MVN 18, 68 für s is k u r ${ }_{2}$-Riten.

Ausnahme ist der Text MVN 18, 77 (15/xi/Š 46), wo neben Ninlil und Enlil auch Iškur, Bēlat-Šuhnir und Bēlat-Deraban Kleinvieh erhalten.

169 Bab 7, Pl. XIX Nr. 4 (7/xi/Š 46); MVN 18, 76 (9/xi/Š 46); MVN 18, 77 (15/xi/Š 46); SRD 10 (30/xii/ŠS 46).

170 Außer in Bab 7, Pl. XIX Nr. 4 (7/xi/Š 46) nur noch in PDT II, 980 (v/Š 35); OIP 115, 99 (22/xii/Š 45) und TCND 192 (16/iii/Š 47). Zu Ninhursaĝa siehe Heimpel, Artikel „Nin-hursaĝa“ in RlA 9 (2000), S. 378-381 und Krebernik, Artikel „Muttergöttin.A.I“ in R1A 8 (1993-1997), S. 505 \$ 3.20.

171 MVN 18, 76 (8, 9/xi/Š 46) und MVN 18, 77 (15/xi/Šs 46).

172 SRD 10 (30/xii/Š 46). Außerdem verbucht diese Urkunde Kleinvieh für siskur ${ }_{2}$ Riten zu Neulicht in Uruk und für den Tempel der Bēlat-Šuhnir und der Bēlat-Deraban in Ur. 
ob hier durch eine glückliche Überlieferungslage einmal die kultischen Aktivitäten der Königin vollständiger dokumentiert sind als das sonst der Fall ist, läßt sich derzeit nicht entscheiden.

Klageriten Šulgi-simtīs in Nippur zum Jahresende sind noch für zwei weitere Jahre belegt, wobei denselben Göttern Opfer dargebracht werden wie im Jahr Š $46^{173}$. Sallaberger hatte angenommen, daß Šulgi-simtī im xi. Monat Klageriten in Nippur vollzogen hat ${ }^{174}$, wobei die beiden von ihm erwähnten Textzeugen jetzt noch durch den Text OIP 115, 99 ergänzt werden können. Allen drei Belegen ist gemeinsam, daß als Verwendungszweck für die Opfertiere Klageriten in Nippur (ér siskur ${ }_{2}$ šà $\mathrm{Nibru}^{\mathrm{ki}}$ ) angegeben werden, daß die Riten zum Jahresende stattfinden, daß mit Ninurta und Nuska Götter beopfert werden, die sonst bei Šulgi-simtī keine Erwähnung finden und daß die Königin die Gaben selber überbringt, also bei den Riten anwesend ist (ĝiri ${ }_{3}$ nin-ĝá). Darüber hinaus kann der Text Bab 7, Pl. XIX Nr. 4 den Klageriten zum Jahresende zugeordnet werden, da aus der folgenden Übersicht zu erkennen ist, daß es sich bei diesem Text nicht nur um die gängigen Opfer zum 7. Tag handelt. Der Ablauf der Klagefeiern scheint nicht bis ins Detail festgelegt zu sein. Auch konnte der genaue Termin im Jahresablauf möglicherweise schwanken. Allerdings könnten die unterschiedlichen Daten auch auf den Kalender von Nippur zurückzuführen sein, der vom in Puzriš-Dagān gebräuchlichen „Reichskalender“ abweicht ${ }^{175}$.

Betrachtet man die drei Texte parallel, so kommt man zu folgendem Bild: Die Feierlichkeiten erstrecken sich über mehrere Tage. Im Jahr S 40 beginnen die Riten am Abend, um dann am folgenden Morgen fortgesetzt zu werden. In den Jahren Š 45 und 46 sind die Opferhandlungen über 3 Tage verteilt. Neben den auch sonst von Šulgi-simtī in Nippur verehrten Gottheiten Ninlil, Enlil, Allatum, Ninĝagia und Allagula werden bei diesen Klagefeiern auch Nanna, der Gott der Hauptstadt, Inanna, der Göttin von Uruk, zu welcher die Königin ein besonders enges Verhältnis hatte, sowie Ninurta und Nuska, die zu den Göttern von Nippur gehören, beopfert. Ninurta und Nuska galten als Kinder von Enlil und Ninlil, darüber hinaus war Ninurta der Stadtgott von Nippur ${ }^{176}$.

\footnotetext{
173 SRD 5 (18/xi/Š 40) und OIP 115, 99 (20, 22/xii/Š 45).

174 Sallaberger, Der kultische Kalender (1993), S. 149-150 und Tabelle 46.

175 Zum Versuch, die beiden Kalendersysteme zu korrelieren siehe Sallaberger, Der kultische Kalender (1993), S. 133-136.

176 Richter, Untersuchungen zu den lokalen Panthea Süd- und Mittelbabyloniens in altbabylonischer Zeit (1999), S. 47, 48 und 69.
} 


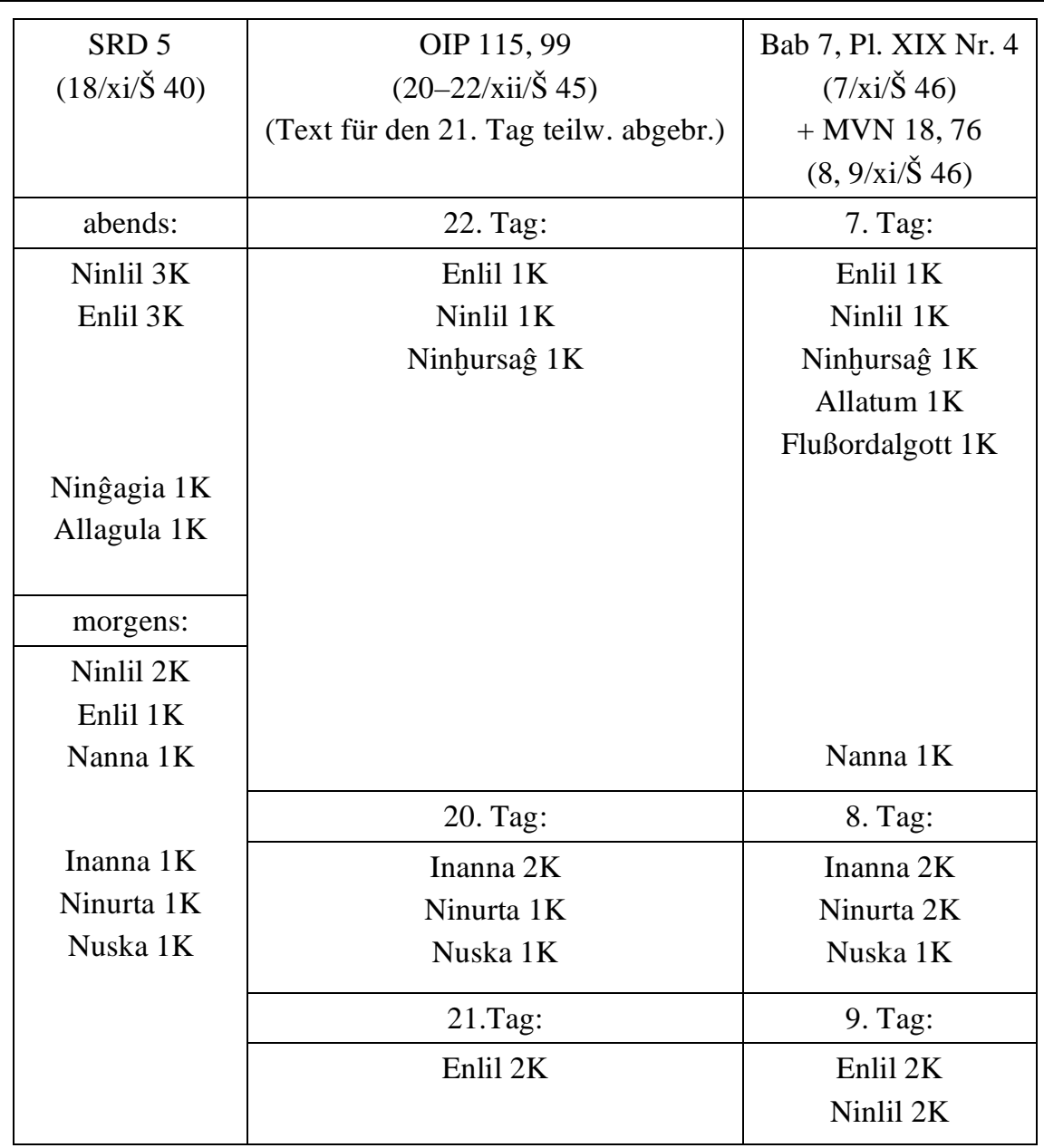

Tabelle 2: Klageriten zum Jahresende

Die Übersicht nennt die Namen der beopferten Götter in der Reihenfolge, wie sie in den Texten auftreten, wobei die gleichen Götternamen in einer Zeile aufgelistet werden, um die Parallelität der Texte deutlich werden zu lassen.

Es ist nicht bekannt, ob diese Klageriten erst in den späteren Amtsjahren Šulgi-simtīs so umfangreich ausgestaltet wurden, vielleicht als Reaktion auf besondere Ereignisse im Königshaus, oder ob es sich um Riten handelte, die regelmäßig jährlich vollzogen wurden. Aus den 30-er Jahren der Herrschaft Šulgis liegt zu diesen Klageriten der Königin bisher erst ein Beleg vor, der aber noch nicht auf ein mehrtätiges Ereignis schließen läßt ${ }^{177}: 1$ Mastschaf, klagend 
umherziehen im Tempel der Allagula (1 udu-niga ér niĝin ${ }_{2}-n$ a é ${ }^{\mathrm{d}} \mathrm{Al}$ la-gu-1a).

Neben den gut belegten Festen zu den monatlichen Feiertagen und den Klageriten zum Jahresende sind noch einzelne schlechter dokumentierte Feierlichkeiten in Nippur zu erwähnen. Als erstes ist hier das Fest $\mathrm{g} \mathrm{u}_{4}-\mathrm{g}_{\mathrm{n}} \mathrm{a}_{2}$ zu nennen, das Šulgi-simtī zum Jahresanfang feierte. Ob das Fest jährlich begangen wurde oder nur zu bestimmten Anlässen, ist nach der derzeitigen Quellenlage nicht zu entscheiden. Bisher ist ein Beleg dem Archiv der Šulgisimtī eindeutig zuzuordnen ${ }^{178}$, ein weiterer Beleg ist nach den genannten Gottheiten und nach dem Festnamen ebenfalls in diesen Kontext zu stellen, doch da es sich hier um die Gabe von Früchten handelt, ist der Zusammenhang mit der Königin nicht absolut gesichert ${ }^{179}$. Bei diesem Fest wurden die Göttinnen Allagula, Ninlil und Ninĝagia (Bab 7, Pl. XIX Nr. 2) sowie Inanna, Enlil und die Statue des Königs (OIP 115, 32) beopfert. Das Fest scheint insbesondere den Göttinnen Allagula und Ninlil gegolten zu haben, welche umfangreichere Gaben erhielten, für Ninlil war einmal die bei Šulgi-simtī äußerst seltene Gabe von zwei Rindern zusätzlich zu drei Stück Kleinvieh bestimmt (OIP 115, 32). Wie bei anderen Feierlichkeiten in Nippur nahm die Königin auch bei diesem Fest persönlich teil und überbrachte die Opfergaben.

Ninlil und Allagula stehen auch im Zentrum von Feierlichkeiten, die Šulgisimtī im Herbst des Jahres $\breve{S} 40$ abhielt $^{180}$. Auch hier erhielten diese beiden Göttinnen je ein Rind und mehrere Stück Kleinvieh. Die Feierlichkeiten erstreckten sich über zwei Tage, am ersten Tag wurden siskur $\mathrm{r}_{2}$-Riten für Allatum sowie Klagen für Inanna abgehalten. Am folgenden Tag wurden neben Ninlil und Allagula wie schon beim $\mathrm{g} \mathrm{u}_{4}$ - gan $\mathrm{a}_{2}$-Fest Opfer für die Statue des Königs dargebracht. Daneben wurden Nintinuga, en-á-nun, Damgalnunna, Nintu und Nin-Tummala, alles Göttinnen, die sonst nicht bei Šulgi-simtī erwähnt werden, mit je einem Schaf bedacht.

Auf die Frage, wie diese besonderen Feste für Ninlil und Allagula interpretiert werden können, sind verschiedene Erklärungsansätze denkbar:

a) Die Texte gehören in die größeren Zusammenhänge der Feste in Nippur (Monat i/ii) bzw. Tummal (Monat viii) ${ }^{181}$. Die Königin beteiligte sich

178 OIP 115, 32 (i/Š 37).

179 Bab 7, Pl. XIX Nr. 2 (ii/Š 44); siehe Sallaberger, Der kultische Kalender (1993), S. 119, welcher hier aufgrund des Datums Opfer der Königin im Zusammenhang mit dem Fest $\mathrm{g} \mathrm{u}_{4}$ - $\mathrm{si}-\mathrm{su}$, dem Hauptfest Ninurtas in Nippur, vermutet.

180 Tel Aviv I, 56 (4, 5/viii/Š 40).

181 Sallaberger stellte den Text Tel Aviv I, 56 aufgrund des Datums und der Erwähnung der Nin-Tummala in den Zusammenhang der Tummalfeste; Der kultische Kalender (1993), Tab. 41. Ebenfalls in den Kontext des Tummalfestes und in das Umfeld der 
regeläßig an diesen Feierlichkeiten, die spärliche Dokumentation ihrer Festteilnahme ist auf den Zufall der Überlieferung zurückzuführen.

b) Die Königin vollzog regelmäßig parallel zu den jeweiligen königlichen Riten eigene Feste, bei denen sie insbesondere den weiblichen Gottheiten Ninlil und Allatum Opfer brachte, während der König bevorzugt den männlichen Gottheiten wie Ninurta und Enlil opferte. Beim Tummalfest im achten Monat gelten allerdings bis zum Jahr Š 47 die Opfer des Königs nicht Enlil, sondern nur Ninlil und Nanna ${ }^{182}$. Bei diesem Erklärungsmodell würde sich wieder die Trennung von männlicher und weiblicher Sphäre zeigen, die schon häufiger zu beobachten war.

c) $\mathrm{Da}$ die Belege für Feste der Königin in dem hier diskutierten Zusammenhang sehr spärlich sind, wäre es auch denkbar, daß es sich bei diesen Feierlichkeiten nicht um zyklische Feste handelt, sondern um besondere Riten, die anläßlich ganz bestimmter Ereignisse vollzogen wurden. Dabei könnte es sich um politische oder familiäre Ereignisse gehandelt haben, die die Durchführung besonderer kultischer Handlungen erforderlich machten.

Gleiches gilt für ein Fest für Inanna in Nippur, für das im Sommer des Jahres $\breve{S} 45$ Vieh aus den Beständen der Šulgi-simtī abgebucht wird ${ }^{183}$. Außer den zu den Vollmondfeiern üblichen Opfern von Kleinvieh für Enlil, Ninlil und Inanna ${ }^{184}$ werden auch Nanna und seine Gemahlin Ningal explizit genannt und mit Opfergaben versorgt, ebenso wie verschiedene kleinere Gottheiten ${ }^{185}$. Außerdem erhält Inanna bei diesem Fest zusätzlich zu der sonst zu Vollmond üblichen Gabe von einem Stück Kleinvieh noch vier weitere Schafe sowie ein Rind. Da Šulti-simtī eine enge Beziehung zu der Götttin Inanna hatte, liegt es nahe, diesen Text dem Hauptfest der Göttin in Nippur zuzuordnen, das im sechsten Monat gefeiert wurde ${ }^{186}$, und anzunehmen, daß die Königin sich regelmäßig an diesen Feiern beteiligte. Doch da derzeit keine weiteren Texte aus dem Archiv Šulgi-simtīs zu diesem Fest vorliegen, wäre auch eine einmalige Teilnahme der Königin an diesen Feierlichkeiten denkbar.

Šulgi-simtī gehört der Text SET 198 (-/vii/Š 44), wo die von der Königin verehrten Göttinnen Granatäpfel und Datteln erhalten. Vgl. Sallaberger, ebd. S. 140 und SuchGutiérrez, Beiträge zum Pantheon von Nippur im 3. Jahrtausend (2003), Teil I S. $118 \mathrm{f}$.

Sallaberger, Der kultische Kalender (1993), Tab. 41. Zum Tummalfest vgl. auch SuchGutiérrez, Beiträge zum Pantheon von Nippur im 3. Jahrtausend (2003), Teil I S. 117120.

183 PDT I, 645 (12-14/v/Š 45).

$184 \mathrm{Zu}$ den monatlichen Feiertagen siehe den folgenden Abschnitt.

185 Nin-ni ${ }_{9}$-garar, Dada, der Flußordalgott und Ninšubur.

186 Sallaberger, Der kultische Kalender (1993), S. 127-129. 


\subsubsection{Monatliche Feiertage $e^{187}$}

Die Ausgaben zu den monatlichen Feiertagen - zu Neulicht, zum 7. und zum 15. Tag - gehören zu den am umfangreichsten dokumentierten kultischen Aufwendungen im Archiv der Šulgi-simtī. Die Riten der Königin zu den monatlichen Feiertagen wurden in der Hauptstsadt Ur, in Nippur und in Uruk vollzogen. Die Opfer des Königs wurden meist den Göttern in Nippur dargebracht, königliche Gaben zu monatlichen Feiertagen in anderen Orten sind eher selten. ${ }^{188}$ Parallel zu den Opfern des Königs in Nippur brachten die Ensis monatliche Opfer für die Götter der einzelnen Provinzhauptstädte dar. Zum 21. Tag eines Monats fanden keine besonderen Riten des Königs oder der Königin statt.

Die Feierlichkeiten der Königin zu Neulicht und zum 15. Tag wurden zumeist in Uruk und Ur begangen ${ }^{189}$, am 7. Tag galten die Opfer dagegen üblicherweise den Göttern von Nippur, wobei aber auch hier Riten zum 15. Tag vollzogen wurden, für die Vieh aus den Beständen Šulgi-simtīs bereitgestellt wurde. ${ }^{190}$ Es fällt auf, daß die Königin zu den monatlichen Feiertagen nur bei den Opfern in Nippur als Überbringerin in den Texten vermerkt wird ( $\mathrm{g} \mathrm{iri}_{3}$ nin- $\hat{a} a$ ), nicht aber bei Gaben an die Götter von Uruk. Sie ist nie als Überbringerin zu Neulichtopfern vermerkt, da diese nicht in Nippur stattfanden. Daraus zu schließen, Šulgi-simtī habe nicht selber an diesen Feierlichkeiten teilgenommen, geht wahrscheinlich zu weit. Möglicherweise handelt es sich lediglich um unterschiedliche Schreibgewohnheiten der verschiedenen Beamten der Königin, denn während sich bei Bēlī-țāb und Ur-Lugal-edenka häufiger der Vermerk ĝ ri $_{3}$ nin- $\hat{g}$ á findet, tritt er bei Apilia eher selten, bei Apilatum gar nicht auf.

Je nach Anlaß und Ort gelten die Opfer der Königin unterschiedlichen Gottheiten: Bei den Neulichtfeiern werden neben drei Stück Kleinvieh für s iskur ${ }_{2}$-Riten in Uruk je ein Stück Kleinvieh an folgende Gottheiten gegeben: Inanna, Bēlat-Šuhnir, Bēlat-Deraban, Nanna, Ninsun und der von der Gottheit verlassne Ort (níĝ-ki-zàḩ ). ${ }^{191}$ Dagegen werden zu den Feiern zum 15. Tag Opfertiere in Uruk bereitgestellt und die Gottheiten Inanna, Bēlat-Šuhnir und Bēlat-Deraban versorgt, Nanna, Ninsun und der von der Gottheit verlassene Ort werden nicht erwähnt, dafür kann Iškur in der Reihe der Empfänger von Gaben

\footnotetext{
187 Siehe Sallaberger, Der kultische Kalender (1993), S. 37-48. Siehe auch Tabelle 3: Monatliche Opfer bei Šulgi-simtī.

188 Sallaberger, Der kultische Kalender (1993), S. 48-59.

189 Siehe unten S. 60f. mit Belegen.

190 Zu den monatlichen Riten in Nippur siehe auch S. 50 mit Belegen.

191 Sallaberger, Der kultische Kalender (1993), Tab. 3.
} 
der Königin auftreten ${ }^{192}$. Wer genau die Tiere erhielt, die mit dem Vermerk ,,in Uruk" verbucht wurden, ist nicht bekannt. Für Inanna wurden separat Tiere für Klageriten abgebucht. Da die Königin offenbar keine Klagen (gerrānum) sonderrn siskur ${ }_{2}$-Riten abhielt, wenn sie selber in Uruk bei der Göttin anwesend sein konnte ${ }^{193}$, ist davon auszugehen, daß die Neulichtfeiern üblicherweise in Ur stattfanden, da auch, von Inanna abgesehen, die in diesem Kontext bei Šulgi-simtī erwähnten Gottheiten nach Ur gehören. Das Kleinvieh für siskur ${ }_{2}$-Riten in Uruk kann folglich auch für Inanna bestimmt gewesen sein, welche diese Opfer in Ihrem Tempel im Rahmen von siskur ${ }_{2}$-Riten erhielt, während gleichzeitig die Königin in Ur nochmals Klageriten für ihre Göttin vollzog, in deren Nähe sie nicht sein konnte.

\begin{tabular}{|c|c|c|}
\hline Gottheit & Ort & Anlaß \\
\hline Inanna (?) & Uruk & Neulicht \\
Inanna & Ur & \\
Bēlat-Šuhnir & & \\
Bēlat-Deraban & & \\
Nanna & & \\
Ninsun & Nippur & \\
\hline Allatum & & \\
Allagula & & \\
Ninlil & & \\
Enlil & & \\
Ninĝgagia & & \\
Flußordalgott & Uruk Tag \\
\hline Inanna (?) & Ur & \\
Inanna & & \\
Bēlat-Šuhnir & & \\
Bēlat-Deraban & & \\
Iškur & & \\
\hline Nanaja & Uruk fester Tag) \\
Tor des Heiligtums & & \\
Tor des Gipar & & \\
\hline
\end{tabular}

Tabelle 3: Monatliche Opfer bei Šulgi-simtī

Ganz anders dagegen ist die Reihe der in Nippur beopferten Gottheiten. Hier gelten die Gaben der Königin den Gottheiten Allatum, Allagula, Ninlil, Enlil und Ninĝagia, wobei es nicht von Bedeutung ist, ob die Opfer am 7. oder am

\footnotetext{
192 Zu den Opfern für Iškur siehe S. 86-88.

193 Siehe unten S. 60.
} 
15. Tag dargebracht werden. In den Jahren ab Š 45 werden die Opfer zum 7. und zum 15. Tag wiederholt ergänzt durch Gaben für den Flußordalgott. In Uruk werden also die Stadtgöttin Inanna, in Ur die persönlichen Göttinnen der Königin von ihr versorgt, außerdem einmal im Monat der Mondgott und die göttliche Mutter der Könige von Ur.

Diese Reihe der zu den verschiedenen Anlässen beopferten Göttern bildete sich offenbar in den ersten Amtsjahren Šulgi-simtīs heraus. Für die Jahre Š 32 bis 34 sind die monatlichen Feiertage bei Šulgi-simtī bisher nicht nachzuweisen, in den Jahren Š 35 und 36 werden für den Neulicht- und den 15. Tag nur ein bis drei Stück Kleinvieh bereitgestellt, ohne daß jedoch die einzelnen Gottheiten erwähnt würden. Feierlichkeiten zum 7. Tag in Nippur sind ab dem Jahr Š 36 belegt, wobei die Reihe der beopferten Götter von Beginn an vollständig ist. Dieser Befund könnte zum einen mit der Überlieferungssituation der Texte aus Puzriš-Dagān erklärt werden, doch dem stehen eine Reihe von Belegen zu kultischen Aktivitäten Šulgi-simtīs anderer Art entgegen. Es könnte aber auch bedeuten, daß die Königin erst im Laufe ihrer Amtszeit einen Kanon ihrer religiösen Aktivitäten entwickelte ${ }^{194}$.

\subsubsection{Weiter Riten für Nanna von Ur}

Nur selten brachte Šulgi-simtī außerhalb der oben beschriebenen monatlichen Feiertage Opfer für Nanna dar. Diese Gaben lassen sich zumeist in den Kontext eines bekannten Festes integrieren.

Eines der wichtigsten Feste im kultischen Kalender der Stadt Ur war das Akiti-Fest zur Aussaat, das im 7. Monat ${ }^{195}$ begangen wurde. Die Königin nahm an diesem wichtigen Fest teil, war aber offenbar nicht während der gesamten Dauer anwesend. Folgende Elemente lassen sich für die Teilnahme der Šulgisimtī am Akiti-Fest der Aussaat feststellen: Dem Mondgott opferte die Königin bei siskur ${ }_{2}$-Riten ein Schaf ${ }^{196}$, ihre persönlichen Göttinnen Bēlat-Šuhnir und Bēlat-Deraban verließen ihren Tempel und reisten mit dem Boot zum Akiti ${ }^{197}$, wohl gemeinsam mit Šulgi-simtī. Ein Text aus dem Jahr $\breve{S} 33$ ist im Zusammenhang mit einer Reise der Königin zu sehen ${ }^{198}$. Hier wird ein

\footnotetext{
194 Siehe Kap. 9.1. S. 179-182.

195 Nach dem Kalender von Ur ist der Monat a-ki - ti der 7. Monat, nach dem in PuzrišDagān verwendeten Reichskalender ist es der 6. Monat.

196 TCND 195 (vi/Š 33); OIP 115, 34 (vi/Š 37); TCNY 48 (vi/Š 46); MVN 18, 83 (19/vi/Š 47), dem Datum nach gehört auch MVN 15, 306 (10/vi/Šs [38-41]) hierher.

197 OIP 115, 130 (vi/Š 35); TCNY 48 (vi/Š 46).

198 UCP 9/2/2, 37 (vi/Š 33). Sallaberger, Der kultische Kalender (1993), S. 176 Anm. 823 und S. 190.
} 
gemästetes Schaf für das Dublamah, den Torbau des Nannatempels in Ur, geopfert „als meine Herrin herausging (nin- $\hat{g} u_{10}$ è-da-ni)“. Aus den Beständen ihres Viehhofes schickte Šulgi-simtī Kleinvieh und Vögel für die Tafel des Königs nach Karzida ${ }^{199}$ und sie begrüßte den aus dem Akitihaus zurückkehrenden König mit Gaben aus ihrem Viehbestand ${ }^{200}$, war also vor dem König nach Ur zurückgekehrt. Des weiteren wurde der von den beiden Göttinnen zeitweilig verlassene Tempel in deren Abwesenheit mit Opfergaben versorgt $t^{201}$, was nötig war, da die Reise der Göttinnen ein Eingriff in die kultische Ordnung darstellt, die ein besonderes Opfer nötig macht. ${ }^{202}$ Aus diesen einzelnen Details ergibt sich das Bild eines komplexen Kultablaufs, bei dem König und Königin mit unterschiedlichen Aufgaben involviert sind. Ob sich das Fest in jedem Jahr nach einem genau gleichen Ablauf vollzog oder ob es bestimmte Abweichungen geben konnte, ist nicht zu sagen, doch ist festzuhalten, daß die Königin bei diesem im agraischen Jahreszyklus wichtigen Fest zur Aussaat präsent war und kultische Funktionen wahrnahm.

Für das zweite Akiti-Fest, das Akiti zur Ernte, das im ersten Monat gefeiert wurde ${ }^{203}$, finden sich im Archiv der Šulgi-simtī keine eindeutigen Hinweise auf eine Teilnahme der Königin. Zwar datieren eine Reihe ihrer Urkunden auf den ersten Monat, doch lassen sich die dort verbuchten Ausgaben stets anderen Ereignissen und Festen zuordnen, wie den Opfern zu Neulicht und regelmäßigen Gaben der Königin an die Götter von Uruk ${ }^{204}$.

Für das dritte große Fest von Ur, das „Erhabene Fest“ (e ze m-mah), welches im neunten Monat ${ }^{205}$ gefeiert wurde, sind bisher nur drei Texte aus dem Archiv der Šulgi-simtī bekannt ${ }^{206}$. Bei diesem Fest handelte es sich um ein mehrtägiges Ereignis, bei dem das Baden und anschließende Einkleiden Nannas im Zentrum standen. Ein Bestandteil der Feierlichkeiten war ein Klageritus, der mit dem Terminus ér-s ù-a „Tränen vergießen“ bezeichnet wurde und mit dem man sich wohl vor dem möglichen Zorn des Gottes schützen wollte. ${ }^{207}$ Die genaue Rolle der Königin bei diesen Feierlichkeiten ist

\footnotetext{
199 TCNY $48(\mathrm{vi} / \mathrm{S} 46)$.

200 MVN 18, $84(22 / v i / S ̌ s 4)$.

201 OIP 115, 34 (vi/Š 37).

202 Sallaberger, Der kultische Kalender (1993), S. 190.

203 Dazu Sallaberger, Der kultische Kalender (1993), S. 1179-183.

204 Siehe unten S. 60.

205 Neunter Monat nach dem Kalender von Drehem, nach dem Kalender von Ur war es der zehnte Monat.

206 MVN 3, 178 (5/ix/Š 40); MVN 18, 64 (6, 10/ix/ŠS 41); MVN 18, 73 (13/ix/Š 45).

207 Zu dem Fest siehe Sallaberger, Der kultische Kalender (1993), S. 191-194 und Tab. 63.
} 
aus den wenigen Belegen nicht zu erschließen. Sicher ist, daß sie an den Feierlichkeiten persönlich teilnahm, wie aus dem Text MVN 18, 73 (Š 45) hervorgeht, wo sie selber als Überbringerin umfangreicher Opfer an verschiedene Götter auftritt. Aus ihren Beständen werden Tiere geliefert, die für die Tafel des Königs oder allgemein für den Palast bestimmt sind. In einem Fall werden Tauben für das Klagefest Nannas (ér-sù d $\mathrm{Nann}$ a-áš) gebracht. Da Vögel sonst nie als Opfergabe verwendet werden, vermutete Sallaberger hier Lieferungen für die Tafel der Königin anläßlich des Festes ${ }^{208}$, doch ist die Formulierung in jeden Fall auffällig, da Ausgaben für die Versorgung des Königs und der Königin sonst stets als solche gekennzeichnet sind (ní $\hat{g}-g u_{7}$ lugal/nin-ĝá). So stellt sich hier die Frage, ob es sich um eine verkürzte Formulierung für eine Ausgabe für die königliche Tafel anläßlich des Festes für Nanna handelte, oder ob Šulgi-simtī dem Gott tatsächlich die sonst ungewöhnliche Gabe von mehreren Tauben darbrachte.

\subsubsection{Der Kult in Uruk - Inanna und Nanaja}

Zu der Göttin Inanna hatte Šulgi-simtī ein sehr enges Verhältnis, was sich darin äußert, daß Inanna während der gesamten Amtszeit der Königin häufiger und in vielfältigeren Kontexten mit Opfergaben versorgt wird als die anderen großen Götter des Landes. Dieses besondere Nahverhältnis der Königin zu Inanna ist ebenso bei Šulgi-simtīs Nachfolgerin Abī-simtī zu beobachten, und auch Geme-Enlila, die letzte namentlich bekannte Königin der Dynastie, kümmerte sich um den Kult dieser bedeutenden Göttin. ${ }^{209}$

Die Opfer für Inanna stehen häufig im Kontext anderer Kulthandlungen wie den Riten zu den monatlichen Feiertagen. Zumeist gelten die Gaben der Königin der Inanna von Uruk, nur in den ersten Jahren ihrer Amtszeit wird explizit die Inanna von Ur, In anna da-bàd-da, genannt ${ }^{210}$, in einem Fall wird die Inanna von Uruk ausdrücklich von der Inanna von Nippur unterschieden ${ }^{211}$. Hier unterschied man die verschiedenen kultischen Manifestationen der Göttin, abhängig von dem Ort, an dem gerade der Stadtkult für die Göttin gefeiert wurde. Bei den regelmäßigen Opfern für Inanna zu Neulicht ${ }^{212}$

208 Sallaberger, Der kultische Kalender (1993), S. 193.

209 Siehe S. 135-141 zu Abī-simtī, S. 168 zu Geme-Enlila und S. 180f allgemein zum Verhältnis der Königin von Ur zur Göttin Inanna in dieser Epoche.

210 PDT II, 1017 (v/Š 33); MVN 18, 53 (ix/Š 33); MVN 18, 57 (i/Š 36); OIP 115, 134 (Datum abgebrochen). Zu Inanna da-bàd-da siehe Sallaberger, Der kultische Kalender (1993), S. 47 Anm. 199.

211 BIN III, 337 (10/ix/Š 47) wo Inanna von Uruk und Inanna von Nippur je ein Stück Kleinvieh erhalten.

212 SET 41 (-/ix/Š 35); MVN 18, 57 (-/i/Š 36); MVN 18, 59 (-/iv/Š 36); MVN 18, 62 (- 
und am 15. Tag $^{213}$ eines Monats erhielt die Göttin aus den Beständen der Königin stets ein Stück Kleinvieh, wobei Šulgi-simtī der Göttin zumeist mit Klagen (gerrānum) gedachte. Nur selten findet sich bei Opfern an Inanna der sonst im Archiv der Königin weit häufigere Terminus s i s ku $\mathrm{r}_{2}$.

Eine eingängige Erklärung für diese Erscheinung bot Sallaberger mit Verweis auf den Text TRU 284 (14/x/Š 42). Hier wird Kleinvieh für s i sk u r ${ }_{2}$ Riten für Inanna und Bēlat-Šuhnir sowie für den von der Gottheit zeitweise verlassenen Tempel der Bēlat-Šuhnir gebucht, außerdem wird Kleinvieh ausgegeben für siskur ${ }_{2}$-Riten zum 15. Tag in Uruk. Bei vergleichbaren Texten zum Neulichttag und zum 15. Tag werden fast immer Klagen für Inanna vermerkt. Sallaberger interpretierte diesen Befund dahingehend, daß sich Šulgi-simtī in jenem Monat in Uruk aufgehalten habe, wobei sie von ihrer persönlichen Göttin Bēlat-Šuhnir begleitet wurde. Deshalb wurden Opfer im zeitweise verlassenen Tempel der Bēlat-Šuhnir in Ur durchgeführt. Da sich die Königin selber in Uruk befand, war ihr Inanna nicht fern und sie brauchte nicht um die Göttin zu klagen, sondern vollzog siskur ${ }_{2}$-Riten. ${ }^{214}$ Wenn diese Interpretation zutreffend ist, könnte damit in einzelnen Fällen die Reisetätigkeit der Königin verfolgt werden. So werden sowohl zum Ende des Monats xii/Š 42 wie auch einen Monat später aus dem Archiv Šulgi-simtīs je ein Schaf für Inanna und zwei Schafe für Bēlat-Šuhnir und Bēlat-Deraban abgebucht, allerdings werden im ersten Fall als Bestimmung Klagen (gerrānum) für Inanna angegeben, im zweiten Fall siskur ${ }_{2}-$ Riten $^{215}$. Ist die Interpretation Sallabergers zutreffend, läßt sich daraus schließen, daß Šulgi-simtī sich zu den Feiern zum 15. Tag im zehnten Monat des Jahres $\breve{S} 42$ in Uruk aufhielt, dann die Stadt verließ, da zwei Monate später Klagen für Inanna abgehalten werden,

/vi/Š 37); CST 47 (30/vi/Š 39); MVN 5, 93 (27/x/Š 39); MVN 18, 65 (30/ix/Š 40); MVN 18, 66 (28/x/ŠS 40); OIP 115, 62 (30/xi/š 40); TRU 274 (30/i/ŠS 41); SET 43 (28/ix/Š 41); TRU 275 (26/vii/Š 41); CST 467 (30/ii/Š 42); OIP 115, 80 (30/viii/Š 42); ŠA XXXIII:1 (30/xii/Š 42); OIP 115, 82 (29/i/Š 43); MVN 18, 75 (27/viii/Š 46); PDT I, 414 (30/x/Š 46); PDT I, 61 (28/xii/Š 46); SRD 10 (30/xii/Š 46); OrAn 11, S. 273 Nr. 2 (30/v/Š 47), vgl. Sallaberger, Der kultische Kalender (1993), Tab. 3.

213 SET 41 (-/ix/ŠS 35); MVN 18, 59 (-/iv/Š 36); CTNMC 9 (-/v/ŠS 37); MVN 18, 90 (-

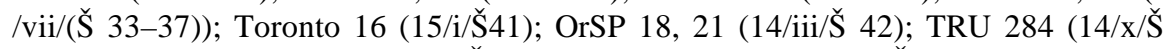
42); Bab 8, Pl. X, Nr. 7 (14/xii/Š (42-44)); PDT I, 645 (13/v/Š 45); OIP 115, 94 (13/vii/Š 45); MVN 18, 72 (15/vii/š 45); MVN 13, 715 (16\%/viii/Š 45); OIP 115, 100 (16/xii/Š 45); CST 170 (14/iv/Š47), vgl. Sallaberger, Der kultische Kalender (1993), Tab. 5. Nicht immer wird die Göttin in diesen Texten explizit genannt, mitunter werden einfach Tiere für Riten ,am 15. Tag in Uruk“ verbucht.

214 Sallaberger, Der kultische Kalender (1993), S. 47.

215 ŠA XXXIII:1 (30/xii/Š 42); OIP 115, 82 (29/i/Š 43). 
aber zu Beginn den Jahres $\breve{S} 43$ wieder nach Uruk kam. ${ }^{216}$ Interessant ist hierzu auch ein weiterer Text, der Ausgaben für die Riten zum 15. Tag verbucht ${ }^{217}$. Am 10. des Monats wird ein Schaf für sisku $r_{2}$-Riten für Inanna ausgegeben, fünf Tage später werden die üblichen Opfertiere für den Kult am 15. Tag in Uruk aufgeführt, wobei jetzt für Inanna Klagen abgehalten werden. Die Buchung wird insgesamt von Tummal aus durchgeführt. Nun fanden im siebten Monat die Riten zum Tummalfest bei Nippur statt ${ }^{218}$. Es scheint so, als habe sich Šulgi-simtī zu Beginn des Monats in Uruk aufgehalten, wo sie der Inanna direkt opfern konnte, daß sie aber noch vor dem 15. Tag die Stadt verließ, um entweder nach Ur zurückzukehren oder aber an den Feierlichkeiten in Tummal teilzunehmen. Diese Beobachtung entspricht durchaus den vorangegangenen, daß die Königin zu den verschiedenen kultischen Ereignissen eines Jahres die unterschiedlichen Heiligtümer des Landes aufsuchte.

Mitunter wird Kleinvieh für Klagen um Inanna schon am 25. eines Monats abgebucht ${ }^{219}$. Hierbei handelt es sich wohl nicht um frühzeitige Buchungen für die Neulichtriten, sondern um Klagen zu einem anderen Anlaß. Da auch die Riten für das Himmelsboot, bei denen Inanna regelmäßig Opfer erhielt, im letzten Viertel eines Monats abgehalten wurden, könnten diese Texte auch im Zusammenhang dieser Feste zu sehen $\operatorname{sein}^{220}$.

In den Jahren Š 46 und $\breve{S} 47$ hielt die Königin wiederholt si skur ${ }_{2}$-Riten für Inanna im Palast $a^{221}$. Nach den Daten könnten diese Opfer den üblichen Gaben zu einem der monatlichen Feiertage zugeordnet werden, allerdings wäre der Wechsel des Formulars auffällig. Daß es sich bei diesen si skur ${ }_{2}$-Riten im Palast um etwas anderes handeln muß, legt der Text OrAn 11, S. 273 Nr. 2 nahe. Hier werden die üblichen Ausgaben zu den Neulichtfeiern in Uruk verbucht, also auch ein Schaf für Klagen um Inanna, darüber hinaus werden aber noch Zicklein für s i s k $\mathrm{r}_{2}$-Riten für Inanna im Palast ausgegeben. Daraus folgt, daß es sich bei diesen s i skur ${ }_{2}$-Riten nicht um die üblichen Opfer für die Göttin handeln kann. Wie schon bei einigen Festen in Nippur ist auch hier die Möglichkeit gegeben, daß es sich um eine direkte religiöse Reaktion der Königin auf besondere äußere Ereignisse handelt, wobei uns der Hintergrund für diese Opfer verborgen bleibt.

\footnotetext{
216 TRU 284 (15/X/S 42); ŠA XXXIII:1 (30/xii/Š 42); OIP 115, 82 (29/i/ŠS 43).

217 MVN 18, $72(10,15 /$ vii/Š 45).

218 Siehe S. 54.

219 TCND 184 (25/xii/Š 40); OIP 115, 95 (25/vii/Š 45); SRD 12 (25/xi/Š 47).

220 Siehe dazu unten S. 66-68.

221 MVN 18, 75 (27/viii/Š 46); OIP 115, 105 (7/v/Š 46); PDT I, 414 (30/x/Š 46); OrAn 11, S. 273 Nr. 2 (30/v/Š 47).
} 
Die übliche Gabe für Inanna bestand aus einem Stück Kleinvieh. Nur bei besonderen Ereignissen erhielt die Göttin umfangreichere Opfer. Ein solches

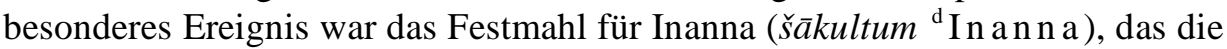
Königin zu Beginn des Jahres Š 36 in Uruk ausrichtete. Sowohl am „Tor des Gipar“ (ká $\mathrm{g}_{6}{ }_{6}-\mathrm{par}_{4}$ ) wie am „Tor des Heiligtums“ (ká èš) wurde je ein gemästetes Rind für das Festmahl der Inanna geopfert ${ }^{222}$. Wie diese Opfer für Inanna zeigen, handelt es sich bei diesen Toren um Teile des Tempelbezirks der Göttin in Uruk. ${ }^{223}$ Die Tore als Ort für das Opfer kennzeichnen die vollzogenen Riten als Übergangsriten, doch noch ist unklar, warum die Opfer an den Eingängen und nicht in den Tempeln selber vollzogen werden mußten.

Nahezu während ihrer gesamten Amtszeit opferte Šulgi-simtī an diesen beiden Toren, wobei in diesem Zusammenhang auch mitunter Rinder geopfert werden, was sonst bei Šulgi-simtī selten der Fall ist. ${ }^{224}$ Ein Grund für die besondere Gabe von Rindern ist in den Texten nicht angegeben. Üblicherweise wurde im Zusammenhang mit den Opfern an den Toren auch Nanaja versorgt, wobei diese Göttin nur Kleinvieh erhielt, auch wenn an den Toren Rinder geopfert wurden. Es fällt auf, daß bei den Urkunden dieser Gruppe nicht gleichzeitig Gaben für Annunītum und Ulmašītum verbucht werden. Auch Opfer für die persönlichen Göttinnen der Königin, für Bēlat-Šuhnir und BēlatDeraban werden in diesem Zusammenhang nicht dargebracht. Zwar finden sich mitunter auf Urkunden, die die Ausgaben für Opfer an den Toren und für Nanaja verbuchen, auch Ausgaben für Bēlat-Šuhnir und Bēlat-Deraban, doch wird aus dem Kontext deutlich, daß es sich dabei um zwei getrennte Vorgänge handelt, die im Text auch deutlich voneinander abgesetzt sind, beispielsweise durch einen $\hat{g}$ iri $_{3}$-Vermerk oder einen Eintrag über den Verwendungszweck der Tiere. So verzeichnet der Text SAT II, 557 (v/Š 47) erst die Ausgabe von Kleinvieh für Bēlat-Šuhnir, Bēlat-Deraban und Iškur in Ur und danach die Ausgabe von einer Ziege am Tor des Gipar in Uruk, wobei für die beiden Transaktionen verschiedene Beamten als Überbringer ( $\left.\hat{\mathrm{g}} \mathrm{iri}{ }_{3}\right)$ fungieren. Es ist also deutlich, daß der Kult für Bēlat-Šuhnir und Bēlat-Deraban nicht verbunden

\footnotetext{
222 SACT I, 132 (ii/Š 36).

$223 \quad$ Sallaberger, Der kultische Kalender (1993), S. 220.

224 MVN 18, 56 (-/x/Š 35); MVN 18, 90 (-/vii/(ك̌ 33-37)); TPTS 96 (-/ii/Š 36); SACT I, 132 (-/ii/Š 36); OIP 115, 31 (-/i/ŠS 37) (hierher?); MVN 18, 69 (2/vii/ŠS 41); PDT II, 1030 (-/iv oder v/(Š 42-45)); Rochester 13 (-/xi/ŠS 45); OIP 115, 103 (20/v/Š 46); CST 157 (-/i/Š 47); BJRL 64, 111 Nr. 66 (1,2/i/Š 47); TCND 191 (7/i/Š 47); Orient 16, 11 (8/i/Š 47); CST 159 (13/i/Š 47); TPTS 99 (28/i/Š 47); DCEPHE 289 (30/i/Š 47); MVN 18, 82 (14/ii/Š 47); CST 167 (7/iii/Š 47); SAT II, 557 (-/v/ŠS 47); OIP 115, 122 (15/vi/Š 47); PDT II, 1272 (-/x/Š 47); TCND 194 (15/x/Š 47); MVN 2, 165 (19/x/Š 47); TCNY 80 (-/v/-), vgl. Sallaberger, Der kultische Kalender (1993), Tab. 72.
} 
ist mit den Riten, die die Königin im Tempelbezirk der Inanna von Uruk vollzieht. Die Bedeutung dieser Riten bei den Toren des Heiligtums und des Gipar wird auch daraus ersichtlich, daß die Königin sehr oft selber als Überbringerin der Gaben auftritt ( $\hat{g}_{i r i_{3}}$ nin-ĝá). Dies und die Gabe von Rindern unterstreicht die enge Beziehung, die Šulgi-simtī zu Inanna von Uruk hatte.

In vielen Fällen lassen sich die Opfer an den beiden Toren und für Nanaja zeitlich mit den Riten der monatlichen Feiertage verbinden, wenn auf der Urkunde vermerkt wird, daß es sich um Ausgaben zum 15. Tag in Uruk handelt oder wenn das taggenaue Datum eine Zuordnung zu einem der monatlichen Feiertage erlaubt. Da aber bis zum Jahr Š 37 die Texte nicht auf den Tag genau datiert sind, ist nicht sicher zu sagen, ob die Opfer in dieser Gruppe konsequent mit den monatlichen Feiertagen verbunden wurden oder ob gerade die Zeugnisse des Jahres Š 47 das Bild verzerren. Denn während für die Jahre Š 35 bis $\breve{S} 37$ sowie $\breve{S} 45$ und $\breve{S} 46$ jeweils zwei bis drei Belege pro Jahr überliefert sind und die Quellen für die Jahre $\breve{S} 38$ bis $\breve{S} 44$ derzeit bis auf eine Ausnahme $^{225}$ noch fehlen, häufen sich die Belege im Jahr $\breve{S} 47$ in auffälliger Weise. Gut die Hälfte aller Texte zu Opfern bei den Toren des InannaTempelkomplexes und für Nanaja stammen aus diesem einen Jahr. Da sich die Königin, wie schon mehrfach gezeigt wurde, regelmäßig zu bestimmten kultischen Anlässen persönlich zu den wichtigen Heiligtümern des Landes begab, reicht es nicht, diese Häufung der Opfer im Jahr $\breve{S} 47$ mit einem Aufenthalt der Šulgi-simtī in Uruk zu erklären ${ }^{226}$, vielmehr ist zu vermuten, daß sich auch hinter dieser Häufung der Opfer in einem Jahr wichtige äußere Ereignisse und Anlässe verbergen, die derzeit noch nicht erschlossen werden können.

Die Göttin Nanaja, die regelmäßig von der Königin versorgt wurde, wenn diese Opfer im Tempelbezirk der Inanna darbrachte, gehörte als Göttin der erotischen Liebe zum Kreis der Inanna und galt wie diese als Tochter des $\mathrm{An}^{227}$. Sie hatte selber ein Heiligtum in Uruk, das aber nur selten in den Texten der Šulgi-simtī explizit erwähnt wird $^{228}$. Diesen Tempel verließ Nanaja zu zwei unterschiedlichen Anlässen, die jedoch beide aufgrund der geringen Zahl der Belege kaum verständlich sind.

Als erstes ist hier ein Klageumzug (ér ni ĝ in $n_{2}-n a$ ) in Uruk zu nennen,

225 MVN 18, 69 (2/vii/Š 41).

226 Dies als eine mögliche Erklärung bei Sallaberger, Der kultische Kalender (1993), S. $58,220$.

227 Stol, Artikel „Nanaja“ im RlA 9 (1998), S. 147.

228 CTNMC 9 (v/Š 37); PDT II, 1030 (iv oder v/Š 45?). 
den Šulgi-simtī in den Jahren $\breve{S} 36$ und $\breve{S} 37$ abhalten ließ..$^{229}$ Die unterschiedlichen Monatsdaten zeigen, daß es sich nicht um ein jährliches Klagefest handelte. Ein verbindendes Element dieser Feier war ein Klageumzug, der einmal als „beim Tor des Gipar“ (MVN 18, 58) und einmal als „in der Stadt“ (CTNMC 9) bezeichnet wird. Ob es sich hierbei um gleichartige Umzüge handelte, muß derzeit offen bleiben. Ein weiteres Kennzeichen für dieses Klagefest war die Tatsache, daß die Göttin Nanaja ihren Tempel verließ, was zur Folge hatte, daß im von der Gottheit zeitweilig verlassenen Tempel Opfer dargebracht werden mußten ${ }^{230}$. Verließ Nanaja möglicherweise sogar die Stadt zu einer Reise, und mußte die Königin deshalb um die abwesende Göttin mit einem Umzug klagen? Im Zusammenhang mit diesen Klagefeiern findet sich die Formulierung $\mathrm{u}_{4}$ zi-ga-zé-na (CTNMC 9) und $\mathrm{u}_{4}$ zi-ša-še-na (MVN 18, 58) „Erhebt-Euch-Tag“(231, wobei unklar ist, ob damit ein besonderer Ritus gemeint ist oder ob es sich um die Festbezeichnung handelt. Im Jahr Š 36 erhielten im Zusammenhang mit diesem Klageumzug auch noch der Gott Muš-a-igi-gál ${ }^{232}$ und Ninigizibarra, die Harfe Inannas, ein Opfer. Die Harfe Inannas wird bei Šulgi-simtī noch zweimal im Zusammenhang mit den Opfern im Tempelbezirk der Inanna erwähnt ${ }^{233}$, ihr Auftreten war also nicht kennzeichnend für das Klagefest.

Ein weiteres nur schwach belegtes Fest im Zusammenhang mit den Opfern in Uruk ist das im 11. Monat gefeierte Fest e-ge ZAR/e $\mathrm{SU}_{7} . \mathrm{SU}_{7}$ (=am Deich blasen? $)^{234}$. Die große Bedeutung dieses Festes wird deutlich angesichts der Tatsache, daß die Königin selber als Überbringerin der Gaben auftrat ( $\hat{i}_{i r i_{3}} \mathrm{nin-} \hat{\mathrm{g} a}$ ) und daß in beiden Fällen am Tor des Heiligtums der Inanna ein Rind geopfert wurde. Des weiteren wird in beiden Fällen Kleinvieh am zag-gú-lá geopfert, wobei die Bedeutung dieses Ausdrucks unklar bleibt ${ }^{235}$.

${ }^{229}$ MVN 18, 58 (i/Š 36); CTNMC 9 (v/Š 37). Sallaberger, Der kultische Kalender (1993), S. 221, Cohen, Cultic Calendars (1993), S. 210.

230 Möglicherweise ist auch AAICAB I/1, Pl. 78 Ashm. 1924-1706 (-/X/-) in den Kontext eines solchen Klagefestes einzuordnen, da auch hier ein Lamm an dem von der Gottheit verlassenen Ort für Nanaja geopfert wird.

231 Zur Lesung siehe Sallaberger, Der kultische Kalender (1993), S. 221.

232 Bisher nur für die Ur III-Zeit und mit wenigen Quellen belegt, Siehe Richter, Untersuchungen zu den lokalen Panthea Süd- und Mittelbabyloniens (1999), S. 260.

233 MVN 18, 90 (vii/Š [ ]); TPTS 99 (28/i/Š 47) hier wird die Harfe nicht mit Namen genannt, sondern einfach als b a la g bezeichnet.

234 MVN 3, 145 (xi/Š 35) hat e-ge Z AR; in MVN 18, 87 (7/xi/Š 47) findet sich e $\mathrm{SU}_{7} . \mathrm{SU}_{7} \cdot \mathrm{Zu}$ diesen Bezeichnungen und zum Fest siehe Sallaberger, Der kultische Kalender (1993), S. 220-221.

235 Vgl. dazu Sallaberger, Der kultische Kalender (1993), S. 220 Anm. 1051. 
Einmal wird dieser zag-gú-lá näher bezeichnet als „,im Palast“ (šà é - gal la), im anderen Fall als „Haus des Statuenortes“ (é ki-alan). Möglicherweise handelt es sich um einen Schrein, eine Kapelle, die im Zusammenhang mit dem Herrscherkult genutzt wurde.

Da beide Feste derzeit nur je zweimal belegt sind, ist nicht zu entscheiden, ob es sich um zyklisch begangene Riten handelte, oder ob auch diese Feiern nur zu bestimmten Anlässen, die nicht in jedem Jahr wiederkehrten, begangen wurden. Bei nur zwei Belegen für das Fest im 11. Monat ist auch hier nicht sicher, ob das Monatsdatum kennzeichnend ist für die genannten Kulthandlungen.

Dies ist anders beim Fest des Himmelsbootes má-an- $\mathrm{na}$. Dieses Fest wurde zweimal jährlich, im sechsten ${ }^{236}$ und im elften ${ }^{237}$ Monat, in Uruk begangen ${ }^{238}$. Es wurde in der gesamten Ur III-Zeit gefeiert, wobei in diesem Kontext auffällig häufig Frauen aus dem Königshaus genannt werden. Neben den häufigen Erwähnungen des Festes bei Sulgi-simtī treten auch GemeNinlila, eine Nebenfrau Šulgis, sowie die Königstöchter Šeleppūtum und Šulgisimtī beim Fest des Himmelsbootes in Erscheinung ${ }^{239}$. Als Empfängerinnen von Gaben im Zusammenhang mit diesem Fest werden SI.A-tum, wohl die Mutter Šulgis, sowie die Damen Libūr-simtī und Eštar-ummī genannt ${ }^{240}$. Nur in

236 TCND 204 (-/vi/Š 33); Hirose 12 (-/vi/Š 34); MVN 18, 62 (-/vi/Š 37); TRU 275 (26/vii/Š 41); ArOr 25, S. 562 Nr. 23 (24/vi/Š42); TCND 189 (25/vi/Š 46), vgl. Sallaberger, Der kultische Kalender (1993), Tab. 71a.

237 MVN 18, 52 (-/xi '̌ك̌32); PDT I, 459 (-/x/Š 34); CST 43 (-/xi/ك̌ 35); OIP 115, 30 (-/x/Š 36); OIP 115, 62 (25/x/Š 40); SRD 12 (25/xi/Š 47), vgl. Sallaberger, Der kultische Kalender (1993), Tab. 71a.

238 Um einen Monat abweichende Daten lassen sich mit den unterschiedlichen Lokalkalendern von Puzriš-Dagān und Uruk erklären. Sallaberger, Der kultische Kalender (1993), S. 217.

239 Geme-Ninlila: JCS 31, S. 176 F (vi/Š 43); Šeleppūtum: ZA 80, S. 32 (22/vii/AS 4); Šulgi-simtī II: Toronto 164 (20/vii/IS 1).

240 Alle drei Frauen erhalten Kleinvieh in MVN 18, 52 (xi/s 32). SI.A-tum erscheint beim Fest des Himmelsbootes zwei Jahre später wieder als Empfängerin von Kleinvieh in PDT I, 459 (x/Š 34). Libūr-simtī und Eštar-ummī treten im selben Zusammenhang auch auf in TRU 275 (26/vii/Š 41). Darüber hinaus ist Eštar-ummī als Empfängerin von Gaben aus dem Bestand Šulgi-simtīs aus TCND 177 (xi/Š 35) und TCND 195 (vi/Š 33) bekannt. Die Daten lassen vermuten, daß auch diese Texte im Zusammenhang mit Feiern für das Himmelsboot stehen könnten. Ob die Gabe von einem Rind und fünf Schafen als Proviant für die Frau des Sukkalmah (CST 43 (xi/Š 35)) auch in den Festkontext gehören (so Sallaberger, Der kultische Kalender (1993), S.217), oder ob es sich hier um einen von der Gabe für das Himmelsboot getrennt $\mathrm{zu}$ betrachtenden Buchungsvorgang handelt, kann ich derzeit nicht entscheiden. 
einem Fall werden auch Männer im Kontext des má-a n-na genannt: Mašgula und Etel-pū-Dagān ${ }^{241}$. Dabei ist zu beachten, daß beide in engem Kontakt zur Königin standen. Maš-gula war der sukkal der Šulgi-simtīi ${ }^{242}$, Etel-pū-Dagān ist mehrfach als Lieferant von mu-DU an die Königin bezeugt ${ }^{243}$. Das bedeutet, daß die Personen, die direkt im Zusammenhang mit diesem Fest erwähnt werden, in enger Verbindung zur Königin standen, was darauf schließen läßt, daß ihr selber eine wichtige Rolle bei diesem Fest zufiel. Wie bei allen anderen Kulthandlungen auch ist es anhand der Wirtschaftstexte nicht möglich, den genauen Ablauf der Feste zu rekonstruieren, sodaß die genaue Funktion Šulgi-simtīs auch hier nicht festgestellt werden kann. In keinem einzigen Text tritt sie als Überbringerin der Gaben ( $\hat{g}$ i ri ${ }_{3}$ nin-g gá) auf.

Einige Elemente des Festes lassen sich dennoch feststellen: Das Fest des Himmelsbootes wurde zweimal jährlich im letzten Viertel des Monats gefeiert $^{244}$. Die erwähnten Gottheiten sind Inanna, für die wie bei den Neulichtfeiern Klagen abgehalten wurden, und Nanaja. Einmal werden für Inanna siskur ${ }_{2}$-Riten im Garten vollzogen ${ }^{245}$, wobei nicht sicher ist, ob der Garten das Ziel einer Prozession mit dem Himmelsboot war $^{246}$. Ein bestimmendes Element des Festes war das „Verbringen der Nacht im Heiligtum“ (èš $\mathrm{g}_{6}$-zal), wobei unklar bleibt, um welches Heiligtum es sich handelte, denkbar wären der Tempel der Inanna oder der Nanajas. Da jedoch in den Texten zu diesem Fest aus anderen Archivkontexten ${ }^{247}$ häufig Inanna, Nanaja aber nie erwähnt wird, liegt es nahe, hier an Inanna als die Hauptgottheit des Festes zu denken und zu vermuten, daß beim „Verbringen der Nacht im Heiligtum“ ihr Tempel gemeint ist. Für Inanna als Hauptgottheit dieses Festes spricht auch ein Beleg aus der Zeit Išbi-Erras von Isin, wo explizit die Lieferung für das Himmelsboot für Inanna (s iskur ${ }_{2}$ má-an-na ${ }^{\mathrm{d}}$ In ann a-šè) verbucht wird. ${ }^{248}$

$241 \quad$ PDT I, 459 (x/Š 34).

242 RIME 3/2.1.2.69: Siegelinschrift des Maš-gula.

243 OIP 115, 16 (xi/Š 29); BIN III, 347 (i/Š 36); JCS 40, S. 244 Nr. 8 (i/Š 37). Auch seine Frau (TCND $182(9 / \mathrm{v} / \mathrm{S}$ 40)) und seine Tochter (TCND 32 (i/Š 39) haben Kontakte zur Königin.

244 Die Buchungen werden um den 25. eines Monats getätigt. In zwei Fällen werden die Ausgaben für dieses Fest und die Gaben für die Neulichtfeiern auf einer Tafel verbucht: MVN 18, 62 (vi/Š 37) und OIP 115, 62 (25, 30/xi/ŠS 40).

245 PDT I, 459 (x/Š 34).

246 Dies vermutete Sallaberger, Der kultische Kalender (1993), S. 219.

247 Vgl. Sallaberger, Der kultische Kalender (1993), Tab. 71 b.

248 BIN 9, 387 (24/viii/IE 12); vgl. Richter, Panthea Süd- und Mittelbabyloniens (1999), S. 238-239. 
Des weiteren ist für dieses Fest bezeichnend, daß regelmäßig ein Rind und mehrere Stück Kleinvieh für das Himmelsboot geopfert werden, was die Bedeutung des Festes unterstreicht.

Da im Mythos „Enki und Inanna“ das Boot der Inanna ebenfalls den Namen má-an-na trägt, vermutete Klein, daß die Reise der Inanna nach Eridu bei diesem Fest nachvollzogen wurde ${ }^{249}$, allerdings findet sich in den Wirtschaftsdokumenten zum Fest des Himmelsbootes kein Hinweis auf eine Reise nach Eridu. Auch besondere Vermerke einzelner Texte dieser Gruppe helfen nicht weiter bei der Frage nach dem generellen Charakter dieses Festes. So wurden einmal Opfer am Narām-Suen-Tor dargebracht ${ }^{250}$, was möglicherweise im Zusammenhang mit dem Herrscherkult zu sehen ist. Dafür spricht, daß unter den Nachfolgern Šulgis Totenopfer für die verstorbenen Herrscher Teil des Festes sein können ${ }^{251}$.

Der überwiegende Teil der Texte zum Fest des Himmelsbootes, der nicht dem Archiv Šulgi-simtīs zuzurechnen ist, stammt aus der Zeit nach Šulgi. Für die Königinnen dieser Zeit ist bisher kein eigenes Archiv nachweisbar. Es ist also durchaus denkbar, daß diese Texte aus dem Staatsarchiv ebenfalls mit den königlichen Frauen zu verbinden sind, auch wenn diese nicht namentlich in den Texten erwähnt werden. Auch Šulgi-simtī tritt hier weder mit ihrem Namen noch mit dem Titel direkt in Erscheinung, nur über die Namen ihrer Beamten lassen sich die Texte ihrem Archiv zuweisen, und gerade dieser Zugang ist für ihre Nachfolgerinnen nicht möglich. Somit besteht die Möglichkeit, daß es sich beim Fest des Himmelsbootes um ein zentrales Fest der königlichen Frauen gehandelt hat, wobei insbesondere die Göttin Inanna, Stadtgöttin von Uruk, der Stadt aus der die Dynastie des Ur-Namma stammte ${ }^{252}$, verehrt und der verstorbenen Herrscher gedacht wurde.

\subsubsection{Annuñ̄tum}

Wie Inanna war auch Annunītum eine kriegerische Göttin. Ihr Kult war seit der Akkadezeit im ganzen Land verbreitet und wurde insbesondere auch im Königshaus von Ur gepflegt. Damit gehört Annunītum, die wie Inanna als

249 Klein, Šeleppūtum, a Hietherto Unknown Ur III Princess, ZA 80 (1990) S. 32. So auch Cohen, Cultic Calendars (1993), S. 217.

250 MVN 18, 52 (xi/šs 32).

251 BCT I, 88 (27/xi/AS 8) Opfer am ki - a - n a ĝ Ur-Nammas; TIM VI, 8 (21/vii/ŠS 1) Opfer am ki-a-na ĝ Amar-Suens. Vgl. Sallaberger, Der kultische Kalender (1993), S. 218.

252 Ur-Namma war wohl ein Bruder des Utu-hegal von Uruk; siehe Wilcke, Das Königtum in der Ur III-Zeit, CRAI 19 (1974), S. 192 Anm. 67 sowie Sallaberger, OBO 160/3 (1999), S. 132. 
„Königin des Himmels“ bezeichnet werden konnte ${ }^{253}$, zu den Gottheiten, die im offiziellen Kult verehrt wurden. Gleichzeitig wird sie in vielen Texten aus dem Archiv der Šulgi-simtī zusammen mit Bēlat-Šuhnir und Bēlat-Deraban, den persönlichen Göttinnen der Königin, genannt. Aufgrund dieser großen Nähe zu den persönlichen Göttinnen wird der Kult, den Šulgi-simtī für Annunītum vollzog oder vollziehen ließ, in diesem Abschnitt besprochen. Wie schon ausgeführt wurde, ist der persönliche Kult des Königs und der Königin aufgrund der religiösen Verankerung und der Konzeption des Königtums in Sumer nicht vom Staatskult zu trennen. ${ }^{254} \mathrm{Im}$ folgenden soll der Kult für Annunītum und der ihr verbundenen Ulmašītum ${ }^{255}$ ebenso dargestellt werden wie die Feste mit akkadischen Namen, die die Königin offenbar aus ihrer Heimat mit nach Ur gebracht hatte und in denen ihre persönlichen Göttinnen besondere Verehrung erfuhren.

Neben Opfern, die Annunītum im Zusammenhang mit anderen kultischen Ereignissen erhielt, wie dem Elūnum und dem Nabrium ${ }^{256}$, wurde die Göttin von Šulgi-simtī bei zwei großen Festen im Jahr geehrt. Dies ist zum einen das ezem-di g i r-ku $u_{4}-\mathrm{ku}_{4}$, das ,Fest zum Eintreten der Gottheit“, das im Frühsommer, im zweiten oder dritten Monat begangen wurde, und zum anderen das Fest des Bierausschenkens für Annunītum (k a š-dé-a), das im Hochsommer, etwa im sechsten Monat, gefeiert wurde. Beide Feste beinhalteten umfangreiche Opfer an verschiedene Gottheiten und bei beiden Festen werden Rinder geopfert, was die Bedeutung dieser Feiern für die Königin unterstreicht. Für beide Feste spiegeln die Quellen ein etwas uneinheitliches Bild, sodaß kein genauer Eindruck vom Ablauf der Feierlichkeiten möglich ist. Es ist auch denkbar, daß der Festverlauf gewisse Variablen enthielt und somit die Königin je nach Anlaß und den momentanen Bedürfnissen des Landes und/oder der Familie festlegen konnte, welche Gottheiten sie mit ihren Opfern positiv stimmen wollte. Da über die Funktion der unterschiedlichen Feste, die Šulgisimtī für ihre Götter feierte, über die allgemeinen Grundlagen hinaus, die zu Beginn des Abschnittes dargelegt wurden, kaum etwas bekannt ist, läßt sich die Frage nach Gründen für die unterschiedliche Ausgestaltung derartiger großer Feste kaum klären.

Das Fest zum Eintreten der Gottheit ${ }^{257}$ könnte im Verlauf der Amtszeit von

253 Selz, Five Divine Ladies NIN 1 (2000), S. 34-35, 38.

254 Siehe S. 48.

255 Die Göttin ist die Manifestation der Ištar ihres Tempels é-u l-maš in Akkade; siehe dazu George, House Most High (1993), Nr. 1168, S. 155.

256 Siehe dazu S. 81-83. Im Zusammenhang mit dem Tummalfest werden in OIP 115, 29 (-/vi/Š 36) Zicklein für s i s k u r ${ }_{2}$-Riten für Annunītum und Ulmašītum verbucht. 
Šulti-simtī an Bedeutung verloren haben, da die Quellen über blutige Opfer stetig geringere Mengen verbuchten. Allerdings ist bei der geringen Anzahl von nur drei Texten bei der Interpretation Vorsicht geboten. Kennzeichnend für dieses Fest waren offenbar Opfer für An sowie für die persönlichen Göttinnen der Königin, Bēlat-Šuhnir, Bēlat-Deraban, Annunītum und Ulmašītum, wobei Annunītum neben Kleinvieh auch ein Rind erhält. Unklar ist, ob das Fest schon im Jahr $\breve{S} 34$ der Annunītum galt, da die Göttin in OrSP 18, 1 nicht genannt wird. Es ist durchaus möglich, daß das Fest in diesem Jahr Bēlat-Šuhnir und Bēlat-Deraban galt, da hier die beiden Göttinnen als Empfängerinnen von je einem Rind und mehreren Schafen auftreten. Daneben wird in diesem Jahr auch der Gott Nanna besonders geehrt mit siskur ${ }_{2}$-Riten und Opfern am Dublamah. Sechs Jahre später wird der Mondgott nicht mehr im Zusammenhang mit diesem Einzugsfest genannt, und nur Annunītum erscheint als Empfängerin eines Rindes, und im Folgejahr werden die Ausgaben zum Elūnum für Bēlat-Šuhnir und Bēlat-Deraban und die Lieferungen für das Einzugsfest der Annunītum gar auf einer Tafel verbucht. Für Letzteres werden außer Annunītum und Ulmašītum keine anderen Götter mehr erwähnt. Der Text aus dem Jahr Š 45 bietet eine interessante Ergänzung, da hier einmal nicht die Tieropfer verbucht sind, sondern die unblutigen Gaben aufgeführt werden. Dabei werden Datteln und Öl versprengt (s ù - dè), wenn die Göttin den Tempel verläßt, es werden verschiedene Speisen wie Kuchen und Früchte auf einem Opfertisch bereitet, der mit Sesamöl gesalbt wurde, und beim erneuten Einzug der Göttinnen in den Tempel werden wieder Datteln und Sesamöl versprengt. Hier ist exemplarisch zu erkennen, daß die blutigen Opfer nur einen Teil des Kultes ausmachten, der insgesamt in der Ausgestaltung der Rituale deutlich komplexer war als die Mehrzahl der Texte dies ahnen lassen. Das Einzugsfest der Annunītum wurde auch unter den folgenden Königen Amar-Suen und ŠuSuen weiter gepflegt ${ }^{258}$, wobei den Texten nicht zu entnehmen ist, ob diese Riten weiterhin unter der Aufsicht und möglicherweise der Mitwirkung der Königin vollzogen wurden.

Das zweite wichtige Fest für Annunītum war das „Bierausschenken“ ( $k$ a š dé-a) für die Göttin, ein Fest, das sich über mehrere Tage erstreckte und bei dem die Königin die Göttin bei sich im Palast empfing. Auch zu diesem Fest sind bisher nur wenige Quellen erhalten ${ }^{259}$, doch scheint es sich um ein jährliches Ereignis gehandelt zu haben, das jedoch nicht genau auf einen

(ii/Š 45). Zu diesem Fest siehe Sallaberger, Der kultische Kalender (1993), S. 203204.

258 Sallaberger, Der kultische Kalender (1993), Tab. 66b.

259 MVN 18, 61 (v/Š 37); TRU 273 (5-7/vii/Š 40); MVN 18, 83 (19, 21/vi/Š 47); zu diesem Fest siehe Sallaberger, Der kultische Kalender (1993), S. 198-201. 
Monat, sondern eher auf eine Jahreszeit, den Spätsommer, festgelegt war. Der Besuch der Göttin wurde am Vorabend mit Klagen (gerrānum) vorbereitet. Bei ihrem Eintreffen wurde Annunītum im Hof des Palastes ein Stück Kleinvieh entgegengebracht. Es folgte offenbar ein Festmahl, zu dem neben weiterem Kleinvieh auch Fisch und Gemüse gereicht wurden. Die Feierlichkeiten endeten mit einem weiteren Opfer für Annunītum bei der Rückkehr der Göttin in ihren Tempel. Im Rahmen der Festlichkeiten zum Besuch der Göttin wurden im Palast ein Rind und mehrere Stück Kleinvieh geopfert, was die Bedeutung dieses Festes für Šulgi-simtī unterstreicht.

Neben Annunītum als der wichtigsten Göttin bei diesem Fest erhalten auch andere Götter von Ur Gaben, darunter Ninsun, Iškur, Nanaja, wobei diese Gottheiten nicht bei jedem Bierausschenken für Annunītum Erwähnung fanden. Auffällig sind Opfer für die Statue des Königs im Jahr Š 37. Ob es mit besonderen politischen Ereignissen des Jahres zusammenhängt, daß die Königin der Statue des Königs ein Opfer brachte, muß Spekulation bleiben.

Das „Eintreten“ (erubbatum) der Göttin Annunītum, das im gleichen Zeitraum wie das „Bierausschenken“ gefeiert wurde, war möglicherweise Teil dieses Festes, bei dem die Göttin im Palast empfangen wurde ${ }^{260}$. Beide Texte zum erubbatum buchen Gaben von Kleinvieh für Annunītum und Ulmašītum ab. Es ist gut vorstellbar, daß hier separat Tiere für Opfer verzeichnet werden, die beim Eintreffen der Göttin im Palast vollzogen wurden. Die Möglichkeit, daß es sich bei diesem „Eintreten“ um einen vom „Bierausschenken“ getrennten Festakt handelte, sollte jedoch nicht ganz außer Acht gelassen werden. ${ }^{261}$ Der Terminus erubbatum allein ist nicht auf ein Fest zu Ehren der Annunītum festgelegt, wie ein Text aus der Zeit Amar-Suens belegt, wobei sich dieses „Einzugsfest“ in nahezu allen Details wie Datum, Opfermaterie und gefeierte Gottheit, vom erubbatum bei Šulgi-simtī unterscheidet ${ }^{262}$.

Zwei Texte aus den frühen Amtsjahren der Šulgi-simtī verbuchen in den Monaten, in denen nach späteren Zeugnissen das „Bierausschenken“ gefeiert wurde, Gaben von Großvieh an Annunītum² ${ }^{263}$. Für das Jahr Š 35 (Boson 337) findet sich vor der Gabe an Annunitum die Gabe von einem Rind für barag

260 CST 41 (v/Š 36); MVN 18, 167 (vi/Š 41); zum erubbatum und der möglichen Verbindung mit dem „Bierausschenken“ siehe Sallaberger, Der kultische Kalender (1993), S. 201.

261 Während Sallaberger die zwei mit einem „Eintreten“ der Göttin verbundenen Ereignisse als separate Feiern beschreibt (Der kultische Kalender (1993), S. 198-201), behandelt Cohen die Quellen als Zeugnisse für ein einziges „Einzugsfest“ (Cultic Calendars (1993), S. 138-139).

262 Hilgert, erubbatum im Tempel des Dagān, JCS 46 (1994), S. 30.

263 PDT II, 1017 (v/Š 33); Boson 337 (vi/Š 35). 
$n \underline{1} \hat{\mathrm{g}}-\mathrm{gu}_{7}$-a (Podest der Mahlzeit), was auf ein Gastmahl hinweist. Es ist denkbar, daß diese Lieferungen sich schon auf ein Fest zu Ehren der Annunītum mit einem Empfang der Göttin im Palast beziehen, dem Šulgi-simtī aber möglicherweise erst im Laufe der Zeit eine größere Ausgestaltung gegeben hat. ${ }^{264}$

\subsubsection{Riten des Bierausschenkens für andere Götter}

Neben Annunītum werden noch andere Göttinnen von Šulgi-simtī mit dem Ritus des Bierausschenkens geehrt. Dabei fällt auf, daß es sich immer um weibliche Gottheiten handelt, denen in dieser Form die Aufmerksamkeit der Königin zuteil wird. Der König dagegen feiert das Bierausschenken für männliche wie weibliche Götter. ${ }^{265}$

Nicht immer wurde das Bierausschenken von Šulgi-simtī so aufwendig inszeniert wie für Annunītum, für die ein mehrtägiges Fest gegeben wurde. So wird für das Bierausschenken für Nin-é-gal ${ }^{266}$ nur ein Schaf abgebucht, was auf einen deutlich bescheidener gestalteten Ritus schließen läßt. Schon umfangreicher fallen die Gaben zum Bierausschenken für Allatum im Palast ${ }^{267}$ aus, zu dem ein Mastrind und zwei Mastschafe geliefert werden. Für beide Göttinnen ist das von der Königin veranstaltete Bierausschenken nur je einmal belegt, woraus folgt, daß es sich wohl um einmalige, oder zumindest nicht regelmäßig wiederholte Ereignisse handelte. Änliches gilt für das Bierausschenken, das Šulgi-simtī für ihre persönlichen Göttinnen Bēlat-Šuhnir und Bēlat-Deraban veranstaltete ${ }^{268}$. Zwei Zeugnisse überliefern ein Bierausschenken für Nanaja ${ }^{269}$, das ebenso wie das Fest für Bēlat-Šuhnir und BēlatDeraban aufwendiger und über mehrere Tage gefeiert wurde (s.u.). Im gleichen Monat wie das Bierausschenken für Allatum findet noch ein weiteres Fest dieser Art statt, wobei der Name der so geehrten Gottheit nicht erhalten ist ${ }^{270}$. Der Umfang der Gaben aus diesem Anlaß, ein Mastrind und insgesamt 5 Schafe, die bei drei aufeinander folgenden Riten geopfert wurden (a-rá

264 Sallaberger spricht davon, daß es sich möglicherweise um „Vorläufer“ des Bierausschenkens gehandelt haben könnte (Der kultische Kalender (1993), S. 201).

265 Unter anderem in AUCT I, 960 (7/xi/Š 45 oder AS 2) und TrD 2 (viii/AS 4).

266 MVN 18, 53 (ix/Š 33), in dieser Urkunde werden Ausgaben für verschiedene kultische Anlässe verbucht.

267 TRU 272 (ix/Š 34), auch hier werden Ausgaben für verschiedene kultische Anlässe verbucht.

268 OIP 115, $65(11 / \mathrm{x} / \mathrm{S}$ 41).

269 MVN 18, 60 (ix/Š 36) und PDT I, 582 (18/xi/Š 45).

270 TRU 272 (ix/Š 34). 
1-kam, a-rá 2-kam, a-rá 3-kam), spricht für eine der für Šulgi-simtī wichtigen Göttinnen. Möglicherweise ist auch hier Nanaja die Empfängerin der Gaben.

Verbindendes Element dieser von Šulgi-simtī veranstalteten Feiern ist die Jahreszeit, alle Belege stammen aus dem Winter (9. bis 11. Monat). Da jedoch die Ausgestaltung der verschiedenen Feiern sehr unterschiedlich ist, bleibt es fraglich, ob es sich um regelmäßige Feste handelte.

Das Bierausschenken für Bēlat-Šuhnir und Bēlat-Deraban ${ }^{271}$ erstreckte sich über drei Tage, wobei die Riten am ersten Tag besonders auffällig sind. Hier werden 1 Mastrind und insgesamt 9 Stück Kleinvieh, davon 4 Jungtiere, sowie Fisch und Gemüse für einen Ritus ausgegeben, der als $\mathrm{ga}^{\mathrm{k}} \mathrm{ku}_{7}$ ${ }^{\mathrm{d}}$ Mes l a m ta e a (Milch-Saugen-Riten für Meslamtaea) bezeichnet wird. Dieser Ritus ist bisher im Archiv der Šulgi-simtī nicht weiter belegt. ga- $\mathrm{ku}_{7}$-Riten in Girsu und Puzriš-Dagān konnte Sallaberger in Zusammenhang bringen mit der Geburt des Viehs ${ }^{272}$, wobei auch hier die Riten häufig in den Wintermonaten stattfinden und mitunter Großvieh geopfert wird. Möglicherweise ist auch dieses Opfer der Königin im Zusammenhang mit der Geburt des Jungviehs in den Herden der Šulgi-simtī zu sehen. In welchem Zusammenhang der Unterweltsgott Melamtaea ${ }^{273}$ mit einem solchen Ritus stehen könnte, ist nicht klar. Am zweiten Tag des Festes werden wieder 1 Rind und 7 Stück Kleinvieh sowie Fisch und Gemüse ausgegeben, was auf ein umfangreiches Festmahl schließen läßt. Die Gabe von zwei Schafen am dritten Tag beschließt die Feierlichkeiten, die insgesamt als Bierausschenken für Bēlat-Šuhnir und BēlatDeraban bezeichnet werden. Die von Cohen getroffene Zuordnung dieses Festes zum Fest des Himmelsbootes ${ }^{274}$ ist unwahrscheinlich, da weder das Himmelsboot erwähnt werden noch ein Hinweis auf Inanna zu finden ist.

Das Bierausschenken für Nanaja ${ }^{275}$ erstreckte sich ebenfalls über mehrere Tage. Im Jahr Š $36^{276}$ wurden eine ganze Reihe von Gottheiten im Rahmen der als kaš-dé-a Nanaja bezeichneten Feierlichkeit beopfert: Ulmašītum, Annunītum, Išhara und Allatum erhielten jeweils zwei oder drei Schafe, eine

271 OIP 115, $65(11 / \mathrm{x} / \mathrm{S}$ 41).

272 Sallaberger, Der kultische Kalender (1993), S. 299-300, Tab. 106.

273 Zu Meslamtaea siehe Katz, The Image of the Netherworld (2003), S. 420-428; v. Weiher, Der babylonische Gott Nergal (1991), S. 6-9. Meslamtaea ist bei Šulgi-simtī noch einmal erwähnt, wohl im Zusammenhang eines Besuches der Königin in Kutha, beim Hauptheiligtum des Gottes: SET 41 (ix/s 35). Darüber hinaus erhält er zusammen mit Allatum Opfer in MVN 18, 59 (iv/Š 36).

274 Cohen, Cultic Calendars (1993), S. 217-218.

275 Siehe Sallaberger, Der kultische Kalender (1993), S. 199 Anm. 944.

276 MVN 18, 60 (ix/Š 36). 
Mastkuh sowie fünf Stück Kleinvieh wurden am Morgen geopfert, darauf folgten die Gaben von einer Ziege für die Götter (di g $\mathrm{g}$ ir-ne) und einem Lamm für den von der Gottheit verlassenen Ort, womit wohl der Tempel der Nanaja gemeint ist, die sich ja bei Šulgi-simtī im Palast aufhielt. Nach diesen Opfern am ersten Tag wurden am zweiten Tag nochmals ein Schaf und eine Ziege verbucht, wobei es sich um die Gaben bei der Rückkehr der Göttin in den Tempel handeln könnte.

Im Jahr Š $45^{277}$ ist das Bierausschenken für Nanaja dagegen deutlich anders gestaltet: Die Feierlichkeiten erstreckten sich nun über drei Tage, wobei die Göttin am ersten Tag die umfangreichsten Opfer erhielt, nämlich 1 Rind, drei Schafe und ein Lamm. Am zweiten und dritten Tag wurden ihr nochmals zwei Schafe und ein Lamm geopfert. Am ersten und zweiten Tag wurden außerdem je ein Stück Kleinvieh für Šulgi um Mitternacht und für sisk ur $_{2}$-Riten für die Götter (diĝir-ne-šè) und zusätzlich am zweiten Tag noch ein Lamm als Nachtgabe (n $1 \hat{\mathrm{g}}-\hat{\mathrm{g}} \mathrm{i}_{6}$-š è) verbucht. Andere Gottheiten werden nicht genannt. Bei diesen Riten fungierte die Königin selber als Überbringerin ( $\hat{\mathrm{g}} \mathrm{iri}{ }_{3} \mathrm{nin}-$ gá ). Da diese Ausgaben von Kalam-henagi verbucht wurden, der insbesondere mit Transaktionen in Uruk verbunden $\operatorname{war}^{278}$, ist davon auszugehen, daß dieser Empfang für Nanaja auch in Uruk stattfand.

Trotz der ähnlichen Daten ist aufgrund der deutlich unterschiedlichen Ausgestaltung dieser verschiedenen Zeremonien zum Empfang einer Göttin im Palast nicht von einer zyklischen Feier auszugehen. Vielmehr ist anzunehmen, daß es sich hier jeweils um besondere Ereignisse handelte, bei denen die Königin die verschiedenen Göttinnen jeweils aus einem bestimmten, uns nicht bekannten Anlaß im Palast empfing.

\begin{tabular}{|c|c|c|c|c|}
\hline Publikation & Datum & Opfergabe & $\begin{array}{l}\text { geehrte } \\
\text { Göttin }\end{array}$ & $\begin{array}{c}\text { andere } \\
\text { Gottheiten }\end{array}$ \\
\hline $\begin{array}{l}\text { MVN 18, } \\
53\end{array}$ & -/ix/Š 33 & 1 Mastschaf & Nin-é-gal & \\
\hline TRU 272 & -/ix/Š 34 & $\begin{array}{l}\text { 2 Mastrinder } \\
\text { 1 Mastrind, } \\
2 \text { Mastschafe zum } \\
\text { 1. Mal } \\
\text { 2 Mastschafe zum } \\
\text { 2. Mal } \\
\text { 1 Mastschaf zum }\end{array}$ & B.-Suhnir & \\
\hline
\end{tabular}

277 PDT I, 582 (17/xi/Š 45).

278 Zu Kalam-hyenagi siehe S. 40. 


\begin{tabular}{|c|c|c|c|c|}
\hline Publikation & Datum & Opfergabe & $\begin{array}{l}\text { geehrte } \\
\text { Göttin }\end{array}$ & $\begin{array}{c}\text { andere } \\
\text { Gottheiten }\end{array}$ \\
\hline & & $\begin{array}{l}\text { 3. Mal } \\
\text { 1 Mastrind, } 2 \text { Mast- } \\
\text { schafe }\end{array}$ & $\begin{array}{l}\text { [Nanaja?] } \\
\text { Allatum }\end{array}$ & \\
\hline $\begin{array}{l}\text { MVN 18, } \\
60\end{array}$ & $\mathrm{ix} / \mathrm{S} 36$ & $\begin{array}{l}\text { 1 Mastschaf } \\
1 \text { Schaf } \\
2 \text { Mastschafe, } 1 \text { Lamm } \\
1 \text { Mastschaf } \\
1 \text { Weideschaf } \\
1 \text { Schaf das den } \\
\text { Ochsen folgt, 1 Lamm } \\
1 \text { Mastkuh, } \\
1 \text { Mastschaf, } 3 \\
\text { Weideschafe morgens } \\
1 \text { Ziege für s i skur }{ }_{2}- \\
\text { Riten } \\
1 \text { Lamm für den von } \\
\text { der Gottheit } \\
\text { verlassenen Ort, } \\
\text { 1. Tag } \\
1 \text { Mastschaf, } 1 \text { Ziege, } \\
\text { 2. Tag }\end{array}$ & Nanaja & $\begin{array}{l}\text { Ulmašītum } \\
\text { Annunītum } \\
\text { Išhara } \\
\text { Allatum } \\
\text { di ĝ̀ir-ne }\end{array}$ \\
\hline OIP 115,65 & $11 / x / S ̌ s 1$ & $\begin{array}{l}\text { 1 Mastrind, } \\
4 \text { Mastschafe, } \\
2 \text { Lämmer } \\
1 \text { gemästetes } \\
\text { Milchzicklein, } \\
1 \text { Lamm zur Gabe von } \\
\text { Fisch und Gemüse, } 1 \\
\text { ausgewachsene Ziege } \\
\text { für g a - k ú-Riten } \\
\text { 1. Tag } \\
1 \text { Mastrind, } \\
2 \text { Mastschafe, } \\
1 \text { ausgewachsene, } \\
\text { gemästete Ziege, } \\
2 \text { gemästete } \\
\text { Milchzicklein zur } \\
\text { Gabe von Fisch und } \\
\text { Gemüse, } 1 \text { Schaf, } 1 \\
\text { Ziege, für den von der } \\
\text { Gottheit verlassenen }\end{array}$ & & Meslamtaea \\
\hline
\end{tabular}


Königinnen

\begin{tabular}{|c|c|c|c|c|}
\hline Publikation & Datum & Opfergabe & $\begin{array}{l}\text { geehrte } \\
\text { Göttin }\end{array}$ & $\begin{array}{c}\text { andere } \\
\text { Gottheiten }\end{array}$ \\
\hline & & $\begin{array}{l}\text { Ort } \\
\text { 2. Tag } \\
\text { 1 Mastschaf } \\
\text { 1 Weideschaf } \\
\text { 3. Tag }\end{array}$ & $\begin{array}{l}\text { B.-Suhnir } \\
\text { und B.- } \\
\text { Deraban }\end{array}$ & \\
\hline PDT I, 582 & 18/xi/ŠS 45 & $\begin{array}{l}\text { 1 Mastrind, } 3 \\
\text { Mastschafe, 1 Lamm } \\
1 \text { Mastschaf } \\
\text { mitternachts } \\
1 \text { gemästetes } \\
\text { weibliches } \\
\text { Milchzicklein für } \\
\text { s i sku } \text { r }_{2} \text {-Riten } \\
\text { 1. Tag } \\
\text { 2 Mastschafe, 1 Lamm } \\
\text { 1 Schaf das den } \\
\text { Ochsen folgt } \\
\text { mitternachts } \\
\text { 1 gemästetes, } \\
\text { weibliches } \\
\text { Milchzicklein für } \\
\text { s i k k r }{ }_{2}-\text { Riten } \\
\text { 1 Lamm als } \\
\text { Nachtgabe } \\
\text { 2. Tag } \\
\text { 2 Mastschafe, } 1 \text { Lamm } \\
\text { 3. Tag }\end{array}$ & Nanaja & $\begin{array}{c}\text { Šulgi } \\
\text { diĝgir - ne } \\
\text { Šulgi } \\
\text { diĝ ir - ne }\end{array}$ \\
\hline
\end{tabular}

Tabelle 4: Šulgi-simtī: Bierausschenken für andere Göttinnen als Annunītum

\subsubsection{Bēlat- ̌̌ uhnir und Bēlat-Deraban}

Neben den Gaben, welche die persönlichen Göttinnen der Šulgi-simtī, BēlatŠuhnir und Bēlat-Deraban, im Rahmen der Opfer zu Neulicht und zum 15. Tag eines Monats erhielten, versorgte die Königin ihre Göttinnen von Anfang an regelmäßig auch zu anderen Anlässen. Mitunter ist kein konkreter Anlaß für ein Opfer genannt, doch da es sich in diesen Fällen in der Regel um die Gabe von einem Stück Kleinvieh für jede Göttin handelt, ist davon auszugehen, daß hier die normalen, vielleicht sogar täglichen Opfergaben verbucht werden. Andere Ausgaben lassen sich in den Kontext eines bekannten Festes wie des

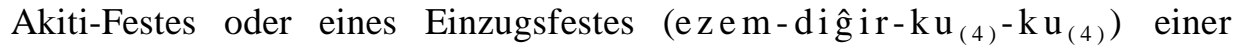


anderen Gottheit einordnen oder sie beziehen sich auf die Feste Elūnum und Nabrium $^{279}$, welche die Königin für ihre Göttinnen feierte. Am häufigsten werden Ausgaben für Klageriten verbucht, mitunter ist kein spezielle Grund für eine Ausgabe angegeben.

\begin{tabular}{|c|c|c|c|}
\hline Publikation & Datum & Gegenstand der Transaktion & Anlaß \\
\hline $\begin{array}{l}\text { OIP } 115, \\
134\end{array}$ & (abgebrochen) & $\begin{array}{l}2 \text { Schafe die den Ochsen } \\
\text { folgen für den Tempel der } \\
\text { B.-S. und B.-D. }\end{array}$ & - \\
\hline $\begin{array}{l}\text { OIP } 115, \\
18\end{array}$ & $-/ \mathrm{vi} / \mathrm{S} 29$ & $\begin{array}{l}2 \text { Mastschafe für den } \\
\text { Tempel der B.-S. und B.-D. }\end{array}$ & - \\
\hline $\begin{array}{l}\text { ASJ 4, S. } \\
64 \text { Nr. } 1\end{array}$ & $-/ x / S ̌ s ~ 29$ & $\begin{array}{l}2 \text { Mastschafe für den } \\
\text { Tempel der B.-S. und B.-D. }\end{array}$ & - \\
\hline $\begin{array}{l}\text { PDT II, } \\
1314\end{array}$ & $-/ \mathrm{x} / \widehat{S} 29$ & $\begin{array}{l}\text { [x] Mastschafe [für den } \\
\text { Tempel'] der B.-D. und B.- } \\
\text { D. }\end{array}$ & - \\
\hline $\begin{array}{l}\text { DCEPHE } \\
306\end{array}$ & -/xi/Š 29 & $\begin{array}{l}2 \text { Mastschafe } \\
2 \text { Mastschafe } \\
\text { [ ] Mastschafe im Tempel }\end{array}$ & $\begin{array}{l}\text { Klagen für B.-S. } \\
\text { siskur }{ }_{2}-\text { Riten am } \\
\text { Morgen im Tempel } \\
\text { der B.-S. } \\
\text { für B.-D. }\end{array}$ \\
\hline $\begin{array}{l}\text { OIP } 115 \\
19\end{array}$ & -/vii/Š 30 & $\begin{array}{l}2 \text { Schafe für den Tempel } \\
\text { der B.-S. und B.-D. }\end{array}$ & - \\
\hline SDU 9 & $\begin{array}{l}-/ \mathrm{vi} / \mathrm{S} 30 \\
-/ \mathrm{ix} / \mathrm{S} 30\end{array}$ & $\begin{array}{l}2 \text { Mastschafe für den } \\
\text { Tempel der B.-S. und B.-D. } \\
2 \text { Mastschafe für den } \\
\text { Tempel der B.-S. und B.-D. }\end{array}$ & - \\
\hline $\begin{array}{l}\text { OIP } 115 \\
20\end{array}$ & $-/ \mathrm{x} / \mathrm{S} 30$ & 2 Mastschafe & $\begin{array}{l}\text { Klagen um B.-S. } \\
\text { und B.-D. }\end{array}$ \\
\hline SAT II, 47 & -/ix/Š 32 & 2 tragende Ziegen & $\begin{array}{l}\text { Klagen um B.-S. } \\
\text { und B.-D. am Tor } \\
\text { dGeštinanna }\end{array}$ \\
\hline $\begin{array}{l}\text { MVN 18, } \\
53\end{array}$ & -/ix/Š 33 & $\begin{array}{l}2 \text { Mastschafe für den } \\
\text { Tempel der B.-S. und B.-D. }\end{array}$ & NE.NE- $\hat{g}$ ar-Fest \\
\hline OrSP 18,1 & -/iii//̌ 34 & $\begin{array}{l}2 \text { Mastrinder, } 6 \text { Mastschafe } \\
2 \text { Mastschafe }\end{array}$ & $\begin{array}{l}\text { - } \\
\text { für den von der } \\
\text { Gottheit verlassenen }\end{array}$ \\
\hline
\end{tabular}

$279 \mathrm{Zu}$ diesen beiden Festen siehe den folgenden Abschnitt. 
Königinnen

\begin{tabular}{|c|c|c|c|}
\hline Publikation & Datum & Gegenstand der Transaktion & Anlaß \\
\hline & & 2 Mastschafe & $\begin{array}{l}\text { für B.-S. und B.-D. } \\
\text { - } \\
\text { Ausgaben im } \\
\text { Rahmen eines } \\
\text { eze m-diĝ ir-ku- } \\
\text { ku }\end{array}$ \\
\hline TRU 272 & -/ix/Š 34 & $\begin{array}{l}1 \text { Mastrind, } 1 \text { Weiderind } \\
2 \text { Mastrinder } \\
1 \text { Schaf } \\
2 \text { Mastschafe } \\
\text { 2x2 Schafe die den Ochsen } \\
\text { folgen }\end{array}$ & $\begin{array}{l}\text { Nabrium im Tempel } \\
\text { der B.-S. } \\
\text { Bierausschenken } \\
\text { der B.-S. im Palast } \\
\text { sá-d u }{ }_{11} \text { im } \\
\text { Tempel der B.-S. } \\
\text { sá-d u }{ }_{11} \text { für B.-S. } \\
\text { - }\end{array}$ \\
\hline $\begin{array}{l}\text { RA 19, } \\
192 \text { Nr. } 4\end{array}$ & $\begin{array}{l}\text {-/vii/ŠS } 34 ? \\
\text {-/i?'/Š } 34 \\
\text {-/vii/Š } 34 \\
\text {-/iii/ŠS } 34 ?\end{array}$ & $\begin{array}{l}\text { je } 1 \text { Mastschaf } \\
4 \text { Mastschafe } \\
2 \text { Mastschafe } \\
2 \text { Mastschafe }\end{array}$ & $\begin{array}{l}\text { für B.-S. und B.-D. } \\
\text { Elūnum der B.-S. } \\
\text { für B.-S. } \\
\text { für B.-S. }\end{array}$ \\
\hline TPTS 95 & $-/ \mathrm{i} / \mathrm{S} 35$ & 2 Ziegen & $\begin{array}{l}\text { Klagen im Tempel } \\
\text { der B.-S. }\end{array}$ \\
\hline $\begin{array}{l}\text { PDT II, } \\
980\end{array}$ & $-/ \mathrm{v} / \mathrm{S} 35$ & 2 Ziegen & $\begin{array}{l}\text { für si sk u } r_{2} \text {-Riten } \\
\text { im Garten }\end{array}$ \\
\hline $\begin{array}{l}\text { PDT II, } \\
1027\end{array}$ & $-/ \mathrm{v} / \mathrm{S} 35$ & {$[\ldots]$} & $\begin{array}{l}\text { für B.-S. und B.-D. } \\
\text { (Text weitgehend } \\
\text { abgebrochen) }\end{array}$ \\
\hline $\begin{array}{l}\text { MVN 18, } \\
55\end{array}$ & -/vi/Šs 35 & $\begin{array}{l}2 \text { weibliche Zicklein } \\
2 \text { Lämmer }\end{array}$ & Klagen \\
\hline $\begin{array}{l}\text { OIP } 115, \\
130\end{array}$ & -/vi/ŠS 35 & 2 Mastschafe & $\mathrm{u}_{4} \mathrm{má}$ è-a \\
\hline $\begin{array}{l}\text { MVN 18, } \\
114\end{array}$ & -/vii/ŠS 35 & je 1 Mastschaf & - \\
\hline $\begin{array}{l}\text { MVN 18, } \\
56\end{array}$ & $-/ x / S ̌ s 5$ & $\begin{array}{l}2 \text { Schafe am Tempel der B.- } \\
\text { S. und B.-D. }\end{array}$ & Klagen \\
\hline TCND 178 & $-/ \mathrm{v} / \mathrm{S} 36$ & 2 Mastschafe & - \\
\hline
\end{tabular}




\begin{tabular}{|c|c|c|c|}
\hline Publikation & Datum & Gegenstand der Transaktion & Anlaß \\
\hline $\begin{array}{l}\text { OIP } 115, \\
33\end{array}$ & -/ii/Š 37 & $\begin{array}{l}2 \text { Mastschafe } \\
2 \text { Ziegen }\end{array}$ & $\begin{array}{l}\text { sá-d u }{ }_{11} \text { für } \\
\text { s iskur } r_{2} \text {-Riten } \\
\text { am von der Gottheit } \\
\text { verlassenen Ort; } \\
\text { beides für das Fest } \\
\text { še-er-še-ru-um }\end{array}$ \\
\hline SET 42 & -/v/Š 37 & $\begin{array}{l}2 \text { Ziegenböcke } \\
2 \text { Mastschafe, } 2 \text { Schafe die } \\
\text { den Ochsen folgen, } 2 \\
\text { Ziegen }\end{array}$ & $\begin{array}{l}\text { Klagen im Tempel } \\
\text { der B.-S. } \\
\text { im Tempel der B.-S. }\end{array}$ \\
\hline $\begin{array}{l}\text { OIP } 115, \\
34\end{array}$ & -/vi/Šs 37 & 2 Ziegen & $\begin{array}{l}\text { für den von der } \\
\text { Gottheit verlassenen } \\
\text { Ort im Tempel der } \\
\text { B.-S. und B.-D. }\end{array}$ \\
\hline $\begin{array}{l}\text { MVN 15, } \\
306\end{array}$ & $\begin{array}{c}\text { 10/vi/Š [38- } \\
41]\end{array}$ & 2 Mastschafe & - \\
\hline TRU 273 & 5/vii/Š 40 & $\begin{array}{l}2 \text { Schafe } \\
2 \text { Mastschafe }\end{array}$ & $\begin{array}{l}\text { für den von der } \\
\text { Gottheit verlassenen } \\
\text { Ort } \\
\text { sisk k } r_{2} \text {-Riten im } \\
\text { Tempel der B.-S. } \\
\text { und B.-D. }\end{array}$ \\
\hline $\begin{array}{l}\text { MVN 18, } \\
63\end{array}$ & $1 / \mathrm{x} / \mathrm{S} 40$ & $\begin{array}{l}2 \text { Mastschafe, } 2 \\
\text { Weideschafe }\end{array}$ & $\begin{array}{l}\text { še-er-še-ru-um der } \\
\text { B.-S. und B.-D. } \\
\text { e ze m-diĝ ir - } \\
\mathrm{k} \mathrm{u}_{4}-\mathrm{ku}_{4} \text { für } \\
\text { Annunītum } \\
\end{array}$ \\
\hline $\begin{array}{l}\text { MVN 18, } \\
67\end{array}$ & 20/ii/Š 41 & $\begin{array}{l}2 \text { ausgewachsene } \\
\text { Ziegenböcke }\end{array}$ & Elūnum \\
\hline SET 44 & $30 /-/ S ̌ S 1$ & $\begin{array}{l}3 \text { Weideschafe, } 1 \\
\text { gemästeter ausgewachsener } \\
\text { Ziegenbock }\end{array}$ & $\begin{array}{l}\text { Elūnum im Tempel } \\
\text { der B.-S. und B.-D. }\end{array}$ \\
\hline $\begin{array}{l}\text { OIP } 115, \\
65\end{array}$ & $11 / \mathrm{x} / \mathrm{S} 41$ & $\begin{array}{l}\text { verschiedene Opfer über } 3 \\
\text { Tage }\end{array}$ & $\begin{array}{l}\text { Bierausschenken für } \\
\text { B.-S. und B.-D. }\end{array}$ \\
\hline PDT I, 162 & 25/viii/Šs 45 & 1 Mastschaf, 1 Lamm & $\begin{array}{l}\text { für den von der } \\
\text { Gottheit verlassenen } \\
\text { Ort für B.-S. und } \\
\text { B.-D.; } \\
\text { im Rahmen eines } \\
\text { Nabrium }\end{array}$ \\
\hline
\end{tabular}


Königinnen

\begin{tabular}{|c|c|c|c|}
\hline Publikation & Datum & Gegenstand der Transaktion & Anlaß \\
\hline $\begin{array}{l}\text { MVN 18, } \\
73\end{array}$ & 13/ix/Š 45 & 2 [Kleinvieh] & $\begin{array}{l}\text {... für B.-S. und } \\
\text { B.-D. }\end{array}$ \\
\hline $\begin{array}{l}\text { OIP } 115, \\
101\end{array}$ & $18 / \mathrm{i} / \mathrm{S}$ S 46 & $\begin{array}{l}1 \text { Mastschaf } \\
1 \text { weibliches Schaf }\end{array}$ & $\begin{array}{l}\text { sá-du } u_{11} \\
\text { siskur-Riten }\end{array}$ \\
\hline $\begin{array}{l}\text { JCS 35, S. } \\
183 \text { Nr. } 1\end{array}$ & $21 / \mathrm{v} / \mathrm{S} 46$ & $\begin{array}{l}\text { 2 Ziegen } \\
2 \text { Mastschafe, } 1 \\
\text { Weideschaf, } \\
1 \text { ausgwachsene Ziege, } 1 \\
\text { Lamm, } \\
1 \text { Ziege }\end{array}$ & - \\
\hline TCNY 48 & -/vi/Š 46 & 1 Schaf, 1 Ziege & $\begin{array}{l}\text { Tempel der Belat- } \\
\text { Suhnir, wenn sie } \\
\text { mit dem Boot des } \\
\text { Nanna zum Akiti } \\
\text { fährt }\end{array}$ \\
\hline TRU 282 & 6/ix/Š 46 & $\begin{array}{l}2 \text { Weideschafe } \\
2 \text { Weiderinder, } 2 \\
\text { Mastschafe, } \\
2 \text { Mastschafe die den } \\
\text { Ochsen folgen, 2 Ziegen }\end{array}$ & $\begin{array}{l}\text { für den von der } \\
\text { Gottheit verlassenen } \\
\text { Ort } \\
\text { für das Nabrium der } \\
\text { B.-S. und B.-D }\end{array}$ \\
\hline $\begin{array}{l}\text { MVN 18, } \\
77\end{array}$ & $15 / x i / S ̌ S 6$ & 1 Mastschaf, 1 Weideschaf & $s a ́-d u_{11}$ \\
\hline $\begin{array}{l}\text { MVN 18, } \\
83\end{array}$ & 19/vi/Šs 47 & $\begin{array}{l}2 \text { Mastschafe die den } \\
\text { Ochsen folgen, } 2 \text { Ziegen }\end{array}$ & $\begin{array}{l}\text { im Rahmen eines } \\
\text { Bierausschenkens } \\
\text { für Annunītum }\end{array}$ \\
\hline $\begin{array}{l}\text { SAT II, } \\
557\end{array}$ & $-/ v / S ̌ s$ & 2 Weideschafe & - \\
\hline $\begin{array}{l}\text { MVN 18, } \\
84\end{array}$ & 22/vi/Š 47 & 2 Weideschafe & - \\
\hline $\begin{array}{l}\text { OIP } 115, \\
127\end{array}$ & -/ix/Š 47 & 2 Weideschafe & - \\
\hline TCND 193 & 20/ix/Š 47 & 1 Mastlamm, 1 Ziege & $s a ́-d u_{11}$ \\
\hline $\begin{array}{l}\text { MVN 2, } \\
165\end{array}$ & 19/x/Š 47 & 2 Weideschafe & $\begin{array}{l}\text { für den von der } \\
\text { Gottheit verlassenen } \\
\text { Ort für B.-S. und } \\
\text { B.-D. }\end{array}$ \\
\hline
\end{tabular}

Tabelle 5: Opfer der Šulgi-simtî für Bēlat-Šuhnir (B.-S.) und Bēlat-Deraban (B.D.) unabhängig von den Gaben zu Neulicht und zum 15. Tag 
Ein Priester der Bēlat-Šuhnir wird in zwei Texten aus dem Archiv der Königin erwähnt. In OIP 115, 49 (-/xii/Š 38) erhält der g udu ${ }_{4}$-Priester 2 Schafe, in YOS 18, 4 (-/viii/Š 46) ist es ein Schaf, das als regelmäßige Lieferung (sá$\left.\mathrm{du}_{11}\right)$ ausgegeben wird.

Nach der Amtszeit von Šulgi-simtī verloren die beiden Göttinnen an Bedeutung im Kult des Königshauses von Ur. Jedoch wurden sie auh später hin und wieder mit Opfergaben versorgt, so u.a. in YBC 4190 aus der Regierungszeit Šu-Suens ${ }^{280}$, wo für Bēlat-Šuhnir eine Ziege verbucht ist, und in SNATBM 271 (20/x/ŠS 1) wo beide Göttinnen je ein Mastschaf erhalten.

\subsubsection{Elūnum und Nabrium}

Zwei Feste mit akkadischen Namen brachte Šulgi-simtī offensichtlich mit nach Ur, das Nabrium ${ }^{281}$ und das Elūnum ${ }^{282}$.

Das Elūnum wurde in altbabylonischer Zeit vor allem in Nordbabylonien gefeiert und erscheint häufig als Monatsname für den zweiten Monat, so auch in Ešnunna, der anzunehmenden Heimat von Šulgi-simt $\overline{1}^{283}$. Die Königin feierte dieses Fest für ihre persönlichen Göttinnen Bēlat-Šuhnir und Bēlat-Deraban ebenfalls im zweiten Monat ${ }^{284}$, wobei jeder Göttin 2 Stück Kleinvieh geopfert wurde, und auch Annunītum und Ulmaš̄itum Gaben erhielten. Das Fest erstreckte sich über mehrere Tage, wie aus den drei Quellen für das Jahr Š 41 hervorgeht, die zwischen dem 22/ii. und dem 1/iii. datiert sind. Der unpublizierte Text RS 332 verbucht Kleinvieh für das Elūnum im Palast am 3. Tag, was ebenfalls auf einen mehrtägigen Festverlauf hinweist.

Im Jahr Š 41 führte auch Geme-Ninlila, eine Nebenfrau Šulgis ${ }^{285}$, im zweiten Monat ein Elūnum durch ${ }^{286}$, für das zwei Mastrinder bereitgestellt wurden. Welcher Gottheit dieses Opfer galt, ist ebenso unklar wie die Frage, ob die beiden königlichen Damen Šulgi-simtī und Geme-Ninlila das Fest gemeinsam gestalteten, was nach den Daten denkbar wäre, oder ob jede ein eigenes Fest für ihre Gottheit veranstaltete.

\footnotetext{
280 FS Levine, S. 132-138, col. 10.

Dazu Sallaberger, Der kultische Kalender (1993), S. $205+$ Tab. 67; Cohen, Cultic Calendars (1993), S. 394-395.

Dazu Sallaberger, Der kultische Kalender (1993), S. $202+$ Tab. 65; Cohen, Cultic Calendars (1993), S. 397-399.

283 Greengus, The Akkadian Calendar at Sippar, JAOS 107 (1987), S. 220.

284 RA 19, 192 Nr. 4 (i/S 34); RS 332 (23/ii/Š 40), (unpubliziert, siehe Sallaberger Der kultische Kalender (1993), Tab. 65.); SET 44 (30/-/Š 41); MVN 18, 67 (20/ii/Š 41); JCS 52, S. 128 (1/iii/Š 41).

285 Zu Geme-Ninlila s. u. S. 202-206.

286 YOS 4, $240\left(17 / \mathrm{ii} / \check{S}_{4} 41\right)$.
} 
Daß ein Fest mit der Bezeichnung Elūnum nicht nur im zweiten Monat stattfand, zeigt der Text MVN 15, 162 aus Umma (viii/Š 33), wo Rohr und Weidenholz für Geštinanna-SI.A-tum verbucht werden ${ }^{287}$. Da auch in altbabylonischer Zeit in den verschiedenen Orten die Elūnum-Feste in verschiedenen Monaten stattfinden konnten ${ }^{288}$, scheint es sich beim Elūnum um ein Fest zu handeln, dessen Plazierung im Kalender von der mit dem Fest geehrten Gottheit abhing.

In der Zeit nach Šulgi führte Abī-simtī offenbar die Tradition des Elūnum fort. Sie ehrte mit diesem Fest, das sie wie ihre Vorgängerin zu Beginn des Jahres feierte, ihre Göttin Inanna und wahrscheinlich auch Bēlat-Šuhnir ${ }^{289}$.

Wie beim Elūnum feierte Šulgi-simtī auch beim Nabrium ihre persönlichen Göttinnen Bēlat-Šuhnir und Bēlat-Deraban sowie Annunītum und Ulmašītum. Dieses Fest fand im 8./9. Monat in Ur statt ${ }^{290}$, das bedeutet im halbjährlichen Wechsel mit dem Elūnum ${ }^{291}$. Auch das Nabrium ist in altbabylonischer Zeit als Fest verbreitet und in verschiedenen Lokalkalendern als Monatsname bekannt. ${ }^{292}$ Das Nabrium wurde aufwendiger gefeiert als das Elūnum, was sich daran erkennen läßt, daß neben Schafe und Ziegen regelmäßig auch Rinder geopfert werden. Möglicherweise dauerte es auch länger, allerdings ist eine allgemeingültige Ausage zum zeitlichen Umfang dieser Feste aufgrund der relativ geringen Anzahl der Quellen schwierig. Die Belege aus dem Jahr Š 46 deuten darauf hin, daß das Nabrium sich über zwei Wochen erstreckte (20/viii in Toronto 592 bis 6/ix in TRU 282), wobei erst Annunītum gefeiert wurde und einige Tage später das Fest für Bēlat-Šuhnir und Bēlat-Deraban stattfand. Es ist unklar, ob die Opfer für Allatum, Išḩara, Bēlat-Nagar, Annunītum und Nanaja, die nach den Aufwendungen für das Nabrium in TRU 282 verbucht sind, sich ebenfalls noch auf dieses Fest beziehen. Da sich das Fest über mehrere Tage

Sallaberger, Der kultische Kalender (1993), S. 202 Anm. 956; Cohen, Cultic Calendars (1993), S. 398. Der Text gehört nicht zum Šulgi-simtī-Archiv.

288 So das Elūnum für Ningal in Ur im zweiten und sechsten Monat oder ein Elūnum in Šubat-Enlil, das im achten und im zehnten Monat stattfinden konnte. Siehe Cohen, Cultic Calendars (1993), S. 398 mit Referenzen.

289 Elūnum für Inanna: MVN 20, 31 (ii/AS 5), für Bēlat-Šuhnir: PTS 830 (unpubliziert, siehe Cohen, Cultic Calendars (1993), S. 398). Zu diesen Festen bei Abī-simtī siehe S. $135 \mathrm{f}$.

290 TRU 272 (ix/Š 34); PDT II, 973 (viii/Š 42); PDT I, 162 (25/viii/ك̌ 45); TRU 282 (6/ix/Š 46) sowie der unpublizierte Text Toronto 592 (20/viii/Š 46), Sallaberger, Der kultische Kalender (1993), Tab. 67.

291 Sallaberger, Der kultische Kalender (1993), S. 205.

292 Greengus, The Akkadian Calendar at Sippar, JAOS 107 (1987), S. 209-229; Sallaberger, Der kultische Kalender (1993), S. 205 Anm. 972 mit weiteren Referenzen. 
erstreckte, ist es jedoch durchaus denkbar, daß im Verlauf der Feierlichkeiten verschiedenen Gottheiten Opfer gebracht wurden. In diesen Kontext könnten auch noch weitere Texte gehören, die Gaben an diese Gottheiten im neunten Monat verbuchen, so MVN 18, 53 (Š 33), wo die Königin Mastschafe für Bēlat-Šuhnir, Bēlat-Deraban, Annunītum, Ulmašītum, Allatum und Išḩara opferte, MVN 18, 60 (Š 36) verbucht Gaben an Inanna von Ur, Allatum, Išhara,

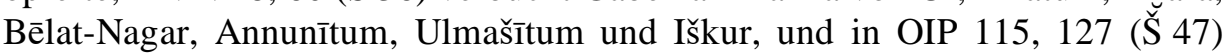
wird je ein Schaf für Bēlat-Šuhnir, Bēlat-Deraban und Iškur in Ur ausgegeben. Ob diese Opfer wirklich in den Zusammenhang des Nabrium gehören oder ob hier andere Kulte die Opfer der Königin nötig machten, ist unklar. Daß die hier genannten Gottheiten auch in anderen Monaten von Šulgi-simtī mit Opfern versorgt wurden, zeigen die Texte MVN 18, 114 (ك̌ 35), wo für den siebten Monat Gaben für Bēlat-Šuhnir, Bēlat-Deraban, Bēlat-Nagar und Išḩara verzeichnet sind, sowie MVN 18, 57 (i/Š 36) mit Opfern an Inanna von Ur, Allatum, Išhara und Bēlat-Nagar. ${ }^{293}$ Ein Opfer an An scheint sicher zum Nabrium gehört zu haben, da es sowohl in TRU 272 (Š 34) als auch in TRU 282 ( ̌ 46$)$ verbucht ist. Wenn nicht ausdrücklich der Anlaß der Opfer mit vermerkt ist, kann bei der Vielzahl der kultischen Pflichten der Königin nur vermutet werden, daß Opfer an bestimmte Gottheiten in einem bestimmten Monat in einen bekannten Festzusammenhang gehören.

Für die Nachfolgerinnen Šulgi-simtīs ist das Nabrium nicht zu belegen, doch da auch für das Elūnum bei Abī-simtī bisher nur zwei Belege vorliegen, ist es durchaus möglich, daß Šulgi-simtis Nachfolgerin auch dieses Fest fortgeführt hat.

\subsubsection{Regelmäßige Lieferungen für die persönlichen Göttinnen der Königin}

Šulgi-simtī versorgte ihre persönlichen Göttinnen Bēlat-Šuhnir und BēlatDeraban sowie die von ihr besonders verehrten Göttinnen Annunītum und Ulmašītum im Rahmen verschiedener regelmäßig stattfindender Feste mit Opfergaben. Darüber hinaus erhielten diese vier Göttinnen regelmäßige monatliche Lieferungen, die von anderen Festzusammenhängen unabhängig waren. Diese Lieferungen sind für die Jahre Š 39 bis $\breve{S} 43$ zu belegen, wobei die Texte stets dem gleichen Formular folgen ${ }^{294}$. Bis zum Monat viii/Š 40 erhalten die Göttinnen zusammen monatlich 8 Stück Kleinvieh, danach sind es

\footnotetext{
293 Vgl. Sallaberger, Der kultische Kalender (1993), S. 205 + Anm. 974.

294 TCND 391 (v, vi/Š 39); TRU 287 (vii, viii/Š 39); OIP 115, 50 (xii, i/Š 39); OIP 115, 57 (i, ii/Š 40); MVN 3, 185 (iv-viii/Š 40); BIN III, 485 (ix-xii/Š 40); TCND 392 (iv/Š 41); MVN 18, 91 (vii/Š 41); OIP 115, 67 (x/Š 41); OIP 115, 68 (xii/Šs 41); SACT I, 180 (xi/Š 42); OIP 115, 131 (ix/Š 43).
} 
jeweils 6 Tiere pro Monat. Die Gaben werden als regelmäßige Lieferungen $\left(\mathrm{s} a-\mathrm{du}_{11}\right)^{295}$ bezeichnet, auf den Tafeln werden keine weiteren Ausgaben vermerkt und bis auf eine Ausnahme (OIP 115, 131) ist nie ein Personenname angegeben. Darüber hinaus wird in dieser Textgruppe nicht wie meist üblich angegeben, wie die Tiere gefüttert wurden (ú, niga), sondern das Geschlecht der Tiere wird als besonderes Merkmal genannt. Es werden weibliche $\operatorname{~ud}_{5}$, munusáš-gàr, $\mathrm{u}_{8}, \mathrm{kir}_{11}$ ) wie männliche (máš-nita ${ }_{2}, \mathrm{udu}-n i a_{2}$, sila $_{4}$ nita $_{2}$ ) Tiere geopfert.

Ebenfalls in diesen Zusammenhang gehört der Text ŠA XXVI: 1a (̌̌ 33), in dem die Ausgabe von 118 Schafen und Ziegen für die vier Göttinnen durch Ahima vermerkt wird. Dieser Text trägt den bisher singulären Vermerk kišib a ma-nin-ĝ́á-ka. Ist Ama-ninĝa hier als Personenname zu lesen oder ist zu übersetzen „Siegel der Mutter meiner Herrin“ (= der Königin)? Der Text ist ungesiegelt, und zur Praxis der Siegelungen in Puzriš-Dagān liegen bisher keine Untersuchungen vor ${ }^{296}$. Parallel zum Urkundenformular aus Umma und Girsu wäre hier zu lesen „,hat die Mutter meiner Herrin angenommen“. Es ist durchaus vorstellbar, daß Šulgi-simtī, die im Jahr $\breve{S} 33$ erst kurze Zeit als Königin amtierte, einen Besuch von ihrer Mutter erhielt ${ }^{297}$, und daß zu diesem Anlaß die große Menge von mehr als 100 Tieren für die Göttinnen der Königin bereitgestellt wurde.

\subsubsection{Verschiedene selten belegte Feste und Riten}

Ein in Ur gefeiertes Fest war das Abum, welches in den Sommermonaten (iv.vi. Monat) begangen wurde. ${ }^{298}$ Abum ist in der Ur III-Zeit und in der altbabylonischen Zeit in verschiedenen Lokalkalendern als Monatsname bezeugt. ${ }^{299}$ Bei diesem Fest handelte es sich um Feiern im Rahmen des Totenkultes für die verstorbenen Herrscher. Zwei Texte aus dem Archiv der Šulgi-simtī nennen explizit Lieferungen von Schafen für dieses $\mathrm{Fest}^{300}$, ein weiterer Text ist aufgrund der Gaben für den Wassertränkort (ki-a-n a $\hat{g}$ ) UrNammas ebenfalls in diesen Kontext zu stellen ${ }^{301}$. Bei diesem letzten Text ist

$295 \mathrm{Zu} \mathrm{sá}-\mathrm{du}_{11}$-Lieferungen in der Ur III-Zeit siehe Sigrist, Le sattukku dans l'Ešumeša durant la période d'Isin et Larsa (1984), S. 185-188.

296 Sallaberger, OBO 160/3 (1999), S. 231.

297 Siehe vergleichbare Besuche zwischen den königlichen Damen von Ebla, S. 151 und 192.

298 Dazu Sallaberger, Der kultische Kalender (1993), S. 205-207.

299 Ebd. S. 206; Cohen, Cultic Calendars (1993), S. 259-261; Greengus, The Akkadian Calendar at Sippar, JAOS 107 (1987), S. 211.

300 TCND 185 (v/Š 41); TCND 192 (16/iii/Š 47).

301 OIP 115, 139 (12/vi/Š 42), dieser Text wird aufgrund des Formulars für das 
der Vermerk auffällig, daß die Buchung in Tummal erfolgte. Da jedoch keine Tiere für Ninlil, die mit dem Tummalfest geehrt wurde ${ }^{302}$, verbucht werden, sondern Lieferungen für den König, den Wassertränkort Ur-Nammas und die sonst bei Šulgi-simtī nicht genannte Göttin Nungal ${ }^{303}$ erfolgen, gehört dieser Text wohl in den Kontext des Abum-Festes. Gaben, die so explizit als Totenopfer bezeichnet werden, sind sonst bei Šulgi-simtī nicht zu finden, doch ist ihre Beteiligung an den Riten für den verstorbenen Ur-Namma aus diesen Quellen eindeutig zu ersehen. Damit erfüllt die Königin zum einen die familiäre Pflicht der Versorgung der $\operatorname{Toten}^{304}$, zum anderen ist sie am Herrscherkult für den verstorbenen König beteiligt. Die Beteiligung am Kult für den lebenden König zeigen Opfer für die Statue des Königs ${ }^{305}$. Ebenfalls zum Totenkult gehört das NE.NE- $\hat{g}$ ar-Fest, das wie das Abum-Fest in der trockenen Zeit des Sommers gefeiert wurde. ${ }^{306}$ Dieses Fest ist im Archiv der Šulgi-simtī bisher nur einmal belegt $\mathrm{t}^{307}$, allerdings feiert die Königin das NE.NE- ga r-Fest im ix. Monat und opfert dazu 2 Schafe im Tempel ihrer Göttinnen Bēlat-šuhnir und Bēlat-Deraban. Hier ist möglicherweise an Riten für Verstorbene aus ihrer Herkunftsfamilie zu denken.

Ein nur selten belegtes Fest ist das šeršerrum, das „Fest der Kette ${ }^{\text {? } 308}$. Die genaue Bedeutung dieses Terminus ist im Zusammenhang mit einem Fest noch nicht zu bestimmen. Es wurde im Frühsommer (ii./iii. Monat) für Bēlat-Šuhnir und Bēlat-Deraban begangen. Möglicherweise gehört es in den Kontext des Festes zum Eintreten der Göttin Annunītum ${ }^{309}$, da beide Ereignisse in MVN 18, 63 (Š 40) auf einer Tafel aufgeführt werden. In OIP 115, 33 (Š 37) werden 2 Ziegen für den von der Gottheit zeitweilig verlassenen Ort (ní $\hat{\mathrm{g}}-\mathrm{ki}$ - zà h $)$ im Tempel der Bēlat-Šuhnir und Bēlat-Deraban für das šeršerrum ausgegeben. Eine mögliche Erklärung wäre eine Teilnahme der persönlichen Göttinnen der Königin am Empfang, den diese für Annunītum im Palast ausrichtete, wozu

Tagesdatum dem Archiv der Königin zugerechnet, siehe Hilgert, OIP 115, S. 12.

Zum Tummalfest siehe Sallaberger, Der kultische Kalender (1993), S. 131-144.

$\mathrm{Zu}$ Nungal, der Göttin des Strafvollzuges und der Gerechtigkeit siehe Cavigneaux/ Krebernik RlA 9 (2001), S., 615-618.

Dazu Groneberg, Zu den mesopotamischen Unterweltsvorstellungen, AoF 17 (1990),

S. 256-257; D. Katz, The Images of the Netherworld (2003), S. 212.

OIP 115, 32 (i/Š 37); MVN 18, 61 (v/Š 37); Tel Aviv I, 56 (5/viii/Š 40).

Sallaberger, Der kultische Kalender (1993), S. 125-127.

MVN 18, 53 (ix/Š 33).

OIP 115, 33 (ii/Š 37) und MVN 18, 63 (1/iii/Š 40), wohl auch RS 90 (unpubliziert), dazu Sallaberger, Der kultische Kalender (1993), S. 203 Anm. 961. Zu šeršerrum CAD Š II S. 321 “chain”, AHw S. 1218 ,(Ketten-)Ring?".

Zu diesem Fest siehe S. 69. 
Bēlat-Šuhnir und Bēlat-Deraban ihren Tempel verließen. Cohen schlug als Erklärung für das šeršerrum eine Verbindung mit einem von ihm angenommenen Mythos vor, in welchem Bēlat-Šuhnir und Bēlat-Deraban in die Unterwelt verschleppt oder dort in Ketten gelegt wurden. ${ }^{310}$ Auf der Basis der bisher bekannten Texte muß diese Interpretation wie jede andere Spekulation bleiben.

Volkommen unklar ist derzeit auch die Bedeutung des Festes g a - ma-g a $\mathrm{mu}-\grave{\mathrm{e}}^{311}$, das im Herbst gefeiert wurde. Hierbei handelte es sich wohl um ein kleineres Fest, da nur jeweils ein Schaf aus dem Bestand der Königin abgebucht wird. Welche Gottheit möglicherweise mit diesem Fest geehrt werden sollte, ist nicht zu sagen. Bei den in OIP 115, 80 aufgeführten Göttern handelt es sich um die regulären Ausgaben zu Neulicht, nicht um Ausgaben zum g a-ma-g a-mu-è-Fest. Ob es sich bei diesem Fest um eine Variante des in Nippur gefeierten Festes g an - $\mathrm{g}$ an - è handelt ${ }^{312}$, muß offen bleiben.

$\mathrm{Zu}$ den selten von Šulgi-simtī beopferten Gottheiten gehört auch die Göttin ${ }^{\mathrm{d} N i n-a n s ̌ e-l a ́, ~ f u ̈ r ~ w e l c h e ~ n u r ~ i n ~ z w e i ~ T e x t e n ~ j e w e i l s ~ d i e ~ A u s g a b e ~ v o n ~ e i n e m ~}$ Schaf für siskur ${ }_{2}$-Riten verbucht werden. Aufgrund der unterschiedlichen Monate ist hier von spontanen Opfern auszugehen, die nicht in den Kontext regelmäßiger Feste gehören. ${ }^{313}$

Ebenfalls ein eindeutig spontanes Opfer ist in CTNMC 9 (v/Š 37) verzeichnet, wo ein Schaf für siskur ${ }_{2}$-Riten nach dem Herzenswunsch (der Königin), siskur ${ }_{2}$ šà-ga gu-ru-a, ausgegeben wird. Vergleichbare spontane Opfer sind auch für den König überliefert ${ }^{314}$. Der Anlaß für diese Opfer außerhalb des feststehenden Kultkalenders ist in den Texten nicht vermerkt.

Während ihrer gesamten Amtszeit kümmerte sich Šulgi-simtī in unregelmäßigen Abständen auch um den Kult des Wettergottes Iškur ${ }^{315}$. Ab dem Jahr $\breve{S} 41$ kann er in der Reihe der in Uruk zum 15. Tag eines Monats beopferten Gottheiten auftreten. Doch auch schon in den Jahren davor finden

310 Cohen, Cultic Calendars (1993), S. 211.

311 SET $43(28 / i x / S$ 41) hier ist der Name des Festes ga-ma-am-mu-ut-tum geschrieben; OIP 115, 80 (28/viii/Š 42).

312 So vermutet Cohen, Cultic Calendars (1993), S. 214. Zu g a n-g a n - è als einem Fest mit nur lokaler Bedeutung siehe Sallaberger, Der kultische Kalender (1993), S. 146.

313 MVN 3, 153 (-/vi/Š 37) und TCND 183 (16/ix/Š 40). In TCND 183 wird die Göttin

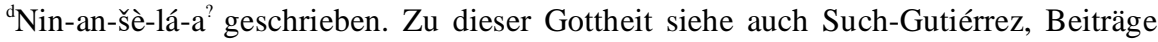
zum Pantheon von Nippur im 3. Jahrtausend (2003), Teil I S. 121.

314 MVN 13, 119 (IS 5), siehe Sallaberger, Der kultische Kalender (1993), S. 74.

315 Zum Kult des Iškur in Nippur vgl, Such-Gutiérrez, Beiträge zum Pantheon von Nippur im 3. Jahrtausend (2003), Teil I S. 251-254. 
sich wiederholt Gaben der Königin an Iškur. Diese Opfer erfolgten mitunter im Rahmen anderer Feste und Riten wie der Neulichtfeier oder dem Bierausschenken für eine der von Šulgi-simtī besonders verehrten Göttinnen, oder sie werden schlicht als regelmäßige Lieferungen $\left(s a ́-d u_{11}\right)$ bezeichnet. Ein besonderer Grund für die Aufnahme Iškurs in die Reihe der jeweils beopferten Gottheiten scheint nicht zu bestehen.

\begin{tabular}{|c|c|c|c|}
\hline Publikation & Datum & Opfergaben & Anlaß \\
\hline TRU 272 & -/ix/Š 34 & $\begin{array}{l}1 \text { Mastschaf als } \\
\text { regelmäßige Lieferung für } \\
\text { den von der Gottheit } \\
\text { verlassenen Ort }\end{array}$ & $\begin{array}{l}\text { Bierausschenken für } \\
{ }^{\mathrm{d}}[\mathrm{]}, \text { ev. im Rahmen } \\
\text { eines Nabrium }\end{array}$ \\
\hline TCND 178 & $-/ \mathrm{v} / \mathrm{S} 36$ & 1 Mastschaf & - \\
\hline MVN 18, 60 & 1/ix/Š 36 & $\begin{array}{l}1 \text { Mastschaf als } \\
\text { regelmäßige Lieferung für } \\
\text { den von der Gottheit } \\
\text { verlassenen Ort, den } \\
\text { Tempel des Iškur } \\
\end{array}$ & - \\
\hline MVN 18, 61 & $-/ \mathrm{v} / \mathrm{S} 37$ & $\begin{array}{l}\text { 1 Lamm für den Tempel } \\
\text { des Iškur }\end{array}$ & $\begin{array}{l}\text { Bierausschenken der } \\
\text { Annunītum }\end{array}$ \\
\hline TRU 273 & -/vii/Šs 40 & $\begin{array}{l}1 \text { Mastschaf, } 1 \\
\text { Weideschaf für den } \\
\text { Tempel des Iškur }\end{array}$ & $\begin{array}{l}\text { in Rahmen eines } \\
\text { Bierausschenkens } \\
\text { der Annunītum } \\
\end{array}$ \\
\hline OIP 115,61 & $18 / \mathrm{x} / \mathrm{S} 40$ & 1 Mastschaf, 1 Ziege & - \\
\hline OIP 115,62 & $30 / \mathrm{xi} / \mathrm{S} 40$ & $\begin{array}{l}{\left[1^{?}\right] \text { Schaf das dem }} \\
\text { Ochsen folgt }\end{array}$ & $\begin{array}{l}\text { si sku r }{ }_{2} \text {-Riten zu } \\
\text { Neulicht }\end{array}$ \\
\hline CST 52 & -/i/ŠS 41 & $\begin{array}{l}\text { 1 Schaf für den von der } \\
\text { Gottheit verlassenen Ort }\end{array}$ & - \\
\hline Toronto 16 & $15 / \mathrm{i} / \mathrm{S} 41$ & 1 Lamm & $\begin{array}{l}\text { s is k u } r_{2} \text {-Riten zum } \\
\text { 15. Tag in Uruk }\end{array}$ \\
\hline DCEPHE 313 & 3/ix/Šs 41 & 1 Mastschaf & siskur ${ }_{2}$-Riten \\
\hline MVN 18, 72 & $15 /$ vii/Š 45 & $\begin{array}{l}1 \text { Weideschaf für den von } \\
\text { der Gottheit verlassenen } \\
\text { Ort }\end{array}$ & $\begin{array}{l}\text { Riten zum 15. Tag in } \\
\text { Uruk }\end{array}$ \\
\hline MVN 13,715 & 15/viii/ŠS 45 & $\begin{array}{l}1 \text { Schaf das dem Ochsen } \\
\text { folgt }\end{array}$ & $\begin{array}{l}\text { Riten zum 15. Tag in } \\
\text { Uruk }\end{array}$ \\
\hline MVN 18, 73 & 13/ix/Š 45 & 1 Schaf und 1-x Ziegen & sá-d u ${ }_{11}$ \\
\hline $\begin{array}{l}\text { NISABA 8, } \\
374\end{array}$ & $15 / \mathrm{x} / \mathrm{S} 45$ & 2 mal 1 Schaf & siskur ${ }_{2}$-Riten \\
\hline OIP 115,100 & $\begin{array}{l}16+x / x i i / S ̌ \\
45\end{array}$ & $\begin{array}{l}{\left[1^{?}\right] \text { Schaf das dem }} \\
\text { Ochsen folgt }\end{array}$ & - \\
\hline $\begin{array}{l}\text { JCS 35, S. } \\
183 \text { Nr. } 1\end{array}$ & 21/v/Šs 46 & 1 Ziege & - \\
\hline MVN 18, 77 & $15 / \mathrm{xi} / \mathrm{S} 46$ & 1 Weideschaf & siskur ${ }_{2}$-Riten \\
\hline
\end{tabular}


Königinnen

\begin{tabular}{|l|l|l|l|}
\hline Publikation & Datum & Opfergaben & Anlaß \\
\hline SAT II, 557 & -/v/Š 47 & 1 Ziege & (in Ur) \\
\hline OIP 115, 127 & -/ix/Š 47 & 1 Weideschaf & - \\
\hline MVN 2, 165 & 19/x/Š 47 & 1 Mastschaf & sá-d u 11 \\
\hline MVN 18, 87 & 7/xi/Š 47 & [x] Weideschaf(e) & $\begin{array}{l}\text { im Rahmen des } \\
\text { Festes e S U } \\
\text { in Uruk }\end{array}$ \\
\hline
\end{tabular}

Tabelle 6: Opfer der Šulgi-simtĩ für Iškur

Neben dem Kult der großen Götter des Landes und ihrer persönlichen Göttinnen hatte Šulgi-simtī auch Riten zu beachten, die mit der Viehhaltung zusammenhängen. So sind mehrfach Riten im Schafstall ( $\mathrm{g}$ á $-\mathrm{udu}$ ) oder beim Besuch des Schafstalles belegt. ${ }^{316}$ Vergleichbare Kulte bei den Hürden sind auch aus Umma bekannt, wo siskur $\mathrm{r}_{2}$-Riten zur Zeit der Paarung des Viehs stattfanden ${ }^{317}$. Šulgi-simtī vollzog ebenfalls s is kur ${ }_{2}$-Riten im Zusammenhang mit ihren Besuchen beim Schafstall, wobei angesichts der geringen Zahl der Belege und bei den unterschiedlichen Daten (vii./ix./xii. Monat) keine Regelmäßigkeiten festzustellen sind. Die Besuche im vii. und ix. Monat dürften in die Zeit des Lammens gehören, von dem man annimmt, daß es zwischen Oktober und Dezember stattgefunden hat ${ }^{318}$. Die Riten bei den offiziellen Besuchen der Königin beim Schafstall sind umfangreich und können sich über mehrere Tage erstrecken. Für den Besuch im xii. Monat (SDU 1, Š 41) werden zwei Schweine bei Apilatum für das „Gehen zum Schafstall“ (g á-u du -šè è-a) abgebucht. Da Schweine bei Šulgi-simtī nie als Opfergabe dienen, waren die Tiere wohl für die Mahlzeiten der Königin während dieses Besuches bestimmt. In OIP 115, 79 ( ̌ك 42) werden Ausgaben für Opfer und für die Verpflegung des Hofes für vier Tage verbucht. Dieser Besuch bei den Tieren war Anlaß für ein Festmahl, zu dem neben Schafen auch Rinder geschlachtet wurden. Die Göttin Ninsun erhielt in diesem Zusammenhang ein Opfer, ebenso wie der von der Gottheit verlassene Ort, wobei nicht deutlich wird, um welche Gottheit es sich hier handelt, wahrscheinlich um eine lokale Schutzgottheit, da sich in DCEPHE

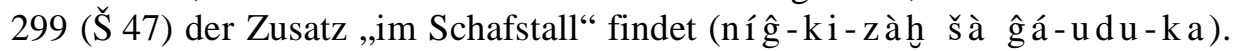
OIP 115, 79 verbucht Opfer im Schafstall getrennt von der Gabe an den von der Gottheit verlassenen Ort. Nach diesem Text wird am ersten Tag der Riten ein Schaf für Allatum geopfert, eine Ausgabe, die sich in DCEPHE 299 nicht findet. Dafür werden dort 2 Schafe im Palast für siskur ${ }_{2}$-Riten für Inanna

\footnotetext{
316 SDU 1 (xii/Š 41); OIP 115, 79 (5-9/vii/Š 42); DCEPHE 299 (20/ix/Š 47).

317 Sallaberger, Der kultische Kalender (1993), S. 90-92 und 270-271.

318 Payne, Comments on Flock Compositions, JSS 20 (1975), S. 19; Maekawa The Management of Fatted Sheep, ASJ 5 (1983), S. 110-111 Anm. 33, 34.
} 
bereitgestellt ,als meine Herrin zum Schafstall ging“ (nin-ĝg $u_{10}$ ĝá-udu-šè è-a). Wie schon bei verschiedenen anderen Kulthandlungen, so ist auch hier zu beobachten, daß die Riten zwar einem bestimmten Schema folgen, welches aber offen für Veränderungen ist und den jeweiligen Bedingungen angepaßt werden kann.

Die umfangreichen Opfer beim Besuch im Schafstall zeigen die große Bedeutung, die die Viehwirtschaft für die Königin hatte. Große Herden waren ein kostbarer Besitz, aus dem nicht nur die diversen Opfer bestritten wurden, sondern die Tiere dienten auch als Geschenke an Angehörige des Hofes ${ }^{319}$ und als Lieferanten für Wolle ${ }^{320}$.

Bisher singulär ist der Text OIP 115, 101 (18/i/Š 46), wo neben Schafen für s isk ur ${ }_{2}$-Riten im Palast für Bēlat-Šuhnir und Bēlat-Deraban auch eine Ente für siskur $r_{2}$-Riten im Vogelhaus (1 uz-tur siskur $r_{2}$ é mušen) ausgegeben wird. Hier liegt der erste eindeutige Beleg vor, daß aus dem Bestand der Šulgisimtī Geflügel für Opfer verwendet wird. Wie bei den Riten im Schafstall wird auch bei diesem Ritus keine Gottheit mit Namen genannt, der das Opfer galt. Der Text zeigt ferner, daß die Königin die Tiere in einem eigenen Vogelhaus hielt, daß also nicht alle Enten und Tauben, die für die Tafel der Königin bestimmt waren ${ }^{321}$, wild gefangen wurden. Der „Vogelfänger“ (mu š en - d ù ) ist aus mehreren Texten aus dem Šulgi-simtī-Archiv bekannt ${ }^{322}$, wobei zu fragen ist, ob es sich bei der Berufsbezeichnung mušen-dù nur um den Vogel-,,Fänger“ handelt, oder ob mu š e n-d ù nicht auch den Verantwortlichen für die Geflügelhaltung, hier der Königin, meinen könnte ${ }^{323}$.

Auffällig ist die Häufung der Opfergaben an den Flußordalgott $\left({ }^{\mathrm{d}} \mathrm{I}_{7}-1\right.$ ú ru-gú) in den Jahren ab $\breve{S} 45^{324}$. Für die Zeit davor ist bisher nur ein vergleichbarer Text bekannt ${ }^{325}$. Opfer dieser Art sind sonst in der Ur III-Zeit nicht bekannt ${ }^{326}$, auch die Nachfolgerinnen der Šulgi-simtī führten diese Praxis

319 Siehe dazu S. 100-103.

320 Zur Rolle der Königin in der Textilwirtschaft siehe S. 103-105.

321 Siehe dazu S. 94f.

322 Unter anderem OIP 115, 39 (29/ix/Š 39); SAT II, 294 (17/viii/Š 41); MVN 13, 273 (ix/Š 44); PDT I, 139 (28/x/Š 47).

323 So Sigrist, Drehem (1992), S. 370 "Responsable de basse-cour"; siehe auch Salonen, Die Namen für Vogler im Alten Mesopotamien, BagMit 7 (1974), S. 170-171.

324 BIN III, 366 (5/iii/Š 45); PDT I, 645 (15/v/ŠS 45); OIP 115, 102 (6/ii/ ك̌ 46); JCS 35, S. 183 Nr. 1 (21/v/Š 46); TLB III, 13 (5/viii/Š 46); Bab 7, Pl. XIX Nr. 4 (7/xi/Š 46); TCND 191=Boson 271 (7/i/Šs 47); MVN 18, 83 (19/vi/Š 47); Rochester 22 (10/i/Š 48). MVN 3, 153 (vi/Š 37).

326 Sigrist, Drehem (1992), S. 173. Zur Verehrung des Flußordalgottes siehe auch SuchGutiérrez, Beiträge zum Pantheon von Nippur im 3. Jahrtausend (2003), Teil I S. 222. 
nicht fort. Der Flußordalgott, der im Zusammenhang mit den Unterweltsgöttern $\operatorname{stand}^{327}$, erhielt von Šulgi-simtī stets ein Stück Kleinvieh. Ein Teil dieser Opfer gehören in den Zusammenhang der Gaben zum 7. Tag ${ }^{328}$, doch werden auch außerhalb dieses Kontextes Opfer der Königin an den Flußordalgott verbucht. Hier ist insbesondere der Text JCS 35, S. 183 Nr. 1 (21/v/Š 46) zu nennen, wo insgesamt 6 Stück Kleinvieh für Bēlat-Šuhnir und Bēlat-Deraban sowie eine Ziege für den Flußordalgott von der Königin selber überbracht wurden. Der konkrete Anlaß für diese Häufung der Opfer an eine ansonsten eher unbedeutende Gottheit bleibt auch hier unbekannt, da die Texte nur die ausgegebenen Tiere und die Empfänger vermerken, nicht aber den Grund für ein Opfer.

Aus dem Beginn der Amtszeit von Šulgi-simtī als Königin von Ur stammt SAT II, 47 (ix/Š 32), in dem zwei tragende Ziegen $\left(\mathrm{ud}_{5}\right.$ máš ná-a ${ }^{329}$ ) für Klagen um Bēlat-Šuhnir und Bēlat-Deraban am Tor Geštinanna, sowie drei tragende Ziegen für siskur ${ }_{2}$-Riten im Palast ausgegeben werden. Die Verwendung von tragenden Tieren als Opfergaben ist bei Šulgi-simtī sonst nicht belegt, und somit stellt sich die Frage, was mit diesen Opfern an ihre persönlichen Göttinnen und beim Tor Geštinanna bezweckt werden sollte. Sieben Monate zuvor waren am selben Ort zwei ausgewachsene Ziegen (máš gal) für Klagen um Annunītum und Ulmašĩtum geopfert worden ${ }^{330}$. In den folgenden Jahren sind keine Opfer der Königin an diesem Ort mehr belegt. Wenn die Annahme zutreffend ist, daß Šulgi-simtī im Jahr Š 32 die Nachfolge von Geme-Suen als Königin von Ur angetreten hat ${ }^{331}$, könnten diese Opfer am Tor Geštinanna genau in die Zeit des Amtswechsels fallen. Wie kann nun die Opferung von tragenden Tieren verstanden werden? Eine mögliche Erklärung wäre die Bitte um eine erfolgreiche Schwangerschaft für die junge Königin. Die Thronfolgeregelung im Reich von Ur III ist bisher noch unklar ${ }^{332}$, doch es ist naheliegend zu vermuten, daß eine neue Königin versuchte, ihre Position am Hof durch die Geburt eines Sohnes und möglichen Thronfolgers zu stärken.

Es fällt auf, daß bisher keiner der Wirtschaftstexte dieser Zeit Opfer im Zusammenhang mit der Geburt eines Prinzen oder einer Prinzessin bezeugt. Auch werden kaum je Geschenke an die Königinnen und königlichen Neben-

327 Frymer-Kensky, The Judicial Ordeal in the Ancient Near East (1977), S. 91; Katz, The Images of the Netherworld (2003), S. 353.

328 Siehe S 56f.

329 Zu ud 5 máš ná-a „nanny goat“ siehe Steinkeller, Sheep and goat terminology in Ur III sources from Drehem, BSA 8, S. 55.

330 OIP 115,128 (iv/Š 32).

331 Siehe oben S. 36.

332 Vgl. Sallaberger, OBO 160/3 (1999), S. 182 zur Frage, ob es einen Kronprinzen im Reich von Ur III gab. 
frauen zur Geburt eines Kindes verbucht ${ }^{333}$. Daß dem Hof nahestehende Damen Geschenke zur Geburt von Kindern erhalten haben, belegt der Text OIP 115, 330 (20/iv/Š 47) aus dem königlichen Archiv von Puzriš-Dagān, wo die Frauen von Šarrum-ilī, Šulgi-ilī und Dukra je ein Rind und fünf weibliche Schafe empfingen „am Tag als sie ein Kind geboren haben“ $\left(u_{4}\right.$ dumu in-tu-eššè). Vergleichbare Gaben von Vieh an die Frauen des Königs sind bisher ebensowenig bekannt, wie Geschenke von Schmuckstücken, wie sie nach dem Archiv von Ebla ${ }^{334}$ bei der Geburt von Königskindern vergeben wurden.

\subsubsection{1. Übersicht über jährliche Feste und Riten}

Šulgi-simtī hatte also neben den monatlichen kultischen Pflichten zu Neulicht, am 7. und am 15. Tag eine große Zahl anderer Kulte und Riten zu beachten. Nicht alle in der untenstehenden Übersicht aufgeführte Feste und Riten sind so gut belegt, daß von einem jährlichen Fest ausgegangen werden kann, bei mancher Kulthandlung mag es sich um ein einmaliges Ereignis gehandelt haben, doch insgesamt ergibt sich hier aus den Quellen des Archives dieser Königin ein sehr komplexes Bild religiöser Aktivitäten, bei denen verschiedene Gottheiten zu den unterschiedlichsten Anlässen beopfert wurden.

\begin{tabular}{|c|c|c|c|c|}
\hline Monat & Ort & $\begin{array}{l}\text { Name des } \\
\text { Festes }\end{array}$ & geehrte Gottheit & Beleg \\
\hline I & Uruk & $\begin{array}{l}\text { ér nî̂in }{ }_{2}- \\
\text { na ká } \\
\operatorname{gi}_{6}-\mathrm{par}_{4}- \\
\mathrm{ra}^{-}\end{array}$ & $\begin{array}{l}\text { Nanaja, Inanna } \\
\text { (Muš-a-igi-gál, } \\
\text { Ninigizibarra) }\end{array}$ & $\begin{array}{l}\text { MVN 18, } 58(\mathrm{i} / \mathrm{S} \\
36)\end{array}$ \\
\hline $\mathrm{I} / \mathrm{II}$ & Nippur & $\begin{array}{l}\text { ezem } \\
\mathrm{gu}_{4}-\mathrm{gana}\end{array}$ & $\begin{array}{l}\text { Allagula, Ninlil } \\
\text { (Ninĝagia, Enlil, } \\
\text { Inanna, Statue des } \\
\text { Königs) }\end{array}$ & $\begin{array}{l}\text { OIP 115, } 32 \text { (i/Š } \\
37) ; \\
\text { Bab 7, Pl. XIX Nr. } \\
2 \text { (ii/Š 44) }\end{array}$ \\
\hline II & Ur & Elūnum & $\begin{array}{l}\text { Bēlat-Šuhnir, Bēlat- } \\
\text { Deraban, Annunītum, } \\
\text { Ulmašîtum }\end{array}$ & $\begin{array}{l}\text { RA 19, } 192 \text { Nr. } 4 \\
\text { (i'/ŠS 34); MVN 18, } \\
67(20 / i \text { ii/ك̌S 41); } \\
\text { SET 44 (30/-/Š 41) }\end{array}$ \\
\hline II/III & Ur & šeršerrum & $\begin{array}{l}\text { Bēlat-Šuhnir, Bēlat- } \\
\text { Deraban }\end{array}$ & $\begin{array}{l}\text { OIP } 115,33 \text { (ii/Š } \\
\text { 37); MVN 18, } 63 \\
(1 / \text { iii//S̆ 40) }\end{array}$ \\
\hline
\end{tabular}

333 Der einzige Text über Geschenke zur Geburt eines Kindes der Königin ist MVN 16, 960 (ŠS 3). Hier erhielt Kubātum Geschenke anläßlich einer Geburt.

334 Siehe S. 189. 
Königinnen

\begin{tabular}{|c|c|c|c|c|}
\hline Monat & Ort & $\begin{array}{l}\text { Name des } \\
\text { Festes }\end{array}$ & geehrte Gottheit & Beleg \\
\hline II/III & Ur & $\begin{array}{l}\text { ezem } \\
\text { digir- } \\
\mathrm{ku}_{4}-\mathrm{ku}_{4}\end{array}$ & $\begin{array}{l}\text { Annunītum, } \\
\text { Ulmašītum, Bēlat- } \\
\text { Šuhnir, Bēlat-Deraban }\end{array}$ & $\begin{array}{l}\text { OrSP 18, } 1 \text { (iii/Š } \\
\text { 34); MVN 18, } 63 \\
(1 / \text { iii/Š 40); SET } \\
44 \text { (30/-/Š 41); } \\
\text { PDT I, } 430 \text { (ii/ŠS } \\
\text { 45) }\end{array}$ \\
\hline IV-VI & Ur & Abum & (Totenkult) & $\begin{array}{l}\text { TCND } 185 \text { (v/Š } \\
\text { 41); TCND } 192 \\
\text { (16/iii/Š 47); OIP } \\
115,139(12 / \mathrm{vi} / \mathrm{S} \\
42)\end{array}$ \\
\hline V & Uruk & $\begin{array}{l}\text { ér niĝin }{ }_{2-} \\
\text { na }\end{array}$ & $\begin{array}{l}\text { Nanaja, Inanna } \\
\left(\mathrm{ká}^{2} \mathrm{è} \mathrm{ká} \mathrm{g} \mathrm{i}{ }_{6}-\right. \\
\left.\mathrm{par}_{4}\right)\end{array}$ & $\begin{array}{l}\text { CTNMC } 9 \text { (v/Š } \\
\text { 37); PDT II, } 1030 \\
\text { (iv oder v/S } 45^{?}\end{array}$ \\
\hline VI & Uruk & $\begin{array}{l}\text { ezem má- } \\
\text { an-na }\end{array}$ & Inanna, Nanaja & 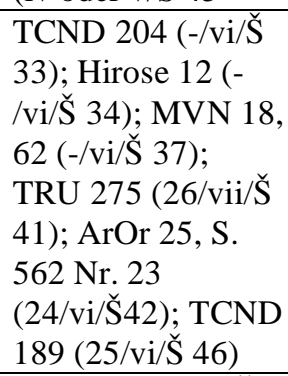 \\
\hline V-VII & Ur & kaš-dé-a & Annunītum & $\begin{array}{l}\text { MVN 18, } 61 \text { (v/Š } \\
\text { 37); TRU 273 (5- } \\
\text { 7/vii/Š 40); MVN } \\
18,83(19,21 / v i / S ̌ \\
47)\end{array}$ \\
\hline V/VI & Ur & erubbatum & $\begin{array}{l}\text { Annunītum, } \\
\text { Ulmašîtum }\end{array}$ & $\begin{array}{l}\text { CST } 41(\mathrm{v} / \mathrm{S} \text { 36); } \\
\text { MVN 18, } 167(\mathrm{vi} / \mathrm{S} \\
41)\end{array}$ \\
\hline VII & Ur & akiti & Nanna & 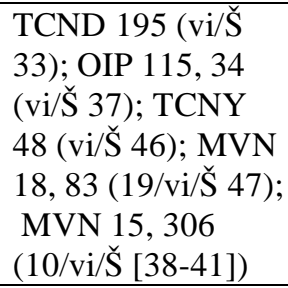 \\
\hline
\end{tabular}




\begin{tabular}{|c|c|c|c|c|}
\hline Monat & Ort & $\begin{array}{l}\text { Name des } \\
\text { Festes }\end{array}$ & geehrte Gottheit & Beleg \\
\hline VIII/IX & Ur & Nabrium & $\begin{array}{l}\text { Annunītum, } \\
\text { Ulmašītum, Bēlat- } \\
\text { Šuhnir, Bēlat-Deraban }\end{array}$ & $\begin{array}{l}\text { TRU } 272 \text { (ix/Š 34); } \\
\text { PDT II, } 973 \text { (viii/Š } \\
\text { 42); PDT I, 162 } \\
\text { (25/viii/ŠS 45); } \\
\text { TRU 282 (6/ix/Š } \\
\text { 46); Toronto 592 } \\
\text { (20/viii/Š 46) } \\
\text { (unpubl.) }\end{array}$ \\
\hline VIII/IX & $\mathrm{Ur}^{?}$ & $\begin{array}{l}\text { ga-ma- } \\
\text { ga-mu- } \\
\text { è/ga-ma- } \\
\text { am-mu- } \\
\text { ut-tum }\end{array}$ & $?$ & $\begin{array}{l}\text { SET } 43 \text { (28/ix/Š } \\
\text { 41) OIP } 115,80 \\
(28 / \text { viii/Š 42) }\end{array}$ \\
\hline IX & $\mathrm{Ur}$ & $\begin{array}{l}\text { ezem- } \\
\text { mah }\end{array}$ & Nanna & $\begin{array}{l}\text { MVN 3, } 178 \\
\left(5 / \mathrm{ix} / \mathrm{SL}_{40}\right) ; \mathrm{MVN} \\
18,64(6,10 / \mathrm{ix} / \check{S} \\
41) ; \mathrm{MVN} 18,73 \\
(13 / \mathrm{ix} / \mathrm{S} \text { 45) }\end{array}$ \\
\hline IX-XI & $\mathrm{Ur}$ & kaš-dé-a & $\begin{array}{l}\text { Nanaja, Nin-é-gal, } \\
\text { Allatum, Bēlat-Šuhnir, } \\
\text { Bēlat-Deraban }\end{array}$ & $\begin{array}{l}\text { MVN 18, } 53 \text { (ix/Š } \\
\text { 33); TRU } 272(\mathrm{ix} / \mathrm{S} \\
\text { 34); MVN 18, } 60 \\
(\mathrm{ix} / \mathrm{S} 36) ; \text { OIP } 115 \text {, } \\
65(11 / \mathrm{x} / \mathrm{S} 41) ; \\
\text { PDT I, 582 } \\
(18 / \mathrm{xi} / \mathrm{S} 45)\end{array}$ \\
\hline IX & Ur & $\begin{array}{l}\text { NE.NE- } \\
\text { gar }\end{array}$ & $\begin{array}{l}\text { Bēlat-Šuhnir, Bēlat- } \\
\text { Deraban }\end{array}$ & $\begin{array}{l}\text { MVN 18, } 53 \text { (ix/Š } \\
33)\end{array}$ \\
\hline XI/XII & Nippur & ér $\mathrm{siskur}_{2}$ & $\begin{array}{l}\text { Ninlil, Enlil, Allatum, } \\
\text { Ningagia und Allagula, } \\
\text { Nanna, Inanna, Ninurta } \\
\text { und Nuska }\end{array}$ & 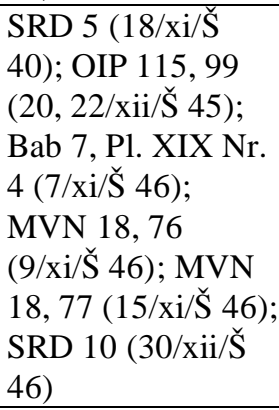 \\
\hline XI & Uruk & $\begin{array}{l}\text { ezem má- } \\
\text { an-na }\end{array}$ & Inanna, Nanaja & $\begin{array}{l}\text { MVN 18, } 52(- \\
\left./ \text { / }^{?} / \mathrm{S} 32\right) ; \mathrm{PDT} I, \\
459(-/ \mathrm{x} / \mathrm{S} 34) ; \\
\text { CST } 43(-/ \mathrm{xi} / \mathrm{S} 35) ; \\
\text { OIP } 115,30(-/ \mathrm{x} / \mathrm{S} \\
\text { 36); OIP } 115,62\end{array}$ \\
\hline
\end{tabular}


Königinnen

\begin{tabular}{|c|c|c|c|c|}
\hline Monat & Ort & $\begin{array}{l}\text { Name des } \\
\text { Festes }\end{array}$ & geehrte Gottheit & Beleg \\
\hline & & & & $\begin{array}{l}\text { (25/x/Š 40); SRD } \\
12(25 / x i / S ̌ S 4)\end{array}$ \\
\hline XI & Uruk & $\begin{array}{l}\text { e-ge } \\
\mathrm{ZAR} / \\
\mathrm{e} \\
\mathrm{SU}_{7} \cdot \mathrm{SU}_{7}\end{array}$ & Inanna & $\begin{array}{l}\text { MVN 3, } 145(\mathrm{xi} / \mathrm{S} \\
\text { 35); MVN 18, } 87 \\
\text { (7/xi/ŠS 47) }\end{array}$ \\
\hline
\end{tabular}

Tabelle 7: Übersicht über die jährlichen Feste und Riten bei Šulgi-simtī

\subsection{Nicht-kultische Ausgaben im Archiv der Šulgi-simtī}

Neben den umfangreichen Ausgaben für kultische Belange werden aus dem Bestand der Königin auch Tiere für profane Zwecke abgebucht. Hier sind verschiedene Gruppen von Empfängern zu unterscheiden: Als erstes ist die Königin selber zu nennen, für deren Tafel Tiere bestimmt sind. Mehrfach sind Empfänge der Königin für verschiedene Personen zu beobachten. Daneben werden häufig Tiere an den Palast geliefert oder direkt für den König ausgegeben. Auch andere, der Königin verbundene Personen erhielten mitunter Vieh aus ihrem Bestand. Als letzte Gruppe von Empfängerinnen und Empfängern ist das Personal der Textilindustrie zu nennen.

\subsubsection{Die Tafel der Königin ${ }^{335}$}

Für die Tafel der Königin sind erstmals im Jahr Š $35^{336}$, regelmäßig dann ab dem Jahr $\breve{S} 38^{337}$ Ausgaben verzeichnet. Das übliche Formular lautet ní $\hat{\mathrm{g}}-\mathrm{g} \mathrm{u}_{7}$ nin-ĝá-šè, ,für die Mahlzeit meiner Herrin“. Hier fällt auf, daß in diesem Zusammenhang nur äußerst selten Schafe oder Ziegen Verwendung finden, Rinder werden gar nicht für die Mahlzeiten der Königin ausgegeben. In der überwiegenden Zahl der Texte aus dieser Gruppe wird Geflügel (Enten und Tauben) bereitgestellt. Ab der Amtszeit von Apilatum (xi/Š 41) als verantwortlichem Beamten der Viehhaltung der Šulgi-simtī werden auch Schweine für die Tafel der Königin verbucht. Ob Šulgi-simtī erst ab dieser Zeit Schweinefleisch gegessen hat, oder ob diese Tiere vorher nicht in ihrer eigenen Administration geführt wurden, sondern in einem anderen Bereich der Verwaltung, ist derzeit nicht $\mathrm{zu}$ entscheiden. Es ist in jedem Fall bemerkenswert, daß mit dem Wechsel des leitenden Beamten hier auch ein Wechsel der verbuchten Tiere zu beobachten ist. Die Lieferungen für die

\footnotetext{
335 Siehe Anhang 2: Ausgaben für die Tafel der Königin Šulgi-simtī und für den Palast.

336 SET $41(\mathrm{ix} / \mathrm{S}$ 35).

337 OIP 115, 48 (viii/Š 38).
} 
Mahlzeiten der Königin sind meist nicht sehr umfangreich, mitunter wird nur eine Ente verbucht. Dies läßt darauf schließen, daß diese Ausgaben „für die Mahlzeit meiner Herrin“ wirklich für den privaten, alltäglichen Konsum der Königin bestimmt waren, mitunter vielleicht für einen kleineren Kreis, der sich für die Mahlzeit bei ihr einfand. Jedenfalls sind die Mengen der gelieferten Tiere zu gering, um hier die Aufwendungen für größere Gesellschaften und Festlichkeiten zu sehen.

Bei einer kleinen Gruppe von Texten findet sich als Verwendungszweck

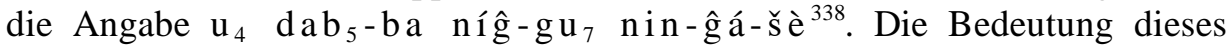
Ausdrucks ist noch nicht ganz klar, Sallaberger übersetzte mit „für 'das des/den gepackten Tag(es)' für die Mahlzeit meiner Herrin““339. Da die so bezeichneten Ausgaben stets am Ende des Monats, zumeist am 26. Tag, abgebucht werden, sprach er die Möglichkeit an, diese Ausgaben mit den Riten der Königin Ab̄̄simtī zum Neumondtag $\left(u_{4}-n u ́-a\right)^{340}$, für welche ebenfalls die Tiere um den 26. Tag des Monats ausgegeben werden, zu verbinden. ${ }^{341}$ Gegen eine solche Verbindung von $\mathrm{u}_{4} \mathrm{dab}_{5}$-ba ní $\hat{\mathrm{g}}-\mathrm{gu} \mathrm{u}_{7} \mathrm{nin}$ - $\mathrm{g}$ á-šè bei Šulgi-simtī mit den Ausgaben zum Neumondtag ihrer Nachfolgerin spricht jedoch, daß hier bei Šulgi-simtī durchweg Vögel, mitunter zusätzlich auch Schweine, ausgegeben werden. Da aber Schweine nie, Vögel nur in seltenen Ausnahmefällen ${ }^{342}$ als Opfergaben verwendet wurden und in den Texten dieser Gruppe keine Gottheiten erwähnt werden, ist hier von einem nichtkultischen Kontext auszugehen. $\mathrm{Da}$ diese Lieferungen nicht den üblichen Ausgaben für die Mahlzeiten der Königin entsprechen, zeigt der Text OIP 115, 56 (26/xi/Š 39),

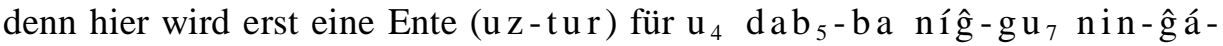

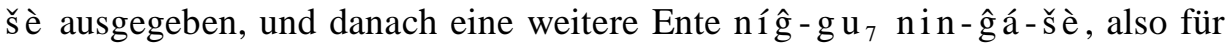
eine gewöhnliche Mahlzeit der Königin. Die Frage nach der genauen Bedeutung von $\mathrm{u}_{4} \mathrm{dab}_{5}$ - $\mathrm{b}$ a muß vorerst offen bleiben. In anderem Kontext als dem Šulgi-simtī-Archiv ist mir der Ausdruck $u_{4} d_{a b} b_{5}$ - b a bisher für diese Zeit nicht bekannt, was eine genauere Definition dieser Buchungen schwierig macht. ${ }^{343}$ Aus den Einlieferungstexten des Šulgi-simtī-Archives ist zwar bei diesen Buchungen eine Präferenz für das Ende des Monats zu beobachten, für

338 OIP 115, 51 (i/ŠS 39); OIP 115, 56 (26/xi/Š 39); SAT II, 226 (27/xii/Š 39); OIP 115, 58 (27/iii/Š 40); TCNY 162 (26/viii/Š 41); SET, 46 (26/xii" ${ }^{\text {II }}$ S 41); OIP 115, 83 (26/iii/Š 43); MVN 18, 74 (30/ix/Š 45); OIP 115, 106 (28/x/Š 46).

339 Sallaberger, Der kultische Kalender (1993), S. 25.

$340 \mathrm{Zu}$ den Riten der Abī-simtī am Schwarzmond-/Neumondtag siehe unten S. 120-126.

341 Sallaberger, Der kultische Kalender (1993), S. 25.

342 Siehe S. 89, Ente für s i s k u $\mathrm{r}_{2}$-Riten beim Vogelhaus.

343 Die Formulierung findet sich noch in dem Text Yang, Adab A 1034 aus der Akkadezeit. Yang übersetzt níg $\mathrm{u}_{4}-\mathrm{d} a b-{ }_{5}-\mathrm{b} a-$ š $\mathrm{S}$ S. 251 mit "to seize the day". 
eine Deutung des Ausdrucks $\mathrm{u}_{4} \mathrm{dab}_{5}$ - $\mathrm{ba}$ hilft dies derzeit jedoch nicht weiter.

\subsubsection{Tiere für den Palast ${ }^{344}$}

Vom Beginn ihrer Amtszeit an ließ Šulgi-simtī regelmäßig Tiere aus ihren Beständen an den Palast liefern. Hierbei findet sich in den Texten die Formel (Menge und Art der Tiere) é-gal-la ba-an-ku ${ }_{4}$ (in den Palast gebracht), die teilweise ergänzt wird durch die genauere Beschreibung der Tiere als

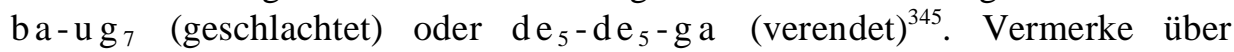
Beamten in ĝ $\mathrm{ri}_{3}$ - oder maški m-Funktion kommen so gut wie nicht vor. $\mathrm{Da} ß$ mit „Palast“ hier nicht die Verwendung für den persönlichen Bedarf der Königin gemeint ist, zeigen ganz deutlich die Texte, auf denen Tiere sowohl für die Tafel der Königin (níg - $\mathrm{gu}_{7}$ nin-ĝá-šè) als auch für den Palast (é gal) verbucht werden ${ }^{346}$. Aufgrund der Parallelität dieser beiden Empfänger ist davon auszugehen, daß die an den Palast gelieferten Tiere dort ebenfalls für die Mahlzeiten bestimmt waren. Wer genau letztendlich Konsument dieser Tiere war, ist nicht zu sagen, denkbar wären hier in erster Linie Hofdamen der Königin, sowie andere Angehörige ihres Hofes, aber auch der König und Personen aus seiner Umgebung. Allerdings werden Gaben an den König persönlich auch als solche gekennzeichnet (s.u.), und da Šulgi-simtī über eine eigene Verwaltung ihrer Viehbestände verfügte, liegt es nahe, als Empfänger der in den Palast verbrachten Tiere Angehörige ihres Haushaltes anzunehmen. Es werden meist Kleinvieh und ab Š 38 Geflügel, seit $\breve{S} 41$ Schweine und erst ab dem Endes des Jahres $\breve{S} 45$ Rinder in den Palast gebracht. Hierbei ist die Menge der Tiere eher gering, selten werden mehr als sechs Tiere einer Art pro Anlaß abgebucht. Erst ab dem Ende des Jahres Š 46 werden Tiere in größerem Umfang an den Palast geliefert, so sind in CST 139 (x/Š 46) insgesamt ein Rind und 64[+x] Stück Kleinvieh als für den Palast bestimmt aufgeführt, MVN 18, 78 (xii/Š 46) verbucht die Lieferung von 81 verendeten Schafen und Ziegen und OIP 115, $122(15 / \mathrm{vi} / \mathrm{S}$ 47) verzeichnet die Ausgabe von 31 geschlachteten Schafen und Zicklein. Größere Aufwendungen wie die in CST 165 (16/ii/Š 47) verbuchte Ausgabe von zwei Rindern, 23 Stück Kleinvieh sowie einer Gazelle $^{347}$ deuten auf ein größeres Festmahl hin. Ein Anlaß für dieses Festmahl

344 Siehe Anhang 2: Ausgaben für die Tafel der Königin Šulgi-simtī und für den Palast.

$345 \mathrm{Zu}$ diesen beiden Termini im Archiv der Šulgi-simtī siehe Sallaberger, Keilschrifttexte einer Privatsammlung, AfO 40/41 (1993/94), S. 53.

346 Zum Beispiel SET 45 (5/xii/Š 41); CST 484 (20/xi/Š 45); TRU 280 (22/vi/Š 46); TCND 404 (7/iv/Š 47); OIP 115, 123 (22/vii/Š 47).

347 Dies ist der einzige Beleg aus dem Šulgi-simtī-Archiv, in dem eine Gazelle ausgegeben wird. Wildtiere kommen sonst in diesem Archivzusammenhang nicht vor. 
könnte das im zweiten Monat in Nippur begangene Fest $\mathrm{gu}_{4}-\mathrm{si}-\mathrm{su}$, das Hauptfest des Gottes Ninurta ${ }^{348}$, gewesen sein.

\subsubsection{Tiere für den König}

In mehreren Texten aus dem Archiv der Šulgi-simtī werden Tiere für den König verbucht. Als Zweckbestimmung ist dabei entweder die Tafel des Königs (ni $\hat{g}-g u_{7} l u g$ al-šè) angegeben ${ }^{349}$, oder die Tiere werden dem König als Begrüßungsgeschenk entgegengebracht (lugal-ra gaba ri-a), wenn er sich an einem anderen Ort aufhält oder aus diesem zurückkommt ${ }^{350}$. Des weiteren werden Tiere als regelmäßige Lieferungen ( $\left.s a ́-d u_{11}\right)$ an den König gegeben ${ }^{351}$. Ein einzelner Text verbucht die Ausgabe von einem toten Lamm zugunsten der Wachen des Königs (mu aga $a_{3}$-ús lugal-ka-šè) $)^{352}$. Dies zeigt, daß der Haushalt des Königspaares zur Zeit von Šulgi-simtī zwar getrennt verwaltet wurde, daß es aber immer auch einen Austausch des Viehs zwischen den einzelnen Haushalten gab. Daß dieser Austausch in beide Richtungen vonstatten ging, zeigen Texte wie MVN 18, 2 (ix/Š 36), wo der König als Lieferant von Tieren für Šulgi-simtī (mu-DU Šulgi-simtī) auftritt, oder OIP 115, 371 (17/vi/Š 44), wo Šulgi-simtī aus der königlichen Viehhaltung zwei Mastschafe erhielt. Da aus dem Bestand der Königin stets nur einzelne Tiere an den König gesandt wurden, man also keinesfalls von einer Versorgung der königlichen Tafel durch die Königin sprechen kann, ist nach der Bedeutung dieser Gaben zu fragen. Einige der Lieferungen an den König können ohne Schwierigkeiten mit kultischen Verpflichtungen des Königs in Verbindung gebracht werden. So ließ die Königin Tiere nach Karzida/Ga'eš bringen als sich der König dort anläßlich der Feiern zum Akiti-Fest aufhielt,

\footnotetext{
348 Zu diesem Fest siehe Sallaberger, Der kultische Kalender (1993), S. 114-122.

349 MVN 3, 179 (5/ix/Š 40); OIP 115, 79 (9/vii/Š 42); PDT I, 582 (17/xi/Š 45); OIP 115 , 117 (20/v/Š 47); Rochester 22 (10/i/Š 48); PDT I, 339 (10/ii/Š 48).

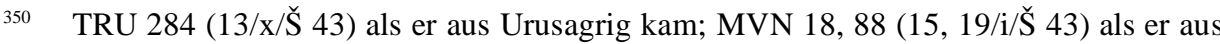
Uruk $^{?} \mathrm{kam}$; MVN 18, $70\left(16,17 / \mathrm{ii} / \mathrm{S}\right.$ 43) in Kisurra; OIP 115, $82\left(26,29 / \mathrm{i} / \check{S}_{4} 43\right)$ in É-g a-ba; TCNY 48 (vi/Š 46) zum Aufenthaltsort des Königs nach Karzida; (ki lugal-šè Kar-zi -d a ${ }^{k i}$ - šè ) MVN 18, 84 (22/vi/Š 47) als er aus Karzida kam; BIN V, $124\left(25 / \mathrm{i} / \breve{S}_{42}\right.$ 42) vom Ort der Ernte/des Erntefestes? (ki še-kin-kin-da). Zu š e-ki n-ki n „,ernten“ siehe Salonen, Agricultura (1968), S. 329, Oppenheim, Eames TT 11; im ersten Monat des Jahres wurde in Umma das Erntefest e ze m š e-KIN $\mathrm{ku}_{5}$ gefeiert (Sallaberger, Der kultische Kalender (1993), S. 231-234). Da der Text aus Umma stammt (Sigrist, Catalogue of the Babylonian Collections at Yale Bd. 3, NBC 1616), gehört er wohl in den Kontext dieses Festes.

351 OIP 115, 139 (12/vi/Š 42); DCEPHE 299 (20/ix/Š 47).

352 Toronto $14(\mathrm{xi} / \mathrm{S}$ 38).
} 
bzw. als er nach Ur zurückkehrte ${ }^{353}$. Im Rahmen des ér-sù-a-Festes für Nanna erhielt der König im Jahr Š 40 zwei Lämmer für seine Tafel (MVN 3, 178), und auch die anderen Lieferungen für die königlichen Mahlzeiten sind mit Ausgaben für den Kult verbunden ${ }^{354}$. Dies legt die Vermutung nahe, daß diese Tiere, die für den Tisch des Königs bestimmt sind, alle als Geschenke der Königin zu besonderen Anlässen zu sehen sind, seien es kultische Ereignisse oder aber die Begrüßung des Königs in bestimmten Orten, wenn er von Reisen oder vielleicht auch Kriegszügen zurückkehrte. Möglicherweise handelte es sich hier um einen ritualisierten Austausch von Geschenken, der die Anteilnahme der Königin an der Lebenswelt und den Aufgaben des Königs sowie ihre Sorge für den Ehemann symbolisiert haben könnte.

\subsubsection{Bierausschenken für Angehörige des Hofes}

Neben der Königin selbst als Empfängerin von Tieren für den Eigenbedarf werden mehrfach Güter für ein Bierausschenken (k a š-dé-a) ausgegeben, das Šulgi-simtī für verschiedene Personen veranstaltete ${ }^{355}$. Bei den so Geehrten handelt es sich um Angehörige des Königshauses wie den König selber, seine Nebenfrau Ea-niša ${ }^{356}$, die Prinzessin Taddin-Eštar ${ }^{357}$ und die Tochter des AbaEnlilgin. Letzterer ist wie seine Tochter als Lieferant von Vieh an die Königin bezeugt ${ }^{358}$. Ein Beamter namens Aba-Enlilgin hatte in den späten Jahres des Viehhofes von Puzriš-Dagān dort eine hohe Position in der Verwaltung inne ${ }^{359}$. In dieser Funktion hatte er auch immer wieder mit den Damen des Hofes Kontakt, sein Name begegnet wiederholt bei Transaktionen von Vieh für die königlichen Frauen ${ }^{360}$. Ob es sich bei diesem Aba-Enlilgin der Zeit von Šu-

353 TCNY 48 (vi/Š 46); MVN 18, 84 (22/vi/Š 47).

354 Ausnahme ist OIP 115, $117(20 / \mathrm{v} / \mathrm{S}$ 47).

355 OIP 115, 56 (10/xii/Š 39); AnOr 1, 2 (22/i/Š 40); OIP 115, 58 (15/iii/Š 40); MVN 18, 68 (4/ii/Š́ 41); TRU 284 (13/x/Š 42); TCNY 79 (21/ii/Š 43). Zu kaš - dé - a bei Šulgisimtī vgl Sigrist, Drehem (1992), S. 178.

356 Zu Ea-niša siehe unten S. 206-211.

357 Vgl. die Liste der Königskinder bei Sigrist, Drehem (1992), S.361 Anm. 41.

358 TCNY 253 (vii/Š 39) 1 Rind, 6 Schafe, 4 Ziegen von Aba-Enlilgin, sowie BIN III, 347 (i/Š 36) 2 Lämmer von der Tochter des Aba-Enlilgin, mu - D U-Lieferung für Šulgisimtī.

359 Sigrist, Drehem (1992), S. 312-313; Maeda, Bringing (mu-túm) of livestock and the Puzriš-Dagan organization for cattle management in the Ur III dynasty, ASJ 11 (1989), S. 88.

360 So in PDT I, 610 (4/vii/ŠS 7), wo ein Opfertier der Ab̄̄-simt̄̄ bei Aba-Enlilgin abgebucht wird oder in BCT I, 114 (13/vii/IS 2), wo er als Überbringer ( $\hat{\mathrm{g}}$ ir i $\mathrm{i}_{3}$ ) von Opfergaben für Nanaja zugunsten der Königin Geme-Enlila fungiert. 
Suen und Ibbi-Suen um die gleiche Person handelt, wie in den Texten aus dem Archiv der Šulgi-simtī, ist nicht sicher. Denkbar wäre es jedoch, wenn man davon ausgeht, daß er in dieser Zeit noch sehr jung war und am Beginn seiner Karriere stand. Auch seine Tochter kann dann kaum älter als etwa 15 Jahre gewesen sein, als Šulgi-simtī das Bierausschenken für sie veranstaltete. Geht man von diesem geschätzten Alter aus und nimmt an, daß ihr Vater zu diesem Zeitpunkt etwa 35 Jahre zählte, dann wäre Aba-Enlilgin im Jahr IS 2 etwas älter als 60 Jahre. Es ist also durchaus möglich, daß es sich hier um nur eine Person dieses Namens handelte. Möglicherweise liegt dann auch hier ein Fall vor, in dem ein enger Kontakt eines Beamten und seiner Familie zur Königin sich fördernd auf die Laufbahn des Betreffenden auswirkte ${ }^{361}$.

Der konkrete Anlaß für ein Bierausschenken wird nur in einem Fall genannt: Im Jahr Š 42 veranstaltete Šulgi-simtī einen solchen Ritus für den König, als er aus Urusagrig kam $^{362}$, wofür 2 Schafe bereitgestellt wurden. Da der Umfang der gelieferten Tiere mitunter relativ gering ist, zwischen zwei (OIP 115, 56) und zwölf Stück Geflügel und ein Ferkel (TCNY 79) oder maximal drei Stück Kleinvieh (MVN 18, 68), scheint es sich beim Bierausschenken der Königin für die von ihr bewirteten Personen nicht immer um große Bankette gehandelt zu haben.

\begin{tabular}{|l|l|l|l|}
\hline Publikation & Datum & geehrte Person & verbuchte Tiere \\
\hline $\begin{array}{l}\text { OIP } 115, \\
56\end{array}$ & $10 /$ xii/Š 39 & Taddin-Eštar & 2 Enten \\
\hline AnOr 1,2 & $22 /$ i/Š 40 & König & 1 Ente, 5 Tauben \\
\hline $\begin{array}{l}\text { OIP } 115, \\
58\end{array}$ & $15 /$ iii/ŠS 40 & Ea-niša & 1 Ente, 5 Tauben \\
\hline $\begin{array}{l}\text { MVN 18, } \\
68\end{array}$ & $4 /$ ii/ŠS 41 & dumu-munus Aba-Enlilgin & 2 Schafe, 1 Ziege \\
\hline TRU 284 & $13 /$ x/Š 42 & König & 2 Schafe \\
\hline TCNY 79 & $21 /$ ii/Š 43 & Taddin-Eštar & 1 Ferkel, 1 Ente, 11 Tauben \\
\hline
\end{tabular}

Tabelle 8: Bierausschenken der Šulgi-simtī für Angehörige des Hofes

Da alle Personen, für die Šulgi-simtī ein solches Fest veranstaltete, direkt mit dem Königshaus verbunden waren, es sich noch dazu außer beim König nur

\footnotetext{
361 Vgl. S. 45.

362 TRU 284 (13/x/Š 42). Zu Urusagrig, in der Nähe von Nippur und Adab gelegen, siehe Edzard, Farber, Die Orts- und Gewässernamen der Zeit der 3. Dynastie von Ur, RGTC II (1974), S. 232-234; Sallaberger, OBO 160/3 (1999), S. 126.
} 
um Frauen handelt, die so geehrt werden, liegt es nahe, als Anlaß für diese Feste jeweils einen Grund in der unmittelbaren Lebenssituation der einzelnen Frauen zu suchen. Denkbar wären hier Feste zur Geburt eines Kindes oder im Rahmen der Vorbereitung einer Hochzeit. Wie schon wiederholt gezeigt werden konnte, nahm sich die Königin den weiblichen Angehörigen des Hofes und der führenden Familien des Reiches besonders an. Die von ihr veranstalteten Riten des Bierausschenkens für Personen ihrer Umgebung gehören somit in den Kontext der Pflege sozialer Beziehungen innerhalb der weiblichen Lebenswelt des Hofes.

\subsubsection{Proviant (igi-kár) und andere Ausgaben an verschiedene Personen}

Dieser Austausch von Gaben, wie er eben zwischen der Königin und dem König sowie anderen ihr eng verbundenen Menschen beschrieben wurde, ist auch auf der Ebene des weiteren Umfeldes von Šulgi-simtī zu beobachten. Während ihrer gesamten Amtszeit gab sie zu bestimmten, nicht näher konkretisierten Anlässen Tiere als „Proviant“ (igi-kár) ${ }^{363}$ an Personen ihrer Umgebung aus.

Wieder läßt sich beobachten, daß die Mehrzahl der so mit „Proviant“ von der Königin versorgten Personen Frauen sind. Bis auf Ušaja, SI.A-tum und Eanuhši sind alle, die solche Gaben von Šulgi-simtī erhielten, auch als Geber im Rahmen der mu-DU-Lieferungen bekannt. Viele sind Mitglieder der königlichen Familie, so SI.A-tum, die Mutter des Königs, Šulgis Nebenfrau Ninkalla ${ }^{364}$, die Königskinder Ur-niĝar, Teșīn-Mama und möglicherweise Ninliltum-imdi ${ }^{365}$, sowie die Frau des Prinzen S̆arrum-ilīi ${ }^{366}$. Darüber hinaus war Šarrum-ilī spätestens seit Š 48 Ensi von Uruk, Ur-niĝar ist für das Jahr Š 42 als Šagina in Uruk bezeugt ${ }^{367}$, der Stadt, deren Göttin die besondere Verehrung der Königin genoß. Mit der Frau des Sukkalmaḩ sowie Șilluš-Dagān ${ }^{368}$ und seinem Sohn sind weitere Angehörige der obersten Gesellschaftsschicht des Reiches als Empfänger von „Proviant“ zu nennen. Die Vermutung liegt nahe, daß es sich bei dieser Gabe von „Proviant, Verpflegung“ durch die Königin um

363 Zu ig i-kár „Proviant“" siehe Steinkeller, On the Reading and Meaning of igi-kár and gúrum (IGI.GAR), ASJ 4 (1982), S. 149-151 und Moran, A Note on igi-kár "provisions, supplies“, ASJ 5 (1983), S. 175-177.

364 Zu Ninkalla siehe S. 211-226.

365 Vgl. S. 43.

366 Zu Šarrum-ilī und Ur-niĝar siehe Michalowski, Dūrum and Uruk during the Ur III Period, Mesopotamia 12 (1977), S. 83-96.

367 Ebd. S. 88-89.

368 Șilluš-Dagān war Ensi von Simurrum, siehe Sallaberger OBO 160/3 (1999), S. 158 Anm. 120. 
Geschenke handelte, die zu besonderen Anlässen vergeben wurden, vielleicht als Zeichen besonderer Gunst, als Dank für bestimmte Dienste oder aus Anlaß spezifischer, persönlicher Ereignissen im Leben der Empfänger:

\begin{tabular}{|c|c|c|c|}
\hline Publikation & Datum & Empfänger & Gabe \\
\hline CST 43 & $\mathrm{xi} / \mathrm{S} \mathrm{S} 35$ & dam sukkalmah ${ }^{369}$ & 1 Rind, 5 Schafe \\
\hline SET 42 & $\mathrm{v} / \mathrm{S} 37$ & Simat-Ea & $\begin{array}{l}1 \text { Rind, } 9 \text { Schafe, } \\
1 \text { Ziege }\end{array}$ \\
\hline OIP 115,55 & 5/v/ŠS 39 & Șilluš-Dagān & 1 Ente \\
\hline OIP 115,60 & $13 / \mathrm{vi} / \mathrm{S} 40$ & Ninkalla & 1 Ente, 5 Tauben \\
\hline Rochester 11 & 30/vii/ŠS 40 & Ušaja & 2 Tauben \\
\hline TCNY 162 & 30/viii/Š 41 & Ur-niĝar & 6 Tauben \\
\hline ŠA XXXIII:1 & 27/xii/Š 42 & SI.A-tum & 2 Schafe \\
\hline CST 484 & 20/xi/ŠS 45 & Ea-nuhšsi & $\begin{array}{l}1 \text { Schaf, } 1 \text { Ziege, } \\
1 \text { Ferkel }\end{array}$ \\
\hline MVN 13, 679 & 2+/viiii/Š 46 & Ninliltum-imdi & $\begin{array}{l}1 \text { Lamm, } 1 \text { Ferkel, } \\
1 \text { Ente }\end{array}$ \\
\hline TCNY 168 & 20/xi/ŠS 46 & dumu Șilluš-Dagān & 5 Ziegen \\
\hline OIP 115,116 & 30/iv/Š 47 & Simat-Eštar & 1 Ferkel \\
\hline OIP 115,117 & 20/v/Š 47 & $\begin{array}{l}\text { Teșīn-Mama } \\
\text { dam Šarrum-ilī }\end{array}$ & $\begin{array}{l}1 \text { Ferkel, } 1 \text { Ente } \\
1 \text { Ferkel }\end{array}$ \\
\hline
\end{tabular}

Tabelle 9: Ausgabe von ig i-k ar durch Šulgi-simtī

In anderen Texten aus dem Archiv der Šulgi-simtī werden vergleichbare Ausgaben von Vieh, zumeist Schafen und Ziegen, an Personen aus der Umgebung der Königin verbucht, wobei wiederum viele der Empfänger und Empfängerinnen als Lieferanten an die Königin bekannt $\operatorname{sind}^{370}$. Zweimal sind als Begünstigte solcher Lieferungen auch die Priester der Bēlat-Šuhnir und Bēlat-Deraban, der persönlichen Göttinnen der Königin, genannt ${ }^{371}$. Es fällt auf, daß sich unter den Empfängern der Gaben, die nicht näher als „Proviant“

369 Der Sukkalmah war der Inhaber des höchsten politischen Amtes nach dem König. Siehe dazu Sallaberger, OBO 160/3 (1999), S. 188-190.

370 Zum Beispiel PDT II, 1017 (v/Š 33) Teșin-Mama; TCND 182 (9/v/Š 40) die Frauen von Etel-pū-Dagān und Banilum; Toronto 17 (8/v/Š 41) die Frau des Nuida; BIN III, 358 (23/xi/Š 42) Simat-Eštar.

371 OIP 115, 49 (xii/Š 38) und MVN 13, 715 (15/viii/Š 45). 
(igi-kár) gekennzeichnet sind, weniger Angehörige der höchsten Verwaltungsebene befinden als unter den Empfängern von „Proviant“, doch ansonsten ähneln sich diese Geschenke der Königin sehr. Auch bei der Frage nach der Art der Gaben gibt es nur den Unterschied, daß die nicht als „Proviant“ bezeichneten Lieferungen kein Geflügel vebuchen und Schweine nur selten genannt sind. Der Umfang der Geschenke scheint nicht standardisiert, sondern dem jeweiligen Anlaß angepaßt worden zu sein.

\begin{tabular}{|c|c|c|c|}
\hline Publikation & Datum & Empfänger & Gabe \\
\hline TLB III, 92 & $\mathrm{v} / \mathrm{S} 30$ & Minari & 5 Schafe \\
\hline TCND 176 & ix/Š 33 & Bēlī-bani & 1 Schaf \\
\hline OIP 115,27 & iv/Š 34 & Buza & 2 Schafe \\
\hline PDT II, 1148 & $\mathrm{v} / \mathrm{S} 34$ & Buza & 1 Ziege \\
\hline SAT II, 107 & vi/ŠS 34 & dam Gutarla & 1 Ziege \\
\hline PDT I, 80 & $6 / \mathrm{i} / \mathrm{S} 40$ & Innuri & 2 Schafe \\
\hline OIP 115,84 & vii/Š 43 & $\begin{array}{l}\text { Bēlī-simtī } \\
\text { Huaba }\end{array}$ & $\begin{array}{l}1 \text { Schaf } \\
1 \text { Lamm }\end{array}$ \\
\hline
\end{tabular}

Tabelle 10: Ausgabe von nicht näher bezeichneten Gaben durch Šulgi-simtī

Der Austausch von Schmuck unter den Damen des Hofes und den hochgestellten Beamten ihrer Umgebung ist für Šulgi-simtī kaum belegt, was aber wohl auf den Zufall der Überlieferung zurückzuführen ist. Erst für Abī-simtī sind Geschenke von Luxusgegenständen sicher nachzuweisen ${ }^{372}$. Doch könnte der Text MVN 15, $208^{373}$ in die Zeit Šulgis gehören. Hier wird die Ausgabe von einem Paar Silberringen mit dem standardisierten Gewicht von $1 / 3$ Schekel $^{374}$ von der Königin in Nippur nach Uruk an $\mathrm{Ni}_{9^{-}}<\mathrm{g} a r>-\mathrm{ki}^{-} \mathrm{du}_{10}$ verbucht. Der Personenname $\mathrm{Ni}_{9^{-}}<$gar $>-\mathrm{ki}-\mathrm{du}_{10}$ ist mehrfach in Texten der Zeit Šulgis belegt, im Kontext mit Šulgi-simtī begegnet er einmal als Lieferant von unterschiedlichen Lebensmitteln (u.a. Kleinvieh, Fische, Geflügel, Vogeleier und Knoblauch) ${ }^{375}$. Es ist also gut möglich, daß es sich bei der in MVN 15, 208 erwähnten Königin um Šulgi-simtī handelt.

372 Siehe unten S. 116.

373 Herkunft und Datierung des Textes ist nicht sicher. Die Datenformel lautet „mu 2 k a m- ú s “, und könnte auf die Jahre Š 26, Š 36 (in Umma) oder Š 48 verweisen.

374 Silberringe mit standardisiertem Gewicht wurden auch als Zahlungsmittel verwendet. Siehe dazu Powell, A Contribution to the History of Money in Mesopotamia prior to the Invention of Coinage, FS Matouš II (1978), S. 211-222.

375 TENS 324 ( $\check{S} 40$ ). 
Diese Gaben der Königin an Personen ihrer Umgebung haben ihre Entsprechung in den Geschenken des Königs an diverse Personen des Hofes, der Verwaltung, des Militärs und anderer Gruppen, die im Zusammenhang eines Systems des Austausches von Gütern und Dienstleistungen zwischen dem König und seiner Umgebung verteilt wurden, womit der König Dienste belohnte und sich der Loyalität der Empfänger des Viehs versicherte. ${ }^{376}$ Ein entsprechendes System des Austausches von Geschenken und Dienstleistungen ist nun auch für den Haushalt der Königin zu beobachten.

\subsection{Textilproduktion für Šulgi-simtī}

Die Textilproduktion war in der Ur III-Zeit ein bedeutender Wirtschaftszweig, in dem mehrere tausend Menschen beschäftigt waren. ${ }^{377}$ Eine kleine Gruppe von Texten aus dem Archiv der Šulgi-simtī gibt einen Einblick in den Teil der Textilproduktion, welcher direkt mit der Königin verbunden war.

Der Kontakt der Königin zu den führenden Beamten der Textilindustrie zeigt sich schon früh in ihrer Amtszeit. So erhielt Šulgi-simtī im Jahr Š 35 mehrere Ziegen als mu-DU-Lieferung von der Schwester des Adalal, des Aufsehers der Weberinnen (nin ${ }_{9}$ A-da-làl ugula uš-bar) ${ }^{378}$. Aus der Amtszeit ihres Beamten Apilia ist mehrfach die Ausgabe von Vieh für Arbeiter in der Textilindustrie, für die Weberinnen ( $\mathrm{geme}_{2} \mathrm{uš}-\mathrm{b}$ ar-e-ne) und die Walker $^{379}$ (lú - a zla g $\left.{ }_{2}\right)$ belegt ${ }^{380}$. Dabei werden die Handwerker nie explizit als die der Königin bezeichnet, die Verbindung zu Šulgi-simtī besteht über Apilia, der als ausgebender Beamter (zi-g a) bei diesen Transaktionen fungierte. Auch fällt auf, daß vergleichbare Ausgaben von Vieh für Beschäftigte in der Textilherstellung bei keinem der anderen Beamten Šulgi-simtīs zu finden sind. Somit stellt sich die Frage, ob diese Weberinnen und Walker exklusiv für die Königin gearbeitet haben und damit als ihr Personal zu betrachten sind, oder ob es sich um Handwerker handelte, welche Aufträge aus dem gesamten Königshaus oder, noch weiter gefaßt, aus der ganzen Oberschicht des Reiches annahmen. Noch kann nicht genau gesagt werden, wem die Leitung der großen Textilindustrie von Ur in letzter Instanz unterstand ${ }^{381}$, doch scheint die Königin

\footnotetext{
376 Vortrag Sallaberger auf der Rencontre in Leiden (2002).

377 Zur Organisation der Webereien in Ur siehe Waetzoldt, Textilindustrie (1972), S. 105108, wo er von einer Zahl von rund 12000 Weberinnen allein in Ur ausgeht.

378 Toronto 10 (vii/š 35).

379 In diesem Beruf waren in der Ur III-Zeit nur Männer beschäftigt. Siehe Waetzoldt, Textilindustrie (1972), S. 153-154.

380 CST 45 (iii/Š 39), CST 50 (22/ii/ŠS 40); OIP 115, 64 (ii/Š 41); OIP 115, 66 (x/Š 41).

381 Waetzoldt, Textilindustrie (1972), S. 107-108, vgl Neumann, Handwerk in Mesopo-
} 
eine eigene Manufaktur in der Stadt unterhalten zu haben.

Darauf weist der Text Orient 16, 174 (xii/Š 43) hin, eine Abrechnung über Wolle, Textilien und Chemikalien zur Textilherstellung, welcher die Unterschrift „Bilanz des Aufsehers der Weber und Walker, Haus der Šulgisimtī in Ur" (ní $\hat{\mathrm{g}}-\mathrm{ka}_{9}-\mathrm{ak}$ ugula uš-bar-ra ù lú-azlag ${ }_{2}$-e-ne é ${ }^{d} \breve{S} u l-$ gi-sí-im-ti šà $\mathrm{Uri}_{5}{ }^{\mathrm{ki}}-\mathrm{ma}$ ) trägt. Der verantwortliche Beamte ist in diesem Text Qudāšum, welcher einmal in g i $\mathrm{r}_{3}$-Funktion und einmal als Aufseher der Weber (ugula uš-bar) auftritt. In OIP 115, 64 (ii/Š 41) begegnet der Aufseher Qudāšum bei der Ausgabe von toten Schafen für die Walker in Ur, wobei dieser Text über Apilia, den ausgebenden Beamten, eindeutig dem Archiv der Šulgi-simtī zuzurechnen ist. Noch ein dritter Text bezeugt die Arbeit von Qudāšum für die Königin: in AAICAB I/2, Pl. 114 Ashm. 1937-635 (Datum abgebrochen) nahm er über $600 \mathrm{~kg}$ Wolle für Textilien unterschiedlicher Qualitäten an, wobei die Wolle als die der Šulgi-simtī bezeichnet wird. Auch Idi-Irra, der Sohn des Qudāšum, arbeitete in der Textilindustrie für die Königin, wie aus dem Text ASJ 17, S. 317 hervorgeht, wo er Wolle der Königin ${ }^{382}$ annahm. Der Text trägt das Siegel des Idi-Irra, auf welchem er sich als Schreiber und Sohn des Qudāšum bezeichnet. ${ }^{383}$ Idi-Irra ist noch in sieben weiteren Texten aus der Zeit Šulgis im Zusammenhang mit der Textilproduktion bekannt ${ }^{384}$. Kuga hatte die Texte aus Ur und Puzriš-Dagān, die einen Idi-Irra nennen, zusammengestellt ${ }^{385}$ und dabei auf die Schwierigkeit verwiesen, die sich bei der Zuordnung der Texte zu einer oder mehreren Personen des Namens Idi-Irra ergeben, so findet sich ein Idi-Irra in einem Textiltext aus Puzriš-Dagān aus dem Jahr Š 37 (PDT I, 497), doch das Siegel weist ihn als Sohn des Buzua, nicht des Qudāšum aus. ${ }^{386}$ Damit sind mindestens zwei Personen dieses Namens in der Regierungszeit Šulgis in der Textilindustrie tätig. Allerdings ist der Idi-Irra aus PDT I, 497 nicht mit einem

tamien (1993), S. 33-34.

382 Wolle für Textilien der Šulgi-simtī wird noch genannt in den Texten PDT I, 518 und Sammlung Maimon A 11 (unpubliziert, RT 37, 129), doch treten in diesen Texten andere Beamten als Qudāšum oder Idi-Irra auf.

383 Text und Siegel sind publiziert und diskutiert von Kuga, A Šulgi-simtum Tablet in the Atarashi Collection, ASJ 17 (1995), S. 309-318.

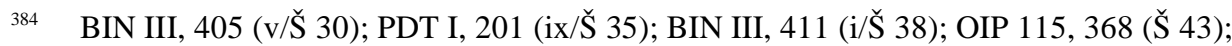
PDT I, 91 (i/Š 43); MVN 18, 155 (x/Š 45); OIP 115, 367 (v/Š 47).

385 Kuga, A Šulgi-simtum Tablet in the Atarashi Collection, ASJ 17 (1995), S. 312-313. Zu ergänzen sind jetzt die Drehemtexte OIP 115, 93; OIP 115, 367 (Š 47); OIP 115, 368 (Š 43); SAT II, 725 (AS 2); und SAT II, 845 (AS 5) sowie AUCT I, 967 (ŠS 7) ein Text über Textillieferungen, zu dem Sigrist keine Herkunftsangaben macht.

386 Kuga, A Šulgi-simtum Tablet in the Atarashi Collection, ASJ 17 (1995), S. 312-315. 
weiteren Titel versehen, wohingegen er in den oben zitierten Texten ab dem Jahr $\breve{S} 38^{387}$ stets mit der Berufsbezeichnung Walker (1 ú-azlag ${ }_{2}$ ) auftritt. Aufgrund dieser Schwierigkeiten ist nicht mit letzter Sicherheit zu sagen, daß es sich immer um denselben Idi-Irra handelt, doch ist die Wahrscheinlichkeit hoch, daß der Walker Idi-Irra der Sohn des Qudāšum war und daß beide in der Textilproduktion der Königin gearbeitet haben. Ein Idi-Irra ist mehrfach unter Šu-Suen und Ibbi-Suen in der Textilindustrie in Ur bezeugt ${ }^{388}$, wobei es sich möglicherweise um dieselbe Person handelt.

Bei der derzeitigen Datenlage geht es zu weit zu sagen, die Königin hätte die Textilproduktion in großem Umfang kontrolliert. Wenn sie die Oberaufsicht über alle großen Textilfabriken in Ur hatte, so ist das derzeit aus den Quellen nicht nachzuvollziehen. Doch ist davon auszugehen, daß sie eigene Textilarbeiter beschäftigte, die für ihren eigenen Bedarf und den ihres Haushaltes arbeiteten. Der Aufseher der Weberinnen, Qudāšum und sein Sohn, der Walker Idi-Irra, waren dabei in leitender Funktion tätig. Dazu paßt, daß ein Idi-Irra im Jahr $\breve{S} 43$ als mu-DU-Lieferant von Kleinvieh für Šulgi-simtī belegt ist ${ }^{389}$, was bestätigt, daß die Beamten, die in Kontakt mit der Königin standen, zumindest einmal auch als mu-DU-Lieferanten auftraten.

\section{Abī-simtī}

\subsection{Herkunft, Amtszeit, Familie}

Ab̄̄-simtī war die Frau Amar-Suens und die einzige Frau, die zu seiner Regierungszeit den Titil der Königin (nin) trug. In der Forschung war einige Zeit umstritten, ob Abī-simtī auch eine Frau Šulgis gewesen sein könnte ${ }^{390}$. Es wurde auch die Vermutung geäußert, sie sei erst die Frau Amar-Suens und

387 Siehe Anm. 385.

388 Kuga, A Šulgi-simtum Tablet in the Atarashi Collection, ASJ 17 (1995), S. 312.

389 RO 11, 96 Nr. 1 (30/xi/Š 43). Der Name ist hier I-din-İr-ra geschrieben, wie auch der Walker in OIP 115, 367 und 368, in den anderen Texten herrscht die Schreibweise Idì-İr-ra vor.

390 So hielt unter anderem Frame (A New Wife für Šu-Sîn (1984), S. 4) es für möglich, daß Abī-simtī Königin zur Zeit Šulgis gewesen sein könnte. Dagegen wollte Steinkeller (More on the Ur III Royal Wives ASJ 3 (1981), S. 79-80) dies nicht ganz ausschließen, hielt es aber eher für unwahrscheinlich, daß Abī-simtī eine der Frauen Šulgis gewesen sein. Zuletzt bezeichnete Vermaak Abī-simtī als Frau des Šulgi (Abīsimtī: A Semitic Matriarch in Sumer, JNSL 21/2 (1995), S. 108), und Dahl hielt es für möglich, daß sie die Frau des Amar-Suen oder des Šulgi war (The quest for eternity, FS Larsen (2004), S. 130). 
danach die des Šu-Suen gewesen ${ }^{391}$. Nach der Veröffentlichung des Siegels des Beamten Babati ${ }^{392}$ wurde deutlich, daß Abī-simtī die Frau des Amar-Suen und die Mutter des Šu-Suen war. Babati bezeichnet sich auf seinem Siegel als Bruder der Abī-simtī, seiner (Šu-Suens) geliebten Mutter (šeš $a$-bí-sí-im-ti | a ma kí - áĝ - ĝá-na). Heute kann als gesichert gelten, daß Abī-simtī die Frau des Amar-Suen war und Mutter seines Sohnes und Nachfolgers Šu-Suen ${ }^{393}$. Den Titel einer Königin ${ }^{394}$ trug sie während der gesamten Regierungszeit ihres Mannes und ihres Sohnes.

Die Herkunft der Abī-simtī ist nicht sicher nachzuweisen. Sallaberger vermutete für sie wie für Šulgi-simtī eine Herkunft aus der Gegend von Ešnunna, da ihr Bruder Babati mit dieser Stadt verbunden war ${ }^{395}$. Allerdings ist für Abī-simtī anders als für ihre Vorgängerin im Amt keine besondere Verehrung der Göttinnen Bēlat-Šuhnir und Bēlat-Deraban nachzuweisen. Vielmehr verehrte Abī-simtī neben der Göttin Inanna insbesondere die Götter Dagān und Išhara sowie Haburītum, also Götter, die alle aus dem nordsyrischen Raum stammten ${ }^{396}$. Es ist daher wahrscheinlich, daß Abī-simtī eher aus Syrien denn aus der Gegend von Ešnunna stammte. Zu diesem Schluß kommen auch Michalowski und Sharlach aufgrund ihrer Untersuchungen zu den familiären Verbindungen des Königshauses von Ur mit der königlichen Familie von Mari. ${ }^{397}$

Möglicherweise hat Šulgi, dessen erste Frau Tarām-Uram aus Mari kam, die Heiratspolitik seines Vaters fortgesetzt und für seinen Sohn Amar-Suen eine dynastische Allianz mit dem Herrscher eines der nordsyrischen

391 Jacobsen, The Reign of Ibi-Suen, JCS 7 (1953), S. 45.

392 Whiting, Tiš-atal of Niniveh and Babati, Uncle of Šu-Sin, JCS 28 (1976), S. 173-182; RIME 3/2.1.4.32.

393 Zur Genealogie der königlichen Familie von Ur und der Frage, ob Amar-Suen und Šu-Suen Brüder waren, was verneint werden kann, siehe Boese, Sallaberger, Apil-kīn von Mari, AoF 23 (1998), S. 36-38.

Die in letzter Zeit wieder geäußerte Vermutung, Šu-Suen sei doch ein Sohn von Šulgi gewesen, beziehen sich auf den Personennamen Šu-Suen-walid-Šulgi (Nesbit 66, Owen NABU 2001/17). Aufgrund des Datums dieses Textes (21/vii/Š́S 4) und des Kontextes (Einlieferung mu-DU lugal) halte ich es für ausgeschlossen, daß hier mit Šu-Suen-walid-Šulgi der regierende König mit seinem vollen Namen genannt ist. Zur Titulatur s.u. S. 235-237.

Sallaberger, OBO 160/3 (1999), S. 184.

Zum Kult und den von Abī-simtī verehrten Gottheiten Kap. 4.4. Zu den syrischen Gottheiten siehe S. 132-135.

Michalowski, The Ideological Foundation of the Ur III State (2004), S. 232; ders. Iddin-Dagan and his Family (2005), S. 66; Sharlach, Beyond Chronology: The Šakkanakkus of Mari and the Kings of Ur (2001), S. 67-68. 
Fürstentümer geschlossen. Dafür spräche auch, daß weder unter Šulgi noch unter Amar-Suen kriegerische Auseinandersetzungen mit Herrschern aus Gebieten im Nordwesten belegt sind ${ }^{398}$. Offenbar war diese Grenze des Reiches von Ur anderweitig, nämlich durch dynastische Beziehungen, abgesichert.

Aus der Regierungszeit Šulgis ist kein Beleg zu Abī-simtī bekannt, sie tritt erst nach seinem Tod in unseren Quellen in Erscheinung. Erstmals namentlich belegt ist sie in einem Text vom 1/i/AS $1^{399}$, zu diesem Zeitpunkt war Šulgisimtī noch am Leben, für die erst am 22/iii/AS 1 (ZVO 25, 134, 2) Totenopfer belegt sind. Dieser Befund könnte mit dem Überlieferungszufall erklärt werden, doch dies ist angesichts der reichen Quellenlage in den späten Jahren der Regierungszeit Šulgis eher unwahrscheinlich. Man könnte auch annehmen, Abī-simtī habe sich bis zum Regierungsantritt ihres Mannes nicht am Hof aufgehalten, was ein Fehlen in den Quellen, gerade aus Puzriš-Dagān, leichter erklärbar macht. Auch Amar-Suen ist vor seinem Regierungsantritt nicht in den Quellen nachweisbar, was zu der Vermutung geführt hat, er habe diesen Namen erst mit der Thronbesteigung angenommen. ${ }^{400}$ Deshalb ist zu vermuten, daß es sich auch bei Abī-simtī um einen Namen handelt, den sie mit dem Amtsantritt als Königin angenommen hat.

Abī-simtī starb wenige Wochen nach ihrem Sohn Šu-Suen. Totenopfer für sie an ihrem „Wassertränkort“ (ki-a-na ĝ) sind belegt am 17/xii/ŠS $9^{401}$. Dieser Totenopferplatz befand sich wahrscheinlich im Tempel der Unterweltsgottheit Ninazu in $\mathrm{Ur}^{402}$.

Lafont hatte vermutet, Abī-simtī sei schon kurz nach ihrem Mann AmarSuen verstorben. ${ }^{403}$ Diese Annahme stützte sich auf ein Gruppe von fünf Texten, in denen Arbeiter für verschiedene Aufgaben abgestellt ${ }^{404}$, bzw. diesen Arbeitern Rationen zugewiesen werden ${ }^{405}$, darunter jeweils ein Arbeiter für das é Ur- ${ }^{\mathrm{d}} \mathrm{Namma}$, das é ${ }^{\mathrm{d}} \breve{S} u 1-g i$, das é ${ }^{\mathrm{d}} \mathrm{Amar}-{ }^{\mathrm{d}} \mathrm{EN}$.ZU sowie drei oder

\footnotetext{
398 Sallaberger, OBO 160/3 (1999), S. 158-159.

399 AUCT II, 152, verbucht die Lieferung von einer Gazelle an Abī-simtī.

400 Sallaberger, OBO 160/3 (1999), S. 163.

401 ASJ 3, S. 86. Totenopfer für Šu-Suen setzten am 4/x/ŠS 9 ein (MVN 10, 172).

402 Der Text ASJ 3, S. 86 verbucht 3 Schafe zum EN.DÍM.G I G, dem Wassertränkort der Abī-simtī (EN.DÍM.GIG-š è ki-a-na ĝ A-bí-sí-im-ti). Zum EN.DÍM. GIG als Tempel der Ninazu siehe D. Katz, The Images of the Netherworld (2003), S. 436-437. Siehe auch Carroué, L'Iturungal et le Sud Sumérien, ASJ 15 (1993), S. 36-37.

403 Lafont, L'avènement de Šu-Sîn, RA 88 (1994), S. 107-108 + Fn 29.

404 ASJ 18, S. 228 (6/xi/AS 9); ASJ 18, S. 223 (8/xi"/AS 9) und UDT 41 (5/xi/-); ITT II, 970 (abgebrochen).

405 Barton HLC III, Pl 104, HLb 175 (kein Datum).
} 
vier Arbeiter für regelmäßige Lieferungen an die Königin (sá-du $\left.\mathrm{u}_{11} \mathrm{nin}\right)^{406}$. Da die drei Könige Ur-Namma, Šulgi und Amar-Suen bei Entstehung dieser Texte schon tot waren, die Arbeiten also im Rahmen des Totenkultes zu sehen sind, lag es nahe, bei dem Eintrag sá-du $u_{11}$ nin ebenfalls einen Bezug zum Totenkult zu sehen. Lafont stützte seine Vermutung, Abī-simtī sei gegen Ende des Jahres AS 9 nicht mehr am Leben gewesen, auf zwei Hypothesen, die jedoch nicht haltbar sind: erstens ging er davon aus, eine als mu-DU PN bezeichnete Lieferung sei normalerweise für einen verstorbenen Herrscher betimmt, und zweitens vertrat er die Auffassung, Buchungen mit dem Vermerk mu - DU Abī-simtī setzten erst im Jahr AS 8 ein. ${ }^{407}$ Eine Vielzahl von Belegen aus dem Archiv der Šulgi-simtī zeigen, daß der Eintrag mu-DU PN die Lieferung an eine lebende Person kennzeichnet, und auch Abī-simtī erhielt seit dem Jahr AS 1 derartige Zuweisungen ${ }^{408}$. Somit ist $\mathrm{zu}$ fragen, wie die Zuweisung von Arbeitern für sá-du $u_{11}$ nin zu verstehen sind. Bleibt man bei der Annahme, die Arbeiter seien im Zusammenhang mit dem Totenkult für verstorbene Königinnen eingesetzt worden, wäre hier an die Damen SI.A-tum, Tarām-Uram, Geme-Suen und Šulgi-simtī zu denken. Dem entspricht, daß für $\mathrm{sá}-\mathrm{du}_{11}$ nin jeweils drei oder vier Arbeiter genannt sind. Es ist jedoch ebenso vorstellbar, daß die der Königin zugewiesenen Arbeiter tatsächlich im Auftrag der noch lebenden Königin Abī-simtī tätig waren, möglicherweise im Zusammenhang mit Aufgaben, welche diese im Rahmen des Totenkultes für Familienangehörige zu erfüllen hatte. Dafür spricht insbesondere, daß kein Text Arbeiter für mehrere Königinnen (nin-e-ne) verzeichnet. Somit ist davon auszugehen, daß mit $s a ́-d_{11}$ nin regelmäßige Lieferungen für die lebende Königin gemeint sind, welche diese möglicherweise im Rahmen des Totenkultes benötigte.

Zwei Geschwister der Abī-simtī sind bekannt. Zum einen ihr schon erwähnter Bruder Babati ${ }^{409}$, der als hoher Beamter in verschiedenen Funktionen in der Verwaltung des Reiches tätig war, sowie eine Schwester namens Bizua $^{410}$. Beide werden, wenn sie in den Texten näher bezeichnet sind, nicht

406 Alle Texte über derartige Einteilungen von Arbeitern aus den Jahren AS 8 bis ŠS 1 hat Uchitel zusammengestellt; Erín-èš-didli (II): Patterns of Conscription and Work Assignment, ASJ 18 (1996), S. 217-228.

407 Lafont, L'avènement de Šu-Sîn, RA 88 (1994), S. 107-108, Fn 29.

408 Zu den mu-D U-Einnahmen der Abī-simtī siehe S. 110-111.

409 Babati als Bruder der Königin: BCT I, 126 (19/iii/AS 3) Siegelinschriften RIME 3/2.1.4.32 und RIME 3/2.1.4.33. Babati in sonstigen Texten u.a. OIP 121, 20 (23/i/AS 4); SAT III, 1186 (xii/ŠS 1); MVN 16, 1428 (-/x/ŠS 4); PDT I, 583 (-/vi/ŠS 6).

410 Texte zu Bizua: OIP 121, 164 (8/ix/AS 4); TCL 2, 5484 (20/viii/AS 5); YBC 16649, ASJ 3, S. 70 (16/viii/AS 4); FS Astour, S. 372 (-/x/AS /); PDT I, 548 (2/vii/AS 8); 
über ihr Patronymikon identifiziert, wie dies sonst in den Urkunden der Zeit üblich war, sondern über den Namen ihrer Schwester, die als Königin im Rang höher als sie stand. Bizua wurde auch nach dem Tod der Abī-simtī noch „Schwester der Königin“ (nin ${ }_{9}$ nin) genannt ${ }^{411}$. Einmal wird die Mutter der Königin (a ma n in ) als Empfängerin von drei Schafen genannt. ${ }^{412}$

Abī-simtī selber war während der Amtszeit ihres Mannes Amar-Suen wie auch unter der Regierung ihres Sohnes Šu-Suen in kultischen wie auch wirtschaftlichen Bereichen sehr aktiv, wobei allerdings eine Veränderung im Tätigkeitsspektrum zu beobachten ist. Dies wird im folgenden zu zeigen sein. Den Titel einer Königin trug Ab̄̄-simtī wohl schon ab dem Jahr AS $1^{413}$, ab dem Jahr ŠS 2 führte auch ihre Schwiegertochter Kubātum diesen Titel, ohne daß für Abī-simtī, die nun eigentlich die Position der „Mutter des Königs“ innehatte, eine Veränderung in der Titulatur festzustellen wäre. ${ }^{414}$

\subsection{Die Quellenlage zu Ab̄̄-simtī}

Šulgi-simtī verfügte über eine eigene Verwaltung ihrer Viehbestände, wobei die Amtszeiten ihrer Beamten bekannt $\operatorname{sind}^{415}$. Die meisten Texte über Ausgaben aus ihrem Archiv sind nicht mit dem Namen der Königin versehen, sondern nur über die in ihrem Auftrag handelnden Beamten der Šulgi-simtī zuzuordnen.

Dieses Zuordnungsverfahren ist für Abī-simtī nicht anzuwenden, da ihre Einnahmen und Ausgaben zentral von der königlichen Verwaltung in PuzrišDagān betreut wurden, welche ihr die benötigten Tiere für den Kult wie für nichtkultische Verwendungszwecke zur Verfügung stellte. Und wenn diese Buchungen nicht mit dem expliziten Vermerk versehen sind, daß sie für ein bestimmtes Ereignis für die Königin ausgegeben werden, ist es nicht möglich, eine Beteiligung der Abī-simtī an einem Fest, einer Kulthandlung oder ähnlichem zu rekonstruieren. Aus diesem Grund ergibt sich für die Aktivitäten

MVN 11, 215 (24/vii/AS 8); UET 3, 1505 (Datum abgebrochen, AS 9?); ASJ 9, S. 270 Nr. 77 (9/vii/ŠS 1); TLB III, 24 (-/xiii/ŠS 1); BCT I, 96 (19/viii/ŠS 2), FS Jones, S. 69 (9/xi/ŠS 6); UET 3, 1504 (IS 2).

411 UET 3, 1504 (IS 2), Lieferung von Wolle für Kleidung an „Bizua, Schwester von Ab̄̄simtī, der Königin“.

412 OrSP 47-49, 15 (16/vi/AS 2).

413 Die Gerichtskunde ITT II, 752 aus dem Jahr AS 1 nennt einen Ur-Ba'u, Hirte der Königin (s i p a n in). Gesichert ist der Titel einer Königin für Abī-simtī ab dem Jahr AS 3, da ihr Bruder Babati in diesem Jahr erstmals als „Bruder der Königin“ (š e š n in ) erwähnt wird (BCT I, 126).

414 Zu Kubātum siehe S. 153-164, zur Frage der Titulatur siehe S. 235-237.

415 Siehe oben S. 37. 
der Abī-simtī möglicherweise ein eingeschränktes Bild, wenn man davon ausgeht, daß nicht alle Buchungen, die für die Königin bzw. in ihrem Auftrag geschahen, als solche für uns erkennbar sind. Damit sind die Belege für die Tätigkeiten der Abī-simtī nur bedingt mit denen von Šulgi-simtī zu vergleichen.

Abī-simtī erhielt wie ihre Vorgängerin von Beginn ihrer Amtszeit an Lieferungen, die mit dem Terminus „mu-DU “ bezeichnet wurden, um ihren verschiedenen Pflichten nachkommen zu können ${ }^{416}$. Da die Verwaltung der Viehbestände der Abī-simtī aber von der zentralen königlichen Administration versehen wird, zeichnet bei allen Lieferungen dieser Art zur Regierungszeit von Amar-Suen der Beamte Abbasaga verantwortlich (ki Ab-ba-s a ${ }_{6}-\mathrm{g} a-t a$ ba-zi). Unter Šu-Suen, wo die mu-DU-Lieferungen an Abī-simtī deutlich abnehmen, ist stets Intaea der verantwortliche Beamte. Abbasaga war unter Amar-Suen einer der führenden Beamten der Verwaltung von Puzriš-Dagān, seine Position wurde unter Šu-Suen weitgehend von Intaea übernommen; insbesondere in der Position des Hauptbeamten für die Annahme eingehender Tierlieferungen, der ranghöchsten Position in der Verwaltung von PuzrišDagān, folgte Intaea dem Abbasaga im Amt nach. ${ }^{417} \mathrm{Da}$ die Lieferungen an die Königin getrennt von denen des Königs verbucht wurden, zeigt eine Bilanz aus dem Jahr AS 3, in dem eine Aufstellung gemacht wird über die Ziegen aus dem Kontingent der mu-DU-Lieferungen des Königs und der Abī-simtī, die zu dem Zeitpunkt im Stall stehen ${ }^{418}$. Nach 132 Ziegen šà mu-DU lugal stehen 10 Ziegen šà mu-DU A-bí-sí-im-ti. Dieser Eintrag wäre nicht zu erklären, ginge man davon aus, daß alle Tiere prinzipiell als Besitz des Königs angesehen wurden, die dann nach Bedarf an die einzelnen Mitglieder der königlichen Familie, und damit auch an die Königin, verteilt wurden. Auch wenn die Buchhaltung der Königin von den gleichen Beamten wie die des Königs geführt wurde, hat man doch ganz offensichtlich deutlich unterschieden zwischen dem Tierbestand des Königs und dem der Königin. Dies zeigt auch die umfangreiche Lieferung von 121 Rindern und 916 Schafen und Ziegen, die als mu-DU-Lieferung der Königin (mu-DU nin) gekennzeichnet ist ${ }^{419}$.

\footnotetext{
416 Der früheste Text dieser Art ist AUCT II, 152 (1/i/AS 1), wo ein junger Gazellenbock an Abī-simtī gegeben wird, der aus der mu - D U-Lieferung des Puzur-Eštar stammt.

417 Zu Abbasaga siehe Sigrist, Drehem (1992), S. 273-292, zu Intaea ebd. S. 295-301. Zur Verwaltung der Viehbestände in Puzriš-Dagān siehe ausführlich Maeda, Bringing (mu-túm) of livestock and the Puzriš-Dagan organization for cattle management in the Ur III dynasty, ASJ 11 (1989), S. 69-111 und Sallaberger, OBO 160/3 (1999), S. 264 266.

418 SAT II, 759 (ix/AS 3).

419 OrSP 47-49, 115 (3/x/AS 8).
} 
Daneben erhielt die Königin auch Vieh, bei dem anhand der Buchungseinträge nicht zu erkennen ist, in welchem Kontext genau die Lieferungen erfolgten ${ }^{420}$.

Bei den mu-DU-Lieferungen an Abī-simtī finden sich anders als bei Šulgi-simtī Unterschiede im Formular. In den Texten aus dem Šulgi-simtī Archiv folgt auf die Angabe, welche Tiere von wem gegeben werden, der

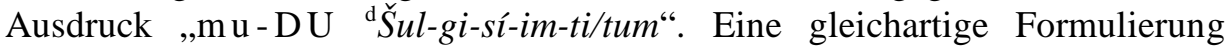
(Tiere, PN des Lieferanten, mu-DU A-bí-sí-im-ti) ist auch bei einigen der Lieferungen für Abī-simtī zu sehen, und zwar von Beginn ihrer Amtszeit an ${ }^{421}$. Weit häufiger ist jedoch ein etwas anderer Satzaufbau: „Tiere, mu-DU PN, $A$-bí-sí-im-ti, PN maški m“422, bzw. seltener „Tiere, A-bí-sí-im-it, mu-DU PN, PN maškim“"423. Ab dem Jahr AS 5 setzte sich zunehmend die Formulierung „Tiere, A-bí-sí-im-ti, PN maški m, šà mu-DU-ra-ta “‘424 durch, wobei nur noch angegeben wird, daß die Tiere aus den mu-DULieferungen stammen, ohne daß wie früher der Name der Lieferanten genannt würde. Dieser Wechsel im Formular der Texte aus Puzriš-Dagān ist derzeit nicht zu erklären. ${ }^{425}$

Neben den Einkünften aus mu-DU-Lieferungen erhielt Abī-simtī in der Regierungszeit Amar-Suens mehrfach eine als sá-du ${ }_{11}$ (regelmäßige Lieferung) bezeichnete Gabe von 30 Schafen $^{426}$, je einmal werden 21 Schafe und 9 Ziegen ${ }^{427}$, bzw. 20 Schafe und 10 Ziegen $^{428}$ für sie verbucht. Bei dieser Bereitstellung von 30 Stück Kleinvieh könnte es sich um eine regelmäßige monatliche Zuweisung handeln, bei der die Königin ein Tier pro Tag zur Verfügung gestellt bekam ${ }^{429}$. Da für bestimmte kultische Pflichten extra Tiere

${ }^{420}$ PDT II, 1036 (5/viii/ŠS 1) und Bab 8, Pupil 30 (24/xi/ŠS 2). In beiden Texten werden Tiere an verschiedene Emplänger, darunter Abī-simtī, ausgegeben.

25

zune S. 20-21.

426 SRD 15 (1/v/AS); OIP 121, 11 (ii/AS 3); TCND 259 (1/xi/AS 4); JCS 52, S. 39 Nr. 35 (ix/AS 9).

${ }_{427}$ OIP 121, 556 (ix/AS 8).

428 NISABA 8, 373 (-/xi/AS 5).

429 Dies vermutete schon Michalowski, der drei vergleichbare Lieferungen an GemeNinlila, Nebenfrau von Šulgi, aufführt: Royal Women of the Ur III Period. Part II: 
bereitgestellt wurden, ist davon auszugehen, daß dieses als $s a ́-d u_{11}$ verbuchte Vieh für den persönlichen Bedarf und den Haushalt der Königin bestimmt war. Möglicherweise gehört auch der Text TrD 27 (i/AS 5) in diesen Bereich, wo mehrere Personen aus dem Umfeld des Hofes Zuweisungen aus dem Kontingent der mu-DU-Lieferungen erhielten. Abī-simtī wird hier an erster Stelle genannt und erhielt 5 Rinder und 30 Schafe.

Im Gegensatz zu Šulgi-simtī, deren Texte fast ausschließlich aus PuzrišDagān stammen, ist das Bild für Abī-simtī deutlich vielfältiger. Zwar kommt der überwiegende Teil der Quellen für diese Königin ebenfalls aus PuzrišDagān, doch gerade aus der Zeit der Herrschaft ihres Sohnes stammen rund 1/3 der Quellen aus Umma. Daneben finden sich Belege aus Girsu und aus Ur. Damit haben die Texte zu Abī-simtī ein weiteres Themenspektrum als dies bei ihrer Vorgängerin der Fall war. Auffallend ist in bezug auf die Tiere die größere Artenvielfalt. So werden nicht nur Rinder $\left(\mathrm{gu}_{4}\right)$ Schafe $(\mathrm{udu})$ und Ziegen (máš) erwähnt, sondern auch Wildtiere wie Gazellen (mašda) ${ }^{430}$ und Hirsche/Wildschafe ( $\breve{s}_{\text {e }} \mathrm{g}_{9}$ - b ar $)^{431}$. Anders als bei Šulgi-simtī begegnen neben den einheimischen Schafen verschiedene andere Arten wie das Fettschwanzschaf (gukkal) $)^{432}$, das Alum-Schaf (udu-a-lum) ${ }^{433}$ oder das lulubäische Schaf (u du - 1 ú - ù lu - u m $)^{434}$.

Neben den Tierlieferungen finden sich im Textkorpus zu Abī-simtī auch Buchungen anderer Gegenstände, die Auskunft geben über das tägliche Leben am Hof der Königin. So wurden Rohrbündel, die regelmäßig an die Königin geliefert wurden ${ }^{435}$, wohl als Brennmaterial benötigt. In SAT I, 66 (i/AS 4) werden diverse Lebensmittel wie Milch, große Mengen an Vogeleiern, Getreide und Schweine zum Aufenthaltsort des Königs (ki-lug al) sowie zum

Geme-Ninlila, JCS 31 (1979), S. 172-173.

430 U.a. AUCT II, 152 (1/i/AS1); Hirose, 179 (25/i/AS 5); TRU 315 (25/x/AS 6); PDT I, 470 (24/ii/ŠS 1); BIN III, 342 (8/vi/ŠS 7); NISABA 8, 76 (14/vii/ŠS 7); in AUCT I, 399 (ŠS, Jahr abgebrochen) werden Gazellen für Abī-simtī und Kubātum geliefert.

431 YBC 3635, FS Levine, S. 115-119 VS Kol 6 (15/ii/AS 2); Toronto 75 (26/v/AS 7); NISABA 8, 70 (26/v/AS 7). Nach Steinkeller ist š e $g_{9}$ - b a r ein Hirsch (Sheep and goat terminology in Ur III sources from Drehem, BSA 8 (1995), S. 50), andere übersetzten diesen Ausdruck als „Wildschaf“. Vgl. Hilgert, OIP 121, Index S. 434.

432 U.a. OIP 121, 9 (10/xii/AS 2); DCEPHE 259 (25/iv/AS 9); MVN 9, 165 (ŠS 5).

433 U.a. Nik. 488 (18/viii/AS 8); TrD 42 (26/v/AS 9); PDT I, 470 (24/ii/ŠS 1); YOS 18, 20 (26/ii/ŠS 8).

434 BIN III, 81 (27/vii/AS 4); TrD 42 (26/v/AS 9). Zu der Rassebezeichnung „Lulubäisches Schaf“ siehe Steinkeller, Sheep and goat terminology, BSA 8 (1995), S. 53.

435 U.a. AAICAB I/2, Pl. 121 Ashm. 1967-1497 (-/i/AS 1); MVN 16, 1042 (ك̌S 1); MVN 16,1370 (ŠS 2). 
Aufenthaltsort der Königin (ki-nin $)^{436}$ gebracht, Datteln werden in MVN 12, 414 (AS 5) geliefert. Diese Trennung in den Haushalt des Königs und den der Königin zeigt sich auch in den regelmäßigen Zuweisungen $\left(s a ́-\mathrm{du}_{11}\right)$ an Getreide für das Haus der Abī-simtī (é A-bí-sí-im-ti-š è $)^{437}$. Gerade in den Texten aus Umma finden sich zahlreiche Hinweise auf den Bereich des täglichen Lebens, wenn Textilien ${ }^{438}$ oder Lebensmittel wie Fische ${ }^{439}$, Zwiebeln und Knoblauch ${ }^{440}$ für die Königin bereitgestellt werden.

\subsection{Dienerschaft/Beamten und das persönliche Umfeld der Abī-simtī}

Anders als Šulgi-simtī, die ihre Viehbestände von eigenen Beamten verwalten ließ und daher mit den führenden Beamten von Puzriš-Dagān nicht zusammenarbeitete, hatte Abī-simtī stets engen Kontakt mit den Hauptbeamten der königlichen Verwaltung. Was diesen Wechsel in der Organistation bezüglich der Tierbestände der Königin bedingte, ist derzeit nicht sicher zu bestimmen. Eine mögliche Erklärung wäre, daß Šulgi-simtī sich bei der Einrichtung des königlichen Viehhofes von Puzriš-Dagān im Jahr Š 39 und der $\mathrm{zu}$ dieser Zeit erfolgten Umstrukturierung der königlichen Viehhaltung erfolgreich gegen die Integration ihrer Verwaltung in die des Königs wehren konnte, daß aber nach ihrem Tod diese getrennte Administration nicht weitergeführt wurde. Hier wäre es denkbar, daß Abī-simtī bei ihrem Amtsantritt noch nicht über den Einfluß verfügte, den Šulgi-simtī nach mehreren Jahres als Königin gehabt hat, weswegen sie nicht die Tierbestände und die damit verbundenen Verwaltungsstrukturen ihrer Vorgängerin übernehmen konnte. Andererseits wäre es zu einseitig, diese Veränderungen in der Administration nur mit einer Schwäche der Position der jungen Königin zu erklären. Eine gemeinsame Verwaltung der Tierbestände des Königspaares könnte auch als Vorteil angesehen worden sein. Daß Abī-simtī durchaus über eigenes Personal verfügte, zeigen die Titel ihrer Dienerschaft. So ist im Jahr AS 9 ein Rịṣ-ilum, der Bote der Königin (rá-gaba nin) in der Funktion des Bevollmächtigten (maški m) bei Übergabe von Silberringen tätig ${ }^{441}$. Ein Hirte

${ }^{436}$ Zum „Ort der Königin“ s.u. S. 169-176. Eine ähnliche Lieferung unterschiedlicher Güter (u.a. Rohr, Bier, Brot, Vogeleier, Fisch) für Abī-simtī, die Königin, findet sich in ITT II, 3802 (Datum abgebrochen).

437 PDT II, 1174 (ix/AS 6).

438 MVN 16, 960 (ŠS 3); MVN 16, 713 (ŠS 4).

439 MVN 16, 1092 (ii/ŠS 3).

$440 \quad$ SNATBM 481 (̌̌S 3).

441 MVN 11, 183. (iv/AS 9). Zur Laufbahn des Rīṣ-ilum siehe Owen, Ur III Geographical and Prosopographical Notes, FS Astour, S. 381f. und 385-387 sowie ders. in NABU 
(na-gada) der Königin Abī-simtī wird in einem Text aus dem Jahr AS 2 erwähnt ${ }^{442}$. Ein Brief trägt das Siegel des Huba, Mundschenk (sagi) der Abīsimtī, ${ }^{433}$ welcher einen gewissen Lu-Narua anweist, Getreide zu liefern. Ein Mann namens Adagaldi wird in einem Text aus Girsu als Mundschenk der Königin genannt ${ }^{444}$, während Lu-Nanna in einem anderen Text aus Girsu lediglich als Mann der Abī-simtī (lú A-bí-sí-im-ti) tituliert wird ${ }^{445}$ Und in einem Text aus Umma sind Lieferungen von Akalla, dem Lederarbeiter der Königin (ašg ab nin) an einen königlichen Schreiber verzeichnet. ${ }^{446}$ Aus dem Jahr AS 3 stammt der Text UDT 27, der das Siegel des Ur-niĝar, šabra der Königin, trägt. Ein weiterer Šabra der Abī-simtī war Lugal-magurre ${ }^{447}$. Der Šabra war der oberste Verwalter eines Tempels oder eines anderen großen Haushaltes, hier des Hauses der Königin. Lugal-magurre war durch seine Ehe mit einer Tochter des Königs Mitglied der königlichen Familie ${ }^{448}$, bei Ur-niĝar könnte es sich um den Sohn von Šulgi handeln, mit dessen Familie schon Šulgi-simtī enge Kontakte pflegte ${ }^{449}$.

Hier zeigt sich, daß die weitverzweigte Familie des Königs nicht nur in der Verwaltung der einzelnen Provinzen des Reiches, sondern auch im Bereich des Hofes und der Verwaltung der königlichen Haushalte eng verwoben war ${ }^{450}$.

Insgesamt liegen für Abī-simtī deutlich weniger Texte vor, die als mu-DU

$1998 / 135$.

442 BM 22874, unpubliziert, Sigrist, Figulla, Walker, Catalogue of the Babylonian Tablets in the British Museum, Vol. II. In zwei Texten aus Girsu, TLB III, 89 (-/-/ŠS 1) und MVN 17, 1 (-/-/ŠS 1), werden einmal Lu-melam und einmal Ur-Ba'u als $\mathrm{n}$ a-g a da $\mathrm{n}$ in genannt. Da kein Name für die n in angegeben wird, wäre es auch möglich, daß hier nicht die Königin von Ur sondern die Frau des Ensi als Herrin (n in ) bezeichnet wird.

443 TCS 1,4 (undatiert).

444 TÉL 59 (-/v/AS 7).

445 TUT $200\left(26 / \mathrm{xi}^{\mathrm{II}} /-\right)$.

446 Toronto II, 407 (-/-/AS 2).

447 AAICAB I/2, Pl. 121 Ashm. 1967-1497 (-/i/AS 1).

448 CTMMA I, 17 (1/vii/AS 4), eine Liste mit Tierlieferungen an verschiedene Gruppen, darunter an die Töchter des Königs (dumu-munus lugal-me), unter denen die Frau (d a m) des Lugal-magurre genannt wird. Aus JCS 54, S. 7-9 Nr. 52 (ŠS, Datum abgebrochen) RS II, 14'-15' wird deutlich, daß es sich bei dieser Frau des Lugalmagurre um die Prinzessin Simat-Šulgi handelte.

449 Zu Ur-niĝar bei Šulgi-simtī vgl. S. 43.

${ }_{450}$ Weiterreichende Aussagen zu diesem Bereich werden erst durch prosopographische Untersuchungen möglich werden. Hier ist auf die von D. Owen angekündigte Studie zur königlichen Familie von Ur zu hoffen (siehe Sigrist, Drehem (1992), S. 357 Anm. 2). 
bezeichnete Lieferungen an die Königin verbuchen, als dies bei Šulgi-simtī der Fall gewesen ist, und durch den Wechsel des Formulars sind nach dem Jahr AS 5 oft die Namen der Geber nicht mehr bekannt. Dennoch sind bei einem Vergleich dieser Lieferanten in den Texten der Šulgi-simtī und der Abī-simtī mehrfach die gleichen Namen wiederzufinden. Diese Personen hatten also über Jahre engere Kontakte mit der Königin, welche auch nach dem Wechsel im Amt weiter aufrecht erhalten wurden. $\mathrm{Zu}$ diesen mit dem Haushalt der Königin in enger Beziehung stehenden Personen gehören Aba-Enlilgin ${ }^{451}$, der Prinz Eštar-alšu ${ }^{452}$, Nir-idaĝal ${ }^{453}$, Șilluš-Dagānn ${ }^{454}$, Ițib-šinat ${ }^{455}$ sowie Šulgi-ilī, der letzte Hauptbeamte der Šulgi-simt $\mathrm{i}^{-56}$.

Zwei Formen der Pflege sozialer Beziehungen, die schon bei Šulgi-simtī zu beobachten waren, finden sich bei Abī-simtī wieder. Dies ist zum einen das Übersenden von Tieren als „Proviant“ (igi-kár) an bestimmte Personen, zum anderen ist es das „Bierausschenken“ $(\mathrm{k} \text { aš-dé-a })^{457}$. Wie gezeigt werden konnte, ist die Gabe von Tieren als „Proviant“" bei Šulgi-simtī wohl als eine Art Ehrengeschenk zu verstehen ${ }^{458}$, und diese Funktion einer solchen Gabe ist auch bei Abī-simtī anzunehmen ${ }^{459}$. Für den Ritus des Bierausschenkens bei Ab̄̄simtī sind mir derzeit nur zwei Belege bekannt, wobei einmal Tiere ${ }^{460}$ und eimal große Mengen verschiedener Mehlsorten ${ }^{461}$ geliefert wurden. Für wen diese Feste gegeben wurde, geht aus den Texten nicht hervor, doch muß es sich um aufwendige und umfangreiche Feierlichkeiten gehandelt haben. Im Jahr

451 TCNY 253 (-/vii/Š 39) mu - D U -Lieferung an Šulgi-simtī; BIN III, 81 (27/vii/AS 4) mu - D U -Lieferung an Abī-simtī. Zu Aba-Enlilgin vgl S. 98.

452 OIP 115, $89(22 / x i i / S ̌$ 46) mu - D U -Lieferung an Šulgi-simtī; TAD 55 und TAD 64 (Duplikate) (26/xi ${ }^{\text {II } / A S ~ 3) ~ m u ~-~ D ~ U ~-L i e f e r u n g ~ a n ~ A b i ̄-s i m t i ̄ . ~}$

${ }_{453}$ Z.B. TCND 27 (-/xi/Š 35); MVN 2, 167 (-/x/Š 38); Orient 16, 16 (13/ix/Š 47) mu DU -Lieferung an Šulgi-simtī, MVN 13, 849 (26/i/AS 5) mu - D U -Lieferung an Abīsimtī. Zu Nir-idaĝal und seine Kontakte zu Šulgi-simtī vgl. S. 43.

Z.B. MVN 15, 324 (25/vi/Š 44); PDT II, 1013 (-/viii/Š 46) mu-DU-Lieferung an Šulgi-simtī, AUCT II, 99 (25/xi ${ }^{\mathrm{II}} / \mathrm{AS}$ 3); OIP 121, 283 (23/ix/AS 5) mu-DULieferung an Abī-simtī.

MVN 13, 415 (-/vi/Š 34); TCND 177 (-/xi/Š 35) Ițib-šinat erhält Tiere aus dem Bestand der Šulgi-simtī, TPTS 81 (26/ix/AS 4) mu - D U -Lieferung an Abī-simtī.

TAD 55 und TAD 64 (Duplikate) (26/xi²/AS 3), MVN 13, 849 (26/i/AS 5) mu - D U Lieferung an Abī-simtī.

457 Siehe S. 98-100.

458 Siehe S. 100-103.

459 ŠA XLII: 5 (6/v/ŠS 4), 5 Schafe für das Haus des Abilaša.

460 SRD 19 (9/ix/AS 8).

461

AUCT II, 114 (xii/AS 6). 
AS 8 wurden zu diesem Anlaß insgesamt 10 Rinder, 90 Schafe und 30 Ziegen bereitgestellt. Die Tiere stammten von Ur-Igalim, dem Viehmäster (k u rušda) der Königin ${ }^{462}$ und wurden von Abbasaga angenommen.

Auch wenn sich für Abī-simtī nicht so viele Belege für Feste zu Ehren von Personen aus ihrem Umfeld und Geschenke von Tieren an Gefolgsleute finden lassen, wie dies für Šulgi-simtī der Fall ist, so kann doch davon ausgegangen werden, daß die Abī-simtī diese Praxis ihrer Vorgängerin fortsetzte.

Ein anderer Aspekt des höfischen Lebens im Reich von Ur ist der Austausch von kostbaren Geschenken wie Schmuckstücken oder Waffen. So erhielt der Bildhauer (tibira) ${ }^{463}$ Elala einen mit Gold überzogenen Dolch von $A b \overline{1}-\operatorname{simt}_{1}{ }^{464}$, ein anderer Text verbucht die Gabe von zwei Silberringen an Nūhnilum, den sukkal der Königin ${ }^{465}$. Es ist auffällig, daß dieser Nūhn-ilum ebenso wie der Viehmäster Ur-Igalim unter Šulgi mit dessen Nebenfrau Geme-Ninlila verbunden $w^{4 r^{466}}$. Im Jahr AS 4 erhielt der Sukkal Šatakuzu zwei Silberringe als Geschenk, als er den Gruß der Königin aus Uruk mitbrachte ${ }^{467}$. In diesem Jahr wurde En-mahgal-ana als neue En des Nanna von Ur berufen ${ }^{468}$, und es ist denkbar, daß diese Grüße der Königin und die damit verbundenen Geschenke an einen hohen Beamten mit den Feierlichkeiten aus Anlaß dieser Berufung zu verbinden sind. Für eine Verbindung mit einem kultischen Anlaß spricht auch, daß Šatakuzu in mehreren Texten aus den Jahren AS 4 und 5 als Bevollmächtigter (mašk i m) bei Opfern für den Thron Šulgis, also im Kult für

462 Ur-Igalim begegnet in dieser Funktion außer in SRD 19 (9/ix/AS 8) noch in den Texten TRU 126 (18/iv/AS 8); Nik. 488 (18/viii/AS 8); OrSP 47-49, 115 (3/x/AS 8). In den letzten Jahren der Regierungszeit Šulgis war er ebenfalls schon als Mäster tätig und stand in Kontakt zu Šulgis Nebenfrau Geme-Ninlila: RA 75, 94; (ك̌ 46); OIP 115,

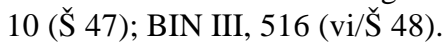

463 Zu DUB.NAGAR (=tibira) „Künstler“ siehe Kutscher, A Torchlight Festival in Lagaš, ASJ 5 (1983), S. 62; Neumann, Handwerk (1993), S. 35-36 Anm. 87 schlägt die provisorische Übersetzung „Bildhauer“ vor. Diese Übersetzung bei der Lesung ti bir a bestätigt Waetzoldt in NABU 1997/96.

464 SET 296 (iii/ŠS 4), der Text gehört zum Schatzarchiv aus Puzriš-Dagān.

465 JCS 10, S. 22 Nr. 11 (iii/AS 6).

466 Nūhn-ilī bei Abī-simtī: SRD 15 (1/v/AS 2); OIP 121, 11 (ii/AS 3); TCND 259 (1/xi/AS 4); JCS 10, S. 22 Nr. 11 (iii/AS 6), bei Geme-Ninlila: SACT I, 8 (iv/Š 44); TRU 278 (i/Š 45); CST 115 (1/vi/ŠS 46); JCS 31, S 172 C (1/iii/Š 48). Zu Geme-Ninlila siehe S. 202-206.

467 JCS 10, S. 30 Nr. 10 (iii/AS 4). Zu den Geschenken von Silberringen in der Ur III-Zeit siehe Michalowski, The Neo-Sumerian Silver Ring Texts, SMS 2/3 (1978), S. 43-58, zu diesem Text insbesondere S. 48. Vgl. Sallaberger, "bringen" im Sumerischen, FS Schretter (2004), S. 563.

468 Jahresdatum AS 4. 
den verstorbenen Herrscher, tätig war ${ }^{469}$.

$\mathrm{Zu}$ einem anderen Anlaß gab Ab̄̄-simtī an verschiedene Damen des Hofes Textilien und Öl aus, die als Zugabe $\left(\mathrm{d}\right.$ a h - h $\mathrm{u}$ ) bezeichnet wurden ${ }^{470}$. Bei den Empfängerinnen handelt es sich unter anderem um Kubātum, wobei möglicherweise die Hauptfrau von Šu-Suen gemeint ist, sowie um mehrere andere Frauen, die aber sonst kaum je im Kontext mit den wichtigsten Damen des Hofes genannt werden. Die Textilien werden auch nicht noch extra mit einer Qualitätsbezeichnung versehen, sondern einfach als „Stoffe“ (túg) geführt, und auch das Öl ist nicht weiter spezifiziert. Der Grund für diese besondere Ausgabe von Textilien und Öl ist nicht bekannt, vorstellbar wäre ein besonderes Fest aus politischem oder familiärem Grund im Königshaus, zu dem Frauen aus dem Gefolge der Abī-simtī die genannten Güter als Geschenke oder zusätzliche Rationen erhielten.

Auch Abī-simtī selber war Empfängerin von kostbaren Geschenken. So schickten Kubātum und Ti'amat-bāštī, die beiden hochrangigsten Frauen von Šu-Suen ${ }^{471}$, je einen Fingerring aus Rotgold (šu - gur kù-sig ${ }_{17}-$ hu uš-a ${ }^{472}$ zu Abī-simtī nach $\mathrm{Ur}^{473}$. In einem anderen Fall erhielt Abī-simtī von Kubātum ein Siegel aus Lapislazuli, dessen Inschrift mit Gold eingelegt war, während der gleiche Text Schmuckstücke aus (Halb-)Edelsteinen und Gold als Geschenke von Abī-simtī an Geme-Nanna, eine Nebenfrau (lukur) des Šu-Suen verzeichnet. ${ }^{474}$ Der Anlaß für dieses Geschenk ist nicht bekannt, doch kann davon ausgegangen werden, daß ein derartiger Austausch von Prestigegütern zur Pflege der sozialen Beziehungen am Hof gehörte.

Ein singulärer Text aus dem Jahr AS 4 vermerkt, daß der Abī-simtī acht Rinder und zwei Kühe aus dem Tribut ( $\mathrm{g}$ ú - u n) verschiedener Heiligtümer aus Zimudar, einem Ort im Dijala-Gebiet, übergeben wurden. ${ }^{475}$. Bislang muß

469 CTMMA I, 17 (1/vii/AS 4); OIP 121, 164 (8/ix/AS 4); TCL 2, 5484 (20/viii/AS 5); MVN 11, 154 (1/ix/AS 5). Alle vier Texte verzeichnen neben den Opfern für den Thron Šulgis auch Tierlieferungen an verschiedene königliche Damen wie die Prinzessin Simat-Ištarān oder Bizua, die Schwester der Königin.

SEL 2, S. 41-42 (ŠS 4). Die Datenformel dieses Textes wurde nachträglich geändert, siehe Foster, SEL 2 (1985), S. 38-40.

471 Zu Kubātum siehe S. 153-164, zu Ti'amat-bāštī siehe S. 226-228.

$472 \mathrm{Zu}$ h u š-a als Farbbezeichnung für rotschimmerndes Gold siehe Reiter, die Metalle im Alten Orient (1997), S. 37-40.

473 UTI VI, 3800 VS Kol. III (ŠS, das genaue Datum ist verloren).

474 JCS 54, S. 7-9 Nr. 52. VS IV und RS II. Das Datum ist nicht erhalten, doch deutet die Bezeichnung der Kubātum als lukur-lugal darauf hin, daß der Text in die ersten drei Jahre ŠS zu datieren ist.

475 ZA 68, S. 38 (2/iii/AS 4). 
offen bleiben, ob die Königin regelmäßig Anteil an derartigen Tributzahlungen hatte, oder ob diese Gabe von insgesamt zehn Rindern eine einmalige Beteiligung der Abī-simtī an Zahlungen aus den Randgebieten des Reiches war.

In mehreren Fällen werden auf einer Tafel Ausgaben von Tieren an Abīsimtī und an fremde Gesandte sowie an Prinzessinnen aus dem Königshaus von Ur, die entweder mit hohen Beamten des Reiches oder mit auswärtigen Herrschern verheiratet wurden ${ }^{476}$, zusammen verbucht. So werden in AUCT I, 110 (2/xi/AS 1) neben Gaben für Enlil, Ninlil und den Thron Šulgis auch 61 Schafe und Ziegen als Brautgabe (níĝ - mí-ú s - sá) für eine gewisse Tuputupu verzeichnet, welche zum Haus der Šeleppūtum ${ }^{477}$, einer Prinzessin, geschickt werden sollen. Außerdem erhielt Abī-simtī Rinder, Schafe und Ziegen. Nach ihr werden Leute aus Zidanum, Simānum und Harši ${ }^{478}$, alles Regionen in Norden und Nordosten des Reiches von Ur, als Empfänger von Vieh genannt. Ein Mann aus Zidanum erhielt auch im folgenden Jahr Vieh, wobei diese Buchung wieder auf einer Tafel zusammen mit Gaben für Abī-simtī und für die Prinzessin Geme-Eanna, die Frau des hohen Beamten Irĝu, verzeichnet wurde ${ }^{479}$. In den Jahren AS 5 und AS 6 werden dreimal auf einer Tafel Tiere für Abī-simtī und für Libanašgubi, den Gesandten von Libanukšabaš, Ensi von Marhaši, einem Gebiet im Norden/Nordwesten von Elam, verzeichnet ${ }^{480}$. Mit Marhaši waren seit dem Jahr Š 18 dynastische Beziehungen etabliert, da eine Tochter des Königs den Herrscher von Marḩaši geheiratet hatte ${ }^{481}$. In den folgenden Jahren bestanden offenbar enge diplomatische Beziehungen zwischen dem Reich von Ur und Marhašsi ${ }^{482}$. Auch Gesandte aus Ebla und Mari werden in zwei Texten gemeinsam mit Abī-simtī erwähnt ${ }^{483}$. Selbst wenn keiner der Texte explizit einen Kontakt zwischen diesen fremden Gesandten und der Königin herstellt, indem beispielsweise von einem Bierausschenken der Königin für diese Gesandten die Rede wäre, so ist es doch auffällig, daß außer Abī-simtī keine andere Königin von Ur zusammen mit Angehörigen

\footnotetext{
476 Zu politisch motivierten Eheschließungen im Reich von Ur III siehe S. 260-266.

477 Zu Šeleppūtum siehe Klein, Šeleppūtum, a Hietherto Unknown Ur III Princess, ZA 80 (1990), S. 20-39.

$478 \mathrm{Zu}$ diesen und den folgenden geographischen Bezeichnungen siehe Edzard, Farber, Die Orts- und Gewässernamen der Zeit der 3. Dynastie von Ur, RGTC II (1974).

479 OIP 121, 9 (10/xii/AS 2). Zu Irĝu siehe Sallaberger, OBO 160/3 (1999), S. $189+$ Anm. 228 mit älterer Literatur.

480 TrD 27 (i/AS 5); Toronto 48 (16/ii/AS 6); MVN 11, 146 (26/iv/AS 6).

481 Jahresname für das Jahr Š 18.

482 Steinkeller, The Question of Marhaši, ZA 72 (1982), S. 259-262.

483 MVN 11, 146 (26/iv/AS 6); Buccellati, Amorites, Pl. X, Nr 21 (14/ix/ŠS 6).
} 
anderer Reiche in den Quellen erwähnt wird. Dies legt die Vermutung nahe, daß Abī-simtī tatsächlich in direktem Kontakt mit diesen Gesandten gestanden hat und auf Entscheidungen über politische Fragen, insbesondere zu dynastischen Verbindungen, direkt Einfluß ausgeübt haben könnte, so wie man dies bei der eblaitischen Königin findet, die bei der Anbahnung dynastischer Ehen beteiligt war ${ }^{484}$.

Diese Vermutung setzt voraus, daß die Buchungen, die gemeinsam auf einer Tafel vermerkt wurden, in einem inhaltlichen Zusammenhang standen, auch wenn dies aus dem Text nicht direkt hervorgeht. Erschwerend kommt hinzu, daß bei einigen dieser Tafeln, auf denen mehrere Transaktionen bezeichnet sind, jeweils unterschiedliche Beamten als Überbringer ( $\hat{\mathrm{g} i \mathrm{i}} \mathrm{i}_{3}$ ) fungieren $^{485}$, auf anderen Tafeln jedoch die einzelnen Eintragungen nicht durch die Namen verschiedener Beamter unterbrochen werden ${ }^{486}$. Hier werden weitere detaillierte Untersuchungen zur Form der Buchungen im Archiv der königlichen Viehhaltung von Puzriš-Dagān und zur Entwicklung innerhalb dieser Textgruppe nötig sein, um diese Frage abschließend beantworten zu können. Geht man jedoch davon aus, daß es sich bei den Transaktionen, die auf einer Tafel verzeichnet wurden, nicht nur um eine mehr zufällig Aneinanderreihung von am gleichen Tag stattfindenden Buchungen handelt, dann ist wahrscheinlich, daß nicht nur ein Kontakt zwischen der Königin und den Vertretern anderer Herrscher bestand, sondern daß Abī-simtī an bestimmten Formen der zwischenstaatlichen Beziehungen, insbesondere dem Zustandekommen von dynastischen Ehen, beteilligt war.

\subsection{Kultische Pflichten der Abī-simtī}

Die kultischen Verpflichtungen der Abī-simtī stellen sich deutlich anders, aber nicht weniger vielfältig dar, als die ihrer Vorgängerin Šulgi-simtī. Dies mag zum einen in der unterschiedlichen Quellenlage ${ }^{487}$ begründet sein, ist zum anderen aber auch ein eindeutiges Zeichen für anders ausgerichtete Präferenzen bezüglich der Verehrung einzelner Gottheiten. Im folgenden sollen die einzelnen Kulte, an denen Abī-simtī beteiligt war, sowie die Gottheiten, welche die besondere Verehrung dieser Königin genossen, vorgestellt werden. Dabei wird auch gezeigt werden, daß sich die kultischen Pflichten der Abī-simtī mit dem Regierungsantritt ihres Sohnes Šu-Suen veränderten. ${ }^{488}$

\footnotetext{
$484 \quad$ Siehe S. 266.

485 So in TrD 27 (i/AS 5); Toronto 48 (16/ii/AS 6) und MVN 11, 146 (26/iv/AS 6).

486 So in AUCT I, 110 (2/xi/AS 1); OIP 121, 9 (10/xii/AS 2) und MVN 13, 636 (i/AS 8).

487 Siehe S. 109-113.

488 Vgl. Jacobsen, The Reign of Ibbi-Suen. JCS 7 (1953), S. 45. Dagegen war Sallaberger
} 


\subsubsection{Neumondfeiern ${ }^{489}$}

Die mit Abstand am besten belegte kultische Verpflichtung der Abī-simtī während ihrer Zeit als Königin an der Seite von Amar-Suen war der Vollzug von Riten zum Neumondtag. Insgesamt bezieht sich etwas mehr als die Hälfte der Texte zu den kultischen Aktivitäten dieser Königin auf die Feierlichkeiten zum Neumondtag, was die besondere Bedeutung dieser Riten für Abī-simtī unterstreicht ${ }^{490}$.

Šulgi-simtī brachte jeweils am Neulichttag, also an dem Tag, an dem die erste dünne Sichel des neuen Mondes sichtbar ist, Opfer für ihre persönlichen Göttinnen Inanna, Bēlat-Šuhnir und Bēlat-Deraban sowie für den Mondgott Nanna und die Göttin Ninsun dar ${ }^{491}$. Dagegen vollzog Abī-simtī Riten bei Neumond, also wenn der Mond gänzlich unsichtbar ist. Der Unterschied in der kultischen Konzeption ist dabei durchaus bemerkenswert. Der Neumondtag galt als Unglückstag, an dem sich der Mondgott in der Unterwelt aufhielt ${ }^{492}$. Abī-simtī war bestrebt, mit ihren Riten an diesem unheilbringenden Tag die Götter zu besänftigen und jenes Unheil vom König und damit vom ganzen Land abzuwenden ${ }^{493}$, während ihre Vorgängerin Šulgi-simtī das Erscheinen des neuen Mondes und damit das Ende der gefährlichen Zeit feiern konnte. Anders als in den Texten aus dem Šulgi-simtī-Archiv sind in den Quellen zu den Neumondfeiern von Abī-simtī nie die Namen bestimmter Gottheiten angegeben. Daher ist unbekannt, ob die Königin nur dem Mondgott Nanna Opfer darbrachte, oder ob sie sich wie ihre Vorgängerin auch an bestimmte andere Gottheiten wandte. Der Ablauf der Feierlichkeiten ist aus den Quellen nicht zu ersehen, doch ist aus einem Vergleich mit den Neumondriten der GemeEnlila $^{494}$, Königin neben Ibbi-Suen, die zu diesem Anlaß Baderiten $\left(a-t u_{5}-a\right)$ vollzog, anzunehmen, daß auch für Abī-simtī Bade- und Reinigungsriten $\mathrm{zu}$ den am Neumondtag $\mathrm{zu}$ vollziehenden Kulthandlungen

(Der kultische Kalender (1993), S. 61) der Auffassung, die Aktivitäten der Abī-simtī hätten sich nach dem Regierungswechsel nicht verändert.

489 Siehe unten Tabelle 11: Neumondfeiern der Abī-simtī, S. 126-128.

490 Drei dieser Belege sind Einträge auf Sammeltafeln, welche die Ausgaben eines Monats zusammenfassen: NISABA 8, 26 (ii/AS 6); NISABA 8, 36 (xi/AS 6); NISABA 8, 70 (v/AS 7); für den letzten Beleg ist auch die Tagesbuchung erhalten, Toronto 75 (26/v/AS 7).

491 Siehe S. 56f.

492 Sallaberger, Der kultische Kalender (1993), S. $61+$ Anm. 257 mit weiteren Referenzen.

493 ebd. + Anm. 256.

$494 \quad \mathrm{Zu}$ Geme-Enlila und den Neumondriten S. 166. 
gehörten ${ }^{495}$. Daß der König sich an diesem Tag Reinigungsriten zu unterziehen hatte, geht aus dem Text AUCT II, 170 (25/iii/ŠS 9) hervor, in dem auch gleichzeitig Tiere für die Neumondriten der Abī-simtī verbucht werden.

Es fällt auf, daß Tiere in weitaus größerem Umfang für Ab̄̄-simtī bereitgestellt werden, als dies bei Šulgi-simtī der Fall war. Dabei schwankt die Anzahl der Tiere wie auch die Zusammensetzung der einzelnen Tierarten. So werden wiederholt nicht nur Schafe und Ziegen, sondern auch Rinder und Wildtiere zur Verfügung gestellt, wobei in Einzelfällen über 100 Tiere in einem Monat überbracht werden konnten ${ }^{496}$. Ein Vergleich mit den Texten zu anderen kultischen Aktivitäten der Abī-simtī zeigt, daß sie ebenso wie Šulgi-simtī in der Regel nicht mehr als drei Tiere je Anlaß und Gottheit opferte. Geht man davon aus, daß die Zahl der zu Neumond beopferten Gottheiten sowie der Umfang dieser Opfer relativ konstant blieben, dann legen die starken Schwankungen in der Art und Zahl der gelieferten Tiere die Vermutung nahe, daß es sich nicht ausschließlich um das für Opferungen vorgesehene Vieh handelte, sondern daß zumindest ein Teil dieser Tiere auch für die Tafel der Königin bestimmt gewesen sein muß. Hier kann an Festlichkeiten am Ende der bedrohlichen Zeit zu Neumond gedacht werden, wobei die unterschiedliche Menge der benötigten Tiere auf jeweils differierende Zahlen der Teilnehmer am Festessen zurückzuführen wäre.

Das Formular ${ }^{497}$ der Texte zu den Neumondriten der Abī-simt ${ }^{498}$ erfährt im Verlauf der Regierungszeit von Amar-Suen zwei wesentliche Veränderungen. Neben dem „Hauptformular“ (A) existieren zwei weitere Formulierungen (B und $\mathrm{C}$ ), die jedoch beide nur unter bestimmten Bedingungen Anwendung fanden. Bei der Verwendung des Hauptformulars war der Hauptbeamte ${ }^{499}$ für die Annahme der mu-DU-Tiere in Puzriš-Dagān als buchender Beamter (bazi) tätig. Alle Buchungen wurden in der Zeit zwischen dem 24. und dem 27. Tag eines Monats ausgeführt, wobei der Schwerpunkt auf dem 25. und 26. Tag

\footnotetext{
495 Sallaberger, Der kultische Kalender (1993), S. 62.

496 UDT 95 (26/ix/AS 8) verzeichnet die Lieferung von 3 Rindern und 123 Schafen und Ziegen.

497 Vgl. zum folgenden Tabelle 11: Neumondfeiern der Abī-simtīAnhang, S. 126-128.

498 Vergleiche zum Formular Sallaberger, Der kultische Kalender (1993), S. 61-63.

499 Zur Verwaltung der Viehbestände in Drehem und den einzelnen für die Annahme der mu-DU-Tiere zuständigen Hauptbeamten vgl. Maeda, Bringing (mu-túm) of livestock and the Puzrish-Dagan organization, ASJ 11 (1989), S. 71-72, Sallaberger, OBO 160/3 (1999), S. 265-266. Vgl auch Hilgert, OIP 121, S. 54, wo die Amtszeiten der einzelnen Hauptbeamten allein auf Grundlage der in diesem Band edierten Texte aufgeführt sind. Damit ergibt sich in einigen Fällen eine Ausweitung der bisher bekannten Amtszeiten.
} 
lag. Damit wurde sichergestellt, daß die benötigten Tiere zum Monatsende am 28./29. Tag auch bereitstanden. ${ }^{500}$

Die erste Änderung des Formulars ist gegen Ende des Jahres AS 6 zu beobachten. Bis dahin findet sich in den Texten kein Hinweis auf den Neumondtag, die Texte sind allein aufgrund der Daten (24.-26. Tag des Monats) und der Erwähnung der Abī-simtī als Empfängerin in diesen Kontext zu stellen. Verzeichnet werden die Lieferungen von unterschiedlichen Mengen an Tieren als mu-DU von einer oder mehreren Personen für Abī-simtī. Diese werden dann bei Abbasaga wieder abgebucht (ba-zi), wobei immer ein weiterer Beamter die Funktion des Bevollmächtigten (maškim) erfüllt. Spätestens ab dem Monat x/AS 6 verwendet Abbasaga das Formular A:

$n \hat{1} \hat{g}-\mathrm{dab} \mathrm{b}_{5} / \mathrm{mu}-\mathrm{DU} \mathrm{u}_{4}-\mathrm{nú}-\mathrm{a}-\mathrm{ka}-\mathrm{ni}$ (šà mu-DU-ra-ta) = das von ihr Übernommene für den Neumondtag (aus den mu - DU -Lieferungen)

Dabei werden die Namen der gebenden Personen nicht mehr mit aufgenommen. Hier findet sich in der Regel kein Beamter in $\hat{g} \mathrm{iri}_{3}$ - oder maškimFunktion $^{501}$. Bei diesen Buchungen durch den Hauptbeamten können große Mengen von mehr als 100 Tieren ausgegeben werden, wobei sich neben Kleinvieh mitunter auch Rinder und Wildtiere finden. Unter der Regierung von Šu-Suen übernimmt Intaea das Amt des Hauptbeamten von Abbasaga und ist bei den Texten über Lieferungen zu Neumondriten für Abī-simtī als buchender Beamter tätig. Ab dem Ende des Jahres AS 8 wird konsequent nach dem buchenden Beamten ein weiterer Beamter als Überbringer ( $\mathrm{g}$ ir $\mathrm{i}_{3}$ ) aufgeführt. Diese Funktion wird häufig von dem Schreiber Nanna-maba übernommen. Daneben können vor der Formel PN ba-zi weitere Beamten als Überbringer ( $\mathrm{g}_{\mathrm{iri}}{ }_{3}$ ) und/oder Bevollmächtigter (maškim) stehen, doch dies ist nicht obligatorisch.

Neben diesem „Hauptformular“ in seinen verschiedenen Entwicklungsstufen finden sich noch das Formular B:

$\mathrm{u}_{4}$-nú-a-ka é-gal-la ba-an-ku ${ }_{4}$ A-bí-sí-im-ti $\left(\mathrm{Uri}_{5}{ }^{\mathrm{ki}}-\mathrm{ma}-\mathrm{s} \mathrm{è}\right)=($ Tiere) werden aus Anlaß des Neumondtages in den Palast gebracht für Abī-simtī (nach Ur)

und Formular C:

1 (2) sila ${ }_{4}$ A-bí-sí-im-ti mu-DU u ${ }_{4}$-nú-a-ka-na ki-ba ba-na-a-ĝar/-ĝáar $=1$ (2) Lämmer für Abī-simtī, es wurde ihr an Stelle ihrer Einlieferungen zum Neumondtag hingesetzt ${ }^{502}$

500 Sallaberger, Der kultische Kalender (1993), S. 61.

501 Ausnahme ist der Text TRU 315 (25/x/AS 6), in dem Šu-Ninšubur noch in m a š k i mFunktion auftritt, doch dieser Text stammt aus der Übergangszeit zur Einführung von Formular A.

502 Zu ki-b a g ar „ersetzten“ siehe Steinkeller, Sale Documents of the Ur III-Period 
In den Fällen, in denen die Formulierung $\mathrm{C}$ verwendet wurde, stand offensichtlich ein Teil der für die kultischen Pflichten der Abī-simtī vorgesehenen Tiere nicht zur Verfügung und es mußte rechtzeitig aus anderen Quellen für Ersatz gesorgt werden. ${ }^{503}$

Auf Urkunden mit diesen beiden Formulierungen werden jeweils nur ein oder zwei Schafe oder Ziegen bzw. Lämmer verbucht, das heißt, sowohl der Umfang der Lieferungen wie auch der Wert der überbrachten Tiere ist deutlich geringer als bei den Transaktionen, für die das Formular A verwendet wird. Die für die jeweiligen Buchungen verantwortlichen Beamten stehen im Rang unter dem Hauptbeamten, was ein Grund für eine veränderte Terminologie sein könnte.

Das Formular B wird von folgenden Beamten verwendet: Šulgi-ajaĝu ${ }^{504}$ (AS 4), Ahu-Wer ${ }^{505}$ und Lu-diĝira ${ }^{506}$ (AS 6), sowie Zubaga ${ }^{507}$ (AS 9). Es ist kein weiterer Beamter in maškim-Funktion beteiligt, und wenn ein Überbringer $\left(\hat{\mathrm{g}} \mathrm{ir}_{3}\right)$ angegeben ist, wird diese Funktion vom buchenden Beamten mit übernommen.

Dagegen findet das Formular C nur im Jahr AS 8 Anwendung, in dem Jahr, in dem Lugal-amarku das Amt des Hauptbeamten für die Entgegennahme der mu-DU-Tiere für wenige Monate anstelle seines Bruders Abbasaga ausübte. In dieser Zeit erhielt Abī-simtī ihre für die Opfer benötigten Tiere nicht vom Hauptbeamten Lugal-amarku ${ }^{508}$, sondern von Šu-Mama ${ }^{509}$ und Duga ${ }^{510}$. Letzterer war in der Zeit von AS 8 bis ŠS 3 verantwortlich für die Kleinviehherden ${ }^{511}$. Von Lugal-amarku sind in seiner Funktion als Hauptbeamter keine Buchungen für die Neumondriten der Königin bekannt.

Der geringe Umfang der Transaktionen, bei denen die Formulare B und C Anwendung fanden, sowie die untergeordnete Stellung der verantwortlichen Beamten legen die Vermutung nahe, daß es sich bei diesen Texten um

(1989), S. 210; Selz, NABU 1989, 94; Sallaberger, Der kultische Kalender (1993), S. $62+$ Anm. 268.

Sallaberger, Der kultische Kalender (1993), S. 62-63.

Zu Šulgi-a'aĝu siehe Sigrist, Drehem (1992) S. 332-334.

Zu Ahu-Wer siehe Sigrist, Drehem (1992), S. 317-319.

Dieser Name ist in Puzriš-Dagān nicht ganz selten, vgl Sigrist, Drehem (1992), S. 324-325.

Zu Zubaga siehe Sigrist, Drehem (1992), S. 336-338.

Zu Lugal-amarku siehe Sigrist, Drehem (1992), S. 327.

Zu Šu-Mama siehe Sigrist, Drehem (1992), S. 331-332.

Zu Duga siehe Sigrist, Drehem (1992), S. 301-305.

Maeda, Bringing (mu-túm) of livestock and the Puzrish-Dagan organization, ASJ 11 (1989), S. 108 Table 1. 
Lieferungen handelte, die zusätzlich zu den vom Hauptbeamten zu veranlassenden Überstellungen von Vieh für die Neumondriten durchgeführt wurden. Für diese Annahme spricht auch, daß uns aus zwei Monaten sowohl die Belege für die Lieferungen des Hauptbeamten Abbasaga als auch für diese Extragaben erhalten sind. Dabei zeigt sich, daß Abbasaga wie üblich eine größere Menge an Tieren für die Königin überstellen ließ.

vi/AS 8

bei Abbasaga werden 22 Stück Kleinvieh verbucht (SAT II, 1089) - Formular A zusätzliche Gabe von einem Lamm, bei Duga abgebucht (CTNMC 5) - Formular C ii/AS 9 bei Abbasaga werden 63 Stück Kleinvieh verbucht (PDT I, 579) - Formular A zusätzliche Gabe von einem Zicklein, bei Zubaga abgebucht (SET 66) - Formular B

Der Hauptteil dieser Tiere war also vorhanden und nicht anderweitig verbraucht worden, die Lieferung von jeweils einem Lamm bzw. Zicklein ist folglich nur eine Ergänzung zur Hauptlieferung.

Wie oben gezeigt wurde, fanden die Riten zu Neumond in Ur statt, wobei zumindest einige Teile der Feierlichkeiten im Palast der Königin anzusetzen sind. In den frühen Texten mit dem Formular A, vor der Einführung des Neumond-Vermerks, verzeichnete Abbasaga häufig auf derselben Tafel auch Lieferungen an das é-uz-ga ${ }^{512}$, nach dem Jahr AS 6 findet sich diese Kombination der Einträge nur noch auf drei Texten ${ }^{513}$. Noch ist nicht abschließend geklärt, was mit é-uz-ga genau gemeint war, es ist aber deutlich, daß mit diesem Ausdruck ein bestimmter Bereich innerhalb des Palastes bezeichnet wurde ${ }^{514}$. Sallaberger vermutete, es habe sich um den inneren Bereich des Palastes gehandelt ${ }^{515}$. Dies paßt gut in das Bild, daß sich das Königspaar, möglicherweise getrennt voneinander, an dem unheilvollen Neumondtag in einem inneren, zurückgezogenen Teil des Palastes aufhielt, wo es sich spezieller Reinigungsriten zu unterziehen hatte.

Während für die Regierungszeit Amar-Suens ab dem Jahr AS 3 die Neumondriten der Abī-simtī durchgängig belegt sind, finden sich unter der Regierung ihres Sohnes nur vereinzelte Belege für diese Riten ${ }^{516}$. Dies ist nicht allein mit der insgesamt geringeren Zahl der bekannten Urkunden aus der Zeit Šu-Suens zu erklären, da in bezug auf Abī-simtī die Zahl der Texte zu

\footnotetext{
512 TAD 55 /TAD 64 (Dupl) (26/xi2/AS 3); BIN III, 81 (27/vii/AS 4); TPTS 81 (26/ix/AS 4); Orient 16, 28 (26;/viii/AS 5); NISABA 8, 36 (xi/AS 6).

513 SAT II, 1089 (27/vi/AS 8), UDT 95 (26/ix/AS 8), TrD 42 (26/v/AS 9).

514 Sigrist, Drehem (1992), S. 158-162.

515 Vortrag Sallaberger auf der Rencontre in Leiden (2002).

516 Siehe unten Tabelle 11: Neumondfeiern der Abī-simtī, S. 126-128.
} 
kultischen Aktivitäten außerhalb der Neumondfeiern deutlich zunehmen. Somit ist zu vermuten, daß Abī-simtī sich zur Zeit Šu-Suens vermehrt anderen Aufgaben zugewandt hat.

Nur ein einziger Text belegt Opfer der Abī-simtī auch zu den Neulichtfeiern in Ur. ${ }^{517}$ Diese Opfer fanden im Rahmen der Feiern zum „Stachelschweinessen des Nanna“ (ní ĝ-dab 5 šah-zé-da dNanna) statt. Bei diesem Fest handelte es sich um die Feiern, die dem dritten Monat im Lokalkalender von Ur den Namen gegeben hatten, wobei šah-zé-da-g u ${ }_{7}$ als eine Parallelform zur verbreiteteren Form des Monatsnamens še š- $\mathrm{da}-\mathrm{g} \mathrm{u}_{7} \mathrm{zu}$ sehen ist. ${ }^{518}$ Anläßlich dieses Festes brachte Abī-simtī einer Reihe von Gottheiten ein bis vier Stück Kleinvieh als Opfergabe dar, wobei sie selber als Überbringerin fungierte. Neben dem Mondgott erhielten auch das Abzu, Ningal, Nungal, Ninkununna ${ }^{519}$, der Thron Ur-Nammas, Gula, Allatum, sowie weitere Gottheiten, deren Namen nicht erhalten sind, ein Opfer von Abī-simtī. Die Mutter des Königs opferte also nicht nur dem Mondgott und Gottheiten aus seinem Umkreis, sondern auch Gottheiten, die mit der Unterwelt verbunden wurden sowie dem Thron $\left({ }^{\hat{g}} \mathrm{i} \check{\mathrm{g}} \mathrm{gu}-\mathrm{za}\right)$ des verstorbenen Königs Ur-Namma. Opfer für die verstorbenen Herrscher waren im Rahmen der Feiern zu Neulicht und Vollmond üblich, wobei diese Opfer in der Regel am Wassertränkort (ki $\mathrm{a}-\mathrm{n}$ a $\hat{\mathrm{g}}$ ) dargebracht wurden. ${ }^{520}$ Der Thron der toten Könige wurde unabhängig vom $\mathrm{ki}-\mathrm{a}-\mathrm{na} \hat{\mathrm{g}}$ beopfert und es ist davon auszugehen, daß es sich um zwei verschiedene Orte gehandelt haben muß, wobei der Thron sich wahrscheinlich an einem besonderen Ort im Palast befunden hat. ${ }^{521}$

$\mathrm{Da}$ die Belege für Neumondriten bei Abī-simtī zahlreich sind, mit MVN 13, 550 aber nur ein einziger Text zu Neulichtriten für diese Königin vorliegt, ist davon auszugehen, daß Opfer von Abī-simtī zu diesem Anlaß nicht üblich waren. Über den Grund für diese außergewöhnlichen Opfer zu Neulicht kann

517 MVN 13, 550 (23-29/Rest abgebrochen). Die Ausgabe von Vieh wird verantwortet von Puzur-Enlil, was die Datierung des Textes auf die Zeit von ŠS 7 bis IS 2 einschränkt, vgl Sigrist, Drehem (1992), S. 328. Die Mitwirkung der Abī-simtī an den hier verbuchten Opfern schränkt die Datierung weiter ein auf die Jahre ŠS 7-ŠS 9. Sallaberger, Der kultische Kalender (1993), S. 195.

519 Diese Göttin gehört in den Kreis der Gottheiten um den Mondgott; siehe Richter, Panthea Süd- und Mittelbabyloniens (1999), S.395-396. Richter schließt aus, daß Ninkununna ein Beiname der Inanna gewesen sei, wie Cavigneaux/Krecher im Artikel „Nin-kununna“, RlA 9 (2001), S. 450 vermutet hatten. Sallaberger, Der kultische Kalender (1993), S. 63-65.

521 ebd. S. 147-148. Sallaberger verweist auf den Vergleich mit Mari, wo ein Raum hinter dem Thronsaal von Durand als Ort des Herrscherkultes bestimmt werden konnte; Durand, L’Organisation de l'espace dans le Palais de Mari, S. 107-109. 
nur spekuliert werden. Möglicherweise ist der Grund in ihrer persönlichen und/oder familiären Situation $\mathrm{zu}$ suchen. Da der Text in die letzten Regierungsjahre ihres Sohnes zu datieren ist, könnte auch an eine ernste Krankheit des Königs als Anlaß für die Opfer seiner Mutter an die Heilgöttin Gula, Unterweltsgötter und den Thron des Dynastiegründers Ur-Namma gedacht werden. Damit wäre das jährlich gefeierte Fest des Stachelschweinessens des Nanna nur der äußere Rahmen für besondere Opfer der Mutter des Königs.

\begin{tabular}{|c|c|c|c|c|c|c|}
\hline Publikation & Datum & $\begin{array}{l}\text { was } \\
\text { wird } \\
\text { geliefert }\end{array}$ & maškim & giriri $_{3}$ & ba-zi & Formel \\
\hline $\begin{array}{l}\text { AUCT II, } \\
99\end{array}$ & $\begin{array}{l}25 / x i 2 / A S \\
3\end{array}$ & $3 \mathrm{G}, 38 \mathrm{~K}$ & Irĝu & - & Abbasaga & - \\
\hline $\begin{array}{l}\text { TAD 55 / } \\
\text { TAD 64 } \\
\text { (Dupl) }\end{array}$ & $\begin{array}{l}\text { 26/xi2/AS } \\
3\end{array}$ & $5 \mathrm{~K}$ & Irĝu & - & Abbasaga & - \\
\hline BIN III, 81 & $\begin{array}{l}27 / \text { vii/AS } \\
4\end{array}$ & $3+[\mathrm{x}]$ & $\begin{array}{l}\text { Rīss-ilum } \\
\text { rá-gaba }\end{array}$ & - & Abbasaga & - \\
\hline TPTS 81 & 26/ix/AS 4 & $11 \mathrm{~K}$ & $\begin{array}{l}\text { Rīṣ-ilum } \\
\text { rá-gaba }\end{array}$ & - & Abbasaga & - \\
\hline $\begin{array}{l}\text { OIP 121, } \\
48\end{array}$ & 26/x/AS 4 & $1 \mathrm{~K}$ & - & $\begin{array}{l}\text { Šulgi- } \\
\text { ajâ̂u }\end{array}$ & $\begin{array}{l}\text { Šulgi- } \\
\text { ajaĝu }\end{array}$ & B \\
\hline Hirose, 179 & 25/i/AS 5 & $1 \mathrm{~K}, 1 \mathrm{~W}$ & $\begin{array}{l}\text { Lugal- } \\
\text { kuzu }\end{array}$ & - & Abbasaga & - \\
\hline $\begin{array}{l}\text { Orient } 16, \\
28\end{array}$ & $\begin{array}{l}266_{i} / \text { viii/AS } \\
5\end{array}$ & $31 \mathrm{~K}$ & $\begin{array}{l}\text { Rīṣ-ilum } \\
\text { rá-gaba }\end{array}$ & - & Abbasaga & - \\
\hline $\begin{array}{l}\text { NISABA } \\
8,26 \text { (ST) } \\
\end{array}$ & 26/ii/AS 6 & $15 \mathrm{~K}$ & $\begin{array}{l}\text { Namhani } \\
\text { sukkal }\end{array}$ & - & Abbasaga & - \\
\hline TCNY 133 & 25/iii/AS 6 & $1 \mathrm{~K}$ & - & Ahu-Wer & Ahu-Wer & B \\
\hline $\begin{array}{l}\text { MVN 11, } \\
146\end{array}$ & 26/iv/AS 6 & $1 \mathrm{~K}$ & - & Ahu-Wer & Ahu-Wer & B \\
\hline TCND 249 & 26/v/AS 6 & $1 \mathrm{~K}$ & - & - & Lu-diĝira & B \\
\hline TRU 315 & 25/x/AS 6 & $\begin{array}{l}10 \mathrm{~K}, \\
1 \mathrm{~W}\end{array}$ & $\begin{array}{l}\text { Šu- } \\
\text { Ninšubur } \\
\text { rá-gaba }\end{array}$ & - & Abbasaga & A \\
\hline $\begin{array}{l}\text { NISABA } \\
8,36 \text { (ST) }\end{array}$ & 24/xi/AS 6 & $13 \mathrm{~K}$ & $\begin{array}{l}\text { Šu- } \\
\text { Ninšubur } \\
\text { rá-gaba }\end{array}$ & - & Abbasaga & - \\
\hline $\begin{array}{l}\text { Fales, } \\
\text { Prima } \\
\text { dell'alf., } 17 \\
\end{array}$ & $\begin{array}{l}25 / x i i / A S \\
6\end{array}$ & $1 \mathrm{~K}$ & - & - & Lu-diĝira & B \\
\hline $\begin{array}{l}\text { OIP 121, } \\
27\end{array}$ & 26/iii/AS 7 & $1 \mathrm{~K}$ & - & Ahu-Wer & Ahu-Wer & B \\
\hline
\end{tabular}




\begin{tabular}{|c|c|c|c|c|c|c|}
\hline Publikation & Datum & $\begin{array}{l}\text { was } \\
\text { wird } \\
\text { geliefert }\end{array}$ & maškim & giri & ba-zi & Formel \\
\hline Toronto 75 & 26/v/AS 7 & $20 \mathrm{~K} 2 \mathrm{~W}$ & - & - & Abbasaga & $\mathrm{A}$ \\
\hline $\begin{array}{l}\text { NISABA } \\
8,70(\mathrm{ST})\end{array}$ & 26/v/AS 7 & $20 \mathrm{~K} 2 \mathrm{~W}$ & - & - & Abbasaga & $\mathrm{A}$ \\
\hline $\begin{array}{l}\text { BIN III, } \\
165\end{array}$ & 26/ii/AS 8 & $1 \mathrm{~K}$ & $\begin{array}{l}\text { Ilum-dan } \\
\text { sukkal }\end{array}$ & Šu-Mama & $\begin{array}{l}\text { Šu- } \\
\text { Mama }\end{array}$ & $\mathrm{C}$ \\
\hline $\begin{array}{l}\text { BIN III, } \\
403\end{array}$ & 26/ii?/AS 8 & $1 \mathrm{~K}$ & - & $\begin{array}{l}\text { Ur-Ba'u } \\
\text { muhaldim }\end{array}$ & Duga & $\mathrm{C}$ \\
\hline $\begin{array}{l}\text { PDT II, } \\
1145\end{array}$ & 26/iv/AS 8 & $2 \mathrm{~K}$ & - & $\begin{array}{l}\text { Ur-Ba'u } \\
\text { muhaldim }\end{array}$ & Duga & $\mathrm{C}$ \\
\hline $\begin{array}{l}\text { ASJ 7, S. } \\
123 \text { Nr. } 19\end{array}$ & $25 / \mathrm{v} / \mathrm{AS} 8$ & $1 \mathrm{~K}$ & - & Ur-Ba'u & Duga & $\mathrm{C}$ \\
\hline $\begin{array}{l}\text { SAT II, } \\
1089\end{array}$ & 27/vi/AS 8 & $22 \mathrm{~K}$ & - & - & Abbasaga & $\mathrm{A}$ \\
\hline CTNMC 5 & 27/vi/AS 8 & $1 \mathrm{~K}$ & - & $\begin{array}{l}\text { Ajakalla } \\
\text { muhaldim }\end{array}$ & Duga & $\mathrm{C}$ \\
\hline UDT 129 & $\begin{array}{l}\text { 26/vii/AS } \\
8\end{array}$ & $17 \mathrm{~K}$ & - & - & Abbasaga & $\mathrm{A}$ \\
\hline UDT 95 & 26/ix/AS 8 & $\begin{array}{l}3 \mathrm{G} \\
123 \mathrm{~K}\end{array}$ & - & $\begin{array}{l}\text { *Dajati } \\
\text { dub-sar* }\end{array}$ & Abbasaga & $\mathrm{A}$ \\
\hline SET 66 & 26/ii/AS 9 & $1 \mathrm{~K}$ & - & $\begin{array}{l}\text { Zubaga } \\
\text { *Adda- } \\
\text { kalla dub- } \\
\text { sar* }\end{array}$ & Zubaga & B \\
\hline PDT I, 579 & 26/ii/AS 9 & $63 \mathrm{~K}$ & Irĝu & $\begin{array}{l}\text { Ulaniš rá- } \\
\text { gaba } \\
\text { *Nūr- } \\
\text { Suen dub- } \\
\text { sar* }\end{array}$ & Abbasaga & $\mathrm{A}$ \\
\hline $\begin{array}{l}\text { Durand, } \\
\text { DCEPHE } \\
259\end{array}$ & 25/iv/AS 9 & $\begin{array}{l}10 \\
{[+\mathrm{x}] \mathrm{K}}\end{array}$ & $\begin{array}{l}\text { Ninlil- } \\
\text { amaĝu } \\
\text { rá-gaba }\end{array}$ & $\begin{array}{l}\text { *Nanna- } \\
\text { maba } \\
\text { dub-sar* }\end{array}$ & Abbasaga & $\mathrm{A}$ \\
\hline $\operatorname{TrD} 42$ & 26/v/AS 9 & $16 \mathrm{~K}$ & - & $\begin{array}{l}* \text { Nūr- } \\
\text { Suen* }\end{array}$ & Abbasaga & $\mathrm{A}$ \\
\hline PDT I, 470 & 24/ii/ŠS 1 & $11 \mathrm{~K} 1 \mathrm{~W}$ & - & $\begin{array}{l}\text { *Nanna- } \\
\text { maba } \\
\text { dub-sar* }\end{array}$ & Intaea & $\mathrm{A}$ \\
\hline $\begin{array}{l}\text { JEOL } 34, \\
\text { S. } 28 \text { Nr. } 2\end{array}$ & 27/iii/ŠS 2 & $11 \mathrm{~K} 3 \mathrm{~W}$ & - & $\begin{array}{l}\text { *Nanna- } \\
\text { maba } \\
\text { dub-sar* }\end{array}$ & Intaea & $\mathrm{A}$ \\
\hline & ŠS 2-3 & \multicolumn{5}{|c|}{ derzeit keine Belege } \\
\hline BCT I, 100 & 27/xi/ŠS 4 & $24 K$ & - & $\begin{array}{l}\text { *Nanna- } \\
\text { maba }\end{array}$ & Intaea & $\mathrm{A}$ \\
\hline
\end{tabular}


Königinnen

\begin{tabular}{|c|c|c|c|c|c|c|}
\hline Publikation & Datum & $\begin{array}{l}\text { was } \\
\text { wird } \\
\text { geliefert }\end{array}$ & maškim & giri & ba-zi & Formel \\
\hline & & & & dub-sar* & & \\
\hline & ŠS 5-7 & \multicolumn{5}{|c|}{ derzeit keine Belege } \\
\hline $\begin{array}{l}\text { YOS 18, } \\
20\end{array}$ & 26/ii/ŠS 8 & $30 \mathrm{~K}$ & - & $\begin{array}{l}\text { Ninlil- } \\
\text { amaĝu rá- } \\
\text { gaba } \\
\text { *Nanna- } \\
\text { maba } \\
\text { dub-sar* }\end{array}$ & Intaea & $\mathrm{A}$ \\
\hline $\begin{array}{l}\text { AUCT II, } \\
170\end{array}$ & 25/iii/ŠS 9 & $3 \mathrm{~K}$ & - & Nūr-Eštar & - & $\mathrm{A}$ \\
\hline
\end{tabular}

Tabelle 11: Neumondfeiern der Abī-simtī

ST Sammeltafel über die Buchungen eines Monats

$\mathrm{mD} \quad \mathrm{mu}-\mathrm{DU}$-Lieferung

G Großvieh (Rind)

K Kleinvieh (Schaf, Ziege, auch Jungtiere)

W Wildtier (Gazelle, Hirsch)

*PN* der Name diees ĝ $\mathrm{iri}_{3}$-Beamten steht am Ende des Textes hinter dem abbuchenden Beamten

Formel:

- $\quad$ keine Neumond-Formel; vermerkt, daß die Tiere als m u - D U von verschiedenen Personen gebracht werden (Ausnahme: Sammeltafel NISABA $8,36)$

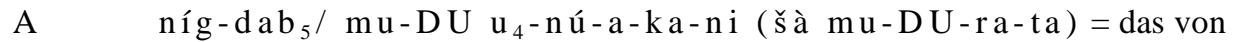
ihr Übernmonnene für den Neumondtag (aus den mu - D U -Lieferungen) --> bis zu 126 Tiere

B $\quad \mathrm{u}_{4}-\mathrm{nú}-\mathrm{a}-\mathrm{ka}$ é-gal-1a ba-an-ku A-bí-sí-im-ti $\left(\mathrm{Uri}_{5}{ }^{\mathrm{ki}}-\mathrm{ma}-\mathrm{s} \mathrm{è}\right)=$ Tiere werden aus Anlaß des Neumondtages in den Palast gebracht für Abīsimtī (nach Ur)

--> je 1 Tier

C $1(2)$ sila $_{4} A$-bí-sí-im-ti mu-DU u u $_{4}$ ú-a-ka-na ki-ba ba-na-ag a r /-g à - ar = 1 (2) Lämmer für Abī-simtī, sie wurden ihr an Stelle ihrer Einlieferungen zum Neumontag hingesetzt --> 1 (2) Lämmer

\subsubsection{Der Kult der großen Göttern Enlil, Ninlil und Nanna}

Während Šulgi-simtī regelmäßig zu Monatsbeginn Nanna mit Opfergaben versorgte und am 7. Tag sowie in der Mitte eines jeden Monats den Gottheiten von Nippur, Ninlil und Enlil, ihre Verehrung bezeugte, sind für die Amtszeit der Abī-simtī als Königin in der Regierungszeit von Amar-Suen keine Texte bekannt, aus denen eindeutig hervorginge, daß sie sich um den Kult dieser 
bedeutenden Gottheiten des Landes kümmerte. Es ist allerdings zu vermuten, daß dies im Kontext der Riten zum Neumond geschah, doch geben die Texte zu diesem wichtigen monatlichen Feiertag keine Hinweise auf die von Abī-simtī verehrten Gottheiten.

Mit den Veränderungen in ihren kultischen Aktivitäten zur Zeit Šu-Suens werden auch die Götter Nanna, Enlil und Ninlil in einigen wenigen Texten namentlich als Empfänger von Gaben der Abī-simtī genannt.

Wie der Text PDT II, 1219 (7/vi/ŠS 3) belegt, brachte Abī-simtī dem Götterpaar Enlil und Ninlil zum 7. Tag des Monats je drei Stück Kleinvieh als Opfer dar, wobei sie selber als Überbringerin ( $\mathrm{g} \mathrm{iri}_{3}$ ) fungierte. Dies entspricht sowohl in bezug auf den Umfang der Gaben wie auch hinsichtlich des Zeitpunktes im Monat (7. Tag) den kultischen Aktivitäten von Šulgi-simtī in Nippur $^{522}$. Hier stellt sich die Frage, ob Abī-simtī die regelmäßige Pflege des Kultes von Enlil und Ninlil von ihrer Vorgängerin übernommen hat und sich regelmäßig um diese wichtigen Gottheiten von Nippur kümmerte, oder ob es sich bei diesem Opfer im Jahr ŠS 3 um eine spontane, auf ein bestimmtes Ereignis bezogene Gabe handelte.

Die Interpretation wird daduch erschwert, daß für die Königinnen der Zeit nach Šulgi-simtī die Zuordnung der einzelnen Texte zum Textkorpus der jeweiligen Damen nahezu unmöglich ist, wenn weder der Name noch der Titel der Frauen im Text selber genannt werden ${ }^{523}$. Es ist durchaus vorstellbar, daß bei verschiedenen Texten über Opferlieferungen, welche weder den König noch die Königin als veranlassende Persönlichkeit explizit vermerken, nicht immer der König als Auftraggeber anzunehmen ist, sondern daß einzelne Texte dem Handlungsbereich der Königinnen zuzurechnen sind. Hier kann als Anhaltspunkt für eine Zuweisung in die Sphäre der Königin das Schema der kultischen Verpflichtungen bei Šulgi-simtī dienen, auch wenn das Aufgabenspektrum der einzelnen Königinnen differieren kann, wie am Beispiel der Neulichtriten bei Šulgi-simtī im Gegensatz zu Neumondriten bei Abī-simtī zu beobachten war.

Wie schon anhand der umfangreichen kultischen Pflichten der Šulgi-simtī sowie der regelmäßigen Durchführung von Riten zu Neumond durch Abī-simtī deutlich wurde, hatte die Königin im Reich von Ur eine bedeutende Funktion im offiziellen Kult. Daher ist es nicht zwingend, alle Texte über kultische Handlungen, in denen kein Auftraggeber bzw. Ausführender genannt wird, automatisch dem König zuzuordnen. Zwei Texte sollen als Beispiel dienen, wie eine solche mögliche Zuweisung einzelner Transaktionen in den Tätigkeits-

\footnotetext{
522 Zur Verehrung von Ninlil und Enlil durch Šulgi-simtī vgl. S. 49-55.

523 Vgl. S. 109.
} 
bereich der Königin begründet werden kann:

1. OIP 121, 283 (23/ix/AS 5):

Es werden je ein Lamm für Enlil und Ninlil aus den mu-DU-Lieferungen des Șilluš-Dagān ausgegeben, außerdem eine Ziege für Abī-simtī aus den mu DU-Lieferungen des lú-mah-Priesters der Šara. Da Șilluš-Dagān als Lieferant sowohl an Šulgi-simtī wie auch an Abī-simtī bekannt ist, und da letztere in diesem Text selber als Empfängerin von Vieh vermerkt ist, wäre es durchaus möglich anzunehmen, der für die Transaktion verantwortliche Beamte Abbasaga habe aus dem Viehbestand der Königin zwei Lämmer für Opfer ausgegeben, während die Ziege für eine andere Verwendung durch die Königin bereitgestellt wurde. Dies wird unterstrichen durch die Tatsache, daß die Buchhaltung über die Viehbestände des Königs und der Königin zwar von den gleichen Beamten ausgeführt wurde, wobei jedoch der Besitz des Königs in der Administration deutlich von dem der Königin getrennt wurde ${ }^{524}$. Angesichts dessen ist es naheliegend anzunehmen, daß Abbasaga auf der hier besprochenen Tafel Transaktionen verzeichnete, die sich in beiden Fällen auf den Viehbestand der Königin bezogen. Abī-simtī wäre damit diejenige, die das Opfer für Enlil und Ninlil in diesem Fall veranlaßte.

2. OIP 121, 432 (22/iii/AS 1):

In diesem Text werden je drei Schafe für Enlil und Ninlil sowie zusätzlich ein weibliches Zicklein für Ninlil abgebucht, außerdem noch 5 Schafe für die Küche zugunsten der Wachen ( $\mathrm{g} \mathrm{a}_{3}$-ú $\left.\mathrm{s}-\mathrm{e}-\mathrm{n} \mathrm{e}\right)$. Die Lieferungen werden von $\mathrm{Nalu}^{525}$ verbucht. Dieser Text gehört in die Zeit wenige Tage vor dem Tod der Šulgi-simtî ${ }^{526}$. Der Umfang der Gaben für Enlil und Ninlil entpricht dem bei Šulgi-simtī Üblichen, ebenso die Tatsache, daß die Göttin ein Tier mehr erhielt als der Gott. Dennoch ist dieser Text wohl nicht Šulgi-simtī zuzurechnen, da ihr Beamter in dieser Zeit Šulgi-ilī war ${ }^{527}$. Es liegt also nahe, hier die junge Königin Abī-simtī als Verantwortliche für das Opfer zu vermuten und anzunehmen, daß sie die Pflichten der Königin gegenüber den Göttern von Nippur von Beginn an übernahm. Wenn diese Annahme zutreffend ist, wäre dieser Text einer der frühesten zu den kultischen Tätigkeiten der Abī-simtī überhaupt.

Ein weiterer Beleg für eine Beteiligung der Ab̄̄-simtī bei Opfern für die Götter von Nippur ist dagegen eindeutiger, da der Name der Königin im Text

$524 \quad$ Siehe oben S. 110.

${ }_{525}$ Zu Nalu siehe Sigrist, Drehem (1992), S. 257-259.

526 Totenopfer für sie wurden am 28/iii/AS 1 verbucht, wobei ebenfall Nalu der verantwortliche Beamte war (ZVO 25, 134, 2).

${ }_{527}$ Die letzten 71 Tiere aus dem Viehbestand der Šulgi-simtī wurden am 4/iv/AS 1 von Nasa in den Bestand der königlichen Viehhaltung übernommen (PDT II, 1215). 
selber zu finden ist. ${ }^{528}$ Bei diesem Text handelt es sich um umfangreiche Ausgaben zu den Vorabendfeiern ${ }^{529}$ für die Riten zum 7. Tag in Nippur. Die Besonderheit dieser Tafel liegt darin, daß explizit die Anwesenheit des Königs (lugal $\mathrm{ku}_{4}$-ra) und der Königin, welche als Überbringerin eines Teils der Gaben fungierte ( $\hat{\mathrm{iri}}_{3} A$-bí-sí-im-ti), vermerkt wurde. Der Grund für die Anwesenheit des Königs und seiner Mutter bei diesen Riten ist wohl im unmittelbar bevorstehenden NE.NE- $\hat{\mathrm{g}}$ ar-Fest zu suchen. Dieses Fest wurde in Nippur in der Mitte des fünften Monats gefeiert und gehört in den Kreis der Feiern zum Totenkult. ${ }^{530} \mathrm{Ob}$ Abī-simtī nach der Durchführung der Vorabendriten auch an den Feierlichkeiten zum NE.NE-g gar-Fest teilnahm, geht aus dem Text nicht hervor.

Nach Opfern von mehreren Schafen für Enlil, den Thron Enlils ( ${ }^{\mathrm{d}} \mathrm{Gu}-\mathrm{za}$ ${ }^{d} E n-111$ l-lá) und das Emblem Enlils (šu-nir $\left.{ }^{d} E n-l i ́ l\right)$ im Tempel des Gottes, sowie für seine Gemahlin Ninlil, bei denen der Mundschenk (sagi) Atu als Bevollmächtigter (maškim) fungierte, wurden weitere Schafe für Suen und andere Götter (Namen abgebrochen) bei s is ku $\mathrm{r}_{2}$-Riten dargebracht. Diese Riten fanden bei der Ankunft des Königs im Palast von Nippur statt. Es folgten Opfergaben für Nintinuga, Nin-é-gal und Nanna, bei denen die Königin als Überbringerin ( $\hat{g}_{i r i_{3}}$ ) auftrat. Nintinuga und Nanna gehörten zu den Gottheiten, die im Tempel der Ninlil verehrt wurden. ${ }^{531}$ Die zu diesem Anlaß vollzogenen Riten waren also umfangreicher und komplexer Art, was auf die Bedeutung des anschließenden NE. NE- $\hat{g}$ ar-Festes hinweist.

Ein anderes Opfer von einem Lamm für Nanna dürfte dagegen eher als spontanes persönliches Opfer angesehen werden ${ }^{532}$, da Abī-simtī die Gabe am Ort der siskur ${ }_{2}$-Riten (ki-siskur ${ }_{2}$ ) selber überbrachte, der Text aber nicht in den Kontext eines größeren Festes gestellt werden kann. In diesem Text werden weiterhin Opfer für die schon von Šulgi-simtī regelmäßig beopferten Göttinnen Ninsun und Allatum verbucht, ebenso für die mit der Unterwelt assoziierten Gottheiten Geštinanna, Dumuzi und Nungal. Bei diesen Opfern fungieren verschiedene Beamten als Bevollmächtigte. Des weiteren werden Tiere für ein Bierausschenken der Kubātum für die Prinzessin Simat-Ištarān

\footnotetext{
${ }_{528}$ MVN 13, 98 (3/v/ŠS 9).
}

$\mathrm{Zu}$ den Vorabendfeiern, Riten die in der Nacht (á- $\left.\hat{\mathrm{g}} \mathrm{i}_{6}-\mathrm{ba}-\mathrm{a}\right)$ vor den Feiern zum Neulicht, 7. Tag und Vollmond vollzogen wurden, siehe Sallaberger, Der kultische Kalender (1993), S. 50-55 und Tabelle 7.

530 Zu diesem Fest siehe Sallaberger, Der kultische Kalender (1993), S. 125-127.

531 Sallaberger, Der kultische Kalender (1993), S. 1 100-101.

532 ASJ 4, S. 140 Nr. 1. Das Datum ist abgebrochen, die Erwähnung der Kubātum deutet aber auf ein ŠS-Datum hin. Zur Interpretation des Opfers als persönliche Gabe siehe Sallaberger, Der kultische Kalender (1993), S. 208 Anm. 987. 
bereitgestellt. SI.A-tum, die Mutter Šulgis, wurde wohl als eine Personifikation der Göttin Geštinanna verehrt ${ }^{533}$, auch alle anderen in diesem Text erwähnten Gottheiten werden von den Königinnen mehrfach mit Opfern geehrt. Die handelnden Personen sind hier neben den verschiedenen Beamten die hochrangigsten Frauen des Hofes, nämlich Abī-simtī, die Mutter des regierenden Königs, seine Frau Kubātum und seine (Halb-)Schwester SimatIštarān. Dies legt die Vermutung nahe, daß alle Opfer im Auftrag einer dieser Frauen ausgeführt wurden, wobei nicht zu entscheiden ist, ob Abī-simtī oder Kubātum hier als Auftraggeberin anzusehen ist.

\subsubsection{Die syrischen Gottheiten Dagān, Išhara und Haburītum}

$\mathrm{Ab}$ dem Jahr AS 8 werden die Belege für kultische Aktivitäten der Abī-simtī außerhalb der Neumondriten zahlreicher ${ }^{534}$. Seit dieser Zeit finden sich regelmäßig Zeugnisse für die Verehrung der syrischen Gottheiten Dagān, Išhara und Haburītum. Dabei wird stets dem Dagān geopfert, meist zusammen mit der Göttin Išḩara. Die Opfer für diese Gottheiten lassen sich nicht in das Raster eines bestimmten Festes oder einer festgelegten Jahreszeit einordnen, und bei allen Opfern der Zeit Šu-Suens fungierte Abī-simtī selber als Überbringerin ( $\hat{\mathrm{giri}}_{3}$ ), wohingegen sich in den Texten aus der Zeit AmarSuens die Formulierung findet, daß die Opfer ,um der Abī-simtī/der Königin willen" (mu-A-bí-sí-im-til nin-šè) dargebracht werden. Ein Anlaß für die Opfer wird in keinem Fall genannt. Diese Charakteristika der Opfer für die syrischen Gottheiten legen die Vermutung nahe, daß es sich um persönliche Gaben der Königin handelte, die nicht in den Kontext der Kulte für die großen Göttern von Sumer wie Enlil und Ninlil in Nippur, Nanna in Ur und Inanna in Uruk gehören, auch wenn Inanna mitunter im selben Kontext beopfert wird. Wie Prechel zeigen konnte, gehört die Göttin Išhara zu den Gottheiten nichtsumerischen Ursprungs, deren Kult in der Ur III-Zeit insbesondere vom Königshaus gefördert wurde. ${ }^{535}$ Išḩara wurde schon von Šulgi-simtī verehrt ${ }^{536}$, während der Kult der Habirītum unter den Frauen der Könige ausschließlich von Abī-simtī gepflegt wurde.

\footnotetext{
$533 \quad$ Siehe oben S. 27.

${ }_{534}$ Vgl. Tabelle 14: Andere kultische Verpflichtungen der Abī-simtī, S. 146-148.

535 Prechel, Die Göttin Išhara (1996), S. 31.

536 MVN 18, 53 (-/ix/Š 33); MVN 18, 114 (vii/Š 35); MVN 18, 57 (-/i/Š 36); MVN 18, 60 (1-2/ix/Š 36); TRU $282(6 /$ ix/ŠS 46).
} 


\begin{tabular}{|c|c|c|c|}
\hline Publikation & Datum & Opfergabe & $\begin{array}{l}\text { Formulierung bzgl. } \\
\text { Abī-simtī }\end{array}$ \\
\hline $\begin{array}{l}\text { AUCT II, } \\
238\end{array}$ & 9/ii/AS 8 & 2 Gazellenböcke für Dagān & $\mathrm{mu}$ nin-šè \\
\hline $\begin{array}{l}\text { Toronto } \\
160\end{array}$ & $\begin{array}{l}18 / x \mathrm{i} / \mathrm{AS} \\
9\end{array}$ & $\begin{array}{l}\text { je } 1 \text { Schaf für Dagān, Išḩara } \\
\text { und Haburītum }\end{array}$ & $\mathrm{mu} A b \bar{l}-\operatorname{sim} t \bar{l}-\check{\mathrm{s}} \mathrm{è}$ \\
\hline PDT I, 269 & $\begin{array}{l}10 / x i i / S ̌ S \\
3\end{array}$ & $\begin{array}{l}2 \text { Schafe, } 2 \text { Lämmer für Dagān, } \\
2 \text { Schafe, } 2 \text { Lämmer für Išhara, } \\
1 \text { Schaf, } 1 \text { Lamm für Inanna für } \\
\text { siskur }_{2} \text { šà é-g a l }\end{array}$ & $\hat{\mathrm{g}} \mathrm{ir} \mathrm{i}_{3} A b \bar{l}-\operatorname{sim} t \bar{\imath}$ \\
\hline $\begin{array}{l}\text { MVN 5, } \\
125\end{array}$ & 4/iii/ŠS 4 & $\begin{array}{l}\text { je [x] Schafe für Dagān und } \\
\text { Išhara, je } 1 \text { Schaf für Inanna, } \\
\text { Nin-niĝar und [ ] für s i s ku r }{ }_{2} \text { - } \\
\text { Riten im Garten, } 2 \text { Schafe, } 2 \\
\text { Lämmer für Haburītum }\end{array}$ & $\hat{\mathrm{g}} \mathrm{ir} \mathrm{i}_{3} A b \bar{l}-\operatorname{simt} \bar{\imath}$ \\
\hline CST 440 & $\begin{array}{l}18 / v i / S ̌ S \\
7\end{array}$ & $\begin{array}{l}\text { 1 Lamm für Dagān, } 1 \text { Schaf für } \\
\text { Haburītum }\end{array}$ & $\hat{\mathrm{g}} \mathrm{ir} \mathrm{i}_{3} A b \bar{l}-\operatorname{simt} \bar{\imath}$ \\
\hline $\begin{array}{l}\text { SAT III } \\
1871\end{array}$ & $\begin{array}{l}15 / \mathrm{vi} / \mathrm{S} S \\
9\end{array}$ & je 1 Rind für Dagān und Išḩara & $\hat{\mathrm{g}} \mathrm{ir} \mathrm{i}_{3} A b \bar{l}-\operatorname{sim} t \bar{\imath}$ \\
\hline
\end{tabular}

Tabelle 12: Abī-simtī und die syrischen Gottheiten Dagān, Išḩara und Haburītum

Der Kult des Dagān, des obersten Gottes im syrischen Pantheon ${ }^{537}$, ist erst ab dem Jahr AS 8 sicher in den Texten zu Lieferungen von Opfergaben nachzuweisen $^{538}$, doch beweist schon die Benennung des königlichen Viehhofes Puzriš-Dagān im Jahr Š 39 die Verehrung dieses Gottes am Hof von Ur ${ }^{539}$. Wann der Kult dieses Gottes nach Ur kam, ist noch nicht abschließend geklärt, es wurde vermutet, Tarām-Uram, die erste Frau Šulgis, habe den Kult aus ihrer Heimatstadt Mari mit nach Ur gebracht ${ }^{540}$, doch wären dann mehr Belege für Opfer an Dagān aus der Regierungszeit Šulgis zu erwarten.

Sicher ist, daß die Verehrung Dagāns insbesondere im Königshaus zur Zeit Šu-Suens gepflegt wurde, wobei der Beginn dieser Verehrung in den letzten Jahren seines Vaters Amar-Suen schon faßbar ist. Auch läßt sich eine besondere Nähe der Königinnen Šulgi-simtī und Abī-simtī zum Kult der Išḩara

537 Waetzoldt, Pettinato, Dagān in Ebla und Mesopotamien, OrNS 54 (1985), S. 248.

538 AUCT II, 238 (9/ii/AS 8); vgl. Hilgert, erubbatum im Tempel des Dagān, JCS 46 (1994), S. 33; Feliu, The God Dagan in Bronze Age Syria (2003), S. 48-52; Sharlach, Foreign Influences on the Religion of the Ur III Court (2002), S. 95.

539 Boese, Sallaberger, Apil-kīn von Mari, AoF 23 (1998), S. 26-27; Feliu, The God Dagan in Bronze Age Syria (2003), S. 53-54; Sharlach, Foreign Influences on the Religion of the Ur III Court (2002), S. 96.

540 Boese, Sallaberger, Apil-kīn von Mari, AoF 23 (1998), S. 26. 
sowie bei Abī-simtī auch des Dagān feststellen ${ }^{541}$. Von den 24 Texten mit Opfern für Dagān und/oder Išḩara, die Hilgert auflistet ${ }^{542}$, stehen 10 zweifelsfrei im Zusammenhang mit diesen Königinnen. Ein Text bezeugt Opfer für Dagān im Haus des Babati, Bruder der Abī-simtî ${ }^{543}$. Ob auch die anderen Belege für den Kult dieser beiden Gottheiten im Zusammenhang mit den königlichen Frauen, insbesondere der Königin Abī-simtī, zu sehen sind, ist nicht zu belegen. Dennoch stellt sich die Frage, ob die zunehmende Verehrung von Dagān und Išhara unter Amar-Suen und Šu-Suen nicht damit zu erklären ist, daß Abī-simtī aus Syrien stammte und die Verehrung der syrischen Gottheiten, die am Hof von Ur nicht unbekannt waren, besonders gefördert hat. Für das Fehlen von Belegen für die ersten Jahre unter Amar-Suen und die Zunahme an Belegen für die Regierungszeit von Šu-Suen gäbe es mehrere Erklärungsansätze, die sich jedoch nicht gegenseitig ausschließen:

a. Der Zufall der Überlieferung.

b. Eine Entwicklung im religiösen Leben der Ab̄̄-simtī. Ähnlich wie bei Šulgi-simtī, deren religiöse Pflichten sich erst im Verlauf der ersten Amtsjahre als Königin entwickelt zu haben scheinen ${ }^{544}$, könnte auch bei Abī-simtī eine vergleichbare Entwicklung stattgefunden haben, bei der sie sich erst an die Aufgaben ihrer Amtsvorgängerin anlehnte ${ }^{545}$, sich später jedoch verstärkt in den von ihr bevorzugten Kulten engagierte, wozu der Kult der syrischen Gottheiten Dagān und Išhara gehörte.

c. Eine veränderte kultische Funktion nach der Thronbesteigung ihres Sohnes. Für letzteres spricht die deutliche Abnahme von Texten zu Neumondriten bei gleichzeitiger Zunahme anderer kultischer Aktivitäten der Abī-simtī. Als Mutter des Königs hatte sie offenbar andere Aufgaben als eine erste Gemahlin des regierenden Königs.

Neben Dagān und Išhara verehrte Abī-simtī auch die Göttin Haburītum. ${ }^{546}$ Belege für diese Göttin in den Texten der Ur III-Zeit sind äußerst selten, ein Tempel der Haburītum ist nicht bekannt. Auch ist umstritten, ob der Name der Göttin vom Fluß Habur abgeleitet ist oder von einer Ortschaft Hुabura, wobei

${ }^{541}$ Zu der besonderen Verehrung der Abī-simtī für Dagān und Išhāara siehe auch SuchGutiérrez, Beiträge zum Pantheon von Nippur im 3. Jahrtausend (2003), Teil I S. 232$234,250$.

542 Hilgert, erubbatum im Tempel des Dagān, JCS 46 (1994), S. 33-35.

${ }^{543}$ OIP 121, $572(14 /$ ix/AS 9) = JAOS 108, 119.

544 Siehe S. 58.

545 Vgl. die Opfer für Nanaja und am Tor des Gipar, S. 143 (bei Abī-simtī) und S. 63-65 (bei Šulgi-simtī).

546 Toronto 160 (18/xi/AS 9); MVN 5, 125 (4/ii/ŠS 4); CST 440 (18/vi/ŠS 7), sowie MVN 20, 31 (ii/AS 5), wo die Göttin als Inanna-Hुaburītum auftritt. 
im letzten Fall mehrere Orte dieses Namens als Herkunftsort der Göttin möglich wären. ${ }^{547}$

Wahrscheinlich wurde Haburītum als eine Inanna-Manifestation gesehen, da im Text MVN 20, 31 (ii/AS 5) ein Elūnum ${ }^{58}$ für Inanna-Haburītum von Abī-simtī durchgeführt wird, in MVN 5, 125 (4/ii/ŠS 4) werden dagegen beide Göttinnen deutlich voneinander getrennt erwähnt ${ }^{549}$. Dies bedeutet, daß InannaHaburītum wohl als eine Gottheit angesehen wurde, die in zwei unterschiedlichen Manifestationen verehrt werden konnte.

\subsubsection{Inanna}

Ebenso wie Šulgi-simtī brachte auch Abī-simti der Göttin Inanna besondere Verehrung entgegen. Aus der Regierungszeit Amar-Suens sind nur zwei Texte zu Opfern der Abī-simtī an Inanna erhalten. Zwei Texte verzeichnet jedoch eine Reise der Königin nach Uruk, wo sie möglicherweise am Kult der Göttin teilnahm. Es ist denkbar, daß sich die beiden Texte NISABA 8, 139 (19/ix/AS 7) und TRU 288 (23/xi/AS 7) auf den selben Aufenthalt der Abīsimtī in Uruk beziehen, denn der erste Text verzeichnet die Anreise, letzterer eine Abreise der Königin.

Unter Šu-Suen sind rund die Hälfte aller Texte zu Opfergaben bei Abīsimtī mit Inanna in Verbindung zu bringen ${ }^{550}$. Dazu kommen mehrere Texte über Reisen der Königin nach Zabalam bzw. ihren Aufenthalt dort. Der Inanna von Zabalam, einem Ort wenige Kilometer nördlich von Umma, war Abī-simtī insbesondere in der Zeit als Mutter des Königs besonders verbunden.

Aus dem Jahr AS 5 stammt ein singulärer Text über ein von Abī-simtī durchgeführtes Elūnum für Inanna-Haburītum ${ }^{551}$. Das Elūnum ist sonst bei Šulgi-simtī belegt, die dieses Fest für ihre Göttinnen Bēlat-Šuhnir und BēlatDeraban feierte ${ }^{552}$. Für ein Elūnum zu Ehren der Inanna ist dies bislang der

547 Sharlach, Foreign Influences on the Religion of the Ur III Court (2002), S. 103-105. Für eine Ableitung des Namens der Göttin von Fluß Habur spricht sich SuchGutiérrez, Beiträge zum Pantheon von Nippur im 3. Jahrtausend (2003), S. 330f, aus.

548 Siehe dazu den folgenden Abschnitt zu Inanna.

549 Siehe Prechel, Die Göttin Išḩara (1996), S. 29 + Anm. 18.

550 Siehe Tabelle 14: Andere kultische Verpflichtungen der Abī-simtī, S. 146-148.

551 MVN 20, 31 (II/AS 5); der Text wurde zuerst publiziert und besprochen von d'Agostino, Ein neuer Text über Abī-simtī und das Elūnum-Fest in Puzriš-Dagān, ZA 88 (1998), S. 1-5.

552 Siehe S. 81-83. In altbabylonischer Zeit ist das Elūnum-Fest in verschiedenen Orten zu finden, wobei es jewils für unterschiedliche Gottheiten gefeiert wurde, so in Sippar für Šamaš oder in Ur für Ningal. Siehe dazu Cohen, Cultic Calendars (1993), S. 398399. 
einzige Beleg. Es ist auch der einzige Text, der sicher die Beteiligung der Abīsimtī an diesem Fest bezeugt. ${ }^{553}$ Außergewöhnlich ist weiterhin, daß MVN 20, 31 (ii/AS 5) einer der wenigen Texte aus dem Schatzarchiv ist, der sich eindeutig einer der königlichen Damen zuordnen läßt. Abī-simtī schenkte der Inanna anläßlich des Elünum eine Reihe von Bronzegegenständen, darunter 16 Trinkbecher $\left(\mathrm{gal}^{\mathrm{zabar}}\right)$ und eine Flöte $\left(\mathrm{gi}-\mathrm{g} \mathrm{i}^{\mathrm{zabar}}\right)$. Der Umfang des Geschenkes von insgesamt 30 Objekten an die Göttin ist ungewöhnlich gro ${ }^{554}$, was darauf hindeutet, daß möglicherweise ein besonderes Ereignis Anlaß zu diesem Elūnum gab. Hier liegt es nahe, die in diesem Jahr (AS 5) erfolgte Amtseinführung des En-unu ${ }_{6}$-gal-an-na als En der Inanna von Uruk als das Ereignis zu sehen, welches ein solch außergewöhnliches Geschenk der Königin an die Göttin bedingte. Auch die Lieferung von zwei Silberringen an den Palast, die nach den Gaben für Inanna auf der Tafel verzeichnet sind, passen in den Kontext eines Festes, in dessen Verlauf nicht nur die Götter geehrt werden, sondern auch einzelnen Teilnehmern des Festes Geschenke überreicht werden. Angesichts der besonderen Umstände für dieses von Abī-simtī durchgeführte Elünum stellt sich die Frage, ob dieses Fest von ihr ebenso wie von ihrer Amtsvorgängerin regelmäßig jährlich gefeiert wurde, oder ob Abī-simtī das Elūnum nur zu besonderen Anlässen begangen hat. Bei der derzeitigen Quellenlage muß diese Frage vorerst unbeantwortet bleiben. Auch der Ort für die Feierlichkeiten ist nicht sicher zu bestimmen. Die in MVN 20, 31 aufgeführten Gegenstände werden in Puzriš-Dagān abgebucht (b a-zi), Šulgisimtī feierte das Elūnum in Ur, doch wenn die Annahme zutreffend ist, daß Abī-simtī mit diesem Fest für Inanna-Huaburītum die Einsetzung des En der Inanna von Uruk feierte, ist nicht auszuschließen, daß Uruk auch als Handlungsort für dieses Elūnum zu sehen ist ${ }^{555}$.

Mehrfach war Abī-simtī als Überbringerin ( $\left(\mathrm{g}_{\mathrm{iri}}{ }_{3}\right)$ von Rindern und Klein-

553 Zwei weitere Texte zu einem Elūnum sind nicht zweifelsfrei in diesen Kontext zu stellen; PDT II, 1120 (2/ii/AS 4) verzeichnet die Ausgabe von je einem Schaf an 6 Sängerinnen für ein Elūnum, wobei nicht bekannt ist, ob die Königin an diesem Fest beteiligt war und für welche Gottheit das Elūnum gefeiert wurde. Möglicherweise bezieht sich auch UET 3, 70 (ohne Datum) auf ein Elūnum, bei dem die Königin beteiligt gewesen sein könnte, da der Text unter anderem auch Lieferungen von Lebensmitteln an ihren Palast (k i - n i n) verzeichnet. Möglicherweise führte Abī-simtī auch die Tradition des Elūnum für Bēlat-Šuhnir weiter (PTS 830 (AS 8), unpubliziert, siehe Cohen, Cultic Calendars (1993), S. 398) .

554 Vgl. Sallaberger, Der kultische Kalender (1993), Tab. 1 mit einer Aufstellung der im Schatzarchiv verzeichneten Gaben des Königs an die Götter, die im Umfang zumeist deutlich unter 10 Objekten liegen.

555 D'Agostino hatte Puzriš-Dagān oder Ur als mögliche Festorte genannt: Ein neuer Text über Abī-simtī und das Elūnum-Fest in Puzriš-Dagān, ZA 88 (1998), S. 5. 
vieh für Inanna tätig. ${ }^{556}$ Wie schon aus den unterschiedlichen Monatsdaten hervorgeht, handelt es sich bei diesen Texten nicht um eine homogene Gruppe, die einem bestimmten Fest oder Ritual zuzuordnen wäre, sondern um verschiedene Anlässe, zu denen Abī-simtī der Inanna Opfer darbrachte.

So nahm sie im Jahr ŠS 9 zusammen mit dem König (l u gal $\mathrm{ku}_{4}-\mathrm{ra}=$ in Anwesenheit des Königs) an einem mehrtägigen Fest für Inanna in Uruk teil, in

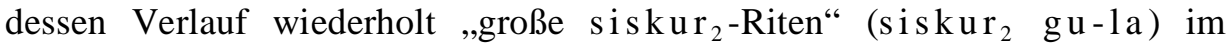
Tempel der Inanna vollzogen wurden. Ein Bestandteil der komplexen Ritualhandlungen zu diesem Anlaß war die Opferung von 5 durch Abī-simtī überbrachten Schafen für die Göttin. ${ }^{557}$ Dieses Fest für Inanna von Uruk wurde wohl jährlich begangen, wobei, wie Sallaberger herausstellte, die einzelnen Quellen zu diesem Fest ein sehr heterogenes Bild von seinem Ablauf vermitteln. ${ }^{558}$ Zum Zeitpunkt der hier beschriebenen Opfer für Inanna im Monat x/ŠS 9 war Šu-Suen nicht mehr am Leben, er starb zu Beginn dieses Monats. ${ }^{559}$ Wahrscheinlich gehört der Text PDT I, 563 (21/x/ŠS 9) ebenfalls in den Kontext dieses mehrtägigen Inannafestes, in dem neben Inanna eine Reihe verschiedener Gottheiten in Uruk beopfert wurden, darunter auch die der Inanna nahestehende Göttin Gansura ${ }^{560}$, welche ein Schaf und ein Zicklein ,um des Königs willen“ (mu-lugal-šè) und drei Schafe „um Geme-Enlilas willen“ (mu ${ }^{d} \mathrm{Geme}_{2}-{ }^{\mathrm{d}} \mathrm{En}-11$ l-1á-šè) erhielt ${ }^{561}$. Bei dem König handelt es sich um Abī-simtīs Enkel Ibbi-Suen, Geme-Enlila war die Königin an seiner Seite $^{562}$. Es stellt sich also bei den Opfern der Abī-simtī für Inanna im Monat x/ŠS 9 die Frage, ob Abī-simtī regelmäßig an diesem Fest für die Göttin von Uruk teilnahm, wofür bisher weitere Belege fehlen, oder ob es sich um ein einmaliges Ereignis handelte, bei dem sie der von ihr besonders verehrten Göttin im Zusammenhang mit dem Thronwechsel dieses Opfer darbrachte.

556 TCNY 357 (15/ii/AS 9); BIN III, 215 (29/iv/ŠS 1); MVN 10, 142 (2/x/ŠS 2); Rochester 7 (7/v/ŠS 5?); MVN 18, 108 (1-30/x/ŠS 9). MVN 18, 108 RS Kol.VI Z. 23-25 (29/x/ŠS 9).

558 Sallaberger, Der kultische Kalender (1993), S. 214-216 + Tab. 70.

559 Sallaberger, OBO 160/3 (1999), S. 171. Sigrist wollte den Text MVN 18, 108 als einen Beleg für eine monumentale Trauerfeier für Šu-Suen verstehen ( Le deuil pour Šu-Sin, FS Sjöberg (1989), S. 499-505). Wie Sallaberger gezeigt hat, sind viele Einträge dieses Textes zyklischen Festen zuzuordnen und stehen damit nicht notwendigerweise in direktem Zusammenhang mit dem Tod des Königs (OBO 160/3 (1999), S. 171 Anm. 173).

560 Zu Gansura siehe Richter, Panthea Süd- und Mittelbabyloniens (1999), S. 236; Sallaberger, Der kultische Kalender (1993). S. 213 + Anm. 1008.

561 PDT I, 563 (21/x/ŠS 9) VS Kol II, 7-13.

562 Zu Geme-Enlila siehe S. 164-169. 
Ein weiterer singulärer Text ist BIN III, 215 (29/iv/ŠS 1). Es werden jeweils zwei Schafe für Inanna und Dumuzi sowie je ein Schaf für die Richtergottheiten Išar und Mišar und eine Ziege für Inannas Wesir Ninšubur verbucht. Abī-simtī hatte diese Gaben selber in Badtibira, dem Kultort des Dumuzi, überbracht. Der Anlaß für diese Opfer ist nicht vermerkt, doch ist sowohl der Kultort im Zusammenhang mit den königlichen Frauen singulär, wie auch die Opfer für Dumuzi, Išar und Mišar. Zwar erscheint der Hochsommer als Zeitpunkt für das Opfer im Kult des mit der Unterwelt verbundenen Gottes Dumuzi naheliegend, doch könnte die Kombination der Gaben für Inanna, die von Abī-simtī besonders verehrt wurde, Dumuzi und die Richtergottheiten Išar und Mišar auch auf ein einzelnes, persönliches Opfer hindeuten, das im Zusammenhang mit einer bestimmten Situation im Leben der $A b \overline{1}$-simtī zu sehen ist, wobei uns die näheren Umstände unbekannt bleiben.

\subsubsection{Reisen zu Inanna von Zabalam}

$\mathrm{Ab}$ dem Jahr AS 9, finden sich zahlreiche Belege für wiederholte Reisen der Abī-simtī nach Zabalam, sowie Opfer der Königin an die dort verehrte Inannagestalt. ${ }^{563}$ Die Inanna von Zabalam wurde schon in altsumerischer Zeit verehrt $^{564}$ und ihr Kult wurde auch in altbabylonischer Zeit noch gepflegt ${ }^{565}$.

Bei den durchweg aus Umma stammenden Texten zu den Aufenthalten der $A b \overline{1}$-simtī in Zabalam ist bemerkenswert, daß nur insgesamt drei Texte direkt Ausgaben für Kulthandlungen verbuchen. Bei allen anderen Texten werden unterschiedliche Güter wie Lebensmittel, Gewänder und Edelmetalle sowie Arbeitskräfte verzeichnet, die entweder in Zabalam selber ausgegeben werden (šà Zabala m ${ }^{\mathrm{ki}}$ ) oder aber „,wenn Abī-simtī/die Königin nach Zabalam geht“ (A-bí-sí-im-ti/nin Zabala m${ }^{\mathrm{ki}}$-šè ĝ en-na). Damit bieten diese Texte einen seltenen Einblick in das Umfeld derartiger königlicher Besuche bei einem wichtigen Heiligtum des Landes. Da die Texte im Zusammenhang mit Reisen der Abī-simtī nach Zabalam in den meisten Fällen nur auf das Jahr datiert sind, ist es nicht möglich, sie in den Kontext von regelmäßigen Festen des nahegelegenen Umma zu stellen. ${ }^{566}$

Bei den Riten, die Abī-simtī für die Inanna von Zabalam durchführte,

Zu den Aufenthalten der Abī-simtī in Zabalam siehe auch Dahl, The Ruling Family of Ur III Umma (2003) http://www.cdli.ucla.edu/staff/dahl/dissertation.pdf (20.06.2007). Ich danke J. Dahl, der mir seine Arbeit schon vor der Veröffentlichung zur Verfügung gestellt hat.

564 Selz, Untersuchungen zur Götterwelt des altsumerischen Stadtstaates von Lagaš (1995), S. 154 sub. 44.

565 Richter, Panthea Süd- und Mittelbabyloniens (1999), S. 312-313.

566 Sallaberger, Der kultische Kalender (1993), S. 263 Anm. 1239. 
handelte es sich nach den Texten, die diesbezügliche Aussagen zulassen, stets um siskur ${ }_{2}$-Riten. Daß diese mitunter mit großem Aufwand gefeiert werden konnten, belegt BIN V, 31 (ŠS 3), wo insgesamt zwei Rinder, zwölf Schafe, neun Lämmer und vier Ziegen bereitgestellt werden. Ebenfalls aus dem Jahr ŠS 3 stammt TPTS 238, wo die Ausgabe von sieben mit Bitumen abgedichteten Körben für si skur ${ }_{2}$-Riten der Königin in Zabalam verzeichnet ist. Der leider nicht vollständig erhaltene Text MVN 18, 241 (vii/ŠS 4) vermerkt die Lieferung verschiedener Bier- und Mehlsorten für ,s iskur ${ }_{2}$-Riten nach dem Herzenswunsch (der Königin) für Inanna von Zabalam“ (siskur ${ }_{2}$ šà-gigur $_{7}$-a ${ }^{\mathrm{d}}$ Inanna Zabalam $\left.{ }^{\mathrm{ki}}\right)^{567}$, bei denen Abī-simtī als Überbringerin $\left(\hat{\mathrm{g} i r i}{ }_{3}\right)$ fungierte. Ein solches spontanes Opfer zeigt die enge Verbundenheit der Königin mit Inanna von Zabalam, an die sie sich gerade auch außerhalb der großen, regelmäßig begangenen Feste mit einem persönlichen Anliegen wenden konnte.

Für ihre Reisen nach Zabalam und den Aufenthalt dort erhielt Ab̄̄-simtī vielfältige Güter, wobei diese Lieferungen häufig vom Ensi von Umma verbucht werden. In einem Fall trat Ninhilia, die Frau des Ensi von Umma, als Überbringerin ( $\hat{\mathrm{g}}_{\mathrm{iri}}{ }_{3}$ ) von Bier, Brot und Mehl als Proviant für die Königin auf. ${ }^{568}$ Ein Brief an Ajakalla, wohl den amtierenden Ensi von Umma, weist diesen an, einem gewissen Ubartum zwei Schafe, Mehl und Bier für si s ku ${ }_{2}$ Riten der Abī-simtī zu übergeben. ${ }^{569}$ Diese Anweisung dürfte im Zusammenhang mit den Reisen der Königin nach Zabalam zu sehen sein, da jene dort siskur ${ }_{2}$-Riten für Inanna durchführte. Dies ist der einzige Text dieser Art, in dem nicht die Lieferung der benötigten Güter verbucht wird, sondern die Anweisungen erhalten sind, welche eine spätere Buchung und Lieferung der Lebensmittel und Tiere erst veranlaßt. Leider ist nicht bekannt, wer der Absender dieses Briefes war.

Es wurden nicht nur Lebensmittel wie Vieh, Fische, Zwiebeln und Knoblauch $^{570}$ gebracht, sondern auch Gegenstände des Alltagsgebrauchs wie

567 Zu šà-gi-gur 7 als spontanes Opfer siehe Sigrist, Drehem (1992), S. 207-208; Sallaberger, Der kultische Kalender (1993), S. 74.

568 SNATBM 422, Sammeltafel über Ausgaben der Jahre AS 9-ŠS 3. Zu Ninhilia siehe Parr, Ninhilia: Wife of Ayakala, Governor of Umma JCS 26 (1974), S. 90-111.

569 JCS 17, S. 32 (undatiert).

570 Schweine in SNATBM 436 (ŠS 1); Rinder und Schafe als máš -da-re-a-Lieferung in MVN 16, 916 (ŠS 3); Zwiebeln und Knoblauch in SNATBM 481 (ŠS 3); Fische in MVN 16, 1092 (ii/ŠS 3) und ITT V, 6960 (undatiert). Wahrscheinlich gehört auch Nakahara 28 (-/-/ŠS 4) in diesen Kontext, der Text aus Umma verbucht Lieferungen von Getreideprodukten an verschiedene Personen, darunter auch an Abī-simtī. 
Schafshäute zum Verschließen von Krügen mit verschiedenen Mehlsorten $^{571}$, Ölgefäß $\mathrm{e}^{572}$ und mit Leder bezogene Körbe ${ }^{573}$. Auch Textilien unterschiedlicher Art und Qualität wurden der Königin geschickt ${ }^{574}$. Ein reich ausgestatteter Wagen wurde nach MVN 16, 796 (vii/ŠS 4) bei Ankunft der Königin in den Palast gebracht. Und in MVN 16, 837 (S̆S 3) erhielt Abī-simtī Gold als Zuteilung/Proviant (igi-kár) ${ }^{575}$. Ein Teil dieser Lieferungen diente sicherlich dem Haushalt der Königin in Zabalam für den täglichen Bedarf, doch läßt sich anhand dieser Texte nicht sicher feststellen, welche Gegenstände möglicherweise auch für den Kult benötigt wurden. So ist es denkbar, daß das Gold als Geschenk für die Göttin bestimmt war, ebensogut könnte es aber auch für Geschenke an Vertreter der lokalen Oberschicht in Umma und Zabalam verwendet worden sein.

Über die notwendigen Transportarbeiten, die bei einem Aufenthalt der Königin in Zabalam erforderlich waren, informieren drei Texte, in denen die für dieses Unternehmen nötigen Arbeitskräfte verzeichnet sind. ${ }^{576}$ Dabei werden die Arbeitsschritte wie das Verladen der Güter, das Treideln des Bootes nach Zabalam und das Entladen einzeln in der Urkunde vermerkt und die jeweils nötige Zahl an Arbeitern angegeben. Anhand dieser Texte wird deutlich, daß eine solche Reise der Königin umfangreiche logistische Planungen erforderte und nicht vollkommen spontan unternommen werden konnte.

In Zabalam selber widmete Abī-simtī sich nicht nur dem Kult der Inanna, sondern kümmerte sich auch um Riten, die mit der Viehzucht verbunden waren. Wie schon für Šulgi-simtī ist auch für Abī-simtī einmal das „,(Gehen) der Herrin zum Schafstall (nin ĝá-udu-šè)“ belegt. ${ }^{577}$ Welche Riten dort

\footnotetext{
571 UTI III, 1724 (汭 1).

572 UTI IV, 2605 (ŠS 1), 1 dug š a g a n, mit Haut bezogen. Dieser Gefäßtyp wurde, nach Waetzoldt, WO 6, S. 21-22, praktisch ausschließlich zur Aufbewahrung von Öl genutzt.

573 SET 288 (iv/ŠS 1). Weitere Texte in diesem Kontext sind UTI IV, 2321 (ŠS 1), TPTS 243 (ŠS 1) und MVN 14, 538 (Datum abgebrochen).

574 UTI III, 2003 (AS 9); MVN 16, 960 (ŠS 3); MVN 16, 713 und MVN 16, 1330 (ŠŠ 4). Die beiden letztgenannten Texte sind Duplikate und unterscheiden sich nur dadurch, daß in MVN 16, 713 die Lieferung für Abī-simtī, die Herrin (n in) verbucht wird während in MVN 16, 1330 nur der Titel (n in ) steht.

575 Wohl auch in diesen Kontext gehört MVN 1, 240 (-/xii/AS 8), wo Silber als ig i - kár n in verbucht wird.

576 UTI IV, 2602 (ŠS 1); UTI V, 3165 (ŠS 1); MVN 18, 235 (ii/ŠS 3); SAT III, 1568 (

577 MVN 16, 796 (vii/ŠS 4) ; zum „Gehen zum Schafstall“ bei Šulgi-simtī siehe S. 88.
} 
vollzogen wurden, ist nicht bekannt. Ob der in MVN 16, 796 beschriebene Wagen speziell für den im selben Text verzeichneten Besuch beim Schafstall verwendet wurde, oder ob es sich dabei um einen Wagen handelte, welcher der Königin üblicherweise zur Verfügung stand, ist nicht festzustellen.

\begin{tabular}{|c|c|c|c|}
\hline Publikation & Datum & $\begin{array}{l}\text { Lieferung/Bereitstellung } \\
\text { von }\end{array}$ & $\begin{array}{l}\text { Formulierung bzgl. der } \\
\text { Königin }\end{array}$ \\
\hline MVN 1, 240 & $\begin{array}{l}-/ x i i / A S \\
8\end{array}$ & Silber & igi-kár nin \\
\hline UTI III, 2003 & -/-/AS 9 & Leinen & zi-g a $A$-bí-sí-im-tinin \\
\hline $\begin{array}{l}\text { SNATBM } \\
422\end{array}$ & $\begin{array}{l}- \text {-/-/AS 9- } \\
\text { ŠS } 1\end{array}$ & $\begin{array}{l}\text { Brot, verschiedene } \\
\text { Mehlsorten, Bier }\end{array}$ & gurum ${ }_{2}$ nin \\
\hline SET 288 & -/iv/ŠS 1 & $\begin{array}{l}17 \text { Körbe mit } \\
\text { Lederhäuten }\end{array}$ & A-bí-sí-im-ti $\mathrm{n}$ in - G A R \\
\hline UTI IV, 2321 & -/iv/ŠS 1 & 17 Körbe & $\hat{\mathrm{g} i r i_{3}} \operatorname{nin}$ \\
\hline MVN 18,508 & - -/-/ŠS 1 & $\begin{array}{l}\text { (Haus der Königin, Text } \\
\text { fragmentarisch) }\end{array}$ & é nin \\
\hline $\begin{array}{l}\text { SNATBM } \\
436\end{array}$ & -/-/ŠS 1 & 8 Schweine & gurum ${ }_{2}$ nin \\
\hline TPTS 243 & $-/-/$ ŠS 1 & verschiedene Gefäße & $\begin{array}{l}\text { Zi-ganin } \\
\text { Zabalaki -šè ĝen- } \\
\text { na-aš }\end{array}$ \\
\hline UTI III, 1724 & -/-/ŠS 1 & $\begin{array}{l}10 \text { Häute zum } \\
\text { Verschließen von Krügen }\end{array}$ & $\begin{array}{l}\text { nin Zabala }{ }_{3}{ }^{k i}-\text { šè i- } \\
\text { im-gen-na-a }\end{array}$ \\
\hline UTI IV, 2602 & $-/-/$ ŠS 1 & $\begin{array}{l}\text { [ ] Arbeiter für versch. } \\
\text { Tätigkeiten }\end{array}$ & 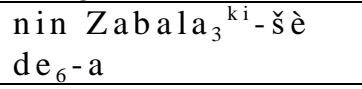 \\
\hline UTI IV, 2605 & $-/-/$ ŠS 1 & Ölgefäß & $\begin{array}{l}\text { ig i-kár A-bí-sí-im-ti } \\
\text { nin }\end{array}$ \\
\hline UTI V, 3165 & -/-/ŠS 1 & $\begin{array}{l}\text { Arbeiter für versch. } \\
\text { Tätigkeiten }\end{array}$ & $\begin{array}{l}\operatorname{nin~Zabala}{ }_{3}{ }^{k i}-\text { šè } \\
\text { gen-na }\end{array}$ \\
\hline BPOA 1, 944 & $-/-/$ ŠS 1 & Arbeiter & $\begin{array}{l}\text { nin } \mathrm{Zabala}_{3}{ }^{\mathrm{ki}}-\mathrm{s} \text { è } \\
\text { gen-na }\end{array}$ \\
\hline $\begin{array}{l}\text { MVN 16, } \\
1092\end{array}$ & -/ii//ŠS 3 & 15 Körbe mit Fischen & $\begin{array}{l}\text { ki-nin-šè šà } \\
\text { Zabala }{ }^{k i}\end{array}$ \\
\hline MVN 18, 235 & -/ii//ŠS 3 & 22 Arbeiter & $\begin{array}{l}\text { A-bí-sí-im-tin in i-im- } \\
\text { gen-na-a }\end{array}$ \\
\hline BIN V, 31 & -I-/ŠS 3 & $\begin{array}{l}2 \mathrm{G} \text { und } 25 \mathrm{~K} \text { für } \\
\text { siskur }_{2}\end{array}$ & 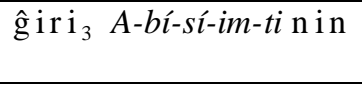 \\
\hline MVN 16, 916 & -I-/ŠS 3 & $\begin{array}{l}1 \mathrm{G} \text { und } 10 \mathrm{~K} \text { als máš }- \\
\text { da-re-a }\end{array}$ & $\begin{array}{l}\text { A-bí-sí-im-ti nin šà } \\
\mathrm{Zabala}_{3}{ }^{\mathrm{ki}}\end{array}$ \\
\hline MVN 16, 960 & - -I/ŠS 3 & Textilien & $\begin{array}{l}\text { igi-kár A-bí-sí-im-ti } \\
\text { nin Zabala }{ }^{\mathrm{ki}}-\mathrm{s} \text { è } \\
\text { gen-na }\end{array}$ \\
\hline
\end{tabular}




\begin{tabular}{|c|c|c|c|}
\hline Publikation & Datum & $\begin{array}{l}\text { Lieferung/Bereitstellung } \\
\text { von }\end{array}$ & $\begin{array}{l}\text { Formulierung bzgl. der } \\
\text { Königin }\end{array}$ \\
\hline MVN 16, 837 & -/-/ŠS 3 & Gold & $\begin{array}{l}\text { igi-kár nin } \\
\text { Zabala }{ }_{3}{ }^{-} \text {-š̀ ĝen- } \\
\text { na }\end{array}$ \\
\hline $\begin{array}{l}\text { SNATBM } \\
481\end{array}$ & -/-/ŠS 3 & $\begin{array}{l}\text { Körbe, Zwiebeln und } \\
\text { Knoblauch }\end{array}$ & $\begin{array}{l}\operatorname{gurum}_{2} \mathrm{nin} \\
\mathrm{Zabala}_{3}{ }^{\mathrm{ki}}-\mathrm{s} \text { è gen- } \\
\mathrm{na}\end{array}$ \\
\hline TPTS 238 & -/-/ŠS 3 & 7 Körbe für siskur $r_{2}$ & $\begin{array}{l}\text { siskur }_{2} \text { nin šà } \\
\mathrm{Zabala}_{3}{ }^{2}\end{array}$ \\
\hline MVN 18, 241 & -/vii/ŠS 4 & $\begin{array}{l}\text { Bier und Mehl für } \\
\text { siskur }_{2}\end{array}$ & $\hat{\mathrm{g}} \mathrm{ir \textrm {i }}{ }_{3} A$-bí-sí-im-ti nin \\
\hline MVN 16, 796 & -/vii/ŠS 4 & Körbe, Wagen, Proviant & $\begin{array}{l}\mathrm{zi}-\mathrm{ga} \mathrm{nin} \\
\mathrm{Zabala}{ }^{\mathrm{ki}}-\text { šè ĝen- } \\
\mathrm{na}\end{array}$ \\
\hline MVN 16, 713 & -/-/ŠS 4 & Textilien & g iri ${ }_{3} A-b i ́-s i ́-i m-t i n \mathrm{in}$ \\
\hline $\begin{array}{l}\text { MVN 16, } \\
1330\end{array}$ & -/-/ŠS 4 & Textilien & $\begin{array}{l}\text { igi-kár nin } \\
\text { Zabala }{ }_{3}{ }^{-} \text {šè ĝen- } \\
\text { na }\end{array}$ \\
\hline SAT III, 1568 & -/-/ŠS 5 & $\begin{array}{l}15 \text { Arbeiter für versch. } \\
\text { Tätigkeiten }\end{array}$ & $\begin{array}{l}\text { nin Zabalaki gub- } \\
\text { ba }\end{array}$ \\
\hline MVN 14, 538 & -/-/ŠS ? & Häute und Mehl & $\begin{array}{l}\text { igi-kár nin } \\
\text { Zabala }{ }^{k i}-\text { šè ĝen- } \\
{[\mathrm{na}]}\end{array}$ \\
\hline ITT V, 6960 & $-/-/-$ & Fische & $\begin{array}{l}\text { nin Zabala }{ }^{k i}-\check{s} \text { è } \\
\text { gen-na }\end{array}$ \\
\hline YOS $18,46^{578}$ & -/ii/- & 4 Schafe & igi-kár nin \\
\hline NISABA 6,9 & $-/-/[$ ] & Getreide & $\begin{array}{l}\mathrm{zi}-\mathrm{ga} \mathrm{nin} \\
\mathrm{Zabala}{ }^{\mathrm{ki}}-\mathrm{s} \text { è } \mathrm{g} \text { en - } \\
\mathrm{na}\end{array}$ \\
\hline $\begin{array}{l}\text { BPOA 1, } \\
1600\end{array}$ & $-/-/-$ & Arbeiter & nin $\mathrm{Zabala}_{3}{ }^{\mathrm{ki}}-\mathrm{s} \mathrm{è}$ \\
\hline
\end{tabular}

Tabelle 13: Güter und Arbeiter für Reisen der Abī-simtī zu Inanna von Zabalam

578 Dieser Text erwähnt werder Inanna von Zabalam noch Abī-simtī namentlich, er ist in diese Aufstellung aufgenommen aufgrund der Herkunft aus Umma und der Formulierung igi-kár n in, die eine Einordnung in diesen Kontext nahelegt. 


\subsubsection{Der Kult verschiedener kleinerer Gottheiten}

Wie Šulgi-simtī brachte auch Ab̄̄-simtī Schafe und Lämmer als Opfer für die Göttinnen Annunītum und Nanaja dar ${ }^{579}$, ein Text belegt auch Opfer am Tor des $\operatorname{Gipar}^{580}$. In beiden Fällen trat Abī-simtī selber als Überbringerin der Gaben auf. Beide Texte gehören in die Regierungszeit Amar-Suens, in der Abī-simtī die Gemahlin, nicht die Mutter des Königs war. Auch wenn die Quellenbasis gering ist, so ist doch in Analogie zu den Gaben der Šulgi-simtī für die Göttinnen Annunītum und Nanaja sowie für Opfer am Tor des Gipar zu vermuten, daß diese Opfer zum Aufgabenspektrum der Königin von Ur gehörten.

In der Regierungszeit des Šu-Suen fand in Nippur zum Ende des zehnten Monats ein Fest des Gottes Ištarān statt, bei dem offensichtlich Frauen einen wichtigen Anteil hatten. Der seit der altsumerischen Zeit ${ }^{581}$ in Sumer verehrte Gott Ištarān hatte in Ur einen lokalen Kult ${ }^{582}$, gehörte aber auch zu den in Nippur verehrten Gottheiten ${ }^{583}$. Das Hauptheiligtum des Ištarān befand sich in Dēr. In zwei Texten ist die Beteiligung der Abī-simtī an den Feiern für diesen Gott in Nippur nachzuweisen ${ }^{584}$. Wie BIN III, 559 zu entnehmen ist, wurde diese Feier für Ištarān aufwendig begangen, da insgesamt 19 Rinder sowie 60 Schafe und Ziegen zu diesem Anlaß für Abī-simtī zur Verfügung gestellt wurden. Ob diese große Anzahl von Tieren nur für den Kult verwendet wurde, oder ob ein Teil der Tiere für ein Festmahl bestimmt waren, das Abī-simtī anläßlich der Feiern gegeben haben mag, geht aus dem Text nicht hervor. Die Textaussage über die Bestimmung der Tiere ist noch nicht abschließend gedeutet worden, sie werden geliefert ,am Tag als Abī-simtī zu Ištarān aufbrach“. In BIN III, 559 findet sich die Formulierung ,A-bí-sí-im-ti $\mathrm{u}_{4}$ ${ }^{\mathrm{d}}$ Ištarān (KA.DI) in-da-a “ ${ }^{585}$. Dagegen formuliert TAD $28, \mathrm{u}_{4}$ A-bí-síim-ti ${ }^{\mathrm{d} I s ̌ t a r a ̄ n ~(K A . D I) ~ i n-d a-a " ~}{ }^{586}$. Möglicherweise ist dies als

579 SAT II, 693 (1/i/AS 2).

580 TCNY 357 (15/iii/AS 9). Zu den Opfern für Nanaja und am Tor des Gipar bei Šulgisimtī siehe S. 63-65.

581 Selz, Untersuchungen zur Götterwelt des altsumerischen Stadtstaates von Lagaš (1995), S. 155.

582 Richter, Panthea Süd- und Mittelbabyloniens (1999), S. 437-438.

583 Sallaberger, Der kultische Kalender (1993), S. 102.

584 BIN III, 558 (23/x/ŠŠ 2); TAD 28 (ŠS 2). Die beiden Texte dürften sich auf dasselbe Ereignis beziehen.

585 Die Deutung von in-da-a diskutiert Sallaberger in Der kultische Kalender (1993), S. $181+$ Anm. 851. Er schlägt für das Verb „d a “ die Bedeutung ,aufbrechen, starten, verlassen" vor.

586 Grégoire übersetzt in AAICAB I/3, wo der Text Bod.A 93 (= TAD 28) neu bearbeitet 
Schreiberfehler anzusehen, da sich in vergleichbaren Texten stets die Phrase „PN u ${ }_{4}{ }^{\mathrm{d}}$ Ištarān (KA.DI) in-da-a “ findet ${ }^{587}$. Die Empfängerinnen von Tieren aus diesem Anlaß sind immer Frauen, so außer Abī-simtī in PDT I, 521 die Frau des Šu-Mama, in Hirose 314 die Frau des Zuhutum, was die Interpretation dieses Festes als Frauenfest nahelegt. Die Phrase „Tag als PN zu als Ištarān aufbrach" könnte auf eine Prozession hindeuten, an der die Frauen teilnahmen. Es könnte auch ein Besuch des Gottes aus seinem Heiligtum in Ur in Nippur gemeint sein, wenn der Ausdruck mit „Tag an dem Ištarān aufbrach“ zu übersetzen ist. Die Bedeutung dieses Festes für einen sonst im Kult des Reiches von Ur eher untergeordneten Gott muß bislang offen bleiben.

Einige wenige Texte bezeugen Opfer, die Abī-simtī verschiedenen kleineren Gottheiten darbrachte, wobei diese Opfer mitunter im Kontext bestimmter Texte zum Staatskult stehen. So ist die Gabe von einem Schaf für Ninkununna in PDT I, 610 (4/vii/ŠS 7) wohl als individuelles Opfer der Abīsimtī im Rahmen des Akiti-Festes zur Aussaat von Ur zu sehen. ${ }^{588}$ Opfer für Ninhursag $\hat{~}^{59}$, Allatum ${ }^{590}$ und Amarazu $^{591}$ sind nicht in einen bestimmten Festkontext einzubinden und können als persönliches Opfer von Abī-simtī an diese Gottheiten angesehen werden.

Ein weiteres Zeugnis für die Vielfältigkeit des religiösen Lebens der Königin ist der dem Schatzarchiv zugehörige Text SAT III, 1277 (v/ŠS 2) $)^{592}$. Hier werden Weihgaben des Königs, seiner Mutter Abī-simtī und seiner Gemahlin Kubātum an die Heilgöttin Gula/Nininsina sowie an die ihrem Umfeld zugehörigen kleineren Gottheiten Damu, Šumah, Gunura ${ }^{593}$ und Niĝar ${ }^{594}$ verzeichnet. Dabei erhält die Herrin von Isin (Gula) vom König und seiner Mutter als Weihgaben ([a-ru-a] lugal [ù] A-bí-sí-im-ti) eine Mine

ist, "alors qu' Abi-șimti avait l'intention de se rendre auprès de la divinité 'Išt ar an a".

587 PDT I, 440 (3/xi/ŠS 7); PDT I, 521 (24/xi/ŠS 7); YBC 15755 (19/ix/ŠS 8); Hirose 314 (30/x/ŠS 8), vgl. Such-Gutiérrez, Beiträge zum Pantheon von Nippur im 3. Jahrtausend (2003), Teil II S. 320. Alle Texte stammen aus Puzriš-Dagān.

588 Sallaberger, Der kultische Kalender (1993), Tab. 62b + Anm. b.

589 TCNY 244 (28/vii/AS 8), 1 Mastrind, ĝ i r i ${ }_{3}$ Abī-simtī.

${ }_{590} \operatorname{TrD} 16$ (12/xii/ŠS 1), 2 Mastschafe bei s i s k u r ${ }_{2}$-Riten im Palast, $\hat{\mathrm{g}}$ ir i ${ }_{3}$ Abī-simtī. AUCT I, 479 = AUCT III, 99 (14/vi/ŠS 7), 2 Mastschafe, ĝ i r i ${ }_{3}$ Abī-simtī.

592 Siehe zu diesem Text auch S. 157.

593 Zum Kult der Gottheiten aus dem Kreis um Gula von Isin siehe Richter, Panthea Südund Mittelbabyloniens (1999), S. 154-160.

594 Ein é- $\mathrm{ni}_{9}-\hat{\mathrm{g}}$ ar-ra ist als Teil des Gula-Tempels von Isin belegt (George, House Most High S. 133 Nr. 886). Möglicherweise ist die in diesem Text genannte Gottheit ${ }^{\mathrm{d}} \mathrm{Ni}_{9}$ - $\mathrm{g}$ ar die Gottheit dieses Gula-Tempels. 
Silber, einen Korb (ma-s á-ab) aus Bronze und Kupfer sowie einen mit Silber überzogenen Bronzedolch (g ir-ni), während Damu, Šumah und Gunura je zwei Silberringe (h ar) empfangen. Kubātum beschenkt Gula und $\mathrm{Ni}_{9}$-ĝar mit einem Korb (ma-sá-ab) und einem Eimer $\left(b a-a n-d u_{8}-d u_{8}\right)$ aus Bronze und Kupfer. Auch für diese Weihgaben wird kein bestimmter Anlaß genannt, sodaß wiederum nur spekuliert werden kann, welches Ereignis diese Geschenke des Königspaares an die Heilgöttin von Isin und an Gottheiten aus ihrem Umfeld bedingte. Aufgrund des Charakters der beschenkten Gottheiten liegt es nahe, an eine Erkrankung eines Angehörigen der königlichen Familie zu denken, die entweder akut bestand oder gerade glücklich überstanden war, wobei diese Weihgaben im letzten Fall als Dankgeschenke angesehen werden können.

Gerade in der Regierungszeit Šu-Suens zeigt sich eine bemerkenswerte Vielfalt in den kultischen Aktivitäten der Abī-simtī. Dies ist wohl auf ihre veränderte gesellschaftliche Stellung als Mutter des regierenden Königs zurückzuführen. Als solche hatte sie offensichtlich die Möglichkeit, sich intensiver um unterschiedliche Kulte zu kümmern, als ihr dies in der Zeit als Frau des Königs Amar-Suen möglich war.

In nahezu allen Texten, die Abī-simtī außerhalb der Neumondfeiern in kultischem Kontext erwähnen, tritt sie als Überbringerin der Gaben für die Götter auf ( $\mathrm{g} \mathrm{iri}_{3} A$-bí-sí-im-ti). Im Vergleich dazu ist ihre Vorgängerin Šulgisimtī im Verhältnis zum Gesamtbestand ihrer kultischen Aktivitäten deutlich seltener als Überbringerin in den Texten genannt. In vielen Texten über kultische Ausgaben aus dem Archiv der Šulgi-simtī ist keine direkte Beteiligung der Königin an den Kulthandlungen zu erkennen. Nur aufgrund der von ihren persönlichen Beamten ausgeführten Buchungen sind diese Texte dem Bereich der Šulgi-simtī zuzuordnen. Überträgt man nun diesen Befund auf die kultischen Pflichten der Abī-simtī, so ist zu erwarten, daß auch sie eine Reihe von Opfern zwar veranlaßte, jedoch nicht selber an den Riten teilnahm. Da ihr Tierbestand anders als der von Šulgi-simtī zentral von der königlichen Administration in Puzriš-Dagān mitverwaltet wurde, ist eine Beteiligung der Abī-simtī am kultischen Geschehen nicht zu verfolgen, wenn sie nicht in den Texten namentlich genannt wird. Es ist davon auszugehen, daß eine Reihe von Ausgaben für den Kult in den Texten aus Puzriš-Dagān auf Veranlassung der Abī-simtī ausgeführt wurden, ohne daß dies aus den Quellen ersichtlich wurde, da Abī-simtī auf den gleichen Beamtenstab zurückgriff wie der König.

\subsection{7. Übersicht über kultische Aktivitäten der Abī-simtī}

Die folgende Übersicht zeigt die kultischen Aktivitäten der Abī-simtī, welche diese neben ihren regelmäßigen Verpflichtungen zu den Neumondfeiern und den Aufgaben im Zusammenhang mit ihrer engen Beziehung zur Göttin Inanna 
von Zabalam wahrnahm. Deutlich ist die zunehmende Vielfalt an Empfängern dieser Opfer in der Regierungszeit von Šu-Suen zu erkennen:

\begin{tabular}{|c|c|c|c|c|c|}
\hline $\begin{array}{l}\text { Publika- } \\
\text { tion }\end{array}$ & Datum & Gabe & Gottheit & Anlaß & $\begin{array}{l}\hat{\mathrm{g}} \mathrm{ir} \mathrm{i}_{3} \\
\text { A.-s. }\end{array}$ \\
\hline $\begin{array}{l}\text { SAT II, } \\
693\end{array}$ & 1/i/AS 2 & $\begin{array}{l}2 \mathrm{~K} \\
1 \mathrm{~K}\end{array}$ & $\begin{array}{l}\text { Annunītum } \\
\text { Nanaja }\end{array}$ & $\begin{array}{l}- \\
-\end{array}$ & $*$ \\
\hline $\begin{array}{l}\text { MVN } \\
20,31\end{array}$ & -/ii/AS5 & $\begin{array}{l}\text { verschie- } \\
\text { dene } \\
\text { Bronze- } \\
\text { gefäße }\end{array}$ & $\begin{array}{l}\text { Inanna- } \\
\text { Haburītum }\end{array}$ & Elunum & \\
\hline $\begin{array}{l}\text { TCNY } \\
244\end{array}$ & $\begin{array}{l}\text { 28/vii/AS } \\
8\end{array}$ & $1 \mathrm{G}$ & Ninhursaĝ & - & $*$ \\
\hline $\begin{array}{l}\text { TCNY } \\
357\end{array}$ & $\begin{array}{l}\text { 15/iii/AS } \\
9\end{array}$ & $\begin{array}{l}\mathrm{K} \\
3 \mathrm{~K} \\
2 \mathrm{~K} \\
\end{array}$ & $\begin{array}{l}\text { Inanna } \\
\text { Tor des Gipar } \\
\text { Nanaja } \\
\end{array}$ & $\begin{array}{l}\operatorname{siskur}_{2} \\
\text { gu-la }\end{array}$ & * \\
\hline $\begin{array}{l}\text { SET } \\
288\end{array}$ & -/iv/ŠS 1 & 17 Körbe & Inanna & - & \\
\hline $\begin{array}{l}\text { BIN III, } \\
215\end{array}$ & 29/iv/ŠS 1 & $\begin{array}{l}2 \mathrm{~K} \\
2 \mathrm{~K} \\
1 \mathrm{~K} \\
1 \mathrm{~K} 6 \\
1 \mathrm{~K}\end{array}$ & $\begin{array}{l}\text { Dumuzi } \\
\text { Inanna } \\
\text { Išar } \\
\text { Mišar } \\
\text { Ninšubur }\end{array}$ & & $*$ \\
\hline $\operatorname{TrD} 16$ & $\begin{array}{l}12 / x i i / S S \\
1\end{array}$ & $2 \mathrm{~K}$ & Allatum & $\begin{array}{l}\text { siskur }{ }_{2} \text { šà } \\
\text { é-gall }\end{array}$ & $*$ \\
\hline $\begin{array}{l}\text { SAT III, } \\
1277\end{array}$ & -/v/ŠS 2 & $\begin{array}{l}\text { Silber, } \\
\text { Metall- } \\
\text { korb, } \\
\text { Dolch aus } \\
\text { Bronze } \\
\text { und } \\
\text { Silber, } \\
\text { Silberring }\end{array}$ & $\begin{array}{l}\text { Nininsina } \\
\text { Damu } \\
\text { Šumah } \\
\text { Gunura von Isin? }\end{array}$ & $\begin{array}{l}\text { Weihgaben } \\
\text { des Königs } \\
\text { und der Abi- } \\
\text { simtī }\end{array}$ & \\
\hline TAD 28 & -/-/ŠS 2 & $1 \mathrm{G}$ & - & $\begin{array}{l}\text { wenn A.-s. } \\
\text { sich zu } \\
\text { Ištarān } \\
\text { begibt }\end{array}$ & \\
\hline $\begin{array}{l}\text { BIN III, } \\
559\end{array}$ & 23/ix/ŠS 2 & $19 \mathrm{G}, 60 \mathrm{~K}$ & - & $\begin{array}{l}\text { wenn A.-s. } \\
\text { sich zu } \\
\text { Ištarān } \\
\text { begibt in } \\
\text { Nippur }\end{array}$ & \\
\hline $\begin{array}{l}\text { MVN } \\
10,142\end{array}$ & 2/x/ŠS 2 & $6 \mathrm{G}$ & Tor der Inanna & $\begin{array}{l}\text { siskur }_{2} \\
\text { lugal }\end{array}$ & $*$ \\
\hline
\end{tabular}


Ab̄̄insimtī

\begin{tabular}{|c|c|c|c|c|c|}
\hline $\begin{array}{l}\text { Publika- } \\
\text { tion }\end{array}$ & Datum & Gabe & Gottheit & Anlaß & $\begin{array}{l}\hat{\mathrm{g}} \mathrm{iri}_{3} \\
\text { A.-s. }\end{array}$ \\
\hline $\begin{array}{l}\text { PDT II, } \\
1219\end{array}$ & 7/vi/ŠS 3 & $\begin{array}{l}3 \mathrm{~K} \\
3 \mathrm{~K}\end{array}$ & $\begin{array}{l}\text { Enlil } \\
\text { Ninlil }\end{array}$ & - & $*$ \\
\hline $\begin{array}{l}\text { MVN 5, } \\
125\end{array}$ & 4/ii/ŠS 4 & $\begin{array}{ll}1 \mathrm{~K} \\
1 \mathrm{~K} \\
1 \mathrm{~K}\end{array}$ & $\begin{array}{l}\text { Inanna } \\
\text { Nin-niĝar } \\
{[\text { ] }}\end{array}$ & $\begin{array}{l}\text { siskur }_{2} \text { im } \\
\text { Garten }\end{array}$ & $*$ \\
\hline $\begin{array}{l}\text { Roche- } \\
\text { ster } 7\end{array}$ & $7 / \mathrm{v} / \mathrm{S} S 5$ & $\begin{array}{l}1 \mathrm{~K} \\
3 \mathrm{~K} \\
\\
1 \mathrm{~K}\end{array}$ & $\begin{array}{l}\text { Inanna } \\
\text { Nanna } \\
\text { Nin-[ ] }\end{array}$ & $\begin{array}{l}\text { um } \\
\text { Mitternacht } \\
\text { sis k u r } 2 ~ \text { šà } \\
\text { é-g a l } \\
\text { bei Ankunft } \\
\text { des Königs }\end{array}$ & $*$ \\
\hline $\begin{array}{l}\text { AUCT } \\
\text { I, } 479\end{array}$ & 14/vi/ŠS 7 & $2 \mathrm{~K}$ & Amarazu & & $*$ \\
\hline $\begin{array}{l}\text { PDT I, } \\
610\end{array}$ & 4/vii/ŠS 7 & $1 \mathrm{~K}$ & Ninkununna & & $*$ \\
\hline $\begin{array}{l}\text { MVN } \\
13,98\end{array}$ & 3/v/ŠS 9 & $\begin{array}{l}4 \mathrm{~K} \\
1 \mathrm{~K} \\
1 \mathrm{~K} \\
5 \mathrm{~K} \\
2 \mathrm{~K} \\
{[\mathrm{~J}} \\
2 \mathrm{~K} \\
\\
1 \mathrm{~K} \\
1 \mathrm{~K} \\
1 \mathrm{~K} \\
\end{array}$ & $\begin{array}{l}\text { Enlil, } \\
\text { Thron d. Enlil, } \\
\text { Aba-Enlilgin } \\
\text { Ninlil, } \\
\text { Enlil, } \\
\text { [ ] } \\
\text { Damgalnunna, } \\
\text { Nintinuga, } \\
\text { Nin-é-gal, Nanna }\end{array}$ & $\begin{array}{l}\text { siskur }{ }_{2} \\
\text { šà é-gal } \\
\text { lugal ku }{ }_{4}- \\
\text { ra šà } \\
\text { Nibru }\end{array}$ & $*$ \\
\hline $\begin{array}{l}\text { MVN } \\
18,108\end{array}$ & 29/X/ŠS 9 & $5 \mathrm{~K}$ & Inanna & & $*$ \\
\hline $\begin{array}{l}\text { MVN } \\
13,550\end{array}$ & $\begin{array}{l}\text { 23/-/ŠS 7- } \\
9 \\
\\
\\
29 /-/ S ̌ S ~ 7- \\
9\end{array}$ & $\begin{array}{l}1 \mathrm{G}, 1 \mathrm{~K} \\
1 \mathrm{~K} \\
1 \mathrm{~K} \\
4 \mathrm{~K} \\
2+\mathrm{x} K \\
1+[\mathrm{x}] \mathrm{K} \\
2 \mathrm{~K} \\
1 \mathrm{G}, 2 \mathrm{~K} \\
1 \mathrm{~K} \\
1 \mathrm{~K} \\
1 \mathrm{~K}\end{array}$ & $\begin{array}{l}\text { Nanna, } \\
\text { Tempelplatt- } \\
\text { form, } \\
\text { Ningal, } \\
\text { Ninsun, } \\
\text { Nin-Gublaga } \\
\text { Stachelschwein- } \\
\text { essen d. Nanna, } \\
\text { Abzu, } \\
\text { in Hof d. Nanna, } \\
\text { Tempelplatt- } \\
\text { form, } \\
\text { Ningal } \\
\text { Nungal, }\end{array}$ & & \\
\hline
\end{tabular}


Königinnen

\begin{tabular}{|c|c|c|c|c|c|}
\hline $\begin{array}{l}\text { Publika- } \\
\text { tion }\end{array}$ & Datum & Gabe & Gottheit & Anlaß & $\begin{array}{l}\hat{\mathrm{g}} \mathrm{iri}{ }_{3} \\
\text { A.-s. }\end{array}$ \\
\hline & & $\begin{array}{l}2 \mathrm{~K} \\
1 \mathrm{~K} \\
5 \mathrm{~K} \\
1 \mathrm{~K} \\
1 \mathrm{~K}\end{array}$ & $\begin{array}{l}\text { Ninkununna, } \\
\text { Thron des Ur- } \\
\text { Namma, } \\
\text { Gula, } \\
\text { Allatum, } \\
\text { [ ]-tum }\end{array}$ & $\begin{array}{l}\text { è š - è š } \\
\text { Feiern zu } \\
\text { Neulicht }\end{array}$ & $*$ \\
\hline $\begin{array}{l}\text { ASJ 4, } \\
\text { S. } 140 \\
\text { Nr. } 1\end{array}$ & $\begin{array}{l}\text { (abgebro- } \\
\text { chen) }\end{array}$ & $1 \mathrm{~K}$ & Nanna & $\mathrm{ki}-\mathrm{siskur}{ }_{2}$ & $*$ \\
\hline
\end{tabular}

Tabelle 14: Andere kultische Verpflichtungen der Abī-simtī

\subsection{Textilproduktion für Abī-simtī}

Abī-simtī erhielt regelmäßig Tiere, um ihren kultischen und gesellschaftlichen Pflichten nachkommen zu können, wie oben gezeigt wurde. Darüber hinaus war sie Besitzerin großer Herden von Schafen, und es ist anzunehmen, daß sie auch über größere Bestände an Ziegen und Rindern verfügte. Häute von verendeten Tieren aus dem Besitz der Königin werden in mehreren Texten aus Puzriš-Dagān und Umma verbucht und an Handwerker für die Weiterverarbeitung gegeben. ${ }^{595}$ Die Herden der Abī-simtī haben wohl hauptsächlich in der Umgebung von Girsu gestanden, wo die Königin eine große Zahl von Hirten mit der Pflege der Tiere betraut hatte. So verzeichnet ein Text aus Girsu die Lieferung von Wolle für unterschiedliche Textilien von 24 Hirten an Abī-simtī ${ }^{596}$, ein anderer verbucht die Lieferung von Textilien unterschiedlicher Art und Qualität aus Wolle von Schafen der Abī-simtī (siki udu A-bí-sí-im-ti) ${ }^{597}$. Anhand der Wollerträge, die hier aufgeführt werden, errechnete Waetzoldt einen Bestand von mehr als 4000 Tieren in den Herden der Abī-simtī im Gebiet von Girsu. ${ }^{598}$ Zwei Tafelkorbetiketten aus den Jahren ŠS 5 und ŠS 6 aus Girsu nennen einen SI.A.A als Viehverwalter $\left(\mathrm{ku} \breve{s}_{7}\right)$ der Abī-simtī. ${ }^{599}$ SI.A.A tritt schon im Jahr AS 8 als Verantwortlicher für die

595 AAICAB I/2, Pl. 106 Ashm. 1937-70 (AS 6): 150 Ziegen- und 76 Schafshäute für Beutel; MVN 15, 198 (v/ŠS 1): 15 Rinderhäute zur Weiterverarbeitung an die Handwerker ( $\hat{\mathrm{g}} \mathrm{i} \breve{s}-\mathrm{ki} \hat{\mathrm{g}}-\mathrm{ti}-\mathrm{s} \mathrm{è}) ;$ AnOr 1, 234 (ix/ŠS 8): 108 Schafs- und 21 Ziegenhäute für die Handwerker.

596 ITT II, 873 (Datum abgebrochen); vergleichbar ist ITT II, 628 (ŠS 7).

597 Barton HLC II Pl 82, HLb 82 (AS 6).

598 Waetzoldt, Textilindustrie (1972), S. 35.

599 MVN 9, 165 mit Duplikat ITT V, 9193 (ŠŠ 5) und MTBM 257 (ŠS 6). Der 
Herden der Königin in einem weiteren Text aus Girsu auf, in dem die Hirten verschiedener Herden der Abī-simti, des Palastes sowie zweier Prinzen Wolle in unterschiedlichen Qualitäten liefern. ${ }^{600}$

Die Wolle aus Girsu wurde per Boot transportiert ${ }^{601}$ und zumindest teilweise in Ur weiterverarbeitet, wie zwei Texte aus Ur belegen. ${ }^{602}$ Hier empfing Ahušuni die Wolle „für das Weben der Abī-simtī, der Herrin“ (t a g A$b i$-sí-im-ti nin). Doch auch an anderen Orten wurden Textilien für die Königin gefertigt. ${ }^{603}$ Wie schon bei Šulgi-simti ${ }^{604}$ stellt sich in diesem Zusammenhang die Frage, ob die Königin die Textilproduktion von Ur in großem Umfang kontrollierte oder ob sie in der Stadt nur für den Eigenbedarf sowie den Bedarf ihres Haushaltes weben ließ. Unklar ist auch, ob sie die Textilproduktion des gesamten Hofes beaufsichtigte und leitete, denn ihre Tiere und damit ihre Wolle wird stets von den Tieren/der Wolle des Palastes getrennt aufgeführt ${ }^{605}$.

Bei dem hohen Arbeitsaufwand, der für die Produktion hochwertiger und repräsentativer Textilien notwendig ist, hat man von einer großen Anzahl von Arbeitskräften auszugehen, die konstant damit beschäftigt waren, für den Eigenbedarf der Königin und ihres Haushaltes zu arbeiten. Dazu gehörten auch eine größere Zahl von Weberinnen. Eine solche Manufaktur für den Eigenbedarf ist jedoch für jeden größeren Haushalt der Zeit anzusetzen, die Aufsicht über Weberinnen, die im Auftrag der Abī-simtī arbeiteten, war sicher keine Besonderheit im Tätigkeitsspektrum dieser Königin. Ob diese

unpublizierte Text BM 22874 (AS 2) nennt einen Ur-ki-gu-la als Hirten (n a-g a d a ) der Abī-simtī (Sigrist, Figulla, Walker, Catalogue of the Babylonian Tablets in the British Museum, Vol. II), der ebenfalls unpublizierte Text BM 24954 beinhaltet eine Aufstellung über die Schafe der Abī-simtī und der Prinzessin Taddin-Eštar (Sigrist, Zadok, Walker, Catalogue of the Babylonian Tablets in the British Museum, Vol. III). DAS 51 (AS 8).

CT 10 Pl. 50, BM 12248 (xi/AS 7), Bearbeitung von Pettinatio in MVN 17, 19, Liste über Lastboote, darunter auch Boote zum Transport der Wolle der Königin. Vgl. auch TCTI 2, 2720 (1/v/ŠS 3) aus Girsu, eine Aufstellung über Lastboote, darunter ein Boot mit einem Fassungsvermögen von 20 Kor, das nach Ur zum Ort der Königin fahren sollte. Mit „,n i n “ kann im Jahr ŠS 3 Abī-simtī oder Kubātum gemeint sein.

UET 3, 1509 (25/iii/AS 4); UET 3, 1757 (Datum abgebrochen). siehe Waetzoldt, Textilindustrie (1972), S. 35 und 142. Vgl. auch Jacobsen, The Reign of Ibbī-Suen, JCS 7 (1953), S. 45.

So verzeichnet auch der Text TMH NF 1/2, 219 (vi/AS 7) aus Nippur die Lieferung von Wolle für Textilien an den Haushalt der Königin (é-nin), wobei aufgrund der Herkunft des Textes davon ausgegangen werden kann, daß hier ihr Palast in Nippur gemeint war.

Siehe S. 103-105

DAS 51 (AS 8); MVN 9, 165 mit Duplikat ITT V, 9193 (ŠŠ 5); MTBM 257 (ŠS 6). 
Weberinnen darüber hinaus einen Überschuß produzierten, der nicht direkt für die Nutzung durch den Hof bestimmt war, sei es für dort getragene Gewänder oder als Geschenke für Personen, welche man mit einer solchen Gabe auszeichnen wollte, ist den Texten nicht zu entnehmen.

\section{Exkurs 1: Die Mutter des Königs in Ebla}

Abī-simtī ist die einzige Königin von Ur, die nach der Amtsübernahme ihres Sohnes noch in prominenter Position am Hof nachzuweisen ist. In den Quellen aus der Regierungszeit ihres Sohnes wird sie nicht anders tituliert als in ihrer Zeit als Ehefrau des regierenden Königs. Einen interessanten Vergleich zur Position der Ab̄̄-simtī als Königsmutter bildet die Stellung der Mutter des Königs von Ebla.

Die einzige uns namentlich bekannte Mutter eines regierenden Königs von Ebla (a ma-gal en) war Dusigu, die Mutter von Išar-Damu, und so bezieht sich alles, was man derzeit über die Funktion und Position der Mutter des Königs von Ebla sagen kann, ausschließlich auf sie, ohne daß sich entscheiden ließe, inwiefern ihre Machtposition eine besondere war oder der Regel entsprach. ${ }^{606}$

In den bisher publizierten Listen der Frauen des Königs (dam en) erscheint Dusigu stets an erster Position. Ihr Aufstieg, von dem Biga vermutet, daß er nach dem frühen Tod der Königin von Irkab-Damu begonnen habe, ist noch nicht allgemein nachzuvollziehen. ${ }^{67} \mathrm{Da}$ sie aber offensichtlich aus den Reihen der vielen Nebenfrauen dieses Königs hervorgegangen ist, war sie möglicherweise die treibende Kraft, die ihren Sohn Išar-Damu auf den Thron brachte.

Die Königsmutter Dusigu war wie die Königin selbst im wirtschaftlichen wie auch im religiösen Bereich sehr aktiv. In den regelmäßigen Metallzuweisungen werden immer wieder wertvolle Güter genannt, die sie zum eigenen Gebrauch erhielt oder den Göttern opferte. ${ }^{608}$ Ebenso wird sie

\footnotetext{
606 Siehe auch S. 187.
}

607 Biga, Prosopographie, Amurru I (1996), S. 40. Zu Dusigu in den Listen der da m e n siehe Tonietti, Le liste delle dam en, QdS 16 (1989). Zum Aufstieg der Dusigu am Hof von Ebla siehe zuletzt Biga, The reconstuction of a relative Chronology, OrNS 72 (2003), S. 354-357.

${ }^{608}$ ARET 12, 490 obv. III 1': Ausgabe von Textilien an ${ }^{\mathrm{d}}$ Rasap von Duneb, ${ }^{\mathrm{d}}$ BAD-mi und ${ }^{\mathrm{d} A d a b a l}$ von Amadu durch die a ma-gal en; MEE 7, 47 obv. III 1-7: a ma-gal en gibt 5 Schekel Dilmunsilber zum Tauschen (šu-bal-aka) und 1 Schekel Dilmungold im Wert eines Anhängers (kù - s al) als Opfer an ${ }^{d}$ Ninkar; MEE 10, 20 obv. XXI 17-24: 5 Schekel Dilmunsiber zum Tausch 1 Schekel Dilmungold für einen Anhänger und einen Anhänger in Form eines Falken (bur u ${ }_{4}$. MU ŠEN), Geschenk der a ma-gal en an Rasap von Atani. Siehe auch Liste der Metallzuweisungen bei 
regelmäßig als Empfängerin von Textil- und Wollrationen genannt, welche sie teilweise für andere annahm. ${ }^{609}$ Mehrfach ist Personal ihr direkt zugeordnet, so finden sich ein Bauer (engar), ein bestimmter Funktionär $\left(\mathrm{ur}_{4}\right)$ sowie Dienerinnen $\left(\mathrm{ge} \mathrm{me}_{2}\right)$ der ama-gal en in den Texten. ${ }^{610}$ Es ist davon auszugehen, dass Dusigu wie auch die Königin ${ }^{611}$ über eine eigene Dienerschaft verfügen konnte, so wie dies später für die königlichen Frauen der dritten Dynastie von Ur zu beobachten ist. Der besondere Rang der Mutter der Königs zeigt sich auch im Besitz eigener Wagen ${ }^{612}$, was neben ihr und der Königin nur den wenigsten Frauen des Hofes zustand. ${ }^{613}$

Dusigu unterhielt enge Beziehungen zu Dati- ${ }^{\mathrm{d}} \mathrm{TU}$, welche wahrscheinlich eine Tochter des Irkab-Damu war und die mit dem König von Lumnan verheiratet worden war. ${ }^{614}$ Diese Kontakte nach dem Fortgang der Dati- ${ }^{\mathrm{d}}$ TU aus Ebla sind wohl primär im persönlichen Bereich zu suchen, da ähnlich intensive Beziehungen zwischen Dusigu und einer anderen auswärts verheirateten Prinzessin nicht belegt sind. Dusigu reiste auch selber nach Lumnan, wie aus dem Text MEE 7, 34 hervorgeht, eine der Listen über Metallzuweisungen, wo verzeichnet ist, daß die a ma-gal en [Anfang abgebrochen] Nadeln/Broschen $(b u-d i)^{615}$ an die Königin von Lumnan übergeben hat am Tag ihrer Abreise nach Uguaš ${ }^{616}$. Diese Textstelle zeigt weiter, daß die Mutter des Königs wie die Königin sich nicht nur in Ebla aufhielt, sondern zu bestimmten Anlässen

Archi, Les comptes rendus annuels de métaux, Amurru I (1996), S. 81-88.

In ARET 3, 616 nimmt sie Wolle für Kleidung des Königs an; in MEE 2, 33 rev VIII 7-12 erhalten Dusigu und Enna-Utu je 3 KIN-Maß Wolle für ein gu-súr-túg; in ARET 4, 11 rev. X 2-9 = \$79 wird verschiedenartige Wolle für Kleidung (túg-túg) der Dusigu ausgegeben. Vgl. auch die fragmentarisch erhaltenen Texte ARET 12, 511 und 1011, wo Dusigu als Empfängerin verschiedener Textilien genannt ist. ARET 12, 504 I', 7 (en g ar); 740 IV' 3 (3 g e m e $_{2}$ ) und 1273 I', 1 ( u r $_{4}$ ).

An Personal der Königin ist unter anderem ein Arzt (ARET 12, 784) erwähnt, in ARET 12, 691 wird eine Person namens Enna-nil als lú maliktum bezeichnte. Wiederholt sind Diener(innen) in $\mathrm{pa}_{4}$ : šeš (-mí)-Funktion zu finden (z.B. ARET 1, 4 rev. VII 11-15 und ARET 12, 179). Zur Bedeutung von $\mathrm{pa}_{4}$ : š ěs siehe Pettinato, MEE 5, S. 107 Anm. zu § 17, ein $\mathrm{pa}_{4}$ : še š tritt auch häufig in priesterlicher Funktion im Dinest verschiedener Gottheiten auf und wird dann als „Salbpriester“ angesprochen.

ARET 12, 769 III' 8-IV' 9 verbucht die Lieferung von Wolle für Zaumzeug für einen vierrädrigen und einen zweirädrigen Wagen der a ma-gal en . Biga, Donne alla Corte di Ebla, PP 46 (1991), S. 288.

${ }_{614}$ Biga, Prosopographie, Amurru I (1996), S. 65f.

${ }_{615} \mathrm{Zu} \mathrm{bu-di}$ siehe Archi, Jewels for the Ladies of Ebla, ZA 92 (2002), S. 188-189. Ausführlich dirkutiert Waetzoldt diesen Begriff in MEE 12 (2001), S. 348-349.

616 MEE 7, 34 obv. XI 26 - XII 8. 
Reisen unternahm. Es ist nicht unwahrscheinlich, daß Dusigu auch zu anderen Höfen Kontakte unterhielt und dort möglicherweise auch politischen Einfluß ausübte. Die Beziehungen zwischen Ebla und Lumnan wurden in den Jahren nach dieser Hochzeit intensiver. ${ }^{617}$

Wie bei der Königin, deren Eltern nicht als Sohn/Tochter ihres Vaters, sondern als Mutter/Vater der Königin in der Verwaltung Eblas registriert werden, sind auch Angehörige Dusigus über sie definiert. So kennt man ihre Mutter, ihren Bruder und mehrere Schwestern. ${ }^{618}$ Die Filiation wurde in Ebla üblicherweise über den Vater angegeben, doch wenn die Mutter oder eine Tochter einen entsprechend hohen Rang hatte, wurde diese Frau der Bezugspunkt für Verwandtschaftsangaben, was das Bild bestätigt, daß die Frauen des Königshauses Einfluß und hohes Ansehen genossen.

Noch ist unklar, aus welcher Familie Dusigu stammte. Mehrfach wird ein Ort Dusigu ${ }^{\text {ki }}$ erwähnt. ${ }^{619}$ Dieser Ort befand sich im Besitz der Familie des Wesirs Ibrium, womit sich die Frage stellt, ob Dusigu aus dieser Familie kam.

Dann bestünde eine Verbindung zwischen der Familie des Königs und der des Wesirs, der sein Amt wie der König auf seinen Sohn vererbte ${ }^{620}$. Durch Textbelege bestätigen läßt sich diese Vermutung derzeit noch nicht, doch erscheint es plausibel, daß es eine Verbindung gibt zwischen der starken Position des Wesirs zur Zeit von Ibrium ${ }^{621}$ und dem Aufstieg Dusigus, der Mutter des Thronfolgers. Dieser Aufstieg begann zur Zeit des Wesirs Arragum, unter Ibrium wurde Dusigu zur einflußreichsten Dame des Hofes. ${ }^{622}$

Dusigus Tod ist als Ereignis in einer Datenformel festgehalten; die dritte Liste von Metallzuweisungen unter dem Wesir Ibbi-Zikir verzeichnet Ausgaben für Totenopfer (Éx P A P ${ }^{623}$ ) für Dusigu. ${ }^{624} \mathrm{Im}$ selben Text werden

617 ebd.

618 ARET 1, $11=$ MEE 2, 19 rev. XI 6-10 = 56 : je 1/2 KIN Wolle für Razitum und Adada, die Mutter (a m a - g a 1) von Dusigu; ihr Bruder Ibbi-Malik ist mehrfach belegt, so in ARET 1, 14 obv. I 15-II 3, MEE 7, 27 rev. V 9-VI 2; MEE 12, 35 obv. XXV 43-45, ARET 4, 13 rev. XII 5-8; ARET 12, 1034 II' 3 (š eš Du-si-gú, ohne Namen); Schwestern der Dusigu sind Išrut (ARET 4, 19 = MEE 7, 24 rev. V 13-17, ARET 12, 297 obv. V 5) und Dadu- ${ }^{\mathrm{d}}$ Utu (ARET 7, 124 = MEE 10, 5 obv. I 1-4). Zu den Eltern der Königin von Ebla siehe S. 186. ARET 4, 25 = MEE 10, 44 rev. I 3-8; MEE 2, 39 obv. XIII 14-18; ARET 12, 822 obv. I 7'. Der Ort ist mit großer Wahrscheinlichkeit nach der Mutter des Königs benannt.

${ }^{620}$ Biga, Prosopographie, Amurru I (1996), S. 30 Anm. 4. Schon 1987 vermuteten Biga und Pomponio, daß Ibrium einer Nebenlinie des Herrscherhauses angehöre (NABU 1987, 106).

${ }^{621}$ Archi, Ebla. La Formazione di uno Stato del III Millennio A.C., PP 46 (1991).

622 Biga, The reconstruction of a relative Chronology, OrNS 72 ( 2003), S. 355.

${ }^{623}$ Zum Bedeutungsspektrum von ÉxPAP vgl. Baldacci, ÉxPAP and the Eblaite 
Ausgaben für Reinigungsriten verzeichnet, die hochrangige dam en und Schwestern der Toten vollziehen mußten. ${ }^{625}$ Der Aufwand der Totenfeiern spiegelt nach Ansicht von Archi nicht den herausragenden Rang der Verstorbenen wider. ${ }^{626}$ Als Vergleich werden die Riten zur Beisetzung der Priesterin Tarib-Damu und ihrer Schwester, der Prinzessin Tište-Damu angeführt, die mit mehr Aufwand begangen wurden. ${ }^{627}$ Doch bis zur vollständigen Publikation aller Metalltexte ${ }^{628}$ ist noch kein direkter Vergleich über den Umfang der Totenopfer von Dusigu, anderen weiblichen Angehörigen des Hofes von Ebla und Königinnen befreundeter Städte, welche ebenfalls in den Metalltexten genannt sind, möglich.

\section{Kubātum}

Im Vergleich zu der reichen Quellenlage, die uns zu den Damen Šulgi-simtī und Abī-simtī zur Verfügung steht, ist die Anzahl der Belege zu den beiden letzten Königinnen des Reiches von Ur III, Kubātum ${ }^{629}$ und Geme-Enlila, deutlich geringer. Sind aus dem Archiv der Šulgi-simtī bisher mehr als 540 Texte publiziert, so umfaßt das Korpus zu Kubātum und Geme-Enlila zusammen nicht einmal 100 Texte. Dies ist zum einen auf die allgemein zu beobachtende Abnahme der Quellen zur Regierungszeit Šu-Suens und noch stärker zur Zeit von Ibbi-Suen zurückzuführen. Des weiteren trifft auch für diese Damen zu, was schon zu der Archivsituation für Abī-simtī im Vergleich zu Šulgi-simtī ausgeführt wurde ${ }^{630}$, daß nämlich die Königinnen nach Šulgisimtī nicht mehr über eine eigene, von der königlichen Administration getrennte, Buchhaltung verfügten, welche die Zuordnung eines Textes zum Handlungsbereich dieser Frauen deutlich erleichtert hätte.

Kubātum war diejenige der Frauen Šu-Suens, die die Position der Königin

Administrative Terminology. WO 22 (1991), S. 10-20.

624 TM.75.G.10088+ 10182, siehe Archi, Les comptes rendus annuels de métaux, Amurru I (1996), S. 78 und 88; Biga Prosopographie, Amurru I (1996), S. 36.

625 Biga, Prosopographie, Amurru I (1996), S. 49.

${ }^{626}$ Archi, Jewels for the Ladies of Ebla, ZA 92 (2002), S. 177.

627 Ebd. S. 173-177.

${ }^{628}$ Siehe auch die Übersicht über die noch unpublizierten Metalltexte bei Archi, Les comptes rendus annuels de métaux, Amurru I (1996), S. 81-93. Einige der Metalltexte sind publiziert bei Waetzoldt in MEE 12 (2001).

629 Die Bedeutung des Namens ist unklar, siehe Sollberger, Art. „Kubatum“, RlA 6 (1980-83), S. 265.

$630 \quad$ Siehe S. 109. 
(nin) innehatte. Sie ist sicher belegt ab dem Jahr $\breve{S} S 2^{631}$. Wahrscheinlich bezieht sich schon ein Text aus dem Jahr AS 9 auf die spätere Königin von Ur, in welchem Schafe für Opfer verbucht werden, darunter auch Tiere für Inanna „um der Kubātum willen“ (mu-Ku $u_{8}-\mathrm{ba}-\mathrm{tu} m-\mathrm{s}$ è $)^{632}$. Dieser Text gehört schon in die Regierungszeit Šu-Suens, da Amar-Suen bereits im zweiten Monat seines neunten Regierungsjahres Totenopfer erhielt ${ }^{633}$, sieben Monate vor dem Datum dieses Textes.

\subsection{Herkunft und Familie}

Der Text CTNMC 17 aus dem Jahr AS 4 nennt eine $\mathrm{Ku}_{8}$-ba-tum als Amme (der Kinder) des Königs (u m-me-da lugal). Sigrist ging davon aus, daß es hier möglich scheint, die Karriere einer Königin von Ur zu verfolgen, welche von der Position einer Amme zur Königin aufstieg. ${ }^{634}$ Dies zweifelte Sallaberger an mit dem Hinweis, daß der Name Kubātum nicht ganz selten ist, und daß der Standesunterschied in einem solchen Fall kaum erklärbar wäre. ${ }^{635}$ Diese Argumentation ist nicht zwingend, da eine Amme durchaus eine angesehene Stellung am Hof innehaben konnte. Dies ist aus Ebla bekannt, wo Gišadu, die Amme des Königs Išar-Damu, bis zu ihrem Tod unter den hochrangigen Damen des Hofes erscheint. ${ }^{636}$ Die angesehene Stellung der beiden Ammen Kinatnunun und Kubātum in CTNMC 17 wird auch daraus ersichtlich, daß sie unmittelbar nach den Töchtern des Königs als Empfängerinnen von Vieh geführt werden. In frühdynastischer Zeit bezeichneten sich Könige wie Eannatum und Entemena als Milchkinder der Göttin Ninhursag $\hat{g}^{637}$, und auch in

${ }^{631}$ Die frühesten Texte sind: MVN 3, 247 (30/iv/ŠS 2), Ausgabe einer Kuh für Kubātum, SAT II, 1277 (v/ŠS 2), Weihgaben des Königs, der Abī-simtī und der Kubātum; MVN 16, 1268 (ك̌Š 2) und MVN 16, 1012 (7/-/ŠS 2), beides Lieferungen von Weidenholz an Kubātum.

${ }^{632}$ MVN 13, 639 (11/ix/AS 9); die Schreibung des Namens mit „, $\mathrm{Ku}_{8}$ “ als erstem Zeichen ist ungewöhnlich, üblicherweise wird der Name $\mathrm{Ku}-\mathrm{ba}-\mathrm{tu}$ m geschrieben. Siehe zu diesem Text auch Steinkeller, More on Ur III Royal Wives, ASJ 3 (1981), S. 80, Anm. 35, der davon ausgeht, daß es sich hier um die Frau Šu-Suens handelt.

633 Sallaberger, OBO 160/3 (1999), S. 167.

${ }^{634}$ Sigrist, Kubatum, RA 80 (1986), S. 185. Ebenso van de Mieroop, Women in the Economy of Sumer (1989), S. 62.

635 Bei der Kubātum, deren Siegel auf der Tafel MVN 3, 278 (ŠS 7) abgerollt ist, handelt es sich mit Sicherheit um eine andere Person, da diese sich als Geme ${ }_{2} \mathrm{Gu}-\mathrm{za}-\mathrm{na}$ bezeichnet. Sallaberger, OBO 160/3 (1999), S. 184 + Anm. 211.

636 Biga, Les nourrices et les enfants à Ebla (1997), S. 38.

${ }^{637}$ Hallo, Early Mesopotamian Royal Titles (1957), S. 136: ,g a-zi-g u 7 -a ${ }^{\mathrm{d}} \mathrm{Nin}-$ hu r-s a g”, 'fed with the effective milk of Ninhursag'“. 
den Hymnen der Könige von Ur III ist das Milchtrinken ein bekannter Topos, sowohl in der Beschreibung der Entwicklung des Herrschers, als auch bezüglich seiner Milchkindschaft zu einer Göttin ${ }^{638}$. Dies deutet darauf hin, daß eine Amme eine durchaus angesehene Stellung am Hof innegehabt haben kann, zumal nicht bekannt ist, aus welcher Gesellschaftsschicht Ammen für die Kinder des Königs ausgewählt wurden. Da über das Trinken der Milch durchaus Verwandtschaftsverhältnisse konstituiert werden konnten $^{639}$, ist es nicht ausgeschlossen, daß anders als in Europa im Mittelalter und in der Neuzeit eine Amme aus den höheren Gesellschaftsklassen kam. Da über die Herkunft der Königin Kubātum nichts bekannt ist ${ }^{640}$ kann nicht ausgeschlossen werden, daß sie entweder als Amme eines Prinzen/einer Prinzessin an den Hof kam oder aber als eine der Damen des Hofes den Auftrag bekam, die Funktion der Amme für eines der Königskinder zu übernehmen, und später dann als Frau des Königs Šu-Suen zu seiner Königin aufstieg ${ }^{641}$.

In drei Texten wird Kubātum als Königin bezeichnet $(K u \text {-ba-tum n in })^{642}$, sie ist darüber hinaus die einzige Königin von Ur, die in einem Wirtschaftstext auch als lukur des Königs bezeichnet wird ${ }^{643}$. Eine Tochter der Kubātum ist in BIN III, 571 (5/xii/ŠS 4) genannt, wo Opfer für verschiedene Gottheiten anläßlich von èš-èš-Feiern zum 7. Tag erwähnt werden, welche „um der Tochter der Kubātum willen (mu dumu-munus Ku-ba-tum-š è)“ erfolgen. Unter den aus diesem Anlaß beopferten Gottheiten finden sich sowohl die

638 Als Beispiel sei die Šulgihymne D, Z. 6 genannt, wo von Šulgi gesagt wird, er habe sich mit reicher Milch genährt (g a - z i - g u ${ }_{7}$ - a), Klein, Three Šulgi Hymns (1981).

So galten Kinder, die die Milch derselben Frau getrunken hatten als Geschwister, eine Vorstellung, die auch heute noch im Orient anzutreffen ist (Vortrag von G. Selz in Göttingen, 2003).

${ }_{640}$ Ihre Mutter war eine Dame namens Șí-lí-a, wie der Text Akkadica 78, S. 13 (13/iv/ŠS 8) zeigt. Foster hatte aufgrund der Analyse der Textes SEL 2, S. 37 (ŠŠ 4) vermutet, die Mutter der Kubātum sei Halhalla gewesen. Vgl. Sallaberger, Der kultische Kalender (1993), S. 65 Anm. 283. Michalowski (The Ideological Foundation of the Ur III State (2004), S. 232 Anm. 37) hielt es für möglich, daß Kubātum eine Tochter der Abī-simtī und damit eine Schwester Šu-Suens gewesen sein.

${ }_{641}$ Das Argument Sallabergers, eine ehemalige Amme sei aus Standesgründen kaum als Königin vorstellbar (OBO 160/3 (1999), S. 184), entspringt heutigen europäischen, seit dem Hochmittelalter entwickelten Vorstellungen von einer Standesgesellschaft. Noch in der Merowingerzeit war es nicht unüblich, daß die Könige Frauen aus unteren Gesellschaftsklassen heirateten, die wie im Fall der Austrechilde mitunter bis in den Rang einer Königin aufsteigen konnen (Hartmann, Aufbruch ins Mittelalter. Die Zeit der Merowinger (2003), S. 95-96).

${ }^{642}$ ASJ 3, S. 91 (9/vi/ŠS 2); MVN 16, 960 (ŠS 3); MVN 9, 165 (ŠS 5).

${ }^{643}$ SAT II, 1277 (v/ŠS 2); zu den Titeln n in und lu kur siehe unten S. 235-240. 
großen Göttern wie Enlil, Ninlil und Inanna, aber auch kleinere Gottheiten wie Šlpae oder Ištarān. Vier nahezu parallele Texte geben diese Liste der anläßlich des siebten Tages im zwölften Monat in Nippur beopferten Götter wieder, weswegen man wohl von einem jährlich begangenen Fest ausgehen kann. ${ }^{644}$ Dabei fällt auf, daß diese Opfer immer für eine der Frauen aus dem Königshaus vollzogen wurden, so in BIN III, 571 für die Tochter der Kubātum, in NISABA 8, 30 und PDT I, 555 für eine Tochter des Königs (mu dumu-munus lu g a l-šè), die in NISABA 8, 30 noch genauer mit ihrem Namen Geme-Enlila bezeichnet $\operatorname{wird}^{645}$. Es hat also den Anschein, daß diese Prinzessinnen bei jenem Fest im letzten Monat des Jahres in Nippur eine herausgehobene Position einnahmen. Sallaberger hatte vermutet, daß es sich immer um dieselbe Person handelte, und daß Geme-Enlila jene Tochter der Kubātum gewesen sei. $^{646}$ Eine Prinzessin dieses Namens ist später als Lukur des Ninurta bezeugt. ${ }^{647}$ Es scheint plausibel, daß es sich bei der mit Opfer zum siebten Tag am Jahresende geehrten Königstochter immer um die gemeinsame Tochter der Kubātum und des Šu-Suen handelte, welche als Lukur des Ninurta spätestens seit dem Jahr ŠS 4 eine besondere Position im kultischen Geschehen des Königshauses einnahm ${ }^{648}$.

Bemerkenswert ist, daß die in BIN III, 571 erwähnte Prinzessin als Tochter der Kubātum und nicht als Tochter des Königs bezeichnet wird. Dies ist nur damit zu erklären, daß es sich hier um ein Kind des Königspaares handelte und nicht um eine Prinzessin, deren Mutter eine der Nebenfrauen des Königs war. Eine vergleichbare Erscheinung ist auch aus Ebla bekannt, wo ein Sohn des Herrscherpaares als dumu-nita maliktum, „Sohn der Königin“ bezeichnet wurde und nicht wie sonst in Ebla üblich als dumu-nita en „Sohn des Königs “649. Auch am Hof von Ur wurde also ein Kind der Königin zumindest in manchen Kontexten aus der großen Gruppe der Kinder des Königs herausgehoben, wobei aufgrund der derzeitigen Quellenlage noch nicht bestimmt werden kann, wann diese Unterscheidung getroffen wurde.

Im Jahr ŠS 3 ist die Geburt eines Kindes der Kubātum belegt (Ku-ba-tum nin-e dumu tu-da), anläßlich deren die Königin verschiedene Textilien als

${ }^{644}$ BIN III, 571 (5/xii/ŠS 4); SET 73 (5/xii/ŠS 5); NISABA 8, 30 (4/xii" IIS 1); PDT I, 555 (5/[xxx]). Sallaberger, Der kultische Kalender (1993), S. 57 + Tab. 9a.

645 In SET 73 ist die entsprechende Zeile abgebrochen.

646 Sallaberger, ZA 82 (1992), S. 134, zu 1056.

647 Siehe S. 165.

${ }^{648} \mathrm{Zu}$ der Prinzessin Geme-Enlila siehe auch Such-Gutiérrez, Beiträge zum Pantheon von Nippur im 3. Jahrtausend (2003), Teil I S. $165 f$.

649 Siehe S. 189. 
„Proviant, Ehrengeschenk“ (igi-kár) erhielt ${ }^{650}$. Dies ist der einzige mir bekannte Beleg für Geschenke an die Königin zur Geburt eines Kindes aus der Ur III-Zeit.

Ob Kubātum die Mutter Ibbi-Suens war, muß derzeit noch offen bleiben. Der Text UET 3, 1242 (iii/IS 6) erwähnt eine Ma-ma? a ma-lugal, jedoch ist sonst keine königliche Frau dieses Namens bekannt, was Steinkeller veranlaßte vorzuschlagen, die Textstelle zu emendieren und ${ }^{ } \mathrm{Ku}^{7}-\mathrm{b} \mathrm{a}^{ }-[\mathrm{tu} \mathrm{m}]$ ama lugal zu lesen. ${ }^{651}$ Nach dem Platz auf der Tafel zu urteilen, wäre diese Lesung gut vorstellbar. Ob die Annahme zutreffend ist, muß derzeit ebenso offen bleiben wie die Frage, ob Kubātum vor ihrem Aufstieg zur Königin als Amme gedient hat.

\subsection{Kultische Pflichten der Kubātum}

Im kultischen Bereich ist Kubātum auffallend unterrepräsentiert. Ihre Beteiligung ist für keine der regelmäßigen Kulte wie den Feiern zu Neumond oder Neulicht, dem Kult von Nippur oder jenem für Inanna belegt. Nur einige wenige Texte aus dem Korpus zu Kubātum bezeugen die kultischen Aktivitäten dieser Königin. Dies ist einmal der schon erwähnte Text MVN 13, 639 (11/ix/AS 9) ${ }^{652}$, wo drei Schafe „um des Königs willen“ (mu lugal-šè) und insgesamt 5 Schafe und Ziegen „um der Kubātum willen“ (mu-Ku-ba-tum-š è) der Inanna dargebracht wurden. Ein Jahr später erhielt Nanna zwei Schafe „um der Kubātum willen“6533. Diese Gaben sind als persönliche Opfer der Königin zu verstehen, deren konkreter Anlaß nicht mehr nachzuvollziehen ist.

Kubātum selber tritt neben dem König und Abī-simtī als Stifterin von Weihgaben (a-ru-a) auf in SAT III, 1277 (v/ŠS 2) ${ }^{654}$, wo sie den Gottheiten Gula und Niĝar einen Korb (ma-sá-ab) und einen Eimer (ba-an-du $\left.u_{8}-d u_{8}\right)$ aus Bronze und Kupfer schenkt. Das é-ni ${ }_{9}$-gar-ra war ein Teil des GulaTempels in Isin ${ }^{655}$, und wie Stol dargelegt hat, eng verbunden mit der Gebärmutter und dem Vorgang der Geburt ${ }^{656}$, wobei das é-ni ${ }_{9}-\hat{g}$ ar-ra möglicherweise als Bestattungsort für Frühgeburten und die Nachgeburt

\footnotetext{
${ }_{650}$ MVN 16, 960 (ŠS 3), der Text stammt aus Umma.

${ }^{651}$ Steinkeller, More on Ur III Royal Wives, ASJ 3 (1981), S. 80.

${ }^{652}$ Siehe S. 154; vgl. Sallaberger, Der kultische Kalender (1993), Tab. 7, wo dieser Textabschnitt in das Umfeld der s i s k u $\mathrm{r}_{2}$-Riten im Palast eingeordnet wird.

653 SNATBM 271 (20/x/ŠS 1).

$654 \mathrm{Zu}$ diesem Text siehe auch S. 144.

655 George, House Most High (1993), 133 Nr. 886.

656 Stol, Birth in Babylonia and the Bible (2000), S. 29, 76.
} 
gedient hat ${ }^{657}$. Bei der oben angenommenen Krankheit eines Angehörigen des Königshauses $^{658}$ mag es sich also um eine Geburt der Königin Kubātum gehandelt haben, anläßlich derer der König, seine Mutter und die Königin der Heilgöttin Gula/Nininsina und Gottheiten aus ihrem Umkreis wertvolle Weihgaben stifteten.

Nur zwei Texte belegen eine Beteiligung der Kubātum am Kult der großen Götter des Landes. Als erstes ist hier BIN III, 213 (12/vii/ŠS 1) zu nennen, wo ein Mastschaf für Enlil und zwei Mastschafe für Ninlil „um der Kubatum willen“ (mu Ku-ba-tum-šè) verbucht werden. Wie schon bei Šulgi-simtī zu beobachten war, erhält die Göttin auch hier ein größeres Opfer als der Gott.

Der zweite Beleg ist PDT I, 294 (19/viii/ŠS 3). Es werden zwei Rinder, acht Schafe und sechs Ziegen für ein nächtliches Bierausschenken ( $\mathrm{k}$ a š - dé - a) der Kubātum verbucht. Es werden keine Namen von Gottheiten angegeben, für die diese Gaben, oder ein Teil davon, bestimmt waren, doch läßt sich der Text aufgrund des Datums in den weiteren Zusammenhang des Tummalfestes und der damit verbundenen Feierlichkeiten in Nippur einordnen ${ }^{659}$. Der Umfang der Lieferung von zwei Rindern und insgesamt 14 Stück Kleinvieh geht über die üblicherweise bei Opfern dargebrachte Menge an Tieren weit hinaus, was ebenso wie die Bezeichnung „Bierausschenken“ als Buchungsanlaß darauf hinweist, daß neben den Göttern auch Menschen zu den Empfängern dieser Tiere gehörten. Der König hielt bei dem im achten Monat für Enlil und Ninlil in Tummal begangenen Fest ein Gastmahl ab, und im selben Monat wurden auch in Nippur vergleichbare Festessen gegeben, die zumeist vom Ensi der Stadt veranstaltet wurden, jedoch auch von Angehörigen des Königshauses wie Kubātum oder dem Prinzen Ahūni ${ }^{660}$. Dabei konnten in diesem Monat mehrere solcher Festessen, die von verschiedenen Personen veranstaltet wurden, nacheinander stattfinden. So gab im Jahr ŠS 3 erst Ahūni ein „Bierausschenken“, wenige Tage später folgte Kubātum, der Ensi von Nippur selber gab wieder ein paar Tage danach sein Fest ${ }^{661}$. Dabei ist der Umfang der gelieferten Tiere nahezu gleichbleibend, auch findet sich stereotyp die Formulierung é-diĝir-re-e-ne-ke $e_{4} \mathrm{ba}-\mathrm{ab}-\mathrm{dab}_{5}$, ,bei den Tempeln wird es übernommen“. Dies läßt darauf schließen, daß es sich bei diesem mehrfach

\footnotetext{
657 Jacobsen, The Harps that once ... (1987), S. 475 Anm. 1.

658 Siehe oben S. 144f.

659 Sallaberger, Der kultische Kalender (1993), S. 144-145 und Tab. 42.

${ }_{660}$ BNC 993 (15/viii/ŠS 3), der Text ist unpubliziert, zitiert nach Sallaberger, Der kultische Kalender (1993), Tab. 42.

${ }_{661}$ BNC 993 (15/viii/ŠS 3) kaš-dé-a A-huu-ni dumu-lugal; PDT I, 294 (19/viii/ŠS 3) kaš-dé-a Ku-b a-tu m; BIN III, 450 (22/viii/ŠS 3) k aš-dé-a ensi $\mathrm{N}_{2} \mathrm{Nibru}{ }^{\mathrm{ki}}$.
} 
in einem Monat durchgeführten Bierausschenken um einen komplexen Ritus handelte, bei dem erst mehrere Gottheiten, darunter sicher Enlil und Ninlil, beopfert wurden, woran sich dann ein Essen anschloß.

Auch für Šulgi-simtī, deren kultische Pflichen sich aufgrund der umfangreichen Quellenbasis am besten verfolgen lassen, ist keine regelmäßige Teilnahme am Tummalfest zu belegen ist ${ }^{662}$, gleiches gilt für Abī-simtī. Dies legt die Vermutung nahe, daß die Königin von Ur nur indirekt am Tummalfest beteiligt war, und zwar durch zeitgleich zu den vom König in Tummal durchgeführten Riten mit von ihr vollzogenen Opfern in Nippur. Möglicherweise zeigt sich hier beim Tummalfest die Aufgabenverteilung des Königspaares, wobei der König Riten in Tummal vollzog und dort einen Teil des Hofes versammelte, während die Königin ihrerseits in Nippur kultische Pflichten zu erfüllen hatte und dort für andere Angehörige des Hofes ein „Bierausschenken“ veranstaltete. Aufgrund der spärlichen Quellenlage zu diesen zum Kult von Nippur gehörenden Festen und Riten im achten Monat muß diese Annahme derzeit noch hypothetisch bleiben. Doch wenn sich diese Rekonstruktion als zutreffend erweisen sollte, wäre dies ein weiterer Hinweis auf die Trennung der Lebensbereiche von König und Königin mit jeweils eigenen kultischen und gesellschaftlichen Pflichten, die sich durchaus auf dasselbe Ereignis, in diesem Fall das jährliche Fest für Enlil und Ninlil, beziehen konnten.

Eventuell ist der nicht gänzlich verständliche Text Orient 16, 37 (x/ŠS 1) ein weiterer Beleg für die Beteiligung der Kubātum am Kult in der Hauptstadt Ur. Hier wird die Ausgabe von einer Mine Silber „B U-RU-UK mu-DU nin PA-KAM šà Uri ${ }_{5}{ }^{{ }^{2}}$-ma " verbucht. Wie Sallaberger gezeigt hat, beziehen sich vergleichbare als máš-da-re ${ }_{6}$-a gekennzeichnete Lieferungen häufig auf eines der Hauptfeste in Ur. ${ }^{63}$ Nach dem Datum wäre hier an das ezem-mah zu denken, das im 10. Monat gefeiert wurde. Ob es sich hier bei der Königin (n in ) um Kubātum oder Abī-simtī handelt, muß offen bleiben.

Bei Sulgi-simtī und Abī-simtī war deutlich zu beobachten, daß sie Pflichten im Rahmen des Kultes der großen Götter des Landes wahrnahmen. Damit standen sie an der Seite des König, der mit regelmäßig ausgeführten Riten und Kulten versuchte, das Wohlwollen und den Segen der Götter für das Königshaus und damit für das ganze Land sicherzustellen. Dies ist, mit Ausnahme der gerade diskutierten Texte BIN III, 213 und PDT I, 294, bei Kubātum nicht zu beobachten. Es stellt sich damit die Frage, ob unser Bild von ihren Aktivitäten aufgrund des Zufalls der Überlieferung verzerrt ist, oder ob

\footnotetext{
662 Vgl. S. 54 zu Šulgi-simtī und ihrer Beteiligung am Tummalfest.

663 Sallaberger, Der kultische Kalender (1993), S. 160-165 und Tab. 59.
} 
sie derartige kultische Pflichten tatsächlich nicht zu erfüllen hatte.

Im Jahr ŠS 8 wurde für Kubātum im Tor des Enliltempels von Nippur eine neue Statue errichtet, welche mit einem Schaf beopfert wurde $(1 \mathrm{udu}-\mathrm{niga}$ alan gibil Ku-ba-tum ká d En-líl-lá) ${ }^{664}$. Anläßlich der Errichtung dieser Statue der Königin erhielten auch Enlil, Ninlil und Nanna Kleinvieh als Opfergaben, wobei Ninlil einen Ziegenbock mehr bekam als Enlil. Hier ist eine Parallele zum Opferverhalten der Šulti-simtī zu beobachten, welche ebenfalls die Göttin reicher beschenkte als den Gott. ${ }^{665}$

Frame hielt es für möglich, diese Statue im Zusammenhang mit einem Kult für Kubātum nach deren Tod zu sehen. ${ }^{666}$ Steinkeller stellte die Bedeutung eines solchen Opfers bei der Statue der Königin heraus, da derartige Opfer im Reich von Ur üblicherweise dem vergöttlichten König vorbehalten gewesen seien. ${ }^{667}$ Es läßt sich aber feststellen, daß die Errichtung einer Statue der Kubātum nicht in direktem Zusammenhang mit dem Totenkult stehen kann, da die Königin zu diesem Zeitpunkt noch am Leben war ${ }^{668}$. Ob nach ihrem Tod Opfer an dieser oder einer anderen Statue der Königin dargebracht wurden, ist nicht bekannt. Am Aufstellungsort der Statue, dem Torbau des Enliltempels in Nippur, befanden sich auch Statuen der Könige von Ur, darunter eine Statue des Šlgi ${ }^{669}$. Die Tatsache, daß die Königin mit einer Statue geehrt wurde, ist nicht auf Kubātum allein beschränkt, wie UET 3, 329 (viii/AS 5) zeigt, wo Gold als Auflage für eine kupferne Statue einer Königin (nin) ausgegeben wird. Aufgrund des Datums kann es sich bei dieser Königin nur um Abī-simtī handeln, die damit Jahre vor ihrem Tod mit einer Statue geehrt worden ist. Man muß folglich davon ausgehen, daß nicht nur die Könige von Ur Statuen von sich errichten ließen, sondern daß dies auch für die Königinnen galt, deren Standbilder an gleicher Stelle wie die der Könige aufgestellt wurden. Auch wenn keine Königin von Ur je vergöttlicht wurde, so ist die Errichtung von Statuen dieser Frauen und die Beopferung derselben doch ein deutliches Zeichen dafür, daß die Königin im religiösen Konzept der Zeit eine solch wichtige Stellung einnahm, daß sie wie der König in Form einer Statue an bestimmter Stelle ständig präsent zu sein hatte.

${ }_{644}$ BiOr 9, S. 173 = JEOL 33 (1995), S. 118 Nr. 7 (21/i/ŠS 8).

665 Such-Gutiérrez, Beiträge zum Pantheon von Nippur im 3. Jahrtausend (2003), Teil I, S. 72.

666 Frame, A New Wife für Šu-Sîn, ARRIM 2 (1984), S. 4 Anm. 10.

667 Steinkeller, More on Ur III Royal Wives, ASJ 3 (1981), S. 80; Kutscher, An Offering to the Statue of Šlgi, Tel Aviv 1 (1974), S. 55.

668 Dies belegen die Texte ASJ 4, S. 142 Nr. 7 und SAT III, 1861 (beide ii/ŠS 8) über wirtschaftliche Transaktionen der Kubātum.

669 TCL 2, 5501 (21/ii/Š 47), siehe Sallaberger, Der kultische Kalender (1993), S. 98-99. 


\subsection{Soziale Beziehungen}

Bezüglich der Pflege sozialer Beziehungen ist für Kubātum keine Parallele zu den bei Šulgi-simtī und Abī-simtī zu beobachtenden Strukturen zu finden, nach denen die Königinnen als mu - DU bezeichnete Lieferungen von einem großen Personenkreis, darunter vielen Frauen, erhielten, und ihrerseits Menschen aus ihrer Umgebung Geschenke/Ehrengaben zukommen ließen ${ }^{670}$. Aus AUCT I, 32 $(25 / \mathrm{ix} / \mathrm{ŠS} 4)^{671}$ wird ersichtlich, daß allerdings auch Kubātum eigene Einkünfte, die als mu-D U Ku-ba-tum bezeichnet wurden, bezog, die von der königlichen Administration verwaltet wurden. Jedoch fehlen derzeit noch Texte, welche die Ausgabe von Vieh an Personen aus dem Umkreis der Kubātum belegen würden $^{672}$.

Drei Texte zeigen, daß auch Kubātum enge Kontakte zu Damen des Hofes pflegte. Nach ASJ 4, S. 140 Nr. 1 (Datum abgebrochen) veranstaltete sie ein Bierausschenken für die Prinzessin Simat-Ištarān ${ }^{673}$, für das 16 Schafe zur Verfügung gestellt wurden. Es handelte sich also bei diesem Essen um eine größere Festlichkeit, deren konkreter Anlaß jedoch nicht genannt wird. SimatIštarān ist die einzige Prinzessin von Ur, die unter Amar-Suen und Šu-Suen regelmäßig im Kult der großen Götter des Landes tätig war ${ }^{674}$, eine Tätigkeit, die sonst dem Aufgabenspektrum der Königin entsprach. Sie war eine Tochter Amar-Suens und damit eine Schwester von Šu-Suen ${ }^{675}$. Dieses Bierausschenken der Kubātum für Simat-Ištarān ist also zu verstehen als ein Beispiel für die Pflege der sozialen Beziehungen zwischen den hochrangigsten Damen des Hofes.

Dasselbe gilt für die Übersendung von Luxusartikeln wie Schmuck ${ }^{676}$ und ein kostbar gearbeitetes Siegel aus Lapislazuli mit Goldeinlagen ${ }^{677}$, welche

${ }^{670}$ Siehe zu Šulgi-simtī S. 41-46, 100-103 und zu Abī-simtī S. 110-111, 115.

671 Lieferung von Rindern als mu-DU für Abī-simtī und Kubātum, wobei die Buchungen für die beiden Frauen getrennt voneinander aufgeführt werden.

672 Möglicherweise ist PDT I, 431 (6/x/ŠS 7) ein Beleg für derartige Ehrengeschenke (igi-kár) von Kubātum. In diesem Text werden je 10 Schafe von Abī-simtī und Kubātum ausgegeben, wobei als Verwendungszweck ,ig i-kár ki-pàr-šé “ angegeben wird.

673 Siehe S. 131.

674 Zu Simat-Ištarān siehe S. 182.

675 Dies geht aus den Siegelinschriften Cornell 98-12-009 und Cornell 99-14-036 (beide unpubl.) hervor, wo sie als „geliebte Schwester des Šu-Suen, des Königs von Ur“ bezeichnet wird. Ich danke D. Owen, der das Archiv der Simat-Ištarān und ihres Mannes Šu-Kabta zusammen mit R. Mayr bearbeitet, für diese Information.

676 UTI VI, 3800 VS Kol. III ( ̌̌S, das genaue Datum ist verloren).

677 JCS 54, S. 7-9 Nr. 52. VS IV. 
Kubātum ihrer Schwiegermutter Abī-simtī als Geschenke schickte. ${ }^{678}$ Der konkrete Anlaß für solche Gaben ist nicht überliefert, denkbar sind besondere Ereignisse im Leben der beschenkten Personen oder bestimmte Festtage, zu denen derartige Prestigegüter innerhalb der königlichen Familie ausgetauscht werden konnten.

Einen Eindruck von der Prachtentfaltung am Hof von Ur vermitteln neben den sachlichen Beschreibungen der Schmuckstücke in den Texten auch die seltenen Funde solcher Luxusartikel. So wurden im Bereich des Eanna von Uruk zwei Ketten gefunden, die aufgrund von Inschriften auf einzelnen Perlen den beiden Damen Kubātum und Ti'amat-bāštī zuzuordnen sind ${ }^{679}$. Die Kette der Kubātum besteht aus mehreren Reihen von Perlen aus Gold, Karneol und dem zu der Zeit in Ur sehr seltenen Türkis, die auf Golddraht aufgezogen waren. ${ }^{680}$ Die Inschrift auf einer der Achatperlen lautet Ku-ba-tum lu kur kiá $\hat{g}{ }^{d} \breve{S}$ u $-{ }^{d}$ EN.ZU (Kubātum, geliebte Lukur des Šu-Suen). ${ }^{681}$

Der Text OrAn 22, S. 203 (ŠS 2) gibt Auskunft über die Einnahme und Ausgabe von Silber durch die herrschenden Familien in Ur. Die insgesamt 10 Minen Silber, die auf der Tafel verzeichnet wurden, stammte aus verschiedenen Quellen, darunter auch aus dem Verkauf von Getreide. Ausgegeben wurde dieses Silber an den König (1 Mine), die Königin (1/2 Mine) sowie andere Mitglieder der Oberschicht, wobei die Lieferungen an König und Königin als $\mathrm{mu-DU}$ bezeichnet werden. Und in TCL 2, 5547 (-/vii/ŠS 6) werden 7 5/6 Minen und 5 Schekel Silber für ein šen-šú (ein Kessel?) der Kubatum in Empfang genommen.

\subsection{Die Viehwirtschaft der Kubātum}

Ein großer Teil der Texte zu Kubātum bezieht sich auf Transaktionen im Bereich der Viehwirtschaft. Rinder, Schafe und Ziegen werden dem Bestand der Kubātum zugeführt oder aus diesem Bestand herausgenommen. So werden in ASJ 3, S. 91 (9/vi/ŠS 2) zwei Rinder als šu-gíd-Abgabe ${ }^{682}$ von Kubātum,

\footnotetext{
678 Siehe dazu auch S. 117.

679 Nöldeke et al., UVB 8, S. 23-24 und Taf. 38, 39; Limper, AUWE 2, S. 63-66 und Taf. 21-25; Braun-Holzinger, Mesopotamische Weihgaben (1991), S. 368 P 16 und P 17; zu den Inschriften zuletzt RIME 3/2.1.4.28 (Kette der Kubātum) und RIME 3/2.1.4.29 (Kette der Ti'amat-bāštī), dort auch weitere Literatur.

680 Limper, AUWE 2, S. 65 und Taf. 22.

${ }^{681}$ RIME 3/2.1.4.28.

${ }^{682}$ Bei šu-gíd handelt es sich wahrscheinlich um eine Abgabe, die auf die Viehherden erhoben wurde. Vgl. Sigrist, Drehem (1992), S. 40-43; Sallaberger, Der kultische Kalender (1993), S. 27.
} 
der Königin, an Enlila, den verantwortlichen Beamten für die Rinderzucht ${ }^{683}$, überstellt. An diesem Text wird deutlich, daß auch die Königin mit ihren Viehbeständen zumindest teilweise in das System der Abgaben des Staates eingebunden war. Der Viehbestand der Kubātum wurde wie jener der Abī-simtī von der königlichen Administration verwaltet ${ }^{684}$ und wie Abī-simtī besaß auch Kubātum große Schafherden bei Girsu. ${ }^{685}$ Verantwortlich für die Schafe der Kubātum waren Izuarik (ŠS 5) und Lu-Nanna (ŠS 6), wobei letzterer den Titel eines Verwalters der Königin (šabra nin) führte und damit weitergehende Aufgaben im Haushalt der Kubātum zu erfüllen hatte als Izuarik, welcher als „Viehverwalter“ $\left(\mathrm{ku} \mathrm{s}_{7}\right)$ bezeichnet wird. Eine Überweisung von 270 Schafen für den Maststall (é udu-niga) der Kubātum wird im Jahr ŠS 6 von AbaEnlilgin $^{686}$ abgebucht und von Rīm-ilī übernommen ${ }^{687}$. Dieser Rīm-ilī gehörte zu den untergeordneten Beamten in der Hierarchie von Puzriš-Dagān und ist wie Aba-Enlilgin in der Regierungszeit von Šu-Suen häufiger im Zusammenhang mit den hochrangigen Frauen des Hofes zu finden ${ }^{688}$.

Interessant sind die zusammengehörigen Texte ASJ 4, S. $142 \mathrm{Nr} .7$ und SAT III, 1861 (beide II/ŠS 8), wobei in ASJ 4, S. 142 Nr. 7 der Hauptbeamte Intaea die Ausgabe von vier Rindern, 90 Schafen und 30 Ziegen für den Schafstall der Kubātum (é udu Ku-ba-tum) verbucht. Die Annahme dieser Tiere für die Königin verzeichnet SAT III, 1861, jedoch sind die Tiere jetzt allgemein für den Haushalt der Kubātum (é Ku-ba-tum) bestimmt. Hier wird deutlich, daß mit dem „Haus“ (é) der Königin ihr gesamter Haushalt einschließlich der landwirtschaftlichen Einheiten gemeint ist.

Es ist davon auszugehen, daß Kubātum wie auch Šulgi-simtī und Abī-simtī

${ }^{683}$ Maeda, Bringing (mu-túm) of livestock and the Puzriš-Dagan organization for cattle management in the Ur III dynasty, ASJ 11 (1989), S. 108 Tab. I.

${ }^{684}$ Belege zur Viehwirtschaft der Kubātum sind BIN III, 220 (26/viii/ŠS 2); BIN III, 558 (x/ŠS 2); MVN 13, 100 (9/xi/ŠS 4); AUCT I, 407 (kein Datum). MVN 9, 165 mit Duplikat ITT V, 9193 (ک̌Š 5) und MTBM 257 (ŠS 6), beides Tafelkorbetiketten.

${ }_{686} \mathrm{Zu}$ diesem Beamten und seinem Kontakt zu den königlichen Frauen siehe S. 98.

687 AUCT I, 159 (xii ${ }^{\text {II }} /$ ŠS 6).

${ }^{688}$ AUCT I, 162 (iv/ŠS 1); AUCT I, 79 (x/ŠS 1); MVN 15, 287 (x/ŠS 2); MVN 16, 1428 (-/X/ŠS 4); AUCT I, 159 (xiï/ǏŠ 6); TPTS 40 (ŠS, Datum teilweise zerstört); AUCT III, 508 (Datum abgebrochen). Bis auf den Ummatext MVN 16, 1428 stammen alle Belege aus Puzriš-Dagān. Der Name des Rīm-ilī wird zumeist Ri-mi-DIĜIR geschrieben, Ausnahmen sind MVN 16, 1428 (Ri-mi-í-lum) und TPTS 40 (Ri-im-ì-lí).

In dem Text aus Umma trägt er den Titel eines Wesirs der Königin (sukkal nin), wobei nicht sicher ist, ob es sich dabei um denselben Beamten handelt wie in den Texten aus Drehem. Mit „nin“ ist wohl Ab̄̄-simtī gemeint, da sie eine enge Beziehung zu Umma und Zabalam hatte, was für Kubātum nicht zu beobachten ist. 
die Wolle ihrer Schafe zumindest für den Eigenbedarf von ihren Weberinnen verarbeiten ließ, doch sind zu dem Tätigkeitsfeld „Textilproduktion“ für Kubātum derzeit noch keine Texte bekannt.

Wie Ab̄̄-simtī bezog Kubātum Rohr und Weidenholz als regelmäßige Lieferungen $\left(\mathrm{s} a ́-\mathrm{du}_{11}\right)$ aus Umma ${ }^{689}$. Diese Buchungen werden stets von Lugal-kuzu für die Damen übernommen. In UTI III, 1920 (ŠS 2) nimmt er für beide Frauen Rohr an, wobei diese nur mit dem Titel genannt werden. Durch den Vergleich mit den Texten, die Kubātum namentlich als Empfängerin von Rohr nennen, ist es eindeutig, daß mit den Königinnen (nin-e-ne) in diesem Text Kubātum und Abī-simtī gemeint sein müssen ${ }^{690}$.

\section{Geme-Enlila}

Die letzte namentlich bekannte Königin von Ur und Frau von Ibbi-Suen war Geme-Enlila. Sie ist erstmals belegt im Monat x/ŠS 9, unmittelbar nach dem Tod Šu-Suens ${ }^{691}$, der letzte datierte Text mit ihrem Namen ist SAT III, 2025 (xii/IS 8) ${ }^{692}$, der letzte datierte Text mit der Erwähnung einer Königin (nin) dieser Epoche stammt dagegen aus dem Jahr IS $22^{693}$. Ob es sich bei dieser Königin um Geme-Enlila gehandelt haben könnte, ober ob nach ihr noch eine weitere Frau das Amt der Königin von Ur ausübte, muß derzeit offen bleiben.

In vier Texten wird Geme-Enlila mit Namen und Titel $\left(\mathrm{Geme}_{2}-{ }^{\mathrm{d}} \mathrm{En}-\mathrm{líl}\right.$ -

689 Lieferung für Kubātum: MVN 16, die Texte 1012, 1268 und 1389 (alle ŠS 2); Lieferung für die Königin (n in ) MVN 16, 1042 (ŠŠ 1), MVN 14, 399 (ŠS 2); MVN 16, 1370 (ŠS 2), hier ist nicht deutlich, ob Abī-simtī oder Kubātum als Empfängerin gemeint ist.

${ }^{690}$ Zum Titel „n in “ siehe S. 235-237. In SAT I, 118 (undatiert) werden verschiedene Mehlsorten zur Versorgung verschiedener Personen am Hof verbucht, wobei die Gesamtlieferung als ,,regelmäßige Lieferung für die Königinnen (sá-du ${ }_{11}$ n in -e n e )“ bezeichnet wird. Auch hier dürften Abī-simtī und Kubātum gemeint sein.

${ }^{691}$ PDT I, 563 (21/x/ŠS 9). Totenopfer für Šu-Suen beginnen am 4/x/ŠS 9 (MVN 10, 172). Zum Tod von Šu-Suen siehe Sallaberger, OBO 160/3 (1999), S. 171.

${ }_{692}$ In UET 3, 1383 (27/iv/IS 9) werden Lieferungen von Ur-Šulpae, den Kanalinspektor der Geme-Enlila, der Königin, verbucht, doch ist dies kein Hinweis darauf, daß GemeEnlila zu diesem Zeitpunkt noch am Leben war, wie das Beispiel der Bizua, Schwester der Abī-simtī zeigt, welche noch im Jahr IS 2, also deutlich nach dem Tod ihrer Schwester als „Bizua, Schwester der Abī-simtī, der Königin „, in einem Text aus Ur auftritt (UET 3, 1504).

693 UET 3, 826 (vi/IS 22). 
lá nin) genannt. ${ }^{694}$ Daneben erscheint sie in einer Reihe von Texten nur mit ihrem Namen. Für Diskussionen in der Forschung hat die Tatsache gesorgt, daß außer der Königin Geme-Enlila auch eine Prinzessin ${ }^{695}$ und eine Lukur des Ninurta ${ }^{696}$ dieses Namens bekannt sind. Daß die Prinzessin und die Lukur Geme-Enlila eine Person waren, geht aus dem Text NATN 859 (30/iv/ŠS 7) hervor, wo sie mit beiden Titeln genannt wird ${ }^{697}$ Steinkeller hatte die schon von Jacobsen angedeutete These, Ibbi-Suen könnte seine eigene Schwester geheiratet haben, wieder aufgegriffen, und einen für Mesopotamien singulären Fall einer Geschwisterehe angenommen. ${ }^{698}$ Dies hatte Michalowski mit dem Verweis auf NISABA 8, 30 (4/xii $2 /$ IS 1), wo Geme-Enlila, Tochter des Königs, auftritt, angezweifelt und darauf hingewiesen, daß es kaum anzunehmen sei, daß die Königin Geme-Enlila, die zu diesem Zeitpunkt schon im Amt war, noch als „Prinzessin“ bezeichnet wurde. ${ }^{699}$ Diese Annahme wird bestätigt von PDT II, 1056 (Datum abgebrochen), wo Lieferungen sowohl an Geme-Enlila (ohne Titel, gemeint ist die Königin) und an Geme-Enlila, Lukur des Ninurta, verbucht werden. ${ }^{700}$ Somit kann als gesichert gelten, daß Ibbi-Suen nicht seine Schwester geheiratet hat. ${ }^{701}$ Woher die Königin Geme-Enlila stammte, ist nicht bekannt.

Nur wenige Texte belegen Lieferungen für den täglichen Bedarf im Haushalt der Geme-Enlila. Eine bunte Mischung verschiedener Lebensmittel als máš-da-re-a-Lieferung ${ }^{702}$ bezeugt UET 3, 379 (2/ix/IS 5), wo unter anderem Butterschmalz, Käse, Datteln, Geflügel und Fische für die Königin

${ }^{694}$ UET 3, 376 (vi/IS 5); SAT III, 2025 (xii/IS 8); UET 3, 1383 (27/iv/IS 9); TCTI 2, 4184 (kein Datum) U.a. in A 24644, ASJ 3, S. 92 (9/ix/ŠS 7).

${ }_{696}$ MVN 13, 123 (3/xii/ŠS 7); PDT II, 1056 (Datum abgebrochen).

${ }^{697}$ Michalowski, Royal Women - Part III, ASJ 4 (1982), S. 136. Zu der Annahme, daß die Prinzessin Geme-Enlila die Tochter der Kubātum und des Šu-Suen war, siehe S. 156.

698 Jacobsen, The Reign of Ibi-Suen, JCS 7 (1953), S. 37; Steinkeller, More on Ur III Royal Wives, ASJ 3 (1981), S. 90-91.

699 Michalowski, Royal Women - Part III, ASJ 4 (1982), S. 137.

700 Vgl. Sallaberger, ZA 82 (1992), S. 134, zu 1056.

701 Sallaberger, OBO 160/3 (1999), S. 184.

702 Zu máš - d a - re - a-Abgaben für Angehörige des Königshauses siehe Sallaberger, Der kultische Kalender (1993), S. 160-170. Hierher gehören auch MVN 14, 598 (AS 8), Rinder und Schafe als máš-da-re ${ }_{6}$-a-nin; SET 104 (x/AS 8), Schafe als mášda-re-a-nin; MVN 16, 916 (-/-/ŠS 3) Rinder und Schafe als máš-da-re-a A-bísí-im-ti n in, Toronto 3 (5/xii/ŠS $4-15 /$ iv/ŠS 5) Viehfütter als máš - d a-re-a-n in. UET 3, 97 (viii/IS 4) Obst als máš-da-re-a-[nin ]. 
verbucht werden. Ebenso wie Abī-simtī erhielt auch Geme-Enlila möglicherweise monatlich eine gleichbleibende Menge von 30 Schafen zugewiesen ${ }^{703}$. Und SAT III, 2025 (xii/IS 8) verzeichnet die Sendung von 5 Sila geseihtem Sesamöl (ì- ĝiš bára-ak) für den „Ort der Geme-Enlila, der Königin“ (ki Geme $2^{\left.-{ }^{d} E n-l i ́ l-1 a ́ ~ n i n-s ̌ e ̀\right) . ~ G e m e-E n l i l a, ~ d i e ~ K o ̈ n i g i n, ~}$ erscheint auch im Kontext einer Aufstellung von Wolle für Textilien von unterschiedlicher Qualität ${ }^{704}$. Die Annahme eines Schafes für die Königin (mu nin-šè) durch eine Person namens Pu-ga-a verzeichnet der wohl aus Nippur stammende Text TRU 59 (viii/ŠS 2). Ein Pu-ga-a ist sonst im Kontext der königlichen Frauen nicht bekannt.

Für einen Besuch im Haus des Prinzen Bakinana erhielt Geme-Enlila verschiedene Lebensmittel, darunter Bier in unterschiedlicher Qualität und Brote aus verschiedenen Mehlsorten. Diese Lieferungen werden mit dem Vermerk versehen: „Proviant der Königin ist es““ (i g i -kár n in -k a m) ${ }^{705}$.

\subsection{Kultische Pflichten der Geme-Enlila}

Obwohl nur wenige Belege über die kultischen Pflichten der Geme-Enlila Auskunft geben, bestätigen diese das Bild der Rolle der Königin von Ur, welches sich aus den Quellen zu Šulgi-simtī und Abī-simtī ergeben hat.

Ebenso wie ihre Vorgängerinnen führte auch Geme-Enlila zum Neumondtag Riten aus, um das mit diesem Tag verbundene Unheil vom König abzuwenden. Dabei wird die schon in den Texten von Abī-simtī verwendete Formel erweitert. Es heißt jetzt „ní ĝ-dab $a_{5} a-t u_{5}-a u_{4}-n u ́-a-k a-n i=d a s$ von ihr Übernommene für Baderiten für den Neumondtag“. ${ }^{706}$ Verantwortlich für diese Buchungen ist wie zur Zeit von Abī-simtī der amtierende Hauptbeamte Intaea, auch im Amt des Überbringers $\left(\hat{\mathrm{g}} \mathrm{ir}_{3}\right)$ hat sich keine Veränderung ergeben, hier sind Nanna-maba und Nūr-Suen weiterhin aktiv. Der Umfang der Lieferungen liegt mit 6 bis $13^{? 707}$ Tieren etwas unter der jeweils für Abī-simtī bereitgestellten Menge. Auch in den Texten der GemeEnlila wird keine Gottheit genannt, der diese Opfer gelten sollten. Somit kann aufgrund des gleichartigen Charakters der Quellen davon ausgegangen werden,

703 PDT II, 1056 (Datum abgebrochen); zur regelmäßigen Lieferung von 30 Schafen an Abī-simtī siehe S. 111.

704 ITT II, 4184 (kein Datum erhalten).

705 TCTI 2, 3716 (v/IS 2).

706 MVN 3, 302 (27/vii/IS 1); MVN 15, 197 (iii/IS 2); AUCT III, 208 (26/x/IS 2). Vgl. Sallaberger, Der kultische Kalender (1993), S. 60-63 + Tab. 11.

707 In MVN 15, 197 (iii/IS 2) sind die Zeilen über die zur Verfügung gestellten Tiere weitgehend abgebrochen. 
daß Geme-Enlila mit ihrem Amtsantritt zumindest im Bereich der Neumondfeiern die kultischen Pflichten einer Königin von Ur übernahm ${ }^{708}$.

Für die kultischen Aktivitäten der Geme-Enlila außerhalb der Neumondriten finden sich nur sehr vereinzelte Belege. So deutet der Text UET 3, 190 (vii/IS 7) auf eine Beteiligung der Königin am Akiti-Fest zur Aussaat. Es werden ein Schaf und ein Lamm zum Ort/in den Palast der Königin (kinin-a-šé) geliefert für das Fest „Boot des Suen“ (e zem má d EN.ZU) ${ }^{709}$. Da die Beteiligung der Königin an den Feierlichkeiten zum Akiti ohnehin kaum dokumentiert ist, ist es schwierig, diesen vereinzelten Beleg in einen größeren Kontext einzubinden.

Zwei Texte belegen Opfer ,um der Geme-Enlila willen“ (mu Geme ${ }_{2}$ ${ }^{d}$ En-1íl-1á-šè) im Zusammenhang mit einem Fest von Uruk, das gegen Ende des zehnten Monats gefeiert wurde. ${ }^{710}$ Hierbei werden verschiedenen in Uruk verehrten Gottheiten Opfer um der Königin willen dargebracht, so den Göttinnen Inanna, Gula, Ninsun, Nanaja, aber auch den verstorbenen Königen Šulgi und Šu-Suen (BIN V, 6) und der Göttin Gansura (PDT I, 563). Ob die Königin bei diesen Riten anwesend war und welche Funktion sie dabei zu erfüllen hatte, geht aus den Texten nicht hervor. Beide Texte belegen lediglich die Anwesenheit des Königs bei diesem Fest (l ugal k $\mathrm{u}_{4}$-ra).

Zwei Texte aus dem Archiv des Inannatempels von Nippur verbuchen die Ausgabe von Naturalien anläßlich einer Reise des Königs und der Königin im Rahmen des Gusisu-Festes. ${ }^{711}$ Dieses Fest war nicht den Hauptgöttern von Nippur, Enlil und Ninlil, geweiht, sondern war das Hauptfest Ninurta, bei dem jedoch Enlil und Ninlil aufgrund ihrer besonderen Bedeutung im Kult von Nippur ebenfalls eine herausragende Position einnahmen. ${ }^{712}$ Hier wird deutlich, daß auch Geme-Enlila zur Erfüllung ihrer kultischen Pflichten Reisen zu den wichtigen Tempeln des Landes unternommen hat.

Opfer „um der Geme-Enlila willen“ (mu Geme ${ }_{2}-{ }^{\mathrm{d}} \mathrm{En-1íl-1á-šè)} \mathrm{für}$

708 Michalowski, Royal Women - Part III, ASJ 4 (1982), S. 137; van de Mieroop, Women in the Economy of Sumer (1989), S. 57.

709 Zum Boot des Nanna im Kontext des Akiti zur Aussaat siehe Sallaberger, Der kultische Kalender (1993), S. 185 + Anm. 877 und Cohen, Cultic Calendars (1993), S. 142, 232.

710 PDT I, 563 (21/x/ŠS 9); BIN V, 6 (8-29/-/-). Zu dem Inanna?-Fest im zehnten Monat siehe Sallaberger, Der kultische Kalender (1993), S. 214-216 + Tab. 70.

7116 NT 366 (-/ii/IS 6) und 6 NT 430 a-b (30/ii/IS 6), Zettler, BBVO 11 S. 279, 281f.. Siehe dazu Such-Gutiérrez, Beiträge zum Pantheon von Nippur im 3. Jahrtausend (2003), S. $213+$ Anm. 916.

712 Zum Gusisu-Fest von Nippur siehe Sallaberger, Der kultische Kalender (1993), S. 114-122. 
die von den Königinnen stets besonders verehrten Göttinnen Inanna und Nanaja bezeugt BCT I, 114 (13/vii/IS 2), wo Inanna drei und Nanaja zwei Stück Kleinvieh erhält. Der Anlaß für diese Gaben wird im Text nicht genannt, doch möglicherweise führte Geme-Enlila die bei Šulgi-simtī eindeutig zu verfolgenden Opfer in Uruk am Tor des Gipar und am Tor des Heiligtums (der Inanna) ${ }^{713}$ fort. Dann könnte auch SAT III, 1928 (28, 29/vii/IS 1) in diesen Kontext gehören, wo zwar weder der Name noch der Titel der Königin genannt ist, doch die Opfer dem von Šulgi-simtī bekannten Schema entsprechen: jeweils ein Schaf oder Zicklein wird am 28. Tag der Inanna im Heiligtum ( ${ }^{\mathrm{d} I n a n n a}$ šà èš) sowie am Tor des Gipar und der Nanaja geopfert ${ }^{714}$.

Gefäße aus Rotgold als Weihgaben des Königs (a-ru-a ${ }^{\mathrm{d}} I-b{ }^{\mathrm{d}}-{ }^{\mathrm{d}}$ EN.ZU

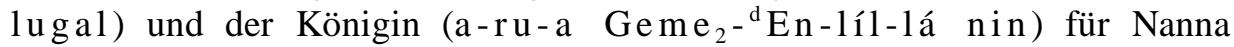
finden sich in UET 3, 376 (vi/IS 5). Vergleichbare Weihgeschenke aus Edelmetall sind auch von den Amtsvorgängerinnen der Geme-Enlila bekannt ${ }^{715}$. Über den Anlaß für diese Weihgeschenke kann nur spekuliert werden, vorstellbar wäre ein Zusammenhang mit der in diesem Jahr geschlossenen Ehe zwischen der Prinzessin Tukīn-hatți-migrīša und dem Ensi von Zabšali ${ }^{716}$, doch ist ebenso auch ein anderer Grund für diese Gaben denkbar.

Es wird somit deutlich, daß Geme-Enlila in der Ausübung ihrer kultischen Pflichten als Königin dem Handlungsspektrum folgte, welches bei Šulgi-simtī und Abī-simtī ausführlich zu beobachten ist. Die besondere Verehrung persönlicher Gottheiten ist für diese letzte bekannte Königin von Ur nicht zu beobachten, was aber in der veränderten Quellenlage für die Regierungszeit des letzten Königs von Ur begründet ist, und nicht etwa in einem nachlassenden Interesse oder einem schwindenden Einfluß der Geme-Enlila als Königin gesucht werden sollte.

Ein Bierausschenken der Geme-Enlila ist nur einmal belegt ${ }^{717}$. Aus diesem Anlaß wurden insgesamt ein Rind, 35 Schafe und 20 Ziegen an die Küche (é muhaldim) geliefert. Dies macht deutlich, daß die Tiere nicht für Opfer bestimmt waren, sondern für ein Festessen, welches die Königin wohl im

713 Siehe S. 63.

714 Es folgt die Gabe von einer Ziege am Tor des Gipar am 29. Tag „mu Me-dig ir $\mathrm{ni}_{9}$ - $\mathrm{g}$ a r-ta-š è “. Dieser Personenname ist mir im Kontext der königlichen Frauen sonst nicht bekannt.

715 SAT III, 1277 (v/ŠS 2), siehe S. 144 und 157; MVN 20, 31 (ii/AS 5), Bronzeobjekte, die Abī-simtī der Inanna schenkt.

716 Jahresdatum IS 5.

717 NISABA 8, 20 II 14-III 6 (9/[vii//IS ]), siehe dazu Sallaberger, Der kultische Kalender (1993), S. $176+$ Anm. 826. 
Rahmen eines der Hauptfeste von Ur gegeben hat. Die weiteren auf dieser Tafel verzeichneten Ausgaben deuten auf das Akiti-Fest zur Aussaat im vii. Monat $^{718}$ als Anlaß für dieses Bierausschenken hin. Das bedeutet, daß die Königin wie ihre Amtsvorgängerinnen zu bestimmten Ereignissen ein festliches Gastmahl gab, bei dem entweder eine bestimmte Persönlichkeit explizit geehrt wurde, oder aber, wie in diesem Fall, das Festmahl Bestandteil eines der großen kultischen Feste im Jahresablauf darstellte. An diesem Essen werden die Angehörigen des Hofes ebenso wie möglicherweise auswärtige Gesandte, die sich zu dem Zeitpunkt in der Hauptstadt aufhielten, teilgenommen haben.

Inwieweit die Königin zu derartigen Anlässen als Gastgeberin die entstehenden sozialen Kontakte auch politisch nutzte, sei es durch Einflußnahme auf die Beamten des Reiches oder auch auf Gäste, muß Spekulation bleiben. Doch ist davon auszugehen, daß die Königin von Ur sehr wohl über die Möglichkeit verfügte, bei solchen gesellschaftlichen Ereignissen gleichsam hinter den Kulissen und nicht greifbar in den uns überlieferten Quellen, ihren Einfluß geltend zu machen.

\section{Der Haushalt der Königin (ki-nin)}

Mehrfach wurde schon darauf hingewiesen, daß die Königinnen von Ur über einen eigenen Haushalt und eigenes Personal verfügten. Dazu gehören nicht nur die bekannten Beamten der Königin Šulgi-simtī und die hochrangigen

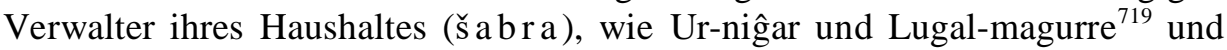
die häufig als Bevollmächtigte (maški m) auftretenden Boten (rá-gaba) wie Šulgi-ilī oder Rīṣ-ilum ${ }^{720}$. Auch auf den unteren Ebenen des Personals werden die für die Königin arbeitenden Personen eindeutig ihr zugeordnet, so bei den Hirten der Königin (n a-gada nin) $)^{721}$, Ur-Guenna, dem Schiffer der Königin $\left(\text { má-lahb }_{5} \text { nin }\right)^{722}$, verschiedenen Handwerkern der Königin (um-mi-a

\footnotetext{
718 Sallaberger, Der kultische Kalender (1993), S. 175-177.

719 Siehe S. 114. Ein weiterer Verwalter der Königin (š a br a n in ) war ein gewisser Nadi (UET 3, 272; Datum abgebrochen), den ich jedoch derzeit keiner Königin zuordnen kann.

720 Ein nicht namentlich genannter Bote der Königin (rá-gaba nin) erscheint als Empfänger einer Brotration in dem nur auf den Monat (-/v/-) datierten Botentext MTBM 336 aus Lagaš.

721 BM 22874, unpubliziert, Sigrist, Figulla, Walker, Catalogue of the Babylonian Tablets in the British Museum, Vol. II; ITT II, 873 (Datum abgebrochen); vergleichbar ist ITT II, 628 (ŠS 7).

722 ITT II, 896 (Datum abgebrochen).
} 
$\operatorname{nin})^{723}$ oder Gartenpersonal $\left(\mathrm{d} u ̀-\mathrm{a}-\mathrm{k} \mathrm{u}_{5} \operatorname{nin}\right)^{724}$.

Relativ selten geben Texte aus dem Schuh- oder dem Schatzarchiv von Puzriš-Dagān Hinweise auf die Prachtentfaltung am Hof der Königin. Neben dem schon angesprochenen Austausch von Prestigegütern wie Schmuck oder Siegeln ${ }^{725}$ bezeugen Lieferungen von kostbaren Textilien ${ }^{726}$ aus Wolle und Leinen die Vielfalt unterschiedlicher am Hof getragener Gewänder, welche man sich mit Edelmetallen und kostbaren Steinen verziert vorstellen darf, wie dies für Schuhe eindeutig belegt ist. So erhielt Geme-Enlila Sandalen, die mit Gold, Karneol und Lapislazuli geschmückt waren. ${ }^{727}$ Mehrere Paar Schuhe unterschiedlicher Art werden in PDT I, 583 (vi/ŠS 6) für Kubātum und Babati, den Bruder der Abī-simtī, ausgegeben.

Auf die kostbare Ausstattung des Hauses der Königin verweisen nur wenige Texte. So erhielt Geme-Enlila ein Bett mit Beinen aus edlem haluppu$\mathrm{Holz}^{728}$, für eine Tür vom Haus der Kubātum wurden kupferne Nägel geliefert $^{729}$. Eine Auflistung der Produkte von acht Handwerksbetrieben in Ur aus dem Jahr IS 11 enthält auch einen Beleg über Holzlieferungen für einen Thron der Königin ${ }^{730}$. Allerdings ist ein Thron in der Ur III-Zeit nicht auf den

723 PDT II, 911 (i/AS 7); zu u m- m i - a „Handwerker“ oder „Fachmann“ siehe Neumann, Handwerk in Mesopotamien (1993), S. 39-40 Anm. 115.

724 PDT II, 911 (i/AS 7); zu dù - a - $\mathrm{ku}_{5}$ "agric. activity performed in an garden, and the pertinent worker" siehe Oppenheim, Eames, S. 229 und E 7, E 26.

725 Siehe S. 117f.

726 UTI III, 1003 (AS 9); MVN 16, 960 (ŠS 3); MVN 16, 713; MVN 16, 1330 (ك̌Š 4) über Lieferungen von Textilien an Abī-simtī anläßlich ihrer Reisen nach Zabalam. UET 3, 1563 (-/i/-) Lieferung verschiedener Textilien an den König, die Königin und einen/eine En-Priester(in) (Ort des/der En = ki-en). TMH NF 1/2, 219 (-/vi/AS 7) Lieferung von Wolle für kostbare Gewänder in das Haus der Königin.

727 Kurth 27 (11/i/IS 2), Neumann, Goldverzierte Schuhe für die Königin, FS Haas (2001), S. 285-289, dort auch Hinweise auf weitere Texte zu kostbar verziertem Schuhwerk.

728 ASJ 4, S. 142 Nr. 8 (Datum abgebrochen). Als buchender Beamter tritt hier wie bei der Lieferung der goldverzierten Schuhe Amur-ilam auf, welcher offensichtlich im wesentlichen für die Herstellung kostbarer Betten verantwortlich war. Vgl. dazu Steinkeller, Mattresses and Felt in Early Mesopotamia, OrAn 19 (1980), S. 84-85; Neumann, Goldverzierte Schuhe für die Königin, FS Haas (2001), S. 288-289 + Anm. 22; Sallaberger, OBO 160/3 (1999), S. 246-247.

729 UET 3, 348 (v/ŠS 6).

730 UET 3, 1498 (i-xii/IS 15); vgl. zu diesem Text Sallaberger, OBO 160/3 (1999), S. 276-279; Neumann, Handwerk in Mesopotamien (1993), passim. siehe Index S. 175; Van De Mieroop, An Accountant's Nightmare: the Drafting of a Year's Summary, AfO 46-47 (1999/2000), S. 111-129. 
König oder das Königspaar beschränkt, auch andere hochrangige Persönlichkeiten können einen Thron besitzen ${ }^{731}$. Dennoch ist der Thron mit Sicherheit als ein Symbol für die herausgehobene Stellung des Besitzers, hier der Königin, zu sehen. Mir ist kein Beleg bekannt, nach dem eine der Nebenfrauen des Königs einen Thron besessen hätte. Die reiche Ausstattung des neuen Schatzhauses der Königin (é-gi-na-ab-tum gibil nin-ke ${ }_{4}$ ) mit unterschiedlichen Hölzern, kupfernen und bronzenen Bauelementen sowie dem Leder von Ochsen und Lämmern für die Türen wird detailliert in UET 3, 826 (vi/IS 22) aufgelistet.

Ein einzigartiges Zeugnis für die luxuriöse Gestaltung des höfischen Lebens ist in Bezug auf die Damen des Hofes der Text Philips 13 (xii/Š 47) ${ }^{732}$. Hier werden in großem Umfang Schmuck aus Gold und Silber, kostbare Gefäße sowie Textilien, Möbel und Butterschmalz für den König und, in etwas geringeren Mengen, für Šulgi-simtī ausgegeben. So erhielt die Königin unter anderem eine Gewandnadel aus Rotgold (tu-ti-da kù-sig 17 hu š-a) mit einem Gewicht von 10 Schekel, 10 silberne Gefäße, welche zusammen einen

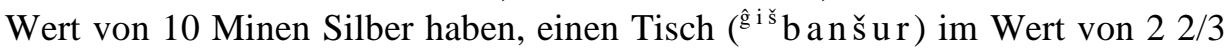
Minen Silber und 69 Gewänder (túg-h hi-a) $)^{733}$. Nach dem Königspaar erhalten die königlichen Nebenfrauen Ninkalla, Simat-Ea und Ea-niša Gold- und Silberschmuck sowie je 26 Gewänder und 1 Topf mit Butterschmalz. Es folgen Gaben von Schmuck, Gewändern und Butterschmalz an verschiedene andere Personen, welche wohl dem Gefolge der Königin angehören ${ }^{734}$, sowie kleinere Geschenke an nicht mehr namentlich genannte Frauen. Nach einem Abschnitt über Gaben an die hohe Priesterschaft ${ }^{735}$ folgt als letztes ein Abschnitt mit der Gabe von Gewändern an Eilboten $\left(\mathrm{kas}_{4}\right)$ der Königin. Als Anlaß für diese

731 Sallaberger, Der kultische Kalender (1993), S. 147 Anm. 696.

732 Der Text gehörte der Sammlung der Phillips University in Enid, Oklahoma und wurde von Marc Cooper im Internet publiziert unter http://history.smsu.edu/mcooper/ Phillips13/phillips13.html. Seit kurzem ist die Tafel Teil der Gratianus-Stiftung, Reutlingen, K. Volk bereitet die Publikation des Textes vor. Er teilte mir das nach der Reinigung der Tafel lesbare Datum mit, wofür ich herzlich danke.

733 Der Abschnitt über die Güter für die Königin umfaßt die Zeilen II 16 - III 25.

734 Die Personennamen Šāt-kukuti, Ili-napišti, Inki-simtī und Inanna-ummi sind sonst in den Texten aus dem Archiv der Šulgi-simtī nicht anzutreffen. Somit ist ihre Zuordnung zum Gefolge der Königin nur auf die Position in diesem Text bezogen und muß vorerst hypothetisch bleiben. Ušaja ist dagegen auch als Empfängerin von ig i kár bekannt (Rochester 11 (30/vii/Š 40)).

735 Die En des Nanna, zwei En der Inanna, den En des Enki von Eridu sowie Tūlid-Šamšī, die nin-diĝ ir des Nanna. Zu letzterer siehe die Dienersiegel RIME 3/2.1.2.92 und RIME 3/2.1.2.93 sowie den Text MVN 8, 115 (13/xii/Š 48) über die Lieferung von Kleinvieh. Vgl. auch Such-Gutiérrez, Beiträge zum Pantheon von Nippur im 3. Jahrtausend (2003), Teil I S. 265f + Anm. 1140 mit weiteren Belegen zu Tūlid-Šamšī. 
umfangreichen Ausgaben wird genannt „Tag, an dem mein König im Haus des Šarrum-bāni Bier trank“" $\left(\mathrm{u}_{4}\right.$ lugal-[ĝ $\left.\mathrm{u}_{10}\right] /$ é Šar-ru[-um-ba-ni]/kašì $-[\mathrm{na} \hat{\mathrm{g}}-\hat{\mathrm{g}} \mathrm{a}])^{736}$.

Šarrum-bāni ${ }^{737}$ war ein Schwiegersohn des Königs, wie aus CTMMA I, 17 (1/vii/AS 4) hervorgeht, wo die Frau des Šarrum-bāni in der Liste der Prinzessinnen aufgeführt wird. Das Biertrinken ist wie das Bierausschenken eine Form der rituellen Bewirtung, mit welcher Götter wie Menschen geehrt werden konnten ${ }^{738}$. Ein rituelles Biertrinken konnte auch konstituierendes Element für eine Eheschließung $\operatorname{sein}^{739}$. Es ist also denkbar, daß jenes Biertrinken im Haus des Šarrum-bāni, zu dem das Königspaar und verschiedene Angehörige des Hofes und der Priesterschaft reichhaltige Gaben erhielten, ein Teil der Hochzeitszeremonie für eine Tochter des Königs war.

Diese Texte über die Ausgabe von Luxusgegenständen können, so bruchstückhaft die Überlieferung auch sein mag, einen Eindruck vermitteln von der Ausgestaltung des Lebens und der Prachtentfaltung am Königshof von Ur.

Weit Alltäglicheres hat eine andere Gruppe von Texten zum Gegenstand, welche die Lieferung von Lebensmitteln und Gegenständen des täglichen Bedarfs wie Rohr und Holz zum „Ort der Königin“ (ki-nin) dokumentieren. Bei den Lebensmitteln findet sich eine Fülle unterschiedlicher Produkte, so werden Wildtiere, Schafe, Ziegen, Geflügel, verschiedene Fische, Knoblauch, Zwiebeln, Eier, Milchprodukte, Getreide, Hülsenfrüchte, unterschiedliche Mehlsorten, Brot und Obst geliefert.

Die Texte dieser Gruppe stammen aus Ur, Umma und Girsu, selten aus Puzriš-Dagān, und nur ein Teil der Texte ist auf das Jahr datiert, etliche sind entweder nur auf den Monat oder gar nicht datiert. Lieferungen „,ür den Ort der Königin“ sind seit der Zeit Šulgis bis zu Ibbi-Suen belegt ${ }^{740}$. Dabei bezeichnet ki-nin nicht einen bestimmten Palast der Königin, sondern ihren momentanen Aufenthaltsort, wie aus den unterschiedlichen Ortsangaben

736 Zeilen VI 12-14. Zu der Ergänzung vgl. Michalowski, The Drinking Gods (1994), S. 31 Anm. 17.

737 So die Ergänzung zutreffend ist. Es wäre auch an den Prinzen Šarrum-ilī zu denken, zu dessen Familie Šulgi-simtī eine enge Beziehung unterhielt. Zu Šarrum-ilī siehe S. 100 und Sallaberger, OBO 160/3 (1999), S. 192.

738 Michalowski, The Drinking Gods (1994), S. 30-32; Sallaberger, OBO 160/3 (1999), S. 250.

739 Gesetze von Ešnunna, § 27-28. Siehe Groneberg, Heirat und Zugehörigkeit (2000), S. 6.

740 TENS 324 ( $\check{S}$ 40) ist der früheste mir bekannte datierte Text dieser Gruppe, der späteste Text ist UET 3, 150 (iii/IS 6). 
hervorgeht. So kann mit ki-nin ihr Palast in Ur gemeint $\operatorname{sein}^{741}$ oder jener in Uruk $^{742}$. Güter für die Königin wurden auch in diesem Bereich von jenen für den König unterschieden, wie dies schon für die mu-DU-Lieferungen von Vieh zu beobachten war. So werden mehrfach auf einer Tafel Lebensmittel und Verbrauchsgüter wie Hölzer für den „Ort des Königs“ (ki-lugal-šè) vor entsprechenden Lieferungen für den „Ort der Königin“ (ki-nin-šè) verzeichnet. ${ }^{743}$ In UET 3, 929 (undatiert) wird der „Ort der Königin“ noch näher als „Palast“ gekennzeichnet, Bierbrot wird ,zum Palast, dem Ort der Königin“" (é-gal-šè ki-nin) gebracht ${ }^{744}$.

\begin{tabular}{|c|c|c|c|c|}
\hline Publikation & Datum & Bestimmungsort & Gegenstand & Beamter \\
\hline TENS 324 & $-/-/ \mathrm{S} 40^{?}$ & $\begin{array}{l}\text { für meine Herrin } \\
\text { in Ur }\end{array}$ & $\begin{array}{l}2 \text { Schafe, } 1 \\
\text { Lamm, } 5 \\
\text { Enten, } 10 \\
\text { Krüge mit } \\
\text { Milch, } 5 \\
\text { Teichfische, } 40 \\
\text { tù n - s u hu u - } \\
\text { Fische, } 180 \\
\text { Vogeleier, } 3 \\
\text { Körbe mit } \\
\text { Feigen, } 3 \\
\text { Körbe mit ku }{ }_{6} \\
\text { s a g, } 10 \text { g ú } \\
\text { Knoblauch, } \\
\text { 200 gú } \\
\text { geriebene } \\
\text { Zwiebeln }\end{array}$ & $\begin{array}{l}\text { Niĝar-kidu } \\
\text { mu-DU }\end{array}$ \\
\hline
\end{tabular}

741 TENS 324 (Š 40), „zum Ort meiner Herrin in Ur“ (ki-n in-ĝá-šè šà U ri ${ }_{5}{ }^{k i}$-ma). In YOS 18, 51 (undatiert, aus Umma) wird vermerkt, daß ein Mastochse von der Königin in Ur nach Urusagrig (n in $\mathrm{Uri}_{5}{ }^{\mathrm{ki}}$ - ta U U u-s ag-rigg ${ }_{7}{ }^{\mathrm{i}}$ - š è) geht. Folgende Texte aus Ur verzeichnen Lieferungen von Mehl ,zum Ort der Königin“ (k i - n i n-š è): UET 3, 901, 902, 908, 912. Alle vier Texte sind nur auf den Monat datiert. Da kein weiterer Ortsname genannt wird, ist davon auszugehen, daß mit k i - n in der Palast der Königin in Ur gemeint ist.

742 YOS 18, 47 (-/iii/-); UET 3, 906 (-/v/-); UET 3, 909 (-/iv/-), ,nach Uruk, zum Ort der Königin“" (Unuk ${ }^{\mathrm{ki}}$-šè ki -nin-šè).

743 So in SAT I, 404 (iv/Š 46); MVN 12, 414 (AS 5); UET 3, 96 (vii/IS 4); UET 3, 99 (viii/IS 4); UET 3, 100 (viii/IS 4).

744 Ebenso in AUCT I, 265 (9/x/AS 2), wo Wildtiere „zum Palast, dem Ort der Königin“ gebracht werden. 
Königinnen

\begin{tabular}{|c|c|c|c|c|}
\hline Publikation & Datum & Bestimmungsort & Gegenstand & Beamter \\
\hline SAT I, 404 & -/iv/ŠS 46 & Ort der Königin & $\begin{array}{l}1 \text { Königskor } \\
\text { Apfelholz }\end{array}$ & $\begin{array}{l}\text { g i iri } i_{3} \text { Ur-Ba'u } \\
\text { dumu Sidu }\end{array}$ \\
\hline $\begin{array}{l}\text { AUCT I, } \\
265\end{array}$ & $9 / \mathrm{x} / \mathrm{AS} 2$ & $\begin{array}{l}\text { Palast, Ort der } \\
\text { Königin }\end{array}$ & $\begin{array}{l}\text { 1 Wildschaf, } 1 \\
\text { Gazelle }\end{array}$ & $\begin{array}{l}\text { Nūr-Adad } \\
\text { maški im }\end{array}$ \\
\hline $\begin{array}{l}\text { MVN 12, } \\
414\end{array}$ & -/-/AS 5 & Ort der Königin & $\begin{array}{l}\mathrm{x}+1.0 .0 \text { Kor } \\
\text { Datteln }\end{array}$ & $\begin{array}{l}\hat{g} \text { ir i } i_{3} \text { Irĝu } \\
\text { dumu Lugal- } \\
\text { pirigtur }\end{array}$ \\
\hline $\begin{array}{l}\text { MVN 16, } \\
1574\end{array}$ & -/ix/AS8 & Ort der Königin & 20 Schafe & $\begin{array}{l}\text { kišib ensi } \\
\text { (von Umma) }\end{array}$ \\
\hline $\begin{array}{l}\text { MVN 16, } \\
1092\end{array}$ & -/ii/ŠS 3 & $\begin{array}{l}\text { Ort der Königin } \\
\text { in Zabalam }\end{array}$ & $\begin{array}{l}15 \text { Körbe mit } \\
\text { je } 30 \text { Fischen }\end{array}$ & $\begin{array}{l}\text { kišib ensi } \\
\text { Ajakalla }\end{array}$ \\
\hline UET 3, 96 & 30/vii/IS 4 & Ort der Königin & $\begin{array}{l}3 \text { Körbe und } 2 \\
\text { Kisten mit } \\
\text { Datteln }\end{array}$ & - \\
\hline UET 3, 99 & 7/viii/IS 4 & Ort der Königin & $\begin{array}{l}2 \text { Körbe mit } \\
\text { Datteln, } 1 \\
\text { Korb mit } \\
\text { giš Ú Rx A- } \\
\text { AN níg - g al }\end{array}$ & - \\
\hline $\begin{array}{l}\text { UET 3, } \\
100\end{array}$ & $\begin{array}{l}12+x / v i i i / I S \\
4\end{array}$ & Ort der Königin & $\begin{array}{l}2 \text { Körbe mit } \\
\text { Datteln, } 1 \\
\text { Korb mit } \\
\text { giš Ú Rx A- } \\
\text { AN níg - g al }\end{array}$ & - \\
\hline $\begin{array}{l}\text { YOS 18, } \\
47\end{array}$ & -/iii/- & $\begin{array}{l}\text { Uruk, Ort der } \\
\text { Königin }\end{array}$ & 1 Schaf & $\begin{array}{l}\text { g i i i }{ }_{3} \text { Lugal- } \\
\text { dalla }\end{array}$ \\
\hline $\begin{array}{l}\text { UET 3, } \\
909\end{array}$ & -/iv/- & $\begin{array}{l}\text { Uruk, Ort der } \\
\text { Königin }\end{array}$ & $\begin{array}{l}\text { verschiedene } \\
\text { Mehlsorten, } \\
\text { Hülsenfrüchte, } \\
\text { Käse, } \\
\text { Kreuzkümmel }\end{array}$ & $\begin{array}{l}\text { giriri }{ }_{3} \text { Puzur- } \\
\text { Esstar }\end{array}$ \\
\hline $\begin{array}{l}\text { UET 3, } \\
906\end{array}$ & $-/ \mathrm{v} /-$ & $\begin{array}{l}\text { Uruk, Ort der } \\
\text { Königin }\end{array}$ & $\begin{array}{l}\text { verschiedene } \\
\text { Mehlsorten, } \\
\text { Hülsenfrüchte } \\
\text { und Gewürze }\end{array}$ & $\begin{array}{l}\text { g iri } i_{3} \text { Lu- } \\
\text { Ninšubur }\end{array}$ \\
\hline $\begin{array}{l}\text { UET 3, } \\
902\end{array}$ & -/via/- & Ort der Königin & $\begin{array}{l}\text { verschiedene } \\
\text { Mehlsorten }\end{array}$ & $\begin{array}{l}\text { g i ir i }{ }_{3} \text { Šarrum- } \\
\text { ilī }\end{array}$ \\
\hline $\begin{array}{l}\text { UET 3, } \\
912\end{array}$ & -/viii/- & Ort der Königin & Mehl & $\begin{array}{l}\text { g } \text { ir i }_{3} \text { Inim- } \\
\text { Inanna }\end{array}$ \\
\hline $\begin{array}{l}\text { UET 3, } \\
908\end{array}$ & $-/ \mathrm{x} /-$ & Ort der Königin & $\begin{array}{l}\text { verschiedene } \\
\text { Mehlsorten } \\
\text { und Linsen }\end{array}$ & 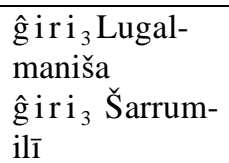 \\
\hline
\end{tabular}




\begin{tabular}{|c|c|c|c|c|}
\hline Publikation & Datum & Bestimmungsort & Gegenstand & Beamter \\
\hline $\begin{array}{l}\text { UET 3, } \\
901\end{array}$ & $-/ x i /-$ & Ort der Königin & $\begin{array}{l}\text { verschiedene } \\
\text { Mehlsorten }\end{array}$ & (abgebrochen) \\
\hline UET 3,70 & $-/-/-$ & Ort der Königin & 1 Bierfaß & $\begin{array}{l}\hat{g ~ i r i ~}_{3} \text { Puzur- } \\
\text { Eštar }\end{array}$ \\
\hline $\begin{array}{l}\text { UET 3, } \\
929\end{array}$ & $-/-/-$ & $\begin{array}{l}\text { Palast, Ort der } \\
\text { Königin }\end{array}$ & 1 Bierbrot & $\begin{array}{l}\hat{\mathrm{g}} \text { iri }{ }_{3} \text { Lugal- } \\
\text { mušḩuš }\end{array}$ \\
\hline $\begin{array}{l}\text { MVN 4, } \\
101\end{array}$ & $-/-/-$ & Ort der Königin & $\begin{array}{l}\text { 1 Schaf } \\
1 \text { Schaf }\end{array}$ & $\begin{array}{l}\text { Alih maškim } \\
\text { Lugal-kugali }\end{array}$ \\
\hline
\end{tabular}

Tabelle 15: Ausgaben an den Haushalt der Königin

Ein Teil dieser Güter wird als máš -da-re-a-Abgabe bezeichnet, wobei diese mitunter noch näher bestimmt wird als máš-da-re-a zum 7./14./30. Tag ${ }^{745}$. Möglicherweise ist dies nicht als Hinweis auf kultische Aktivitäten, sondern auf die regelmäßige Belieferung des königlichen Haushaltes mit verderblichen Produkten $\mathrm{zu}$ verstehen.

Einige wenige Texte haben die sonst nur aus dem Šulgi-simtī-Archiv bekannte Formulierung nin- $\hat{g}$ a $^{746}$, zumeist ohne den Empfängervermerk ki nin. Es ist zu vermuten, daß sich auch diese Texte auf Transaktionen beziehen, die im Auftrag der Šulgi-simtī durchgeführt wurden, auch wenn die sonst für die Texte dieser Königin kennzeichnenden Beamten hier nicht auftreten. Dies ist wohl mit der Herkunft der Texte außerhalb von Puzriš-Dagān zu erklären. Nur für MVN 1, 134 gilt die Herkunft aus Umma als gesichert, für die anderen drei Texte (TENS 443; MVN 10, 223 und SNATBM 9) ist die Herkunft unsicher. Möglicherweise stammen auch diese Texte aus Umma. Nik. 250 ( ̌́ 48) über die Lieferung von Kleie ist der einzige Ummatext, der aufgrund der Nennung der Šulgi-simt̄̄ als Empfängerin eindeutig ihr zuzuordnen ist. Bisher waren Aktivitäten der Šulgi-simtī in Umma nicht nachzuweisen, doch diese Texte über wirtschaftliche Transaktionen legen den Schluß nahe, daß auch sie sich wiederholt hier aufhielt. Unterstützt wird diese Annahme durch eine Gruppe von Texten über Opfergaben an verschiedenen Gottheiten in Umma, welche wohl auch der Šulgi-simtī zuzurechnen sind. ${ }^{747}$ Zwei Texte aus $\mathrm{Ur}^{748}$

745 SAT I, 66 (i/AS 4) maš-da-re-a des ensi ${ }_{2}$; UET 3, 99 (viii/IS 4) ma š - da - re - a zum 7. Tag; UET 3, 100 (viii/IS 4). máš-da-re-a zum 14?. Tag; UET 3, 96 (vii/IS 4); máš - d a - r e - a zum 30. Tag.

746 So TENS 443 (undatiert) über Mehllieferungen sá-du ${ }_{11}$ nin-ĝá; MVN 10, 223 (-/[x]/-) über Schafe für den Ort der Königin, zi - g a nin-ĝ́ á MVN 1, 134 (-/xii/-) 1 Ziege in Nippur für die Küche zi-g a n in- $\hat{g} a ́$; SNATBM 9 (viii/Š 38) über Futter für Mastschafe, $\hat{\mathrm{g}}$ iri ${ }_{3}$ nin- $\hat{\mathrm{g}} a$.

747 Siehe nachfolgendes Kapitel 9.

748 UET 3, 929 (undatiert) und 933 (Datum abgebrochen). 
verbuchen die Lieferung von Mehl bzw. Bierbrot mit dem Vermerk „bei Anwesenheit meiner Herrin“ (nin-g $\left.\mathrm{u}_{10} \quad \mathrm{ku}_{4}-\mathrm{ra}\right)$. Und MVN 4, 254 (-/v/Š 38) verzeichnet die Ausgabe von Mehl und Datteln durch Šulgisimtī ( $\hat{g} \mathrm{ri}_{3}$ nin-ĝá). Neben den Quellen, aus denen der Glanz der Hofhaltung in Ur erkennbar wird, geben diese Texte einen Einblick in das alltägliche Leben am Hof der Königin. Diese unterhielt eindeutig einen eigenen Haushalt, mit dem sie sich, je nach Bedarf, an unterschiedlichen Orten des

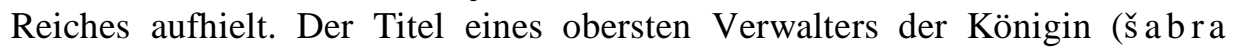
nin $)^{749}$ war also kein reiner Ehrentitel, sondern mit umfangreichen Verwaltungsaufgaben verbunden.

\section{Die Königin in einigen Texten aus Umma}

Aus Umma stammt eine kleine Gruppe von Texten, die Ausgaben für zumeist kultische Zwecke verbuchen. Verbindendes Kennzeichen dieser Textgruppe ist, daß die Texte nicht auf das Jahr, sondern entweder gar nicht oder aber nur auf den Monat datiert sind. Des weiteren tragen sie alle den Vermerk „Abbuchung bei meiner Herrin“" (zi-ga nin-ĝá). Sallaberger hatte in seiner Arbeit zum kultischen Kalender der Ur III-Zeit diese Texte im Zusammenhang mit „Gaben für den von der Gottheit verlassenen Ort zum Neulichttag“ besprochen und die Frage gestellt, um welche Königin es sich in diesen Texten aus Umma handelt. ${ }^{750}$ Die Beantwortung dieser Frage wird erschwert duch das Fehlen von Beamtennamen in den meisten Texten dieser Gruppe. ${ }^{71}$

Eine genauere Analyse der Texte macht deutlich, daß nicht alle Urkunden in den gleichen inhaltlichen Kontext gehören.

Nur drei Texte verbuchen die Ausgabe von je einem Schaf für den von der

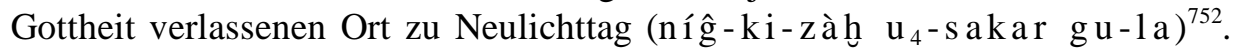
Aufgrund fehlender Vergleichstexte zu den Neulichtriten der Königin in Umma läßt sich nicht sicher entscheiden, welche Dame sich hinter dem Titel der Königin verbirgt. Allerdings spricht die Formulierung ní $\hat{g}-k i$ - zàh für Šulgi-

749 Ur-niĝar und Lugal-magurre waren šabra der Abī-simtī, siehe S. 114. Ein weiterer šabra der Königin war Šeškalla, der sich jedoch bisher keiner Königin zuweisen läßt, da der Text NATN 732, der ihn nennt, nur fragmentarisch und ohne ein Datum erhalten ist.

750 Sallaberger, Der kultische Kalender (1993), S. 44-45.

751 In BIN V, 158 (undatiert), wo die Annahme von Butterschmalz ki énsi-ka-šè durch „meine Herrin“ ( $\mathrm{n}$ in- $\hat{\mathrm{g}} \mathrm{u}_{10}$ ) verbucht wird, dürfte mit $\mathrm{n}$ in eher die Frau des Stadtfürsten von Umma als die Königin von Ur gemeint sein.

752 AAS 152 (-/viii/-); BIN V, 57; SACT II, 257 (beide undatiert). SACT II, 257 schreibt

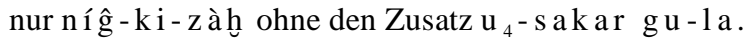


simtīe da Abī-simtī und Geme-Enlila üblicherweise den Neumondtag $\left(\mathrm{u}_{4}-\mathrm{nú}\right.$ a) und nicht das Erscheinen der ersten Sichel des Mondes am Neulichttag feierten.

Die größte zusammenhängende Gruppe innerhalb der hier besprochenen Texte aus Umma bilden acht Tafeln, auf welchen Vieh als Opfer an Gottheiten aus dem Kreis der Inanna/Ištar verbucht werden. Je ein bis drei Stück Kleinvieh werden dem Tempel der Inanna, der Annunītum, Kilili und der Eštar-Dallatum geopfert. ${ }^{753}$ In MVN 1, 143 wird nur Annunītum als Empfängerin von Opfern aufgeführt, die hier neben fünf Stück Kleinvieh auch ein Rind erhält. Die Göttinnen Kilili und Eštar-Dallatum sind mir für diese Epoche aus keinem anderen Kontext bekannt. Beides sind Gottheiten aus dem Kreis der Ištar $^{754}$.

Da diese Opfer für ganz unterschiedliche Monate belegt sind, läßt sich kein jährlich wiederkehrendes Fest, das möglicherweise im Zusammenhang mit dem Totenkult gestanden haben konnte, erkennen. Auch werden nicht immer alle vier Göttinnen beopfert, dafür können vereinzelt andere Gottheiten wie Geštinanna, Geštinanna-ama-lugal oder Martu zum Kreis der Empfänger von Kleinvieh hinzutreten. Annunītum ist die Göttin, welche in jedem Fall und am umfangreichsten Gaben erhält. Während der Kult der Inanna von allen Königinnen von Ur gepflegt wurde, ist eine besondere Beziehung zu Annunītum nur für Šulgi-simtī nachzuweisen. Aus diesem Grund liegt es nahe, diese kleine Gruppe von Texten aus Umma im Zusammenhang mit Šulgi-simtī zu sehen. In SACT II, 257 werden die Opfer an die Göttinnen aus dem Kreis der Inanna/Ištar zusammen mit Opfern für den von der Gottheit verlassenen Ort zum Neulichttag verbunden. Somit ist zu fragen, ob die Texte dieser Gruppe alle im Kontext der Neulichtopfer stehen, also dem Mondkalender folgend jeweils am Monatsanfang vollzogen wurden, oder ob SACT II, 257 einen Einzelfall darstellt und der Kult der Ištargottheiten in Umma nicht zwingend an den Neulichttag gebunden war. Dies ist bei der derzeitigen Quellenlage nicht zu entscheiden.

Fünf weitere Texte aus Umma tragen den Buchungsvermerk, ,zi - g a ning a a “755. Da alle Dokumente mit der Formulierung ni n- $\hat{g}$ á, seien sie aus Puzriš-

753 SACT II, 257 (undatiert); Santag 6, 344 (ii); BIN V, 55 (vi); Santag 6, 349 (vi); MVN 1, 143 (vi); SACT II, 258 (viii); YOS 18, 50 (xi); BCT II, 20 (xii).

754 Zu Kilili siehe Jacobsen, Pictures and Pictorial Language (The Burney Relief) (1987) und Maul, kurgarrû und assinnu und ihr Stand in der babylonischen Gesellschaft (1992), S. 164-165.

755 YOS 18, 45 (i), Opfer für Ninlil und Nin-é-kù; YOS 18, 49 (vi'), Ausgabe von Proviant und 1 Mastschaf für Ninsun; MVN 4, 99 (undatiert), Ausgabe von Proviant; BIN V, 127 (ix), 1 Rind und 10 Schafe für das Ki-Utu-Fest; MVN 1, 135 (xii), 15 
Dagān oder Umma, dem Textkorpus der Šulgi-simtī zuzuweisen waren, ist davon auszugehen, daß auch diese fünf Belege zu ihren Urkunden gerechnet werden müssen. Damit ist die Schlußfolgerung von Cooper bestätigt, der bei seiner Untersuchung des Ausdruckes nin-g gá zu der Schlußfolgerung gelangte, "NIN.GA ${ }_{2}$ means "the queen" in reference to Shulgisimt 1 "“756. Dies ist insbesondere deshalb von großer Bedeutung, da nun mit dem Ausdruck ninga á neben den Namen der persönlichen Göttinnen und der Beamten ein weiteres Indiz für die Identifikation der Texte zu dieser Königin zur Verfügung steht. Darüber hinaus ist Šulgi-simtī nun erstmals auch in den Quellen aus Umma sicher nachzuweisen.

\begin{tabular}{|c|c|c|c|}
\hline Publikation & Datum & Gegenstand & Empfänger \\
\hline \multicolumn{4}{|c|}{ Neulichttag } \\
\hline AAS 152 & -/viii/- & $1 \mathrm{~K}$ & $\begin{array}{c}\text { níĝ-ki-zàh } \mathrm{u}_{4}-\mathrm{sakar} \\
\mathrm{gu}-1 \mathrm{a}\end{array}$ \\
\hline BIN V, 57 & - & $\begin{array}{l}2 \mathrm{~K} \\
1 \mathrm{~K} \\
1 \mathrm{~K}\end{array}$ & $\begin{array}{c}\text { Ninsun } \\
\text { Küche } \\
\text { níĝ̀-ki-zà } \mathrm{u}_{4}-\mathrm{s} a \mathrm{kar} \\
\mathrm{gu}-1 \mathrm{a}\end{array}$ \\
\hline $\begin{array}{l}\text { SACT II, } \\
257\end{array}$ & - & $1 \mathrm{~K}$ & níĝ - ki-zà h, \\
\hline \multicolumn{4}{|c|}{ Gaben für Gottheiten aus dem Kreis der Inanna/Ištar } \\
\hline $\begin{array}{l}\text { SACT II, } \\
257\end{array}$ & - & je $1 \mathrm{~K}$ & $\begin{array}{l}\text { Simat-Nisaba, Martu, } \\
\text { Geštinanna, é Inanna, } \\
\text { Annunīum, Kilili }\end{array}$ \\
\hline $\begin{array}{l}\text { Santag 6, } \\
344\end{array}$ & -/ii/- & je $1 \mathrm{~K}$ & $\begin{array}{l}\text { Eštar-Dallatum, Annunītum, } \\
\text { im Garten }\end{array}$ \\
\hline $\begin{array}{l}\text { Santag 6, } \\
349\end{array}$ & -/vi/- & $\begin{array}{c}\text { je } 1 \mathrm{~K} \\
\text { je } 2 \mathrm{~K} \\
1 \mathrm{~K}\end{array}$ & $\begin{array}{c}\text { é Inanna, Kilili, Allašaniša }^{757} \\
\text { Eštar-Dallatum, Annunītum } \\
\text { Küche, i g i - kár Puzur- } \\
\text { Šamaš }\end{array}$ \\
\hline
\end{tabular}

Schafe als regelmäßige Lieferung (sá-du $u_{11}$ ). Zum an den Sonnengott gerichteten Gebetsritus Ki- ${ }^{\mathrm{d}} \mathrm{Utu}$, welcher der kultischen Reinigung des Königs diente, siehe Sallaberger, Der kultische Kalender (1993), S. 215-216.

Ob auch der Text MVN 4, 98 (vi) in diesen Kontext gehört, ist nicht klar, der Buchungsvermerk zi - g a n in - $\hat{g}$ á fehlt, doch die Erwähnung von Geštinana n in und Geštinana lug al könnte eine Zugehörigkeit in die Gruppe der hier genannten Texte sprechen.

756 Cooper, JCS 38 (1986), S. 124-126.

$757 \mathrm{Zu}$ dieser ansonsten unbekannten Gottheit (?) siehe die Anmerkung in SANTAG 6, S. 275. 
Die Königin in einigen Texten aus Umma

\begin{tabular}{|c|c|c|c|}
\hline BIN V, 55 & $-/ \mathrm{vi} /-$ & $\begin{array}{c}2 \mathrm{~K} \\
\text { je } 1 \mathrm{~K} \\
2 \mathrm{~K} \\
1 \mathrm{~K}\end{array}$ & $\begin{array}{c}\text { Annunīum } \\
\text { Eštar-Dallatum, Kilili } \\
\text { Küche, k a š - dè - a Ur- } \\
\text { Šulpae }\end{array}$ \\
\hline $\begin{array}{c}\text { MVN 1, } \\
143\end{array}$ & -/vi/- & $\begin{array}{c}1 \mathrm{~K} \\
1 \mathrm{G}, 5 \mathrm{~K}\end{array}$ & $\begin{array}{c}\text { Küche } \\
\text { Annunītum }\end{array}$ \\
\hline $\begin{array}{l}\text { SACT II, } \\
258\end{array}$ & viii & $\begin{array}{l}\text { je } 1 \mathrm{~K} \\
2 \mathrm{~K}\end{array}$ & $\begin{array}{c}\text { é Inanna, Eštar-Dallatum, } \\
\text { Kilili, Alitum } \\
\text { Annunīum, Geštinanna-ama- } \\
\text { lugal }\end{array}$ \\
\hline $\begin{array}{l}\text { YOS } 18 \\
50\end{array}$ & $-/ x i /-$ & $\begin{array}{l}3 \mathrm{~K} \\
\text { je } 2 \mathrm{~K} \\
3 \mathrm{~K} \\
\text { je } 1 \mathrm{~K}\end{array}$ & $\begin{array}{c}\text { ig i-kár [PN] } \\
\text { é Inanna, Eštar-Dallatum } \\
\text { Annunītum, Kilili }\end{array}$ \\
\hline BCT II, 20 & -/xii/- & je $1 \mathrm{~K}$ & $\begin{array}{c}\text { é Nanna, Eštar-Dallatum, } \\
\text { Annunītum }\end{array}$ \\
\hline \multicolumn{4}{|c|}{ weitere Texte } \\
\hline MVN 4, 99 & - & $6 \mathrm{~K}$ & igi-kár Arašuta? \\
\hline $\begin{array}{l}\text { YOS } 18 \\
45\end{array}$ & $-/ \mathrm{i} /-$ & $\begin{array}{l}2 \mathrm{~K} \\
1 \mathrm{~K}\end{array}$ & $\begin{array}{c}\text { Ninlil } \\
\text { Nin-é-kù }\end{array}$ \\
\hline $\begin{array}{l}\text { YOS } 18 \\
49\end{array}$ & $-/ \mathrm{vi}^{?} /-$ & $\begin{array}{l}2 \mathrm{~K} \\
1 \mathrm{~K}\end{array}$ & $\begin{array}{l}\text { ig i-kár Laram-Ea } \\
\text { Ninsun }\end{array}$ \\
\hline $\begin{array}{c}\text { BIN V, } \\
127\end{array}$ & -/ix/- & $1 \mathrm{G}, 10 \mathrm{~K}$ & $\mathrm{Ki}^{\mathrm{d}}{ }^{\mathrm{d}} \mathrm{Utu}$ \\
\hline $\begin{array}{l}\text { MVN 1, } \\
135\end{array}$ & -/xii/- & $15 \mathrm{~K}$ & sá-du ${ }_{11}$ nin-gá \\
\hline
\end{tabular}

Tabelle 16: $\mathrm{n}$ in-ĝ́ in Texten aus Umma

\section{Die Rolle der Königin von Ur}

Das Tätigkeitsspektrum der Königinnen von Ur war sehr komplex, folgte jedoch nur in begrenztem Rahmen einer festen, für alle Frauen, welche dieses Amt ausübten, gleichen Vorgabe. Insbesondere im religiösen Bereich hatte jede Amtsinhaberin bestimmte Präferenzen für einzelne Gottheiten, welchen sie nachgehen konnte.

\subsection{Im religiösen Bereich}

Die großen Unterschiede im Umfang der Informationen zu den kultischen Pflichten der einzelnen Königinnen machen einen genauen Vergleich schwierig. Die Dokumentation aus dem Archiv der Šulgi-simtī ist ungleich detaillierter als die Quellenlage zu Geme-Enlila, der letzten Königin von Ur. 
Dennoch lassen sich sowohl Gemeinsamkeiten als auch deutliche Unterschiede zwischen den einzelnen Frauen in der Ausübung ihrer religiösen Verpflichtungen beobachten.

Gemeinsam war allen Königinnen von Ur die besondere Verehrung weiblicher Gottheiten, insbesondere der Inanna. Dies ist schon bei SI.A-tum, der Frau des Ur-Namma festzustellen, von der eine Achatperle erhalten ist, die die Königin der Inanna gestiftet hat ${ }^{758}$. Šulgi-simtī brachte der Inanna von Uruk monatlich Opfergaben dar und war darüber hinaus auch an großen, nicht monatlich begangenen Festen zu Ehren der Inanna beteiligt, wie am Fest des Himmelsbootes (má-an-na), das zweimal jährlich gefeiert wurde. ${ }^{759}$ Abīsimtī verehrte dagegen insbesondere die lokale Manifestation der Inanna von Zabalam. ${ }^{760}$ Und auch Geme-Enlila, die letzte namentlich bekannte Königin dieser Dynastie, war dem Kult der Inanna verbunden.

Ebenfalls in den größeren Kontext des Kultes für Inanna gehören die Opfer, die in Uruk an den Toren ihres Heiligtums für Inanna und Nanaja vollzogen wurden. Auch diese Riten lassen sich bei Šulgi-simtī gut verfolgen, sind jedoch auch bei Geme-Enlila zu finden. Daß hier die Quellenlage, gerade für die Königinnen nach Šulgi-simtī, deren Bedarf an Tieren von der zentralen königlichen Administration mit verwaltet wurde, mitunter wenig umfangreich ist, liegt wohl auch daran, daß Texte, welche keinen eindeutigen Hinweis auf eine der königlichen Frauen enthalten, zumeist automatisch dem Bereich des Königs zugewiesen werden. Doch auch die Texte über Ausgaben der Šulgisimtī sind in der Regel nur über die Namen ihrer Beamten der Königin zugeordnet. Fehlt diese Möglichkeit der Identifikation einzelner Texte als dem Bereich der königlichen Frauen zugehörig, dann bleibt nur die Zuordnung über den Kontext einzelner Opfer und Riten. Hier sollte gerade bei Texten, die keinen Angehörigen des Königshauses explizit als Auftraggeber/Teilnehmer einer Kulthandlung nennen, nicht automatisch der König als treibende Kraft angesetzt werden. Opfer für Inanna, Nanaja, das Tor des Gipar in Uruk und Annunītum gehören zu denen, für die immer auch eine Beteiligung der Königin vermutet werden kann, ohne daß damit gleich alle Opfer für diese Gottheiten ausschließlich der Königin zugerechnet werden sollen.

So ist es denkbar, daß auch das Einzugsfest des Annunītum in Ur, das von Šulgi-simtī gefeiert wurde, auch von ihren Nachfolgerinnen regelmäßig begangen wurde ${ }^{761}$. Den Texten aus der Regierungszeit von Amar-Suen und

\footnotetext{
758 RIME 3/2.1.2.66.

759 Zu den kultischen Aufgaben der Šulgi-simtī in Uruk siehe S. 60-68, zum Fest des Himmelsbootes insbesondere S. 66-68.

760 Siehe S. 135-141.

${ }^{761}$ Zu diesem Fest siehe Sallaberger, Der kultische Kalender (1993), S. 203-204 und Tab.
} 
$\breve{S}$ u-Suen ${ }^{762}$ ist kein Hinweis auf eine Beteiligung der Königin zu entnehmen, doch stellt sich im Vergleich mit den Quellen aus dem Archiv der Šulgi-simtī die Frage, ob die Beteiligung an diesem Fest für Annunītum zu den kultischen Pflichten einer Königin von Ur gehörte.

Neben der bei allen Königinnen von Ur zu beobachtenden Verehrung der Inanna, ist die am besten dokumentierte kultische Aufgabe dieser Frauen der Vollzug bestimmter Riten zum Monatsbeginn. Doch hier zeigen sich auch Unterschiede. Während Šulgi-simti regelmäßig zum Erscheinen der neuen Sichel des Mondes unter anderem dem Mondgott Nanna, der Inanna und ihren persönlichen Göttinnen Bēlat-Šuhnir und Bēlat-Deraban opferte, finden sich in den Texten ihrer Nachfolgerinnen keine Hinweise auf die zum Monatsbeginn beopferten Gottheiten. Abī-simtī und Geme-Enlila vollzogen ihre Riten schon einen Tag früher, zum Neumond, dem Hinweis „für das Baden“ ( $\left(a-t_{5}-a\right)$ in den Texten der Geme-Enlila ist zu entnehmen, daß Reinigungsriten zumindest einen Teil der Kulthandlungen ausmachten. Aufgrund der knappen Informationen aus den Wirtschaftstexten, die nur die Bereitstellung der für die Riten benötigten Tiere verbuchten, nicht aber die Riten beschreiben wollten, ist nicht zu erkennen, wie weitreichend jeweils Unterschiede und Gemeinsamkeiten der Riten der einzelnen Königinnen zum Monatsbeginn waren.

Neben diesen Differenzen in der Ausführung der Riten zum Monatsanfang lassen sich insbesondere zwischen Šulgi-simtī und Abī-simtī Unterschiede bezüglich der Verehrung ihrer persönlichen Gottheiten, Bēlat-Šuhnir und Bēlat-Deraban bei Šulgi-simtī, Dagān, Išhara und Haburītum bei Abī-simtī, feststellen.

Damit wird deutlich, daß zwar der Kult der Inanna wie auch die Durchführung von Riten zum Monatsbeginn bei fast allen Königinnen von Ur zu beobachten sind, daß aber darüber hinaus jede der Frauen die Möglichkeit hatte, den Kult eigener Gottheiten einzuführen und auszuüben. ${ }^{763}$

Prinzipiell läßt sich sagen, daß ein König zwar mehrere Frauen heiraten konnte, daß jedoch nur eine Frau am Hof, üblicherweise die amtierende Königin, kultische Pflichten gegenüber den großen Göttern des Landes wahrnahm. Abweichungen von dieser Regel sind jedoch in zweierlei Hinsicht bei Abī-simtī zu beobachten.

66.

762 AUCT I, 312 (1/iv/AS 2); PDT II, 1093 (1/v/AS 5); BCT I, 91 (30/v/AS 9); AUCT II, 82 (30/iii/ŠS 1); MVN 8, 133 (28/v/ŠS 2); TCL 2, 5552 (2/iii/ŠS 3).

763 Der Auffassung van de Mieroops (Women in the Economy of Sumer (1989), S. 57), Abī-simtī habe die Aufgaben der Šulgi-simtī übernommen, ist damit nur eingeschränkt zuzustimmen. 
Zum einen erfüllt sie auch während der Regierungszeit ihres Sohnes ŠuSuen ihre kultischen Pflichten, während Kubātum nur sehr selten überhaupt im religiösen Kontext auftritt. Dies läßt sich damit erklären, daß Abī-simtī, die ja auch den Titel der Königin (nin) weiterhin führte, im Rang über ihrer Schwiegertochter Kubātum stand. Damit wurde der Kult der großen Göttern des Landes auch zur Zeit von Šu-Suen von der hochrangigsten weiblichen Angehörigen des Herrscherhauses ausgeführt. Diese Beobachtung bezüglich der Rangfolge unter den Frauen des Hofes führt zu der Schlußfolgerung, daß die aus Syrien stammende Abī-simtī in Ur als Mutter des regierenden Königs den ersten Rang unter den Frauen beanspruchte, wie dies in Ebla schon von Dusigu, der Mutter des Königs, die ebenfalls im Rang über der Königin stand, bekannt ist. Möglicherweise handelt es sich hier um ein syrisches Gesellschaftsmuster ${ }^{764}$, denn die Position von SI.A-tum, der Mutter von Šulgi, ist während der Regierung ihres Sohnes eine deutlich andere. SI.A-tum übernahm als Mutter des Königs keine Aufgaben im Kult der großen Göttern, diese Pflichten erfüllte jeweils die Hauptfrau des Herrschers, die amtierende Königin.

Die zweite Abweichung von der oben formulierten Regel, nach der nur die Königin regelmäßige kultische Pflichten gegenüber den großen Götternn des Landes wahrnahm, ist möglicherweise die Tatsache, daß die Prinzessin SimatIštarān $^{765}$ unter Amar-Suen und Šu-Suen regelmäßig Riten zum Vollmondtag vollzog $^{766}$. Die Zahl der zu diesem Zweck bereitgestellten Tiere schwankt stark zwischen drei und 49. Außer der Angabe, daß die Tiere für Simat-Ištarān zum 15. Tag des Monats bestimmt sind, findet sich in den Texten kein Hinweis auf den genauen Verwendungszweck. ${ }^{767}$ Da Šulgi-simtī nicht nur zum Neumondtag, sondern auch in der Monatsmitte Opfer für ihre Göttinnen vollzogen hatte, liegt die Vermutung nahe, daß Abī-simtī und Simat-Ištarān sich die Pflichten zum Monatsanfang und zum 15. eines jeden Monats geteilt haben und damit Simat-Ištarān als einzige Prinzessin, die kein Priesterinnenamt innehatte, an den regelmäßigen Kulten der großen Göttern teilnahm. Wenn diese Vermutung zutrifft, ist zu fragen, wie es kommt, daß eine Prinzessin

764

765 Simat-Ištarān ist belegt in der Zeit von AS 1 (TCL 2, 4682) bis IS 4 (Cornell 99-15143:2; unpubliziert; ich danke D. Owen, der mir diese Information vor der Publikation seiner Arbeit zu Simat-Ištarān zur Verfügung gestellt hat). Zu dieser Prinzessin siehe auch Such-Gutiérrez, Die Prinzessin Meištarān, AuOr 19 (2001).

766

Zu Simat-Ištarān und ihren Riten zum Vollmondtag siehe Sallaberger, Der kultische Kalender (1993), S. 59-60 und Tab. 10.

767 Ausnahme ist MVN 5, 129 (12/ix/ŠS 8), wo das Baden $\left(\mathrm{a}-\mathrm{tu}_{5}-\mathrm{a}\right)$ als Anlaß für die Lieferungen genannt wird. 
Aufgaben erfüllte, die eigentlich der Königin oblagen. Hier kann nur vermutet werden, daß Simat-Ištarān die Tochter der Abī-simtī und des Amar-Suen ${ }^{768}$ war und als solche eine besondere Rolle im Kult an der Seite ihrer Mutter übernehmen konnte. Ansonsten könnte man auch annehmen, daß es sich bei den Tieren, die Simat-Ištarān monatlich erhielt, um Opfergaben für ihre persönlichen Götter und, zumindest teilweise, um Tiere für den profanen Gebrauch gehandelt haben könnte, womit kein Widerspruch mehr bestünde zwischen ihrer Stellung als Königstochter und der Ausübung kultischer Pflichten. Diese Frage ist bisher nicht abschließend zu beantworten.

Sallaberger hat die überragende Bedeutung des Kultes, der Sorge für die Götter, im Selbstverständnis des Königtums der III. Dynastie herausgestellt. ${ }^{769}$ Es ist die Pflicht des Königs, mit seiner Sorge für die Götter deren Wohlwollen und Segen für das Land sicherzustellen. Die Beobachtung, daß jeweils die Königin in ihr eigenen Bereichen an diesem offiziellen Kult beteiligt war, ist nur so zu verstehen, daß auch sie als weibliche Vertreterin des Herrscherhauses in der Verantwortung vor den Göttern stand und mit ihren Opfern wie der König für das Wohl des Landes zu sorgen hatte. Diese Verantwortung unterschied die Königin von den Nebenfrauen des Herrschers.

Die Bevorzugung der weiblichen Gottheiten sowie der enge Kontakt zu den Frauen der Gesellschaft zeigt die deutliche Trennung der Lebenswelten von König und Königin. Letztere ist insbesondere verantwortlich für das Wohlergehen der Frauen, seien sie göttlicher oder menschlicher Natur.

Auch wenn keine Königin von Ur je vergöttlicht wurde, so ist die Errichtung von Statuen dieser Frauen ${ }^{770}$ doch ein Zeichen dafür, daß dieses Konzept getrennter Lebens- und Aufgabenbereiche von König und Königin auch in der Herrscherrepräsentation nach außen hin fortgeführt wurde. Erst gemeinsam bildeten König und Königin das Königspaar und konnten damit alle Aufgaben, die an das Königtum gestellt wurden, ausführen. Dabei unterschieden sich König und Königin insofern deutlich voneinander, als die starke Repräsentation des Königs nach außen über Königsinschriften und Hymnen keine Parallele in der weiblichen Sphäre hatte. Auch wurden die Königinnen nach ihrem Tod nicht als Schutzgöttinnen (la ma) ihres Landes

768 Es ist sicher, daß Simat-Ištarān eine Tochter des Amar-Suen war. Dies geht aus den Siegelinschriften Cornell 98-12-009 und Cornell 99-14-036 (beide unpubl.) hervor, wo sie als „geliebte Schwester des Šu-Suen, des Königs von Ur“ bezeichet wird. Ich danke D. Owen für diese Information.

769 Sallaberger, Königtum und Kult in der Hauptstadt Ur unter den Herrschern ihrer III. Dynastie (1999), S. 255-256.

770 UET 3, 329 (viii/AS 5), Statue der Königin; BiOr 9, S. 173 (21/i/ŠS 8), Statue der Kubātum. 
angesehen und nicht wie die Könige mit eigenen, im Kalender festgeschriebenen Festen geehrt. Doch die regelmäßig von ihnen wahrgenommenen Pflichten im Bereich des offiziellen Kultes zeigen, daß sie in dem wichtigen Bereich der Vertretung des Landes vor den Göttern in ähnlicher Weise wie der König in der Verantwortung standen.

\subsection{Im sozialen und wirtschaftlichen Bereich}

Die getrennten Lebensbereiche von König und Königin sind nicht nur im kultischen, sondern auch im sozialen Bereich zu beobachten. Besonders gut ist dies im Archiv der Šulgi-simtī zu verfolgen, doch sind auch bei Abī-simtī und in eingeschränkter Art bei Kubātum die gleichen Formen sozialer Beziehungspflege zu beobachten. Dazu gehört, daß die Königinnen wie die Könige als mu-DU bezeichnete Lieferungen von einer Reihe von Einzelpersonen erhielten. Hierbei ist $\mathrm{zu}$ beobachten, $\mathrm{da} \beta$ bestimmte Persönlichkeiten und Familien über lange Zeit mit dem Haushalt der Königin in Kontakt standen, auch über einen Wechsel im Amt hinaus. ${ }^{711}$ Gleiches gilt für einige Beamte, die über einen längeren Zeitraum im Dienst der königlichen Damen standen, so Nūhn-ilum ${ }^{772}$, Ur-Igalim und Rịṣ-ilum ${ }^{773}$. Die Königin ihrerseits zeigte ihre Gunst einmal über die Vergabe kleinerer Mengen von Tieren als „Proviant/Ehrengeschenk“ (igi-kár) oder, durch den Ritus des „Bierausschenkens“ ( $\mathrm{k}$ a š - dé-a), mit dem Menschen ebenso wie Götter geehrt werden konnten. Bei diesen sozialen Beziehungen der Königinnen ist zu beobachten, daß viele ihrer Lieferanten Frauen aus den führenden Familien des Reiches waren, ebenso wie Frauen häufig als Empfängerinnen von igi-kár und kaš-dé-a auftreten. Dabei waren die Lebensbereiche von Männern und Frauen nicht so vollständig getrennt, daß Kontakte kaum mehr vorgekommen wären, im Gegenteil, die Königin unterhielt auch immer Beziehungen zu den hohen Beamten der Verwaltung. Das Bild der im öffentlichen Leben aktiven Frauen wird unterstützt durch die Belege zu den Reisetätigkeiten der Königinnen. So reiste Abī-simtī während der Regierungszeit ihres Sohnes wiederholt nach Zabalam, Šulgi-simtī ist bei der Erfüllung ihrer Pflichten gegenüber den Göttern Enlil und Ninlil in Nippur zu finden, sie muß also

\footnotetext{
$771 \quad$ Siehe S. 115.

772 Nūhn-ilī bei Abī-simtī: SRD 15 (1/v/AS 2); OIP 121, 11 (ii/AS 3); TCND 259 (1/xi/AS 4); JCS 10, S. 22 Nr. 11 (iii/AS 6), bei Geme-Ninlila: SACT I, 8 (iv/Š 44); TRU 278 (i/Š 45); CST 115 (1/vi/Š 46); JCS 31, S. 172 C (1/iii/Š 48).

773 Zu Ur-Igalim siehe S. 205; zu Rīṣ-ilum siehe Owen, Ur III Geographical and Prosopographical Notes, FS Astour (1997), S. 384-387.
} 
regelmäßig die Reise von Ur nach Nippur angetreten haben ${ }^{774}$.

Im wirtschaftlichen Bereich konnten sich die Königinnen auf eigenen Besitz stützen, über den sie wohl weitgehend frei verfügen konnten. Erwähnt seien hier nur die großen Schafherden der Ab̄̄-simtī sowie die bei allen Königinnen zu beobachtende eigene Haushaltsführung. Dieser Haushalt der Königin war zwar sicher mit dem des Königs verflochten, wobei das genaue Ausmaß dieser Verflechtungen auf der Grundlage einer Prosopographie der Epoche zu untersuchen wäre, doch verfügten die Königinnen mit einer eigenen Administration ihres Haushaltes über wirtschaftliche Unabhängigkeit.

Der herausragende soziale Rang der Königinnen zeigt sich besonders eindrücklich darin, daß auch männliche Familienangehörige über diese Frauen und nicht wie sonst in Mesopotamien allgemein üblich über ihren Vater näher definiert wurden. So wird der hohe Beamte Babati stets nur als „Bruder der Abī-simtī" bezeichnet, eine Definition, die er selber in seinem Siegel übernimmt. ${ }^{775}$ Bekannt ist ferner Bizua, die Schwester der Abī-simtī, sowie eine namentlich nicht bekannte Schwester der Šulgi-simtī. ${ }^{776}$

Ein weiteres wichtiges Indiz für die dem König vergleichbare Position der Königin ist die Nutzung ihres Titels (nin) in Personennamen, so wie sonst der Namen oder Titel des Königs ein Bestandteil von Personennamen sein konnte. Als Beispiele seien hier nur die Namen Lú-nin-ĝá und Šà-nin-ĝa ${ }^{777}$ genannt.

Die Frage nach der Rolle der Königinnen bei der Thronfolge ist bisher nicht zu beantworten. Bis heute ist nicht bekannt, nach welchen Kriterien der Thronfolger im Reich von Ur bestimmt wurde. ${ }^{778}$ Da während der gut 100jährigen Geschichte dieser Dynastie die Nachfolge offensichtlich stets ohne größere Konflikte geregelt wurde, ist davon auszugehen, daß der Thronerbe stets rechtzeitig bestimmt werden konnte. Ob jedoch der König seinen Erben benannte, ob die Priesterschaft den Kandidaten stützen mußte oder ob die königlichen Frauen einen entscheidenden Einfluß in dieser Frage geltend machen konnten, ist nach der derzeitigen Quellenlage nicht zu entscheiden.

774 MVN 2, 336 (ix/Š 33) verbucht explizit die Ausgabe von einem Schaf für das Dublamah in Ur, von der Königin überbracht, als sie nach Nippur ging.

775 Siegel des Babati: RIME 3/2.1.4.32; BCT I, 126 (19/iii/AS 3) Ausgabe von Tieren für

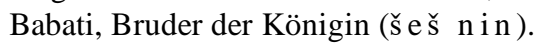

776 Zu Bizua u.a. OIP 121, 164 (8/ix/AS 4); TCL 2, 5484 (20/viii/AS 5); UET 3, 1504 (IS

2) und UET 3, 1505 (Datum abgebrochen); die Schwester der Šulgi-simtī (n i n ${ }_{9}$ - n in ist als Verantwortliche für die Ausgabe von Tieren für den Kult in MVN 22, 145 (xi ${ }^{\mathrm{II}} / \check{\mathrm{S}}$ 36) zu finden.

777 Lú-nin-ĝá u.a. in OIP 115, 199 und 253, Šà-nin-ĝá u.a. in SAT III, 1809 und 1822.

778 Sallaberger, OBO 160/3 (1999), S. 182. Zu den verschiedenen Modellen der Nachfolgeregelung siehe Dahl, The Quest for Eternity. FS Larsen (2004). 


\section{Exkurs 2: Königinnen in Ebla und Akkade}

\section{Die Königin von Ebla}

In den Quellen von Ebla wird die Königin zumeist ohne Namen und nur mit ihrem Titel (maliktum) genannt. Deshalb ist es oftmals nicht eindeutig, um welche Person es sich in einem bestimmten Text im einzelnen handelt. Eine neue Königin wurde nur kurz nach der Hochzeit noch mit ihrem Namen in der Verwaltung geführt ${ }^{779}$, danach war für die Schreiber deutlich, wer mit maliktum gemeint war, weswegen eine zusätzliche Nennung des Namens unnötig war.

Bisher sind zwei Königinnen von Ebla namentlich bekannt. Die erste ist Kešdut, welche mit großer Wahrscheinlichkeit zur Zeit von Igriš-Halam Königin war. ${ }^{780}$ Aus dieser frühen Zeit des Archives stammen nur relativ wenige Texte, und die meisten Erwähnungen einer Person namens Kešdut beziehen sich auf die Prinzessin Kešdut, Tochter von König Išar-Damu und Königin Tabur-Damu ${ }^{781}$, welche mit dem König von Kiš verheiratet wurde ${ }^{782}$.

Die zweite namentlich bekannte Königin ist Tabur-Damu, die Hauptfrau des Išar-Damu, des letzten Königs von Ebla. Über sie weiß man deutlich mehr als über Kešdut, da das Quellenmaterial aus ihrer Zeit weit umfangreicher ist. Ihre Eltern waren NEtibudu und Irib-Damu. ${ }^{783}$ Wer zur Zeit von Irkab-Damu die Position der Königin einnahm, ist derzeit noch nicht zu erschließen. Aus seiner Zeit gibt es kaum Belege für eine maliktum in den Texten, was zu der Annahme geführt hat, die betreffende Frau sei sehr bald nach der Eheschließung verstorben und es habe danach für viele Jahre keine Königin in Ebla gegeben. Archi hielt es sogar für denkbar, daß es aus rituellen Gründen dem König nicht erlaubt war, eine weitere Frau zur Königin zu erheben, was dazu geführt habe, daß während der Herrschaft von Irkab-Damu stets Dusigu, die Mutter des Thronfolgers, die erste Position unter den Damen einnahm. ${ }^{784}$

779 TM.75.G.2417, über die monatliche Ausgabe von Textilien; Biga, The reconstruction of a relative chronology, OrNS 72 (2003), S. 358.

780 Archi, Les femmes du roi Irkab-Damu, Amurru I (1996), S. 105; Biga, The reconstruction of a relative chronology, OrNS 72 (2003), S. 349.

781 Biga, The Marriage of Eblaite Princess Tagriš-Damu, Subartu IV (1998), S. 17.

782 Archi, Gifts for a Princess, Eblaitica 1 (1987); ders. The Role of Women in the Society of Ebla, CRAI 47 (2002), S. 6.

${ }^{783}$ ARET 1, 15, obv. II 14-17 NEtibudu a ma-g al maliktum; MEE 10, 29, rev. IX 3-9 Irib-Damu a-mu maliktum. Ferner sind zwei Brüder der Königin bekannt; MEE 5, 1 obv. III 7-11 = ARET 8, $521 \S 7$ Mikalum še š maliktum; ARET 12, 1248 I' Si-dib še š maliktum; MEE 2, 30 obv. V 13 erwähnt einen š e š maliktum ohne den Namen zu nennen.

784 Archi, Chronologie relative, Amurru I (1996), S. 24; ders., The Role of Women in the 
Diese Position behielt Dusigu bis zu ihrem Tod. Auch als ihr Sohn IšarDamu Tabur-Damu geheiratet hatte und diese die Königin von Ebla geworden war, rangierte Dusigu noch vor ihr in den Listen der dam en ${ }^{785}$ Es stellt sich die Frage, ob die Mutter des Königs, die a ma-gal en, in Ebla immer diese herausragende Position innegehabt hat, oder ob es sich bei Dusigu um einen Sonderfall handelte. Da neben Dusigu keine andere ama-gal en namentlich bekannt ist, kann man nur vermuten, daß in den Texten, die diesen Titel, aber keinen Namen nennen, mitunter nicht Dusigu, sondern eine andere Königinmutter gemeint ist ${ }^{786}$. Diese Frage wird sich beantworten lassen, wenn die interne Chronologie der Texte aus Ebla gesichert ist.

Ebenso ist derzeit noch keine genaue Aussage darüber möglich, wie der Thronfolger in Ebla bestimmt wurde, denn für eine detaillierte Aussage reicht das Archiv des Palastes G nicht weit genug zurück. Da Dusigu nie Königin (maliktum) genannt, sondern in den Listen erst als dam en, später als a magal en geführt wurde ${ }^{787}$, ist anzunehmen, daß sie eine Nebenfrau des Königs Irkab-Damu war, die ihren Sohn auf den Thron brachte. Man kann davon ausgehen, daß es unter den Frauen des Königs interne Machtkämpfe gegeben hat, bei denen jede versuchte, sich selbst und damit auch ihr Kind in eine möglichst vorteilhafte Position zu bringen. Hatte das Königspaar dagegen einen Sohn, so hat man möglicherweise dieses Kind von Geburt an als Thronfolger betrachtet. ${ }^{788}$ Dafür könnte der große Aufwand sprechen, mit dem die Geburt des Sohnes der Königin Tabur-Damu gefeiert wurde. Allerdings war auch die Geburt des Prinzen Ir'ag-Damu ein solch bedeutendes Ereignis, daß es in einer Datenformel festgehalten wurde ${ }^{789}$, und Ir'ag-Damu war, wie Biga kürzlich zeigen konnte, nicht der Sohn des Königspaares, da er schon vor der Hochzeit von Išar-Damu und Tabur-Damu in den Quellen erwähnt wird, sondern wohl der Sohn des Königs mit einer seiner Nebenfrauen. ${ }^{790}$ Damit stellt sich die Frage, ob der erste Sohn des Königs als Thronfolger angesehen wurde, unabhängig davon, welche der Frauen des Königs seine Mutter war, oder ob dieser Rang dem ersten Sohn der Königin zukam. Dem geht die Frage voraus,

Society of Ebla, CRAI 47 (2002), S. 4.

785 Tonietti, Le liste delle dam en, QdS 16 (1989), S. $101 \mathrm{ff}$.

786 Biga/Pomponio, Chronological Division, JCS 42 (1990), S. 194 Anm. 31.

787 Archi, Les comptes rendus annuels de métaux, Amurru I (1996), S. 76.

788 Biga, Prosopographie, Amurru I (1996), S. 37.

789 ARET 1, 40.

790 Archi, Chronologie relative, Amurru I (1996), S. 12 ging davon aus, daß es sich bei diesem Kind um den Prinzen Ira'g-Damu gehandelt habe. Inzwischen lassen sich viele Texte chronologisch genauer einordnen; Biga, The reconstruction of a relative Chronology, OrNS 72 (2003), S. 358-359. 
ob überhaupt ein Sohn des Königs von Geburt an als dessen Erbe angesehen wurde, bzw. generell, wie in der Gesellschaft von Ebla die Frage der Thronfolge geregelt war.

Von der Geburt eines Sohnes der Königin berichten die Texte ARET 1, 15 und ARET 4, 7. Diese Texte listen die Geschenke auf, die anläßlich der Entbindung der Königin mit Angehörigen befreundeter Königshäuser sowie mit Personal aus Ebla ausgetauscht wurden. Nach der Überzeugung von Biga beziehen sich beide Texte auf dasselbe Ereignis. ${ }^{71}$ Es besteht aber das Problem, daß in den Texten unterschiedliche Personen als Mutter der Königin (a ma-gal maliktum) genannt werden: in ARET 1, $15 \S 8$ ist es NEtibudu, in ARET 4, 7 §24 SumPEŠdu. Da es in Ebla nicht zwei verschiedene Königinnen gleichzeitig gegeben hat, bleiben nur zwei Erklärungsmöglichkeiten (Schreiberfehler ausgenommen). Entweder sind die Texte bei aller Ähnlichkeit doch nicht zeitgleich, oder aber eine der beiden a ma-gal maliktum ist nicht die leibliche Mutter der Königin. Für die zweite Erklärung haben sich Biga und Pomponio entschieden, welche annehmen, a ma-gal könne möglicherweise eine allgemeine Bezeichnung für ,weibliche Verwandtschaft der vorhergehenden Generation" bedeuten ${ }^{792}$. Angesichts der Tatsache, daß es sich bei den Geschenklisten aus Ebla um Wirtschaftsdokumente, um Buchhaltung, handelt, bei der es sicher von großer Bedeutung war, an wen genau bestimmte Güter abgegeben wurden, frage ich mich, ob derartig ungenaue Verwandtschaftsbezeichnungen denkbar waren. ${ }^{793}$ Die Argumentation von Biga/Pomponio, beide Texte gäben dasselbe Ereignis wieder, halte ich nicht für unbedingt zwingend. Sie selbst sprechen die Möglichkeit an, daß die Texte sich auf verschiedene Ereignisse, die einige Jahre auseinanderliegen, beziehen könnten. Dafür spräche vor allem die Nennung von zwei verschiedenen a magal maliktum, von denen ich aus oben genannten Gründen annehme, daß der Terminus wirklich die Mutter einer Königin meint. Daneben muß der in beiden Texten erwähnte dumu-nita en Haba nicht wie von Biga/Pomponio

791 Biga, Prosopographie, Amurru I (1996), S. 31

792 Biga/Pomponio, Critères de rédaction comptable, MARI 7 (1990), S. $109 f$.

793 Der Ausweg, eine Verwandtschaftsbezeichnung nicht nur im eigentlichen Wortsinn zu verstehen, wird immer dann gewählt, wenn eine andere Erklärung nicht möglich scheint. Vgl. auch Archi, The high priestess, dam-dingir, at Ebla, (1998), S. 48-49, zur Frage, ob dumu-munus en neben der Bedeutung „Tochter des (amtierenden) Königs“ auch noch allgemein „Prinzessin“ heißen kann, was er auf S. 48 für TinibDulum annimmt, auf S. 49 für Amaga jedoch nicht. Bei allen Schwierigkeiten der Chronologie und Interpretation der Ebla-Texte bleibt ein ungutes Gefühl bei einer solchen Leseweise, denn wann muß dann eine Verwandtschaftsbezeichnung wörtlich genommen werden und wann übertragen? Und wohin führt das bei der Rekonstruktion der Chronologie und Genealogie des Königshauses von Ebla? 
angedeutet der Sohn der Königin sein, er kann ebenso der Sohn einer Nebenfrau des Königs sein, was die Annahme einer dritten Königin in der Regierungszeit eines En überflüssig macht. Da beide Texte in die Regierungszeit von Išar-Damu datieren ${ }^{794}$, wäre es auch denkbar, daß es sich bei ARET 4, 7 um einen sehr späten Text handelt, die Königin Tabur-Damu gestorben war $^{795}$, und SumPEŚdu die Mutter einer neuen Königin war. Wirklich befriedigend ist diese Deutung allerdings auch noch nicht.

Die Geburt eines Kindes der Königin war Anlaß zu Feierlichkeiten und dem Austausch wertvoller Geschenke. Nicht nur hochrangige Personen wurden beschenkt, sondern auch die Hebamme und die Amme der Königin (ARET 1, $15 \S 17$ und 20). Außerdem wurde den Göttern geopfert (ARET 1, 15 § 13). In den Texten, die in unmittelbarem Zusammenhang stehen mit der Entbindung der Königin wird das Kind stets als dumu-nita maliktum und nicht wie sonst üblich als dumu-nita en bezeichnet, wohl auch um deutlich zu machen, daß es sich bei diesem Kind nicht um einen der vielen Söhne des En von einer mehr oder weniger hochstehenden Nebenfrau, sondern um einen Sohn des Königspaares handelte ${ }^{796}$, womit wahrscheinlich gewisse Privilegien, möglicherweise auch die Thronfolge, verbunden waren. Ein paar Jahre später brachte TaburDamu ein weiteres Kind zur Welt, von dem Biga vermutet, es handele sich um eine Tochter. ${ }^{797}$ Diese Vermutung ist vor allem auf die Tatsache gestützt, daß die Feierlichkeiten zur Geburt dieses Kindes deutlich geringer ausfallen als bei der Geburt des ersten Sohnes. Es ist allerdings zu fragen, ob dies damit zu erklären ist, daß das Kind ein Mädchen war, oder ob nur die Geburt des Thronerben außergewöhnlich aufwendig gefeiert wurde. Gegen eine Geringschätzung von Mädchen läßt sich die hohe Stellung, die einige Prinzessinnen als Priesterinnen innehatten, anführen ${ }^{798}$, sowie allgemein die einflußreiche Position, welche die Frauen der Oberschicht einnahmen.

Die Königin selbst war in Ebla eine bedeutende und einflußreiche

${ }^{794}$ Ibbi-Zikir ist bereits Wesir, weder Dusigu noch eine a ma-g a 1 en werden erwähnt, die Texte sind offenbar nach dem Tod Dusigus, im dritten Jahr von Ibbi-Zikirs Amtszeit (Archi, Chronologie relative, Amurru I (1996), S. 24) verfaßt.

795 Allerdings ist zumindest in den bisher publizierten Texten kein Hinweis auf ihren Tod $\mathrm{zu}$ finden.

796 Biga/Pomponio, Critères de rédaction comptable, MARI 7 (1990), S. 110 Anm. 10.

797 Biga, Donne alla Corte di Ebla, PP 46 (1991), S. 294; dies.: Prosopographie, Amurru I (1996), S. 62. In TM.75.G.2507 ist ein Sohn der Königin, in TM.75.G.1896 eine Tochter erwähnt. Aufgrund inhaltlicher Vergleiche geht Biga davon aus, daß beide Texte sich auf das selbe Ereignis beziehen und in einem Fall ein Schreiberfehler vorliegt.

798 Siehe S. 245-249. 
Persönlichkeit. Schon vor ihrer Hochzeit war Tabur-Damu die zweite Dame des Hofes, nach Dusigu, der Mutter des Königs. ${ }^{799}$ Ihre Mutter NEtibudu ist schon aus den ältesten Texten des Archives bekannt, und erscheint als Empfängerin von Totenopfern in unmittelbarer Nähe zur Königin Kešdut. ${ }^{800}$ Es stellt sich also die Frage, ob ihre Tochter Tabur-Damu aufgrund der hohen Position der Mutter als erste Frau und Königin für den Kronprinzen Išar-Damu gewählt wurde, oder ob gerade umgekehrt die Tatsache, daß Tabur-Damu zur künftigen Königin bestimmt worden war, die hohe Position der Mutter zur Folge hatte. Wann und wie die zukünftige Königin in Ebla bestimmt wurde, ist bisher nicht bekannt.

Beim Hochzeitsritual hatte die Königin eine zentrale, aktive Funktion. Die Hochzeitsrituale der letzten beiden Eblakönige sind überliefert. ${ }^{801}$ Dieses Ritual zog sich über etliche Tage hin und fand vor allem in Ebla und Nenaš statt, wo jeweils verschiedene rituelle Handlungen durchzuführen waren. Einzelne Ritualteile, wie das Betreten einzelner Tempel zu bestimmten Zeiten und das Darbringen von Gaben für die Götter, wurden von der Königin allein ausgeführt, andere Handlungen führte sie zusammen mit dem König aus. So werden in den ersten 19 Abschnitten der Texte ARET 11, 1 und 2 nur die Handlungen der Königin beschrieben, welche sich offenbar nach dem Verlassen des väterlichen Hauses erst durch Opfer an die Götter Kura und Barama sowie durch Salbungen auf das Zusammentreffen mit dem König vorbereiten muß. Nach dem Zusammentreffen des Paares begab dieses sich zusammen mit den Göttern Kura und Barama von Nenaš aus auf eine Rundreise zu verschiedenen Kultorten, wo Opfer dargebracht wurden. Nach der Rückkehr nach Nenaš fanden dort mehrere Tage lang Riten und Opfer statt, wobei das Königspaar teilweise getrennt untergebracht war. ${ }^{802} \mathrm{Im}$ weiteren Verlauf wurden Statuen von König und Königin im Tempel des Gottes Šagiš in Nenaš aufgestellt. ${ }^{803}$ In der Abrechnung über die Metallieferungen im

799 Biga/Pomponio, Chronological Division, JCS 42 (1990), S. 188f; Tonietti, Le liste delle dam en, QdS 16 (1989), S. 101-103. Der Text TM.75.G.1770 ist die erste Liste der dam en, in der Tabur-Damu nicht mehr mit Namen, sondern, wie in allen späteren Listen, nur noch mit ihrem Titel (maliktum) genannt wird. Archi, Les femmes du roi Irkab-Damu, Amurru I (1996), S. 104; Texte z.B. TM.75.G.1335 obv. IX 18-X 1, ARET 4, 19 (=MEE 7, 24) obv. IX 4-14.

801 Pettinato, Il rituale per la successione al trono ad Ebla, St. Sem. NS 9 (1992); Fronzaroli, ARET 11, 1993. ARET 11, 1 ist mit großer Wahrscheinlichkeit das Ritual zur Hochzeit von Irkab-Damu, während ARET 11, 2 das entsprechende Ritual zur Zeit von Išar-Damu und Tabur-Damu beschreibt; siehe Fronzaroli ARET 11, S. 21 und 72. Siehe auch Fronzaroli, The Ritual Texts of Ebla, QdS 18 (1992), S. 163-185.

${ }^{802}$ ARET 11, 1 rev. III 12-19; ARET 11, 2 rev. II 22- III 4.

803 ARET 11, 1 rev. XVII 2-11; ARET 11, 2 rev, XVI 1-12. 
Zusammenhang mit der Hochzeit von Išar-Damu wird auch das Silber für diese Statuen aufgeführt. ${ }^{804}$ Das Ritual fand nicht, wie ursprünglich angenommen, zur Thronbesteigung des Königs statt. Išar-Damu war bereits König, bevor er Tabur-Damu heiratete ${ }^{805}$, doch Archi vermutet, daß der König erst mit der Eheschließung die ganze Vielfalt seiner Funktionen, gerade wohl auch im kultischen Sinne, erreicht ${ }^{806}$. Dafür spricht, daß nur bei der Eheschließung des Königs mit jener Frau, die danach den Titel Königin (maliktum) erhielt, die umfangreichen Hochzeitsriten ( $\mathrm{n}$ í $\mathrm{g}$ - m u - sá) zelebriert wurden. ${ }^{807}$

Die Eheschließung des Königspaares war ein Großereignis, zu dem wertvolle Geschenke an die Gäste aus Ebla sowie an die Angehörigen befreundeter Herrscherhäuser gegeben wurden ${ }^{808}$, und das auch zur Bezeichnung des ganzen Jahres in der Datenformel genutzt wurde ${ }^{809}$.

Die Königin hatte auch nach ihrer Hochzeit diverse kultische Verpflichtungen. In verschiedenen Texten werden Opfergaben der Königin an verschiedene Götter verbucht. So werden in MEE 7, 44 diverse Rinder aufgelistet, die die Königin an verschiedenen Tagen unterschiedlichen Göttern als Opfer darbrachte, darunter den bedeutenden Göttern Kura, Rasap und Nidakul. ${ }^{810} \mathrm{Zu}$ einem anderen Anlaß gab die Königin Textilien und ein Goldobjekt an Ruṣi-Malik für ein Opfer, das dieser in Martum $^{\mathrm{ki}}$ vollzogen hat. ${ }^{811}$ Auch in den Aufstellungen über regelmäßige Metallieferungen sind immer wieder wertvolle Geschenke der Königin an verschiedene Götter verzeichnet. So gab sie einmal diverse Gold- und Silberobjekte wie Becher und

${ }^{804}$ MEE 7, 34 rev. VI 24-32; Biga, Osservazioni sui criteri di redazione dei testi di Ebla, VO 8 (1992), S. 7.

Pomponio, Ebrium e il matrimonio dell'En di Ebla, AfO 40/41 (1993/94), S. 39f.; Biga, Prosopographie, Amurru I (1996), S. 37.

Archi, Chronologie relative, Amurru I (1996), S. 26.

Archi, The Role of Women in the Society of Ebla, CRAI 47 (2002), S. 4. Zu níg mu-sá in den Texten aus Ebla siehe Greengus, Bridewealth in Sumerian Sources, HUCA 61 (1990), S. 29 Anm. 10 und S. 61-65.

Biga, Osservazioni sui criteri di redazione dei testi di Ebla, VO 8 (1992), S. 5-7. So ist der Text MEE 7, 34 eine Auflistung der Edelmetallobjekte, die verschiedene auswärtige Gäste, wie die Königin von Lumnan und Tiša-Lim von Emar, erhielten. Außerdem werden wertvolle Gegenstände aufgeführt, die Angehörige des Hofes von Ebla empfingen.

809 Biga, Prosopographie, Amurru I (1996), S. 36.

810 MEE 7, 44 obv. V 12-16: die Königin hat 2 Rinder für Kura geopfert; obv. V 17-23: die Königin hat 12 Rinder für Rasap von AtaNItu geopfert; obv. VI 11-17: 6 Rinder von der Königin für Nidakul von Luban.

811 MEE 5, 7 = ARET 8, 527 obv. XIII 16-24 = $\$ 39$. 
Schmuck an Išhara von MaNE und Išhara von Zuramu ${ }^{812}$, in einem anderen Text werden 5 Schekel Dilmunsilber zum Tausch und 1 Schekel Dilmungold für einen Anhänger (kù-sal) und einen Anhänger in Form eines Falken $\left(\mathrm{buru}_{4} \text {. MU ŠEN }\right)^{813}$ als Geschenke (ní $\hat{\mathrm{g}}-\mathrm{b}$ a) der Königin an Nidakul von Arukatu aufgeführt ${ }^{814}$ und die Göttin Adamma erhielt einen goldenen Anhänger von der Königin ${ }^{815}$. Die Vertretung des Landes vor den Göttern war in Ebla nicht nur Aufgabe des Königs, sondern auch der königlichen Frauen, insbesondere der Königin, ihrer Tochter Kešdut sowie ihrer Schwiegertochter Za'aše ${ }^{816}$ Die Riten für die Götter wurden regelmäßig vollzogen, wie die Monatsabgechnungen über Schafe als Opfertiere zeigen. So werden in den Texten MEE 12, 5, 26 und 41 jeweils an erster Stelle Tiere für Opfer des Königs, des Kronprinzen, der Königin und danach der Za'aše und Kešdut verzeichnet, gefolgt von den Opfergaben von hochrangigen Angehörigen des Hofes. ${ }^{817}$

Die Aktivitäten der Königin beschränkten sich nicht nur auf die Stadt Ebla selbst. Ebenso wie die Königinnen benachbarter Gebiete wie Emar oder Lumnan, ging sie zu bestimmten Anlässen auf Reisen. Die Verwaltung von Ebla verbuchte Lebensmittel, die als Proviant für diese Reisen ausgegeben wurden $^{818}$, sowie Zahlungen/Geschenke, die befreundete Königinnen anläßlich einer Reise erhielten ${ }^{819}$. Die Gründe für eine Reise waren vielfältig: Neben diversen religiösen Pflichten, welche die Anwesenheit der Königin an bestimmten Kultorten vorschrieb ${ }^{820}$, waren familiäre Ereignisse wie die Geburt eines Kindes ein Anlaß zu Besuchen. So reisten z.B. die Königinnen Zugalum von Harran und Zimini-barku von Burman nach der Geburt des Prinzen Ir'ag-

\footnotetext{
812 MEE 10, 20 rev. XIX 5-25.

813 Zu k ù - s al siehe Archi, Jewels for the Ladies of Ebla, ZA 92 (2002), S. 192-193, zu b u ru 4 - M UŠ EN ebd. S. 189.

814 MEE 10, 29 rev. V 22-29.

815 MEE 12, 35 obv. vi 42-48.

816 Archi, The Role of Women in the Society of Ebla, CRAI 47 (2002), S. 6-7. Gleiches läßt sich auch für die Königinnen der dritten Dynastie von Ur feststellen, siehe S. 179ff.

817 Siehe die Übersichten über drei Monatsabrechnungen in MEE 12, S. 103f., 218f. und 578f..

818 Z.B. ARET 9, 66 und 88, wo die Ausgabe von Biermaische ${ }^{(?)}$ (še-titab) als Reiseproviant (n í ĝ - kaskal) für en wa maliktum verbucht wurde.

819 So erhielt Tiša-Lim von Emar z.B. 1 z ara ${ }_{6}$-Gewand und 2 Nadeln zu 20 Schekel Gold als Reisegeld (n í $\hat{g}-\mathrm{k} \mathrm{a} \mathrm{s}_{4}$ ) für die Reise nach Ebla (MEE 2, 40 obv. X 6-13).

${ }^{820}$ An verschiedenen (Kult-) Orten besaß der König Nebenresidenzen mit eigenem Harem, Dienerschaft etc. Biga, Prosopographie, Amurru I (1996), S. 30 Anm. 4.
} 
Damu nach Ebla. ${ }^{821}$ Bei der Bewertung dieser Besuche sind allerdings zwei Dinge zu beachten: Erstens stammen die benachbarten Königinnen, die als Besucher in den Eblatexten erwähnt werden, selber aus Ebla. Sie sind im Zuge der Heiratspolitik des Königs von Ebla an benachbarte, meist untergeordnete Könige gegeben worden ${ }^{822}$. Zweitens ist es auffallend, daß diese Damen zur Geburt eines Prinzen selber nach Ebla reisten, daß aber im umgekehrten Fall, also bei der Niederkunft einer dieser ehemaligen Eblaprinzessinnen, die Königin von Ebla nicht selber kam, sondern ihre Geschenke schicken lie $\beta^{823}$. Dies zeigt sowohl wie die nach auswärts verheirateten Prinzessinnen mit dem Königshaus von Ebla verbunden blieben, als auch die Rangunterschiede unter den einzelnen Königinnen: Die Herrin von Ebla konnte erwarten, daß man zu ihr kam, sie selber mußte sich nicht auf den Weg machen, sie schickte Boten, die ihre Geschenke überbrachten.

Es ist anzunehmen, daß Königinnen in dieser Zeit über eigene Ländereien verfügten, wie dies für die Königin von Ebla und Tiša-Lim von Emar belegt ist. Letztere besaß mehrere tausend Schafe sowie Land in verschiedenen Gebieten $^{824}$, worüber sie offenbar auch selbständig verfügen konnte, denn ihr Viehbesitz ist getrennt von dem ihres Mannes Enzi-Damu aufgelistet und nicht als Gesamtbesitz des Königshauses von Emar. ${ }^{825}$ Texte, die Auskunft geben über den Landbesitz des Königshauses von Ebla und die Königin erwähnen, stammen aus der frühen Phase des Archives. ${ }^{826}$ Auch hier werden die Besitzungen der Königin, die über mehrere Dörfer verteilt lagen und unter

821 TM.75.G.10074 obv. XVII und XXVIII; Archi, Harran in the III Millennium B.C., UF 20 (1988), S. 3; Ders. Les comptes rendus annuels de métaux, Amurru I (1996), S. 89.

$822 \mathrm{Zu}$ den dynastischen Ehen siehe S. 266-268.

823 TM.75.G.1464 obv. XVI 15-XVII 1: Zimini-barku, Königin von Burman erhält Silber und Gold als Geschenk zur Geburt einer Tochter; s. Biga, Prosopographie, Amurru I (1996), S. 46. Auch Zugalum von Harran erhielt Geschenke zur Geburt eines Kindes (TM.75.G.10127), S. Archi, Harran in the III Millennium B.C., UF 20 (1988), S. 3-4. Neben den Prinzessinnen erhielten auch andere Frauen der Oberschicht Geschenke zur Geburt eines Kindes, s. Sallaberger, Nachrichten aus dem Palast von Ebla, FS Fronzaroli (2003), S. $619+$ Anm. 13.

824 Archi, Imâr au IIIème Millénaire d'après les Archives d'Ebla, MARI 6 (1990); Ders. Un autre Document de Tiša-Lim. Reine d'Imâr, MARI 7 (1993); Dietrich, Besitz der Tiša-Lim. Zuwendungen des Königs von Ebla an die Königin von Emar, UF 25 (1993).

825 TM.75.G.2304, Archi, Imâr au IIIème Millénaire d'après les Archives d'Ebla, MARI 6 (1990), S. 24f.

826 TM.75.G.12448+,TM.75.G.2340 und TM.75.G.2646+. Die Texte sind bisher unpubliziert, siehe Milano, Ébla: Gestion des terres et gestion des ressources alimentaires, Amurru I (1996), S. 149. 
anderem auch Weinberge mit einschlossen, getrennt von denen des Königs geführt. ${ }^{827} \mathrm{Da}$ die Königin die Verfügungsgewalt über ihre eigenen Besitzungen hatte, zeigt die Tatsache, daß sie Ländereien an andere Personen, wie die Priesterin Tirin-Damu, vergeben konnte. ${ }^{828}$ Sie war in das Wirtschaftssystem Eblas eingebunden wie der König und der Wesir. ${ }^{829} \mathrm{Ob}$ und in welchem Umfang die Damen zur Beaufsichtigung der Wirtschaft reisten, ist aus den derzeit publizierten Quellen nicht zu ersehen.

Es ist ferner anzunehmen, daß die Königin die Oberaufsicht über die Textilproduktion hatte, welche ein Pfeiler der Wirtschaft von Ebla war. ${ }^{830}$ Zwar gibt es, zumindest in den bisher publizierten Texten, keinen direkten Beleg dafür, doch ist bekannt, daß verschiedene hochrangige Damen des Hofes wichtige Funktionen in der Wirtschaft innehatten. Diese Frauen werden in einigen Texten als dam-mah bezeichnet, in den Listen der dam en stehen sie stets an erster Stelle nach der Königin. ${ }^{831}$ Und diese Damen sind auch immer wieder am Ende der monatlichen Textillieferungen als Empfängerinnen von Wolle aufgeführt ${ }^{832}$, ebenso die Königin selbst ${ }^{833}$. Vor allem Rautum scheint sehr aktiv in der Textilwirtschaft gewesen zu sein. ${ }^{834}$ Die hochrangigen Damen erhielten bei Wollrationen stets mehr und höherwertigere Qualität als andere. Es ist zu vermuten, daß die Königin die Oberaufsicht über diese da mmah hatte, welche ihrerseits die weiblichen Arbeitskräfte des Palastes beaufsichtigten. Die Königin verfügte über eine umfangreiche eigene Dienerschaft $^{835}$, zu der natürlich auch Weberinnen gehörten. Die übrigen dam

${ }^{827}$ TM.75.G.12448+, s. Archi, The city of Ebla and the organization of the rural territory (1990), S. 18f.

828

829

830

831 (ebd. S. 160ff); ARET 3, 366; TM 75.G.2331 obv. VII 12-16: Rautum, Tešma-Damu, Magaradu, ${ }^{\mathrm{d}}$ Enna-Utu d a m - ma h en (Tonietti, Le liste delle dam en, QdS 16 (1989), S. 106).

${ }^{832}$ ARET 1, 16 = MEE 2, 8 rev. IV 1-5: Rautum nimmt Wolle an. Ebenso in MEE 7, 26 rev. V 6-10.

833 Z.B. MEE 5, 12 = ARET 8, 532 rev. X 10-13 und ARET 4, 9 rev. VI 1-4.

${ }^{834}$ ARET 4, 11 rev. X 13- XI 2; ARET 1, 16 = MEE 2, 8 rev. IV 1-5; MEE 7, 26 rev. III 4-10 und rev. V 6-10, wo Rautum insgesamt 35 Ballen unterschiedliche Wolle annimmt.

835 Zu der aus Männern und Frauen bestehenden Dienerschaft der Königin s. Mander, The Function of the Maliktum, HSAO 2 (1988), S. 264f; Biga, Donne alla Corte di Ebla, PP 46 (1991), S. 292. 
en hatten Weberinnen, die von den Frauen, die für das „Haus des Königs“, das é e n, arbeiteten, getrennt waren. ${ }^{836}$ So wundert es nicht, daß die Wolle für das é en getrennt von den Zuteilungen der $\mathrm{dam}$ en aufgelistet ist ${ }^{837}$, eine Trennung, die sich auch bei den Lebensmittelrationen findet. Wie genau die Bewohner des Palastes intern organisiert waren und wer zu welcher Gruppe gerechnet wurde, ist bisher jedoch noch nicht endgültig zu bestimmen. ${ }^{838}$

Es ist nicht weiter erstaunlich, daß die Königin sowohl bei Textilien als auch bei Lebensmitteln höhere Zuweisungen und bessere Qualitäten erhielt als andere Frauen. So erhielten nur die hochrangigen Damen zara ${ }_{6}$-Gewänder, hochwertige Textilien, die auch gerne an Götter und fremde Königinnen als Geschenk gegeben wurden ${ }^{839}$. Neben Schmuck und luxuriösen Textilien besaß die Königin als eine der wenigen Frauen am Hof von Ebla einen eigenen Wagen. ${ }^{840}$ Bei all ihren wirtschaftlichen und religiösen Aktivitäten ist die Erwähnung eines kostbaren Siegels der Königin nicht weiter überraschend. ${ }^{841}$

$\mathrm{Da}$ die Königin nicht nur im religiösen und wirtschaftlichen Bereich tätig war, sondern sehr wohl auch im Zusammenhang mit militärischen Aktionen auftrat, zeigen ihre Geschenke an den Feldherren Igbi anläßlich einer Kampagne gegen die Stadt Nabu, bei der es offensichtlich um die gewaltsame Durchsetzung von Wirtschaftsinteressen Eblas ging. ${ }^{842}$

\section{Die Königin von Akkade}

Im Vergleich zur nachfolgenden Ur III-Zeit sind die Königinnen der Akkadezeit in sehr wenigen Quellen zu finden. Dennoch lassen sich einige Aussagen zu der Position dieser Frauen machen.

836 In ARET 1, 22 nimmt Arzi Textilien für die Weberinnen der da m en an, die Königin empfängt Textilien für ihre eigenen Weberinnen.

${ }^{837}$ ARET 1, 13 § $38=$ MEE 2, 7 rev. IX 1-X 4

${ }^{838}$ Milano, Cibo e Società nel Regno di Ebla (1990), S. 332f.

839 MEE 2, 41 rev. IX 1-3: $1 \mathrm{z}$ ara ${ }_{6}$ - $\mathrm{túg}$ für die Königin von Gublu ${ }^{\mathrm{ki}}$; ARET 4, 22 rev. VIII 10-IX $14=\S 40: 24 \mathrm{zara}_{6}$-túg für die da m en: maliktum, Amaga, Ra'utum und andere. In ARET 4, $19=$ MEE 7, 24 werden $2 \mathrm{zara}_{6}$-túg und $2 \mathrm{~g} \mathrm{u}$-súr-túg für Kešdut und NEtibudu als Totenopfer (ÉxP AP) geliefert (rev. IX: 4-14 = $\S 18 / 192$ ). Auch als Opfer für die Götter werden $\mathrm{zara}_{6}$-túg verwendet: ARET 1, 15 $=$ MEE 2, 2 rev. IV 10-17 = 13 : Die Königin gibt $2 \mathrm{zara}_{6}-\mathrm{tú} \mathrm{g}$ an ${ }^{\mathrm{d}} \mathrm{Rasap}$ am Tag des maš-da-ù ihres Sohnes.

840 Biga, Donne alla Corte di Ebla, PP 46 (1991), S. 288.

${ }^{841}$ MEE 7, 34 rev. XI 23'-30': 1 Mine 40 Schekel Silber zum Tausch (šu-bal-aka) und 20 Schekel Gold für 2 Siegel für König und Königin.

842 Biga, Prosopographie, Amurru I (1996), S. 54. Der fragliche Text ist noch unpubliziert. 
Nur zwei Königinnen dieser Zeit sind uns namentlich bekannt. Die erste ist TašLULtum, die Frau des Dynastiegründers Sargon. Ihr Name findet sich in einer Weihinschrift ihres Haushofmeisters (šabra é) auf dem Fragment einer Alabasterschale ${ }^{843}$ Die zweite ist Tūta-šar-libbiš, Königin an der Seite von Šarkali-šarrī. Ihr Name und Titel finden sich auf den Siegeln von drei ihrer Haushofmeister ${ }^{844}$ Während TašLULtum lediglich als Frau Sargons (dam) bezeichnet ist, trägt Tūta-šar-libbiš auf zweien der Siegel den Titel einer Königin (nin), auf dem Siegel des Dada wird sie "Geliebte des Königs“ (narāmat šarrim) genannt.

Tūta-šar-libbiš ist auch in mehreren Wirtschaftstexten erwähnt ${ }^{845}$, allerdings ohne Titel, so daß man nur aufgrund ihres seltenen Namens und im Zusammenhang mit den neben ihr erwähnten Personen darauf schließen kann, daß es sich um die Königin handelte. In einem weiteren Text wird ihr Haushofmeister Dada mit dem Zusatz ,šu* n i “ “ genannt. ${ }^{846}$ In den Texten, die die Königin mit Namen aufführen, geht es um die Abrechnung von Getreide. Es fällt auf, daß Tūta-šar-libbiš erst nach anderen Personen genannt ist, auch ist die für sie verbuchte Menge an Getreide nicht höher als die der anderen Personen. Bei dem Text MAD 5, 67 handelt es sich um eine Auflistung von 14 Feldern an verschiedenen Orten, die an verschiedene Personen, unter anderem hochrangige Angehörige der königlichen Verwaltung, vergeben werden. Als erstes wird hier Dada, der šabra é der Königin, genannt. ${ }^{847}$ Foster hat gezeigt, daß das Königshaus große Ländereien unter seiner direkten Kontrolle hatte, die bei Bedarf an Mitglieder des königlichen Haushaltes gegeben wurden. ${ }^{848}$ Auch im Dijalagebiet besaß das Königshaus Ländereien. ${ }^{849}$ In mehreren Texten aus dem Dijala taucht eine NIN É im Zusammenhang mit Land und Tieren auf. ${ }^{850}$ Allerdings ist nicht bekannt, wer mit dieser Bezeichnung gemeint ist, ob es sich um die Königin, eine Prinzessin oder allgemein die „Hausherrin“ handelte, wer immer das im Einzelfall dann gewesen sei ${ }^{851}$ Foster ist der Überzeugung, daß die Königin der Akkadezeit über eigenen Landbesitz verfügte ${ }^{852}$, und verweist

\footnotetext{
843 RIME 2 Sargon E2.1.1.2001.

${ }_{844}$ RIME 2 Šar-kali-šarrī E2.1.5.2001-2003.

${ }^{845}$ MAD 1, 292, 306, 331.

${ }^{846}$ MAD 5, 67. Im Text steht „ši nin “. S. auch Foster, An Agricultural Archive from Sargonic Akkad, ASJ 4 (1982), S. 37.

847 MAD 5, 67, I 1-3.

${ }^{848}$ Foster, Agricultural Archive, ASJ 4 (1982), S. 25, 36-37.

849 Sommerfeld, Tutub (1999), S. 119-120.

850 ebd. Nr. 32 Z. 17; Nr. 63 Z. 8 '.

851 ebd. S. 120.

852 Foster, Notes on Women in Sargonic Society, CRAI 33 (1987), S. 53.
} 
dabei auf MAD 5, 67 und BIN 8, 144. In beiden Texten geht es um Landbesitz unter der direkten Kontrolle des Königshauses, jedoch ist kein Landbesitz der Königin explizit aufgeführt. Vielmehr wird Land an verschiedene Personen ausgegeben, unter denen sich auch ihre Untergebenen, wie der šabra é Dada, befinden. Ein Beleg für Landbesitz der Königin könnte der von Sommerfeld als Nr. 63 publizierte Text aus Tutub sein ${ }^{853}$, eine Auflistung von Gärten (kiri $\left.{ }_{6}\right)$, die Angehörigen des Königshauses zur Verfügung standen. Da die NIN É neben dem Prinzen Bin-kali-šarrī und dem hohen Funktionär Ețib-Mêr genannt wird, kann man davon ausgehen, daß es sich hier um die Königin handelt. Belegt ist, daß die Königin eigenes Vieh besaß. ${ }^{854}$ Wie schon A. Westenholz ausführte, bedeutet die Existenz von Verwaltungsbeamten der Königin, daß es auch Besitz der Königin gab, welcher verwaltet werden mußte. ${ }^{855}$ Gegen die Vermutung, daß es sich um einen Ehrentitel gehandelt habe, der mit keiner realen Funktion verbunden war, sprechen die oben genannten Quellen, sowie die Tatsache, daß sowohl in der vorangegangenen wie auch in der auf die Akkadezeit folgenden Epoche die Königinnen über Besitz an Land und Vieh verfügten und mit diesem Besitz auch eigenständig wirtschaften konnten. In den altakkadischen Texten aus Umma ist wiederholt ein é munus erwähnt, jedoch ist derzeit noch nicht bekannt, ob es sich dabei ebenso wie in präsargonischer Zeit um den Wohnsitz der Frau des Herrschers handelte, oder ob das é munus in akkadischer Zeit eine andere Funktion hatte. ${ }^{856}$ Denkbar wäre, daß das é munus in dieser Zeit das Verwaltungszentrum der Domänen der Königin in dem umliegenden Gebiet gewesen ist, und ihr, kam sie bei Reisen in diese Stadt, als Wohnung dienen konnte.

Iškun-Dagān, einer der šabra é der Königin, war, wie aus der Legende seines Siegels zu ersehen, nicht nur Haushofmeister, sondern auch ihr Schreiber ${ }^{857}$. Ein anderer Schreiber bezeichnet sich auf seinem Siegel als Diener der Königin, wobei er ihren Titel akkadisch wiedergibt (İR rubātim). ${ }^{858}$ Neben Verwaltungsbeamten und Schreibern erscheint in einem Rationentext ein Sänger des Hauses der Königin. ${ }^{859}$

853 Sommerfeld, Tutub (1999), Nr. 63 S. 119-120.

${ }^{854}$ RTC 133 rev. 1'-2', Jochrinder sind mit dem Zeichen der Königin versehen. Michalowski, Tudanapšum, Naram-Sin and Nippur, RA 75 (1981), S. 173f.. Siehe auch Foxvog, Sumerian Brands an Branding Irons, ZA 85 (1995), S. 2 + Anm. 7. Westenholz, The Old Akkadian Period (1999), S. 70 Fn. 321. MCS 9, 239; AO 5656; Foster, Umma in the Sargonic Period (1982), S. 27, 96.

857 RIME 2 Šar-kali-šarrī E2.1.5.2001. Ein weiterer Schreiber der Königin war Abūbu, RA 79, S. 21-22 Nr. 3. BIN 8, 160B; Westenholz, Old Akkadian Period (1999), S. 70.

859 OSP II 177: LUGAL-GÁNA-zi, Sänger des Hauses der Königin, empfängt Zwiebeln. 
In einer Reihe von Texten erhält die Königin Rationen verschiedener Art: Gold, Tiere, Fische oder Eier ${ }^{860}$, die wohl für ihren persönlichen Gebrauch bestimmt waren. Die Königin steht dabei stets als Empfängerin hinter dem König, nach ihr werden oftmals diverse andere Angehörige des Hofes als Empfänger von Rationen aufgelistet. Eine besondere Gruppe bilden die Texte von Rationszuweisungen, die König und Königin auf Reisen erhielten. Foster hat diese Texte zusammengestellt, die im Zusammenhang stehen mit einer Reise des Königspaares nach Nippur und Girsu. ${ }^{861}$ Nach Fosters Rekonstruktion wurden Narām-Suen und seine Gemahlin dabei von ihren Kindern Šar-kali-šarrī, Bin-kali-šarrī und Tūta-napšum begleitet. ${ }^{862}$ Da die Prinzessin Tūta-napšum von Narām-Suen in Nippur als En-Priesterin des Enlil eingesetzt wurde ${ }^{863}$, stellt sich die Frage, ob die Reise der königlichen Familie im Zusammenhang mit dieser Einsetzung stand. Wenn die Annahme zutreffend ist, wäre dies ein Hinweis darauf, daß die Königin in der Akkadezeit bei bedeutenden Anlässen öffentlich auftrat, um repräsentative und kultische Aufgaben wahrzunehmen. Daß die Königin kultische Verpflichtungen hatte, geht aus Texten hervor, die Lieferungen für Opfergaben verzeichnen, wie CT 50, 52, einer langen Liste von kostbaren Gegenständen und Lebensmitteln, die für nindaba-Opfer des Königs, der Königin und einer weiteren Person, wahrscheinlich des Prinzen, nach Zabala geliefert wurden, als der König nach Sumer reiste. ${ }^{864}$ Sie hat wohl auch selbständig Reisen unternommen,

${ }_{860}$ ITT II, 4566 (Eier); RTC 134b (Gold und Tiere); RTC 135b; CT 50, 172 (Schafe und Fische); Donbaz/Foster (1982), 181 (Gold und Tiere).

${ }^{861}$ Foster, Notes on Sargonic Royal Progress, JANES 12 (1980).

${ }^{862}$ Ebd. S. 29-31. Diese Rekonstruktion stützt sich auf einen von Thureau-Dangin nur zum Teil publizierten Text, in welchem Schafe an den König, die Königin, die drei genannten Kinder des Königspaares sowie an hohe Offizielle des Hofes, wie Ețib-Mêr, geliefert werden (RA 9 (1912), S. 82). Im Gegensatz zu Thureau-Dangin geht Foster davon aus, daß die Tiere nicht nach Akkade geliefert wurden, da erstens nur drei Kinder des Königspaares Lieferungen erhielten, die anderen nicht, was bei einer Lieferung in die Hauptstadt aber zu erwarten sei, und zweitens von einigen der Würdenträger bekannt sei, daß sie sich in Girsu aufgehalten haben.

Diese Argumente sind nicht absolut zwingend. Es ist ebensogut möglich, daß sich die anderen Prinzen und Prinzessinnen an anderen Orten aufgehalten haben, ebenso wie die Würdenträger, von denen Foster annimmt, sie seien in Girsu gewesen, sich nicht ständig dort aufgehalten haben müssen. Dazu kommt, daß die chronologische Reihenfolge der Texte nicht festzustellen ist, es also gar nicht sicher ist, ob alle von Foster der einen Reise zugeordneten Texte auch wirklich so einzuordnen sind. Andererseits spricht auch nichts ausdrücklich gegen die Rekonstruktion von Foster. Siehe S. 256-259.

${ }_{864}$ Der Text ist bearbeitet bei Foster, Umma in the Sargonic Period (1982), S. 133-134. 
möglicherweise um kultischen Verpflichtungen nachzukommen oder sich während der Abwesenheit des Königs um wirtschaftliche Belange zu kümmern $^{865}$.

In einem Brief des Iškun-Dagān an Puzur-Eštar wird dieser unter Anrufung der Stadtgötter von Akkade und Adab, sowie beim Leben des Königs und der Königin beschworen, sofort zu kommen. ${ }^{866}$ Der Absender des Briefes war Schreiber und šabra é der Königin Tūta-šar-libbiš und gehörte so zum Kreis der führenden Personen des Reiches. Es stellt sich die Frage, ob die Anrufung des Königspaares als Schwurgötter, die Westenholz im Zusammenhang mit der Vergöttlichung Narām-Suens sieht ${ }^{867}$, weitere Verbreitung in der Bevölkerung fand, oder ob dies ein Phänomen war, das sich auf den Hof, auf die unmittelbare Umgebung des Königspaares, beschränkte.

Aus den spärlichen Quellen ist nicht zu erschließen, ob die Königin auch über politischen Einfluß verfügte. Die Tatsache, daß die Gemahlin von NarāmSuen mit dem König und einigen ihrer Kinder Orte wie Nippur und Girsu/Lagaš besuchte, die in der vorangegangenen Epoche im politischen, wirtschaftlichen und religiösen Bereich eine prominente Stellung eingenommen hatten, könnte ein Indiz dafür sein, daß sie versuchte, wie die Könige vor Narām-Suen, an die Traditionen Sumers anzuknüpfen und sich durch die Wahrnehmung von kultischen Pflichten in die Nachfolge der sumerischen Königinnen zu stellen. Dies wäre ein wichtiges politisches Signal an den oft unruhigen sumerischen Süden gewesen, daß die Kontinuität des Königtums auch in kultischer Hinsicht gewahrt wurde.

${ }^{865}$ Nik II, 53. Tiere als Rationen für die nin é-kaskal-šè. Wilcke, Die KeilschriftTexte der Sammlung Böllinger, AfO 25 (1974/1977), S. 89.

866 FAOS 19, Ad 12, S. 53-55. S. dazu Westenholz, The World View of Sargonic Officials (1993), S. 158-159.

867 Westenholz, The Old Akkadian Empire in Contemporary Opinion (1979), S. 111. 



\section{Nebenfrauen}

Neben den Frauen, welche den Titel einer Königin (nin) trugen, hatten die Könige von Ur eine Reihe von Nebenfrauen. Von diesen sind insbesondere die Damen Geme-Ninlila, Ninkalla und Ea-niša, Frauen von Šulgi, sowie Ti'amatbāštī, die wohl bedeutendste der Nebenfrauen von Šu-Suen, in einer größeren Anzahl von Quellen faßbar. Auf der Grundlage dieser Texte ist es möglich, die Rolle und Position der untergeordneten Frauen der Könige zu untersuchen und ihre Stellung kontrastiv zu jener der Königin zu vergleichen.

\begin{tabular}{|c|c|c|}
\hline König & Königin & Nebenfrau \\
\hline Ur-Namma & SI.A-tum & $?$ \\
\hline Šulgi & $\begin{array}{l}\text { Tarām-Uram } \\
\text { Geme-Suen } \\
\text { Šulgi-simtī }\end{array}$ & $\begin{array}{l}\text { Geme-Ninlila } \\
\text { Ea-niša } \\
\text { Ninkalla } \\
\text { Šuqurtum } \\
\text { Simat-Ea? }\end{array}$ \\
\hline Amar-Suen & Abī-simtī & $\begin{array}{l}\text { Puzur }_{4} \text {-ú-ša } \\
\text { Udat-șenat } \\
\text { Za-ga-an-bi } \\
\text { [. . . ]-natum }\end{array}$ \\
\hline Šu-Suen & Kubātum & $\begin{array}{l}\text { Ti'amat-bašti } \\
\text { Takūn-mātum } \\
\text { Šalim-niaš } \\
\text { Geme-Nanna }\end{array}$ \\
\hline Ibbi-Suen & Geme-Enlila & Simat-Nisaba \\
\hline
\end{tabular}

Tabelle 17: Die Frauen der Könige von Ur 


\section{Geme-Ninlila}

Eine der prominentesten Frauen am Hof von Šulgi war Geme-Ninlila. Ihre herausgehobene Stellung ist zum einen aus der Häufigkeit der Belege und der Art ihrer Tätigkeit innerhalb der Viehwirtschaft von Puzriš-Dagān erschlossen. Deutlicher wird ihre Stellung aber noch aus der Tatsache, daß Geme-Ninlila wahrscheinlich zusammen mit dem Königspaar, Šulgi und Šulgi-simtī, bestattet wurde $^{868}$. Am 28/iii/AS 1 erhielt Geme-Ninlila zusammen mit Šulgi-simtī und dem König Totenopfer an ihrem „Wassertränkort“ (ki-a-na $\hat{g})^{869}$. Der letzte Beleg aus der Lebenszeit der Geme-Ninlila ist eine Viehlieferung an sie vom 23/ix/Š $48^{870}$. Das früheste Zeugnis ist eine Urkunde über Schmuckgeschenke an verschiedene Damen des Hofes, darunter Geme-Ninlila ${ }^{871}$. Bisher ist keine Quelle bekannt, welche einen Titel für Geme-Ninlila nennen würde. Auf dem Siegel, das sie von Šulgi erhielt, wird sie als „seine (Šulgis) Geliebte“ bezeichnet. ${ }^{872}$ Daher kann nur auf der Basis der Wirtschaftstexte auf ihre Stellung geschlossen werden. Es wird aber allgemein angenommen, daß sie eine der Nebenfrauen Šulgis war. ${ }^{873}$

Wie die Königinnen erhielt auch Geme-Ninlila regelmäßige Zuweisungen von Kleinvieh. Insbesondere die als „regelmäßige Lieferung“ $\left(\mathrm{s} a ́-\mathrm{du} \mathrm{u}_{11}\right)$ bezeichnete Gabe von 30 Schafen in einem Monat entsprechen gleichartigen Gaben an die Königin Abī-simtīi ${ }^{874}$ Es kann somit angenommen werden, daß derartige regelmäßige Zuweisungen von einem Stück Kleinvieh pro Tag der üblichen Menge für den alltäglichen Bedarf der einzelnen hochrangigen Frauen und ihrer unmittelbaren Umgebung entsprachen.

868 Michalowski, The Death of Šulgi, OtNS 46 (1977), S. 223.

${ }^{869}$ ZVO 25, 134, 2.

$870 \quad$ TRU 298.

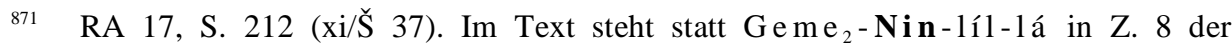
Personenname Ge $\mathrm{me}_{2}-\mathbf{E} \mathbf{n}-1$ íl-1á. Dies ist aber wohl als Irrtum des Schreibers zu sehen, da eine Geme-Enlila erst unter Šu-Suen in prominenter Position am Hof bekannt ist.

872 RIME 3/2.1.2.82; die Siegellegende lautet ${ }^{\mathrm{d}} \check{\mathrm{S}} \mathrm{u} \mathrm{l}-\mathrm{gi} / \mathrm{nita-kala-ga/lugal-}$ uri $_{5}{ }^{\mathrm{ki}}$ - ma/lugal-an-ub-da-limmu $\mathrm{m}_{2}-\mathrm{ba-ke}{ }_{4} / \mathrm{Geme}_{2}-{ }^{\mathrm{d}} \mathrm{Nin-1}$ - 1 -lá/kiá $\hat{g}-\hat{g}$ á -ni - ir/i n - n a-b a (Šulgi, der starke Mann, der König von Ur, König der vier Weltgegenden, hat Geme-Ninlila, seiner Geliebten, (dieses Siegel) gegeben).

873 Michalowski, Royal Women of the Ur III Period. Part II: Geme-Ninlila, JCS 31 (1979), S. 175; v.d. Mieroop, Women in the Economy of Sumer (1989), S. 59.

${ }^{874}$ TRU 278 (i/Š 45); CST 115, (1/vi/Š 46); JCS 31, S. 172 C (1/iii/Š 48). Zu den regelmäßigen Lieferungen von 30 Stück Kleinvieh an Abī-simtī siehe S. 111. Vgl. dazu Michalowski, Royal Women of the Ur III Period. Part II: Geme-Ninlila, JCS 31 (1979), S. 172-173. 
Neben diesen mit $s a ́-d u_{11}$ bezeichneten Lieferungen erhielt Geme-Ninlila ebenso wie das Königspaar Tiere zugewiesen, welche als mu-DU-Lieferung gekennzeichnet wurden. Da neben dem König praktisch nur die hochrangigsten Frauen des Hofes derartige Zuweisungen erhielten ${ }^{875}$, ist die Tatsache, daß Geme-Ninlila als Empfängerin von mu-DU-Tieren auftritt, ein deutlicher Hinweis auf ihre besondere Stellung innerhalb des Königshauses ${ }^{876}$. Dabei können als Lieferanten dieselben Personen auftreten, die auch für die Königin Šulgi-simtī Tiere zur Verfügung stellen. So erhielt Geme-Ninlila in einem Fall Enten und Tauben von Bamu und der Frau des Izuarik, die beide aus dem Šulgi-simtī-Archiv bekannt sind. ${ }^{877}$ Mitunter erhielt Geme-Ninlila auch Tiere direkt aus dem Bestand der mu-DU-Lieferungen an den König (mu-DUlugal $)^{878}$, eine Form der Distribution, die in dieser Art für die Königinnen nicht $\mathrm{zu}$ beobachten ist.

Nun ist für Geme-Ninlila zu beobachten, daß sie in den letzten Regierungsjahren von Šulgi wiederholt in annehmende Funktion (ì- $\left.d a b_{5}\right)$ bei Transaktionen von Rindern, Schafen und Ziegen, die als mu-DU-lugal gekennzeichnet werden, auftrat. ${ }^{879}$ Die von ihr empfangenen Tiere stammten stets aus der Verwaltungseinheit von Narām-ilī (ki Na-ra-am-ì-lí-ta), einem wichtigen Beamten von Puzriš-Dagān in dieser Zeit ${ }^{800}$. Da alle diese Transaktionen im Monat vi/vii stattfinden, dem Monat des Akiti-Festes zur Aussaat $^{881}$, liegt es nahe, eine Verwendung der von Geme-Ninlila

875 Sallaberger, Der kultische Kalender (1993), S. 29.

876 AUCT I, 431 (ii/Š 41) Dies ist der einzige Text, in dem die Formulierung „,mu - D U Geme ${ }_{2}{ }^{\mathrm{d}} \mathrm{Nin-1}$ 1́l-1á “ auftritt, welche absolut parallel zu „mu-DU-lugal“ und „mu - D U ${ }^{~} \breve{S} u l$-gi-si-im-ti“ zu sehen ist. In RA 49, 88 Nr. 12 (17/i/Š 43) und TRU 298 (23/ix/Š 48) findet sich die Phrase „,(Tiere) für Geme-Ninlila, m u - D U -Lieferung von PN“.

877 AUCT I, 431 (ii/Š 41). Izuarik selber beliefert Šulgi-simtī in BIN III, 409 (ii/Š 37) und CST 49 (viii/Š 39). Bamu ist in TCND 34 ( ̌S 39) an der Transaktion von 112 Schafen und Ziegen für Šulgi-simtī beteiligt.

BCT I, 34 (vii/Š 39); BIN V, 20 (i/Š 48); ,,(Tiere) mu - D U - lu gal ki - PN - t a mu Geme ${ }_{2}{ }^{\mathrm{d}} \mathrm{Nin-1íl-1á-šè.} \mathrm{Wie} \mathrm{Michalowski} \mathrm{zu} \mathrm{BIN} \mathrm{V,} 20$ anmerkt (Royal Women of the Ur III Period. Part II: Geme-Ninlila, JCS 31 (1979), S. 174), wurde dieser Text mit der Herkunftsangabe „Umma“ publiziert. Sollte die Tafel aus Drehem stammen, müßte der Text aufgrund des anderen Kalenders in Drehem auf den 12. Monat datiert werden.

BIN III, 610 (vi/ŠS 45); RA 75, 94, Eremitage-Text Nr. 14933 (vi/ŠS 46), dieser Text trägt ihr Siegel (RIME 3/2.1.2.82); OIP 115, 6 (vii/Š 47); BIN III, 516 (vi/Š 48).

Zu Narām-ilī siehe Sigrist, Drehem (1992), S. 259-269.

$881 \mathrm{Zu}$ diesem Fest siehe Sallaberger, Der kultische Kalender (1993), S. 183-190; Cohen, Cultic Calendars (1993), S. 150-153. 
angenommenen Tiere im Kontext dieses wichtigen Festes in Ur zu sehen. Welche Funktion Geme-Ninlila beim Akitifest möglicherweise zu erfüllen hatte, und warum sie gerade in diesem Monat einzelne Tiere aus den mu - DU Lieferungen des Königs annahm, muß vorerst offen bleiben.

Wie aus mehreren Texten hervorgeht, verfügte Geme-Ninlila über einen Bestand eigener Rinder, Schafe und Ziegen, über deren Verwendung sie möglicherweise ebenso wie die Königinnen frei entscheiden konnte. ${ }^{882}$

Für den Text PDT II, 1068 (ix/Š 46) über die Ausgabe von Sesamöl kann ein gesellschaftlicher Kontext als Anlaß für die Buchung vermutet werden. Das bei Geme-Ninlila abgebuchte Öl (zi-ga Geme ${ }_{2}-{ }^{d} \mathrm{Nin-líl-lá-ka)} \mathrm{ist}$ bestimmt für eine Geme-Nanna, Schwiegertochter eines gewissen Būdu. Eine Geme-Nanna ist als Prinzessin bekannt ${ }^{883}$, sodaß es sich bei dieser Sendung von Sesamöl möglicherweise um ein Geschenk im Rahmen der Hochzeit handelte. Denkbar ist auch, daß das Öl während der Riten der Eheschließung benötigt wurde. Es ist nicht festzustellen, in welchem Verhältnis Geme-Ninlila zur Braut stand und warum sie dieses Öl zur Verfügung stellte, doch es bleibt festzuhalten, daß die königliche Nebenfrau Geme-Ninlila im wirtschaftlichen und gesellschaftlichen Leben des Hofes eine nicht unbedeutende Rolle spielte.

Dies wird weiterhin bestätigt durch die Beobachtung, daß Geme-Ninlila wie Ea-niša, eine weitere Nebenfrau Šulgis ${ }^{884}$, einen Anteil von zwei weiblichen Schafen aus der Beute des Feldzuges gegen Šimaški erhielt. ${ }^{885} \mathrm{Ob}$ auch die anderen Damen des Hofes, insbesondere die Königinnen regelmäßig an der Beute aus Feldzügen beteiligt wurden, oder ob es sich bei dieser Gabe an die beiden Nebenfrauen Šulgis um ein besonderes Geschenk handelte, ist nach der derzeitigen Quellenlage nicht zu beantworten.

Dem Alltagsbereich zugehörig ist der Text AUCT I, 65 (ك̌ 38) über die Zuweisung von Wolle für Gewänder der Geme-Ninlila. Hierbei ist bemerkenswert, daß ihr Wolle in verschiedenen Qualitätsstufen zur Verfügung stand, je gut drei Minen für ein Gewand erster und zweiter Qualität (túg-lugal und túg-ús-lugal) sowie 31 Minen Wolle dritter und 2 gú (=120 Minen $\approx$ $60 \mathrm{~kg}$ ) Wolle vierter Qualität, die Mengenangabe der Wolle fünfter Qualität ist

882 BIN III, 484 (iii/Š 40); ASJ 4, S. 133-134 Nr. 3 (10-30/ix/Š 43); SACT I, 8 (iv/Š 44); BCT I, 39 (xi-xii/Š 46); OIP 115, 10 (ॅ̌ 47); RA 74, 47 Nr. 116 (13/-/-). Im letzten Text, einer Liste von Rindern für verschiedene Personen, erhält Geme-Ninlila 2 Rinder, erst dann ist die Königin Šulgi-simtī noch nach der Prinzessin Taddin-Eštar als Empfängerin von nur einem Rind aufgeführt.

883 Sigrist, Drehem, S. 361 Anm. 41.

${ }_{884}$ Zu Ea-niša siehe unten S. 206-211.

${ }_{885}$ ZVO 25, 134,1 (ii/Š 47); siehe Michalowski, Royal Women of the Ur III Period. Part II: Geme-Ninlila, JCS 31 (1979), S. 175. 
abgebrochen. Als Aufseher (u gula) bei dieser Transaktion fungiert Ur-Igalim, welcher in diesem Text den Titel eines šabra trägt. Ein Beamter dieses Namens ist häufig im Kontext der königlichen Frauen anzutreffen, bei GemeNinlila üblicherweise mit dem Titel eines Viehmästers (kurušda) ${ }^{886}$, für Abīsimtī ist ein Viehverwalter $\left(\mathrm{ku}_{7} \breve{s}_{7}\right)$ dieses Namens belegt ${ }^{887}$, wobei es gut vorstellbar ist, daß es sich hier um dieselbe Person handelt.

Neben der Königin Šulgi-simtī ist Geme-Ninlila die einzige der königlichen Frauen, für die zur Zeit von Šulgi kultische Aktivitäten belegt $\operatorname{sind}^{888}$. Welchen Göttern die besondere Verehrung der Geme-Ninlila galt, ist den Texten jedoch nicht zu entnehmen. Die Zeugnisse für ihre kultischen Tätigkeiten sind bei weitem nicht so umfangreich wie für die Königin. So führte Geme-Ninlila im Jahr Š 43 siskur ${ }_{2}$-Riten durch, bei denen die Häute von drei Mastschafen Verwendung fanden ${ }^{889}$. Der Name einer Gottheit wird hier ebensowenig erwähnt wie der Anlaß für diese Riten, es könnte sich hier also um eine Beteiligung der Geme-Ninlila an einem der großen Feste des Reiches handeln, doch ist es ebenso möglich, in diesem Text das Zeugnis für ein persönliches Opfer zu sehen, das nicht im Kontext der Kulte für die großen Götter des Landes stand.

Ähnlich undeutlich ist der Text PDT II, 1113 (xi/Š 46), wo Sesamöl bei Geme-Ninlila für siskur ${ }_{2}$-diĝir-ra abgebucht wird (zi-ga Geme ${ }_{2}$ ${ }^{\mathrm{d}} \mathrm{Nin}-1$ líl-1á-ka). Ob Geme-Ninlila an den Riten beteiligt war, ist nicht zu erkennen, möglicherweise war sie nur als Lieferantin für das Öl tätig.

Eindeutig ist dagegen, daß sie zumindest einmal ein Elūnum durchführte, für welches sie zwei gemästete Rinder, also eine wertvolle Gabe, die über die üblichen Kleinviehopfer hinausging, erhielt ${ }^{890}$. Während von Šulgi-simtī bekannt ist, daß sie das Elūnum zu Ehren ihrer Göttinnen Bēlat-Šuhnir und Bēlat-Deraban sowie Annunītum und Ulmašītum durchführte ${ }^{891}$, ist im Text der Geme-Ninlila kein Göttername genannt, was die Interpretation des Textes erschwert. Abī-simtī führte einmal ein Elūnum für die Göttin Inanna durch ${ }^{892}$, woraus deutlich wird, daß ein solches Fest für verschiedene Gottheiten abgehalten werden konnte. Das Elūnum der Geme-Ninlila könnte nun auch

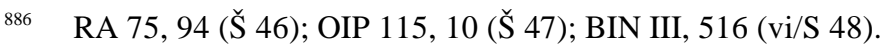

887 TRU 126 (18/iv/AS 8); Nik. 488 (18/viii/AS 8); SRD 18 (9/ix/AS 8).

${ }_{888}$ Vgl. Sallaberger, Der kultische Kalender (1993), S. 19.

889 JCS 31, S. $175 \mathrm{G}$ (iii/Šs 43).

890 YOS 4, $240\left(17 / \mathrm{ii} / \check{S}_{4} 41\right)$.

891 Zum Elūnum bei Šulgi-simtī siehe oben S. 81-83; vgl. Sallaberger, Der kultische Kalender (1993), S. 202-203.

892 MVN 20, 31 (II/AS 5); d'Agostino, Ein neuer Text über Abī-simtī und das ElūnumFest in Puzriš-Dagān, ZA 88 (1998), S. 1-5. Siehe oben S. 135.
} 
Bēlat-Šuhnir und Bēlat-Deraban, den Göttinnen der Königin, gegolten haben, denkbar wären auch Riten für eine andere, von Geme-Ninlila besonders verehrte Gottheit. Da Šulgi-simtī im selben Monat wie Geme-Ninlila selber ihr Elūnum feierte ${ }^{893}$, ist auch vorstellbar, daß es sich nicht um zwei verschiedene Feste handelte, sondern daß die beiden Frauen das mehrtägige Fest gemeinsam gestalteten. Dann wäre der Eintrag in YOS 4, 240 zu verstehen als „für das Elūnum-Fest, für Geme-Ninlila“ im Gegensatz zu den für das gleiche Fest gemachten Ausgaben an Šulgi-simtī.

Auch am Fest des Himmelsbootes (má-an-na) zu Ehren der Inanna von Uruk war Geme-Ninlila zumindest einmal beteiligt. Dies geht aus dem von Michalowski publizierten Text YBC 15624 (vi/S 43) hervor ${ }^{894}$, in dem die Lieferung von Tierhäuten für das (Fest des) Himmelsbootes der Geme-Ninlila an einen Abdecker bescheinigt wird ${ }^{895}$. Die Teilnahme der Geme-Ninlila an diesem Fest verwundert nicht, da gerade das Fest des Himmelsbootes eng verbunden ist mit den Frauen des Königshauses ${ }^{896}$. Unklar muß bleiben, ob Geme-Ninlila als hochrangige Nebenfrau des Königs regelmäßig an diesem Fest teilnahm, oder ob ihre explizite Erwähnung im Jahr $\breve{S} 43$ darauf zurückzuführen ist, daß möglicherweise die Königin in diesem Jahr nicht an den Riten teilnehmen konnte und deshalb das Fest von Geme-Ninlila geleitet wurde ${ }^{897}$.

Insgesamt ergibt sich aus den Quellen zu Geme-Ninlila der Eindruck, daß diese als königliche Nebenfrau vorrangig im wirtschaftlichen Bereich tätig war. Sie besaß eigenes Vieh und erhielt regelmäßige Zuweisungen von Tieren. Bei einigen Riten und Festen, die von der Königin durchgeführt wurden, war sie ebenfalls beteiligt.

\section{Ea-niša}

Eine weitere hochrangige Nebenfrau Šulgis war Ea-niša, die ab dem Jahr Š 38 in den Texten aus Puzriš-Dagān in Erscheinung tritt. Der derzeit früheste Text zu Ea-niša ist eine dem Šulgi-simtī-Archiv zugehörige Urkunde über die

893 SET 44 (30/-/Š 41); MVN 18, 67 (20/ii/ك̌ 41); JCS 52, S. 128 (1/iii/Š 41); siehe S. 81.

${ }^{894}$ Michalowski, Royal Women of the Ur III Period. Part II: Geme-Ninlila, JCS 31, S. 175 G.

${ }_{895}$ Vgl. Sallaberger, Der kultische Kalender (1993) S. 217. Zum Fest des Himmelsbootes bei Šulgi-simtī siehe S. 206-206.

896 Siehe oben S. 68.

${ }^{897}$ Aus dem Šulgi-simtī-Archiv ist für das Jahr $\breve{S} 43$ bislang kein Beleg für dieses Fest bekannt, was aber auch einfach auf den Zufall der Überlieferung zurückgeführt werden kann. 
Ausgabe von einer Ziege für die Mahlzeit (ní $\hat{\mathrm{g}}-\mathrm{g} \mathrm{u}_{7}$ ) der Ea-niša. ${ }^{898}$ Anders als Šulgi-simtī und Geme-Ninlila ist Ea-niša nicht kurz nach Šulgis Tod ebenfalls verstorben, sondern noch bis in die Regierungszeit von Šu-Suen belegt ${ }^{899}$.

Von ihrem Siegel sowie von zwei Weihinschriften ist der Titel dieser Dame bekannt. Ebenso wie Šulgi-simtī auf den Siegeln ihrer Diener bezeichnete sich Ea-niša in ihren Weihinschriften als lukur-lugal, auf ihrem Siegel trug sie den Titel lukur-kaskal ${ }^{900}$. Ihr Siegel ${ }^{901}$ zeigt eine Einführungsszene, in der die Siegelinhaberin, begleitet von einer fürbittenden Göttin, vor eine thronende Person tritt, welche die Rundkappe der Könige von Ur trägt und somit als Šulgi identifiziert werden kann. Ea-niša steht mit ausgestrecktem Unterarm vor dem König, eine Haltung, die für weibliche Siegelinhaber typisch zu sein scheint. ${ }^{902}$ Nach der Inschrift hat Šulgi dieses Siegel der Ea-niša, seiner lukur-kaskal geschenkt (in-na-ba). Derartige königliche Geschenksiegel wurden nur an Personen von besonders hohem Rang vergeben. Abgerollt ist das Siegel auf einer Ausgabeurkunde über die Lieferung von Vieh für den Kult der Nanaja in Uruk $^{903}$.

In Weihinschriften der Ea-niša für das Leben des Šulgi bezeichnet sie sich einmal als seine lukur, einmal als lukur-kaskal. Dies könnte darauf schließen lassen, daß lukur-kaskal der vollständige Titel war, während lukur als Kurzform zu betrachten ist ${ }^{904}$.

Die erste dieser beiden Inschriften befindet sich auf einer Achatperle, welche Ea-niša der Inanna geweiht hat ${ }^{905}$. Die zweite Inschrift ist nur auf einer

898 OIP 115, 47 (viii/Š 38), siehe auch die Ausgabe von verschiedenen Mehlsorten für die Mahlzeit der Ea-niša in NISABA 8, 71 (-/v/Š 40).

899 Der letzte datierte Text ist MVN 15, 287 (x/ŠS 2), eine Urkunde über die Lieferung von 3 Rindern und 120 Schafen und Ziegen als regelmäßige Lieferung ( $\left.\mathrm{s} a-d u_{11}\right)$ an Ea-niša. Aus dem Jahr ŠS 6 stammt der Text AUCT III, 412, der das Siegel von LuNarua, Gärtner der Ea-niša, trägt.

Zum Titel „1 u ku r“ siehe S. 237-240.

901 Die Inschrift wurde zuerst von Grégoire publiziert in RA 73, S. 191, siehe RIME 3/2.1.2.75. Das Siegelbild ist publiziert und besprochen bei Fischer, Siegelabrollungen im British Museum auf Ur -III-zeitlichen Texten aus der Provinz Lagaš, BagMit. 28 (1997), S. 139-140 und 173 Abb. 8; die Tafelhülle mit Text und Siegel ist jetzt zu finden in AAICAB I/1, Pl. 139 Ashm. 1971-346.

Fischer, Siegelabrollungen im British Museum, BagMit. 28 (1997), S. 140; Mayr, The Depiction of Ordinary Men and Women on the Seals of the Ur III Kingdom, CRAI 47 (2002), S. 363-366.

903 AAICAB I/1, Pl. 139 Ashm. 1971-346 (iii (iv)/Š 44).

904 Vgl. Grégorie, RA 73 (1979), S. 191; zum Titel „1 u k u r“ siehe S. 237-240.

905 RIME 3/2.1.2.72, dort auch frühere Literatur. Die Perle stammt aus dem Kunsthandel. Hier bezeichnet sich Ea-niša nur als lu k u r des Königs. 
altbabylonischen Sammeltafel aus Nippur erhalten ${ }^{906}$. Der Text, der auf der altbabylonischen Tafel in verkürzter Form wiedergegeben ist, hat sich offensichtlich auf einer Statue des Königs befunden, welche Ea-niša hat anfertigen und aufstellen lassen. In der Inschrift erklärt Ea-niša, sie habe ,(eine Statue) ihres Königs angefertigt und (die Statue) ihres Mannes vor sich aufgestellt ${ }^{\star 907}$.

Die Tatsache, daß Ea-niša über ein eigenes Siegel verfügte und Weihgaben wie eine große Achatperle ${ }^{908}$ und eine Statue des Königs anfertigen lassen konnte, geben einen Hinweis auf den hohen Rang, den diese königliche Nebenfrau eingenommen haben muß. Dies wird unterstrichen von den Siegeln ihrer Diener, welche zeigen, daß Ea-niša wie die Königinnen über eigenes Personal verfügte und nicht nur eine der rangniederen Hofdamen war. Neben ihren Schreibern Lu-Namma ${ }^{909}$ und Ur-Ninšubur ${ }^{910}$ hatte auch ihr Schiffer Enunku ${ }^{911}$, der Gärtner Lu-Narua ${ }^{912}$ und ihr Diener ( $\mathrm{i}_{11}$ ) Inzuzu ${ }^{913}$ ein eigenes Siegel. Ein Diener namens NaDI ist aus zwei verschiedenen Siegellegenden als Diener der Ea-niša bekannt ${ }^{914}$, wobei als Patronymikon einmal Ur-èš-bar-ra und einmal Ur-ab-ba-diĝir-ra angegeben ist ${ }^{915}$. Aus Verwaltungstexten sind zwei Hausverwalter (̌̌abra) der Ea-niša bekannt, Lu-duga und Šulgi-bāni ${ }^{916}$,

906 RIME 3/2.1.2.81, hier nennt Ea-niša sich lukur-kaskal-1a lukur-ki - á $\hat{g}$ - $\hat{g}$ a n i - e, seine (des Königs) lu k u r-k a ska l, seine geliebte lu k u r . RIME 3/2.1.2.81 Z. 9'-12': lugal-a-ni/mu-tu/mu-ud-na-ni/igi-ni-šè in$\mathrm{gu}[\mathrm{b}]$.

908 Die Perle ist $8,1 \mathrm{~cm}$ lang und 0,8 cm dick; Pohl, Eine neusumerische Achatperle, OrNS 16 (1947), S. 464.

RIME 3/2.1.2.79 = AUCT III, 322.

910 RIME 3/2.1.2.77, das Siegel ist abgerollt auf der Tafel SAT II, 234 (ک̌ 39), einer Bestandsaufnahme über 14 Minen Wolle.

911 RIME 3/2.1.2.76, das Siegel ist auf der zum großen Teil zerstörten Tafel MVN 15, 357 (Š 46) abgerollt.

912 RIME 3/2.1.2.80, das Siegel ist abgerollt auf der Tafel AUCT III, 412 (ix/ŠS 6), einem Beleg über die Annahme von Bronze durch Lu-Narua.

913 RIME 3/2.1.2.78, das Siegel ist abgerollt auf der Tafel AUCT III, 321 (xii/Š 45), quittiert wird die Annahme von Datteln durch Inzuzu.

914 RIME 3/2.1.2.73 und RIME 3/2.1.2.74.

915 Steinkeller stellte bezüglich der korrekten Lesung des Namens die Frage "is the name to be corrected to u r-ab-ba(!)- [dig ir ]-ra in the first seal, or is it to be read u r è š - b a - a n - r a in the second seal?"; RA 73 (1979), S. 190.

916 Lu-duga tritt in SACT I, 131 (13/cii/Š 46) und PDT I, 99 (4/iii/ŠS 47) als Lieferant von Vieh als mu-D U auf, Šulgi-bāni trägt auf der Sammeltafel NISABA 8, 27 (ŠS 2-3) den Titel des šabr a der Ea-niša. 
weiterhin wird ein Šeškalla als lú Ea-niša tituliert ${ }^{917}$.

Der hohe Rang der Ea-niša als königliche Nebenfrau wird weiterhin deutlich durch die Tatsache, daß ihr Bruder Idī-Ea ${ }^{918}$ in Verwaltungstexten nicht über den Namen des Vaters definiert wird, sondern über den Namen seiner Schwester ${ }^{919}$. Diese genauere Bestimmung einer Person über eine besonders hochrangige weibliche Angehörige ist sowohl aus Ebla bekannt wie auch aus der Ur III-Zeit, wie das Beispiel der Geschwister der Abī-simtī zeigt $^{920}$. Daß der Bruder der Ea-niša über den Namen seiner Schwester definiert wurde, unterstreicht die besondere Stellung dieser Dame am Hof von Ur.

Wie Geme-Ninlila erhielt auch Ea-niša im Jahr Š 47 zwei Schafe als Anteil aus der Beute des Feldzuges gegen Šimaški. ${ }^{921}$ In drei weiteren Texten aus der Regierungszeit Šulgis begegnet Ea-niša in höfischen Kontext und in unmittelbarer Nähe zu der Königin Šulgi-simtī. So veranstaltete die Königin im Jahr Š 40 ein Bierausschenken (k aš-dé-a) zu Ehren der Ea-niša ${ }^{922}$, zu dem eine Ente und fünf Tauben aus dem Bestand der Šulgi-simtī bereitgestellt wurden. Drei Jahre später erhielt sie ebenso wie die Königin 7 Schafe, die als Proviant/Ehrengeschenk (igi-kár) bezeichnet wurden ${ }^{923}$. In diesem Text werden mehrere Hundert Schafe für verschiedene Zwecke ausgegeben, darunter an den König sowie an die hochrangigsten Damen aus seiner Umgebung, an die Königin Šulgi-simtī sowie an Geme-Ninlila, Ninkalla, Simat-Ea, Ea-niša und Taddin-Eštar. Auffällig ist hier, daß die Königin nicht an erster Stelle nach dem König steht, sondern erst an vierter Stelle. Die Tiere für Geme-Ninlila, Ninkalla und Simat-Ea werden nicht weiter spezifiziert, wohingegen die Gaben an Šulgi-simtī, Ea-niša und Taddin-Eštar als i g i-kár bezeichnet werden. Da der Text teilweise zerstört ist, läßt sich keine Ausage treffen über den Umfang der Lieferung an den König und die drei erstgenannten Frauen. Šulgi-simtī und Ea-niša erhielten je sieben Schafe, während Taddin-Eštar die doppelte Menge empfing. Ein Grund für diese

\footnotetext{
917 NISABA 8, 46 (-/vi/Š 44).

Zur Problematik der Transkription von Personennamen des Typs I-dì-GN entweder als Idī-GN „Meine Stärke ist GN“ oder als Iddin-GN „GN gab“ siehe Hilgert, Akkadisch in der Ur III-Zeit (2002), S. 294-296.

919 OIP 115, 199 (19/iii/Š 46); AAICAB I/2, Pl. 140 Ashm. 1971-351 (18/vii/Š 48).

Siehe S. 108 zu den Geschwistern der Abī-simtī; S. 186 und 152 zu den Frauen aus Ebla.

921 Michalowski, Royal Women of the Ur III Period. Part II: Geme-Ninlila, JCS 31 (1979), S. 175 H.

922 OIP 115, 58 (15/iii/Š 40).

923 Michalowski, Royal Women of the Ur III Period. Part III, ASJ 4 (1982), S. 133-134 Nr. 3, Kelsey 89203 (10-30/ix/Š 43).
} 
Ausgabe an die bedeutendsten Frauen des Hofes ist nicht genannt. Zusammen mit Ninkalla und Simat-Ea empfing Ea-niša anläßlich des Besuches des Königspaares im Haus des Šarrum-bāni Schmuck aus Gold und Silber, Textilien und Butterschmalz ${ }^{924}$. Ein weiterer Text nennt Ea-niša zusammen mit einer Reihe hochrangiger Personen als Empfängerin von Schuhen. ${ }^{925}$

Aus diesen Texten wird deutlich, daß Ea-niša zu den bedeutendsten Frauen am Hof von Ur zur Zeit Šulgis gehörte. Sie nahm Teil an wichtigen gesellschaftlichen Ereignissen und unterhielt einen eigenen Haushalt. Wirtschaftliche Aktivitäten der Ea-niša sind bis in die ersten Jahre der Regierung Šu-Suens zu verfolgen, wobei hier davon ausgegangen wird, daß es sich stets um dieselbe Person handelt.

Aus der Zeit Šulgis sind die Belege über die Viehwirtschaft der Ea-niša eher spärlich, so nahm sie im Jahr Š 451 gú $(30 \mathrm{~kg})$ Wolle $a^{926}$, jedoch stammte diese Wolle wohl nicht von ihren eigenen Tieren, da sie von En-diĝirgu abgebucht wurde, welcher in der Zeit von Š 40 bis AS 9 für die Ausstattung des Tummalfestes verantwortlich war ${ }^{227}$, der Text über die Ausgabe von Wolle an Ea-niša stammt aus dieser Zeit und aus dem Monat des Tummalfestes, was die Vermutung zuläßt, Ea-niša habe anläßlich dieses Festes aus dem königlichen Bestand Wolle erhalten. Aus dem Jahr Š 46 nahm der sukkal Lugal-nirĝal vier Schafe für Ea-niša an, die aus dem königlichen Viehbestand stammten $^{928}$. Erst unter Amar-Suen und Šu-Suen werden größere Bestände als Tiere der Ea-niša bezeichnet. So besaß sie wie die Königin Abī-simtī Schafherden in der Gegend von Girsu ${ }^{929}$. Zur Zeit Šu-Suens erhielt sie Rinder und Schafe aus den königlichen Beständen, wobei diese Zuweisungen zumeist als „regelmäßige Lieferungen“ $\left(\mathrm{s} a ́-\mathrm{d} \mathrm{u}_{11}\right)$ bezeichnet wurden und es auffällt, daß der Umfang der Ausgaben deutlich zunahm ${ }^{930}$. Dies deutet darauf hin, daß

924 Philips 13, Kol III 26-IV 6 (xii/Š 47); zu diesem Text siehe S. 171.

925 NISABA 8, 386 (-/viii/Š 41).

926 ASJ 4, S. 141 Nr. 5 (vii/Š 45).

927 Zu En-diĝir-ĝu siehe Sigrist, Drehem (1992), S. 322-323.

928 SRD 11 (18/v/Š 46) JSOR 13, S. 179 Nr. 48 ist möglicherweise ein Duplikat, der Text ist praktisch identisch, JSOR 13 verzeichnet nur ein Schaf mehr.

929 CT 7, 19 (AS 6), Bericht über große Mengen Wolle unterschiedlicher Qualität von verschiedenen Hirten wird als „Wolle der Ea-niša“ aufgeführt; BM 18299 (AS 2), Bericht über die Herden der Ea-nisa in Girsu, unpubliziert, Sigrist, Figulla, Walker, Catalogue of the Babylonian Tablets in the British Museum, Vol. II; ITT II, 747 (AS 9) = TCTI 1, 1989; Häute von toten Schafen der Ea-niša. Dazu wohl auch BM 21986 über Lederobjekte von den Schafen der Ea-niša, unpubliziert, Sigrist, Figulla, Walker, Catalogue of the Babylonian Tablets in the British Museum, Vol. II.

930 AUCT I, 162 (iv/ŠS 1): 2 Rinder; AUCT I, 79 (x/ŠS 1): 4 Rinder; BIN III, 555 (ii/ŠS 2): 3 Rinder, 60 Schafe/Ziegen; MVN 15, 287 (x/ŠS 2) 3 Rinder, 120 Schafe/Ziegen. 
Ea-niša nach dem Tod Šulgis weiterhin in enger Beziehung zum Hof stand, und dabei über einen eigenen Haushalt und Besitz verfügen konnte. Ob die als sá$\mathrm{du}_{11}$ gekennzeichneten Lieferungen zur Zeit Šu-Suens auf eine Veränderung der wirtschaftlichen Grundlagen der Ea-niša hindeuten oder nur eine Veränderung im Urkundenformular darstellen, vermag ich derzeit nicht zu entscheiden.

Kultische Tätigkeiten der Ea-niša sind kaum zu fassen. Ein Text aus Umma verzeichnet Getreidelieferungen verschiedener Personen, darunter der Ea-niša, an Šara, den Hauptgott von Umma ${ }^{931}$. Der Anlaß dieser Ausgabe ist nicht bekannt, und da bisher keine weiteren Belege für eine Beziehung der Ea-niša zu Umma vorliegen, ist erstens nicht sicher, ob es sich bei der in diesem Text genannten Person um die Nebenfrau Šulgis handelte und in welchem Kontext diese Gabe von Getreide an Šara zu sehen ist.

In zwei Texten aus Puzriš-Dagān erhält Ea-niša zusammen mit anderen Personen Vieh, wobei zugleich auch Tiere für Opfergaben verzeichnet werden ${ }^{932}$. Die Erwähnung der Gottheiten Enlil-Ninlil in OIP 121, 276 läßt auf Opfer in Tummal schließen ${ }^{933}$, bei denen Ea-nisa zusammen mit anderen Damen wie der Frau des Lu-Nanna und der Tūlid-Šamšī, ni n-dig ĝir des Suen, Rinder und Kleinvieh erhielt. Ob Ea-niša zu derartigen Anlässen selber Opfergaben spendete und bestimmte Riten vollzog, oder ob sie als Angehörige des Hofes am Festgeschehen teilnahm und in diesem Zusammenhang ebenso wie andere Personen königliche Geschenke empfing, ist bisher nicht endgültig zu entscheiden. Da jedoch kein Text explizit Opfer der Ea-niša erwähnt, möchte man davon ausgehen, daß sie als königliche Nebenfrau zwar an religiösen Festen teilnahm, jedoch nicht aktiv am Vollzug der Kulthandlungen beteiligt gewesen ist.

\section{Ninkalla}

Die Dokumentation für Ninkalla ist weniger eindeutig als jene für die anderen Gemahlinnen Šulgis. Es sind eine Reihe von Texten aus verschiedenen Fundorten erhalten, in welchen der Personenname „Ninkalla“ auftritt. Diese stammen aus Puzriš-Dagān, Umma, Nippur und Girsu und datieren in die Zeit

\footnotetext{
931 AAICAB I/1, P1. 40 Ashm. 1911-230 (Datum abgebrochen).

932 OIP 121, 276 (15/ix/AS 5); UTI VI, 3757 (Datum abgebrochen).

933 Sallaberger, Der kultische Kalender (1993), S. 136-139 und Tab. 41. Problematisch ist die Datierung von OIP 121, 276 auf den neunten Monat, da das Tummalfest üblicherweise im siebten oder achten Monat gefeiert wurde.
} 
zwischen $\breve{S} 35^{934}$ und IS $1^{935}$. Das bedeutet, eine Frau namens Ninkalla ist über einen Zeitraum von rund 30 Jahren belegt, was prinzipiell nicht gegen die Annahme spricht, es handele sich bei allen Quellen um dieselbe Person. Jedoch ist „Ninkalla“ (Die Schwester ist kostbar) ein nicht ganz seltener Frauenname in dieser Zeit, und einige Texte, in denen sich dieser Name findet, beziehen sich mit Sicherheit nicht auf die Dame aus der königlichen Familie ${ }^{936}$.

Eine weitere Schwierigkeit liegt in der Orthographie des Personennamens selber, welcher zumeist $\mathrm{Nin}_{9}-\mathrm{kal}-1 \mathrm{a}$, mitunter aber auch Nin-kal-1a geschrieben wurde ${ }^{937}$. Aufgrund der Ähnlichkeit der Zeichen hat Maekawa die Vermutung geäußert, daß bei älteren Autographien die Zeichenform von den Kopisten/Bearbeitern mitunter nicht korrekt wiedergegeben wurde ${ }^{938}$. Darüber hinaus scheinen auch die antiken Schreiber nicht immer genau zwischen den einzelnen Zeichen unterschieden zu haben, bzw. es können sich auch schon in dieser frühen Zeit die Bedeutungsunterschiede verwischt haben. ${ }^{939}$. So findet sich in vier Texten aus Nippur über die Annahme von Wolle durch eine Ninkalla im Jahr AS 8 einmal die Schreibvariante Nin-kal-1a und dreimal $\mathrm{Nin}_{9}-\mathrm{kal}^{-1} \mathrm{a}^{940}$.

Im Folgenden sollen die Quellen zu Ninkalla erst nach Fundorten getrennt vorgestellt werden, wobei Texte, welche sich eindeutig auf Frauen dieses

934 Barton HLC I Pl 3, HLb 17 (Š 35); Rinder im Besitz der Ninkalla in Girsu. Unsicher ist, ob der Text Contenau, Umma 70 (vii/Š 34) sich auf die Dame Ninkalla bezieht, oder ob es sich bei der Lieferantin von Rohrbündeln um eine andere Person handelte.

935 MVN 15, 118 (11/v/IS 1); eine Ninkalla ist unter den Empfängern von Gaben für das NE. NE- $\hat{g}$ ar -Fest.

936 So z.B. SAT III, 1507 (22/xi/ŠS 4, aus Umma), wo eine Ninkalla, Arbeiterin in der Mühle (g e me $e_{2}-k i k k e n$ ), eine Getreideration empfängt, oder TENS 360 (undatiert, aus Umma), wo eine Ninkalla unter den Textilarbeiterinnen (uš-bar) als Empfängerin eines Gewandes geführt ist. Auch bei der in RA 19, 192 Nr. 8 (-/vi/Š 45) genannten „Ninkalla, Kind des Ensi“ dürfte es sich um eine andere Person dieses Namens handeln.

937 Maekawa, The Agricultural Texts of Ur III Lagash of the British Museum (V), ASJ 9 (1987), S. 104-109.

938 Maekawa, ebd. S. 105. Siehe dazu Borger, Mesopotamisches Zeichenlexikon, Nr. 886: nin $_{9}=$ MUNUS-KU, Nr. 887: NIN = MUNUS-TÚG. Deutlich wird die Schwierigkeit anhand der Texte PDT I, 341, 434 und 581, in denen der Personenname Ninkalla in der Edition Nin-kal-la gelesen wurde, die Kollationen von Gomi ergaben jedoch in allen drei Fällen die Lesung $\mathrm{Nin}_{9}-\mathrm{kal-1a}$ (Gomi, Neue Kollationen zu den Texten PDT, I, Orient 24 (1988), S. 108-123).

${ }_{939}$ Immer vorausgesetzt, daß die publizierte Kopie des Textes die Zeichenform korrekt wiedergibt.

940 Nin-kal-1a TMH NF 1/2, 183; N in ${ }_{9}$-kal-1 a TMH NF 1/2, 184, 186, 188. 
Namens aus unteren gesellschaftlichen Schichten beziehen, nicht berücksichtigt werden. Im Anschluß daran soll versucht werden, die Belege für die der königlichen Familie angehörige Dame Ninkalla von denen zu trennen, welche sich auf eine andere Person desselben Namens beziehen, um schließlich ein Tätigkeitsprofil jener Ninkalla erstellen zu können, welche als Nebenfrau des Šulgi bekannt ist.

\subsection{Ninkalla in Texten aus Puzriš-Dagān}

In den Texten der staatlichen Buchhaltung von Puzriš-Dagān ist Ninkalla ab dem Jahr Š 36 zu finden ${ }^{941}$. In die Zeit nach Šulgi datieren nur zwei Texte, je einer aus der Regierungszeit von Amar-Suen und von Ibbi-Suen ${ }^{942}$, aus der Zeit Šu-Suens stammen Texte zu Ninkalla nur aus Umma und Nippur.

Bezüglich der Schreibweise des Namens ist für diesen Fundort festzuhalten, daß knapp die Hälfte der Texte „Nin - “ schreiben, womit PuzrišDagān der einzige Ort ist, wo die Schreibweise „Nin -“ und „N in ${ }_{9}$ - " nahezu ausgewogen verteilt sind, an allen anderen Orten überwiegt die Orthographie mit ,Nin ${ }_{9}$ - “.

Betrachtet man die Texte aus der Zeit von Šulgi, so zeigt sich, daß eine Ninkalla eindeutig eine Angehörige des Königshauses gewesen ist, und daß deren Aktivitäten denen der anderen Nebenfrauen vergleichbar sind.

Bisher ist kein Text bekannt, welcher einen Titel der Ninkalla als königliche Nebenfrau (lukur) enthielte, doch mehrere Quellen zeigen eindeutig die Zugehörigkeit dieser Dame zum Königshaus. So ist Ninkalla zusammen mit Simat-Ea und Ea-niša als Empfängerin von Gold- und Silberschmuck, Textilien und Butterschmalz anläßlich des Besuches des Königspaares im Haus des Šarrum-bāni aufgeführt ${ }^{943}$. Alle drei Damen werden unmittelbar nach der Königin Šulgi-simtī genannt, was ihren hohen Rang unterstreicht. Direkt nach dem König und seiner Nebenfrau Geme-Ninlila erscheint Ninkalla in dem Text ASJ 4, S. 133-134 Nr. 3 (ix/Š 43) als Empfängerin von Schafen, weswegen Michalowski, der den Text bearbeitet hat, die Vermutung äußerte, es handele sich bei Ninkalla wie auch bei den anderen in diesem Text erwähnten Damen um königliche Gemahlinnen ${ }^{944}$. Schon im Jahr Š 37 erhielt Ninkalla zusammen mit anderen hochrangigen Frauen, darunter der königlichen Lukur Geme-Ninlila, Luxusgegenstände, wobei die Gabe von einem Schekel Rotgold für Ninkalla die geringste

\footnotetext{
941 TLB III, 20 (ix/Š 36).

942 AUCT I, 287 (iii/AS 3); MVN 15, 118 (11/v/IS 1).

943 Philips 13 (-/xii/Š 47). Zu diesem Text siehe S. 171.

944 Michalowski, Royal Women - Part III, ASJ 4 (1981), S. 135-136.
} 
ausgegebene Zuweisung ist, die Frau des Narām-ilī, Geme-Ninlila und TaddinInanna erhielten jeweils wertvollere Gaben. ${ }^{945}$ Nach einem Text aus dem Schuharchiv empfing Ninkalla ebenso wie die Königin Šulgi-simtī ein Paar Stiefel aus grünem Leder $\left(1{ }^{k u s ̌ s} \text { suhub }_{2} \mathrm{du}_{8} \text {-ši-a é-ba-an }\right)^{946}$. Als Empfängerin von wertvollen Objekten und Luxusgegenständen im höfischen Kontext tritt Ninkalla also in Positionen auf, welche denen der anderen königlichen Gemahlinnen absolut vergleichbar sind.

Ebenso wie Geme-Ninlila nahm Ninkalla Schafe und Ziegen aus dem Bestand des Narām-ilī an, welche als „Lieferung für den König“ (mu-DU lugal) gekennzeichnet waren. ${ }^{947}$ Dabei erscheint Ninkalla einmal direkt in annehmender Funktion ( $\breve{\mathrm{u}} \mathrm{-}-\mathrm{ba}-\mathrm{ti})^{948}$, im anderen Fall werden die Tiere von Nin-hamati angenommen, während die Tafel mit der Formulierung „Siegel(urkunde) der Ninkalla (kišib $\left.\mathrm{Nin}_{9}-\mathrm{kal}^{-1 \mathrm{a}}\right)^{\text {“ }}$ gekennzeichnet ist ${ }^{949}$. Die Texte datieren in die beiden Monate vor dem Tod Šulgis am oder kurz vor dem 2/xi/Š $48^{950}$, Geme-Ninlila ist zuletzt am 23/ix/Š 48 aktiv (TRU 298). Möglicherweise hat Ninkalla in dieser Zeit Aufgaben der Geme-Ninlila innerhalb der königlichen Viehhaltung übernommen.

Wie andere Angehörige des Königshauses erhielt Ninkalla Vieh zugewiesen und war in das System des Güteraustausches der Šulgi-simtī eingebunden. So lieferte Ninkalla im Jahr Š 36 sechs Schafe und eine Ziege als $\mathrm{mu}$ - DU an die Königin ${ }^{951}$, sie selber erhielt knapp vier Jahre später eine Ente und fünf Tauben aus dem Bestand der Šulgi-simtī als „Proviant/ Ehrengeschenk" (igi-kár) ${ }^{952}$. Aus dem königlichen Viehhof wurden ihr einmal als „Proviant“ die große Menge von zwei Rindern, mehr als 50 Schafen

945 RA 17, S. 212 (xi/Š 37). Zu diesem Text siehe Michalowski, Royal Women of the Ur III Period. Part II: Geme-Ninlila, JCS 31 (1979), S. 172; van de Mieroop, Gold Offerings of Šulgi, Or NS 55 (1986), S. 147.

946 PDT I, 434 (viii/Š 41).

947 TCND 26 (ix/Š 48); OIP 115, 14 (x/S 48). Zu Geme-Ninlila als annehmende Person von $\mathrm{mu}-\mathrm{DU}-\mathrm{lug}$ al siehe S. 203.

948 TCND 26 (ix/Š 48).

949 OIP 115, 14 (x/S 48); die Verwendung dieser Phrase in den Wirtschaftstexten aus Puzriš-Dagān ist bisher noch nicht näher untersucht worden (Sallaberger, OBO 160/3 (1999), S. 231).

950 Am 2/xi/Š 48 sind erstmals Totenopfer für Šulgi belegt; Michalowski, The Death of Šulgi, Or NS 46 (1977), S. 225.

951 MVN 18, 2 (ix/Š 36).

952 OIP 115, 60 (13/vi/Š 40). Zum System des Güteraustausches bei Šulgi-simtī siehe oben S. 42-46 und S. 100-103. 
und 4 Ziegen ausgegeben ${ }^{953}$, wohl für eine Reise. Im Text findet sich die Formulierung „, igi-kár dag-ga-šè ( (Proviant (für die Reise) nach Dagga). Ein Ortsname „Dagga“ ist mir nicht bekannt, jedoch ist ein Ort namens Udagga (Ù-dag-ga) in mehreren Texten aus Girsu zu finden ${ }^{954}$ und möglicherweise hier gemeint. Der früheste Text zu Ninkalla belegt die Ausgabe von einem Rind und insgesamt zehn Schafen und Ziegen an sie wohl anläßlich eines Festmahls ${ }^{955}$. Jedoch ist die genaue Bedeutung der Phrase $\left(u_{4} d a g\right.$ ? níg $-b i ́-$ $\mathrm{gu}_{7}-\mathrm{a}$ ) nicht deutlich.

Bemerkenswert ist die Lieferung von insgesamt 34 Rindern und Eseln, die über Narām-ilī für Ninkalla eingebracht und von Urmes angenommen wurden ${ }^{956}$. Die Tiere werden als „Besitz“ (ní $\mathrm{g}-\mathrm{gur}_{11}$ ) der Söhne des Abili und des Mama-kešda, sowie der Tochter des Mama-kešda bezeichnet ${ }^{957}$. Auch hier ist wieder eine Frau unter den Lieferanten für eine der Damen des Hofes. Auffällig ist an diesem Text, daß unter anderem Esel und Jochrinder genannt werden, Tiere, die sonst nicht im Kontext der königlichen Frauen auftreten. Auch werden die Jungtiere genau nach Geschlecht und Alter differenziert. Insgesamt werden für Ninkalla (mu Nin ${ }_{9}-\mathrm{kal}-1 \mathrm{a}-\mathrm{s}$ è $) 12$ Jochrinder $\left(\mathrm{g} \mathrm{u}_{4}\right.$ g $\mathrm{i}$ š), 1 einjähriges Rind ( $\left.\mathrm{gu}_{4}-\mathrm{mu}-1\right), 7$ geschlechtsreife Kühe (áb-AL), 1 zweijährige Kuh (áb-mu-2), 3 säugende, weibliche Kälber (3 áb-amarga), 3 Joch-/Pflugesel ( $3 \mathrm{dusu}_{2}-\mathrm{nita}_{2}$ - $\mathrm{g}$ i š), 1 säugendes Eselhengstfohlen ( $1 \mathrm{dusu}_{2}$-nita $\mathrm{n}_{2}$-amar-ga), 5 geschlechtsreife Eselstuten (5 dusu $\mathrm{d}_{2}-\mathrm{sal}$ $\mathrm{AL})$ und 1 säugendes Eselstutfohlen ( $1 \mathrm{dusu}_{2}$-sal-amar-ga) verbucht. Diese Zusammenstellung der Tiere weist darauf hin, daß es sich um Rinder und Esel handelte, welche in der landwirtschaftlichen Produktion, der Zucht und der Feldarbeit, eingesetzt werden sollten. Da die Tiere für Ninkalla in die königliche Verwaltung aufgenommen wurden, ist davon auszugehen, daß Ninkalla über entsprechende landwirtschaftliche Betriebe verfügte, in denen diese Tiere eingesetzt werden sollten. Produkte dieser Betriebe, nämlich Öl, Käse und die Häute von Rindern, Schafen und Ziegen der Ninkalla wurden als $\mathrm{mu}$-DU-Lieferung von der königlichen Verwaltung verbucht $\mathrm{t}^{958}$.

Wie die anderen bedeutenden Frauen des Hofes verfügte auch Ninkalla

953 OrSP 18, 17 (9/ix/Š 48).

954 Meakawa, The Agricultural Texts of Ur III Lagash of the British Museum (IX), ASJ 15 (1993), S. 119.

955 TLB III, 20 (ix/Š 36).

956 PDT I, 341 (iv/Š 44) mit Koll. von Gomi, Orient 24, S. 113.

957 Zur Herkunft von Tieren aus dem „Besitz“ von Personen im königlichen Viehhof von Puzriš-Dagān siehe Sallaberger, Der kultische Kalender (1993), S. 27.

${ }_{958}$ PDT I, 581 (xii/Šs 48). 
über eigenes Personal. Derzeit ist der Koch Lugal-sisa ${ }^{959}$, der Viehmäster Ur${ }^{\mathrm{d}} \mathrm{Ba}^{\prime} \mathrm{u}^{960}$ und die Sängerin Taddin-KI.ZA ${ }^{961}$ nach den Texten aus Puzriš-Dagān als Dienerschaft der Ninkalla bekannt. Ein Text aus Umma, in welchem Viehbestand in Ur aufgeführt ist, nennt darüber hinaus einen Ur-zikumma, Viehmäster der Ninkalla. ${ }^{962}$

Ur-Suen, der Bruder der Ninkalla, ist ebenfalls in das System der staatlichen Viehverwaltung eingebunden. Zwei Texte nennen ihn als Lieferanten von Lämmern als mu-DU ${ }^{963}$. In beiden Texten wird Ur-Suen als „Bruder der Ninkalla“ (šeš Nin-kal-1a) bezeichnet, es wird sich folglich um eine andere Persönlichkeit handeln als bei dem Prinzen Ur-Suen, welcher als šagina in Uruk stationiert war $^{964}$, denn dieser würde als „Sohn des Königs“ (dumu-lugal) tituliert werden. Jener Bruder der königlichen Nebenfrau Ninkalla wird wie auch Babati, Bruder der Abī-simtī, über die ranghohe Schwester und nicht über den Vater identifiziert.

Abiati, der Sohn einer Ninkalla, wird in AUCT I, 537 (vi/Š 41) als Empfänger von Gerste genannt. Wenn dieser Abiati der Sohn des Königs und der Ninkalla ist, wäre zu erwarten, daß er als „Sohn des Königs“ und nicht als „Sohn der Ninkalla“ bezeichnet würde. Aus diesem Grund ging Maekawa davon aus, daß die in AUCT I, 537 genannte Dame Ninkalla nicht mit der gleichnamigen Angehörigen des Königshauses von Ur identisch sei ${ }^{965}$. Kinder des Königs wurden üblicherweise in den Wirtschaftsdokumenten als solche bezeichnet. Ausnahmen von dieser Regel konnte es geben, wenn die Mutter des Kindes die amtierende Königin war ${ }^{966}$. Gegen die Identifizierung der in AUCT I, 537 genannten Ninkalla mit der Nebenfrau des Königs spricht vor allem die

\footnotetext{
959 CTMMA I, $11 \mathrm{a}\left(\mathrm{v}^{\mathrm{II}}, \stackrel{\mathrm{S}}{\mathrm{S}} 44\right)$.
}

960 BIN III, 491 (v/Š 43).

961 DPOA E1, 37 = TrD 85 (ii/Š 47). Möglicherweise ist mit KI.ZA die im Enlil-Tempel in Nippur beheimatete Gottheit gemeint, ohne daß das Gottesdeterminativ geschrieben wurde; vgl Sallaberger, Der kultische Kalender (1993), S. 99, 102. Zu Taddin-KI.ZA siehe auch Hilgert, Akkadisch in der Ur III-Zeit (2002), S. 303 Anm. 59. Der Text AUCT I, 356 (Datum abgebrochen, Herkunft unklar) verbucht Gemüserationen für Sängerinnen der Ninkalla.

962 SAT II, 309 ( $\breve{S} 42)$.

963 Boson 328 (x/Š 43); TCND 55 (22/i/Š 47).

964 Zu dem Prinzen Ur-Suen siehe Sallaberger, OBO 160/3 (1999), S. 192; Michalowski, Dūrum and Uruk during the Ur III Period, Mesopotamia 12 (1977), S. 83-96.

965 Maekawa, The Agricultural Texts of Ur III Lagash of the British Museum (V), ASJ 9 (1987), S. 108.

966 Vgl. die in BIN III, 571 (5/xii/ŠS 4) erwähnte Tochter der Königin Kubātum; siehe dazu S. 156. 
Tatsache, daß die hier ausgegebenen Getreidemengen an Arbeiter wie Schiffer und Pflüger gehen. Die Erwähnung eines Angehörigen des Königshauses würde in diesem Kontext überraschen.

Aus der Regierungszeit von Amar-Suen und Ibbi-Suen ist jeweils nur ein Beleg zu Ninkalla aus Puzriš-Dagān bekannt, Quellen aus diesem Fundort aus der Zeit Šu-Suens fehlen. Im Jahr AS 3 erhielt Ninkalla ein gemästetes Rind zugewiesen. ${ }^{967}$ Alle anderen in diesem Text als Empfänger von Rindern genannten Personen gehören der obersten Gesellschaftsschicht des Reiches an, wie der Sukkal Iddin-Irra und der $\mathrm{zabar}-\mathrm{dab}_{5}{ }^{968}$. Deshalb ist davon auszugehen, daß die an zweiter Stelle genannte Dame Ninkalla die Nebenfrau des verstorbenen Königs Šulgi war. Ob die im Jahr IS 1 im Kontext des NE.NE- g ar-Festes von Nippur erwähnte Ninkalla ${ }^{969}$ jene aus der Zeit Šulgis bekannte Dame ist, muß unsicher bleiben. Bisher fehlt aus Puzriš-Dagān jegliche Dokumentation zu Ninkalla für die Jahre AS 4 bis ŠS 9. Der Text verbucht die Ausgabe von Schafen für verschiedene Gottheiten, darunter 2 Schafe für Nin-É-gal [xxx] Nin ${ }_{9}-k a l-1 a$ (VS 20-RS 1). Sallaberger schlug als Rekonstruktion von RS Z. 1 die Lesung ,[šà é?] Nin ${ }_{9}-\mathrm{kal}-1 \mathrm{a}$ “ vor $^{970}$. Auch wenn die Rekonstruktion zutreffend sein sollte, ist damit nicht zu klären, ob die erwähnte Ninkalla die Nebenfrau Šulgis ist oder eine andere Angehörige des Königshauses, die denselben Namen trug. Dies wäre nicht ungewöhnlich, wie das Beispiel der Prinzessin Šulgi-simtī zeigt, welche in fünf Texten aus der Zeit Šu-Suens und Ibbi-Suens belegt ist ${ }^{971}$.

In zwei Weihinschriften für Šulgi bezeichnet Ninkalla sich als „Ninkalla, Bewohnerin von Nippur, seine (S̆ulgis) Geliebte“ (Nin ${ }_{9}-\mathrm{kal}-\mathrm{la} / \mathrm{dumu}$ $\mathrm{Nibru}{ }^{\mathrm{ki}} / \mathrm{ki}$-á $\hat{\mathrm{g}}-\hat{\mathrm{g}} \mathrm{a}-\mathrm{ni}$ ). Die Inschriften befinden sich zum einen auf einem Gefäßfragment, welches in Ur im Hof des Mausoleums von Šulgi und AmarSuen gefunden wurde ${ }^{972}$, zum anderen auf einer altbabylonischen Sammeltafel,

967 den Siegeln der Vorsteher der Opferschauer Nannazišaĝal und Enlilzišaĝal, ZA 96 (2006), S. 178-184.

MVN 15, 118 (11/v/IS 1); siehe zu dem Text und seiner Einordnung in den Kontext des NE.NE-ĝ a r-Festes Sallaberger, Der kultische Kalender (1993), S. 125-126 sowie Such-Gutiérrez, Beiträge zum Pantheon von Nippur im 3. Jahrtausend (2003), Teil I S. 196.

970 Sallaberger, Der kultische Kalender (1993), S. 125.

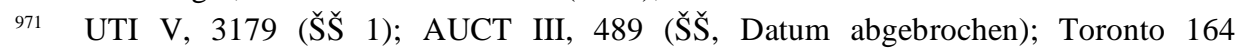
(20/vii/IS 1); UET 3, 116 (xii/IS 5); UET 3, 1211 (Datum abgebrochen).

972 RIME 3/2.1.2.83. 
welche vermerkt, der Text habe sich auf der Schulter einer Statue des Šulgi befunden $^{973}$. In jener Inschrift von der Schulter der Statue des Šulgi hält Ninkalla fest, daß sie die besagte Statue für ihn (Šulgi) gemacht habe (mudím). Ninkalla verfügte folglich über genug Kapital, eine solche Statue in Auftrag geben zu können.

\subsection{Ninkalla in Texten aus Nippur}

Eine kleine Gruppe von Texten aus Nippur verbucht die Annahme von Wolle durch eine Ninkalla. ${ }^{974}$ Da die königliche Dame Ninkalla sich in ihren Inschriften als „Bewohnerin von Nippur“ bezeichnet, läge der Schluß nahe, in diesen Wirtschaftsdokumenten aus Nippur jene Ninkalla aus dem Königshaus zu sehen. Allerdings datieren diese Nippurtexte alle in die Jahre AS 8 und ŠS 1 und nicht in die Regierungszeit Šulgis.

Die Identifikation der Ninkalla aus Nippur mit der Stifterin einer Statue für Šulgi kann mit hinreichender Wahrscheinlichkeit ausgeschlossen werden, da sich jene nippuräische Ninkalla auf ihrem Siegel als "geme ${ }_{2}{ }^{\mathrm{d}} \mathrm{Nin}$-urta “ bezeichnet ${ }^{975}$. Da die bisher bekannten Texte aus Nippur nicht aus dem Kontext der staatlichen Verwaltung stammen ${ }^{976}$, ist davon auszugehen, daß jene Ninkalla aus Nippur zum Personal des lokalen Ninurtatempels gehörte und dort im Bereich der Textilproduktion beschäftigt war ${ }^{977}$.

\subsection{Ninkalla in Texten aus Umma}

Eine kleine Gruppe von Texten aus Umma aus den Jahren Š 41 bis Š 44 zeigt Ninkalla nicht nur in höfischem Kontext im weiteren Sinne, sondern in unmittelbarer Nähe zum König. In diesen stets nur auf das Jahr datierten Texten werden zum einen Gold und Silber als máš-da-re/re ${ }_{6}$-a-Abgabe an

973 RIME 3/2.1.2.84; der Name der Ninkalla ist in diesem Text zur Hälfte abgebrochen.

974 TMH NF 1/2, 183 (12/vi/AS 8); TMH NF 1/2, 184 (15/vii/AS 8); TMH NF 1/2, 186 (9/viii/AS 8); TMH NF 1/2, 188 (25/xii/AS 8); TMH NF 1/2, 204 (10/iv/ŠS 1). Ninkalla findet sich auch in folgenden Texten aus Nippur: TMH NF 1/2, 239 (30/?/ŠS), Ninkalla als Lieferantin von Textilien; AUCT II, 118 (19/iii/-), Ninkalla nimmt s á- $\mathrm{du}_{11}$ an.

975 TMH NF 1/2, Siegel 100.

976 Sallaberger, OBO 160/3 (1999), S. 330-331.

977 Die Weberei in Nippur hatte keinen großen Umfang und konnte wahrscheinlich nicht einmal den lokalen Bedarf an Textilien vollständig decken. Waetzoldt, Textilindustrie (1972), S. 100; Such-Gutiérrez, Beiträge zum Pantheon von Nippur im 3. Jahrtausend (2003), Teil I S. 168f. 
den König und an Ninkalla verbucht ${ }^{978}$, zum anderen werden Bier und große Mengen verschiedener Tiere für ein Bierausschenken des Königs und der Ninkalla bereitgestellt ${ }^{979}$.

Bei den als máš-da-re-a bezeichneten Lieferungen handelt es sich, wie Sallaberger gezeigt hat, um Abgaben an den König und andere Angehörige der königlichen Familie, nicht um Opfergaben, da in den Urkunden über die Lieferung von Waren als máš-da-re-a niemals die Namen von Gottheiten auftreten. ${ }^{980}$ Die genauen Verwendungszwecke der Gold- und Silbergaben an den König und Ninkalla sind nicht zu bestimmen, da die Texte nicht auf den Monat genau datiert sind und selber kein konkreter Anlaß für die geleisteten Abgaben festgehalten wurde. Da máš-da-re-a-Lieferungen aus Ur und Girsu wie auch aus Umma überwiegend für eines der drei Hauptfeste von Ur, das Akiti zur Ernte (i. Monat), das Akiti zur Aussaat (vii. Monat) und das ezem-mah (x. Monat), bestimmt waren ${ }^{981}$, kann vermutet werden, daß auch jene Lieferungen an den König und an Ninkalla im Kontext eines dieser Feste zu betrachten sind. Im Jahr Š 41 erhielt Ninkalla insgesamt zehn Schekel Gold in zwei verschiedenen Qualitätsstufen, sowie eine Mine Silber für einen Ring ${ }^{982}$, im Folgejahr empfing sie sieben Schekel Gold, in zwei Qualitätsstufen ${ }^{983}$. Auch die Gold- und Silbermengen, welche an den König ausgezahlt wurden, sind in Qualität und Menge genau bestimmt und liegen in der Menge über den an Ninkalla ausgezahlten Quantitäten.

Bemerkenswert ist im Zusammenhang dieser maš-da-re ${ }_{6}$-a-Lieferungen, daß Ninkalla die Edelmetalle von Ninmelam, der Frau des Ur-Lisi, des

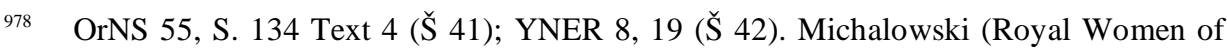
the Ur III Period. Part II: Geme-Ninlila, JCS 31 (1979), S. 172 Anm. 8) erwähnt einen weiteren, noch unpublizierten Text über máš-da-re-a-Lieferungen an den König und Ninkalla.

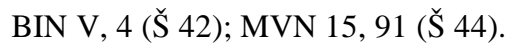

980 Sallaberger, Der kultische Kalender (1993), S. 169.

981 Sallaberger, Der kultische Kalender (1993), S. 169.

982 OrNS 55, S. 134 Text 4 (ك̌ 41) Z. 1-10: 3 gín kù-sig 17 20-ta/kù-bi 1 ma$\mathrm{na} / \mathrm{n} 1$ ĝ-buru $14-\mathrm{da} \mathrm{ku}_{4}-\mathrm{ra} / 2$ gín kù-sig $20-\mathrm{ta} / \mathrm{kù-bi} 2 / 3 \mathrm{ma}-\mathrm{na} / 5$ gín kù-sig 17 - $10 / \mathrm{a}$ ù-bi $5 / 6 \mathrm{ma}-\mathrm{na} / 1 \mathrm{ma}-\mathrm{na}$ kù-babbar ha aršè/maš-da-re ${ }_{6}-\mathrm{a} \mathrm{Nin}_{9}-\mathrm{kal}-1 \mathrm{a} / \mathrm{g}$ iri ${ }_{3} \mathrm{Nin}-\mathrm{me}-\mathrm{lám}$ (3 Schekel Gold (sein Wert in Silber ist das) 20-fache/sein Wert in Silber ist 1 Mine/es kam mit der Ernte/2 Schekel Gold (sein Wert in Silber ist das) 20-fache/sein Wert in Silber ist 2/3 Minen/5 Schekel Gold (sein Wert in Silber ist das) 10-fache/sein Wert in Silber ist 5/6 Minen/1 Mine Silber für einen Ring/maš-da- $\mathrm{re}_{6}-\mathrm{a}-$ Abgabe für Ninkalla (Überbringer war Ninmelam).

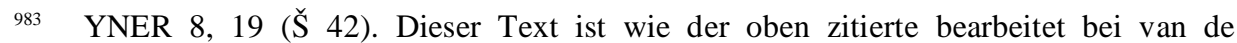
Mieroop, Gold Offerings of Šulgi, OrNS 55, S. 134-137 Text 4 und 5. 
Ensi von $\mathrm{Umma}^{984}$, erhielt. Der König empfing die für ihn bestimmten Zahlungen von Akalla, welcher in Umma für verschiedene Abgaben zuständig war. ${ }^{985}$ Auch wenn Ninkalla nicht die amtierende Königin war, so zeigt sich auch bei einer königlichen Nebenfrau, die in öffentlicher Funktion auftrat, die Trennung von Männer- und Frauenwelt. Akalla zahlte nicht gesammelt die anstehenden Abgaben an die verschiedenen Angehörigen des Königshauses aus, sondern nur an den König, während die Frau des Ensi verantwortlich war für die Übergabe von Gold und Silber an die Gemahlin des Königs.

Über die Verwendung der Edelmetalle kann nur spekuliert werden. Denkbar sind die Verwendung als Gaben an die Götter, welche im Zusammenhang mit einem der Hauptfeste von Ur Geschenke erhielten. Ebenso ist es möglich, daß die Metalle zu Schmuckstücken verarbeitet wurden, welche bei einem Empfang oder Gastmahl, einem Bierausschenken (kaš-dé-a) anläßlich des religiösen Festes an andere Angehörige des Hofes oder auswärtige Gäste verschenkt wurden.

Zwei ebenfalls nur auf das Jahr datierte Urkunden aus Umma verbuchen Ausgaben für zwei solche Bierausschenken des Königs und der Ninkalla ${ }^{986}$. Auch bei diesen Urkunden findet sich kein Hinweis darauf, aus welchem Anlaß das Bierausschenken stattfand und wer möglicherweise damit geehrt werden sollte. Ein Hinweis auf die zeitliche Einordnung des Textes BIN V, 4 ( ̌̌ 42) im Jahresverlauf könnte der Eintrag „Erstlingsgabe für Enlil “ (nesa $\hat{g}{ }^{\mathrm{d}}$ En-1í1lá-š è) (Z. 46) geben. Derartige Gaben für Enlil und Ninlil und den Unterhalt der Tempel in Nippur wurden zum Jahreswechsel, möglicherweise auch in einem halbjährigen Rythmus, zu Beginn des ersten und des siebten Monats, gezahlt. ${ }^{987}$ Somit ist es denkbar, daß das große Bierausschenken des Königs und der Ninkalla in Ur anläßlich des Akiti-Festes zur Aussaat im siebten Monat stattgefunden haben könnte. Ein anderer möglicher Anlaß ist das im selben Monat gefeierte Tummalfest, zu dem ein königliches Bierausschenken veranstaltet wurde ${ }^{988}$. Für diese letztgenannte Interpretation könnte die Tatsache sprechen, daß Ninkalla sich in ihren Inschriften als ,seine (Šulgis) geliebte Bewohnerin von Nippur “989 bezeichnet, doch sind diese Inschriften allein kein ausreichender Beleg für eine zweifelsfreie Zuordnung des in BIN V,

${ }_{984} \mathrm{Zu}$ dieser Dame siehe Parr, Ninhilia: Wife of Ayakala, Governor of Umma JCS 26 (1974), S. 92.

985 Sallaberger, Der kultische Kalender (1993), S. 170.

BIN V, 4 (Š 42), Ausgabe von großen Mengen Rinder, Schafe und Ziegen; MVN 15, 91 (Š 44) Ausgabe von Bier unterschiedlicher Qualität.

987 Sallaberger, Der kultische Kalender (1993), S. 154-155.

988 Sallaberger, Der kultische Kalender (1993), S. 143-144.

989 RIME 3/2.1.2.83 und RIME 3/2.1.2.84. 
4 genannten königlichen Bierausschenkens in den Kontext des Tummalfestes. Bemerkenswert ist bei diesen Bierausschenken, daß sie vom König und Ninkalla gemeinsam veranstaltet wurden. Die Bierausschenken der Königinnen werden stets von diesen allein bestritten.

Der überwiegende Teil der für dieses Festmahl benötigten Tiere, mehr als 100 Rinder und über 1500 Schafe und Ziegen, stammte aus den balaLieferungen aus Nippur und Ur. Mit b al a ${ }^{990}$ wird ein komplexes System der Verteilung von und Verfügung über verschiedene Güter wie Tiere, Holz, Getreide und anderes bezeichnet. Dabei konnte sowohl der König als auch auf Provinzebene der Ensi bestimmte als $\mathrm{b}$ ala bezeichnete Pfründe an Einzelpersonen vergeben. Ein Inhaber solcher Pfründe empfing entsprechend seinem Amt (bala) bestimmte Güter, war aber auch verpflichtet, bestimmte, ebenfalls als bala bezeichnete Lieferungen an den königlichen Haushalt abzuführen. Je nach der Finanzkraft der einzelnen Inhaber eines solchen balaAmtes wurden diese Abgabeverpflichtungen nur für einzelne Tage im Monat, oder aber auch, wie im Fall des Ensi von Girsu, für mehrere Monate im Jahr übernommen. Aus den bala-Abgaben an den König wurden sowohl die Ausgaben für den Unterhalt des Hofes wie auch Opfer in den verschiedenen Tempeln des Landes bestritten.

Es stellt sich die Frage, welchen gesellschaftlichen Rang Ninkalla bei diesen Festen von Ur und Nippur hatte, anläßlich derer sie gemeinsam mit dem König Edelmetalle erhielt sowie mehrfach ein Bierausschenken veranstaltete. Nach den bisher besprochenen Quellen nahm Ninkalla die Position einer königlichen Nebenfrau ein. Bei den Feierlichkeiten in Ur und Nippur konnten offensichtlich nicht nur König und Königin als Gastgeber eines Bierausschenkens auftreten, sondern auch andere Gemahlinnen des Königs als ausrichtende Persönlichkeit in Erscheinung treten. Dies muß nicht bedeuten, daß Ninkalla in den Jahren $\breve{S} 41$ bis $\breve{S} 44$, aus denen die oben besprochenen Texte stammen, die Position einer Favoritin des Königs eingenommen haben muß. Auch die Vermutung van de Mieroops, sie sei ab dem Jahr Š 41 zur führenden Gemahlin Šulgis in Umma geworden ${ }^{991}$, ist nicht überzeugend, betrachtet man die zeitgleichen Quellen zu Šulgi-simtī, welche keinen Hinweis auf eine Schwächung der Position der Königin enthalten.

Möglicherweise kann der Befund der Quellen dahingehend interpretiert werden, daß sowohl die Königin wie auch die Nebenfrauen bestimmte

\footnotetext{
990 Zum bala-System siehe Hallo, A Sumerian Amphictyony, JCS 14 (1960), S. 88-114; Steinkeller, The Administrative and Economic Organization of the Ur III State, SAOC 46 (1987), S. 27-30; Sigrist, Drehem (1992), S. 339-356; Sallaberger, Der kultische Kalender (1993), S. 32-34; Sharlach, Provincial Taxation and the Ur III State (2004).

991 van de Mieroop, Gold Offerings of Šulgi, OrNS 55 (1986), S. 148.
} 
Pflichten wahrzunehmen hatten, daß aber auch einzelne Aufgaben von unterschiedlichen Frauen ausgeführt werden konnten. So war es möglich, daß auch Ninkalla beim Bierausschenken repräsentative Pflichten an der Seite des Königs wahrnahm. Ob dies gleichsam in Vertretung der Königin geschah, oder ob diese zur selben Zeit anderen Pflichten nachzukommen hatte, hier also eine Aufgabenteilung der königlichen Frauen vorliegt, ist derzeit nicht zu entscheiden.

In mehreren Umma-Texten aus der Zeit nach Šulgi wird eine Ninkalla als Empfängerin von Lebensmittel- oder Textilrationen aufgeführt. Hier ist jeweils keine Verbindung zur königlichen Familie zu beobachten, es wird sich in allen Fällen um eine oder auch verschiedene Frauen aus untergeordneten Gesellschaftsschichten handeln. ${ }^{992}$

\subsection{Ninkalla in Texten aus Girsu}

Schon zwei Jahre vor dem ersten Beleg zu Ninkalla in den Quellen aus PuzrišDagān ist sie in den Texten aus der Provinz Girsu zu finden ${ }^{993}$. Inhaltlich gehören alle Texte aus Girsu, in denen sie auftritt, zum Bereich Landwirtschaft und Viehzucht. Wie Abī-simtī besaß auch Ninkalla in der Provinz Girsu große Herden, doch anders als für Abī-simtī sind für Ninkalla nicht nur Schafherden ${ }^{994}$ sondern auch große Rinderherden ${ }^{995}$ nachzuweisen.

Andere Texte verbuchen Lieferungen von Bier $^{996}$ oder Getreide ${ }^{997}$, wobei

992 JCS 52, S. 47 Nr. 69 (vii/AS 5) Getreide für Ninkalla und eine Tochter; SNATBM 499 (ix/ŠS 4), Textilien für Sänger, darunter zwei Kinder einer Ninkalla; SAT III, 1507 (22/xi/ŠS 4), geringe Mengen an Getreide für verschiedene Personen, darunter eine Ninkalla; SAT III, 1684 (ii/ŠS 6), Bier von verschiedenen Personen geliefert; TENS 360 und 403 (undatiert), Textilrationen an Weberinnen; SAT III, 2183 (Datum abgebrochen), Brotrationen; SET 250 (undatiert), zwei Kinder einer Ninkalla als Empfänger von Rationen.

In der Gesellschaftsschicht der Arbeiter wurden Kinder zumeist zusammen mit den Müttern in den Rationenlisten geführt, für Töchter galt dies auch noch im Erwachsenenalter; siehe Waetzoldt, Die Situation der Frauen und Kinder anhand ihrer Einkommensverhältnisse zur Zeit der III. Dynastie von Ur, AoF 15 (1988), S. 40. OMRO 56, 09 ( ̌S 34) und Barton HLC I Pl 3, HLb 17 (ك̌ 35) sind die frühesten Belege. TLB III, 142 (ك̌ 47), Wolle von Schafen der Ninkalla; BPOA 2, 1889 (-/-/Š 46) Aufstellung über 416 Schafe der Ninkalla..

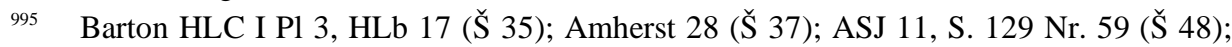
ITT II, 961 (AS 3 - ŠS 2); MVN 22, 108 (AS 4); BM 15308 (undatiert), (unpubliziert, Maekawa, ASJ 9, S. 107).

996 MVN 12, $136\left(\mathrm{xi}^{\mathrm{II} / \mathrm{S}} 46\right)$, Bier als Proviant für Ninkalla.

${ }_{997}$ ASJ 2, S. 31 Nr. 87 und CT 7, 27 (beide Š 42). 
das Getreide aus dem Ort Ú.URUxA ${ }^{\mathrm{ki}}$ bzw. Ú.URUxGU ${ }^{\mathrm{ki}}$ stammt. Der ähnliche Ortsname URUxA ${ }^{\mathrm{ki}}$ begegnet in TRU 126 (18/iv/AS 8), wo die Lieferung von Vieh als mu-DU für Abī-simtī durch Truppen $\left(\mathrm{erin}_{2}\right)$ aus diesem Ort vermerkt wird. Hierbei handelt es sich wohl stets um den gleichen Ort bzw. Landstrich Urua, welcher, in Elam gelegen, zum abgabenpflichtigen Randgebiet des Reiches von Ur gehörte ${ }^{998}$. Folglich erhielt nicht nur der König und seine Verwaltung Abgaben aus den Randgebieten des Reiches, auch die königlichen Frauen bezogen direkt Lieferungen aus diesen Regionen. Das Vieh und Getreide wurde in diesen Fällen nicht erst von der zentralen königlichen Verwaltung verbucht und von dort an die Frauen weiterverteilt, wobei die Herkunft der Naturalien nicht mehr von Bedeutung gewesen wäre, sondern es wurde direkt vermerkt, daß Teile der Lieferungen aus den Randgebieten des Reiches den hochrangigen Frauen zur Verfügung standen.

Es überrascht nicht, auch in den Quellen aus Girsu die Namen von Hirten und Funktionären, wie den des Magazinverwalters (ka-gur ${ }_{7}$ ) Urmes, zu finden, welche im Dienst der Ninkalla standen. ${ }^{999}$

Einen gänzlich neuen Aspekt bezüglich der wirtschaftlichen Verhältnisse der königlichen Damen bietet die undatierte Urkunde ASJ 9, S. 126 Nr. 57. Der Text listet die Ausgabe von Ländereien von Seiten des Königs an verschiedene Personen auf, darunter Nin $_{9}$-kal-la, Tochter des Lú-giri $i_{17}-Z a l$, Nin-hé-du ${ }_{11}$ und Nin-kal-la $n$ in. Nin-hé-du ${ }_{11}$ wird in diesem Text als Frau des Großwesirs (dam sukkal-mah) bezeichnet ${ }^{1000}$, und es ist anzunehmen, daß es sich bei ihr um die Tochter des Amar-Suens handelte ${ }^{1001}$. Die hochrangigen Frauen verfügten folglich nicht nur über Vieh, sondern auch über Land, welches sie vom König zur Verfügung gestellt bekamen (gán zi-ga lugal). ${ }^{1002}$ Offensichtlich konnten die Frauen aufgrund der Erträge ihrer Güter auch in das

$998 \mathrm{Zu}$ Urua siehe Steinkeller, The Administrative and Economic Organization of the Ur III State, SAOC 46 (1987), S. 36-40. Vgl. Edzard, Farber, Die Orts- und Gewässernamen der Zeit der 3. Dynastie von Ur, RGTC II (1974), S. 227, 238-239. Dahl vermutet, daß Ninkalla die Grundbesitzerin dieses Ortes gewesen sei. (The Ruling Family of Ur III Umma (2003) http://www.cdli.ucla.edu/staff/dahl/ dissertation.pdf (20.06.2007), S. 104 Anm. 256.

Die Namen verschiedener Hirten finden sich in den oben genannten Texten zum Viehbesitz der Ninkalla. Urmes, Magazinverwalter der Ninkalla, wird in TUT 155 (ک̌ 38-40? ) genannt.

Kol. III, Z. 13.

1001 CTMMA I, 17 (vii/AS 4), Kol I, Z. 28 nennt Nin-hé-du ${ }_{11}$ als eine der Töchter des Königs.

1002 AUCT I, 380 (undatiert, aus Girsu) nennt ein Feld der Königin vor dem Feld des Palastes. 
System der bal a-Abgaben eingebunden werden ${ }^{1003}$.

Auffallend ist, daß in ASJ 9, S. 126 Nr. 57 zwei Frauen namens Ninkalla auftreten, wobei Nin-kal-la den Titel ,n i “ “ trägt. Dies ist der einzige Text, in welchem der Titel „, nin“ mit dem Namen Nin-kal-la verbunden ist, in zwei anderen Texten aus Girsu steht ,n in “ mit dem Namen Nin -kal-la $^{1004}$. Geht man davon aus, daß alle Texte, die eine „Ninkalla n in “ erwähnen, sich auf dieselbe Person beziehen, so wäre dies ein Beleg dafür, daß schon in der Ur IIIZeit die semantischen Unterschiede der Zeichen ,nin “ (Herrin) und „nin ${ }_{9}$ “ (Schwester) auf der Schriftebene nicht mehr immer wahrgenommen wurden. Für diese Annahme spricht nicht nur der Befund der Texte aus Puzriš-Dagān, wo die Schreibung des Namens mit $\mathrm{nin}$ und $\mathrm{nin}_{9}$ nahezu 1:1 verteilt ist, sondern auch die Belege aus Umma, wo zwar zumeist die Zeichenvariante $\mathrm{nin}_{9}$ geschrieben wird, aber in identischem Kontext auch nin vorkommen kann $^{1005}$. In Girsu schließlich herrscht die Schreibweise nin ${ }_{9}$ vor, doch zeigt der Text ASJ 9, S. 126 Nr. 57, daß auch hier beide Schreibvarianten möglich waren.

Bemerkenswert ist insbesondere die Tatsache, daß Ninkalla in Girsu den Titel ,n in “ tragen konnte. Allgemein wird angenommen, daß dieser Titel stets nur von einer Frau aus dem Königshaus getragen wird, der amtierenden Königin. In der Zeit, zu der Ninkalla so tituliert wurde, war Šulgi-simtī und nach ihr Abī-simtī Königin. Diese Problematik wird im folgenden noch detailliert zu erörtern sein. ${ }^{1006}$

\subsection{Ergebnisse der Untersuchungen zu Ninkalla}

Die Dame Ninkalla ist als Angehörige des Königshauses in der Zeit von Š 35 bis AS 4 sicher nachzuweisen ${ }^{1007}$. Ihre Herkunft ist ungewiß, zumal kein Beleg

1003 TIM VI, 3 (xii/AS 1), Getreide als bala-Abgaben für den König, unter den Lieferanten ist auch eine $\mathrm{Nin}_{9}$-kal-la (Kol I, Z. 1-9).

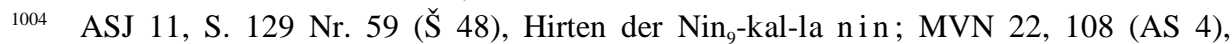

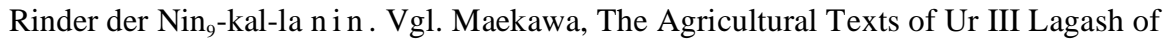
the British Museum (V), ASJ 9 (1987), S. 101-103.

1005 Texte über das Bierausschenken der Ninkalla; BIN V, 4 (̌̌ 42) schreibt nin ${ }_{9}$, MVN $15,91(\check{S} 44)$ schreibt n in.

1006 Zum Titel „n in “ siehe S. 235-237.

1007 Der früheste Text ist Barton HLC I Pl 3, HLb 17 (Š 35), der späteste MVN 22, 108 (AS 4). Da aus der zweiten Hälfte der Regierungszeit von Amar-Suen sowie aus der gesamten Amtszeit von Šu-Suen keine Belege der königlichen Dame Ninkalla sicher zugeordnet werden können, muß offen bleiben, ob sich MVN 15, 118 (11/v/IS 1) auf diese Frau bezieht, oder ob es sich um eine andere Angehörige des Königshauses handelt. 
über Opfer an die Götter mit Ninkalla zu verbinden ist und daher auch nicht anhand von persönlichen Gottheiten auf einen möglichen Herkunftsort geschlossen werden kann.

Alle Belege zu Ninkalla beziehen sich auf wirtschaftliche Vorgänge oder auf höfische Repräsentation wie den Austausch von Geschenken oder die Veranstaltung von Festen/Bierausschenken. Auch wenn diese Auftritte im höfisch-repräsentativen Kontext im Zusammenhang mit den großen kultischen Festen des Jahres, wie den Akiti-Festen von Ur, standen, so liegen doch keine Hinweise auf eine aktive Teilnahme der Ninkalla am kultischen Geschehen vor, wie dies für Šulgi-simtī und Abī-simtī der Fall ist.

Der hohe Rang der Ninkalla drückt sich sowohl in der Form ihres Auftretens am Hof, als Empfängerin von kostbaren Geschenken und als Gastgeberin neben dem König beim Bierausschenken, aus, wie auch in der Tatsache, daß ihre Brüder wie der Bruder der Abī-simtī nicht über den Vater, sondern über die ranghohe Schwester definiert werden ${ }^{1008}$. Es ist weiterhin davon auszugehen, daß Ninkalla wie die Königinnen über einen eigenen Haushalt verfügte. Dafür spricht die Erwähnung ihres Personals wie auch die Tatsache, daß Tiere „zum Ort der Ninkalla“ (ki Nin ${ }_{9}$-kal-la-šè) $)^{1009}$ geliefert wurden. Diese Formulierung entspricht der Phrase „zum Ort der Königin“"(ki -nin-šè) ${ }^{1010}$.

Nach der Analyse der Quellen zu der königlichen Dame Ninkalla ergibt sich ein Tätigkeitsspektrum, welches denen der anderen königlichen Gemahlinnen vergleichbar ist. In einigen Quellen aus Girsu trägt sie jedoch den Titel „n in “, ohne daß für sie eine Beteiligung am Kult, insbesondere dem Kult der großen Göttern des Landes nachzuweisen wäre. Nebenfrauen wurden üblicherweise nicht als „, n in “ tituliert, amtierende Königin zu jener Zeit war Šulgi-simtī. Somit stellt sich die Frage, in welchem Verhältnis Ninkalla zu Šulgi gestanden hat. Wenn sie eine leibliche Sschwester des Königs gewesenn wäre, müßte sie in den Quellen als Prinzessin/Tochter des Königs (du mu munus lugal) bezeichnet werden. Denkbar wäre es, Ninkalla als eine dem König persönlich besonders nahestehende Verwandte zu sehen, vielleicht gar eine Milchschwester, die leibliche Tochter der Amme des Königs. Doch da

1008 Neben den Texten aus Puzriš-Dagān, wo Ur-Suen als Lieferant von mu - DU -Tieren

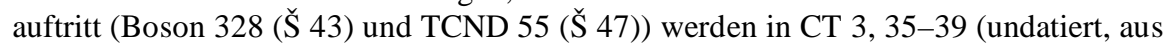
Girsu) drei Brüder der Ninkalla genannt, welche zu Arbeiten am Kanalsystem verpflichtet waren. Dies ist neben dem schon bekannten Ur-Suen (Kol. I, 26) ein Irĝu (Kol. I, 17) und Enlila der Koch (Kol. I, Z. 28). Zu den Geschwistern der Abī-simtī siehe oben S. 108. DPOA E1, 81 (undatiert, aus Girsu).

1010 Zum Haushalt der Königin siehe S. 169-176. 
dies vorerst rein spekulativ bleiben muß, soll Ninkalla hier als, möglicherweise bevorzugte, königliche Nebenfrau des Šulgi angesprochen werden.

\section{Ti'amat-bāštī}

Neben Abī-simtī und Kubātum war Ti'amat-bāštī (A-ab-ba-ba-aš-ti) die bedeutendste Frau am Hof von Šu-Suen. Nur wenige Texte geben Anhaltspunkte über ihre Herkunft und ihr Aufgabenspektrum, doch diese zeigen, daß Ti'amat-bāštī einen vergleichbar hohen Rang einnahm wie GemeNinlila und Ea-niša, die Nebenfrauen von Šulgi.

Mit großer Wahrscheinlichkeit stammte Ti'amat-bāštī aus Ninive ${ }^{1011}$, denn sie verehrte die hurritische Göttin $\breve{S} a(w)$ uška, eine Ištar-Gestalt ${ }^{1012}$. Diese Göttin ist in den Quellen der Ur III-Zeit nur sehr selten zu finden, fast alle Belege stammen aus der Regierungszeit von Šu-Suen ${ }^{1013}$. Dies legt den Schluß nahe, daß Ti'amat-bāštī im Zuge einer dynastischen Eheschließung aus Ninive nach Ur gekommen war und ihre Göttin mitgebracht hatte ${ }^{1014}$. Vergleichbar damit ist die Verehrung der Göttinnen Bēlat-Šuhnir und Bēlat-Deraban durch Šulgi-simtī, welche diese aus ihrer Heimat in der Gegend von Ešnunna mit nach Ur gebracht hatte. Für Ti'amat-bāštī sind anders als für Šulgi-simtī außer den Opfern für ihre persönliche Göttin Ša(w)uška keine Gaben an andere Gottheiten bekannt.

Wie alle anderen hochrangigen Frauen des Königshauses besaß auch Ti'amat-bāštī einen eigenen Viehbestand, wie aus TPTS 56 (iv/ŠS 8) hervorgeht, wo je 15 Schafe und Ziegen von Šulgi-bāni für das Haus des Viehmästers (é kurušda) der Ti'amat-bāštī angenommen wurden. Bei Šulgibāni handelt es sich möglicherweise um den gleichen Beamten, welcher sechs Jahre zuvor als šabra der Ea-niša auftritt ${ }^{1015}$. Damit läge hier die schon häufiger zu beobachtende Erscheinung vor, daß bestimmte Beamte, welche im

1011 Möglicherweise war sie eine Angehörige des Tiš-atal von Niniveh, Sallaberger, OBO 160/3 (1999), S. 161. Zu Tiš-atal siehe Whiting, Tiš-atal of Niniveh, JCS 28 (1976), S. 174-178; Collon, The Life and Times of Teheš-atal, RA 84 (1990), S. 132 und dazu Matthews/Eidem, Tell Brak and Nagar, Iraq 55 (1993), S. 203.

1012 BIN III, 382 und der Paralleltext OIP 121, 576 (17/xi/AS 9), 1 Schaf für Ša(w)uša, wegen Ti'amat-bāštī; SACT I, 172 (ŠŠ 1), 1 Lamm für Ša(w)uša (von) Ti'amat-bāštī.

1013 Neben den Texten, in denen sie im Kontext mit Ti'amat-bāštī erwähnt wird findet sich die Göttin in MVN 18, 79 (9/xii/Š 46), 1 weibliches Schaf für ${ }^{\mathrm{d}}$ Ša-u ${ }_{18}$-ša Ni-nu-a ${ }^{k i}$; Nik.

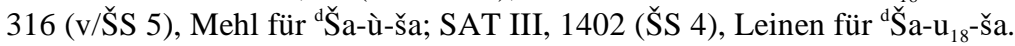

1014 Wilcke, A Note on Ti'amat-bāštī and the Goddess Š A(W)UŠ (K)A of Niniveh, DV 5 (1988), S. 22-23, 227; Sallaberger, OBO 160/3 (1999), S. 161.

1015 NISABA 8, 27 (ŠS 2-3). 
Dienst einer der königlichen Damen standen, später für eine andere hochrangige Angehörige des Königshauses arbeiteten. Šulgi-bāni veranlaßte auch die Lieferung von 600 Rohrbündeln an Ti'amat-bāštī. ${ }^{1016}$

Ti'amat-bāštī ist ist in einem Text als Empfängerin einer mu-DU-Lieferung bezeugt. In ASJ 19, S. 20723 (1/xi/AS 9) nimmt Intaea 2 gemästete Rinder und 20 Schafe an, die von Habru für Ti'amat-bāštī geliefert wurden. Der Wagenlenker (rá-gaba) Habru tritt bei der Lieferung eines Opfertieres für Ša(w)uška als Bevollmächtigter (maški m) auf ${ }^{1017}$. In einem anderen Fall gibt Intaea Kleinvieh aus, das als Rückstand (lá-ì) der Ti'amat-bāštī gekennzeichnet ist ${ }^{1018}$.

Im Zusammenhang mit der Viehwirtschaft steht noch ein weiterer Text, nach welchem Ti'amat-bāštī sechs weiße Schafe erhielt, ,als sie aus dem Magazin des Schafstalls herauskam" (6 udu-babbar A-A B-B A-ba-aš-t $t$ é-udu-šu-tum-ta è-a $)^{1019}$. Die genaue Bedeutung dieses Texes ist unklar, doch ist die explizite Erwähnung der Farbe der gelieferten Tiere bemerkenswert. Möglicherweise gehört der Text in einen Kontext mit den Besuchen von Šulgi-simtī und Abī-simtī beim Schafstall ${ }^{1020}$. Hier ist an die Durchführung bestimmter Riten für die Gesundheit, das Wohlergehen und die Fruchtbarkeit der Tiere zu denken.

Der hohe Rang der Ti'amat-bāštī unmittelbar nach Abī-simtī und Kubātum wird erkennbar an mehreren Texten, welche sie in unmittelbarer Nähe zu diesen beiden Damen zeigen. So erhielt Ti'amat-bāštī nach BIN III, 558 (17/x/ŠS 2) eine „regelmäßige Lieferung“ $\left(s a ́-d u_{11}\right)$ von Schafen. Der Text verzeichnet erst die Ausgabe von Tieren an die verstorbenen Könige Šulgi und Amar-Suen, gefolgt von Abī-simtī, Huaršitum, Kubātum und Ti'amat-bāštī sowie zwei weiteren Personen namens Unabatal und Zilili, außerdem werden Tiere für siskur ${ }_{2}$-Riten im Straußentempel (é-ga-nu $\left.{ }_{11}{ }^{m u s ̌ e n}\right)^{1021}$ ausgegeben.

Auch an dem bei Hofe üblichen Austausch wertvoller Geschenke beteiligte sich Ti'amat-bāštī, wie aus der Sammeltafel UTI VI, 3800 hervorgeht. Nach

1016 UTI V, 3495 (Datum abgebrochen), RS I, 1-4. Im selben Text veranlaßt Ti'amat-bāštī eine Lieferung an Kubātum, wobei nicht erhalten ist, um welche Güter es sich handelte (RS I Ende (abgebrochen) -II, 3). In beiden Fällen diente Ibni-Suen als Überbringer ( $\mathrm{g} \mathrm{iri}_{3}$ ).

1017 BIN III, 382 und der Paralleltext OIP 121, 576 (17/xi/AS 9).

1018 AUCT III, 428 (-/10/ŠS 6).

1019 PDT I, 244 (i/ŠS 1), dazu Wilcke, NABU 1990, 36.

1020 Zu Šulgi-simtī und dem „Gehen zum Schafstall“ siehe S. 88, zu Abī-simtī siehe S. 140.

1021 Zu Opfern im Straußentempel siehe Sallaberger, Der kultische Kalender (1993), S. 59. 
diesem Text schickte sie wie Kubātum einen Fingerring aus Rotgold an Ab̄̄simtī nach $\mathrm{Ur}^{1022}$, einer weiteren Person schickte sie zwei Dolche ${ }^{1023}$.

Eine Perle einer in Uruk gefundenen Kette aus goldgefaßten Achatperlen und kleinen Goldperlen trägt die Inschrift A - A B - B A-ba-áš-ti lu kur - ki -á $\hat{g}$ ${ }^{\mathrm{d}} \breve{S} \mathrm{u}-{ }^{\mathrm{d}} \mathrm{EN} . Z \mathrm{Z}$ lugal Uri ${ }_{5}{ }^{\mathrm{ki}}-\mathrm{ma-ka}$ (Ti'amat-bāštī, geliebte lukur des Šu-Suen, des Königs von Ur) ${ }^{1024}$.

Auch wenn die Zahl der Quellen zu dieser Gemahlin Šu-Suens geringer ist als das Material zu den Nebenfrauen von Šulgi, so lassen sich ihre gesellschaftliche Position am Hof von Ur und ihre wirtschaftliche Situation doch unmittelbar mit denen von Ea-niša und Geme-Ninlila vergleichen. Somit ist zu vermuten, daß auch Ti'amat-bāštī über eigene Dienerschaft und einen eigenen Haushalt verfügte, auch wenn dieses bisher nicht durch Textfunde verifiziert werden kann.

\section{Andere Nebenfrauen}

Die im vorangehenden besprochenen Nebenfrauen der Könige von Ur sind alle aus mehreren Belegen bekannt, was es erlaubt, ihre Tätigkeitsfelder am Hof zumindest in den Ansätzen zu verfolgen. Darüber hinaus kennt man die Namen einer Reihe weiterer königlicher Gemahlinnen, welche sich jedoch bisher nicht näher fassen lassen, da zumeist nur ein einziger Text über die jeweilige Dame und ihre Beziehungen zum König Aufschluß gibt.

Für Šulgi ist nur eine weitere Ehefrau sicher zu bestimmen. Die Dame Šuqurtum hat auf einem knapp $30 \mathrm{~cm}$ hohen Kalzitgefäß, welches in Ur im Énun-mah, einem Gebäude innerhalb des Tempelbezirkes des Nanna ${ }^{1025}$, gefunden wurde, eine Weihinschrift für Šulgi hinterlassen ${ }^{1026}$. In dieser Inschrift bezeichnet sie sich als ,seine (Šulgis) geliebte lukur“ (lukur-kiá $\hat{g}-\mathrm{g} a ́-n i)$. In der Fluchformel werden die Götter Ninsun und Lugalbanda, die göttlichen Eltern der Könige von Ur ${ }^{1027}$, angerufen, wobei die Göttin Ninsun

\footnotetext{
1022 UTI VI, 3800 (Datum abgebrochen), VS III, 23'-30'.

1023 UTI VI, 3800 VS IV, 19'-21'.

1024 Nöldeke et al., UVB 8, S. 23-24 und Taf. 39; Limper, AUWE 2, S. 63-66 und Taf. 21, 23-25; Braun-Holzinger, Mesopotamische Weihgaben (1991), S. 368 P 16; zu der Inschrift zuletzt RIME 3/2.1.4.29, dort auch weitere Literatur. Zu der an gleicher Stelle gefundenen Kette der Kubātum siehe oben S. 162.

1025 Charpin, Le clergé d'Ur (1986), S. 331.

1026 UET 1, 57 = RIME 3/2.1.2.85, der Personenname ist nicht vollständig erhalten, zu lesen ist $\breve{S} u$-qur-[...].

1027 Siehe S. 27.
} 
von Šuqurtum als ihre persönliche Gottheit $\left(\mathrm{di} \hat{\mathrm{g} i r}-\hat{\mathrm{g}} \mathrm{u}_{10}\right)$ angesprochen wird. In der Inschrift wird der Name des Königs noch ohne das Gottesdeterminativ geschrieben, der Text stammt also aus der ersten Hälfte der Regierung Šulgis ${ }^{1028}$. Dem entspricht, daß kein Wirtschaftstext bekannt ist, in dem die Dame Šuqurtum genannt wird, was sich daraus erklärt, daß aus der ersten Hälfte von Šulgis Regierungszeit kaum Verwaltungstexte erhalten sind. Šuqurtum war also eine der ersten Frauen des Königs und eine Zeitgenossin von Tarām-Uram, vielleicht auch noch von Geme-Suen.

Allgemein wird auch Simat-Ea (ME-Ea) zu den Frauen von Šulgi gerechnet ${ }^{1029}$. Diese Einschätzung beruht auf dem Text ASJ 4, S. 133-134 Nr. 3 (ix/Š 43), in welchem sechs hochrangige Frauen nach dem König Schafe zugewiesen bekommen. Von dreien dieser Damen ist der Titel und damit ihre Stellung gegenüber dem König bekannt. So ist Šulgi-simtī die zu jener Zeit amtierende Königin, Ninkalla und Ea-niša tragen den Titel einer lukur. Geme-Ninlila wird als Nebenfrau des Königs angesehen, da sie mit großer Wahrscheinlichkeit mit dem Königspaar bestattet wurde, sicher ist, daß sie zusammen mit Šulgi und Šulgi-simtī Totenopfer erhielt ${ }^{1030}$. Die beiden anderen Frauen sind Simat-Ea und Taddin-Eštar. Aufgrund des parallelen Auftretens von Simat-Ea und Taddin-Eštar in diesem Text vermutete Michalowski, es handele sich um zwei weitere Frauen von Šulgi. ${ }^{1031}$ Von Taddin-Eštar ist inzwischen bekannt, daß sie keine königliche Nebenfrau, sondern Tochter von Amar-Suen war $^{1032}$. Folglich ist auch die Annahme, Simat-Ea sei eine Gemahlin Šulgis gewesen, nicht zwingend. Für diese Annahme könnte die Position von Simat-Ea in dem Text Philips 13 angesehen werden, wo sie zusammen mit den Nebenfrauen Ninkalla und Ea-niša Schmuck, Textilien und Butterschmalz erhielt ${ }^{1033}$. Es wäre jedoch ebenso möglich, Simat-Ea als Prinzessin anzusehen, welche einen ähnlich hohen Rang innerhalb der Hierarchie unter den Frauen am Hof einnahm, wie Taddin-Eštar.

Andere Texte geben keinen weiteren Hinweis zur Stellung und Funktion der Simat-Ea am Hof. Sie ist für die Zeit von $\breve{S} 29$ bis Š $43^{1034}$ in den Quellen

1028 Die Vergöttlichung des Königs ist in der Zeit zwischen $\check{S} 10$ und $\check{S} 20$ anzusetzen, Sallaberger, OBO 160/3 (1999), S. 152.

1029 van de Mieroop, Women in the Economy of Sumer (1989), S. 59; Sallaberger, OBO 160/3 (1999), S. 183.

1030 ZVO 25, 134, 2 (28/iii/AS 1).

1031 Michalowski, Royal Women - Part III, ASJ 4 (1982), S. 135-136. van de Mieroop, Women in the Economy of Sumer (1989), S. 59.

1032 CTMMA I, 17 (vii/AS 4).

1033 Philips 13, III 26 - IV 6 (-/xii/Š 47).

1034 OIP 115, 16 (xi/S 29) ist der früheste, ASJ 4 (1982), S. 133-134 Nr. 3 (ix/Š 43) der 
zu finden. In drei Texten, die zum Archiv der Šulgi-simtī gehören, ist Simat-Ea als Empfängerin von Kleinvieh genannt ${ }^{1035}$. Zwei andere Texte erwähnen sie als Empfängerin von je einem Paar grüner Stiefel im Stil von Eban (1 ${ }^{\mathrm{k} u s ̌}{ }^{5} \mathrm{suhub} \mathrm{b}_{2} \mathrm{du}_{8}$-ši-a É-ba-an ${ }^{1036}$. Auf der Grundlage dieser Texte ist nicht abschließend zu entscheiden, ob Simat-Ea eine Frau oder eine Tochter des Königs gewesen ist.

Von Šulgis Nachfolgern sind insgesamt neun Nebenfrauen bekannt ${ }^{1037}$, welche alle den Titel lukur trugen. Zu jeder dieser Frauen gibt es derzeit nur einen Beleg, somit können über die Aufgaben und Funktionen, welche von den Damen erfüllt wurden, nur im Vergleich mit den besser dokumentierten königlichen Gemahlinnen einzelne Aussagen getroffen werden.

Als lukur von Amar-Suen sind folgende Frauen bekannt: Puzur ${ }_{4}$-ú-ša, Udat-șenat, Za-ga-an-bi und [...]-natum. Puzur $r_{4}$-ú-ša erhielt ein Schaf und eine Ziege zugewiesen ${ }^{1038}$, Udat-șenat empfing 13 Rinder $^{1039}$. Ein besonderer Anlaß für die Lieferungen wird nicht genannt. Za-ga-an-bi erhielt ebenfalls ein Schaf ${ }^{1040}$, der Grund für diese Ausgabe ist der „Tag ihres Eintretens“ ( $\mathrm{u}_{4} \mathrm{ku}_{4}$ ra-ni-a). Der Name der letzten bekannten lukur des Amar-Suen ist nicht vollständig erhalten. [...]-natum empfing im Rahmen von Feierlichkeiten zum 7. Tag im Monat des Akiti-Festes zur Aussaat mehrere Schafe, als sie in den Tempel der Išḩara ging ${ }^{1041}$. Die Göttin Išḩara wurde von den Königinnen Šulgisimtī und insbesondere von Abī-simtī verehrt ${ }^{1042}$. Bei den Opfern der [...]natum dürfte es sich um persönliche Gaben an die Göttin gehandelt haben, da

späteste Text.

1035 OIP 115, 16 (xi/S 29); MVN 18, 2 (ix/Š 36); SET 42 (v/Š 37) in diesem Text erhält Simat-Ea „Proviant” (i g i - kár).

1036 DPOA E1, 27 (xi/Š 34); PDT I, 593 (viii/Š 37). Beide Texte gehören zum Schuharchiv.

1037 Steinkeller, More on Ur III Royal Wives, ASJ 3 (1981), S. 84; van de Mieroop, Women in the Economy of Sumer (1989), S. 59-60; Sallaberger, OBO 160/3 (1999), S. 183. Die Damen Šalim-niaš, Geme-Nanna und Simat-Nisaba sind hier noch nicht aufgeführt.

1038 Nik. 484 (24/ix/AS 5).

1039 BIN III, 134 (1/iv/AS 7).

1040 SCT 24 = ASJ 4, S. 141 Nr. 6 (22/i/AS 8). Die Lesung des Personennamens Za-ga-anbi ist nicht abschließend gesichert, siehe Michalowski, Royal Women - Part III, ASJ 4 (1982), S. 137. Owen, FS Astour (1997) S. 390 liest statt „1 u d u Za-ga-an-bi lu k u r lugal" „1 udu $4 \mathrm{gu}_{4}$ ! DINGIR.BI lukur-lugal” und merkt an, daß der Text kollationiert werden sollte. Gegen diesen Vorschlag spricht, daß normalerweise Rinder vor Schafen verbucht werden.

1041 MVN 5, 113 (5/vii/AS 5).

1042 Zur Verehrung der Išḩara bei Abī-simtī siehe S. 132. 
eine Beteiligung der Nebenfrauen am Kult der großen Götter des Landes (Enlil, Ninlil, Nanna, Inanna) schon für die besser bekannten Damen wie GemeNinlila und Ea-niša nicht nachzuweisen ist. Ein einziger Text ist jedoch nicht ausreichend, um den Schluß zu ziehen, daß auch diese ansonsten umbekannte lu kur wie die Königin aus Syrien stammte.

Neben Tiamat-bāštī kennt man die Namen von drei weiteren lukur des Šu-Suen: Takūn-mātum, Šalim-niaš und Geme-Nanna ${ }^{1043}$. Auch über diese Frauen sind nur wenige Details bekannt. Für Takūn-mātum werden am 24/iv/ŠS 6 Totenopfer verbucht ${ }^{1044}$, zwei gemästete Schafe werden für ihren „Wassertränkort“ (ki-a-na ĝ) im Haus des Amur-ilī ausgegeben. Weshalb dieses Opfer im Haus des Amur-ilī, welcher bei der Transaktion auch als Bevollmächtigter (maškim) fungiert, stattfand, vermag ich nicht zu sagen. Vorstellbar wäre eine Verwandschaft zwischen Takūn-mātum und Amur-ilī, was einen Totenkult im Haus dieses Beamten erklären würde.

Šalim-niaš und Geme-Nanna sind als lukur des Šu-Suen durch Textpublikationen der letzten Jahre bekannt geworden. Beide Frauen treten im Kontext des Austausches von Luxusgegenständen am Hof auf. Geme-Nanna erhielt Schmuck aus Gold und Halbedelsteinen von Abī-simtî̀ ${ }^{1045}$.

Šalim-niaš schickte ebenso wie Kubātum und Ti'amat-bāštī einen Goldring an $\mathrm{Ab} \overline{\mathrm{I}}-\operatorname{sim}^{1046}$ :

UTI VI, 3800 VS III18'-31':

1 šu-gur kù-sig $17-$ hu šs-a

ki-lá-bi 1 gín

$\breve{S} a$-lim-ni-aš lukur lug al/k $\mathrm{e}_{4}$

Še-en-nam rá-gaba-ni-e

$B e-l i ́-k i-i n$ rá-g aba/maškim

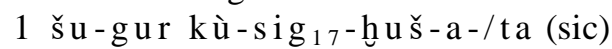

ki-lá-bi 1 gín-ta (sic)

$\mathrm{Ku}_{8}$-ba-tum-e

1 A-A B - B A -ba-áš-ti-a

šu in-na-an-ús -éš

Puzur $_{4}-i \check{s ̆}_{8}$-tár šu-i-e

1 Fingerring aus Rotgold sein Gewicht ist 1 Schekel (von) Šalim-niaš, der Lukur des Königs von Šennam, ihrem Boten Beli-kīn der Bote war Bevollmächtigter 1 Fingerring aus Rotgold sein Gewicht ist 1 Schekel haben Kubātum und Ti'amat-bāštī gesandt Puzur-Eštar, der Šu-i

1043 Steinkeller, More on Ur III Royal Wives, ASJ 3 (1981), S. 84 Anm. 44 nennt den unpublizierten Text A 5326 (10/xi/ŠS 8) mit der Erwähnung einer S UHU Š - k i - in lukur lugal, Sallaberger hält dies aufgrund des Namens für unwahrscheinlich (OBO 1602/3 S. 183 Anm. 209).

1044 ARRIM 2, S. 3. Z. 15-17.

1045 JCS 54, S. 7-9 Nr. 52 (Datum abgebrochen), RS II.

1046 UTI VI, 3800 (Datum abgebrochen), VS III18'-31'. 
A-bí-sí-im-ti-/r a

$\mathrm{Uri}_{5}{ }^{\mathrm{ki}}-\mathrm{s} \mathrm{è}$

ì-n a-an-túm-éš hat sie der Abī-simtī

nach Ur

geschickt.

Eine Person namens Šalim-niaš kommt auch in TCNY 120 und dem nahezu parallelen Text STA 16 vor $^{1047}$, doch ist aufgrund des Kontextes davon auszugehen, daß es sich hier um eine andere Person als die lukur des Königs handelt.

Seit kurzem ist auch für Ibbi-Suen eine Nebenfrau bekannt, eine Frau namens Simat-Nisaba (ME-Nisaba) wird in Zusammenhang mit Erdarbeiten an einem Kanal, die wahrscheinlich auf ihrem Land ausgeführt werden, als lu ku r lu gal genannt. ${ }^{1048}$

Aus diesen wenigen Zeugnissen wird deutlich, daß auch jene königlichen Gemahlinnen, über die aufgrund einer geringen Anzahl überlieferter Quellen nur wenige Details bekannt sind, in ähnlicher Weise am höfischen Leben teilnahmen, wie das für die gut bezeugten königlichen Frauen zu rekonstruieren ist. Auch diese Nebenfrauen erhielten für ihre Bedürfnisse und Opfergaben an die persönlichen Gottheiten Vieh zugewiesen, sie nahmen am luxuriösen Leben am Hof teil und wurden nach ihrem Tod mit Totenopfern geehrt.

\section{Die Rolle der königlichen Nebenfrauen}

Im Gegensatz zu den komplexen Aufgaben der Königinnen, insbesondere auch im kultischen Bereich, waren die Nebenfrauen der Könige von Ur überwiegend im wirtschaftlichen Bereich aktiv. Sie verfügten wie die Königinnen über eigenes Kapital, insbesondere in Form von Viehherden, aber auch von Land, wie dies bei Ninkalla zu beobachten ist ${ }^{1049}$. Diesen Besitz ließen sie durch ihnen unterstellte Diener verwalten.

Mit ihrem Reichtum konnten sich die Nebenfrauen aktiv am gesellschaftlichen Leben des Hofes beteiligen. Dies zeigt sich sowohl beim Austausch von kostbaren Geschenken unter den Angehörigen der Oberschicht, als auch anhand von Weihgaben wie Statuen oder Perlen, welche die Frauen für das Leben der Könige stiften konnten.

1047 TCNY 120 = Eames G 34 (ii/IS 2) Kol. IV 9; STA 16 (ii/IS 2) Kol. IV 7.

1048 Toronto II, 141 (-/-/IS 1). Der Text ist nicht ganz eindeutig. Zum Zusammenhang zwischen Simat-Nisaba und den genannten Kanalarbeiten, vgl. die Anmerkung von Sigrist in Toronto II zu diesem Text.

1049 Siehe S. 223. 
Das hohe Ansehen der königlichen Gemahlinnen, welche nicht den Rang einer Königin einnahmen, zeigt sich jedoch nicht nur in ihrem Reichtum, sondern insbesondere auch in der Tatsache, daß auch männliche Angehörige dieser Frauen mitunter wie bei den Königinnen über ihre Schwestern definiert wurden ${ }^{1050}$.

Diese Frauen waren jedoch nicht nur mit der Verwaltung ihres eigenen Besitzes beschäftigt, sondern konnten in das System der königlichen Administration eingebunden werden, wo sie wie männliche Beamten verantwortlich waren für eine Reihe von Transaktionen. Am deutlichsten faßbar wird dies bei den Nebenfrauen von Šulgi. Geme-Ninlila und Ninkalla sind mehrfach bezeugt als Verantwortliche für die Annahme von Tieren für den König (mu-DU-lugal) ${ }^{1051}$. Diese Aufgabe wird im allgemeinen von den ranghöchsten Beamten des Königs ausgeführt. ${ }^{1052}$ Die Tatsache, daß hier die Frauen in wichtigen Verwaltungsfunktionen zu beobachten sind, zeigt zum einen, daß auch in diesem Bereich der soziale Rang einer Person wichtiger sein konnte, als das biologische Geschlecht, eine Frau konnte Funktionen übernehmen, welche üblicherweise von Männern erfüllt wurden, wenn sie eine entsprechend hohe gesellschaftliche Stellung einnahm. Zum anderen zeigt die Beteiligung der königlichen Frauen an der staatlichen Verwaltung, daß diese Damen nicht im Verborgenen in einer abgeschlossenen Welt der Frauen lebten, sondern durchaus aktiven Anteil an den wirtschaftlichen Belangen des Hofes nahmen und mit öffentlichen Aufgaben betraut wurden.

Der einzige Bereich, in welchem die Nebenfrauen der Könige nicht zu finden sind, ist der Kult der großen Götter des Landes. Wenn kultische Aktivitäten dieser Frauen nachzuweisen sind, so beziehen sich diese auf den Bereich der Verehrung persönlicher Gottheiten, nicht jedoch auf eine Beteiligung an den Hauptfesten der großen Kultzentren wie Nippur und Ur. Dieser Bereich war nur ganz bestimmten Frauen des Königshauses vorbehalten, was mit der besonderen Beziehung des Königs als Repräsentant seines Volkes vor den Göttern, sowie der entsprechenden Aufgabe der Königin zusammenhängen dürfte.

1050 Idī-Ea, Bruder der Ea-niša: OIP 115, 199 (19/iii/Š 46) und AAICAB I/2, Pl. 140 Ashm. 1971-351 (18/vii/Š 48); Ur-Suen, Bruder der Ninkalla: TCND 55 (22/i/Š 47) und Boson 328 (-/x/Š 43).

1051 Siehe S. 203 zu Geme-Ninlila und S. 214 zu Ninkalla.

1052 Maeda, Bringing (mu-túm) of livestock and the Puzrish-Dagan organization, ASJ 11 (1989) S. 71-72; Sallaberger, OBO 160/3 (1999), S. 265-266. 


\section{Die Titel der königlichen Frauen: „da m“, „,nin“ und „lukur"}

In Verbindung mit den als Gemahlinnen der Könige von Ur zu bezeichnenden Frauen finden sich in Inschriften und Wirtschaftstexten drei verschiedene Titel: „dam“, „nin“ und „lukur“. Von diesen bereitet einzig der Titel „dam“ (Ehefrau) keine interpretatorischen Schwierigkeiten. Die Bedeutung von ,n in “ (Herrin) ist zwar unumstritten, doch die Verwendung dieses Titels, insbesondere die Frage, ob mehrere Frauen gleichzeitig als „nin“ bezeichnet werden konnten und wie dieser Titel dann zu verstehen ist, bedarf einer genaueren Betrachtung. Schwierig ist insbesondere der Titel „lu ku r “, welcher in der Literatur immer wieder diskutiert und unterschiedlich interpretiert wurde. Im Folgenden sollen diese drei Titel in ihrer jeweiligen Verwendung dargestellt werden.

\section{1. dam}

„dam“ ist die in allen Wirtschafts- und Rechtsurkunden sowie in den Gesetzestexten der Zeit gebräuchliche Bezeichnung für die Ehefrau. Im Kontext der königlichen Damen ist diese Bezeichnung üblich für die verheirateten Prinzessinnen, wenn jene nicht selber mit ihrem Namen genannt, sondern nur als „dam + Name des Ehemannes“ bezeichnet werden ${ }^{1053}$. Die Ehefrau des Königs von Ur wird nur zur Zeit Ur-Nammas und in den ersten Jahren der Regierung von Šulgi mit diesem Titel benannt. Dies betrifft die Frau des Ur-Namma in dem literarischen Text „Ur-Nammas Tod“1054, sowie GemeSuen, eine der ersten Gemahlinnen Šulgis, deren Name und Titel auf einem Dienersiegel erhalten sind ${ }^{1055}$. In der Siegelinschrift wird der Name des Königs noch ohne das Gottesdeterminativ geschrieben. Nach der Vergöttlichung der Könige von Ur wurden deren Ehefrauen nicht mehr als „da m“ bezeichnet, sondern als „lu k ur“. ${ }^{1056}$

1053 So z.B. in CTMMA I, 17 (1/vii/AS 4), wo die Ehefrau (d a m) des Lugal-magurre unter den Töchtern des Königs (du mu-munus lugal) geführt wird, ohne daß ihr Name genannt würde.

1054 Ur-Nammas Tod A Z. 151 und 193; Flückiger-Hawker, Urnamma of Ur in Sumerian Literary Tradition (1999).

1055 Inschrift auf dem Siegel des Šu-Kūbum, Diener der Geme-Suen: Ge me $e_{2}$ dEN.ZU/dam Š ul-gi/lugal Uri ${ }_{5}{ }^{k i}-\mathrm{ma} / \mathrm{S}_{\mathrm{u}}-\mathrm{ku}-\mathrm{bu}-[\mathrm{u} \mathrm{m}] / \mathrm{rá}-\mathrm{gab}[\mathrm{a}] /$ $\mathrm{ir}_{11}-\mathrm{z}$ [u] (RIME 3/2.1.2.67). Michalowski, Royal Women of the Ur III Period. Part I: The Wife of Šulgi, JCS 28 (1976), S. 169-170.

1056 Steinkeller, More on Ur III Royal Wives, ASJ 3 (1981), S. 81; Sallaberger, OBO 160/3 (1999), S. 182. 


\section{2. $\operatorname{nin}$}

Die Bedeutung von „nin “ als „Herrin“ ist unumstritten ${ }^{1057}$, die Verwendung dieses Titels ist dagegen noch nicht vollständig geklärt. Während Sallaberger davon ausgeht, daß nur jeweils eine Frau als „n in “ bezeichnet werden kann, welche von ihm folglich als „regierende Königin“ angesehen wird ${ }^{1058}$, wies schon Michalowski darauf hin, daß einzelne Texte von „den Königinnen/Herrinnen“ (n in-e-ne) sprechen, es also möglicherweise mehrere Frauen gab, welche gleichzeitig diesen Titel trugen ${ }^{1059}$. Mir sind insgesamt sechs Texte bekannt, in denen die Formulierung „, in - e- $\mathrm{ne}$ “ $\mathrm{zu}$ finden ist. ${ }^{1060}$

Dabei ist meist nicht sicher festzustellen, welche Damen mit „den Königinnen/Herrinnen“" gemeint waren, insbesondere wenn die Texte undatiert oder die Daten verloren sind. In dem Ummatext UTI III, 1920 (ŠS 2) über die Lieferung von Rohr ist aufgrund des Datums davon auszugehen, daß Abī-simtī und Kubātum mit „nin-e-ne“ gemeint waren. Schwieriger ist die Interpretation von ,nin-e-ne“ in MVN 15, 91 (ك̌ 44). Michalowski hatte vermutet, es seien Šulgi-simtī und SI.A-tum, die Mutter des Königs, gemeint, er hatte jedoch eine andere Interpretation nicht ausgeschlossen. ${ }^{1061}$ Da Ninkalla, welche in MVN 15, 91 als Gastgeberin eines Bierausschenkens auftritt, in Texten aus Girsu den Titel „,n in “ tragen konnte, kann auch vermutet werden, daß in diesem Text mit „nin-e-ne“ die amtierende Königin Šulgi-simtī und die Dame Ninkalla gemeint waren.

Michalowskis Vermutung, daß mehrere Frauen gleichzeitig den Titel „,nin“ tragen konnten, ist nun für die Regierungszeit von Š́u-Suen zu bestätigen. Spätestens seit seinem zweiten Jahr trug seine Gemahlin Kubātum den Titel einer Königin ${ }^{1062}$, doch auch Abī-simtī wurde während der Regierung

1057 Steinkeller, More on Ur III Royal Wives, ASJ 3 (1981), S. 79; Sallaberger, OBO 160/3 (1999), S. 183. Marchesi, (Who Was Buried in the Royal Tombs of Ur? OrNS 73 (2004), S. 186-189) diskutierte jüngst die verschiedenen Lesungen für das Zeichen N IN und kam zu dem Ergebnis, daß in der Bedeutung „Königin“ und „Herrin“ e re š gelesen werden sollte, während für die Bedeutung „Eigentümerin“ die Lesung n in beibehalten werden sollte.

Sallaberger, OBO 160/3 (1999), S. 183.

Michalowski, Royal Women - Part III, ASJ 4 (1982), S. 136. Sallaberger selber weist in "Der Kultische Kalender" (1993), S. 45 darauf hin, daß Abī-simtī und Kubātum zur Zeit des Šu-Suen den Titel ,n in “ teilten.

MVN 15, 91 (Š 44); UTI III, 1920 (ŠS 2); UET 3, 1505 (AS 9 oder IS 1'); UET 3, 1504 (IS 2?); SAT I, 118 (undatiert); TENS 402 (undatiert).

1061 Michalowski, Royal Women - Part III, ASJ 4 (1982), S. 136.

1062 ASJ 3, S. 91 (9/vi/ŠS 2). 
ihres Sohnes als Königin/Herrin (n in) tituliert ${ }^{1063}$. MVN 16, 960 (ŠS 3) ist der einzige Text, in welchem beide Frauen mit diesem Titel bezeichnet werden. Dagegen verwendete der Schreiber des Tafelkorbetiketts MVN 9, 165 (ŠS 5) den Titel nur für Kubātum, die amtierende Königin, Ab̄̄-simtī wird in diesem Text zwar vor Kubātum genannt, trägt jedoch keinen Titel.

Steinkeller hatte vermutet, daß Abī-simtī während der Regierungszeit ihres Sohnes den Titel einer „nin-GAR “ (Königinwitwe) getragen habe ${ }^{1064}$. Heute sind eine Reihe von Texten aus Umma publiziert, welche Steinkeller noch nicht kannte, und aus denen eindeutig hervorgeht, daß Abī-simtī auch unter Šu-Suen noch den Titel „n i n “ trug. Ein Titel „n in - GAR “ ist daher zu streichen. ${ }^{1065}$

Abī-simtī und Kubātum wurden zur Zeit von Šu-Suen beide als „,nin“ bezeichnet, doch die Frage, ob eine vergleichbare Situation schon zur Zeit von Šulgi für Šulgi-simtī und Ninkalla anzunehmen ist, läßt sich weniger eindeutig beantworten. Šulgi-simtī ist seit dem Jahr $\breve{S} 32$ eindeutig als amtierende Königin zu betrachten. Sie wird in den Dokumenten ihrer Beamten entweder mit ihrem Namen oder mit dem Titel genannt, Ninkalla dagegen erhält nur in einigen Texten aus Girsu die Bezeichnung „nin “1066. Wie die Phrase nin-ene in MVN 15, 91 ( $\breve{S} 44)$ belegt, konnten auch zur Zeit von Šulgi schon mehrere Damen gleichzeitig diesen Titel tragen. Diese Beobachtung führt zu der Frage, welche Frauen unter welchen Umständen neben der amtierenden Königin als „nin “ tituliert werden konnten.

Für Abī-simtī ist diese Frage leicht zu beantworten, sie war Königin neben Amar-Suen und behielt ihren Titel und ihre Funktionen auch unter der Herrschaft ihres Sohnes. Gleichzeitig trug Kubātum als Hauptfrau des Šu-Suen diesen Titel. Schwieriger ist die Situation bei Šulgi-simtī und Ninkalla, da letztere nie die kultischen Pflichten einer Königin wahrnahm und somit nicht als amtierende Königin angesehen werden kann. Erschwerend kommt hinzu, daß die genauen familiären Beziehungen von Ninkalla zur königlichen Familie von Ur nicht zu bestimmen sind. Ninkalla konnte auch unter Amar-Suen in Girsu noch als ,n in “ bezeichnet werden ${ }^{1067}$.

Weiterhin ist zur Verwendung dieses Titels nicht nur zu beachten, welche

1063 Der späteste Text, der Abī-simtī mit diesem Titel bezeugt, ist ITT II, 628 (ŠS 7), einer Liste über Wolle für Textilien für Abī-simtī, die Königin.

1064 Steinkeller, More on Ur III Royal Wives, ASJ 3 (1981), S. 79, 81 + Anm. 28, 29. Diese Annahme bezieht sich auf die Texte SET 288 (-/iv/ŠS 1) und BIN V, 31 (ŠS 3), wobei das Zeichen G A R in BIN V, 31 ergänzt wurde.

1065 Sallaberger, Der kultische Kalender (1993), S. 45 Anm. 190.

1066 CT 7, 27 (Š 42); ASJ 11, S. 129 Nr. 59 (Š 48); ASJ 9, S. 126, 127 Nr. 57 (undatiert); MVN 22, 108 (AS 4).

1067 MVN 22, 108 (AS 4), Aufstellung über Jungrinder der Ninkalla. 
Frauen überhaupt so angesprochen werden konnten, sondern auch aus welchem Ort die Quellen jeweils stammen, sowie in welchem Kontext und auf welchem Schriftträger der Titel verwendet wurde. So ist zu beobachten, daß Šulgi-simtī in den Texten aus Puzriš-Dagān entweder namentlich oder mit dem Titel genannt wurde ${ }^{1068}$. Ab̄i-simtī, Kubātum, Ninkalla und Geme-Enlila begegnen, wenn auch selten, so doch wiederholt mit Namen und Titel in den Verwaltungstexten aus Girsu, Umma und Ur. Auffällig ist dabei, daß Ninkalla nur in Texten aus Girsu als „nin“ bezeichnet wird, wohingegen Abī-simtī vorwiegend in den Quellen aus Umma, im Zusammenhang mit ihren Reisen zur Inanna von Zabalam, diesen Titel trägt. Wirtschaftsdokumente, welche nur den Titel ohne den Namen der Amtsinhaberin nennen, sind aus allen großen Fundorten bekannt.

Während die Königinnen von Ur in den Wirtschaftstexten auch als solche angesprochen werden, tragen sie auf ihren Siegeln sowie in den Inschriften von Dienersiegeln praktisch immer den Titel „lukur “ oder „lukur-kaskal “, die einzigen mir bekannten Ausnahmen sind die Siegelinschriften des Ur-niĝar, der sich als „,̌abra nin“ bezeichnet ${ }^{1069}$, und des Ur-Enlil, der den Titel „nubanda ${ }_{3}$ nin " trägt ${ }^{1070}$. Auch auf beschrifteten Objekten wie der Schmuckperle der Kubātum ${ }^{1071}$ werden die Frauen stets als „lukur“ angesprochen. Dies läßt darauf schließen, daß der Titel „Königin“ (nin) vorwiegend im administrativen Bereich Verwendung fand und folglich als Amtstitel anzusehen ist.

\section{3. lukur}

Die genaue Bedeutung des Titels ,1 uk u r“ ist noch ungeklärt. In Bezug auf die Ehefrauen der Könige von Ur schlug Michalowski die Übersetzung „,consort“ vor. ${ }^{1072}$ Dies ist nach wie vor für diese Epoche die neutralste Übersetzung.

Die Problematik bei der Interpretation dieses Titels besteht darin, daß zum einen jede Ehefrau des Königs als „lukur“ bezeichnet werden konnte, unabhängig davon, ob es sich um die amtierende Königin oder eine andere Gemahlin handelte. So wurde auch die Königin Šulgi-simtī in den Inschriften der Siegel ihrer Diener als „1ukur“ tituliert. ${ }^{1073}$ Zum anderen konnten auch

\footnotetext{
1068 Die einzige Ausnahme ist MVN 8, 97 (v/Š 32).

1069 UDT 27 (iv, v/AS 3). Zur Lesung des Personennamens gegen die Kopie siehe Sigrist, Neo-Sumerian Archival Texts in the Nies Babylonian Collection, S. 8, NBC 27.

1070 MVN 3, $130(-/ \mathrm{i} / \mathrm{S}$ 31).

1071 RIME 3/2.1.4.28.

1072 Michalowski, Death of Šulgi, OrNS 46 (1977), S. 222.

1073 Steinkeller, More on Ur III Royal Wives, ASJ 3 (1981), S. 79.
} 
Götter eine „lukur“ haben, so ist die Prinzessin Geme-Enlila ${ }^{1074}$ sowie eine Dame namens Wiruruti ${ }^{1075}$ als lukur des Ninurta bekannt. Wie schon Steinkeller vorgeschlagen hat, könnte der Wechsel in der Titulatur der königlichen Gemahlinnen von dam zu nin/lukur mit der Vergöttlichung der Könige spätestens seit dem Jahr Š 21 zusammenhängen. ${ }^{1076}$ Dann wäre eine Parallele zu ziehen zwischen der lukur als Gemahlin eines Gottes und als Gemahlin des vergöttlichten Königs. Gegen die Annahme, daß eine lukur ausschließlich als die Gefährtin eines Gottes angesehen wurde, spricht jedoch die Tatsache, daß schon in der Ur III-Zeit mitunter auch die Ehefrauen anderer Männer aus höheren Gesellschaftsschichten als lukur bezeichnet werden konnten ${ }^{1077}$.

Für Ešnunna in der altbabylonischen Zeit konnte Steinkeller zeigen, daß die beiden Begriffe dam und lukur als Bezeichnung für die Ehefrau eines Mannes mitunter frei wechseln konnten. ${ }^{1078}$ In dieser Epoche hatten die nadĩtu, eine Klasse von Frauen, welche zumeist aus den höheren gesellschaftlichen Kreisen stammten und die gewisse priesterliche Funktionen ausübten, welche sich bisher nicht exakt bestimmen lassen ${ }^{1079}$, eine angesehene Stellung in der Gesellschaft. Die akkadische Bezeichnung nadītu wurde fast immer mit dem Logogramm lukur wiedergegeben, was dazu führte, daß man den Titel „1 u k u r “ für die Ur III-Zeit mit ,priesterly wife“ übersetzte ${ }^{1080}$.

Auch wenn heute Konsens darüber besteht, daß jede königliche Gemahlin als „lukur“ bezeichnet werden konnte, so ist die genaue Bedeutung dieses Titels nach wie vor nicht zu bestimmen. Das Bild wird noch komplizierter durch die Tatsache, daß sowohl Šulgi-simtī als auch Ea-niša, beides Gemahlinnen des Šulgi, in Siegelinschriften als lukur-kaskal des Königs

\footnotetext{
1074 PDT II, 1056 (Datum abgebrochen).

1075 Toronto 27 (3/ix/Š 47).

1076 Steinkeller, More on Ur III Royal Wives, ASJ 3 (1981), S. 81.

1077 A - n a-a lukur des Nawir-ilum, MVN 11, 183 (iv/AS 9); siehe Steinkeller, More on Ur III Royal Wives, ASJ 3 (1981), S. 81-82 und Sallaberger, OBO 160/3 (1999), S. 182-183.

1078 Steinkeller, More on Ur III Royal Wives, ASJ 3 (1981), S. 81-82.

1079 Renger, Untersuchungen zum Priestertum in altbabylonischer Zeit. Teil 1, ZA 58 (1967), S. 150-176; Harris, The Nadītu Woman, FS Oppenheim (1964), S. 106-135; Dies.: Ancient Sippar (1975), S. 302-312 und 315-323.

1080 Kang, SACT I, S. 261 mit älterer Literatur. Zu den verschiedenen Interpretationen und Übersetzungsvorschlägen, die von „Priesterin in der Rolle der Göttin bei der heiligen Hochzeit“ bis zu „Frau des Königs" reichen, siehe Leick, Sex and Eroticism (1994), S. 148.
} 
bezeichnet wurden ${ }^{1081}$. Dieser Titel ist bisher im Zusammenhang mit den königlichen Damen nicht im Kontext von Wirtschaftsurkunden belegt. Auch ist mir kein Beleg aus der Zeit nach Šulgi bekannt. Grégoire sah eine Funktion der lukur-kaskal darin, daß sie den Herrscher auf seinen Reisen begleitete, wobei er diese Frauen aufgrund der sonstigen Quellenlage nicht als einfache Konkubinen und Reisegefährtinnen, sondern sehr wohl als sozial hochstehende Damen ansah. ${ }^{1082}$ Ferner nahm Grégoire an, es handele sich bei lukurkaskal um die vollständige Form des Titels ${ }^{1083}$, 1 u k ur allein wäre damit eine Kurzform desselben. Das Vorhandensein des Titels lukur-kaskal in nur zwei Inschriften erschwert die Interpretation. Das Bedeutungsspektrum von kaskal/harrānu (Reise, Straße, Weg, Handelsunternehmung, Kriegszug) führte zur Interpretation dieses Titels als „Reisegefährtin des Königs/Nebenfrau, welche den König auf Reisen begleitet“. Nun wäre einzuwenden, daß Šulgi-simtī, eine der beiden Trägerinnen dieses Titels, keine Nebenfrau, sondern Königin war. Jedoch ist dabei zu beachten, daß das Siegel des Sukkal Mašgula, auf welchem er sich als Diener der Šulgi-simtī, der lukur-kaskal, bezeichnet, auf einer Tafel abgerollt ist, welche das Datum vi/Š 32 trägt $^{1084}$. Wenn die Rekonstruktion zutreffend ist, daß Šulgi-simtī in der ersten Hälfte des Jahres Š 32 das Amt der Königin von Geme-Suen übernommen hat ${ }^{1085}$, kann argumentiert werden, daß dieses Siegel in einer Zeit geschnitten wurde, als Šulgi-simtī noch nicht Königin, sondern die offensichtlich bevorzugte Nebenfrau des Königs war, der es später gelang, die Position der Königin zu übernehmen.

Auch wenn drei Belege noch keine verläßliche Aussage zulassen, so soll doch hier vermutet werden, daß der Titel einer luku r-kaskal die bevorzugte königliche Nebenfrau bezeichnete. Diese Position hätte dann in späteren Jahren Ea-niša eingenommen, deren Siegel, auf welchem sie diesen Titel trägt, auf einer Tafel aus dem Jahr $\breve{S} 44$ zu finden ist ${ }^{1086}$. Die Königin selbst konnte sich aufgrund ihrer umfangreichen Verpflichtungen nicht immer am selben Ort wie der König aufhalten. Die lukur-kaskal dagegen konnte den Herrscher auch dann begleiten, wenn er sich nicht in der Hauptstadt aufhielt. Sie war folglich keine Konkubine, die den König nur auf seinen Reisen begleitete, sondern

1081 RIME 3/2.1.2.69, Siegel des Mašgula, Diener der Šulgi-simtī; RIME 3/2.1.2.75, Siegel der Ea-niša; RIME 3/2.1.2.81, Weihinschrift der Ea-niša für das Leben des Šulgi. Grégoire, Le sceau d'Ea-niša. RA 73 (1979), S. 191; vgl Sigrist, Drehem (1992), S. 215.

1083 ebd.

1084 RT 37, 130 Nr. 3.

1085 Siehe oben S. 36.

1086 AAICAB I/2, Pl. 139; Ashm 1971-346. 
vielmehr eine „bevorzugte Gefährtin“, deren soziale Position es ihr ermöglichte, sich stets am selben Ort aufzuhalten wie der König und diesen auch auf seinen Reisen zu begleiten.

Während der Titel „nin “ vorwiegend im administrativen Bereich anzutreffen ist, findet sich „lukur" in 3/4 aller Fälle auf Siegel- oder Weihinschriften. Wird lukur in Wirtschaftstexten verwendet, so handelt es sich zumeist um Transaktionen von kostbaren Gegenständen innerhalb des königlichen Haushaltes oder als Weihgaben an Götter ${ }^{1087}$. Nur in drei Texten, in denen eine lukur des Königs erwähnt wird, wird die Ausgabe von Vieh verzeichnet, in einem dieser drei Texte geht es um die Bereitstellung von Vieh für Totenopfer ${ }^{1088}$. Dies deutet darauf hin, daß der Titel „,lukur “ stärker die persönlichen Bindungen zwischen dem König und seiner jeweiligen Frau beschreibt, während „nin “ als ein Amtstitel anzusehen ist. Auch die Königin wurde folglich als „lukur“ bezeichnet, wenn weniger ihre Funktion im Amt als vielmehr ihre besondere Nähe und persönliche Beziehung zum König hervorgehoben werden sollte. Für „lukur“ sei auf dieser Grundlage die Übersetzung „Gefährtin“ vorgeschlagen.

Aus Umma stammen vier Texte, die Getreidelieferungen an das Haus der

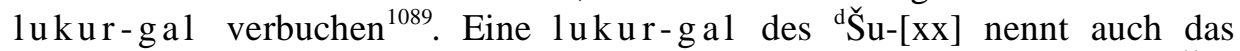
Siegel auf einer Tafel aus Nippur ${ }^{1090}$. Ob die Siegellegende zu lukur-gal d $\breve{S} u-$ [Suen] zu ergänzen ist ${ }^{1091}$, muß bislang offen bleiben. Die Texte aus Umma lassen keinen Zusammenhang mit den königlichen Damen erkennen, und somit ist es derzeit nicht möglich zu entscheiden, ob der Titel lukur-gal für Angehörige des Königshauses verwendet wurde, oder ob sich hinter dieser Bezeichnung Frauen verbergen, die in nicht näher zu spezifizierender Weise zum Personal eines Tempels gehörten.

1087 UTI VI, 3800 und JCS 54, S. 7-9 Nr. 52 (Datum bei beiden Texten abgebrochen), Austausch von kostbaren Geschenken zwischen den königlichen Damen; SAT III, 1277 (v/ŠS 2), Weihgaben der Kubātum, lukur-lugal, an die Götter Gula und Niĝar.

1088 Nik. 484 (24/ix/AS 5), Kleinvieh für Puzur-uša lu ku r-1 u g a 1 ; BIN III, 134 (1/iv/AS 7), Rinder für Udat-ṣenat lukur-lugal; ARRIM 2, S. 3 (24/iv/ŠS 6), Schafe als Totenopfer für Takūn-mātum, lu k u r-lu g a 1 .

1089 SAT II, 45 (diri-i/Š 32); SAT II, 48 (diri-ii/Š 32); SAT II, 55 (diri-i/Š 32) und SAT II, 69 (i/Šs 32 bis ii/Š 33).

1090 NATN 768 (Datum der Tafel nicht erhalten).

1091 Frame, A New Wife of Šu-Sîn, ARRIM 2 (1984), S. 4 Anm. 6, wo auf einen mündlichen Vorschlag Steinkellers zu dieser Ergänzung verwiesen wird. 


\section{Prinzessinnen}

\section{Die En-Priesterinnen des Nanna von Ur}

Mit der Einsetzung der En-hyedu-ana als En des Nanna von Ur durch ihren Vater Sargon von Akkade wird die große politische Bedeutung der Installation der En-Priesterinnen des Mondgottes in Ur erstmals greifbar. Die Frage, ob schon vor En-hedu-ana Töchter der jeweiligen Herrscher als En des Nanna eingesetzt wurden, ist bei der derzeitigen Quellenlage noch nicht zu beantworten.

Stets war es eine direkte Angehörige des Königs, zumeist eine Tochter ${ }^{1092}$, die für dieses Amt ausgewählt wurde. Sowohl ihre Wahl durch ein Omen wie auch ihre nachfolgende Inthronisation waren Ereignisse von solch großer Wichtigkeit im religiösen und politischen Leben der Zeit, daß sie in den Jahresnamen der Könige von Ur wie auch der Herrscher der nachfolgenden Dynastien zu finden sind. Neben der En des Nanna von Ur wird noch die Einsetzung der En des Nanna von Ga'ě̌/Karzida, jenes der Inanna von Uruk sowie der En des Enki von Eridu in den Datenformeln der Könige von Ur erwähnt. ${ }^{1093}$

Angesichts dieser Situation wäre zu erwarten, daß diese Priesterinnen auch in den Wirtschaftsquellen der Ur III-Zeit häufig anzutreffen sind. Doch dies ist nicht der Fall. Es sind kaum Texte erhalten, die Aufschluß geben können über die kultischen Pflichten dieser Damen, ihren Haushalt oder ihre wirtschaftlichen Rahmenbedingungen. Für die/den En der Inanna ist eine Beteiligung am System der mu-DU-Lieferungen in mehr als 100 Texten bezeugt, für die En des Nanna von Ur sind vergleichbare Texte bisher nicht bekannt. Weder im Korpus der Texte aus Ur noch im weit umfangreicheren

\footnotetext{
1092 Warad-Sîn von Larsa ließ seine Schwester En-anedu als En-Priesterin installieren; vgl. Renger, Untersuchungen zum Priestertum in altbabylonischer Zeit, ZA 58 (1967), S. 120.

1093 Š 15/17, Š 43, AS 4 (Ur), AS 9 (Ga'eš), Un-Namma 8, AS 5, IS 2/4 (Uruk), Š 28, AS 8, IS 11 (Eridu).
} 
Bestand der Quellen aus Puzriš-Dagān ist die En des Nanna von Ur häufig zu finden.

Dieser Befund könnte auf unterschiedliche Weise erklärt werden, wobei alle Modelle bei der derzeitigen Quellenlage Hypothese bleiben müssen:

Es wäre möglich, daß die En des Nanna in den Wirtschaftstexten nicht mit dem Namen genannt wurde, den sie in Inschriften verwandte und der auch in den Datenformeln aufgeführt wurde. Möglicherweise handelte es sich bei diesen, stets mit dem Element „En“ gebildeten Namen um Amtsnamen, welche nur in bestimmten Kontexten verwendet werden durften. In diesem Fall würde sich die Priesterin des Mondgottes in Texten aus dem alltäglichen Wirtschaftsleben hinter einem anderen Namen verbergen. Hier wäre entweder an den Namen zu denken, den sie als Prinzessin vor ihrer Amtseinführung getragen hat, oder an einen anderen ,profanen“ Namen. Eine derartige Situation ist derzeit jedoch nicht nachzuweisen.

Vorstellbar wäre auch, daß die Versorgung des Haushaltes der En des Nanna sowie aller von ihr verantworteten kultischen Handlungen nicht über den zentralen königlichen Viehhof in Puzriš-Dagān erfolgte, sondern anderweitig organisiert war. In diesem Fall wäre das zum Haushalt der En gehörige Archiv, das in Ur vermutet werden muß, noch nicht gefunden. Bei den wenigen Erwähnungen der En in den Texten der königlichen Verwaltung handelte es sich dann um Sonderfälle, nicht aber um die regelmäßige Versorgung des täglichen Kultbetriebes.

Die Frage nach Gründen für die Unterrepräsentanz der En des Nanna in den Quellen kann derzeit zwar erhoben, jedoch nicht zufriedenstellend beantwortet werden.

Vier Priesterinnen, die das Amt der En des Nanna von Ur während dieser Epoche nacheinander ausübten, sind sicher zu identifizieren. Ur-Namma setzte seine Tochter unter dem Namen En-nirĝal-ana ein. Von dieser En sind nur die Weihinschriften auf dem Fragment einer Schale sowie auf dem Fußfragment eines Ständers erhalten. Diese Objekte hatte sie der Göttin Ningal für das Leben ihres Vaters gestiftet ${ }^{1094}$. Ihr folgte im Jahr Š 17 En-nirzi-ana nach, wie der Jahresname deutlich macht. Ihre Bestimmung durch ein Omen ist das namengebende Ereignis für das Jahr Š 15 , zwischen ihrer Erwählung und der eigentlichen Inthronisation lagen also zwei Jahre.

En-nirzi-ana ist nicht nur aufgrund der Jahresnamen bekannt, das Siegel ihres Schreibers Girine-isa ist auf einer Urkunde über die Rückzahlung von

1094 RIME 3/2.1.1.54; nach Schriftträgern getrennt werden die Inschriften bei BraunHolzinger, Mesopotamische Weihgaben (1991), aufgeführt: S. 184 G. 339 und S. 216217 Ständer 8. 
Getreide aus dem Jahr $\breve{S} 37$ erhalten ${ }^{1095}$. Weiterhin findet sich der Name der Ennirzi-ana in einer Urkunde über die Ausgabe von Mehl, wobei ein Feld der Ennirzi-ana erwähnt wird ${ }^{1096}$. Dies ist eines der wenigen Zeugnisse über die wirtschaftliche Situation der En-Priesterinnen des Nanna von Ur.

Die Nachfolgerin der En-nirzi-ana ist nur durch das Zeugnis der Datenformel des Jahres Š 43 bekannt, das an die Bestimmung dieser En-uburziana genannten Dame durch ein Omen erinnert. Wann sie in ihr Amt eingesetzt wurde ist nicht überliefert. Sollberger wollte in En-uburzi-ana und der im Jahr AS 4 inthronisierten En-mahgal-ana dieselbe Person sehen ${ }^{1097}$, doch dagegen spricht die Verschiedenheit der Namen ${ }^{1098}$. Somit ist davon auszugehen, daß En-uburzi-ana im Jahr Š 43 für das Amt der En bestimmt wurde und dieses bis zum Jahr AS 4 ausübte. Ihr folgte En-mahgal-ana im Jahr AS 4, wobei nicht bekannt ist, wann letztere durch ein Omen zur En des Nanna bestimmt wurde. Von En-mahgal-ana ist eine kurze Weihinschrift auf einem Gefäß erhalten, die ihren Namen und Titel nennt ${ }^{1099}$, außerdem ist einmal die Ausgabe eines Gewandes für sie bezeugt ${ }^{100}$. Darüber hinaus ist ihr Name in einer fragmentarisch erhaltenen Gerichtsurkunde zu finden, wobei der Gegenstand der Auseinandersetzung nicht zu bestimmen ist ${ }^{1101}$.

Ob En-mahgal-ana im Jahr IS 10 von En-nirzi-ana abgelöst wurde, muß vorerst offen bleiben. Die Datenformel für dieses Jahr nennt die Bestimmung der En-nirsi-ana durch ein Omen, jedoch ist dieses Datum nur in der Liste UET 1, 292 erhalten, welche die Datenformeln der letzten Jahre der dritten Dynastie von Ur sowie der nachfolgenden ersten Dynastie von Isin enthält. Dabei bleibt unsicher, ob die Formel $[\mathrm{en}]-{ }^{\mathrm{d}} \mathrm{In}$ ann a zu $[\mathrm{en}]-{ }^{\mathrm{d}} \mathrm{N}$ ann a emendiert werden muß, wie Sollberger es annahm ${ }^{1102}$. Inschriften oder Wirtschaftstexte sind von

\footnotetext{
1095 UET 3, 1320 (ixii/Š 37); für die Siegelinschrift s. RIME 3/2.1.2.87.

1096 UET 3, $911(-/ \mathrm{i} /-)$.

1097 Sollberger, Sur la chronologie des rois d' Ur, AfO 17 (1954-56), S. 23-24.

1098 Renger, Priestertum, ZA 58 (1967), S. 118 Anm. 35.

1099 RIME 3/2.1.3.19.

1100 UET 3, 1717 (viii/IS 6).

1101 UET 3, 45 (ix/IS 14) = Falkenstein NSGU 114. Falkenstein vermutete einen Streit um Tempelpfründe, vgl. dagegen Kraus, BiOr 15 (1958), S. 27 und Sollberger, Sur la chronologie des rois d' Ur, AfO 17 (1954-56), S. 24.

1102 Sollberger, Sur la chronologie des rois d' Ur, AfO 17 (1954-56), S. 24 mit Anm. 70 und S. 41. Sollberger nahm einen Vorschlag von Falkenstein (JAOS 72 (1952), S. 41 Anm. 10) auf. In der jüngeren Literatur wird die Frage, ob En-nirsi-ana als die En des Nanna oder der Inanna angesehen werden soll, unterschiedlich behandelt. Sigrist/Gomi, (Comprehensive Catalogue (1991), S. 328) entscheiden sich für Inanna, wohingegen Sallaberger sie als En des Nanna betrachtet (OBO 160/3 (1999), S. 138 und 173).
} 
En-nirsi-ana nicht erhalten.

Neben diesen wenigen Zeugnissen, in denen die En-Priesterinnen namentlich genannt werden, begegnen uns die En noch in einigen Texten nur mit ihrem Titel. Hier stellt sich die Schwierigkeit, daß mit en ${ }^{\mathrm{d}} \mathrm{Nann}$ a nicht immer die En des Gottes von Ur gemeint war. So wirkten auch in Ga'eš ${ }^{1103}$ bei Ur und in Urum ${ }^{1104}$ eine En des Nanna. In Ga'eš gab es einen kontinuierlichen Kult des Nanna, der wohl entstand, da Nanna von Ur zu den beiden Akitifesten zweimal jährlich aus seinem Heiligtum in Ur zum Heiligtum Karzida in Ga'eš reiste $^{1105}$. Im Kontext der Hauptfeste, dem Akiti zur Ernte, dem Akiti zur Aussaat und dem Ezem-mah, erhielt die En des Nanna von Karzida Kleinviehgaben, die als königliche máš-da-re-a-Lieferungen zum Ort der

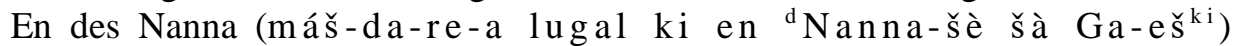
bezeichnet werden ${ }^{1106}$. Bei zwei Texten, die nach dem Datum und der Art der Lieferung ebenfalls in den Kontext des Ezem-mah gehören, fehlt die Ortsangabe ,in Ga'eš ${ }^{\star 1107}$, und somit ist nicht zu entscheiden, ob die Gaben von je 20 Stück Kleinvieh für die En des Nanna von Ur oder die En des Nanna von Karzida bestimmt waren.

Es ist folglich davon auszugehen, daß die En-Priesterinnen des Nanna von Ur und des Nanna von Karzida an den drei Hauptfesten von Ur beteiligt waren. Worin ihr Anteil an den Feierlichkeiten und den kultischen Handlungen bestand, ist jedoch auf der Basis der Wirtschaftstexte nicht zu ermitteln.

Zwei Urkunden aus Puzriš-Dagān zeigen, daß die En des Nanna auch an den Festen zu Ehren der Götter an anderen Orten Anteil nahm. So erhielt sie im Jahr AS 9 zehn Schafe aus dem Bestand der königlichen máš-da-re-aAbgaben, als sie eine Reise nach Eridu unternahm ${ }^{1108}$. Und im Jahr $\breve{S} 48$ schickte die En des Nanna mehrere Lämmer nach Tummal zum dortigen

1103 In den Jahren AS 2 und AS 9 wurde jeweils eine En des Nanna von Karzida, dem Tempel in Ga'eš, eingesetzt. PDT II, 767 (AS 2) verbucht Ausgaben für Opfer zu diesem Anlaß, im Jahr AS 9 war die Installation der En das namengebende Ereignis. Sallaberger, Der kultische Kalender (1993), S. 171 und ZA 82 (1992), S. 132.

1104 TCNY 374 (i/IS 2), Vieh für sis ku $\mathrm{r}_{2}$-Riten am Tag als die En des Nanna von Urum gewählt wurde.

1105 Sallaberger, Der kultische Kalender (1993), S. 170-172.

1106 JCS 52, S. 42 Nr. 45 (8/i/ŠS 7); Nakahara 46 (7/i/ŠS 9); PDT II, 1213 (11/x/IS 2). Sallaberger, Der kultische Kalender (1993) S. 163-164. Die Überweisung von einem Rind (AUCT III, 326 (viii/AS 7)) gehört wohl in einen anderen Zusammenhang.

1107 MVN 2, 164 (7/x/AS 9); AAICAB I/2, Pl. 118 Ashm. 1954-208 (8/x/ŠS 8). Zu den máš-da-re-a-Abgaben an die En des Nanna vgl. Sallaberger, Der kultische Kalender (1993), Tab. 52.

1108 Toronto 82 (5/i/AS 9). 
Hauptfest im achten Monat ${ }^{1109}$. Zur Zeit von Šulgi und Amar-Suen erhielt Nanna beim Tummalfest regelmäßig zwei Schafe ${ }^{1110}$, ob die Gaben der En ebenfalls dem Mondgott galten oder ob sie anläßlich dieses Festes den Göttern Enlil und Ninlil von Nippur, denen das Tummalfest in erster Linie galt, opferte, ist nicht zu entscheiden.

Anders als aus der Zeit der ersten Dynastie von Larsa ist aus der Ur III-Zeit keine Bauinschrift einer En-Priesterin erhalten ${ }^{1111}$.

Diese wenigen Zeugnisse für die En-Priesterinnen des Nanna erlauben keine Rekonstruktion der Aufgabenbereiche dieser Frauen. Die hohe politische Bedeutung ihres Amtes ist aus den Datenformeln zu ersehen. Darüber hinaus weist der Umfang von kostbaren Grabbeigaben, die eine En erhielt, sie als eine Person höchsten Ranges aus ${ }^{1112}$.

Das Fehlen eines umfangreicheren Textkorpus zu den En-Priesterinnen im Gesamtkorpus der Texte aus Puzriš-Dagān legt den Schluß nahe, daß der Bereich des Tempelkultes und der zugehörigen Wirtschaft des Nannatempels, von der anzunehmen ist, daß sie von der En-Priesterin geleitet wurde, in einer von der königlichen Viehwirtschaft unabhängigen Form organisiert war. Die königlichen Opfer für den Mondgott wurden dagegen von Puzriš-Dagān aus verwaltet.

\section{Exkurs 3: Königstöchter als Priesterinnen in Ebla und Akkade}

\section{Priesterinnen aus dem Königshaus von Ebla}

Den dam-dighir-Priesterinnen in Ebla hat Archi kürzlich eine Studie gewidmet, in welcher er zu den bisher bekannten dam-diĝir zusammengestellt hat, was derzeit über diese Frauen ausgesagt werden kann. ${ }^{113}$ Die meisten dieser dam-diĝir entstammten der königlichen Familie von Ebla, einige kamen aus anderen Königshäusern oder aus der Familie des Wesirs Ibrium. Auch für Ebla kann die Frage nach der Funktion dieser Priesterinnen in Kult bisher nicht beantwortet werden.

Die Eblaprinzessinnen, welche die Funktion einer dam-di ĝir ausübten,

\footnotetext{
1109 TPTS $122(29 /$ viii/Š 48).

1110 Sallaberger, Der kultische Kalender (1993), S. 136-137.

1111 RIME 4, Rīm-Sîn I E4.2.14.20, Bauinschrift der En-anedu, Schwester des Rīm-Sîn, in der sie an die Bauarbeiten am Gipar erinnert.

1112 Sallaberger, Eine reiche Bestattung im neusumerischen Ur, JCS 47 (1995), S. 15-21, wo der Text UET 3, 335 (viii/AS 8) überzeugend als Liste der Grabbeigaben für Enaga $_{3}$-zi-an-na, die En des Nanna von Karzida interpretiert wird.

1113 Archi, The high priestess, dam-dingir, at Ebla, FS Loretz (1998).
} 
waren Priesterinnen des Gottes Idabal von Luban, doch auch die Göttin Adamma, Gemahlin des Rasap von Adani, hatte eine dam-digirPriesterin. ${ }^{1114}$ Kura, der wichtigste Gott im Stadtpantheon von Ebla, hatte indes keine dam-diĝir, ihm diente eine „Salbpriesterin“ ( $\mathrm{pa}_{4}$-šeš-munus). Obwohl Kura die Hauptgottheit in Ebla war, stand seine Priesterin im Rang unter der dam-dig ir des Idabal von Luban. In den Listen über regelmäßige Metallzuweisungen steht stets Kura an erster Stelle, gefolgt von der amtierenden dam-diĝir. ${ }^{1115}$ Dies ist damit zu erklären, daß Idabal überregional für das Land die wichtigste Gottheit war. ${ }^{1116}$

Die Funktion der $\mathrm{pa}_{4}$ - ̌̌ eš des Kura wurde unter anderem von Enna-Utu, eine der Frauen des Königs, ausübte. Auch eine Išrut ist einmal als $\mathrm{p} \mathrm{a}_{4}$-š eš ${ }^{\mathrm{d}}$ Kura belegt. ${ }^{1117} \mathrm{Ob}$ es sich bei ihr um die gleichnamige Schwester der Dusigu handelt, ist nicht zu sagen, doch ist ein solches Amt sicher bevorzugt, wenn nicht gar ausschließlich, an Frauen aus dem unmittelbaren Umfeld des Königshauses gegeben worden. Der Name Enna-Utu ist in Ebla für zwei Frauen belegt, die beide zu den dam en zählten. ${ }^{1118}$ Welche dieser beiden Frauen die Schwester der Tirin-Damu war, der ersten uns bekannten damdi ĝir und Tochter des Königs ${ }^{1119}$, ist nicht zu sagen. Es liegt jedoch nahe zu vermuten, bei der Schwester der Tirin-Damu habe es sich um die $\mathrm{pa}_{4}$ - šešPriesterin gehandelt hat, da derart hohe Priesterämter zumeist mit Töchtern des Königs besetzt wurden. Namensgleichheit kam in Ebla häufiger vor, sowohl bei Frauen, die gleichzeitig dam en waren ${ }^{1120}$, als auch in späteren Generationen, wo man die Namen bedeutender Vorfahrinnen wieder aufnahm, wie dies z.B. bei Kešdut, Tochter des Išar-Damu, der Fall ist. Auch eine weitere Dusigu erscheint in einem der späten Texte als dumu-munus en ${ }^{1121}$ Dies macht die Identifikation einzelner Personen in den Texten mitunter schwierig.

Den im wesentlichen aus Distributionslisten bestehenden Quellen aus Ebla ist nicht zu entnehmen, welche Aufgaben eine $\mathrm{p}_{4}$ - š e š- Priesterin zu erfüllen

\footnotetext{
1114 ebd. S. 52.

1115 Z.B. MEE 10, 20 und 29.

1116 Archi, La religione e il culto nel Periodo Protosiriano (1995), S. $134 f$.

1117 In MEE 2, 40 rev. V 5-8 empfängt sie ein $\mathrm{z}$ r a ${ }_{6}-\mathrm{t}$ ú $\mathrm{g}$.

1118 TM.75.G.2328 rev. IV 2-26 und MEE 5, $22=$ ARET 8, 542 rev. I 5-II $16=\S 35$. Im Text TM.75.G.1890 werden beide Enna- ${ }^{\mathrm{d}}$ Utu ohne einen weiteren Titel geführt, s. Tonietti, Le liste delle dam en, QdS 16 (1989), S. 105, 108f.

1119 Archi, Les femmes du roi Irkab-Damu, Amurru I (1996), S. 107.

1120 Z.B. Rapeštum oder Kirsut, wobei die zweite Trägerin des Namens als Rapeštum II bzw. Kirsut II erscheint. TM.75.G.1793 und TM.75.G.10150, Tonietti, Le liste delle dam en, QdS 16 (1989), S. 102f.

${ }^{1121}$ ARET 9, 50 obv. III, 4.
} 
hatte, und auch über die kultischen Funktionn der da m-di ĝ ir läßt sich derzeit noch keine Aussage machen, doch ist zumindest etwas mehr über sie bekannt als über die $\mathrm{pa}_{4}$-šeš. Die Frauen, die dieses Amt innehatten, wurden weiter in den Listen der dam en geführt, sie wurden folglich auch nach ihrer Amtseinführung von Ebla aus versorgt. Ferner ist davon auszugehen, daß die dam-di ĝir unverheiratet waren. Die Amtseinführung der Frauen wurde mit großem Aufwand gefeiert, die Geschenke, die sie zu diesem Anlaß erhielten, entsprechen in Art und Umfang einer Mitgift. Die Liste der Geschenke, welche Tinib-Dulum anläßlich ihres Zuges nach Luban empfing, hat Archi veröffentlicht. ${ }^{1122}$ Sie erhielt von verschiedenen Würdenträgern Silberohrringe, die im Gewicht standardisiert waren, sowie wertvolle Textilien und Anhänger $(\mathrm{kù}-\mathrm{s} \mathrm{a} 1)^{1123}$. Ob die Tatsache, daß die finanzielle Last zur Zusammenstellung der Mitgift auf die Würdenträger verteilt war, eine Besonderheit bei der Ausstattung der dam-dighir darstellt, oder ob dies bei der Mitgift einer Eblaprinzessin üblich war, kann bei der derzeitigen Quellenlage nicht entschieden werden. Der Umfang der Mitgift von Tinib-Dulum ist, wie Biga gezeigt hat, sehr wohl mit der Ausstattung einer Prinzessin zu vergleichen, die an einen fremden Königshof verheiratet wurde. ${ }^{1124}$

Die dam-di ĝir verfügten zum Teil über beachtlichen Besitz, so ist von Tirin-Damu bekannt, daß sie sowohl eine große Zahl von Schafen als auch Ländereien besaß. ${ }^{125}$ Den Landbesitz hatte sie von der Königin zum Geschenk erhalten. ${ }^{1126}$ Auch Amaga, die letzte dam-di ĝir aus dem Königshaus, die wir kennen, besaß Land und hatte verschiedene Handwerker in ihren Diensten. ${ }^{1127}$ Auch wenn von den anderen Frauen, die dieses Amt bekleideten (noch) nicht bekannt ist, ob sie ähnlich vermögend waren, ist dies doch anzunehmen. Der hohe Rang dieser Frauen zeigt sich in ihrer prominenten Stellung in den Listen der dam en, wo sie stets direkt nach der Königin genannt werden, TirinDamu führt diese Liste nach dem Tod der Königin Kešdut sogar an. ${ }^{1128}$

1122 Archi, Gifts for a Princess, Eblaitica 1 (1987) S. 115-124 = MEE 10, 41.

1123 Zu k ù - s al siehe die ausführliche Diskussion bei Waetzoldt, MEE 12 (2001), S. 135138, der darlegt, daß es sich bei kù - s al um einen Anhänger gehandelt hat, der in der Regel aus dünnem Gold- oder Silberblech hergestellt wurde. kù-s al konnte auch einen Teil des Zaumzeugs bezeichnen und zumindest teilweise aus Wolle gefertigt worden sein. Biga, The Marriage of Eblaite Princess Tagriš-Damu, Subartu IV (1998), S. 20 Anm. 14; Archi, Jewels for the Ladies of Ebla, ZA 92 (2002).

1125 Archi, The high priestess, dam-dingir, at Ebla, FS Loretz (1998), S. $45 f$.

1126 Siehe oben S. 194.

1127 Archi, The high priestess, dam-dingir, at Ebla, FS Loretz (1998), S. 50.

1128 TM.75.G.2551 Archi, Les femmes du roi Irkab-Damu, Amurru I (1996), S. 109; Ders., 
Angesichts der einflußreichen Stellung, die allgemein für hochrangige Damen in dieser Zeit festzustellen ist, und bei der offensichtlich bedeutsamen Stellung, die eine Priesterin des Idabal von Luban hatte, ist zu erwarten, daß sie über ein recht umfangreiches eigenes Vermögen verfügen konnte. Noch ist zu wenig über die Religion in Ebla bekannt, um sagen zu können, welchen politische Wert es für den König hatte, eine Schwester oder Tochter als dam-dig gir in Luban einzusetzen, doch war diese Position wohl mit einer machtpolitisch ähnlich bedeutsamen Stellung verbunden wie jene der En-Priesterin des Nanna von Ur.

Ein intensiv diskutiertes Problem ist die Verwandtschaftsbezeichnung zwischen den dam-diĝir und dem König. Tinib-Dulum wird im Text, der ihre Ausstattung beim Zug nach Luban beschreibt, als „Tochter des Königs“ (dumu-munus en) bezeichnet. In allen späteren Texten wird sie dagegen „Schwester des Königs“ genannt. Tarib-Damu wird im einzigen Text, der sie als dam-diĝir nennt, als ihre Schwester (nin-ni-sù) und Tochter des Königs geführt ${ }^{1129}$. Dieser Text stammt aus der Zeit des Išar-Damu, dessen Tochter Tarib-Damu offensichtlich war. Nach Tinib-Dulums Tod wird Amaga dam-dig gir, und auch sie wird Schwester der Tarib-Damu und Tochter des Königs genannt. Die Frage, wessen Tochter Tinib-Dulum ist, war länger umstritten, inzwischen wird sie allgemein als Tochter des Königs Irkab-Damu anzusehen ${ }^{1130}$. Amaga und Tarib-Damu dagegen sind Töchter des Königs IšarDamu. Wie kann es nun sein, daß sowohl Tinib-Dulum und Tarib-Damu wie auch Tarib-Damu und Amaga als Schwestern bezeichnet werden? Diese Situation ist auf verschiedene Weise erklärt worden, wobei man sich immer bewußt war, daß Verwandtschaftsbezeichnungen nicht immer wörtlich zu verstehen seien. So nahmen Biga/Pomponio an, nin-ni könne auch die Bedeutung „Tante“ haben ${ }^{1131}$, wogegen Archi den Ausdruck dumu-munus en im Text MEE 10, 41 (Zug nach Luban) allgemein mit „Prinzessin“ übersetzen möchte ${ }^{1132}$. Meiner Ansicht nach sind derartige Hilfskonstruktionen jedoch in diesem Fall nicht nötig. Archi datiert den Text MEE 10, 41 in die Regierungszeit des Wesirs Ibrium und übersetzt dumu-munus en mit „Prinzessin“, da Tinib-Dulum in allen anderen Ibrium-zeitlichen Texten

The high priestess, dam-dingir, at Ebla, FS Loretz (1998), S. 45f und 50.

1129 Archi, The high priestess, dam-dingir, at Ebla, FS Loretz (1998), S. 48.

1130 Archi, ebd.; Biga, Prosopographie, Amurru I (1996), S. 31. Biga und Pomponio nahmen früher an, sie sei eine Tochtes von Igriš-Halam und damit Schwester des Irkab-Damu (Biga/Pomponio, Chronological Division, JCS 42 (1990), S.182 Anm. 10).

1131 Biga/Pomponio, Chronological Division, JCS 42 (1990), S. 182 Anm. 11.

1132 Archi, The high priestess, dam-dingir, at Ebla, FS Loretz (1998), S. 48. 
„Schwester des Königs“ (Išar-Damu) genannt wird. Doch wie Archi selber an anderer Stelle ausgeführt hat, war Ibrium schon beim Tod von Irkab-Damu Wesir ${ }^{1133}$. Wenn man nun davon ausgeht, daß Tinib-Dulum kurz vor dem Tod ihres Vaters dam-digir wurde, ist sowohl die Bezeichnung „Tochter des Königs“ in MEE 10, 41, wie auch die als „Schwester des Königs“ in allen späteren Texten korrekt. Bleibt das Problem der drei Frauen, die untereinander als „Schwestern“ bezeichnet werden. Doch auch hier ist keine übertragene Lesung von nin-ni nötig, wenn man davon ausgeht, daß ein neuer König beim Tod seines Vorgängers dessen Frauen übernahm. Dafür spricht auch, daß in den Listen der da m en kein Bruch beim Herrscherwechsel zu erkennen ist. Ich halte es für denkbar, daß Tinib-Dulum und Tarib-Damu verschiedene Väter, aber dieselbe Mutter hatten, wogegen Tarib-Damu und Amaga beide Kinder eines Vaters, nämlich des Königs Išar-Damu waren. $\mathrm{Ob}$ es eine Bedeutung hat, daß die letzten drei dam-dig ir -Priesterinnen jeweils (Halb)Schwestern waren, ob also auch der Grad der Verwandtschaft der Amtsinhaberinnen untereinander bei der Wahl einer neuen dam-dig $\mathrm{g}$ ir eine Rolle spielte, oder ob hier lediglich die Herkunft aus dem Königshaus von Bedeutung war, ist nicht zu entscheiden.

\section{Priesterinnen aus dem Königshaus von Akkade}

\section{En-hedu-ana}

Eine der herausragendsten Gestalten der Akkadezeit war En-hedu-ana, die Tochter des Dynastiegründers Sargon und En-Priesterin des Mondgottes von Ur. Nur wenige Quellen aus ihrer Zeit sind erhalten: die Siegel von dreien ihrer Diener ${ }^{1134}$ sowie die bekannte Alabasterscheibe aus $\mathrm{Ur}^{1135}$ mit einer Inschrift, von der auch eine altbabylonische Abschrift existiert ${ }^{1136}$. Daneben sind aus altbabylonischer Zeit mehrere Literaturwerke überliefert, welche En-hyedu-ana zugeschrieben werden. Es handelt sich dabei im einzelnen um die Hymnen an Inanna nin-me-šara ${ }^{1137}$ und in-nin šà-gur ${ }_{4}-\mathrm{ra}^{1138}$, sowie um die

\footnotetext{
1133 Archi, Chronologie relative, Amurru I (1996), S. 25.

1134 RIME 2, Sargon E2.1.1.2003-2005.

1135 Orthmann, Der alte Orient (1985), Taf. 101.

1136 RIME 2, Sargon E2.1.1.16 = FAOS 7, Sargon A 1 (S. 64/65), wo Original und Kopie nebeneinander gestellt sind.

1137 Hallo/van Dijk, The Exaltation of Inanna (1968); Zgoll, Der Rechtsfall der En-hyeduAna (1997).

1138 Sjöberg, in-nin šá-gur ${ }_{4}$-ra (1975/76).
} 
sumerischen Tempelhymnen ${ }^{1139}$ und möglicherweise das Epos „Inanna und Ebeh “"1140. Obwohl von diesen literarischen Werken keine Zeugen aus der Akkadezeit selber überliefert sind, wird die Autorenschaft En-hedu-anas, die in den Hymnen nin-me-šara und in-nin šà-gur ${ }_{4}$-ra im Text ausdrücklich genannt ist, allgemein nicht angezweifelt. ${ }^{1141}$ Dasselbe gilt für die Tempelhymnen, deren Kolophon angibt, sie seien von En-hyedu-ana zusammengestellt worden. ${ }^{1142}$

Auf der Alabasterscheibe ist im Relief eine kultische Handlung dargestellt, bei welcher eine männliche Person eine Libation darbringt. Hinter ihm steht eine weibliche Figur in Falbelgewand und mit einem Turban/einer Wulstkappe bekleidet, hinter ihr stehen zwei weitere, möglicherweise männliche Teilnehmer an dem Geschehen. Es ist davon auszugehen, daß es sich bei der Person im Falbelgewand um En-hyedu-ana selber handelt, da die Inschrift auf der Rückseite besagt, sie, die Priesterin des Nanna (MUNUS.NUNUZ.ZI $\left.{ }^{d} n a n n a\right)$ und Frau des Nanna (dam dnanna) habe im Tempel der Inanna.ZA.ZA einen Altar errichtet und diesen „Altar, Tisch des An“ mit Namen benannt ${ }^{1143}$. Daß die Inschrift in einer Kopie aus altbabylonischer Zeit vorliegt, zeigt, welch hohe Stellung und welche Bedeutung En-hedu-ana gehabt haben muß, denn dieser Inschrift der En-Priesterin wurde dieselbe Wichtigkeit beigemessen wie den Inschriften von Königen, die in späteren Zeiten kopiert wurden. ${ }^{1144}$

En-hyedu-ana wurde von ihrem Vater oder von einem seiner Nachfolger in das Amt der En-Priesterin des Mondgottes in Ur eingesetzt. Wann genau dies geschah, ist nicht bekannt, da anders als bei Tūta-napšum ${ }^{1145}$ keine Datenformel

1139 Sjöberg/Bergmann, TCS III (1969); Wilcke, Der aktuelle Bezug der Sammllung der sumerischen Tempelhymnen und ein Fragment eines Klageliedes, ZA 62 (1972), S. 35-61.

1140 Bottéro/Kramer, Lorsque les dieux faisaient l'homme (1989), S. 219-229. Siehe dazu Volk, Inanna und Šukaletuda (1995), S. 15 und Zgoll, Ebeh und andere Gebirge in der politischen Landschaft der Akkadezeit (2000), S. 83-90.

1141 Zgoll hat die Argumente für eine Entstehung von in-nin šà-gur ${ }_{4}-r a$ in der Akkadezeit ausführlich diskutiert. Der Rechtsfall der En-ḩedu-Ana (1997), S. 179184.

1142 Sjöberg/Bergmann, TCS III (1969), S. 5.

1143 Zur Darstellung s. Winter, Women in Public, CRAI 33 (1987), S. 190-192; Collon, Depiction of Priests and Priestesses (1999), S. 20-21.

1144 Westenholz, Enheduanna, FS Sjöberg (1989), S. 540. Nicht nur En-hyedu-anas Inschrift wurde später kopiert, auch Inschriften ihrer Nachfolgerin En-men-ana (RIME 2, Narām-Sîn E2.1.4.33) und der Enlilpriesterin Tūta-napšum (RIME 2, Narām-Sîn E2.1.4.20) liegen in späteren Abschriften vor.

1145 Siehe S. 257. 
auf die Bestimmung der En-hyedu-ana zum Priesteramt oder auf ihre Einsetzung hinweist. Sie bezeichnet sich selber auf der Alabasterscheibe aus Ur als Tochter Sargons, und zwei ihrer Diener geben eben diese Filiation ihrer Herrin auf ihren Siegeln an ${ }^{1146}$. Nach der Analyse von Nagel und Strommenger sind alle drei Inschriften auf die Zeit nach Sargons Tod zu datieren, da er ohne seinen Titel genannt wird, was darauf deutet, daß der Königstitel zum Entstehungszeitpunkt der Inschriften von einem seiner Nachfolger getragen wurde. ${ }^{1147}$ Doch sagt das nichts darüber aus, ab wann En-hyedu-ana Priesterin in Ur war.

Ihr Name (En, Zierde Ans) ist mit Sicherheit ein Amtsname, da alle ihre Nachfolgerinnen einen mit dem Element „En“ beginnenden Namen führten, in dem bis auf zwei Ausnahmen auch das Element „An“ enthalten war ${ }^{1148}$. Ob sie diesen Namen bei der Inthronisation angenommen hat, oder schon, nachdem sie für das Amt bestimmt worden war, ist nicht mehr festzustellen.

Ebensowenig ist bekannt, wie die Einsetzung der En-Priesterin des Nanna vonstatten ging. Nach Westenholz ist das von ihr publizierte Preislied an Nanna möglicherweise zur Inthronisation En-hyedu-anas geschrieben worden, da es sie namentlich nennt und ihre priesterlichen Funktionen auflistet. ${ }^{1149}$ Nach diesem Text gehörten verschiedene Reinigungsriten sowie die Annahme des neuen Namens zur Zeremonie der Inthronisation, bei welcher die Priesterin auch zum ersten Mal das Giparu, ihren Amtssitz, betrat. ${ }^{1150}$ Allerdings ist fraglich, ob dieser Text wirklich auf die Einsetzung der En-hyedu-ana zurückgeht, oder ob er ein später gängiges Ritual widerspiegelt und den Namen der Sargontochter nur erwähnt, weil sie eine berühmte Vorgängerin der Amtsinhaberin zur Zeit der Abfassung des Textes war.

Wie das Giparu in Ur zur Zeit der En-hyedu-ana ausgesehen hat, ist nicht bekannt, aus der Akkadezeit sind keine architektonischen Strukturen an der

1146 Siegel des Ilum-palil (RIME 2, Sargon E2.1.1.2003): en-hye-du $_{7}-\mathrm{an}-\mathrm{n}$ a/du mu sár-ru-GI; beim Siegel des [x]-kituš teilweise ergänzt (RIME 2, Sargon E2.1.1.2005).

1147 Nagel/Strommenger, Reichsakkadische Glyptik, BJVF 8 (1968), S. 146-150. Stilistisch ordnet Boehmer (Entwicklung der Glyptik während der Akkad-Zeit) die Siegel den Stufen Reichsakkadisch Ib (Nr 184 = RIME 2, Sargon E2.1.1.2003) und Ic (Nr. 458 = RIME 2, Sargon E2.1.1.2005) zu, was nach seinem Schema eine Datierung in die Zeit Sargons (Ib) bis in die ersten Jahre von Rimuš (Ic) bedeuten würde.

1148 Hallo/van Dijk, Exaltation (1968), S. 8-9; zu der Form der Namen s. Edzard, Enmebaragezi von Kiš, ZA 53 (1959), S. 15-19.

1149 Westenholz, Enheduanna, FS Sjöberg (1989), S. 552-555.

1150 Westenholz, Enheduanna, FS Sjöberg (1989), S. 545; Zgoll, Rechtsfall der En-hyeduAna (1997), S. 113. 
Stelle des Bauwerks erhalten. Daß es ihr als Wohn- und Amtssitz gedient hat, ist mehr als wahrscheinlich, da es in den nachfolgenden Epochen der Sitz der En des Nanna gewesen ist. Es ist gut möglich, daß die En-Priesterinnen der Akkadezeit in den Gebäuden lebten, die im späten Frühdynastikum errichtet worden waren, da aus dieser Zeit Gebäudereste erhalten sind, auf welche direkt die Ur III-zeitlichen Strukturen erbaut worden sind. ${ }^{151}$ Ob die Pflicht, die Tempel auch baulich zu erhalten, zu verschönern oder auszubauen für die EnPriesterinnen schon in dieser Zeit bestand, wie Westenholz mit Hinweis auf den von ihr publizierten literarischen Text postuliert ${ }^{1152}$, ist nicht durch Bauoder Gründungsinschriften zu belegen, doch im Vergleich zu den Inschriften ihrer Nachfolgerinnen im $\mathrm{Amt}^{1153}$ als wahrscheinlich anzunehmen.

Der auffallendste Aspekt im literarischen Werk der En-hyedu-ana ist die Tatsache, daß sie, obwohl sie En-Priesterin des Nanna war, die beiden großen Hymnen nin-me-šara und in-nin šà-gur ${ }_{4}-\mathrm{ra}$ an die Göttin Inanna richtete. Diese besondere Verehrung für Inanna war kein Zufall, sondern vielmehr Bestandteil der Politik der Akkadekönige zur Sicherung ihrer Herrschaft in Sumer. Dort kam es nach dem Sieg Sargons über Lugalzagesi von Uruk wiederholt zu Aufständen, da der neue König als fremder Herrscher gesehen wurde, der nicht wie die Könige vor ihm das Königtum als Stadtfürst in seine Stadt holte, sondern erstmals in der mesopotamischen Geschichte ein großes Reich unter seiner Herrschaft vereinte und sich damit nicht „traditionell“ verhielt. Sargon und seine Nachfolger versuchten, sich in der Tradition der sumerischen Stadtfürsten und als deren legitime Nachfolger darzustellen ${ }^{154}$, gleichzeitig setzten sie Familienangehörige in hohen Positionen ein, um so ihre Machtposition zu sichern ${ }^{1155}$. In diesem Zusammenhang wurde En-hedu-ana in Ur, der Stadt, die kulturelles Zentrum und zuvor Sitz des Königtums gewesen war, als Priesterin und Gemahlin (dam) des Nanna eingesetzt. Sie engagierte sich in dieser Funktion jedoch auch für den Kult der Göttin Inanna. Man nimmt heute an, daß eine akkadische Ištarmanifestation als Göttin der neuen Hauptstadt Akkade und Schutzpatronin des Königshauses betrachtet wurde. En-hyedu-ana soll versucht haben, Inanna

\footnotetext{
1151 Weadock, The Giparu at Ur, Iraq 37 (1975), S. 105-106.

1152 Westenholz, Enheduanna, FS Sjöberg (1989), S. 549.

1153 Vgl. die Inschrift der En-ane-du, RIME 4, Rīm-Sîn I E4.2.14.20.

1154 Dazu gehörte, daß Sargon sich als der von Enlil, dem obersten Gott des sumerischen Pantheons erwählte König darstellte (PBS 5, 34 und 41 und PBS 15, 41; Sollberger/ Kupper, IRSA (1971), IIA1a.
}

1155 Foster, Management and Administration (1993), S. 28; Winter, Women in Public, CRAI 33 (1987), S. 200-201. 
als Tochter des Mondgottes zu erhöhen und als Reichsgöttin zu etablieren, ${ }^{1156}$ vielleicht wurde die Synkretisierung der Inanna von Uruk mit Ištar von Akkade angestrebt. ${ }^{1157} \mathrm{Ob}$ En-hyedu-ana auch in Uruk, der Stadt der Inanna, priesterliche Funktionen wahrnahm, wie Hallo/van Dijk es annehmen ${ }^{1158}$, ist aus den Quellen nicht zu belegen.

Die Herrschaft der Akkadekönige wurde in Sumer immer wieder durch Unruhen und Aufstände gefährdet. Im Zusammenhang mit dem Aufstand eines Lugal-Ane in Ur wurde En-hyedu-ana zeitweise aus ihrem Amt und aus Ur vertrieben. Die Rekonstruktion der Ereignisse, die mit diesem Aufstand zusammenhingen, ist historisch nicht unproblematisch, da sie sich ausschließlich auf literarische Quellen, nämlich die der En-hyedu-ana zugeschriebenen Hymnen, stützen, welche uns nur in Abschriften aus altbabylonischer Zeit vorliegen. Es läßt sich daher nicht sagen, inwiefern die historischen Aussagen dieser Texte in späterer Zeit überarbeitet und verändert worden sind ${ }^{1159}$.

Die politischen und religiösen Aspekte von nin-me-šar a sind von Zgoll ausführlich diskutiert worden. Dabei weist sie auf folgende Problematik hin, vor die En-hyedu-ana sich gestellt sah: Der Aufstand des Lugal-Ane richtete sich gegen die Herrschaft der Könige von Akkade, deren Vertreterin En-hyeduana war. Gleichzeitig jedoch war sie auch Priesterin des Nanna von Ur, und als solche hätte sie den von Nanna erwählten siegreichen Lugal-Ane in sein Amt einführen müssen ${ }^{1160}$. En-hyedu-ana vertrat jedoch die Auffassung, daß das Recht der Investitur des Herrschers nun auf Inanna, die Tochter des Nanna und Göttin der Akkadekönige übergegangen war, und rief An als Richter in diesem Streit $a^{1161}$. Im Zuge der Auseinandersetzung wurde En-hedu-ana aus Ur vertrieben, konnte jedoch nach der Niederschlagung des Aufstandes in ihr Amt

1156 Zgoll, Rechtsfall der En-hedu-Ana (1997), S. 121.

1157 Hallo/van Dijk, Exaltation (1968), S. 9. Dazu paßt die Beobachtung von Zgoll, daß der Name der Inanna selbst in n in - m e-šar a selten auftaucht. Die Göttin wird eher als „meine Herrin“ oder „Tochter Suens“ bezeichnet, wobei der Name des Mondgottes akkadisch geschrieben ist, was der akkadischen Bezeichnung der Inanna als Ištar entsprechen würde. Möglicherweise ist INANNA in diesem Text logographisch für Ištar zu lesen (Zgoll, Rechtsfall der En-hुedu-Ana (1997), S. 156 Anm. 628). Hallo/van Dijk, Exaltation (1968), S. 8-9.

1159 Huber hat kürzlich in ihrer Studie "La Correspondance Royale d'Ur, un corpus apocryphe" (ZA 91 (2001), S. 169-206) gezeigt, daß die Korrespondenz der Ur IIIKönige erst in altbabylonischer Zeit verfaßt wurde. Es ist zu fragen, ob dies auch bei einigen der En-hedu-ana-Hymnen der Fall ist und diese somit nicht als Primärquelle für die altakkadische Zeit verwendet werden können.

1160 Zgoll, Rechtsfall der En-hedu-Ana (1997), S. 155.

1161 Zgoll, Rechtsfall der En-hyedu-Ana (1997), S. 99-107. 
zurückkehren. Welche Ereignisse zur Rückkehr En-hyedu-anas nach Ur führten und wie lange dieser Aufstand dauerte, ist nicht bekannt. Falkenstein wies darauf hin, daß es keinen authentischen Beleg für eine formale Amtsenthebung En-hyedu-anas gibt. ${ }^{162}$ Es ist also gut möglich, daß sie zwar als Angehörige des Königshauses aus Ur vertrieben wurde, es aber nicht zu einer förmlichen Amtsenthebung kam, sei es, weil der Aufstand zu schnell niedergeschlagen wurde, oder weil religiöse Gründe gegen ein derartiges Vorgehen sprachen. Auch in späterer Zeit gibt es Belege dafür, daß eine En-Priesterin nach der Eroberung von Ur von dem neuen Herrscher im Amt belassen wurde. ${ }^{1163}$

Das Bild, das uns durch den Hymnus nin-me-šara von En-hyedu-ana vermittelt wird, ist das einer engagierten Frau, die sich im Rahmen ihrer hohen priesterlichen Funktion aktiv am politischen Geschehen beteiligt und versucht, die Herrschaft ihrer Familie religiös zu untermauern.

Immer wieder ist die Frage diskutiert worden, ob das Amt der En-Priesterin des Nanna von Ur von Sargon neu geschaffen worden ist, oder ob es sich um eine Institution handelte, die schon lange vorher bestand. Fest steht, daß Enhedu-ana die erste Amtsinhaberin ist, die wir (bisher) namentlich kennen. Glassner, Hallo und Steinkeller haben neben anderen die Auffassung vertreten, Sargon habe mit der Einsetzung seiner Tochter als En des Nanna eine neue Tradition begründet, mit der er seine Herrschaft in Sumer sichern wollte ${ }^{1164}$. Dagegen argumentiert Winter, daß eine Konsolidierung der Herrschaft durch die Einsetzung einer Prinzessin aus dem Herrscherhaus von Akkade in Sumer nur möglich gewesen sei, wenn es für das Amt einer En des Nanna schon eine längere kultische Tradition gegeben habe ${ }^{165}$. Van Dijk wies darauf hin, daß die Tatsache, daß wir keine Namen von Vorgängerinnen haben, nicht bedeute, daß es sie nicht gegeben hat ${ }^{1166}$, und Zgoll nennt Belege für das Amt einer Priesterin des Nanna in präsargonischen Texten ${ }^{1167}$. Als ein Beleg dafür, daß Sargon einer Tradition folgte, sieht Westenholz die Tatsache, daß auch die Ur III-Könige, die bestrebt waren, vorsargonische Verhältnisse wieder herzustellen, ihre Töchter in dieses Amt einsetzten. ${ }^{1168}$

\footnotetext{
1162 Falkenstein, Enheduanna, die Tochter Sargons von Akkade, RA 53 (1958), S. 130.

1163 So z.B. Enannatuma, Tochter des Išme-Dagān, die nach der Eroberung Urs durch Gungunum in ihrem Amt belassen wurde. Sollberger, Sur la chronologie des rois d'Ur, AfO 17 (1954-56), S. 25.

1164 Hallo, Women of Sumer, BiMes 4 (1976), S. 29; Glassner, La Chute d'Akkadé, BBVO 5 (1986), S. 12; Steinkeller, On Rulers, Priests (1999), S. 124.

1165 Winter, Women in Public, CRAI 33 (1987), S. 200-201.

1166 Van Dijk, Les contactes ethniques (1969), S. 192.

1167 Zgoll, Rechtsfall der En-hyedu-Ana (1997), S. 100.

1168 Westenholz, The Old Akkadian Period (1999), S. 38.
} 


\section{En-men-ana und ک̌umšan̄}

Von En-men-ana und Šumšan̄i, beides Töchter von Narām-Suen, ist nur sehr wenig bekannt. Von Šumšanī ist nur eine einzige Inschrift auf einem in Mari gefundenen Bronzegefäß erhalten. In der Inschrift bezeichnet sie sich als Tochter Narām-Suens und Entu des Šamaš in Sippar(?) ${ }^{1169}$. Wann sie ihr Amt angetreten hat, wie lange sie es innehatte und welche Funktionen sie genau in diesem Zusammenhang zu erfüllen hatte, ist nicht zu sagen.

Nur wenig mehr weiß man von En-men-ana, der Nachfolgerin von Enhedu-ana. Von ihr ist ein Türangelstein aus dem Giparu in Ur erhalten, der in der Kassitenzeit wiederverwendet wurde und auf dem nur der Name der Enmen-ana ohne einen Titel eingeschrieben ist ${ }^{1170}$. Des weiteren ist das Fragment der Abschrift einer Inschrift von ihr erhalten, in welcher sie sich als zirru des Nanna, dam des Nanna, en des Suen und Tochter Narām-Suens bezeichnet. ${ }^{1171}$ Daneben sind die Siegel von zwei ihrer Diener erhalten, ihres Türwächters und ihres Schreibers ${ }^{1172}$, sowie eine Weihplatte mit Inschrift aus Ur, welche Ištup-Ilum, ihr Haushofmeister, dem Gott Nin-Gublaga von Asuggišdua für das Leben des Narām-Suen und der En-men-ana geweiht hat ${ }^{1173}$. Diese Weihplatte stammt ebenso wie das Siegel des Schreibers aus der zweiten Hälfte der Regierungszeit Narām-Suens, da dessen Name mit dem Gottesdeterminativ geschrieben ist. En-men-ana ist die erste En des Nanna, deren Bestimmung durch ein Omen in einer Datenformel überliefert ist ${ }^{1174}$. Da die Reihenfolge der Datenformeln für Narām-Suen nicht bekannt ist, wissen wir nicht, wann En-men-ana für das Priesteramt bestimmt wurde. Es gibt auch keine zweite Datenformel, die auf ihre Einsetzung in das Amt verweisen

1169 Der zweite Teil der Inschrift ist von Frayne (RIME 2, Narām-Sîn E2.1.4.51) etwas anders rekonstruiert als von Gelb/Kienast (FAOS 7, S. 112, Narāmsîn B 10). Er liest in

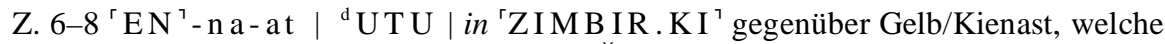

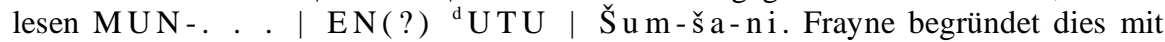
einer Korrektur nach dem veröffentlichten Foto und einer Skizze, welche jedoch beide (zumindest in den Publikationen) von schlechter Qualität sind. Siehe auch Kienast/Sommerfeld, FAOS 8, S. 340f., wo die Inschrift nochmals aufgenommen wurde. Die Bearbeitung entspricht jener in RIME.

RIME 2, Narām-Sîn E2.1.4.34.

RIME 2, Narām-Sîn E2.1.4.33.

RIME 2, Naram-Sîn E2.1.4.2019, Siegel des Türwächters Ursi; RIME 2, Narām-Sîn E2.1.4.2020, Siegel des Schreibers LU-X.

RIME 2, Narām-Sîn E2.1.4.2018.

Naram-Sin Jahr "ll", RIME 2, S. 87, [mu] en dnanna na-<ra $\rangle-a m-{ }^{d}$ en-zu ${ }^{r} \mathrm{maš}{ }^{\urcorner}-\mathrm{e}{ }^{\ulcorner} \mathrm{id}^{\urcorner}-\mathrm{dab} \mathrm{b}_{5}-\mathrm{ba}$,Jahr, die En-Priesterin des Nanna, Tochter des NaramSuen, wurde durch Omen bestimmt". 
würde. Somit ist nicht zu sagen, wieviel Zeit zwischen ihrer Bestimmung durch das Omen und der Investitur vergangen ist. Da in der Datenformel der Königsname ohne Gottesdeterminativ geschrieben wird, ist die Bestimmung En-men-anas in die erste Hälfte der Regierung ihres Vaters zu datieren. Wie sie ihr Amt ausgefüllt hat, und ob sie ähnlich ihrer Vorgängerin auch politisch aktiv geworden ist, ist derzeit nicht festzustellen. Die Überlegung von Nagel/Strommenger, bei En-men-ana handele es sich möglicherweise um die Narām-Suen-Tochter ME-Ulmaš, die ansonsten nur durch eine Inschrift auf einem Bronzegefäß aus Mari bekannt ist ${ }^{1175}$, und En-men-ana sei der Priesterinnenname, den ME-Ulmaš angenommen habe ${ }^{1176}$, ist interessant, da damit auf die Problematik aufmerksam gemacht wird, daß wir aufgrund der Annahme eines Amtsnamens die Aktivitäten einer Priesterin vor ihrer Amtseinführung nicht verfolgen können. Belegen läßt sich die Vermutung, ME-Ulmaš sei En-men-ana, ebensowenig wie widerlegen.

Möglicherweise war En-men-ana die Empfängerin von Zwiebeln in OSP II 143. ${ }^{1177}$ Da der Text undatiert ist, lässt sich nicht sagen, wer die hier erwähnte En des Nanna war. Für En-men-ana spricht, daß die Texte aus dem sogenannten „Zwiebelarchiv“, zu dem OSP II 143 gehört, hauptsächlich in die Regierungszeiten von Narām-Suen und Šar-kali-šarrī datieren.

\section{Tūta-napšum}

Neben Šumšan̄i und En-men-ana setzte Narām-Suen eine weitere Tochter als En-Priesterin ein: die Prinzessin Tūta-napšum als En des Enlil in Nippur. Zur Frage, wie sie ihr Amt geführt hat, ist ebensowenig bekannt wie bei ihrer Schwester En-men-ana, doch anders als die En-Priesterinnen des Nanna von Ur, wird Tūta-napšum in Wirtschaftstexten erwähnt. Ob es sich beim Namen der Prinzessin um einen Amtsnamen als Priesterin handelte, ähnlich den Amtsnamen der En-Priesterinnen des Nanna von Ur, ist nicht zu sagen, auffällig ist jedoch die Tatsache, daß die Prinzessin keinen mit dem Element En- beginnenden Namen trug. ${ }^{1178}$

In zwei Quellen wird sie als En-Priesterin des Enlil bezeichnet. Das eine ist das Siegel ihrer Dienerin Aman-Aštar ${ }^{1779}$, das andere die altbabylonische Kopie einer Inschrift der Tūta-napšum, in welcher sie sich Tochter des Narām-Suen

\footnotetext{
1175 RIME 2, Narām-Sîn E2.1.4.52.

1176 Nagel/Strommenger, Reichsakkadische Glyptik, BJVF 8 (1968), S. 181.

1177 Dies vermutet Such-Gutiérrez, Beiträge zum Pantheon von Nippur im 3. Jahrtausend (2003), Teil I S. 254.

1178 Westenholz, The Clergy of Nippur (1992), S.304.

1179 RIME 2, Narām-Sîn E2.1.4.2017.
} 
nennt ${ }^{180}$. Auf zwei weiteren Fragmenten ist der Name der Tūta-napšum möglicherweise zu ergänzen, doch wäre in beiden Fällen auch eine andere Lesung denkbar. Das eine ist das Fragment einer Weihplatte, das andere das Fragment eines Steingefäßes ${ }^{1181}$. Tūta-napšum wurde wie En-men-ana durch Omen für ihr Amt bestimmt, und dieses Ereignis war für Narām-Suen so bedeutsam, daß es in einer Datenformel festgehalten wurde ${ }^{1182}$. Ähnlich wie bei En-hyedu-ana stellt sich die Frage, ob Narām-Suen mit der Einsetzung seiner Tochter einer Tradition folgte, oder ob er das Amt neu geschaffen hat. Bisher ist sie die einzige En-Priesterin des Enlil, die uns heute bekannt ist, und es hat den Anschein, als habe Narām-Suen hier eine Neuerung vorgenommen, der seine Nachfolger nicht gefolgt sind ${ }^{1183}$.

Die Entscheidung des Königs, Tūta-napšum als En-Priesterin in Nippur zu installieren, ist wohl im Zusammenhang mit Unruhen im Süden zu sehen, denen Narām-Suen mit verschiedenen Maßnahmen begegnete. Daß er dem Enliltempel von Nippur größere Aufmerksamkeit schenkte, zeigt sich an einer Datenformel, die an Bauarbeiten an diesem Tempel erinnert ${ }^{184}$. Die Einsetzung seiner Tochter als En-Priesterin und möglicherweise seines Sohnes Šar-kališarrī als Gouverneur in Nippur ${ }^{1185}$, also von zwei Familienangehörigen in hoher Position in dieser Stadt, könnte ein Zeichen dafür sein, daß Narām-Suen sowohl die Aktivitäten der Priesterschaft wie auch der städtischen Verwaltung genau unter Kontrolle haben wollte. Wenn Fosters Rekonstruktion einer Reise

1180 RIME 2, Narām-Sîn E2.1.4.20.

1181 RIME 2, Narām-Sîn E2.1.4.18 (Weihplatte) und RIME 2, Narām-Sîn E2.1.4.19 (Gefäß). Zu der Weihplatte s. Westenholz/Oelsner, Zu den Weihplattenfragmenten der Hilprechts-Sammlung Jena, AoF 10 (1983), S. 212-214.

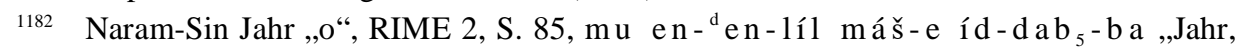
die En-Priesterin des Enlil wurde durch Omen bestimmt“. Auch das Jahr Naram-Sin „o" “ verweist auf die En-Priesterin des Enlil: in $1 \mathrm{mu}$ nin-diĝir den-líl-lá (RIME 2, S. 86). Michalowski nimmt an, daß das Datum „o“ sich nicht auf die Bestimmung der Tūta-napšum bezieht, da die Priesterin im einen Fall als „en “, im anderen als „,nin-dig ir “ bezeichnet wird. Er räumt aber ein, daß die Beziehungen zwischen den einzelnen Termini für Priesterinnen noch unklar sind (Michalowski, Tudanapšum, RA 75 (1991), S. 174). Zur Titulatur der Tūta-napšum siehe auch SuchGutiérrez, Beiträge zum Pantheon von Nippur im 3. Jahrtausend (2003), Teil I S. 4547.

1183 Michalowski, Tudanapšum, RA 75 (1991), S. 175.

1184 Naram-Sin Jahr "n", RIME 2, S. 85, in 1 mu dna-ra-am-den-zu ús-sí é denlíl [i]n nibruki 'ù é dinanna in ${ }^{7}$ abalaki 1 s-ku-nu ,Jahr, in dem Naram-Sin die Fundamente des Enliltempels in Nippur und des Ištartempels in Zabala legte“.

1185 Michalowski, Tudanapšum, RA 75 (1991), S. 175. 
von Narām-Suen, seiner Königin und den Kindern Šar-kali-šarrī, Bin-kali-šarrī und Tūta-napšum nach Girsu und Nippur zutreffend ist ${ }^{1186}$, wäre es durchaus denkbar, daß diese Reise im Zusammenhang mit der Investitur der Tūtanapšum als En-Priesterin des Enlil zu sehen ist, und daß bei diesem wichtigen Ereignis das Königspaar durch die gemeinsame Anwesenheit die Verbundenheit mit dem alten Kultzentrum des Enlil zeigen wollte. Schließlich war Enlil in frühdynastischer Zeit als König der Götter einer der Gottheiten gewesen, der die Königswürde verliehen und in dessen Stadt die Ratsversammlung der Götter getagt hatte ${ }^{1187}$. Auch wenn sich die Akkadekönige nicht mehr über Enlil, sondern eher über dessen Sohn Nanna/Suen legitimierten, war der Einfluß der Priesterschaft von Nippur sicher nicht zu unterschätzen, und die Anwesenheit des Königspaares bei bestimmten kultischen Handlungen, sowie die ständige Anwesenheit der Tūta-napšum sind wirkungsvolle Maßnahmen gewesen, die Herrschaft des Königs in Nippur zu festigen ${ }^{1188}$.

Einige Wirtschaftstexte, die Tūta-napšum erwähnen, zeigen, daß die Prinzessin über Vieh und Ländereien verfügte, die von ihren eigenen Funktionären verwaltet wurden. So verzeichnet die Urkunde MVN 3, 1 Silbereinzahlungen in einen Fonds an den Haushofmeister (šabra é) der Tūtanapšum über einen Zeitraum von $10 \mathrm{Jahren}^{1189}$. Da die Prinzessin hier ohne jeden Titel genannt ist, ist nicht bekannt, ob der Text in die Zeit vor ihrer Inthronisation in Nippur zu datieren ist, oder ob ihr Priesteramt für die Transaktion nicht von Bedeutung war. Tiere mit ihrem Brand erwähnt der Text RTC 133b, wo ihre Ochsen nach denen der Königin aufgeführt sind. Auch in diesem Text trägt Tūta-napšum keinen Titel ${ }^{190}$. Ein Text aus Ešnunna nennt einen ihrer Diener in der Zeugenliste ${ }^{1191}$, und ein möglicherweise aus Isin

1186 Foster, Sargonic Royal Progress, JANES 12 (1980).

1187 Westenholz, Old Akkadian Empire (1979), S. 109; Wilcke, Politik im Spiegel der Literatur (1993), S. 30.

1188 Zur Bedeutung Nippurs in frühdynastischer und altakkadischer Zeit siehe Sallaberger, Nippur als religiöses Zentrum Mesopotamiens (1997), S. 148-152. Zum Bauprojekt am Ekur von Nippur unter der Herrschaft der Akkadekönige siehe auch A. Westenholz, OSP II, S. 24-27.

1189 Westenholz/Westenholz, Die Prinzessin Tutanapsum, AoF 10 (1983).

1190 ebd. S. 387; Michalowski, Tudanapšum, RA 75 (1991), S. 173-174.

1191 MAD 1, 179; Michalowski, Tudanapšum, RA 75 (1991), S. 173; Westenholz/ Westenholz (Die Prinzessin Tutanapsum, AoF 10 (1983), S. 387) weisen darauf hin, daß nicht sicher ist, ob es sich hier um die Prinzessin handelt, da sie (wie in den vorher genannten Texten) ohne Titel genannt ist, doch wiesen sowohl der seltene Name wie die Tatsache, daß Frauen selten so selbstverständlich durch Repräsentanten vertreten seien, auf die Prinzessin hin. 
stammender Text, der im Zusammenhang mit der Reise des Königs nach Nippur steht, führt eine Transaktion von 26 gur Datteln der Tūta-napšum auf ${ }^{192}$.

Des weiteren wird Tūta-napšum in zwei Texten über Lieferungen von Zwiebeln genannt. OSP II 170 verzeichnet Ausgaben von Zwiebeln ,als die Tochter des Königs zum Tempel des Enlil ging“, in OSP II 178 werden Zwiebeln geliefert „am Tag als Tūta-napšum (eintrat?)“. Westenholz/ Westenholz hatten angemerkt, daß OSP II 170 sich nicht auf Tūta-napšum, sondern auf ihre Nachfolgerin beziehen müsse, da das Zwiebelarchiv in die Zeit von Šar-kali-šarrī gehöre ${ }^{1193}$, doch da OSP II 178, zum gleichen Archiv gehörig, sie namentlich nennt, ist zu fragen, ob es sich bei dem ,zum Tempel gehen" um die Investitur oder um ein bestimmtes Ritual handelte. Wenn letzteres der Fall ist, könnten sich beide Angaben auf Tūta-napšum beziehen, anderenfalls wäre OSP II 170 möglicherweise ein Beleg dafür, daß Tūtanapšum nicht die einzige En-Priesterin des Enlil in Nippur war, daß zumindest Narām-Suens Nachfolger dem Vorbild des Vaters mit der Einsetzung einer Tochter in Nippur gefolgt wäre.

Betrachtet man die Wirtschaftsdokumente, die Tūta-napšum nennen, und nimmt man die Belege für den ausgedehnten Landbesitz von namentlich nicht bekannten nin-diĝir Priesterinnen dieser Zeit hinzu ${ }^{194}$, so ist davon auszugehen, daß nicht nur Tūta-napšum über Ländereien und Vieh verfügte, sondern daß dies ebenso für alle anderen En-Priesterinnen, wie En-hedu-ana und En-men-ana, galt. Auch wenn die mäßige Quellenlage keine eindeutigen Belege bietet, so gehe ich doch davon aus, daß die Frauen des Königshauses in der Akkadezeit wirtschaftlich unabhängig waren und ihren Besitz von einer eigenen Dienerschaft verwalten und bearbeiten ließen. In Wirtschaftsdokumenten scheint es nicht notwendig gewesen zu sein, diese Damen mit Name und Titel zu bezeichnen. Man kann beobachten, daß die Königin entweder mit ihrem Namen oder dem Titel genannt wird, wohingegen Tūtanapšum in diesen Texten stets ohne Titel auftaucht. Ganz offensichtlich reichte dies, um deutlich zu machen, um wessen Güter es sich bei den Transaktionen handelte.

1192 Foster, Sargonic Royal Progress, JANES 12 (1980), Text 2 (NBC 6848) S. 37-38. Aufgrund von prosopographischen Übereinstimmungen nimmt Foster an, daß dieser Text in denselben Archivzusammenhang gehört wie MVN 3, 1.

1193 Westenholz/Westenholz, Die Prinzessin Tutanapsum, AoF 10 (1983), S. 387.

1194 Foster, Administration and Use of Institutional Land, Mesopotamia 9 (1982), S. 21, 38; ITT II, 2923; STTI 32. 


\section{Politische Ehen}

Wie schon die Könige von Ebla und von Akkade nutzten auch die Herrscher der dritten Dynastie von Ur die Möglichkeiten, durch dynastische Ehen ihre Beziehungen $\mathrm{zu}$ den Herrschern anderer Regionen zu festigen. Dieser personelle Austausch vollzog sich in beide Richtungen, das heißt, die Könige von Ur heirateten ebenso Töchter auswärtiger Herrscher wie sie ihre eigenen Töchter an fremde Höfe schickten. ${ }^{1195}$ Neben diesen ehelichen Beziehungen zwischen dem Königshaus von Ur und benachbarten Fürsten läßt sich auch eine Heiratspolitik innerhalb des eigenen Reiches beobachten. Mehrere hochrangige Beamten der Administration von Ur waren durch die Ehe mit einer Prinzessin dem Herrscherhaus verbunden. Auf diese Weise versuchten die Könige, im innen- wie im außenpolitischen Bereich einflußreiche Familien der eigenen Dynastie zu verpflichten.

Die dynastischen Beziehungen zu auswärtigen Herrschern sind im größeren Kontext der gesamten Außenpolitik der Reiches von Ur zu sehen. Eine detaillierte Darstellung derselben ist im Rahmen dieser Arbeit nicht möglich. Gleiches gilt für die Thematik der ehelichen Verbindungen der lokalen Elite mit dem Herrscherhaus. Um hier Aussagen über die Auswirkungen einer solchen Eheschließung auf die Laufbahn des einzelnen beurteilen zu können, wäre eine detaillierte Studie zu den familiären Beziehungen der einzelnen einflußreichen Familien untereinander und zum Königshaus erforderlich. Dies ist jedoch ohne umfangreiche prosopographische Vorarbeiten nicht möglich. Im Folgenden sollen deshalb die bekannten dynastischen Verbindungen der Könige von Ur dargestellt werden, politische Ehen im innenpolitischen Bereich jedoch nur in Auswahl, ohne detailliert auf die politischen Hintergründe der einzelnen Eheschließungen einzugehen. Die einzelnen Frauen erscheinen im Augenblick der Eheschließung eher als Objekt eines politischen Abkommens denn als aktiv handelndes Subjekt. Eine aktive Rolle im gesellschaftlichen Leben ist insbesondere für die Frauen zu beobachten, die nach Ur verheiratet wurden. Ob die Prinzessinnen, die aus Ur an einen anderen Hof geschickt wurden, dort eine vergleichbare Stellung einnehmen konnten, ist nicht festzustellen.

1195 Vgl. die Übersicht über die Heiraten zwischen Prinzessinnen aus Ur und auswärtigen Herrschern bei Röllig, RlA 4 (1972-75), S. 283 Artikel „Heirat“, diese Liste ist jetzt zu ergänzen. Die dynastischen Beziehungen zwischen dem Reich von Ur und benachbarten Herrschern sind zusammengestellt bei Sallaberger, OBO 160/3 (1999), S. 160-161. 


\subsection{Der außenpolitische Bereich}

Von vier königlichen Gemahlinnen ist der Herkunftsort bzw. die Herkunftsregion mit großer Sicherheit zu bestimmen. Die Herkunft der TarāmUram aus Mari ist durch eine Weihinschrift gesichert ${ }^{1196}$.

Die Heimat der Šulgi-simtī wird aufgrund ihrer persönlichen Göttinnen Bēlat-Šuhnir und Bēlat-Deraban in der Gegend von Ešnunna vermutet. ${ }^{1197}$ Die ursprünglichen Herkunftsorte der beiden Göttinnen, die Ortschaften Deraban und Suhnir, sind wohl nordöstlich des Gebel-Hamrīn zu lokalisieren, weshalb Frayne die Herkunft der Šulgi-simtī aus dieser nördlichen Region vermutet ${ }^{1198}$. Doch da die Göttinnen Bēlat-Šuhnir und Bēlat-Deraban zu den Hauptgottheiten von Ešnunna zu rechnen sind, und da Ešnunna innerhalb der Verwaltung der Randgebiete des Reiches eine Sonderstellung einnahm, liegt die Vermutung nahe, daß Šulgi-simtī aus dieser Stadt stammte ${ }^{1199}$.

Die Herkunft der Abī-simtī kann auch nur indirekt erschlossen werden. Da ihr Bruder Babati sich auf seinem Siegel als ,šabra der beiden Damen BēlatŠuhnir und Bēlat-Deraban“ bezeichnet ${ }^{1200}$, nahm Sallaberger an, daß auch Abīsimtī aus dieser Region stammte ${ }^{1201}$. Dagegen spricht jedoch, daß diese Königin insbesondere die syrischen Gottheiten Dagān, Išhāra und Haburītum verehrte, was auf eine syrische Herkunft schließen läßt. ${ }^{1202}$

Ti'amat-bāštī verehrte insbesondere die Göttin Ša(w)uška, und dies weist darauf hin, daß sie aus der Gegend von Ninive stammte. ${ }^{1203}$

Folglich läßt sich beobachten, daß die königlichen Gemahlinnen, deren Heimat mit hinreichender Sicherheit zu bestimmen ist, entweder aus dem Norden des Reiches (Ešnunna, Ninive), oder aus dem Westen, aus Syrien, stammten. Eine dynastische Verbindung eines Königs von Ur mit einer Prinzessin aus den östlichen Gebieten ist derzeit nicht bekannt. Die Prinzessinnen aus Ur, die im Zuge einer dynastischen Eheschließung den Hof

\footnotetext{
1196 RIME 3/2.1.1.52, Weihinschrift der Tarām-Uram, Tochter des Apil-kīn von Mari, auf einer altbabylonischen Sammeltafel aus Nippur. Zu Tarām-Uram siehe S. 29.

1197 Siehe S. 32.

1198 Frayne, The Zagros Campaigns of Šulgi and Amar-Suena, SCCNH 10 (1999), S. 156159.

1199 Sallaberger, Der kultische Kalender (1993) S. 19; ders. OBO 160/3 (1999), S. 160; Steinkeller, The Administrative and Economic Organization of the Ur III State, SAOC 46 (1987), S. $22+$ Anm. 12.

1200 RIME 3/2.1.4.32.

1201 Sallaberger, OBO 160/3 (1999), S. 184.

1202 Siehe S. 106.

1203 Siehe S. 226.
} 
von Ur verließen, wurden bevorzugt in Gegenden südöstlich oder nördlich des Reiches geschickt. Eine weitere Verbindung mit einem der syrischen Fürsten scheint für die Könige von Ur nicht erforderlich gewesen zu sein. Offensichtlich waren die Beziehungen zu diesen Regionen im Westen durch die dynastischen Vebindungen mit den aus Syrien stammenden Königinnen Tarām-Uram und Abī-simtī hinreichend gesichert. Dies zeigt sich auch im Fehlen von kriegerischen Auseinandersetzungen der Könige von Ur mit Herrschern von syrischen Staaten.

Schwieriger gestalteten sich dagegen die Beziehungen zu den Territorien im Osten des Reiches von Ur. Während der gesamten Epoche unternahmen die Herrscher zahlreiche Feldzüge in den Norden und Nordosten, gegen Simānum, Urbilum und Zabšali, sowie gegen den Südosten, in die Gebiete von Elam und Anšan. Die Datenformeln aller Könige von Ur weisen derartige Feldzüge aus. Dabei handelte es sich einerseits um Raubzüge, bei denen reiche Beute mit nach Ur gebracht werden konnte, aber auch um um die Versuche, diese Regionen dauerhaft zu beherrschen. ${ }^{1204}$ Dennoch wurde immer wieder versucht, auch diese Regionen auf dem Wege der dynastischen Verbindungen enger an das Königshaus von Ur zu binden.

Die Prinzessin Liwwir-mițțsašu, wurde, wie ihr Vater Šulgi in der Datenformel seines 18. Regierungsjahres festhalten ließ, zur Königin von Marhaši erhöht. 12 Jahre später verheiratete Šulgi eine andere Tochter mit dem Ensi von Anšan. Während über den Erfolg der Beziehungen zu Marḩaši nichts weiter bekannt ist, war die Verheiratung der Prinzessin nach Anšan offensichtlich nicht von Erfolg gekrönt, denn schon im Jahr Š 34 vermerkt die Datenformel die Zerstörung Anšans, und Wirtschaftstexte verzeichnen die Beute aus diesem Feldzug ${ }^{1205}$. Wie Steinkeller ausführte, dienten diese Eheschließungen wohl dazu, jene Region südlich der Susiana ruhig zu halten, während Šulgi Feldzüge in die Gebiete östlich des Tigris und in die Susiana unternahm. ${ }^{1206}$

Auch Šu-Suen gab eine seiner Töchter nach Anšan, wie ein Wirtschaftstext aus dem Jahr ŠS 2 belegt, in dem Lebensmittel, welche die Prinzessin mitnahm, verzeichnet sind. ${ }^{1207} \mathrm{Ob}$ diese Verbindung für Ur positivere Folgen hatte, ist nicht bekannt. Ebenso ist nicht zu ermitteln, ob die Eheschließung der Tarām-Šulgi mit dem Herrscher von Pašime, am Nordostufer des Persischen

\footnotetext{
1204 Potts, Mesopotamia and the East (1994), S. 124-142.

1205 Potts, Mesopotamia and the East (1994), S. 129.

1206 Steinkeller, The Question of Marhaši, ZA 72 (1982), S. 259-260.

1207 Virolleaud, ZA 19 (1905/1906), S. 385 oben; dazu Sigrist/Butz, Wirtschaftliche Beziehungen zwischen der Susiana und Südmesopotamien in der Ur-III-Zeit, AMI 19 (1986), S. 27-29.
} 
Golfes gelegen, die Beziehungen dieser Region zum Reich von Ur positiv beeinflussen konnte. An diese Heirat wurde nicht in einer Datenformel erinnert, bekannt ist diese Verbindung lediglich durch einen Wirtschaftstext aus dem Jahre Š 48, in welchem 10 Stück Kleinvieh ,für das Haus der Tarām-Šulgi, der Tochter des Königs, Ehefrau des Šudda-bāni, des Mannes aus Pašime“ verbucht werden ${ }^{1208}$.

Drei Prinzessinnen aus Ur wurden in den Norden und Nordosten des Reiches verheiratet, wobei auch diese Politik nicht immer die wohl angestrebten stabilen Beziehungen zu den jeweiligen Regionen sicherte ${ }^{1209}$. So wird Kunš̄i-mātum, eine Tochter des Šu-Suen, in Texten aus den Jahren AS 5 bis ŠS 1 als Schwiegertochter (é-g i ${ }_{4}$-a) des Iphuha ${ }^{1210}$ oder des Aribatal ${ }^{1211}$, der Söhne des Pušam von Simānum, bezeichnet. Kunšī-mātum wird nicht als Ehefrau (d a m) einer der Männer aus Simānum angesprochen, welchen Status sie als é-gi $\mathrm{i}_{4}$-a am Hof von Simānum innehatte, ist noch nicht näher zu bestimmen $^{1212}$. Möglicherweise war sie zum Zeitpunkt der Eheabsprache noch ein Kind und lebte zwar schon im Haus ihres Schwiegervaters, jedoch ohne daß die Ehe schon vollzogen worden war. Ob es ein Fehler des Schreibers war, daß sie in ŠA LVIII: 35 (12/vi/AS 5) als é-g $\mathrm{i}_{4}$-a des Iphuha, in den Texten des Jahres ŠS 1 jedoch immer als é - $\mathrm{gi}_{4}$-a des Aribatal genannt wird, oder ob man sich später erst entschied, wem sie zur Frau zu geben war, muß derzeit offen bleiben. Ebenso ist nicht bekannt, wann Kunšī-mātum nach Simānum ging ${ }^{1213}$. Das dritte Regierungsjahr des Šu-Suen ist nach dem Feldzug gegen Simānum benannt, in dessen Verlauf der König seine Tochter, die wohl in Folge innerer Unruhen in Simānum vertrieben worden war $^{1214}$, wieder einsetzte ${ }^{1215}$.

1208 Transliteration und Übersetzung dieses Textes bei Steinkeller, The Question of Marhaši, ZA 72 (1982) S. 241 Anm. 16.

1209 Stolper, On the Dynasty of Šimaški and the Early Sukkalmahs, ZA 72 (1982), S. 8283.

ŠA LVIII: 35 (12/vi/AS 5).

1211 PDT I, 572 (22/ii/ŠS̆ 1); TENS 480 (9/iii/ ̌̌S $\breve{S}$ 1); MVN 15, 216 (9/iii/ŠS 1); AUCT III,

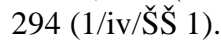

1212 Michalowski, The Bride of Simanum, JAOS 95 (1975), S. 718. Zu den Verwandtschaftstermini siehe Wilcke, Familiengründung im Alten Babylonien (1985), S. 227-228 und 239-240.

1213 Michalowski vermutet, dies sei schon unter Šulgi geschehen; The Bride of Simanum, JAOS 95 (1975), S. 718, Potts (Mesopotamia and the East (1994), S. 132) vermutet eher ein Datum in der Regierungszeit von Amar-Suen.

1214 So die Rekonstruktion der Ereignisse von Michalowski, The Bride of Simanum, JAOS 95 (1975), S. 719.

1215 RIME 3/2.1.4.1, Kol IV Z. 26-33. 
Auffallend ist der Name der nach Simānum verheirateten Prinzessin: Kunš̄̄mātum (Land, unterwirf dich!). Hier liegt es nahe, die Namenswahl in einem Zusammenhang mit dem Heimatland des Bräutigams und dem Herrschaftsanspruch der Könige von Ur zu sehen.

Auch der Name der zweiten Prinzessin aus Ur, die über einen längeren Zeitraum den Status einer é-gi $i_{4}$-a einnahm, kann als politisch motiviert angesehen werden: Tabūr-ḩatțum (das Zepter ist dauerhaft). Sie ist in der Zeit von AS 9 bis ŠS 7 als é-gi ${ }_{4}$-a des Ur-Iškur, Ensi von Hamazi, zwischen Oberem Zab und Diyala gelegen ${ }^{1216}$, belegt ${ }^{1217}$. Auch sie wird in den bekannten Quellen nie als Ehefrau (da m) eines Sohnes des Ur-Iškur bezeichnet. Möglicherweise lebte sie bis zum Jahr ŠS 9 noch in Ur, denn der letzte Text, in dem sie zu finden ist, verbucht Vieh für ihre Reise nach Hamazi (PDT I, 454). ${ }^{1218} \mathrm{Ob}$ sie erst zu diesem Zeitpunkt nach Hamazi ging, oder schon länger dort gelebt hatte und sich im Jahr ŠS 7 nur zu einem Besuch in Ur aufgehalten hat und die Tiere für ihre Rückreise bereitgestellt wurden, ist nicht zu entscheiden. Möglicherweise reiste sie auch schon im Jahr AS 9 nach Hamazi, kehrte jedoch zu einem späteren Zeitpunkt nach Ur zurück. So werden in TCND 261 (19/ix/AS 9) Ziegen als Proviant/Ehrengeschenk (igi-kár) verbucht.

Auch Ibbi-Suen versuchte, seine Grenzen mittels einer dynastischen Ehe einer Tochter zu sichern. Er verheiratete seine Tochter Tukīn-ḩațti-migrīša (Sie hat beständig gemacht das Zepter ihres Favoriten) mit dem Ensi von Zabšali ${ }^{1219}$. Doch auch diese Verbindung konnte den Zerfall des Reiches nicht aufhalten. ${ }^{1220}$

\subsection{Der innenpolitische Bereich}

Auch im innenpolitischen Bereich nutzen die Könige von Ur die Vorteile politischer Ehen und verheirateten eine Reihe ihrer Töchter mit hohen Beamten der Reiches ${ }^{1221}$. Anders als in der Dynastie des Gudea von Lagaš ${ }^{1222}$ kam jedoch

1216 Edzard, Farber, Die Orts- und Gewässernamen der Zeit der 3. Dynastie von Ur, RGTC II (1974)), S. 72-73.

1217 BIN III, 382 (17/xi/AS 9); TrD 87 (xii"/ŠS 2); Newell 1600 (ك̌Š 5) (unpubliziert); PDT I, 454 (29/xi/ŠS 7). Hallo, Contibutions to Neo-Sumerian, HUCA 29 (1958); S. 79; Michalowski, The Bride of Simanum, JAOS 95 (1975), S. 718.

1218 Michalowski, The Bride of Simanum, JAOS 95 (1975), S. 718-719.

1219 Datenformel IS 5; zu diesem weitgehend unbekannten Landstrich im Nordwestiran siehe Steinkeller, The Question of Marhaši, ZA 72 (1982), S. 243-244.

1220 Stolper, On the Dynasty of Šimaški, ZA 72 (1982), S. 52-53; Potts, Mesopotamia and the East (1994), S. 131.

1221 Hierzu insbesondere Michalowski, Charisma and Control, SAOC 46 (1987), S. 58-59 und Kutscher, From the Royal Court to Slavary in the Ur III Period, Tel Aviv 11 
in Ur kein Schwiegersohn des Königs auf den Thron. Mit dem Instrument der familiären Bindungen konnten die Herrscher von Ur sich die Loyalität ihrer führenden Beamten sichern, was insbesondere dann von Bedeutung war, wenn die königlichen Schwiegersöhne als Ensi in einer entfernteren Provinz eingesetzt wurden, wo sie sich leichter der direkten Kontrolle durch die Zentralregierung entziehen konnten. ${ }^{1223}$

So war Ninhedu, eine Tochter von Šulgi, mit Hašib-atal verheiratet ${ }^{1224}$, welcher möglicherweise in Arraphum eingesetzt war ${ }^{1225}$. In ASJ 9, S. 126, 57 (ohne Datum) wird Ninhedu als Frau des Sukkalmah bezeichnet. Da Ninhedu in diesem Text unmittelbar nach der Dame Ninkalla auftritt, ist davon auszugehen, daß es sich hier ebenfalls um die Prinzessin handelt.

Auch Irĝu ${ }^{1226}$, einer der einflußreichsten Beamten des Reiches, war mit dem Königshaus verschwägert, einer seiner Söhne heiratete die Prinzessin GemeEanna ${ }^{1227}$. Diese wird in OIP 121, 9 als Schwiegertochter (é-gi $\mathrm{i}_{4}$-a) des Irĝu angesprochen, andere Prinzessinnen werden als Frau (dam) hoher Beamter bezeichnet, wie die Frauen von Lugal-magurre, Šarrum-bāni und Lu-Nanna ${ }^{1228}$.

Auch hier stellt sich die Frage, ob die Benennung der Frauen als Schwiegertochter oder als Ehefrau dazu dient, ihre Stellung innerhalb der Familie des Ehemannes genau zu beschreiben, oder ob es den Schreibern eher darum ging, die jeweils bedeutendste männliche Persönlichkeit aus der Familie des Ehemannes als Bezugsperson zu nennen. Sollte die zweite Annahme zutreffen, erklärte dies auch, warum verschiedene Prinzessinnen als

(1984).

1222 Röllig, Politische Heiraten im Alten Orient, Saeculum 25 (1974), S. 12-13.

1223 Kutscher, From the Royal Court to Slavery in the Ur III Period, Tel Aviv 11 (1984), S. 185.

1224 TRU 110 (4/xii/Š 47) verzeichnet mu - D U -Lieferungen von verschiedenen Personen, darunter Hašib-atal und Ninhedu, der é-g $\mathrm{i}_{4}$-a des Hašib-atal. In CTMMA I, 17 (vii/AS 4) wird Ninhedu unter den Töchtern des Königs als Empfängerin von Vieh geführt.

1225 Michalowski, Charisma and Control, SAOC 46 (1987), S. 59 + Anm. 16; PDT I, 166 (25/v/AS 5).

1226 Allgemein wird davon ausgegangen, daß es sich bei Irĝu und Ir-Nanna um zwei Namen derselben Person handelt. Siehe dazu Sallaberger, Der kultische Kalender (1993), S. 17 Anm. 55 (mit weiterer Literatur), kritisch gegenüber dieser Gleichsetzung ist Waetzoldt, JAOS 111 (1991), S. 639-640.

1227 Geme-Eanna ist in CTMMA I, 17 (vii/AS 4) als Tochter des Königs genannt, in OIP 121, 9 (10/xii/AS 2) erhielt Geme-Eanna, die Schwiegertochter des Irĝu, des Sukkalmah 3 Schafe: (3 udu-niga/mu Geme $_{2}$-é-an-na é-gi - $_{4} / \mathrm{a} \mathrm{Ir}_{11}$ g u ${ }_{10}$ sukkal-mah-š̀̀ $)$.

1228 CTMMA I, 17 (vii/AS 4), die Namen der Ehefrauen werden hier nicht genannt. 
Schwiegertöchter auswärtiger Ensis angesprochen werden: solange der Schwiegervater noch im Amt ist, steht er im Rang höher als sein Sohn, der Ehemann der betreffenden Prinzessin, und dient folglich als Bezugsperson

\section{Exkurs 4: Politische Ehen in Ebla und Akkade}

\section{Ebla}

Eheschließungen waren auch für die Könige von Ebla ein wichtiges Instrument ihrer Politik. Die Prinzessinnen wurden sowohl mit Würdenträgern in Ebla wie mit den Königen befreundeter Städte verheiratet ${ }^{1229}$. Auf diese Weise wurden, wie in Ur, die Funktionäre ebenso wie benachbarte Könige an das Herrscherhaus von Ebla gebunden. So war der Prinz Ir'ag-Damu mit Za'aše, der Tochter des Wesirs Ibbi-Zikir verheiratet. ${ }^{1230}$ Bemerkenswert ist die Tatsache, daß die nach auswärts verheirateten Prinzessinnen stets einen sehr hohen Rang, oftmals sogar den der Königin an ihrem neuen Hof einnahmen. Auch nach ihrer Eheschließung blieben die Prinzessinnen dem Hof von Ebla verbunden. Sie erhielten weiterhin Güter wie Textilien und Gegenstände aus Edelmetallen aus Ebla, nur erscheinen sie in den Listen nicht mehr als Töchter des Königs (dumu-munus en) sondern mit ihrem neuen Titel. Ihrerseits schickten sie zu bestimmten Anlässen, wie der Geburt eines Kindes der Königin von Ebla, Geschenke oder kamen selber, um diese zu übergeben ${ }^{1231}$.

Wie sorgfältig eine solche dynastische Ehe vorbereitet wurde, ist am Beispiel der Prinzessin Tagriš-Damu, Tochter des Išar-Damu, zu verfolgen, die mit dem Sohn des Königs von Nagar verheiratet wurde. Biga hat kürzlich die einzelnen Quellen im Zusammenhang mit dieser Eheschließung zusammengestellt und die Ereignisse im einzelnen beschrieben ${ }^{1232}$. Das Besondere an dieser Verbindung war die Tatsache, daß Tagriš-Damu nicht mit einem im Rang unter dem König von Ebla stehenden Herrscher verheiratet wurde, sondern in eines der bedeutendsten Königshäuser der Zeit einheiratete. Die Königin selber reiste in diesem Zusammenhang nach Nagar, und diese Reise war wichtig genug, um als Datenformel des Jahres verwendet zu werden. ${ }^{1233}$ Nach dieser Verbindung suchte Išar-Damu den Kontakt zu einem weiteren Machtzentrum seiner Zeit und verheiratete seine Tochter Kešdut mit dem

\footnotetext{
1229 Biga, Femmes de la Familie Royale d'Ebla, CRAI 33 (1987), S. 46f; Dies., I rapporti diplomatici (1995).

1230 Biga, The reconstruction of a relative Chronology, OrNS 72 (2003), S. 355.

1231 Siehe oben S. 192.

1232 Biga, The Marriage of Eblaite Princess Tagriš-Damu, Subartu IV (1998), S. 17-22.

1233 Archi, Chronologie relative, Amurru I (1996), S. 12.
} 
König von Kiš. ${ }^{1234}$ Ebla war zu dieser Zeit auf dem Höhepunkt seiner Macht, konnte diese jedoch nur noch wenige Jahre halten, bis die Stadt zerstört wurde ${ }^{1235}$, wovor auch die dynastischen Bindungen an mächtige Nachbarreiche nicht schützen konnten.

Bevor man daran denken konnte, dynastische Verbindungen $\mathrm{zu}$ den wichtigsten Städten der Zeit zu knüpfen, hatte man sich über einen längeren Zeitraum hinweg die Könige der benachbarten Länder durch familiäre Verbindungen verpflichtet. So ging Zimini-barku nach Burman, Dati- ${ }^{\mathrm{d}}$ TU und Tagmul-Damu wurden nacheinander Königinnen von Lumnan ${ }^{1236}$ und Zugalum heiratete den König von Harran ${ }^{1237}$. Auch Tiša-Lim, Königin von Emar, war mit an Sicherheit grenzender Wahrscheinlichkeit eine Prinzessin aus Ebla, doch ist sie nirgends als „Tochter des Königs“ in den Texten zu finden ${ }^{1238}$. Sie wird später als „Mutter des Königs von Emar“ bezeichnet ${ }^{1239}$. Ein Verwandtschaftsverhältnis zu einem benachbarten König war für den Herrscher von Ebla zwar kein Garant für Frieden und gute Beziehungen, doch zeigen viele Beispiele aus der mesopotamischen Geschichte, welche politische Bedeutung solchen dynastischen Verbindungen beigemessen wurde ${ }^{1240}$. Ob und in welcher Form die Könige von Ebla daraus Erbfolgeansprüche ableiteten, ist bisher nicht zu sagen.

Zur Mitgift der Prinzessinnen gehörte auch eine bestimmte Menge an

1234 Archi, Gifts for a Princess, Eblaitica 1 (1987), S. 121f; Biga/Pomponio, Chronological Division, JCS 42 (1990), S.185f Anm 15; Biga, The Marriage of Eblaite Princess Tagriš-Damu, Subartu IV (1998), S. 17.

${ }^{1235}$ Archi, The Role of Women in the Society of Ebla, CRAI 47 (2002), S. 6. Unklar ist, ob die Zerstörung Eblas auf eine Kampagne Sargons von Akkade zurückzuführen ist; Westenholz, The Old Akkadian Period (1999), S. 38 + Fn. 113.

Biga, Prosopographie, Amurru I (1996), S. 65f.; Archi, Les comptes rendus annuels de métaux, Amurru I (1996), S. 75.

1237 Zu Zugalum und Harran s. Archi, Harran in the III Millennium B.C., UF 20 (1988), mit einer Zusammenstellung der vielfach noch unpublizierten Belege zu Zugalum.

Die Vermutung, daß Tiša-Lim aus Ebla stammte, ist wiederholt geäußert worden (Biga/Pomponio, Chronological Division, JCS 42 (1990), S. 199 Anm. 42; Archi, Imâr au IIIème Millénaire, MARI 6 (1990), S. 27). Inzwischen nimmt Archi dies als gesichert an und geht davon aus, daß Tiša-Lim die Ländereien und das Vieh, welches sie von Irkab-Damu erhalten hatte, als Geschenk zur Hochzeit empfing (Archi, The Regional State of Nagar, Subartu IV (1998), S. 2). Bisher gibt es keinen eindeutigen Beleg für die Herkunft der Tiša-Lim, doch ist aufgrund der Art, wie sie immer wieder in den Eblatexten Erwähnung findet, eine deutliche Prarallele zur Behandlung der nach auswärts verheirateten Prinzessinnen aus Ebla zu sehen.

1239 Archi, Imâr au IIIème Millénaire, MARI 6 (1990), S. 28.

1240 Röllig, Politische Heiraten im Alten Orient, Saeculum 25 (1974). 
Personal. ${ }^{1241}$ Dieses war sicher sowohl eine Prestige- wie auch eine Machtfrage, denn die Diener standen den Frauen an ihrem neuen Wohnort zur Verfügung und stellten selber einen nicht ganz unwesentlichen Faktor für die Braut dar, welche sich auf ihre vertraute Dienerschaft verlassen konnte. Man kann sich vorstellen, daß es für die Prinzessinnen bei allem Einfluß des Königs von Ebla nicht ganz leicht war, die eigene Position in der bestehenden Hierarchie des neuen Hofes durchzusetzen. In diesem Zusammenhang ist auch das Schmuckgeschenk der Dati- ${ }^{\mathrm{d}} \mathrm{TU}$ an die Mutter des Königs von Lumnan zu verstehen, welches sie wohl gleich nach ihrer Ankunft überreichte ${ }^{1242}$. Angesichts des hohen Ranges, der für die Königsmutter in Ebla im Falle der Dusigu zu erkennen ist, wundert es nicht, daß die Schwiegertöchter aus Ebla es nicht nur für eine Frage der Höflichkeit, sondern auch für taktisch wichtig hielten, die Schwiegermutter positiv zu stimmen. Auch Dati- ${ }^{\mathrm{d}} \mathrm{TU}$ wird als junge Königin von Lumnan mit dieser Maßnahme wohl rasch eine wichtige Stellung und politischen Einfluß angestrebt haben.

\section{Akkade}

Während sowohl für das Herrscherhaus von Ebla in der vorangegangenen Epoche als auch für das Königshaus von Ur in der nachfolgenden Epoche eine Reihe von Belegen für dynastische Ehen von Töchtern des Herrschers mit Angehörigen fremder Herrscherhäuser belegt sind, ist die Quellenlage für diese Form der Politik für das Reich von Akkade derzeit noch sehr spärlich. Der Fund einer Abrollung vom Siegel der Tarām-Agade, einer Tochter NarāmSuens, in Urkeš ${ }^{1243}$ zeigt jedoch, daß auch die Könige von Akkade sich der dynastischen Ehe als Mittel der Politik bedient haben.

Mit großer Wahrscheinlichkeit ist Tarām-Agade als Ehefrau des Herrschers oder seines Sohnes und Nachfolgers nach Urkeš gekommen. In der Zeit, aus der die Abrollung, die in Urkeš an einer Tür gefunden wurde, stammt, hat Tarām-Agade wohl die Position einer Königin oder die der Königinmutter eingenommen. Die Möglichkeit, daß die Tochter Narām-Suens in einer priesterlichen Funktion nach Urkeš gekommen sein könnte, ist nicht ganz auszuschließen, wurde jedoch von Buccellati/Kelly-Buccellati aus mehreren Gründen für unwahrscheinlich gehalten: So sprechen sowohl der Fundkontext im Palastbereich, wie auch das Siegelbild, eine Tierkampfszene, gegen einen

1241 Biga, Frauen in der Wirtschaft von Ebla, HSAO 2 (1988), S. 169f.; dies., Prosopographie, Amurru I (1996), S. 71.

1242 Biga, Prosopographie, Amurru I (1996), S. 65.

1243 Buccellati/Kelly-Buccellati, The Royal Palace of Urkesh, MDOG 132 (2000), S. 139, 153-155. Buccellati/Kelly-Buccellati, Tar'am-Agade, Daughter of Naram-Sin, at Urkesh, FS Oates (2002), S. 11-31. 
priesterliche Funktion der Siegelinhaberin ${ }^{1244}$.

Die Inschrift erwähnt keinen Titel, Tarām-Agade nennt sich nur Tochter des Narām-Suen. Dies in Verbindung mit ihrem Namen "Sie liebt Akkade“, den sie möglicherweise erst zu ihrer Eheschließung angenommen hat, zeigt die starke Bindung der Prinzessin von Akkade an ihre Herkunftsdynastie. Sie nennt sich nicht „Herrin/Königin von Urkeš“ oder „Ehefrau des en d an “. Es ist daher anzunehmen, daß sie sich bewußt als Vertreterin der mächtigen Dynasie von Akkade in Norden darstellte.

1244 Buccellati/Kelly-Buccellati, Tar'am-Agade, Daughter of Naram-Sin, S. 15. 



\section{Zusammenfassung}

Die königlichen Frauen der dritten Dynastie von Ur, und hier insbesondere die ranghöchsten Damen, die Königin und die Mutter des Königs, hatten, wie gezeigt werden konnte, eine starke Position in den Gesellschaften ihrer Zeit. Dies ist sowohl im Bereich des Kultes zu beobachten, wie auch im wirtschaftlichen Sektor. Und auch im gesellschaftlichen Kontext nahmen die Frauen der Herrscherfamilien eine herausgehobene Stellung ein.

Sowohl in Ebla wie auch im Reich von Ur III waren die Könige mit mehreren Frauen gleichzeitig verheiratet, lebten also polygyn. Für das frühdynastische Lagaš ist zur Zeit jeweils nur eine Ehefrau jedes Herrschers bekannt, ${ }^{1245}$ gleiches gilt auch für die Frauen des Reiches von Akkade, wo die Quellenlage keine Aussagen darüber zuläßt, ob die Könige polygyn gelebt haben. Es ist jedoch davon auszugehen, daß auch die Herrscher von Lagaš und Akkade nicht zuletzt aus politischen Gründen mehr als eine Ehe eingingen.

Ebenso wie in Mari in altbabylonischer Zeit übernahm in Ebla ein neuer Herrscher die Frauen seines Vorgängers ${ }^{1246}$. Dabei konnte es sich bei dem neuen König um den Sohn oder auch, wie im Fall von Zimrî-Lîm in Mari, um einen Eroberer handeln. Ob diese Frauen dem neuen König auch gleichzeitig sexuell zur Verfügung standen, oder ob der König im wesentlichen die administrativen und sozialen Strukturen unangetastet ließ, damit das reibungslose Funktionieren der Palastwirtschaft weiterhin gewährleistet blieb, an dem die Frauen einen nicht unwesentlichen Anteil hatten, ist nicht zu entscheiden.

Die Rangfolge unter den Damen war abhängig von der Stellung jeder einzelnen Frau zum König, und diese dürfte nicht zuletzt auch dadurch bestimmt gewesen sein, ob eine Frau dem König einen Sohn geboren hatte. Über ihren Sohn hatte eine Frau die Möglichkeit, ihre soziale Position am Hof deutlich zu verbessern. Für Ebla ist zu beobachten, daß Dusigu, die Mutter des

\footnotetext{
1245 Siehe die Zusammenstellung der bekannten Frauen aus dem Herrscherhaus von Lagaš bei Asher-Greve, Frauen in altsumerischer Zeit (1985), S. 146-147.

1246 Zu dieser Erscheinung in Ebla siehe Archi, The Role of Women in the Society of Ebla, CRAI 47 (2002), S. 3; zur Mari siehe Ziegler, Le Harem du vaincu, RA 93 (1999).
} 
Königs Išar-Damu, während der Regierungszeit ihres Sohnes bis zu ihrem Tod die Position der ersten Dame des Hofes einnahm, noch vor der Ehefrau und amtierenden Königin Tabur-Damu. Eine vergleichbar hohe Position bekleidete Abī-simtī am Hof von Ur zur Zeit der Regierung ihres Sohnes Šu-Suen. Auch sie stand als Mutter des Königs gesellschaftlich höher als ihre Schwiegertochter Kubātum. Somit kann, bei aller gebotenen Vorsicht angesichts von nur zwei eindeutigen Beispielen, welche noch dazu unterschiedlichen Gesellschaften angehören, angenommen werden, daß die Mutter des Herrschers im dritten Jahrtausend die wichtigste und einflußreichste Position unter den Frauen am Hof einnahm. Dieser hohe Rang der Mutter eines Königs war auch in der altbabylonischen Zeit noch zu finden. So ist in Mari zu beobachten, daß die Mutter des Zimrî-Lîm, Addu-dûrî, eine vergleichbar prominente Stellung am Hof von Mari hatte, welche erst nach ihrem Tod von der Königin Šîbtu übernommen wurde. ${ }^{1247} \mathrm{Da}$ sowohl Ebla wie auch Mari zum syrischen Kulturkreis gehören, und da auch Abī-simtī mit großer Wahrscheinlichkeit aus Syrien stammte, ist die herausragende Position der Mutter des Herrschers möglicherweise ein Phänomen, das typisch war für die syrischen Gesellschaften. Dafür spricht auch, daß man in Ebla einen eigenen Titel für die Mutter des Königs kannte, die „Große Mutter des Königs“ (a ma-gal en), während es in der Terminologie der Verwaltung von Ur III keine gesonderte Bezeichnung für die Mutter des Königs gab. Andererseits könnte die Situation in Lagaš in frühdynastischer Zeit ähnliche Strukturen wiederspiegeln. So ist Dimtur, die Mutter des Lugalanda von Lagaš in dessen erstem Regierungsjahr noch als Verantwortliche für die Verwaltung des é-munus, des Haushaltes der Frau des Herrschers ${ }^{1248}$, bekannt, erst danach übernimmt ihre Schwiegertochter Baranamtara die Verwaltung ihres Haushaltes selber. ${ }^{249}$ Da nicht bekannt ist, ob Lugalanda schon zu Beginn seiner Herrschaft verheiratet war, und ob nicht Dimtur im ersten Jahr der Regierung ihres Sohnes ihre Schwiegertochter in die Verwaltungsvorgänge einführte, sich danach aber zurückzog ${ }^{1250}$, kann nicht mit der gleichen Sicherheit wie im Falle der Damen Dusigu und Abī-simtī auf eine Führungsrolle der Mutter des Königs in Lagaš im Frühdynastikum geschlossen werden. Auch ist keine vergleichbare Stellung für die Mutter einer der Könige von Akkade bekannt. Somit kann auf der Grundlage der heute bekannten Quellen vermutet werden, daß die Institution der „Mutter des Herrschers“ und ihre Stellung als erste Dame der Gesellschaft

\footnotetext{
1247 Ziegler, Le Harem de Zimrî-Lîm (1999), S. 50-51.

1248 Zum é-munu s siehe ausführlich Maekawa, The Development of the É-MÍ in Lagash during Early Dynastic III, Mesopotamia 8 (1973), S. 77-144.

1249 Asher-Greve, Frauen in altsumerischer Zeit (1985), S. 149.

1250 Ebd.
} 
ein syrisches Phänomen ist. ${ }^{1251}$ Angesichts der sehr unterschiedlichen Dichte der Dokumentation für unterschiedliche Epochen könnte dieses Bild jedoch auch aufgrund der Überlieferungszufälle und der fragmentarischen Quellenlage für andere Epochen zustande kommen. Der Abī-simtī muß es als Königin von Amar-Suen gelungen sein, ihre Position am Hof soweit zu stärken und auszubauen, daß sie nach dem Tod ihres Ehemannes den in ihrer Heimat bekannten Rang der „Mutter des Königs“ einnehmen konnte.

In allen angesprochenen Gesellschaften des dritten Jahrtausends ist zu beobachten, daß die königlichen Frauen im wirtschaftlichen Bereich sehr aktiv waren. Sie verfügten selbständig über ihren eigenen Besitz an Land und Vieh. Im frühdynastischen Lagaš stand die Frau des Stadtfürsten der Verwaltung ihres komplexen Haushaltes vor, welcher ursprünglich als „Frauenhaus“ (émunus) bezeichnet, unter UruKAgina zu „Haus der Göttin Ba'u“ (é d Ba-ú) umbenannt wurde. Die wesentlichen Funktionen der Institution blieben auch nach den Reformen des UruKAgina unverändert erhalten. ${ }^{1252}$ Diese Beobachtung der eigenen Haushaltsführung der Königin ist auch in Ebla zu machen, wo Lieferungen an den Haushalt des Königs getrennt verbucht werden von den Lieferungen an die „Frauen des Königs“, denen die Mutter des Königs und die Königin vorstanden. Gleiches gilt für die Königinnen und königlichen Nebenfrauen zur Zeit der III. Dynastie von Ur. ${ }^{1253}$ Auch in den altbabylonischen Quellen aus Mari ist belegt, daß verschiedene Damen des Königshauses über eigene Residenzen verfügten. So kennt man den Briefwechsel zwischen dem Vater der Königin Šîbtu und Asqudum, einem Beamten des Königs Zimrî-Lîm, in dem es um die Frage geht, wann und wie lange sich Šîbtu in ihrem eigenen Haus oder im Palast des Königs aufhalten sollte. ${ }^{1254}$

In Ebla, Lagaš und in Ur III ist der Einfluß der königlichen Frauen in der Textilproduktion, einem bedeutsamen Wirtschaftszweig, zu beobachten. Es ist davon auszugehen, daß die Frauen der herrschenden Familien im 3. Jahrtausend über die Erträge ihrer Besitzungen eigenständig zur Erfüllung ihrer Aufgaben verfügen konnten. Besonders in Ur ist zu beobachten, daß die Königinnen gezielt einzelne Persönlichkeiten aus ihrer Umgebung durch Geschenke oder ein festliches „Bierausschenken“ begünstigen konnten. Der Austausch kostbarer Geschenke unter den Frauen ist in Ur wie in Ebla zu

1251 Zur Institution der Königinmutter im syrisch-palestinensischen Raum im 2. und 1 Jt. v. Chr. siehe Pettinato, Semiramis (1988), S. 210-214. Skeptischer dagegen Archi, The Role of Women in the Society of Ebla, CRAI 47 (2002), S. 8

1252 Zur Wirtschaft und Verwaltung dieser Institution in Lagaš zuletzt Bauer, OBO 160/1 (1998), S. 532-555.

1253 Zum Haushalt der Königin von Ur (k i - n i n ) siehe S. 169-176.

1254 Durand, ARM 26.1 Nr. 13 und S. 104-105. 
verfolgen, und es kann davon ausgegangen werden, daß mit derartigen Gunstbeweisen seitens der höchsten Damen des Landes entsprechende Erwartungen bezüglich des politischen und gesellschaftlichen Verhaltens der so Begünstigten verbunden waren, da $\beta$ also diese Geschenke nicht nur Ausdruck freundschaftlicher oder familiärer Verbundenheit waren, sondern ein Mittel der politischen Einflußnahme. Derartiges ist bisher nicht feststellbar für die königlichen Frauen der Akkadezeit, doch hier ist zu vermuten, daß dies nur eine Folge der spärlichen Quellenlage für die Damen dieser Epoche ist, und nicht, daß sich hier tatsächlich Unterschiede in der Gesellschaftsstruktur manifestieren, welche den Frauen weniger Einflußmöglichkeiten eröffnete, als dies in Ebla und Ur III der Fall war.

Der gesellschaftlich herausragende Rang der königlichen Frauen zeigt sich in Ebla wie in Ur III nicht nur in Form ihrer wirtschaftlichen Situation, sondern besonders eindrücklich auch darin, daß in beiden Kulturen entgegen der üblichen Gepflogenheiten auch männliche Angehörige über die Verwandtschaft zu diesen Damen identifiziert werden konnten. In allen hier besprochenen Gesellschaften war es gebräuchlich, den Namen des Vaters anzugeben, wenn eine Person über den eigenen Namen hinaus näher identifiziert werden sollte. Doch Angehörige der Königinnen, der Mutter des Herrschers und besonders hochrangiger königlicher Nebenfrauen konnten auch über diese definiert werden. In Ebla galt dies selbst für den Vater der Königin. Es stellt eine Verkehrung der sonst üblichen gesellschaftlichen Gepflogenheiten dar, daß ein Mann über seine hochstehende Tochter identifiziert wurde. ${ }^{1255}$ Aus diesen Beobachtungen muß geschlossen werden, daß die nähere Bezeichnung von Personen in den Kulturen des 3. Jahrtausends also nicht zwangsläufig über den Vater zu erfolgen hatte, sondern über den jeweils ranghöchsten Angehörigen. Dies war sicher in den meisten Fällen der Vater, doch konnte es in bestimmten Fällen auch eine Schwester oder Tochter sein.

Als ein weiterer Hinweis auf die große Wertschätzung, welche die Frauen genossen, kann die Beobachtung gewertet werden, daß Prinzessinnen in Ebla wie in Ur den Namen bedeutender Frauen aus vorangegangenen Generationen tragen konnten. So ist in Ebla die Prinzessin Dusigu nach der Mutter des Königs benannt worden, in Ur findet man zur Zeit von Šu-Suen und Ibbi-Suen eine Königstochter namens Šulgi-simt ${ }^{1256}$. Daß diese Referenzen sich nicht auf die Königin Šulgi-simtī beziehen können, ist eindeutig, da für die Königin 9 Jahre vor der ersten Erwähnung der Prinzessin dieses Namens Totenopfer

1255 Siehe zu Ebla S. 186, zu den Frauen der III. Dynastie von Ur S. 185-233.

1256 UTI V, 3179 (ŠS 1); Sigrist, Toronto 164 (20/vii/IS 1); UET 3, 116 (xii/IS 5); UET 3, 1211 (Datum abgebrochen); AUCT III, 489 (Datum abgebrochen). 
verbucht werden. ${ }^{1257}$

Die politische Bedeutung der Königstöchter zeigt sich seit dem Frühdynastikum auch darin, daß sie von ihren Eltern eingesetzt wurden, um dynastische Beziehungen zu anderen Herrscherhäusern schließen zu können. Dies ist sowohl in Ebla als auch in Ur III wiederholt zu beobachten. In Ebla konnte die Königin sogar persönlich soweit in die Vorbereitungen einer wichtigen Eheschließung involviert sein, daß sie selber die Reise zur Familie des Bräutigams unternahm, um die Verbindung beider Häuser im Detail zu organisieren. Dies war der Fall bei der Eheschließung der eblaitischen Prinzessin Tagriš-Damu, welche den Sohn des Herrschers von Nagar heiratete. ${ }^{1258}$ Die Könige von Ebla und Ur nutzten das Instrument der ehelichen Verbindung sowohl mit Herrschern außerhalb ihres Reiches wie auch zur Festigung der Beziehungen innerhalb der Oberschicht ihres eigenen Reiches. ${ }^{1259}$

Als ein Sonderfall dynastischer Beziehungen kann in diesem Zusammenhang die Einsetzung einer Königstochter als Priesterin eines bedeutenden Gottes verstanden werden ${ }^{1260}$. In Ebla dienten Prinzessinnen als Priesterinnen (dam-diĝir oder $\mathrm{pa}_{4}$-šeš) der Götter Idabal von Luban und Kura, seit der Akkadezeit ist nachzuweisen, daß im Süden Mesopotamiens Töchter der Herrscher als Priesterinnen (en) des Nanna von Ur eingesetzt wurden. Mit der Installation einer Tochter des Herrschers als Priesterin einer bedeutenden Gottheit stellte der König eine enge familiäre Beziehung zwischen seinem Haus und dem Haushalt jener Gottheit her, er wird gleichsam zum Schwiegervater der Gottheit. Die reiche Ausstattung, die eine Prinzessin von Ebla bei ihrer Einsetzung als Priesterin erhielt, entspricht einer Mitgift, was den Charakter einer dynastischen Verbindung des Königshauses mit dem Haus der Gottheit noch unterstreicht.

Ein Phänomen, das nach dem derzeitigen Kenntnisstand auf das Frühdynastikum beschränkt bleibt, ist der freundschaftliche Kontakt zwischen den Gemahlinnen verschiedener Herrscher. Baranamtara, die Frau des Lugalanda von Lagaš, unterhielt freundschaftliche Beziehungen zur Ehefrau des Fürsten von Adab, was sich im wiederholten Austausch von Geschenken ausdrückte. ${ }^{1261}$ Die Damen aus Ebla pflegten vergleichbare Beziehungen zu den

\footnotetext{
1257 ZVO 25, 134, 2 (28/iii/AS 1).

1258 Biga, The Marriage of Eblaite Princess Tagriš-Damu, Subartu IV (1998).

$1259 \mathrm{Zu}$ Ebla siehe Exkurs 4, zu Ur III siehe Kap. 18.

${ }^{1260}$ Archi spricht von einer „Allianz mit der Gottheit“, The Role of Women in the Society of Ebla, CRAI 47 (2002), S. 7.

1261 Asher-Greve, Frauen in altsumerischer Zeit (1985), S. 151.
} 
Königinnen benachbarter Städte, wobei hier zu beobachten ist, daß diese Königinnen der Orte wie Lumnan oder Harran selber aus Ebla stammten und in der Folge dynastischer Eheschließungen ihre Heimatstadt verlassen hatten. Hieraus schließen zu wollen, daß die Dame Ninizkimti von Adab ursprünglich aus Lagaš stammte, und daß freundschaftliche Beziehungen zwischen den Frauen von Stadtfürsten nur auf der Grundlage verwandtschaftlicher Beziehungen zustandekamen, geht wohl zu weit. Es ist jedoch bemerkenswert, daß aus dem überaus reichen Bestand der Quellen der III. Dynastie von Ur keine Hinweise auf vergleichbare Beziehungen zwischen den Königinnen von Ur und einigen der nach Außerhalb verheirateten Prinzessinnen zu finden sind. Dies könnte in der Zufälligkeit der Überlieferung begründet liegen, ließe aber möglicherweise auch den Schluß zu, daß die königlichen Frauen der Ur IIIZeit, anders als ihre Amtskolleginnen im Frühdynastikum, im Bereich der diplomatischen Beziehungen zu Regionen außerhalb des Reiches nicht mehr involviert waren. Diese Überlegung wird noch dadurch gestützt, daß bisher nur für die Herrschergemahlinnen im frühdynastischen Lagaš eine Beteiligung am Außenhandel zu beobachten ist. So ist von Baranamtara bekannt, daß in ihrem Auftrag Kaufleute Handel mit mesopotamischen Städten wie auch mit Elam und Dilmun betrieben. ${ }^{1262}$ Die Königin von Ebla trat selbst im Zusammenhang mit der Auszeichnung eines Feldherren, also in militärischem Kontext, auf. ${ }^{1263}$ Eine vergleichbare Situation ist derzeit weder für die Frauen der Akkadezeit, für welche die Quellenlage aber ohnehin sehr schwach ist, noch für die Damen der III. Dynastie von Ur zu beobachten.

Neben der häuslichen Sphäre, wobei dieser Begriff hier sehr weit gefaßt werden soll und neben den wirtschaftlichen Belangen des großen Haushaltes der Königinnen auch die sozialen Beziehungen am Hof beinhaltet, ist die herausragende Funktion der Königinnen im kultischen Bereich zu sehen. Kultische Aufgaben der Königinnen sind für alle besprochenen Gesellschaften gleichermaßen zu konstatieren ${ }^{1264}$. Dies zeigt, daß die Beteiligung der Königinnen am offiziellen Kult des Landes im 3. Jahrtausend ein bestimmendes Element für die Position der Hauptfrau des Königs darstellte. Den Königinnen war nicht nur der häuslich-wirtschaftliche Tätigkeitsbereich überlassen, den sie nicht zuletzt in den Zeiten der Abwesenheit ihrer Männer aufgrund von kriegerischen Auseinandersetzungen in verantwortlicher Position leiten mußten. Sie hatten darüber hinaus einen wesentlichen Anteil am Königtum, da sie zusammen mit dem König Verantwortung trugen für die

\footnotetext{
1262 Ebd. S. 150.

1263 Siehe S. 195.

1264 Zu Ebla siehe S. 191, zur Königin von Akkade S. 60 und zu den Königinnen von Ur S. 179-182.
} 
ausreichende Versorgung der Götter. Dies wiederum garantierte das Wohlwollen der Götter für das Land und damit das Wohlergehen seiner Bewohner. Anders jedoch als im benachbarten Ägypten ${ }^{1265}$ war in Mesopotamien kein öffentliches, repräsentatives Königinnentum bekannt, das sich in einer Fülle bildlicher Darstellungen, in literarischer Überhöhung der königlichen Frauen, oder in einer Vielzahl unterschiedlicher Titel ausgedrückt hätte, wie dies für die mesopotamischen Könige der Fall ist. Die Könige schmückten sich stets mit unterschiedlichen Epitheta, die entweder ihren Herrschaftsanspruch ausdrückten, wie „König von Ur“ und „König von Sumer und Akkade“, oder aber das besondere Verhältnis des Herrschers zu den Göttern unterstrichen, wie „den Enlil liebt“ oder „den Enlil bei seinem Namen gerufen hat“. Ihre Taten wurden in der Form von Hymnen und epischen Erzählungen verherrlicht. Weder Epen und Hymnen noch derartige Epitheta sind für die königlichen Frauen bezeugt. Lediglich in dem sogenannten „Lyrischen Dialog“ Šu-Suen $\mathrm{A}^{1266}$ werden die Damen Abī-simtī und Kubātum in einem literarischen Kontext erwähnt. In diesem Liebeslied wird Abī-simtī als „Zeugbaum“ ( $\mathrm{g}$ i š-gi -na),

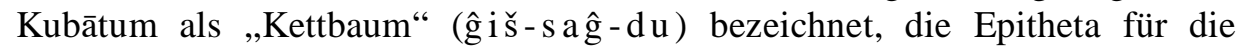
beiden Frauen sind also aus dem Bereich der weiblichen Tätigkeit, der Weberei, gewählt. Dies unterstreicht einmal mehr die Trennung der Lebenswelten von Männern und Frauen, aber auch das Ansehen der Damen, die in literarischer Überhöhung mit der Weberei, einer der wichtigsten Wirtschaftszweige des Landes, in enge Beziehung gesetzt werden. Diese Trennung der männlichen und der weiblichen Sphäre ging jedoch nie so weit, daß die Frauen nur Kontakte zu anderen Frauen unterhalten konnten. Die Königinnen pflegten bevorzugt die Kulte weiblicher Gottheiten, opferten aber auch männlichen Göttern. Sie unterhielten wirtschaftliche Beziehungen zu den Frauen der Oberschicht, hatten in diesem Bereich jedoch ebenso Kontakte zu den führenden Männern ihrer Gesellschaft.

Eine den mesopotamischen Herrschergemahlinnen vergleichbare Stellung wird für die fürstlichen Frauen der frühen griechischen Gesellschaften der ersten Hälfte des ersten Jahrtausends v. Chr. angenommen, wo die Frauen ebenfalls in der häuslichen Wirtschaft eine entscheidende Position bekleideten und ganz selbstverständlich Anteil nahmen am Kult für die Götter, letzteres sogar noch in der klassischen Zeit, als die Frauen aus allen anderen

1265 Hier sei nur die Arbeit von L. Troy, Patterns of Queenship in ancient Egyptian myth and history, (1986) genannt, sowie die Studie von S. Roth, Bemerkungen zur Rolle der Königsmütter von der Frühzeit bis zum Ende der 12. Dynastie (1999), S. 111-123.

1266 SRT 23, zuletzt bearbeitet von Sefati, Love Songs in Sumerian Literature (1988), S. 344-352 mit Diskussion des Textes und früherer Literatur. 
öffentlichen Bereichen weitgehend verdrängt waren. ${ }^{1267}$

In Mesopotamien ist auch in den auf die Ur III-Zeit folgenden Epochen der Isin-Larsa- und der altbabylonischen Zeit zu beobachten, daß die königlichen Frauen insbesondere im wirtschaftlichen Bereich ihre starke Position halten konnten. Bekannt ist die leitende Funktion, welche die Königin Šîbtu in der Administration des Palastes von Mari einnahm. ${ }^{1268}$ Ob diese Frauen jedoch auch im kultischen Bereich eine Stellung bekleiden konnten, die jener der Königinnen des ausgehenden dritten Jahrtausends vergleichbar ist, oder ob sich das Konzept des Königtums in der ersten Hälfte des zweiten Jahrtausends soweit gewandelt hatte, daß die Königinnen nicht mehr als integraler Bestandteil des Herrscherpaares, insbesondere auch bei der Vertretung des Landes vor den Göttern, angesehen wurden, sollte Gegenstand weiterer Untersuchungen sein.

1267 Schuller, Frauen in der griechischen Geschichte (1985), S. 13-33.

1268 Zigeler, Le Harem de Zimrî-Lîm (1999), S. 54-55, mit weiterer Literatur. 
Anhang

\begin{tabular}{|c|c|c|c|c|}
\hline Name & Anzahl & $\begin{array}{c}\text { Was } \\
\text { geliefert? }\end{array}$ & Datum & Beleg \\
\hline Aba-Enlilgim & 1 & $1 \mathrm{G}, 10 \mathrm{~K}$ & -/vii/Š 39 & TCNY 253 \\
\hline $\begin{array}{l}\text { dumu-munus } \\
\text { Aba-Enilgim }\end{array}$ & 1 & $2 \mathrm{~K}$ & $-/ \mathrm{i} / \mathrm{S} 36$ & BIN III, 347 \\
\hline Abbasaga & 1 & $1+[\mathrm{x}] \mathrm{K}$ & -/ix/Š 44 & RT 37,130 Nr. 6 \\
\hline A-[x]-na & 1 & $30 \mathrm{~V}$ & -/iv/Š 38 & Boson 358 \\
\hline Abani & 1 & $2 \mathrm{~K}$ & -/viii/ŠS 35 & MVN 3, 143 \\
\hline Abili & 2 & $\begin{array}{l}2 \mathrm{~V} \\
1 \mathrm{~K}\end{array}$ & $\begin{array}{l}\text { 24/x/Š } 42 \\
\text {-/x/Š } 46\end{array}$ & $\begin{array}{l}\text { OIP } 115,71 \\
\text { TCND } 45\end{array}$ \\
\hline dam Abilia & 3 & $\begin{array}{c}5 \mathrm{~K} \\
2 \mathrm{~K} \\
30 \mathrm{~V}\end{array}$ & $\begin{array}{l}\text { 19/ii//Š } 40 \\
\text {-/xi/Š } 45 \\
\text { 23/ix/Š } 47\end{array}$ & $\begin{array}{c}\text { SACT I, } 57 \\
\text { SACT I, } 59 \\
\text { CST } 184\end{array}$ \\
\hline Adda-banda & 1 & $1 \mathrm{~K}$ & $-/ x / S ̌ S 38$ & MVN 2, 167 \\
\hline $\operatorname{nin}_{9}$ Adalal & 1 & $5 \mathrm{~K}$ & -/vii/Šs 35 & Toronto 10 \\
\hline Adanahhuni & 1 & $46+x \mathrm{~V}$ & - -/vi/Š 38 & AnOr 1,1 \\
\hline Addatur & 1 & $1 \mathrm{~K}$ & 13/ix/Š 47 & Orient 16,16 \\
\hline Admu na-gada & 1 & $1 \mathrm{~K}$ & -/v/Š 39 & MVN 18,3 \\
\hline $\begin{array}{l}\text { dumu-munus } \\
\text { Agalum }\end{array}$ & 1 & {$[\mathrm{x}] \mathrm{V}$} & 10/ix/Š 41 & MVN 3, 179 \\
\hline Ajama & 1 & $1 \mathrm{~V}$ & $23 / \mathrm{x} / \mathrm{S} 42$ & OIP 115,71 \\
\hline Akalta & 1 & $3+[\mathrm{x}] \mathrm{K}$ & -/ix/Š 32 & YOS 4, 79 \\
\hline dam Alla & 2 & $\begin{array}{l}1 \mathrm{~K} \\
3 \mathrm{~K} \\
\end{array}$ & 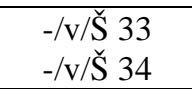 & $\begin{array}{c}\text { CST 42 } \\
\text { MVN 18, } 147\end{array}$ \\
\hline Allamu & 2 & $\begin{array}{l}5 \mathrm{~K} \\
2 \mathrm{~V}\end{array}$ & 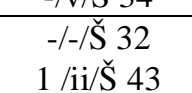 & $\begin{array}{c}\text { BIN V , } 11 \\
\text { OIP } 115,72\end{array}$ \\
\hline Ama-bara & 5 & $\begin{array}{l}4 \mathrm{~K} \\
4 \mathrm{~K} \\
3 \mathrm{~K} \\
5 \mathrm{~K} \\
1 \mathrm{~K}\end{array}$ & $\begin{array}{l}\text {-/iv/Š } 31 \\
\text {-/ix/ŠS } 32 \\
\text {-/x/Š } 36 \\
\text {-/xii/ŠS } 39 \\
\text { 2/ix/Š } 47\end{array}$ & $\begin{array}{c}\text { OIP } 115,17 \\
\text { YOS } 4,79 \\
\text { Hirose } 14 \\
\text { TPTS } 10 \\
\text { MVN } 18,15\end{array}$ \\
\hline Ama-zakum & 1 & $6 \mathrm{G}, 60 \mathrm{~K}$ & $-/ \mathrm{x} / \mathrm{S} 34$ & OIP 115,22 \\
\hline Amur-Utu & 2 & $\begin{array}{l}1 \mathrm{~K} \\
1 \mathrm{~K}\end{array}$ & $\begin{array}{c}\text {-/xii//̌s } 46 \\
\text { 22/xii/Š } 48 ?\end{array}$ & $\begin{array}{c}\text { MVN 18, } 11 \\
\text { MVN 13, } 794\end{array}$ \\
\hline Apil-kēn & 1 & $4 \mathrm{~V}$ & $21 / \mathrm{iii} / \mathrm{S} 47$ & OIP 115,92 \\
\hline Arag-ilī & 1 & $5 \mathrm{~K}$ & $-/ \mathrm{v} / \mathrm{S} 34$ & MVN 18, 147 \\
\hline Aršiah & 1 & $1 \mathrm{G}, 1 \mathrm{~K}$ & 30/xi/Š 43 & RO 11,96 Nr. 1 \\
\hline $\begin{array}{l}\text { Asišara nu-giš- } \\
\text { kiri }_{6}\end{array}$ & 1 & $2 \mathrm{~V}$ & 5/vi/ŠS 44 & MVN 18, 8 \\
\hline $\begin{array}{l}\text { Babatum dam } \\
\text { Nuida }\end{array}$ & 1 & $5 \mathrm{~K}$ & $3+x / i i i / S ̌ s 6$ & PDT II, 1035 \\
\hline
\end{tabular}




\begin{tabular}{|c|c|c|c|c|}
\hline Name & Anzahl & $\begin{array}{c}\text { Was } \\
\text { geliefert? }\end{array}$ & Datum & Beleg \\
\hline Bagum mušen-dù & 6 & $\begin{array}{c}9 \mathrm{~V} \\
8 \mathrm{~V} \\
80 \mathrm{~V} \\
1 \mathrm{~K}, 29 \mathrm{~V} \\
40 \mathrm{~V} \\
6 \mathrm{~V}\end{array}$ & $\begin{array}{c}\text { 17/viii/Š } 41 \\
\text { 5/viii/Š } 42 \\
\text { 10/vi/ŠS } 44 \\
\text { 15/vi/ŠS } 44 \\
\text { 23/i/ŠS } 45 \\
\text { 28/x/ŠS } 47\end{array}$ & $\begin{array}{c}\text { SAT II, } 294 \\
\text { MVN 13, } 275 \\
\text { MVN 18, } 8 \\
\text { RT 37, } 129 \text { Nr. } 4 \\
\text { RA 73, 26 Nr. } 1 \\
\text { PDT I, } 139\end{array}$ \\
\hline Balaja & 1 & $1 \mathrm{~K}$ & $-/ \mathrm{v} / \mathrm{S} 36$ & Orient 16,3 \\
\hline dam Balaja & 2 & $\begin{array}{l}1 \mathrm{~K} \\
1 \mathrm{~K}\end{array}$ & $\begin{array}{l}-/-/ \text { Š } 32 \\
-/ \text { /ŠS } 36\end{array}$ & $\begin{array}{c}\text { BIN V, 11 } \\
\text { Orient } 16,3\end{array}$ \\
\hline dam Banilum & 5 & $\begin{array}{c}1 \mathrm{~K} \\
5 \mathrm{~K} \\
10 \mathrm{~K} \\
10 \mathrm{~K} \\
1 \mathrm{G}, 10 \mathrm{~K}\end{array}$ & $\begin{array}{l}\text {-/ix/Š } 36 \\
\text {-/ii/ŠS } 37 \\
\text {-/iv/ŠS } 38 \\
\text {-/vii/Š } 38 \\
\text { 9/v/ŠS } 40\end{array}$ & $\begin{array}{c}\text { MVN 18, } 2 \\
\text { BIN III, } 409 \\
\text { PDT II, } 994 \\
\text { TCNY } 235 \\
\text { Toronto } 11\end{array}$ \\
\hline Barbarlia & 8 & $\begin{array}{l}3 \mathrm{~V} \\
3 \mathrm{~V} \\
3 \mathrm{~K} \\
6 \mathrm{~V} \\
2 \mathrm{~V} \\
6 \mathrm{~V} \\
\mathrm{~V} \\
3 \mathrm{~V}\end{array}$ & $\begin{array}{c}\text {-/iv/ŠS } 38 \\
\text {-/v/Š } 38 \\
\text {-/vii/ŠS } 38 \\
\text {-/iii/ŠS } 39 \\
\text { 6/iv/ŠS } 39 \\
\text { 29/iv/Š } 39 \\
\text { 8/vi/ŠS } 41 \\
\text { 24/ii/Š } 42\end{array}$ & $\begin{array}{c}\text { OIP } 115,35 \\
\text { TCNY } 105 \\
\text { TCNY 235 } \\
\text { MVN 3, } 161 \\
\text { AUCT I, } 952 \\
\text { OIP 115, } 38 \\
\text { BCT II, } 246 \\
\text { SET } 7\end{array}$ \\
\hline Beli-bani & 2 & $\begin{array}{l}2 \mathrm{~V} \\
3 \mathrm{~K}\end{array}$ & 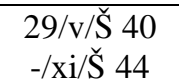 & $\begin{array}{c}\text { RT } 37,129 \text { Nr. } 2 \\
\text { UCP } 9 / 2 / 2,70\end{array}$ \\
\hline dumu Buza & 1 & $1 \mathrm{~K}$ & -/ii/ŠS 42 & OIP 115,70 \\
\hline Dagān-gu-Dagān & 1 & $32 \mathrm{~V}$ & 27/i/Š 44 & MVN 3, 200 \\
\hline Dajati & 1 & $4 \mathrm{~F}$ & 30/i/Š 44 & MVN 3, 200 \\
\hline dam Dakiki & 2 & $\begin{array}{c}6 \mathrm{~K} \\
1 \mathrm{G}, 10 \mathrm{~K} \\
\end{array}$ & $\begin{array}{l}\text {-/viii/Š } 36 \\
\text {-/ix/Š } 39\end{array}$ & $\begin{array}{l}\text { OIP } 115,24 \\
\text { OIP } 115,40 \\
\end{array}$ \\
\hline dam Dannia & 1 & $3 \mathrm{~K}$ & -/xi/ŠS 39 & TPTS 7 \\
\hline $\operatorname{nin}_{9}$ Dannia & 2 & $2 \mathrm{G}, 20 \mathrm{~K}$ & -/v/ŠS 37 & OIP 115,25 \\
\hline Dudu & 1 & $4 \mathrm{~K}$ & -/vii/ŠS 33 & MVN 15, 309 \\
\hline Ea-bani (ensi) & 4 & $\begin{array}{ll}1 \mathrm{~K} \\
1 \mathrm{~K} \\
1 \mathrm{~K} \\
3 \mathrm{~K}\end{array}$ & $\begin{array}{l}\text {-/vi/ŠS } 31 \\
\text {-/ix/ŠS } 32 \\
\text {-/iv/Š } 33 \\
\text {-/vii/ŠS } 38\end{array}$ & $\begin{array}{c}\text { BIN III, } 360 \\
\text { YOS 4, } 79 \\
\text { MVN 3, } 136 \\
\text { TCNY } 235\end{array}$ \\
\hline En Inanna & 4 & $\begin{array}{ll}1 \mathrm{~K} \\
1 \mathrm{~K} \\
2 \mathrm{~K} \\
1 \mathrm{~K}\end{array}$ & $\begin{array}{c}\text {-/ii/ŠS } 37 \\
\text { 22/i/ŠS } 42 \\
\text { 2/ii/ŠS } 47 \\
\text { 13/ix/Š } 47\end{array}$ & $\begin{array}{l}\text { BIN III, } 409 \\
\text { SET } 6 \\
\text { OIP } 115,90 \\
\text { Orient } 16,16\end{array}$ \\
\hline Ennia nar-mí & 1 & $1 \mathrm{~V}$ & -/iii/ŠS 39 & OIP 115,37 \\
\hline Enlil-iša & 2 & $\begin{array}{l}3 \mathrm{~K} \\
1 \mathrm{~K}\end{array}$ & $\begin{array}{l}-/ \text { vii/Š } 38 \\
22 / v / \text { Š } 45\end{array}$ & $\begin{array}{l}\text { TCNY } 235 \\
\text { PDT I, } 475\end{array}$ \\
\hline
\end{tabular}


Anhang 1: mu-DU-Lieferanten der Šulgi-simtī

\begin{tabular}{|c|c|c|c|c|}
\hline Name & Anzahl & $\begin{array}{c}\text { Was } \\
\text { geliefert? }\end{array}$ & Datum & Beleg \\
\hline $\begin{array}{c}\text { dam dumu ensi } i_{2} \\
\text { Adab }\end{array}$ & 1 & $1 \mathrm{~K}$ & $-/ \mathrm{v} / \mathrm{S} 34$ & TLB III, 15 \\
\hline ensi $_{2}$ Kazallu & 2 & $\begin{array}{l}1 \mathrm{~K} \\
1 \mathrm{~K}\end{array}$ & $\begin{array}{l}\text {-/iv/ŠS } 31 \\
\text {-/v/ŠS } 36\end{array}$ & $\begin{array}{l}\text { OIP } 115,17 \\
\text { Orient } 16,3\end{array}$ \\
\hline ensi $_{2}$ Nippur & 1 & $5 \mathrm{~K}$ & -/vii/ŠS 35 & Toronto 10 \\
\hline ensi $_{2}$ Umma & 1 & $10 \mathrm{~K}^{1269}$ & -/vi/ŠS 35 & MVN 13, 873 \\
\hline $\begin{array}{l}\text { Eštar-alšu dumu } \\
\text { lugal }^{1270}\end{array}$ & 2 & $\begin{array}{c}20 \mathrm{~V} \\
1 \mathrm{G}, 23+[\mathrm{x}] \\
\mathrm{K}\end{array}$ & $\begin{array}{l}\text { 22/xii/Š } 46 \\
\text { 22/xii/Š } 46\end{array}$ & $\begin{array}{c}\text { OIP } 115,89 \\
\text { MVN } 13,794\end{array}$ \\
\hline Etel-pu-Dagān & 6 & $\begin{array}{ll}1 & \mathrm{~K} \\
1 \mathrm{~K} \\
2 \mathrm{~K} \\
1 \mathrm{~K} \\
1 \mathrm{~K} \\
6 \mathrm{~K}\end{array}$ & $\begin{array}{c}\text {-/xi/Š } 29 \\
\text {-/i/Š } 36 \\
\text {-/i/Š } 37 \\
\text {-/ii/ŠS } 38 \\
\text { 10/i/ŠS } 45 \\
\text { 3+x/iii/ŠS } 46\end{array}$ & $\begin{array}{c}\text { OIP 115, } 16 \\
\text { BIN III, } 347 \\
\text { JCS 40, 244 Nr. } 8 \\
\text { TCND 50 } \\
\text { Bab 8, Pupil } 17 \\
\text { PDT II, 1035 }\end{array}$ \\
\hline $\begin{array}{l}\text { ummeda dumu- } \\
\text { munus } \\
\text { Etel-pu-Dagan }\end{array}$ & 1 & $1 \mathrm{~S}$ & -/i/ŠS 39 & TCND 32 \\
\hline Eue $\left(e n s i_{2}\right)$ & 4 & $\begin{array}{ll}1 \mathrm{~K} \\
1 \mathrm{~K} \\
1 \mathrm{~K} \\
1 \mathrm{~K}\end{array}$ & 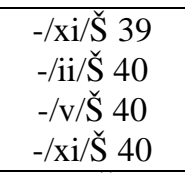 & $\begin{array}{c}\text { TPTS } 7 \\
\text { OIP } 115,43 \\
\text { OIP } 115,45 \\
\text { NISABA } 8,169 \\
\end{array}$ \\
\hline Galla & 2 & $\begin{array}{l}3 \mathrm{~K} \\
3 \mathrm{~K} \\
\end{array}$ & $\begin{array}{l}\text { 23/v/Š } 42 \\
15 / \mathrm{ii} / \mathrm{S} 44\end{array}$ & $\begin{array}{c}\text { CST } 469 \\
\text { MVN } 18,7 \\
\end{array}$ \\
\hline Garaja & 4 & $\begin{array}{l}3 \mathrm{~K} \\
2 \mathrm{~K} \\
3 \mathrm{~K} \\
1 \mathrm{~K}\end{array}$ & $\begin{array}{l}\text {-/x/ŠS } 38 \\
\text {-/iv/ŠS } 39 \\
\text {-/xii/Š } 42 \\
\text {-/vii/ŠS } 47\end{array}$ & $\begin{array}{c}\text { MVN 18, } 153 \\
\text { CST } 46 \\
\text { Hirose } 19 \\
\text { TPTS } 36\end{array}$ \\
\hline Girine-iša & 1 & $2 \mathrm{~K}$ & $-/ \mathrm{v} / \mathrm{S} \mathrm{S} 32$ & TCND 1 \\
\hline $\begin{array}{l}\text { dumu Geme- } \\
\text { girniše }\end{array}$ & 1 & $3 \mathrm{~K}$ & -/v/ŠS 34 & MVN 18, 147 \\
\hline dam Halaja & 1 & $2 \mathrm{~V}$ & 22/v/Š 45 & PDT I, 475 \\
\hline Halhalla & 1 & $1 \mathrm{G}, 10 \mathrm{~K}$ & -/v/ŠS 34 & MVN 18, 147 \\
\hline Huba & 1 & $1 \mathrm{G}, 10 \mathrm{~K}$ & $-/ \mathrm{v} / \mathrm{S} 33$ & CST 42 \\
\hline dumu-munus Ibih & 1 & $3 \mathrm{~K}$ & -/iii/ŠS 31 & MVN 3, 117 \\
\hline Ibi-Suen & 2 & $\begin{array}{l}14 \mathrm{~V} \\
13 \mathrm{~V}\end{array}$ & $\begin{array}{l}1 / \mathrm{vi} / \mathrm{S} 40 \\
23 / \mathrm{ii} / \mathrm{S} 42\end{array}$ & $\begin{array}{l}\text { BIN III, } 363 \\
\text { SET } 7\end{array}$ \\
\hline
\end{tabular}

1269 als b a la

1270 In OIP 115, 133 (Datum abgebrochen) tritt Eštar-alšu als Lieferantin von 4 Schweinen auf. 


\begin{tabular}{|c|c|c|c|c|}
\hline Name & Anzahl & $\begin{array}{c}\text { Was } \\
\text { geliefert? }\end{array}$ & Datum & Beleg \\
\hline Idin-Irra & 2 & $\begin{array}{l}2 \mathrm{~K} \\
5 \mathrm{~K}\end{array}$ & $\begin{array}{c}\text { 30/xi/Š } 43 \\
\text {-/ix/ŠS } 44\end{array}$ & $\begin{array}{l}\text { RO 11, } 96 \text { Nr. } 1 \\
\text { RT } 37,130 \text { Nr. } 6\end{array}$ \\
\hline Igi-(a)nakezu & 3 & $\begin{array}{c}7 \mathrm{~K} \\
1 \mathrm{G}, 10 \mathrm{~K} \\
{[\mathrm{x}] \mathrm{K}}\end{array}$ & $\begin{array}{l}-/ \mathrm{v} / \breve{S} 34 \\
-/ \mathrm{ix} / \breve{S} 36 \\
19 / \mathrm{ii} / \breve{S} 40\end{array}$ & $\begin{array}{c}\text { MVN 18, } 147 \\
\text { MVN 18, } 2 \\
\text { SACT I, } 57\end{array}$ \\
\hline Igi-lamazi & 1 & $2 \mathrm{~V}$ & 26/ii/Š 47 & MVN 13, 677 \\
\hline Ikunum & 3 & $\begin{array}{l}1 \mathrm{G} \\
3 \mathrm{~K} \\
3 \mathrm{~K}\end{array}$ & $\begin{array}{l}10 / \mathrm{i} / \mathrm{S} \mathbf{S} 45 \\
22 / \mathrm{v} / \mathrm{S} 45 \\
13 / \mathrm{ix} / \mathrm{Š}_{4} 47\end{array}$ & $\begin{array}{c}\text { Bab 8, Pupil } 17 \\
\text { PDT I, } 475 \\
\text { Orient } 16,16\end{array}$ \\
\hline Ilum-bani & 5 & $\begin{array}{ll}7 & \mathrm{~K} \\
1 \mathrm{~K} \\
3 \mathrm{~K} \\
1 \mathrm{~K} \\
2 \mathrm{~K}\end{array}$ & $\begin{array}{l}\text {-/iv/ŠS } 33 \\
\text {-/iv/ŠS } 35 \\
\text {-/xii/ŠS } 35 \\
\text {-/ii/ŠS } 37 \\
\text {-/ii/ŠS } 38\end{array}$ & $\begin{array}{c}\text { MVN } 3,136 \\
\text { OIP } 115,23 \\
\text { TPTS } 55 \\
\text { TCND } 28 \\
\text { TCND } 50\end{array}$ \\
\hline Imid-ilum (šabra) & 10 & $\begin{array}{c}3 \mathrm{~K} \\
1 \mathrm{~K} \\
19 \mathrm{~V} \\
1 \mathrm{~K} \\
1 \mathrm{~K} \\
1 \mathrm{~K} \\
{[\mathrm{x}] \mathrm{K}} \\
2 \mathrm{~K} \\
1 \mathrm{~K} \\
1 \mathrm{~K}\end{array}$ & 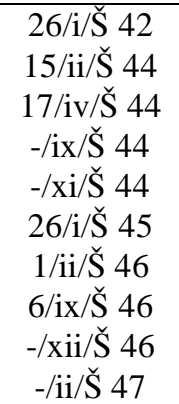 & $\begin{array}{c}\text { OIP 115, } 69 \\
\text { MVN 18, } 7 \\
\text { OIP 115, } 76 \\
\text { RT 37, 130 Nr. } 6 \\
\text { UCP 9/2/2, } 70 \\
\text { RA 73, 26 Nr. } 1 \\
\text { OIP 115, 86 } \\
\text { DCEPHE 302 } \\
\text { MVN 18, } 11 \\
\text { TCND 46 }\end{array}$ \\
\hline Imid-ilī na-gada & 1 & $2 \mathrm{~K}$ & -/viii/Š 38 & MVN 18, 42 \\
\hline Imid-Suen & 6 & $\begin{array}{l}5 \mathrm{~K} \\
5 \mathrm{~K} \\
4 \mathrm{~K} \\
4 \mathrm{~V} \\
1 \mathrm{~K} \\
1 \mathrm{~K}\end{array}$ & $\begin{array}{c}\text {-/viii/ŠS } 36 \\
\text {-/iv/Š } 38 \\
\text {-/iv/ŠS } 39 \\
\text { 28/iv/ŠS } 39 \\
\text { 30/xi/ŠS } 43 \\
\text {-/i/ŠS } 47\end{array}$ & $\begin{array}{c}\text { OIP } 115,24 \\
\text { AnOr } 1,24 \\
\text { CST } 46 \\
\text { OIP } 115,38 \\
\text { RO } 11,96 \text { Nr. } 1 \\
\text { PDT I, } 113\end{array}$ \\
\hline dam Imid-Suen & 1 & $5 \mathrm{~K}$ & $-/ \mathrm{x} / \mathrm{S} 38$ & MVN 18, 153 \\
\hline é-gi ${ }_{4}$-a_ Inim-Šara & 1 & $3 \mathrm{~V}$ & 29/viii/Š 40 & CST 51 \\
\hline Inim-kuga & 5 & $\begin{array}{l}9 \mathrm{~V} \\
2 \mathrm{~V} \\
5 \mathrm{~K} \\
1 \mathrm{~V} \\
2 \mathrm{~V}\end{array}$ & $\begin{array}{c}\text { 28/i/Š } 44 \\
\text { 15/xii/Š } 44 \\
\text {-/vi/Š } 45 \\
\text { 28/x/Š } 46 \\
\text { 2/ix/Š } 47\end{array}$ & $\begin{array}{c}\text { MVN 3, } 200 \\
\text { SACT I, } 58 \\
\text { PDT II, } 982 \\
\text { PDT I, } 56 \\
\text { SACT I, } 61\end{array}$ \\
\hline Inri & 1 & $4 \mathrm{~K}$ & -/vii/ŠS 33 & MVN 15, 309 \\
\hline Innuri & 2 & $\begin{array}{c}1 \mathrm{G}, 10 \mathrm{~K} \\
2 \mathrm{~V}\end{array}$ & 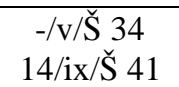 & $\begin{array}{l}\text { MVN 18, } 147 \\
\text { MVN 3, } 179\end{array}$ \\
\hline Izuarik (ensi ${ }_{2}$ ) & 2 & $\begin{array}{l}1 \mathrm{~K} \\
1 \mathrm{~K}\end{array}$ & $\begin{array}{l}\text {-/ii/Š } 37 \\
\text {-/viii/ŠS } 39\end{array}$ & $\begin{array}{l}\text { BIN III, } 409 \\
\text { CST } 49\end{array}$ \\
\hline
\end{tabular}


Anhang 1: mu-DU-Lieferanten der Šulgi-simtī

\begin{tabular}{|c|c|c|c|c|}
\hline Name & Anzahl & $\begin{array}{c}\text { Was } \\
\text { geliefert? }\end{array}$ & Datum & Beleg \\
\hline $\begin{array}{l}\text { Kallamu dumu } \\
\text { Inim-Šara }\end{array}$ & 1 & $1 \mathrm{G}, 10 \mathrm{~K}$ & 26/xi/ŠS 41 & TCND 52 \\
\hline dam Kallia & 1 & $3 \mathrm{~K}$ & -/viii/Š 39 & CST 49 \\
\hline KA-ra & 1 & $1 \mathrm{G}, 2 \mathrm{~K}$ & 2/ii/Š 47 & OIP 115,90 \\
\hline Katar & 1 & $10 \mathrm{~S}$ & $-/ \mathrm{x} / \mathrm{S} 46$ & MVN 18, 9 \\
\hline $\begin{array}{c}\text { dumu-mmunus } \\
\text { Kinaja }\end{array}$ & 1 & $2 \mathrm{~K}$ & -/vi/ŠS 31 & BIN III, 360 \\
\hline König/Palast & 6 & $\begin{array}{c}1 \mathrm{G}, 10 \mathrm{~K} \\
2 \mathrm{~K} \\
3 \mathrm{~V} \\
2 \mathrm{~V} \\
2 \mathrm{~K} \\
2 \mathrm{G} \\
\end{array}$ & $\begin{array}{c}\text {-/ix/ŠS } 36 \\
\text {-/ii/ŠS } 39 \\
26 / \text { i/ŠS } 42 \\
\text { 21/ii/ŠS } 42 \\
\text { 22/vi/ŠS } 44 \\
\text { 18/vii/ŠS } 44 \\
\end{array}$ & $\begin{array}{c}\text { MVN 18, } 2 \\
\text { TCND } 51 \\
\text { TCND } 37 \\
\text { SET } 7 \\
\text { TCND } 53 \\
\text { OrSP } 18,6 \\
\end{array}$ \\
\hline Kuliĝu & 1 & $1 \mathrm{~K}$ & -/iv/ŠS 31 & OIP 115,17 \\
\hline Kuli šabra & 1 & $1 \mathrm{G}, 6 \mathrm{~K}$ & $-/ \mathrm{v} / \mathrm{S}$ S2 & DCS 53 \\
\hline Kurrub-Irra & 6 & $\begin{array}{l}6 \mathrm{~K} \\
6 \mathrm{~K} \\
1 \mathrm{~K} \\
1 \mathrm{~K} \\
3 \mathrm{~K} \\
3 \mathrm{~K}\end{array}$ & $\begin{array}{c}\text {-/viii/ŠS } 38 \\
\text {-/viii/ŠS } 42 \\
\text {-/x/ŠS } 46 \\
\text {-/i/ŠS } 47 \\
\text {-/iii/ك̌ } 47 \\
\text { 2/ix/Š } 47\end{array}$ & $\begin{array}{c}\text { TCND } 29 \\
\text { TCND } 41 \\
\text { TCND } 45 \\
\text { PDT I, } 113 \\
\text { PDT II, } 1003 \\
\text { MVN 18, } 15\end{array}$ \\
\hline é kurušda & 2 & $\begin{array}{l}31 \mathrm{~S} \\
2 \mathrm{~K} \\
\end{array}$ & 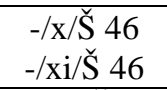 & $\begin{array}{l}\text { OIP } 115,87 \\
\text { OIP } 115,88\end{array}$ \\
\hline Larabum na-gada & 1 & $2 \mathrm{~K}$ & -/viii/Šs 38 & MVN 18, 42 \\
\hline Lu-diĝir-Ea & 1 & $2 \mathrm{~V}$ & 30/iv/ŠS 39 & OIP 115,38 \\
\hline Lugal-ezem kušs & 1 & $1 \mathrm{~K}$ & $-/ \mathrm{v} / \mathrm{S} 39$ & MVN 18, 3 \\
\hline Lugal-bandaše & 1 & $1 \mathrm{~K}$ & 29/ix/ŠS 45 & RA 49, 86 Nr. 4 \\
\hline Lugal-ôgu & 1 & $10 \mathrm{~K}$ & $-/ \mathrm{xi} / \mathrm{S}$ 29 & OIP 115,16 \\
\hline $\begin{array}{l}\text { Lugal-melam } \\
\text { sukkal }\end{array}$ & 1 & $2 \mathrm{~V}$ & $5 / \mathrm{xi} / \mathrm{S} 47$ & OIP 115,115 \\
\hline Lu-girizal & 1 & $3 \mathrm{~V}$ & 15/i/Šs 46 & $\begin{array}{c}\text { JCS 29, 1S. } 117 \\
\text { Nr. } 1\end{array}$ \\
\hline Lu-hyegala & 1 & $3 \mathrm{~K}$ & -/x/Šs 38 & MVN 2, 167 \\
\hline Lu-Magan & 3 & $\begin{array}{l}3 \mathrm{~K} \\
1 \mathrm{~K} \\
1 \mathrm{~K} \\
\end{array}$ & $\begin{array}{l}\text {-/iv/ŠS } 31 \\
-/ \mathrm{ii} / \check{S} 34 \\
10 / \mathrm{i} / \mathrm{S} 45 \\
\end{array}$ & $\begin{array}{c}\text { OIP } 115,17 \\
\text { OIP } 115,21 \\
\text { Bab } 8, \text { Pupil } 17\end{array}$ \\
\hline Lu-šaga & 1 & $2 \mathrm{~K}$ & 15/vii/Š 42 & Toronto 12 \\
\hline $\mathrm{Lu}-\mathrm{uru}^{\mathrm{ki}}$ & 6 & $\begin{array}{c}1 \mathrm{~K} \\
1 \mathrm{~V} \\
1 \mathrm{~K} \\
9 \mathrm{~V} \\
1 \mathrm{~K}, 1 \mathrm{~S} \\
1 \mathrm{~K} \\
\end{array}$ & 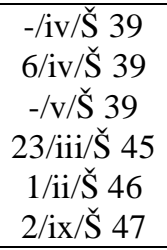 & $\begin{array}{c}\text { CST 46 } \\
\text { AUCT I, 952 } \\
\text { MVN 18, } 3 \\
\text { RT 37, 129 Nr. } 5 \\
\text { OIP 115, 86 } \\
\text { MVN 18, } 15 \\
\end{array}$ \\
\hline
\end{tabular}


Anhang 1: mu - DU -Lieferanten der Šulgi-simtī

\begin{tabular}{|c|c|c|c|c|}
\hline Name & Anzahl & $\begin{array}{c}\text { Was } \\
\text { geliefert? }\end{array}$ & Datum & Beleg \\
\hline Madati & 4 & $\begin{array}{ll}1 & \mathrm{~K} \\
1 \mathrm{~K} \\
3 \mathrm{~K} \\
1 \mathrm{~K}\end{array}$ & $\begin{array}{c}\text {-/iv/ŠS } 39 \\
\text { 30/xi/ŠS } 43 \\
\text { 9/v/ŠS } 44 \\
\text {-/vii/Š } 47\end{array}$ & $\begin{array}{c}\text { CST } 46 \\
\text { RO } 11,96 \text { Nr. } 1 \\
\text { StOr } 9,22 \\
\text { TCND } 47\end{array}$ \\
\hline mušen-dù & 3 & $\begin{array}{l}4 \mathrm{~V} \\
1 \mathrm{~V} \\
8 \mathrm{~V}\end{array}$ & 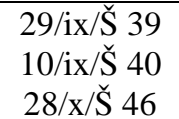 & $\begin{array}{c}\text { OIP } 115,39 \\
\text { BIN III, } 486 \\
\text { PDT I, } 56\end{array}$ \\
\hline $\begin{array}{l}\text { Nabium dumu } \\
\text { lugal }\end{array}$ & 1 & $3 \mathrm{~K}$ & 4/xii/Š 41 & SET 5 \\
\hline Namzitarra & 1 & $1 \mathrm{~K}$ & -/vi/ŠS 44 & SAT II, 364 \\
\hline Namutum & 2 & $\begin{array}{c}3 \mathrm{~K} \\
1 \mathrm{G}, 10 \mathrm{~K}\end{array}$ & 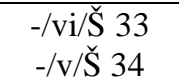 & $\begin{array}{c}\text { MVN 3, } 137 \\
\text { MVN 18, } 147\end{array}$ \\
\hline Nida na-gada & 1 & $1 \mathrm{~K}$ & -/v/Š 39 & MVN 18, 3 \\
\hline Ninkalla & 1 & $1 \mathrm{G}, 10 \mathrm{~K}$ & -/ix/ŠS 36 & MVN 18, 2 \\
\hline Ninliltum-imdi & 15 & $\begin{array}{c}1 \mathrm{~K} \\
9 \mathrm{~V} \\
2 \mathrm{~V} \\
2 \mathrm{~K} \\
11 \mathrm{~V} \\
{[\mathrm{x}] \mathrm{V}} \\
2 \mathrm{~K} \\
1 \mathrm{~K} \\
4 \mathrm{~V} \\
30 \mathrm{~K} \\
1 \mathrm{~K} \\
5 \mathrm{~V} \\
3 \mathrm{~K}, 3 \mathrm{~V} \\
2 \mathrm{~K}\end{array}$ & 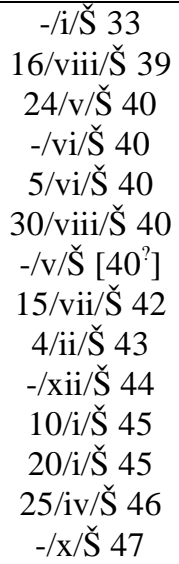 & $\begin{array}{c}\text { BIN III, 335 } \\
\text { PDT II, 1006 } \\
\text { OIP 115, } 44 \\
\text { TCND 35 } \\
\text { BIN III, } 363 \\
\text { CST 51 } \\
\text { TCND 44 }{ }^{1271} \\
\text { Toronto } 12 \\
\text { OIP 115, } 72 \\
\text { SET 8 } \\
\text { Bab 8, Pupil } 17 \\
\text { RA 73, 26 Nr. } 1 \\
\text { MVN 13, } 664 \\
\text { OIP 115, } 114\end{array}$ \\
\hline Nin-uma & 1 & $3 \mathrm{~K}$ & -/vi/ŠS 31 & BIN III, 360 \\
\hline $\begin{array}{l}\text { Nin-unummuni- } \\
\text { kiấg }\end{array}$ & 1 & $1 \mathrm{~K}$ & -/xi/ŠS 39 & TPTS 7 \\
\hline Nir-idaĝal & 13 & $\begin{array}{c}5 \mathrm{~K} \\
1 \mathrm{G}, 10 \mathrm{~K} \\
5 \mathrm{~K} \\
3 \mathrm{~K} \\
53 \mathrm{~K} \\
2 \mathrm{~K} \\
14 \mathrm{~V} \\
2 \mathrm{~K} \\
3 \mathrm{~V}\end{array}$ & 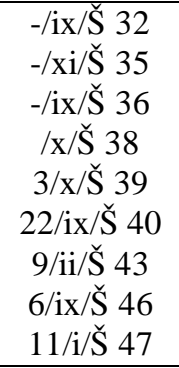 & $\begin{array}{c}\text { YOS 4, } 79 \\
\text { TCND 27 } \\
\text { MVN 18, } 2 \\
\text { MVN 2, } 167 \\
\text { OIP 115, } 41 \\
\text { RT 37, 129, Nr. } 3 \\
\text { OIP 115, } 72 \\
\text { DCEPHE } 302 \\
\text { TRU } 78\end{array}$ \\
\hline
\end{tabular}

1271 Das Datum ist teilweise abgebrochen, die Zuweisung in das Jahr Š 40 ist unsicher. 
Anhang 1: mu-DU-Lieferanten der Šulgi-simtī

\begin{tabular}{|c|c|c|c|c|}
\hline Name & Anzahl & $\begin{array}{c}\text { Was } \\
\text { geliefert? }\end{array}$ & Datum & Beleg \\
\hline & & $\begin{array}{c}3 \mathrm{~K} \\
2 \mathrm{~K} \\
1 \mathrm{G}, 10 \mathrm{~K} \\
3 \mathrm{~K}\end{array}$ & $\begin{array}{c}\text { 2/ii/ŠS } 47 \\
\text { 13/ix/Š } 47 \\
\text { 15/ix/ŠS } 47 \\
\text { 20/ix/ŠS } 47\end{array}$ & $\begin{array}{l}\text { OIP } 115,90 \\
\text { Orient } 16,16 \\
\text { BIN III, } 21 \\
\text { OIP } 115,112\end{array}$ \\
\hline nu- ${ }^{\text {giš }}$ kiri $_{6}-\mathrm{ke}_{4}$-ne & 3 & $\begin{array}{l}2 \mathrm{~V} \\
5 \mathrm{~V} \\
9 \mathrm{~V}\end{array}$ & $\begin{array}{c}\text { 7/iii/ ̌̌ } 44 \\
20 / \mathrm{iii} / \mathrm{S}_{4} 44 \\
19 / \mathrm{iv} / \mathrm{S} 44\end{array}$ & $\begin{array}{c}\text { TCND } 42 \\
\text { RA } 19,192 \text { Nr. } 7 \\
\text { OIP } 115,76^{1272}\end{array}$ \\
\hline Nuida & 1 & $7 \mathrm{~K}$ & 17/vii/Š 44 & OrSP 18,6 \\
\hline dam Nuida & 1 & $5 \mathrm{~K}$ & 17/vii/Š 44 & OrSP 18,6 \\
\hline Puzur-Eštar & 10 & $\begin{array}{c}3 \mathrm{~K} \\
{[\mathrm{x}] \mathrm{K}} \\
1 \mathrm{~K} \\
6 \mathrm{~K} \\
2 \mathrm{~K} \\
2 \mathrm{~K} \\
2 \mathrm{~K} \\
2 \mathrm{~K} \\
1 \mathrm{~K} \\
1 \mathrm{~K} \\
\end{array}$ & 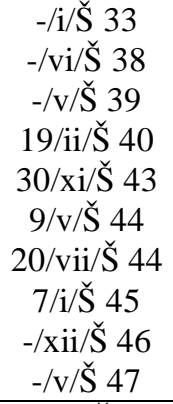 & $\begin{array}{c}\text { BIN III, } 335 \\
\text { OIP 115, } 36 \\
\text { MVN 18, } 3 \\
\text { SACT I, } 57 \\
\text { RO 11, 96 Nr. } 1 \\
\text { StOr 9, } 22 \\
\text { OrSP 18, } 6 \\
\text { Bab 8, Pupil } 17 \\
\text { MVN 18, } 11 \\
\text { MVN 18, } 14 \\
\end{array}$ \\
\hline Puzur-Šamaš & 1 & $5 \mathrm{G}, 2 \mathrm{~K}$ & -/viii/Š 35 & MVN 3, 143 \\
\hline Riqmuša & 1 & $1 \mathrm{~V}$ & -/i/ŠS 39 & TCND 32 \\
\hline $\begin{array}{l}\text { Rubatum dam } \\
\text { Nuida }\end{array}$ & 3 & $\begin{array}{c}2 \mathrm{G}, 20 \mathrm{~K} \\
6 \mathrm{~K} \\
5 \mathrm{~K} \\
\end{array}$ & $\begin{array}{c}\text { 25/xi/Š } 39 \\
\text {-/v/ŠS } 40 \\
\text {-/viii/ŠS } 46 \\
\end{array}$ & $\begin{array}{c}\text { OIP } 115,42 \\
\text { OIP } 115,45 \\
\text { PDT II, } 1013 \\
\end{array}$ \\
\hline SI.A.A & 1 & $2 \mathrm{~K}$ & -/viii/Š 42 & TCND 40 \\
\hline Šibat-ekur & 4 & $\begin{array}{l}1 \mathrm{~V} \\
3 \mathrm{~K} \\
1 \mathrm{~K} \\
5 \mathrm{~K}\end{array}$ & 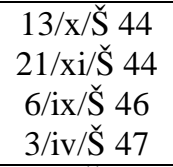 & $\begin{array}{c}\text { TRU } 77 \\
\text { Orient 16, } 6 \\
\text { DCEPHE } 302 \\
\text { PDT I, } 157 \\
\end{array}$ \\
\hline Simat-Ea & 2 & $\begin{array}{c}3 \mathrm{~K} \\
1 \mathrm{G}, 10 \mathrm{~K} \\
\end{array}$ & 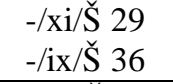 & $\begin{array}{l}\text { OIP } 115,16 \\
\text { MVN } 18,2\end{array}$ \\
\hline Simat-Eštar & 14 & $\begin{array}{l}12 \mathrm{~V} \\
3 \mathrm{~V} \\
2 \mathrm{~K} \\
7 \mathrm{~V} \\
1 \mathrm{~V} \\
1 \mathrm{~V} \\
1 \mathrm{G} \\
7 \mathrm{~V} \\
\end{array}$ & 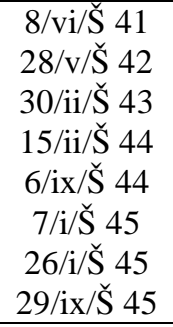 & $\begin{array}{c}\text { BCT II, } 246 \\
\text { TCND } 39 \\
\text { OLP 8, } 7 \text { Nr. } 2 \\
\text { OIP 115, } 75 \\
\text { TCND } 43 \\
\text { Bab 8, Pupil } 17 \\
\text { RA 73, } 26 \text { Nr. } 1 \\
\text { RA 49, } 86 \text { Nr. } 4 \\
\end{array}$ \\
\hline
\end{tabular}

1272 Die Abgabe ist als á-gi š-gar-ra (Arbeitsquote) deklariert. Siehe dazu Sigrist, Drehem, S. 91-92. 
Anhang 1: mu - DU -Lieferanten der Šulgi-simtī

\begin{tabular}{|c|c|c|c|c|}
\hline Name & Anzahl & $\begin{array}{c}\text { Was } \\
\text { geliefert? }\end{array}$ & Datum & Beleg \\
\hline & & $\begin{array}{c}1 \mathrm{~K} \\
2 \mathrm{~S} \\
10 \mathrm{~K} \\
1 \mathrm{~K} \\
6 \mathrm{~V} \\
1 \mathrm{~K} \\
\end{array}$ & 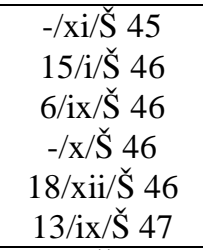 & $\begin{array}{c}\text { OIP } 115,85 \\
\text { JCS } 29,117 \text { Nr. } 1 \\
\text { DCEPHE } 302 \\
\text { TCND } 45 \\
\text { OIP } 115,89 \\
\text { Orient } 16,16 \\
\end{array}$ \\
\hline sipa-e-ne & 1 & $1 \mathrm{~K}$ & $-/ \mathrm{v} / \mathrm{S} \mathrm{S} 32$ & DCS 53 \\
\hline Suen-nada & 1 & $1 \mathrm{~V}$ & 19/ix/Š 40 & BIN III, 486 \\
\hline $\begin{array}{c}\text { SUHUUŠ- } \\
\text { kēn/Suruš-kēn }\end{array}$ & 7 & $\begin{array}{c}3 \mathrm{~K} \\
6 \mathrm{~K} \\
12 \mathrm{~K} \\
3 \mathrm{~V} \\
5 \mathrm{~K} \\
1 \mathrm{~K} \\
2 \mathrm{~K}\end{array}$ & 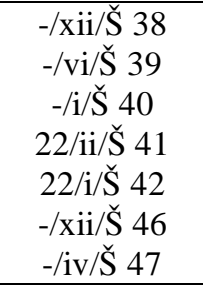 & $\begin{array}{c}\text { TCND 31 } \\
\text { TCND 33 } \\
\text { AUCT I, } 89 \\
\text { TCND 36 } \\
\text { SET 6 } \\
\text { MVN 18, } 11 \\
\text { TCND 24 }\end{array}$ \\
\hline Șilluš-Dagān & 7 & $\begin{array}{c}2 \mathrm{~K} \\
3 \mathrm{~K} \\
4 \mathrm{~K} \\
50 \mathrm{~K} \\
5 \mathrm{~V} \\
13 \mathrm{~V} \\
1 \mathrm{~K}\end{array}$ & $\begin{array}{c}\text {-/i/ŠS } 33 \\
\text { 30/xi/Š } 43 \\
\text { 25/vi/Š } 44 \\
\text {-/viii/ŠS } 46 \\
\text { 28/x/ŠS } 46 \\
\text { 20/i/ŠS } 47 \\
\text { 2/ii/ŠS } 47\end{array}$ & $\begin{array}{c}\text { BIN III, } 335 \\
\text { RO 11, 96 Nr. } 1 \\
\text { MVN 15, } 324 \\
\text { PDT II, } 1013 \\
\text { PDT I, } 56 \\
\text { ŠA IX, } 41 \\
\text { OIP } 115,90\end{array}$ \\
\hline nin $_{9}$ Șilluš-Dagān & 5 & $\begin{array}{l}11^{?} \mathrm{~K} \\
3 \mathrm{~V} \\
2 \mathrm{~V} \\
7 \mathrm{~V} \\
5 \mathrm{~V} \\
\end{array}$ & $\begin{array}{c}\text {-/i/ŠS [ ] }]^{1273} \\
\text { 23/vii/Š } 41 \\
\text { 20/ix/Š } 43 \\
\text { 27/i/Š } 44 \\
\text { 22/vii/ŠS } 47 \\
\end{array}$ & $\begin{array}{c}\text { TRU } 76 \\
\text { YOS 18, } 5 \\
\text { OIP } 115,74 \\
\text { MVN 3, } 200 \\
\text { OIP } 115,110 \\
\end{array}$ \\
\hline $\begin{array}{c}\text { dumu Șilluš- } \\
\text { Dagān }\end{array}$ & 1 & $20 \mathrm{~V}$ & $8 / \mathrm{i} / \mathrm{S} 46$ & $\begin{array}{c}\text { JCS } 29, \text { S. } 117 \\
\text { Nr. } 1\end{array}$ \\
\hline dam sukkal-mah & 1 & $1 \mathrm{~K}$ & -/i/ŠS 36 & Hirose 13 \\
\hline šeš šabra & 1 & $5 \mathrm{~K}$ & $-/ \mathrm{xi} / \mathrm{S} 38$ & MVN 18, 40 \\
\hline Šalim-[niaš?] & 1 & $6 \mathrm{~V}$ & $8 / \mathrm{i} / \mathrm{S} 46$ & $\begin{array}{c}\text { JCS } 29, \text { S. } 117 \\
\text { Nr. } 1\end{array}$ \\
\hline Šamaš-illat & 2 & $\begin{array}{l}5 \mathrm{~K} \\
10 \mathrm{~V}\end{array}$ & $\begin{array}{l}\text {-/viii/Š } 38 \\
\text { 22/ix/ŠS } 39\end{array}$ & $\begin{array}{c}\text { TCND } 30 \\
\text { STD } 4\end{array}$ \\
\hline Šara-kam & 2 & $\begin{array}{c}\mathrm{x}] \mathrm{V} \\
1 \mathrm{G}, 10 \mathrm{~K}\end{array}$ & $\begin{array}{l}\text { 7/iv/Š } 40 \\
\text { 2/ii/Š } 47\end{array}$ & $\begin{array}{l}\text { PDT II, } 993 \\
\text { OIP } 115,90\end{array}$ \\
\hline dam Šara-kam & 4 & $\begin{array}{c}3+2 \mathrm{~V} \\
1 \mathrm{~V}\end{array}$ & $\begin{array}{c}\text { 17,19/ix/Š } 43 \\
\text { 8/xii/Š } 43\end{array}$ & $\begin{array}{c}\text { OIP } 115,74 \\
\text { Hirose } 22\end{array}$ \\
\hline
\end{tabular}

1273 Nach Sallaberger, OBO 160/3, S. 389, gegen Lafont, ASJ 7, S. 169f. bilden die beiden Fragmente TRU 76 und TRU 77 keinen Join. 
Anhang 1: mu-DU-Lieferanten der Šulgi-simtī

\begin{tabular}{|c|c|c|c|c|}
\hline Name & Anzahl & $\begin{array}{c}\text { Was } \\
\text { geliefert? }\end{array}$ & Datum & Beleg \\
\hline & & $\begin{array}{l}3 \mathrm{~K} \\
8 \mathrm{~V}\end{array}$ & $\begin{array}{l}13 / \mathrm{ix} / \check{\mathrm{S}} 47 \\
15 / \mathrm{i} / \mathrm{S} 46\end{array}$ & $\begin{array}{c}\text { Orient } 16,16 \\
\text { JCS } 29, \text { S. } 117 \\
\text { Nr. } 1\end{array}$ \\
\hline Šarrum-ilī ensi ${ }_{2}$ & 1 & $5 \mathrm{~K}$ & $22 / \mathrm{v} / \mathrm{S} 45$ & PDT I, 475 \\
\hline Šarrum-ilī sukkal & 3 & $\begin{array}{l}2 \mathrm{~V} \\
3 \mathrm{~S} \\
1 \mathrm{~K}\end{array}$ & $\begin{array}{c}\text { 24/vii/ŠS } 42 \\
\text { 15/xii/ŠS } 46 \\
\text {-/ii/Š } 47\end{array}$ & $\begin{array}{c}\text { TCND } 38 \\
\text { OIP } 115,89 \\
\text { OIP } 115,91\end{array}$ \\
\hline Šarrum-ilī & 1 & $1 \mathrm{~K}$ & 13/ix/ŠS 47 & Orient 16,16 \\
\hline $\begin{array}{l}\text { dam Śarrum-ilī } \\
\text { kušs }_{7}\end{array}$ & 1 & $1 \mathrm{~V}$ & 22/viii/Š 42 & TPTS 59 \\
\hline $\begin{array}{c}\text { dam Šarrum-ilī } \\
\text { nu-banda }\end{array}$ & 1 & $3 \mathrm{~V}$ & 11/ix/Š 47 & OIP 115,111 \\
\hline dam Šarrum-ilī & 2 & $\begin{array}{l}77 \mathrm{~V} \\
5 \mathrm{~V} \\
\end{array}$ & $\begin{array}{l}\text { 7/iii//Š } 44 \\
\text { 2/xi/Š } 44 \\
\end{array}$ & $\begin{array}{l}\text { TCND } 42 \\
\text { BIN III, } 7 \\
\end{array}$ \\
\hline $\begin{array}{l}\text { Šu-Eštar (dumu } \\
\text { lugal) }\end{array}$ & 7 & $\begin{array}{c}1 \mathrm{~K} \\
5 \mathrm{~V} \\
1 \mathrm{~K}+[\mathrm{x}] \\
2 \mathrm{~V} \\
{[\mathrm{x}] \mathrm{K}} \\
{[\mathrm{x}] \mathrm{K}} \\
1 \mathrm{~K} \\
\end{array}$ & $\begin{array}{l}\text { 30/xi/Š } 43 \\
\text { 20/iii/Š } 44 \\
\text {-/vii/Š } 44 \\
\text { 23/i/ŠS } 47 \\
\text {-/iv/Š } 47 \\
\text {-/vii/ك̌ } 47 \\
\text {-/vii/Š } 47 \\
\end{array}$ & $\begin{array}{c}\text { RO 11, } 96 \text { Nr. } 1 \\
\text { RA 19, } 192 \text { Nr. } 7 \\
\text { ASJ 9, } 318 \text { Nr. } 12 \\
\text { PDT II, } 1022 \\
\text { TCND } 24 \\
\text { TCND } 47 \\
\text { TPTS } 36 \\
\end{array}$ \\
\hline ama $\breve{S} u-{ }^{d} B E$ & 2 & $\begin{array}{c}6+[\mathrm{x}] \mathrm{K} \\
3 \mathrm{~K}\end{array}$ & $\begin{array}{l}-/ \mathrm{x} / \mathrm{Š} 38 \\
\text { 9/v/ŠS } 44\end{array}$ & $\begin{array}{c}\text { MVN 18, } 153 \\
\text { StOr 9, } 22\end{array}$ \\
\hline dam Šu- ${ }^{\mathrm{d}} \mathrm{BE}$ & 1 & $1 \mathrm{G}, 10 \mathrm{~K}$ & -/viii/Š 36 & OIP 115,24 \\
\hline Šu-kubum & 3 & $\begin{array}{l}5 \mathrm{~K} \\
4 \mathrm{~K} \\
1 \mathrm{~K} \\
\end{array}$ & $\begin{array}{l}\text {-/vi/ŠS } 42 \\
\text {-/vii/ŠS } 47 \\
\text { 20/ix/ŠS } 47\end{array}$ & $\begin{array}{c}\text { PDT II, } 983 \\
\text { TPTS } 41 \\
\text { OIP } 115,112 \\
\end{array}$ \\
\hline Šu-Utu & 1 & $23 \mathrm{~K}$ & -/viii/Š 38 & MVN 18, 42 \\
\hline Šulgi-bala & 1 & $1 \mathrm{~K}$ & $-/ \mathrm{x} / \mathrm{S} 38$ & MVN 2, 167 \\
\hline $\begin{array}{l}\text { dam Šulgi-ilī } \\
\text { šaggina }\end{array}$ & 1 & $2 \mathrm{G}, 20 \mathrm{~K}$ & -/ix/ŠS 47 & OIP 115,113 \\
\hline $\begin{array}{l}\text { dam Šulgi-ilī } \\
\text { šakkanakku }\end{array}$ & 1 & $2 \mathrm{G}, 20 \mathrm{~K}$ & $-/$ viii/Š 45 & RT 37,130 Nr. 7 \\
\hline Tabadarah & 2 & $\begin{array}{c}6 \mathrm{~K} \\
1 \mathrm{G}, 10 \mathrm{~K}\end{array}$ & $\begin{array}{l}\text {-/ii/Š } 34 \\
\text {-/v/Š } 34\end{array}$ & $\begin{array}{l}\text { OIP } 115,21 \\
\text { TLB III, } 15\end{array}$ \\
\hline dam Tabadarah & 2 & $\begin{array}{c}1 \mathrm{G}, 7+[3] \mathrm{K} \\
2 \mathrm{G}, 10 \mathrm{~K} \\
\end{array}$ & 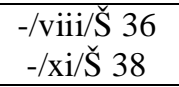 & $\begin{array}{l}\text { OIP } 115,24 \\
\text { MVN 18, } 40\end{array}$ \\
\hline Taba-ilī na-gada & 2 & $\begin{array}{l}2 \mathrm{~K} \\
2 \mathrm{~K} \\
\end{array}$ & $\begin{array}{c}\text { 30/ii//S } 43 \\
-/ \mathrm{i} / \mathrm{S} 47\end{array}$ & $\begin{array}{c}\text { OLP 8, } 7 \text { Nr. } 2 \\
\text { Boson } 335\end{array}$ \\
\hline Talim-Enlil & 2 & $\begin{array}{l}1 \mathrm{~K} \\
1 \mathrm{~K} \\
\end{array}$ & $\begin{array}{c}\text {-/ii//Š } 37 \\
\text { 22/i/ŠS } 42 \\
\end{array}$ & $\begin{array}{c}\text { BIN III, } 409 \\
\text { SET } 6\end{array}$ \\
\hline Tamkara & 1 & $2 \mathrm{~V}$ & 18/ix/Š 47 & TCND 48 \\
\hline
\end{tabular}




\begin{tabular}{|c|c|c|c|c|}
\hline Name & Anzahl & $\begin{array}{l}\text { Was } \\
\text { geliefert? }\end{array}$ & Datum & Beleg \\
\hline Teșīn-Mama & 13 & $\begin{array}{l}20 \mathrm{~K} \\
2 \mathrm{~K} \\
2 \mathrm{~K} \\
1 \mathrm{~K} \\
1 \mathrm{~K} \\
2 \mathrm{~K} \\
1 \mathrm{~K} \\
1 \mathrm{~K} \\
3 \mathrm{~K} \\
58 \mathrm{~V} \\
1 \mathrm{~K} \\
2 \mathrm{~K} \\
1 \mathrm{~K}\end{array}$ & $\begin{array}{l}\text {-/xi/ŠS } 29 \\
\text {-/i/Š } 33 \\
\text {-/ix/Š } 35 \\
\text {-/xii/ŠS } 35 \\
\text {-/ii/Š } 37 \\
\text {-/vii/Š } 38 \\
\text {-/xi/Š } 38 \\
\text {-/ii/Š } 39 \\
\text {-/iii/ŠS } 39 \\
\text { 6/iv/ŠS } 39 \\
\text {-/ii/Š } 42 \\
\text { 30/xi/Š } 43 \\
\text {-/iv/Š } 47\end{array}$ & $\begin{array}{c}\text { OIP 115, } 16 \\
\text { BIN III, } 335 \\
\text { RT 37, } 129 \text { Nr. } 1 \\
\text { TPTS 55 } \\
\text { TCND 28 } \\
\text { TCNY 235 } \\
\text { MVN 18, 40 } \\
\text { TCND 51 } \\
\text { MVN 3, } 162 \\
\text { AUCT I, } 952 \\
\text { Hirose } 19 \\
\text { RO } 11,96 \text { Nr. } 1 \\
\text { TCND 24 }\end{array}$ \\
\hline Teșīn-Mati & 1 & $2 \mathrm{~V}$ & 19/ix/Šs 40 & BIN III, 486 \\
\hline Ur-Ba'u mušen-dù & 1 & $20 \mathrm{~V}$ & -/ix/ŠS 44 & MVN 13, 273 \\
\hline Ur-daga & 1 & $2 \mathrm{~V}$ & 11/iii/ŠS 44 & TCND 42 \\
\hline Ur- Ištarān & 2 & $\begin{array}{l}2 \mathrm{~V} \\
4 \mathrm{~K} \\
\end{array}$ & $\begin{array}{l}\text { 2/ii/Š } 41 \\
\text { 29/i/ŠS } 47\end{array}$ & $\begin{array}{l}\text { Hirose } 16 \\
\text { SACT I, } 60\end{array}$ \\
\hline Urkununna & 1 & $5 \mathrm{~K}$ & -/v/Š 38 & SACT I, 55 \\
\hline Ur-lugal-edinka & 1 & $5 \mathrm{~S}$ & $-/ \mathrm{x} / \mathrm{S} 46$ & MVN 18, 9 \\
\hline Ur-Manna? & 1 & $2^{?} \mathrm{G}, 10 \mathrm{~K}$ & 30/xi/Šs 43 & RO 11, 96 Nr. 1 \\
\hline Ur-mes & 1 & $1 \mathrm{~V}$ & 22/xii/Šs 46 & OIP 115,89 \\
\hline Ur-mes dub-sar & 1 & $18 \mathrm{~K}$ & 22/xii/ Š 46 & MVN 13, 794 \\
\hline Ur-mes mušen-dù & 1 & $20 \mathrm{~V}$ & -/ix/ Š 44 & MVN 13, 273 \\
\hline Ur-mes na-gada & 1 & $1 \mathrm{~K}$ & -/v/Š 39 & MVN 18, 3 \\
\hline Ur-niĝar $\left.(\mathrm{kuš})_{7}\right)$ & 4 & $\begin{array}{c}5 \mathrm{~K} \\
2 \mathrm{~K} \\
1 \mathrm{G}, 10 \mathrm{~K} \\
1 \mathrm{~K}\end{array}$ & 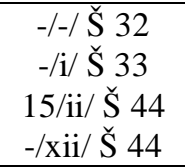 & $\begin{array}{c}\text { BIN V, } 11 \\
\text { BIN III, } 335 \\
\text { MVN 18, } 7 \\
\text { SET } 8\end{array}$ \\
\hline dam Ur-niĝar & 6 & $\begin{array}{c}1 \mathrm{~K} \\
1 \mathrm{~K} \\
1 \mathrm{G}, 10 \mathrm{~K} \\
14 \mathrm{~V} \\
5 \mathrm{~V} \\
9 \mathrm{~V} \\
\end{array}$ & 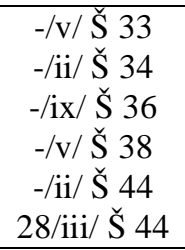 & $\begin{array}{c}\text { CST } 42 \\
\text { OIP } 115,21 \\
\text { MVN } 18,2 \\
\text { TCNY } 105 \\
\text { YOS } 18,6 \\
\text { RA } 19,192 \text { Nr. } 7\end{array}$ \\
\hline $\begin{array}{l}\text { dumu-munus Ur- } \\
\text { niĝar }\end{array}$ & 1 & $10 \mathrm{~V}$ & -/iv/ ŠS 38 & Boson 358 \\
\hline Ur-Ninmug & 1 & $25 \mathrm{~V}$ & -/iii/ Š 39 & OIP 115,37 \\
\hline $\begin{array}{c}\text { Ur-Nisaba ensi }{ }_{2} \\
\text { Nippur }\end{array}$ & 1 & $5 \mathrm{~K}$ & 19/vii/ Š 44 & OrSP 18,6 \\
\hline Ur-Zababa ${ }^{\mathrm{ki}}$ & 1 & $3 \mathrm{~K}$ & -/iv/ Š 33 & MVN 3, 136 \\
\hline $\begin{array}{c}\text { dam Ur-Suen ensi }{ }_{2} \\
\text { Uru } \\
\end{array}$ & 1 & $4 \mathrm{~K}$ & 15/vii/ Š 42 & Toronto 12 \\
\hline
\end{tabular}


Anhang 1: mu - D U-Lieferanten der Šulgi-simtī

\begin{tabular}{|c|c|c|c|c|}
\hline Name & Anzahl & $\begin{array}{c}\text { Was } \\
\text { geliefert? }\end{array}$ & Datum & Beleg \\
\hline Ur-saga mušen-dù & 1 & $20 \mathrm{~V}$ & -/ix/ Š 44 & MVN 13, 273 \\
\hline Ur-Šulgira & 1 & $6 \mathrm{~V}$ & 25/viii/ Š 39 & CST 48 \\
\hline Ur-Šulpae & 4 & $\begin{array}{c}1 \mathrm{~K} \\
1 \mathrm{~K}, 11 \mathrm{~K} \\
1 \mathrm{G}, 10 \mathrm{~K} \\
1 \mathrm{G}, 10 \mathrm{~K} \\
\end{array}$ & 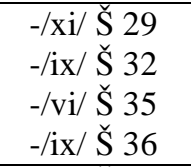 & $\begin{array}{l}\text { OIP } 115,16 \\
\text { YOS } 4,79 \\
\text { TCND } 49 \\
\text { MVN } 18,2 \\
\end{array}$ \\
\hline Watrat (ugula) & 13 & $\begin{array}{l}10 \mathrm{~V} \\
2 \mathrm{~K} \\
4 \mathrm{~V} \\
2 \mathrm{~V} \\
4 ? \mathrm{~V} \\
3 \mathrm{~K} \\
1 \mathrm{~K} \\
5 \mathrm{~V} \\
1 \mathrm{~K} \\
5 \mathrm{~K} \\
4 \mathrm{~V} \\
4 \mathrm{~V} \\
2 \mathrm{~K} \\
\end{array}$ & 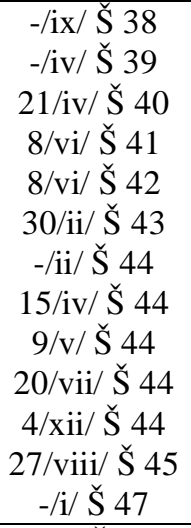 & $\begin{array}{c}\text { BIN III, 1 } \\
\text { SACT I, } 56 \\
\text { PDT II, } 993 \\
\text { BCT II, } 246 \\
\text { ŠA III, 45 } \\
\text { OLP 8, 7 Nr. } 2 \\
\text { MVN 3, } 201 \\
\text { OIP 115, 76 } \\
\text { StOr 9, } 22 \\
\text { OrSP 18, } 6 \\
\text { OIP 115, 77 } \\
\text { MVN 4, 105 } \\
\text { MVN 18, } 16 \\
\end{array}$ \\
\hline zabar-dab $_{5}$ & 3 & $\begin{array}{l}5 \mathrm{~K} \\
3 \mathrm{~K} \\
2 \mathrm{~K}\end{array}$ & $\begin{array}{c}\text {-/ix/ŠS } 36 \\
\text { 3/x/ Š } 39 \\
\text { 30/xi/ ك̌ } 43\end{array}$ & $\begin{array}{c}\text { MVN 18, } 2 \\
\text { OIP 115, } 41 \\
\text { RO } 11,96 \text { Nr. } 1\end{array}$ \\
\hline Zak-ilī & 4 & $\begin{array}{ll}2 \mathrm{~K} \\
1 \mathrm{~K} \\
1 \mathrm{~K} \\
1 \mathrm{~K}\end{array}$ & 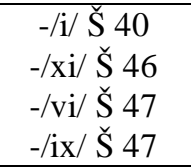 & $\begin{array}{c}\text { AUCT I, } 89 \\
\text { MVN 13, } 675 \\
\text { OIP } 115,109 \\
\text { OIP } 115,113\end{array}$ \\
\hline Zalaja & 2 & $\begin{array}{l}3 \mathrm{~K} \\
2 \mathrm{~K}\end{array}$ & $\begin{array}{l}\text {-/iv/ Š } 32 \\
\text {-/vii/ ك̌ } 35\end{array}$ & $\begin{array}{c}\text { MVN 2, } 308 \\
\text { Toronto } 10\end{array}$ \\
\hline ama Zalaja & 1 & $1 \mathrm{G}, 5 \mathrm{~K}$ & -/v/ Š 34 & MVN 18, 147 \\
\hline dam Ze/arara & 2 & $\begin{array}{l}2 \mathrm{~V} \\
1 \mathrm{~K}\end{array}$ & $\begin{array}{l}\text { 22/ix/ Š } 43 \\
\text {-/xii/ Š } 44\end{array}$ & $\begin{array}{l}\text { OIP } 115,74 \\
\text { SET } 8\end{array}$ \\
\hline dumu Zuzaja & 1 & $3 \mathrm{~K}$ & -/xi/ Š 38 & MVN 18,40 \\
\hline [ ] dumu Rabi-NE & 1 & $20 \mathrm{~K}$ & -/viii/ Š 46 & PDT II, 1013 \\
\hline
\end{tabular}

Tabelle 18: mu - D U -Lieferanten der Šulgi-simtī. 


\begin{tabular}{|c|c|c|c|c|}
\hline Publikation & Datum & $\begin{array}{c}\text { Tafel } \\
\text { der } \\
\text { Königin }\end{array}$ & Palast & zusätzlicher Vermerk \\
\hline MVN 8, 97 & $-/ \mathrm{v} / \mathrm{S} 32$ & & $\begin{array}{l}1 \mathrm{~K} \\
3 \mathrm{~K}\end{array}$ & $\begin{array}{c}\text { im Palast } \\
\text { für die Küche in Uruk } \\
\hat{\mathrm{g}} \mathrm{i} \mathrm{ri}_{3} \quad \mathrm{n} \text { in }{ }^{d} \breve{S} u l g i \text {-simt } \bar{\imath}\end{array}$ \\
\hline PDT II, 998 & -/vi/Š 35 & & $1 \mathrm{~K}$ & \\
\hline TCND 179 & -/iv/Š 38 & & $3 \mathrm{~V}$ & \\
\hline $\begin{array}{l}\text { OIP } 115, \\
46\end{array}$ & -/v/Šs 38 & & $2 \mathrm{~V}$ & \\
\hline $\begin{array}{l}\text { OIP } 115, \\
48\end{array}$ & -/viii/Š 38 & $17 \mathrm{~V}$ & $5 \mathrm{~V}$ & \\
\hline $\begin{array}{l}\text { OIP } 115, \\
51\end{array}$ & $-/ \mathrm{i} / \mathrm{S} 39$ & $4 \mathrm{~V}$ & $\begin{array}{l}4 \mathrm{~V} \\
2 \mathrm{~V} \\
1 \mathrm{~V}\end{array}$ & 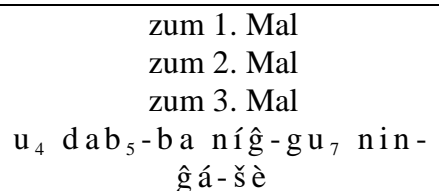 \\
\hline $\begin{array}{l}\text { OIP } 115, \\
52\end{array}$ & -/iii/Š 39 & & $3 \mathrm{~V}$ & \\
\hline $\begin{array}{l}\text { OIP } 115, \\
53\end{array}$ & -/iii/Š 39 & $1 \mathrm{~V}$ & & $\begin{array}{c}\text { níĝg-gu }{ }_{7} \text { nin- } \mathrm{g} a ́-\text { šè é- } \\
\text { gal-1a ba-an-ku }\end{array}$ \\
\hline $\begin{array}{l}\text { OIP } 115, \\
54\end{array}$ & $\begin{array}{l}12 / \mathrm{iv} / \mathrm{S} 39 \\
14 / \mathrm{iv} / \mathrm{S} 39 \\
15 / \mathrm{iv} / \mathrm{S} S\end{array}$ & $1 \mathrm{~V}$ & $\begin{array}{l}4 \mathrm{~V} \\
2 \mathrm{~V}\end{array}$ & \\
\hline TCND 181 & $\begin{array}{l}\text { 17/iv/Š } 39 \\
\text { 19/iv/Š } 39\end{array}$ & & $\begin{array}{l}2 \mathrm{~V} \\
1 \mathrm{~V}\end{array}$ & \\
\hline $\begin{array}{l}\text { Bab } 8, \text { Pl. } \\
\text { X HG } 8\end{array}$ & $\begin{array}{l}17 / \mathrm{v} / \text { Š } 39 \\
18 / \mathrm{v} / \text { Š } 39 \\
{[\mathrm{]} / \mathrm{v} / \mathrm{S} 39}\end{array}$ & $\begin{array}{l}1 \mathrm{~V} \\
5 \mathrm{~V} \\
1 \mathrm{~V}\end{array}$ & $\begin{array}{l}1 \mathrm{~V} \\
1 \mathrm{~V}\end{array}$ & \\
\hline Hirose 15 & 2/vi/ŠS 39 & $7 \mathrm{~V}$ & & \\
\hline Toronto 15 & 14/vi/ŠS 39 & $4 \mathrm{~V}$ & & \\
\hline TPTS 101 & 3/ix/Š 39 & & $2+[\mathrm{x}] \mathrm{V}$ & \\
\hline $\begin{array}{l}\text { PFAK II, D } \\
49\end{array}$ & -/xi/ŠS 39 & & $3 \mathrm{~V}$ & \\
\hline $\begin{array}{l}\text { OIP } 115, \\
56\end{array}$ & $\begin{array}{l}\text { 26/xi/ŠS } 39 \\
\text { 28/xi/ŠS } 39 \\
\text { 30/xi/Š́ } 39 \\
\text { 10/xii/ŠS } 39\end{array}$ & $\begin{array}{l}1 \mathrm{~V} \\
1 \mathrm{~V}\end{array}$ & $\begin{array}{l}1 \mathrm{~V} \\
1 \mathrm{~V} \\
1 \mathrm{~V}\end{array}$ & 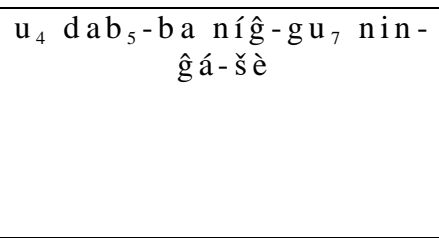 \\
\hline SAT II, 226 & $\begin{array}{l}\text { 26/xii/Š } 39 \\
\text { 27/xii/ŠS } 39\end{array}$ & $6 \mathrm{~V}$ & $1 \mathrm{~V}$ & 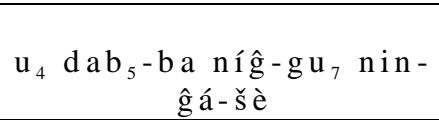 \\
\hline AnOr 1,2 & $\begin{array}{l}20 / \mathrm{i} / \mathrm{S} 40 \\
22 / \mathrm{i} / \check{\mathrm{S}} 40\end{array}$ & & $\begin{array}{l}1 \mathrm{~V} \\
6 \mathrm{~V}\end{array}$ & $\begin{array}{l}\text { für das Bierausschenken des } \\
\text { Königs }\end{array}$ \\
\hline
\end{tabular}


Anhang 2: Ausgaben für die Tafel der Königin und für den Palast

\begin{tabular}{|c|c|c|c|c|}
\hline Publikation & Datum & $\begin{array}{c}\text { Tafel } \\
\text { der } \\
\text { Königin }\end{array}$ & Palast & zusätzlicher Vermerk \\
\hline TLB III, 14 & 8/iii/Š 40 & $6 \mathrm{~V}$ & & \\
\hline $\begin{array}{l}\text { OIP } 115, \\
58\end{array}$ & 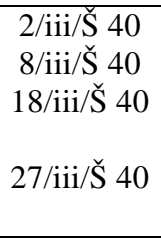 & $\begin{array}{l}4 \mathrm{~V} \\
1 \mathrm{~V}\end{array}$ & $\begin{array}{l}{[\mathrm{x} \mathrm{V}]} \\
1 \mathrm{~V} \\
1 \mathrm{~V}\end{array}$ & 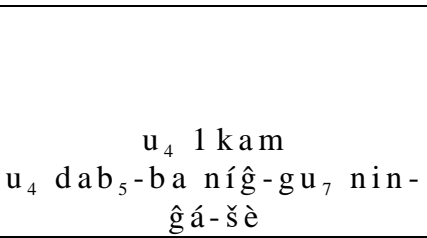 \\
\hline $\begin{array}{c}\text { OIP } 115, \\
59\end{array}$ & 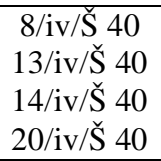 & $1 \mathrm{~V}$ & $\begin{array}{l}1 \mathrm{~V} \\
1 \mathrm{~V} \\
1 \mathrm{~V} \\
1 \mathrm{~V}\end{array}$ & \\
\hline $\begin{array}{l}\text { AAICAB } \\
\text { I/2, Pl. } 97 \\
\text { Ashm. } \\
1935-561\end{array}$ & $\begin{array}{l}\text { 19/v/ŠS } 40 \\
\text { 20/v/Š } 40\end{array}$ & $1 \mathrm{~V}$ & $2 \mathrm{~V}$ & \\
\hline $\begin{array}{l}\text { OIP } 115, \\
60\end{array}$ & 13/vi/Š 40 & & $1 \mathrm{~V}$ & \\
\hline BIN V, 73 & -/vii/ŠS 40 & & $11 \mathrm{~K}$ & in $\mathrm{Ur}$ \\
\hline $\begin{array}{c}\text { Rochester } \\
11\end{array}$ & 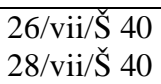 & & $\begin{array}{c}\mathrm{x}] \mathrm{V} \\
1 \mathrm{~V}\end{array}$ & \\
\hline $\begin{array}{l}\text { MVN 18, } \\
66\end{array}$ & 28/x/Šs 40 & & $\begin{array}{l}1 \mathrm{~K} \\
1 \mathrm{~K}\end{array}$ & $\begin{array}{l}\text { zum 1 Mal } \\
\text { zum 2. Mal }\end{array}$ \\
\hline $\begin{array}{l}\text { AfO 40/41, } \\
\text { S. } 52 \mathrm{Nr} .1\end{array}$ & 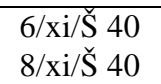 & & $\begin{array}{l}4 \mathrm{~V} \\
2 \mathrm{~V}\end{array}$ & \\
\hline CST 52 & -/i/ŠS 41 & & $1 \mathrm{~K}$ & \\
\hline PDT II, 970 & $\begin{array}{c}8 / \mathrm{i} / \mathrm{S} 41 \\
11 / \mathrm{i} / \mathrm{S}^{\mathrm{S}} 41 \\
18 / \mathrm{i} / \mathrm{S} 41\end{array}$ & $1 \mathrm{~V}$ & $\begin{array}{l}1 \mathrm{~V} \\
1 \mathrm{~V}\end{array}$ & \\
\hline Toronto 16 & $15 / \mathrm{i} / \mathrm{S} 41$ & & $\begin{array}{l}1 \mathrm{~K} \\
1 \mathrm{~K}\end{array}$ & $\begin{array}{l}\text { zum 1 Mal } \\
\text { zum 2. Mal }\end{array}$ \\
\hline $\begin{array}{c}\text { MVN 18, } \\
67\end{array}$ & 20/ii/ŠS 41 & & $1 \mathrm{~K}$ & \\
\hline TPTS 8 & -/iii/Š 41 & & $\begin{array}{l}1 \mathrm{~K} \\
1 \mathrm{~K} \\
\end{array}$ & $\begin{array}{l}\text { zum } 1 \text { Mal } \\
\text { zum 2. Mal }\end{array}$ \\
\hline $\begin{array}{c}\text { JCS 52, S. } \\
128\end{array}$ & 1/iii/ŠS 41 & & $1 \mathrm{~K}$ & \\
\hline $\begin{array}{c}\text { SACT I, } \\
133\end{array}$ & 2/iv/Š 41 & & $1 \mathrm{~V}$ & \\
\hline Toronto 17 & $8 / \mathrm{v} / \mathrm{S} 41$ & & $2 \mathrm{~K}$ & \\
\hline TPTS 98 & $-/ \mathrm{ix} / \check{\mathrm{S}} 41$ & & $3 \mathrm{~K}$ & \\
\hline $\begin{array}{l}\text { MVN 18, } \\
64\end{array}$ & 6/ix/Šs 41 & & $6 \mathrm{~V}$ & \\
\hline SET 45 & 5/xii/ŠS 41 & $1 \mathrm{~S}, 1 \mathrm{~V}$ & $2 \mathrm{~S}, 1 \mathrm{~V}$ & \\
\hline Hirose 17 & 15/xii/Š 41 & $3 \mathrm{~S}$ & & \\
\hline
\end{tabular}




\begin{tabular}{|c|c|c|c|c|}
\hline Publikation & Datum & $\begin{array}{c}\text { Tafel } \\
\text { der } \\
\text { Königin }\end{array}$ & Palast & zusätzlicher Vermerk \\
\hline TCND 186 & $\begin{array}{l}25 / \mathrm{xii}^{\mathrm{II}} / \mathrm{S} \\
41\end{array}$ & $1 \mathrm{~K}$ & & \\
\hline SET 46 & 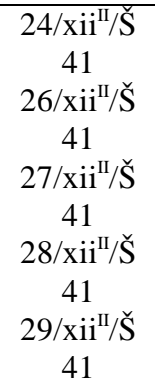 & $\begin{array}{c}1 \mathrm{~S} \\
1 \mathrm{~S}, 5 \mathrm{~V}\end{array}$ & $\begin{array}{l}2 \mathrm{~V} \\
1 \mathrm{~S}\end{array}$ & $\begin{array}{c}\mathrm{u}_{4} \mathrm{dab}_{5}-\mathrm{ba}-\mathrm{s} \mathrm{è} \\
\text { zum } 1 \mathrm{Mal} \\
\text { zum 2. Mal }\end{array}$ \\
\hline TCND 187 & $\begin{array}{l}\text { 1/iv/Š } 42 \\
\text { 3/iv/Š } 42\end{array}$ & & $\begin{array}{l}1 \mathrm{~V} \\
1 \mathrm{~V}\end{array}$ & $\begin{array}{l}\text { zum } 1 \mathrm{Mal} \\
\text { zum } 2 \mathrm{Mal}\end{array}$ \\
\hline $\begin{array}{c}\text { OIP } 115, \\
78\end{array}$ & 3/iv/Š 42 & & $1 \mathrm{~K}$ & \\
\hline Hirose 18 & -/viii/Šs 42 & & $1 \mathrm{~K}$ & \\
\hline TCND 188 & $\begin{array}{l}\text { 26/viii/Š } \\
41 \\
28 / \text { viii/Šs } \\
41\end{array}$ & $1 \mathrm{~S}$ & $1 \mathrm{~V}$ & \\
\hline $\begin{array}{c}\text { OIP 115, } \\
\quad 80\end{array}$ & $\begin{array}{l}\text { 28/viii/S } \\
42 \\
30 / v i i i / S ̌ S \\
42\end{array}$ & & $\begin{array}{l}1 \mathrm{~K} \\
2 \mathrm{~K}\end{array}$ & \\
\hline TRU 284 & 14/x/Š 42 & & $4 \mathrm{~K}$ & \\
\hline $\begin{array}{c}\text { OIP } 115, \\
81\end{array}$ & 29/xi/Š 42 & $1 \mathrm{~S}$ & & \\
\hline $\begin{array}{c}\text { MVN 18, } \\
88\end{array}$ & $22 / \mathrm{i} / \mathrm{S} 43$ & & $1 \mathrm{~V}$ & \\
\hline $\begin{array}{l}\text { OIP } 115, \\
82\end{array}$ & $24 / \mathrm{i} / \mathrm{S} 43$ & & $1 \mathrm{~K}$ & \\
\hline $\begin{array}{c}\text { MVN 18, } \\
70\end{array}$ & $\begin{array}{l}11 / \text { ii/Š } 43 \\
13 / \text { ii/ŠS } 43 \\
15 / \text { ii/Šs } 43\end{array}$ & & $\begin{array}{c}2 \mathrm{~V} \\
4 \mathrm{~V}, 1 \mathrm{~S} \\
4 \mathrm{~V}\end{array}$ & $\begin{array}{l}\text { zum 2. Mal } \\
\text { zum 3. Mal }\end{array}$ \\
\hline TCNY 79 & $\begin{array}{l}\text { 20/ii/Š } 43 \\
\text { 22/ii/Š } 43\end{array}$ & $4 \mathrm{~V}$ & $\begin{array}{l}1 \mathrm{~V} \\
1 \mathrm{~V}\end{array}$ & \\
\hline $\begin{array}{l}\text { OIP } 115, \\
\quad 83\end{array}$ & 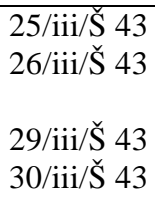 & $6 \mathrm{~V}$ & $\begin{array}{l}2 \mathrm{~V} \\
1 \mathrm{~V}\end{array}$ & 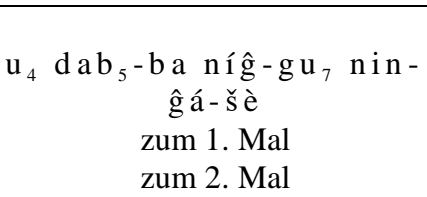 \\
\hline $\begin{array}{c}\text { MVN 13, } \\
820\end{array}$ & $-/ \mathrm{v} / \mathrm{S} 43$ & & {$[\mathrm{x}]+6 \mathrm{~K}$} & \\
\hline
\end{tabular}


Anhang 2: Ausgaben für die Tafel der Königin und für den Palast

\begin{tabular}{|c|c|c|c|c|}
\hline Publikation & Datum & $\begin{array}{c}\text { Tafel } \\
\text { der } \\
\text { Königin }\end{array}$ & Palast & zusätzlicher Vermerk \\
\hline $\begin{array}{l}\text { BIN III, } \\
366\end{array}$ & 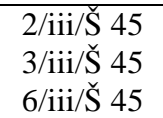 & & $\begin{array}{l}1 \mathrm{~S}, 2 \mathrm{~V} \\
2 \mathrm{~V} \\
1 \mathrm{~V}\end{array}$ & \\
\hline PDT I, 645 & $\begin{array}{l}13 / \mathrm{v} / \mathrm{S} 45 \\
14 / \mathrm{v} / \mathrm{S} 45\end{array}$ & & $\begin{array}{l}2 \mathrm{~K} \\
2 \mathrm{~K}\end{array}$ & \\
\hline $\begin{array}{c}\text { OIP 115, } \\
94\end{array}$ & 12/vii/Š 45 & $1 \mathrm{~V}$ & $10 \mathrm{~V}$ & \\
\hline $\begin{array}{c}\text { MVN 18, } \\
72\end{array}$ & $10 /$ vii/Š 45 & & $4 \mathrm{~V}, 2 \mathrm{~K}$ & \\
\hline $\begin{array}{l}\text { OIP 115, } \\
\quad 96\end{array}$ & 18/vii/Š 45 & $1 \mathrm{~S}$ & $4 \mathrm{~K}, 8 \mathrm{~V}$ & \\
\hline $\begin{array}{c}\text { MVN 13, } \\
715\end{array}$ & $\begin{array}{c}10 / \text { viii/ŠS } \\
45 \\
12 / \text { viii/ŠS } \\
45 \\
18 / v i i i / \check{S} \\
45 \\
19 / \text { viii/ } \\
45\end{array}$ & & $\begin{array}{c}1 \mathrm{G}, 3 \mathrm{~K}, \\
2 \mathrm{~V} \\
1 \mathrm{~V} \\
3 \mathrm{~V} \\
3 \mathrm{~V}\end{array}$ & \\
\hline CST 484 & 20/xi/Š 45 & $1 \mathrm{~S}$ & $1 \mathrm{~K}, 1 \mathrm{~S}$ & \\
\hline $\begin{array}{c}\text { NISABA 8, } \\
374\end{array}$ & $\begin{array}{l}12 / \mathrm{x} / \mathrm{S} 45 \\
15 / \mathrm{x} / \mathrm{S} 45\end{array}$ & $1 \mathrm{~S}$ & $\begin{array}{l}3 \mathrm{~V} \\
1 \mathrm{~V}\end{array}$ & \\
\hline Nakahara 8 & 30/x/S 45 & & $\begin{array}{c}\mathrm{x}]+1 \mathrm{~K}, \\
4+[\mathrm{x}] \mathrm{V}, 1 \\
\mathrm{~S}\end{array}$ & \\
\hline $\begin{array}{c}\text { OIP } 115 \\
97 \\
\end{array}$ & 4/xi/Š 45 & & $\begin{array}{c}1 \mathrm{G}, 1 \mathrm{~K}, 2 \\
\mathrm{~V}\end{array}$ & \\
\hline $\begin{array}{c}\text { OIP } 115, \\
98\end{array}$ & $24 / \mathrm{xi} / \mathrm{S} 45$ & & $1 \mathrm{~K}, 1 \mathrm{~V}$ & \\
\hline $\begin{array}{l}\text { OIP } 115, \\
100\end{array}$ & 16/xii/Š 45 & & $1 \mathrm{~K}, 1 \mathrm{~V}$ & \\
\hline $\begin{array}{c}\text { OIP 115, } \\
101\end{array}$ & $18 / \mathrm{i} / \mathrm{S} \mathrm{S} 46$ & & $1 \mathrm{~V}$ & \\
\hline $\begin{array}{c}\text { OIP } 115, \\
102\end{array}$ & 4/ii//̌s 46 & $1 \mathrm{~V}$ & $4 \mathrm{~K}$ & \\
\hline $\begin{array}{c}\text { AAICAB } \\
\text { I/2, Pl. } 96 \\
\text { Ashm. } \\
1935-554\end{array}$ & 6/iii/Š 46 & & $1 \mathrm{~K}, 3 \mathrm{~V}$ & \\
\hline $\begin{array}{c}\text { OIP 115, } \\
103\end{array}$ & $20 / \mathrm{v} / \mathrm{S} 46$ & $2 \mathrm{~V}$ & $3 \mathrm{~V}$ & \\
\hline TRU 280 & 22/vi/Š 46 & $1 \mathrm{~V}$ & $6 \mathrm{~V}$ & \\
\hline TLB III, 13 & 5/viii/ŠS 46 & $\begin{array}{c}22 \mathrm{~V}, \\
1 \mathrm{~S} \\
\end{array}$ & $2 \mathrm{~K}, 37 \mathrm{~V}$ & \\
\hline
\end{tabular}


294 Anhang 2: Ausgaben für die Tafel der Königin und für den Palast

\begin{tabular}{|c|c|c|c|c|}
\hline Publikation & Datum & $\begin{array}{c}\text { Tafel } \\
\text { der } \\
\text { Königin }\end{array}$ & Palast & zusätzlicher Vermerk \\
\hline $\begin{array}{c}\text { OIP } 115, \\
104\end{array}$ & $\begin{array}{c}18 / \text { viii/Š } \\
46\end{array}$ & & $2 \mathrm{~V}$ & \\
\hline $\begin{array}{l}\text { MVN 18, } \\
75\end{array}$ & $\begin{array}{c}27 / \text { viii/Š } \\
46\end{array}$ & & $7 \mathrm{~K}$ & \\
\hline TRU 281 & $\begin{array}{c}\text { 30/viii/Š } \\
46\end{array}$ & $1 \mathrm{~S}, 6 \mathrm{~V}$ & $2 \mathrm{~S}, 14 \mathrm{~V}$ & \\
\hline TCND 190 & 27/ix/Š 46 & $1 \mathrm{~V}$ & & \\
\hline $\begin{array}{l}\text { CST } 139 \\
\end{array}$ & $-/ \mathrm{x} / \mathrm{S} 46$ & & $\begin{array}{c}1 \mathrm{G}, 64-[\mathrm{x}] \\
\mathrm{K}\end{array}$ & \\
\hline PDT I, 414 & $30 / \mathrm{x} / \mathrm{S} 46$ & & $6 \mathrm{~K}$ & \\
\hline $\begin{array}{l}\text { OIP } 115, \\
106\end{array}$ & $28 / \mathrm{x} / \mathrm{S} 46$ & $1 \mathrm{~S}, 2 \mathrm{~V}$ & $2 \mathrm{~V}$ & $\begin{array}{c}\mathrm{u}_{4} \mathrm{dab}_{5}-\mathrm{ba} n \hat{n} \hat{\mathrm{g}}-\mathrm{gu} \mathrm{u}_{7} \text { nin- } \\
\text { gáa-šè }\end{array}$ \\
\hline $\begin{array}{l}\text { Bab 7, Pl. } \\
\text { XIX Nr. } 4\end{array}$ & 7/xi/ŠS 46 & & $1 \mathrm{~K}$ & \\
\hline $\begin{array}{c}\text { MVN 18, } \\
77\end{array}$ & 15/xi/Š 46 & & $4 \mathrm{~K}$ & \\
\hline $\begin{array}{l}\text { RA } 49,87 \\
\text { Nr. } 6\end{array}$ & 29/xi/Š 46 & & $5 \mathrm{~K}$ & \\
\hline $\begin{array}{c}\text { MVN 18, } \\
78\end{array}$ & -/xi/ŠS 46 & & $81 \mathrm{~K}$ & \\
\hline $\begin{array}{c}\text { MVN 18, } \\
80\end{array}$ & $\begin{array}{l}\text { 13/xii/Šs } 46 \\
\text { 14/xii/Š } 46\end{array}$ & & $\begin{array}{c}2 \mathrm{~S}, 4 \mathrm{~V} \\
6 \mathrm{~V}\end{array}$ & \\
\hline PDT I, 61 & $28 / x i i / S ̌ s 6$ & & $1 \mathrm{~V}$ & \\
\hline $\begin{array}{c}\text { OIP 115, } \\
107\end{array}$ & 19/i/ŠS 47 & $2 \mathrm{~V}$ & $2 \mathrm{~V}$ & \\
\hline CST 165 & 16/ii/Š 47 & & $\begin{array}{c}2 \mathrm{G}, 23 \mathrm{~K} \\
1 \mathrm{~W}\end{array}$ & \\
\hline $\begin{array}{l}\text { MVN 18, } \\
81\end{array}$ & 15/iii/Š 47 & & $15 \mathrm{~V}, 4[\mathrm{x}]$ & \\
\hline TCND 404 & 7/iv/Š 47 & $6 \mathrm{~V}$ & $1 \mathrm{~V}$ & \\
\hline SAT II, 541 & 10/iv/Š 47 & $6 \mathrm{~V}$ & & \\
\hline CST 170 & 14/iv/Š 47 & $1 \mathrm{~K}$ & $1 \mathrm{~K}$ & sá-du $u_{11}$ níĝ́g-gu $\underset{\text { sè }}{ }$ \\
\hline $\begin{array}{l}\text { OIP 115, } \\
108\end{array}$ & 18/iv/Š 47 & & $2 \mathrm{~K}$ & \\
\hline CST 173 & 28/iv/Š 47 & & $5 \mathrm{~V}$ & \\
\hline $\begin{array}{c}\text { Toronto II, } \\
212\end{array}$ & 14/v/Š47 & $1 \mathrm{~S}, 2 \mathrm{~V}$ & $1 \mathrm{~V}$ & \\
\hline $\begin{array}{c}\text { OIP 115, } \\
117\end{array}$ & 20/v/Š 47 & & $1 \mathrm{~V}$ & \\
\hline $\begin{array}{l}\text { ZA 93, S. } \\
58 \text { Nr. } 10\end{array}$ & 25/v/Š 47 & & $7 \mathrm{~V}$ & \\
\hline
\end{tabular}


Anhang 2: Ausgaben für die Tafel der Königin und für den Palast

\begin{tabular}{|c|c|c|c|c|}
\hline Publikation & Datum & $\begin{array}{c}\text { Tafel } \\
\text { der } \\
\text { Königin }\end{array}$ & Palast & zusätzlicher Vermerk \\
\hline $\begin{array}{c}\text { OIP } 115, \\
118\end{array}$ & 30/v/Š 47 & & $20 \mathrm{~V}$ & \\
\hline $\begin{array}{c}\text { OIP 115, } \\
119\end{array}$ & 7/vi/Š 47 & $2 \mathrm{~V}$ & $7 \mathrm{~V}$ & \\
\hline $\begin{array}{c}\text { OIP } 115, \\
120\end{array}$ & $10 / v i / S ̌ S 47$ & $2 \mathrm{~V}$ & & \\
\hline $\begin{array}{c}\text { OIP } 115, \\
121\end{array}$ & 15/vi/ŠS 47 & $2 \mathrm{~V}$ & & \\
\hline $\begin{array}{c}\text { OIP } 115, \\
122\end{array}$ & $15 / v i / S ̌ S 47$ & & $31 \mathrm{~K}$ & \\
\hline $\begin{array}{c}\text { OIP } 115, \\
123\end{array}$ & 22/vii/Š 47 & $22 \mathrm{~V}$ & $5 \mathrm{~V}$ & \\
\hline $\begin{array}{c}\text { OIP } 115, \\
125\end{array}$ & -/vii/Š 47 & & $2 \mathrm{~K}$ & \\
\hline $\begin{array}{c}\text { OIP } 115, \\
126\end{array}$ & 8/viii/Š 47 & $\begin{array}{l}1 \mathrm{~S}, \\
22 \mathrm{~V}\end{array}$ & $1 \mathrm{~S}, 23 \mathrm{~V}$ & \\
\hline $\begin{array}{c}\text { MVN 18, } \\
85\end{array}$ & -/ix/ŚS 47 & & $3 \mathrm{~K}$ & \\
\hline $\begin{array}{c}\text { DCEPHE } \\
299\end{array}$ & 20/ix/Š 47 & & $1 \mathrm{G}, 4 \mathrm{~K}$ & \\
\hline $\begin{array}{c}\text { RA 79, } 27 \\
\text { Nr. } 22\end{array}$ & 30/x/ŠS 47 & & $2 \mathrm{~V}, 1 \mathrm{~S}$ & \\
\hline $\begin{array}{c}\text { AUCT I, } \\
881\end{array}$ & $\begin{array}{c}\text { 5/xi/Š } 47 \\
\text { 10/xi/Š } 47\end{array}$ & & $\begin{array}{c}1 \mathrm{G}, 3 \mathrm{~K} \\
2 \mathrm{G}\end{array}$ & \\
\hline $\begin{array}{c}\text { MVN 18, } \\
86\end{array}$ & $7 / x i / S ̌ S 7$ & & $4 \mathrm{~V}$ & \\
\hline SET 53 & 19/xi/ŠS 47 & & $1 \mathrm{~S}, 8 \mathrm{~V}$ & \\
\hline
\end{tabular}

Tabelle 19: Ausgaben für die Tafel der Königin Šulgi-simtī und den Palast 
Tabellenverzeichnis

Tabelle 1: Hauptbeamten der Šulgi-simtī $\quad 38$

Tabelle 2: Klageriten zum Jahresende $\quad 53$

Tabelle 3: Monatliche Opfer bei Šulgi-simtī 57

Tabelle 4: Šulgi-simtī: Bierausschenken für andere Göttinnen als $\quad$ 74-76 Annunītum

Tabelle 5: Opfer der Šulgi-simtī für Bēlat-Šuhnir und Bēlat-Deraban 77-80 unabhängig von den Gaben zu Neulicht und zum 15. Tag

Tabelle 6: Opfer der Šulgi-simtī für Iškur 87-88

Tabelle 7: Übersicht über die jährlichen Feste und Riten bei 91-94 Šulgi-simtī

Tabelle 8: Bierausschenken der Šulgi-simtī für Angehörige des Hofes 99

Tabelle 9: Ausgabe von ig i-kár durch Šulgi-simtī 101

Tabelle 10: Ausgabe von nicht näher bezeichneten Gaben durch 102 Šulgi-simtī

Tabelle 11: Neumondfeiern der Abī-simtī

$126-128$

Tabelle 12: Abī-simtī und die syrischen Gottheiten Dagān, Išḩara und Haburītum

Tabelle 13: Güter und Arbeiter für Reisen der Abī-simtī zu Inanna 141-142 von Zabalam

Tabelle 14: Andere kultische Verpflichtungen der Abī-simtī

$146-148$

Tabelle 15: Ausgaben an den Haushalt der Königin

$173-175$

Tabelle 16: $\mathrm{nin}$ - $\mathrm{g}$ á in Texten aus Umma

$178-179$

Tabelle 17: Die Frauen der Könige von Ur

Tabelle 18: mu - DU-Lieferanten der Šulgi-simtī

279-289

Tabelle 19: Ausgaben für die Tafel der Königin Šulgi-simtī und

290-295 den Palast 


\section{Literaturverzeichnis}

D'Agostino, Franco: Ein neuer Text über Abī-simtī und das Elūnum-Fest in Puzriš-Dagān. ZA 88 (1998), S. 1-5.

Archi, Alfonso.: Gifts for a Princess. Eblaitica 1 (1987), S. 115-124.

- $\quad$ Harran in the III Millennium B.C. UF 20 (1988), S. 1-8.

- The city of Ebla and the organization of the rural territory. In: H. Klengel (Hg.): The town as regional economic center in the ancient near east, Leuven 1990, S. 15-19.

- Imâr au IIIème Millénaire d'après les archives d'Ebla. MARI 6 (1990), S.21-38.

- Ebla. La Formazione di uno Stato del III Millennio A.C. PP 46 (1991), S. 195-219.

- Culture de l'olivier et production de l'huile à Ebla. In: D. Charpin, F. Joannès (Hg.): Marchands, Diplomates et Empereurs. Études sur la civilisation mésopotamienne offertes à Paul Garelli, Paris 1991, S. 211-222.

- $\quad$ Un autre document de Tiša-Lim, reine d'Imâr. MARI 7 (1993), S. 341342.

- Gli Archivi Reali e l'organizzazione istituzionale e amministrativa protosiriana. In: P. Matthiae, F. Pinnock, G. Scandone Matthiae (Hg.): Ebla. Alle origini della civilità urbana. Trent'anni di scavi in Siria dell’Università di Roma "La Sapienza“, Milano 1995, S. 112-119.

- La religione e il culto nel Periodo Protosiriano. In: P. Matthiae, F. Pinnock, G. Scandone Matthiae (Hg.): Ebla. Alle origini della civilità urbana. Trent'anni di scavi in Siria dell'Università di Roma "La Sapienza“, Milano 1995, S. 134-139.

- Chronologie relative des archives d'Ébla. In: J.-M. Durand (Hg.): Amurru I. Mari, Ébla et les Hourrites. Dix ans de travaux, Paris 1996, S. 11-28.

- $\quad$ Les comptes rendus annuels de métaux (CAM). In: J.-M. Durand (Hg.): Amurru I. Mari, Ébla et les Hourrites. Dix ans de travaux, Paris 1996, S. 73-99.

- $\quad$ Les femmes du roi Irkab-Damu. ebd. S. 101-124.

- The high priestess, dam-dingir, at Ebla. In: M. Dietrich, I. Kottsieper (Hg.): „Und Moses schrieb dies Lied auf“. Studien zum Alten Testament und zum Alten Orient. Festschrift für Oswals Loretz zur Vollendung seines 70. Lebensjahres mit Beiträgen von Freunden, Schülern und Kollegen. AOAT 250, 1998, S. 43-53.

- The Regional State of Nagar According to the Texts of Ebla. Subartu IV. 2, 1998, S. 1-15.

- The Role of Women in the Society of Ebla. In: S. Parpola, 
R.M.Whiting (Hg.): Sex and Gender in the Ancient Near East. Proceedings of the XLVIIe Rencontre Assyriologique Internationale, Helsinki 2002, S. 1-9.

- Jewels for the Ladies of Ebla. ZA 92 (2002), S. 161-199.

- Archival Record-Keeping at Ebla 2400-2350 BC. In: M. Brosius (Hg.): Ancient Archives and Archival Traditions. Concepts of RecordKeeping in the Ancient World. Oxford 2003, S. 17-36.

Asher-Greve, Julia: Frauen in altsumerischer Zeit. BiMes 18, Malibu, CA 1985.

- Women and Gender in Ancient Near Eastern Cultures. Bibliography 1885-2001 AD. NIN 3 (2002), S. 33-114.

- 'Golden Age' of Women? Status and Gender in Third Millenium Sumerian and Akkadian Art. In: S. Schroer (Hg.): Images and Gender. Contributions to the Hermeneutics of Reading Ancient Art. OBO 220, Fribourg, Göttingen 2006, S. 41-81.

Astour, Michael C.: An Outline of the History of Ebla (Part 1). Eblaitica 3 (1992), S. 3-82.

- A Reconstruction of the History of Ebla (Part 2). Eblaitica 4 (2002), S. 57-195.

Bahrani, Zainab: Women of Babylon. Gender and representation in Mesopotamia. London und New York, NY 2001.

Baldacci, Massimo: ÉxPAP and the Eblaite Administrative Terminology. WO 22 (1991), S. 10-20.

Bauer, Josef: DU $=\mathrm{ku}_{\mathrm{x}}\left(-\mathrm{d}^{\mathrm{r}}\right)$,eintreten, hineinbringen“?. ZA 94 (2004), S, 1617.

Bauer, Josef/Englund, Robert K./Krebernik, Manfred: Mesopotamien. Späturuk-Zeit und Frühdynastische Zeit. Annäherungen 1, Herausgegeben von P. Attinger u. M. Wäfler, OBO 160/1, Göttingen 1998.

Beal, Richard H.: Is KUŠ $\breve{7}_{7}$ the Reading of IŠ = kizû?. NABU 1992/48.

Biga, Maria Giovanna: Femmes de la familie royale d'Ebla. In: J.-M. Durand (Hg.): La Femme dans le Proche-Orient Antique, CRAI XXXIII, Paris 1987, S. 41-47.

- $\quad$ Frauen in der Wirtschaft von Ebla. In: H. Waetzoldt (Hg.): Wirtschaft und Gesellschaft von Ebla, HSAO 2, Heidelberg 1988, S. 159-171.

- Donne alla Corte di Ebla. PP 46 (1991), S. 285-303.

- Osservazioni sui criteri di redazione dei testi di Ebla: TM.75.G.1730 e i testi del rituale per il re e la regina. VO 8 (1992), S. 3-11.

- I rapporti diplomatici nel Periodo Protosiriana. In: P. Matthiae, F. Pinnock, G. Scandone Matthiae (Hg.): Ebla. Alle origini della civilità urbana. Trent'anni di scavi in Siria dell'Università di Roma "La Sa pienza", Milano 1995, S. 140-147. 
- Prosopographie et datation relative des Textes d'Ébla. In: J.-M. Durand (Hg.): Amurru I. Mari, Ébla et les Hourrites. Dix ans de travaux, Paris 1996, S. 29-72.

- $\quad$ Les nourrices et les enfants à Ebla. In: Ktema 22 (1997), S. 35-44.

- The Marriage of Eblaite Princess Tagriš-Damu with a Son of Nagar's King. Subartu IV, 2 (1998), S. 17-22.

- The reconstruction of a relative chronology for the Ebla texts. OrNS 72 (2003), S. 345-367.

Biga, Maria Giovanna/Pomponio, Francesco: Iš’ar-Damu, roi d'Ebla. NABU 1987, 106.

- Elements for a Chronological Division of the Administrative Documentation of Ebla. JCS 42 (1990), S. 179-201.

- Critères de rédaction comptable et chronologie relative des textes d'Ebla. MARI 7 (1993), S. 107-128.

Boehmer, Rainer Michael: Die Entwicklung der Glyptik während der AkkadZeit. Untersuchungen zur Assyriologie und Vorderasiatischen Archäologie Bd. 4, Berlin 1965.

Boese, Johannes/Sallaberger, Walther: Apil-kīn von Mari und die Könige der III. Dynastie von Ur. AoF 23 (1998), S. 24-39.

Borger, Rykle: Mesopotamisches Zeichenlexikon. AOAT 305, Münster 2003.

Bottéro, Jean/Kramer, Samuel Noah: Lorsque les dieux faisaient l'homme: Mythologie mésopotamienne. Paris 1989.

Braun-Holzinger, Eva Andrea: Mesopotamische Weihgaben der frühdynastischen bis altbabylonischen Zeit. HSAO 3, Heidelberg 1991.

Buccellati, Giorgio/Kelly-Buccellati, Marilyn: The Royal Palace of Urkesh. Report on the 12th Season at Tell Mozan/Urkesh: Excavations in Area AA, June-October 1999. MDOG 132 (2000), S. 133-183.

- Tar'am-Agade, Daughter of Naram-Sin, at Urkesh. In: L. al-Gailani Werr, J. Curtis, H. Martin, A. McMahon, J. Oates, J. Reade (Hg.): On Pots and Plans. Papers on the Archaeology and History of Mesopotamia and Syria presented to David Oates in Honour of his 75th Birthday. London 2002, S. 11-31.

Castellino, Giorgio Raffaele: Two Šulgi Hymns (BC). Studi Semitici 42, Roma 1972.

Carroué, François: Etudes de géographie et de topographie Sumériennes III.

L'Iturungal et le Sud Sumérien. ASJ 15 (1993), S. 11-69.

Cavignaeux, Antoine: SAHAR $=$ kušs $_{7}$ ?, NABU 1992/103.

Cavignaeux, Antoine/Krebernik, Manfred: Artikel „Nungal“. RlA 9 (2001) S. 615-618.

- Artikel „Nin-kununna“. R1A 9 (2001) S. 450-451. 
Carnahan, John und Hillard Kent: Collations to the Rosicrucian Museum and Stanford University Texts in SET. ASJ 15 (1993), S. 193-264.

Charpin, Dominique: Le clergé d'Ur au siècle d'Hammurabi $\left(\mathrm{XIX}^{\mathrm{e}}-\mathrm{XVIII}{ }^{\mathrm{e}}\right.$ siècle av. J.-C.). Genève, Paris 1986.

Chiara, Edward: Selected Temple Accounts from Telloh, Yokha and Drehem. Cuneiform Tablets in the Library of Princeton University, Philadelphia, PA 1921.

Cohen, Mark E.: The cultic calendars of the ancient Near East. Bethesda, MD 1993.

Collon, Dominique: The Life and Times of Teheš-atal. RA 84 (1990), S. 129136.

- Depictions of Priests and Priestesses in the Ancient Near East. In: K. Watanabe (Hg.): Priests and Officials in the Ancient Near East. Papers of the Second Colloquium on the Ancient Near East - The City and its Life, held at the Middle Eastern Culture Center in Japan (Mitaka/Tokyo) March 22-24 1996, Heidelberg 1999, S. 17-46.

Cooper, Marc: Rezension zu: Marcel Sigrist: Textes économiques néosumériens de l'Université de Syracuse. Paris 1983; JCS 38 (1986), S. $120-126$.

Dahl, Jacob L.: The Ruling Family of Ur III Umma: A Prosopographical Analysis of a Provincial Elite Family in Southern Iraq ca. 2100-2000 BC (2003), http://www.cdli.ucla.edu/staff/dahl/dissertation.pdf (20.06.2007).

- The quest for eternity. Studies in Neo-Sumerian systems of succession. In: J.G. Dercksen (Hg.): Assyria and Beyond. Studies presented to Mogens Trolle Larsen. Leiden 2004, S. 117-136.

Dietrich, Manfred: Besitz der Tiša-Lim. Zuwendungen des Königs von Ebla an die Königin von Emar. UF 25 (1993), S. 93-98.

Dijk, Johannes J.A. van: Les contactes ethniques dans la Mésopotamie et les syncrétismes de la religion sumérienne. In: S. S. Hartman (Hg.): Syncretism. Based on Papers read on the Symposium on Cultural Contact, Meeting of Religions, Syncretism. Held at Åbo on the 8th10th of September 1966, Stockholm 1969, S. 171-206.

Donbaz, Veysel/Foster, Benjamin R.: Sargonic Texts from Telloh in the Istanbul Archaeological Museums. Philadelphia, PA 1982.

Durand, Lean-Marie (Hg.): La Femme dans la Proche Orient Antique, CRAI XXXIII 1986, Paris 1987.

- L L'Organisation de l'espace dans le Palais de Mari: Le Témoignage des Textes. In: E. Levy (Hg.): Le système Palatial en Orient, en Grèce et à Rome, Strasbourg 1987, S. 39-110.

- $\quad$ Archives Épistolaires de Mari I/1. ARM 26.1, Paris 1988. 
Edzard, Dietz Otto, Enmebaragezi von Kiš. ZA 53 (1959), S. 9-26.

Edzard, Dietz Otto/Farber, Gertrud: Die Orts- und Gewässernamen der Zeit der 3. Dynastie von Ur. RGTC II, Wiesbaden 1974.

Falkenstein, Adam, Die neusumerischen Gerichtsurkunden, München 19561957.

- $\quad$ Enhedu'anna, die Tochter Sargons von Akkade. RA 52 (1958), S. 129131.

Feliu, Lluís: The God Dagan in Bronze Age Syria. Culture and History of the Ancient Near East 19, Leiden, Boston 2003.

Fischer, Claudia: Siegelabrollungen im British Museum auf Ur-III-zeitlichen Texten aus der Provinz Lagaš. Untersuchungen zu den Verehrungsszenen, BagMit 28 (1997), S. 97-183.

Fish, Thomas.: Catalogue of Sumerian Tablets in the John Rylands Library. Manchester 1932.

Flückiger-Hawker, Esther: Urnamma of Ur in Sumerian Literary Tradition. OBO 166, Fribourg, Göttingen 1999.

Foster, Benjamin R.: Notes on Sargonic Royal Progress. JANES 12 (1980), S. $29-42$.

- Umma in the Sargonic Period. Memoirs of the Connecticut Academy of Arts and Science 20, Hamden, CT 1982.

- Administration and the Use of Institutional Land in Sargonic Sumer. Mesopotamia 9, Copenhagen 1982.

- $\quad$ An Agricultural Archive from Sargonic Akkad. ASJ 4 (1982), S. 7-51.

- $\quad$ The donation of Abī-simtī. SEL 2 (1985), S. 37-42.

- Notes on Women in Sargonic Society. In: J.-M. Durand (Hg.): La Femme dans la Proche Orient Antique, CRAI XXXIII 1986, Paris 1987, S. 53-61.

- Management and Administration in the Sargonic Period. In: M. Liverani (Hg.): Akkad. The First World Empire, HANES 5, Padova 1993, S. 25-39.

Foxvog, Daniel A.: Cuneiform Tablets in California Private Collections. ASJ 15 (1993), S. 71-79

- $\quad$ Sumerian Brands an Branding Irons. ZA 85 (1995), S. 1-7.

Frayne, Douglas: The Zagros Campaigns of Šulgi and Amar-Suena. SCCNH 10 (1999), S. 141-201.

Frame, Grant: A New Wife for Šu-Sîn. ARRIM 2 (1984), S. 3-4.

Fronzaroli, Pelio: The Ritual Texts of Ebla. QdS 18 (1992), S. 163-185.

- $\quad$ Testi Rituale della Regalità. ARET XI, Roma 1993.

Frymer-Kensky, Tikva Simone: The Judicial Ordeal in the Ancient Near East. Yale University 1977, University Microfilms International. 
Gelb, Ignaz /Kienast, Burkhard : Die Altakkadischen Königsinschriften des 3. Jahrtausends v.Chr.. FAOS 7, Stuttgart 1990.

George, Andrew R.: House most high. The temples of ancient Mesopotamia. Mesopotamian Civilizations 5, Winona Lake, IN 1993.

Gomi, Tohru: Shulgi-simti and her libation place $(K I-A-N A G)$. Orient 12 (1976), S. 4-5.

- $\quad$ Neue Kollationen zu den Texten PDT, I. Orient 24 (1988), S. 108-123.

Gordon, Cyrus H.: Smith College Tablets. 110 Cuneiform Texts Selected from the College Collection. Smith College Studies in History Vol. XXXVIII, Northampton, MA 1952.

Glassner, Jean-Jacques: La Chute d'Akkadé. L'événement et sa mémoire. BBVO 5, Berlin 1986.

Greengus, Samuel: The Akkdian Calendar at Sippar. JAOS 107 (1987), S. 209229.

- Bridewealth in Sumerian Sources. HUCA 61 (1990), S. 25-88.

Grégoire, Jean-Pierre: Le sceau d'Ea-niša. RA 73 (1979), S. 190-191.

- Contribution à l'histoire sociale, économique, politique et culturelle $\mathrm{du}$ Proche-Orient ancien. Archives Administratives et Inscriptions Cunéiformes de l'Ashmolean Museum et de la Bodelein Collection d'Oxford I. Les Sources 1-3, Paris 1996-2001.

Groneberg, Brigitte: $\mathrm{Zu}$ den mesopotamischen Unterweltsvorstellungen: Das Jenseits als Fortsetzung des Diesseits. AoF 17 (1990) S. 244-261.

- Heirat und Zugehörigkeit. In: Th. Späth, B. Wagner-Hasel (Hg.): Frauenwelten in der Antike. Geschlechterordnung und weibliche Lebenspraxis. Stuttgart, Weimar 2000, S. 1-16.

Hallo, William W.: Contributions to Neo-Sumerian. HUCA 29 (1958); S. 69108.

- $\quad$ A Sumerian Amphictyony. JCS 14 (1960), S. 88-114.

- Women of Sumer. In: D. Schmandt-Besserat (Hg.): The Legacy of Sumer. Invited Lectures on the Middle East at the University of Texas at Austin. BiMes 4 (1976), S. 23-40.

- Appendix to David Owen: Tax Payments from Some City Elders in the Northeast. ASJ 3 (1981), S. 69-76.

- Origins. The Ancient Near Eastern Background of Some Modern Western Institutions. Studies in the History and Culture of the Ancient Near East 6. Leiden, New York, NY und Köln 1996.

Hallo, William W./van Dijk, Johannes J.A.: The Exaltation of Inanna. YNER 3, New Haven, CT und London 1968.

Harris, Rivkah: The Nadītu Woman. In: R. D. Biggs, J. A. Brinkman (Hg.): Studies Presented to L. A. Oppenheim. June 7, 1964. Chicago, IL 1964, S. 106-135. 
- Ancient Sippar. A Demographic Study of an Old-Babylonian City (1894-1595 B.C.). Istanbul 1975.

Hartmann, Martina: Aufbruch ins Mittelalter. Die Zeit der Merowinger. Darmstadt 2003.

Heimpel, Wolfgang: Artikel „Nin-hursaĝa. A.“. RlA 9 (2000)S. 378-381.

Hilgert, Markus: erubbatum im Tempel des Dagān - Eine Ur III-Zeitliche Urkunde aus Drēhim. JCS 46 (1994) S. 29-39.

- Cuneiform Texts from the Ur III Period in the Oriental Institute Volume 1. Drehem Administrative Documents from the Reign of Šulgi. OIP 115, Chicago, IL 1998.

- $\quad$ Akkadisch in der Ur III-Zeit. IMGULA 5, Münster 2002.

- Cuneiform Texts from the Ur III Period in the Oriental Institute Volume 2. Drehem Administrative Documents from the Reign of Amar-Suena. OIP 121, Chicago, IL 2003.

Hillard, Kent: niga sá-du ${ }_{11}$ as a Fattening Grade in Ur III Textes. ZA 85 (1995) S. 8-18.

- $\quad$ "While my article“. NABU 1995, 79.

Huber, Fabienne: La Correspondance Royale d`Ur, un corpus apocryphe. ZA 91 (2001). S. 169-206.

Jacobsen, Thorkild: The Reign of Ibbi-Suen. JCS 7 (1953); S, 36-47.

- The Harps that once... Sumerian Poetry in Translation. New Haven, CT und London 1987.

- $\quad$ Pictures and Pictorial Language (The Burney Relief). In: M. Mindlin, M.J. Geller, J.E. Wansbrough (Hg.): Figurative Language in the Ancient Near East. London 1987, S. 1-11.

Jones, Thomas B./Snyder, John W.: Sumerian Economic Texts from the Third Ur Dynasty. A Catalogue and Discussion of Documents from various Collections, Minneapolis, MN 1961.

Kang, Shin T.: Sumerian and Akkadian Cuneiform Texts in the Collection of the World Heritage Museum of the University of Illinois. I: Sumerian Economic Texts from the Drehem Archive. Urbana 1972.

Katz, Dina: The Image of the Netherworld in the Sumerian Sources. Bethesda, MD 2003.

Kienast, Burkhard/Volk, Konrad: Die sumerischen und akkadischen Briefe des III. Jahrtausends aus der Zeit vor der III. Dynastie von Ur. FAOS 19, Stuttgart 1995.

Kienast, Burkhardt/Waetzoldt, Hartmut: Zwölf Jahre Ebla: Versuch einer Bestandsaufnahme. Eblaitica 2 (1990), S. 31-77.

Klein, Jacob: Three Šulgi Hymns. Sumerian Royal Hymns Glorifying King Šulgi of Ur. Ramat-Gan 1981. 
- S Šeleppūtum, a Hietherto Unknown Ur III Princess. ZA 80 (1990), S. 20-39.

Kramer, Samuel Noah: The Death of Ur-Nammu. In: M. Mori, H. Ogawa, M. Yoshikawa (Hg.): Near Eastern Studies Dedicated to H.I.H. Prince Takahito Mikasa on the Occasion of His Seventy-Fifth Birthday. Bulletin of the Middle Eastern Culture Center in Japan Vol. V., Wiesbaden 1991, S. 193-214.

Kraus, Fritz Rudolf: Di til.la. Sumerische Prozessprotokolle und Verwandtes aus der Zeit der III. Dynastie von Ur. Rezension zu Falkenstein, Die neusumerischen Gerichtsurkunden. BiOr 15 (1958) S. 70-84.

Krebernik, Manfred: Artikel „Muttergöttin. A.I. In Mesopotamien“. RlA 8 (1993-1997), S. 502-516.

Krebernik, Manfred/Cavignaeux, Antoine: Artikel „Nungal“. RlA 9 (2001) S. 615-618.

Krecher, Joachim: DU $=\mathrm{ku}_{\mathrm{x}}(-\mathrm{r})$ "eintreten“, ”hineinbringen“. ZA 77 (1987), S. 7-21.

Kuga, Yokiku: A Šulgi-simtum Tablet in the Atarashi Collection. ASJ 17 (1995), S. 309-318.

Kutscher, Raphael: An Offering to the Statue of Šulgi. Tel Aviv 1 (1974), S. 55-59.

- $\quad$ A Torchlight Festival in Lagaš. ASJ 5 (1983), S. 59-66.

- $\quad$ From the Royal Court to Slavary in the Ur III Period. Tel Aviv 11 (1984), S. 183-188.

Lafont, Bertrand: Relecture des Tablettes de L. Legrain, "Le Temps des Rois d'Ur“. ASJ 7 (1985), S. 165-188.

- L L'avènement de Šu-Sîn. RA 88 (1994), S. 97-119.

Lafont, Sophie: Femmes, Droit et Justice dans l'Antiquité orientale. Contribution à l'étude du droit pénal au Proche-Orient ancien. OBO 165, Fribourg, Göttingen 1999.

Leick, Gwendolyn: Sex and Eroticism in Mesopotamian Literature. London 1994.

Lesko, Barbara S. (Hg.): Women's Earliest Records from Ancient Egypt and Western Asia. Proceedings of the Conference on Women in the Ancient Near East, Brown University, Providence, Rhode Island November 5-7, 1987. Brown Judaic Studies 166, Atlana, GA 1989.

Limet, Henri: Deux documents de la 3e dynastie d'Ur. Akkadica 78 (1992), S. $11-17$.

- $\quad$ Le Sacrifice siskur. In: J. Quaegebeur (Hg.): Ritual and Sacrifice in the Ancient Near East. Proceedings of the International Conference organized by the Katholieke Universiteit Leuven from the 17th to the 20th of April 1991. OLA 55, Leuven 1993, S. 243-255. 
Limper, Klaudia: Uruk. Perlen - Ketten - Anhänger. Grabungen 1912-1985. AUWE 2, Mainz 1988.

Maaijer, Remko de: Land Tenure in Ur III Lagaš. In: B. Haring, R. de Maaijer (Hg.): Landless and Hungry? Access to Land in Early and Traditional Societies. Proceedings of a Seminar held in Leiden, 20 and 21 June 1996, Leiden 1998, S. 50-73.

- $\quad$ B. Ur III-Texts (Nos. 2-15). In: A.C.V.M. Bongenaar, Th.J.H Krispijn, R. de Maaijer, K.R. Veenhof: Cuneiform Tablets of the Schoneveld Collection. JEOL 33 (1995), S. 109-142.

Maeda, Tohru: Bringing (mu-túm) of livestock and the Puzriš-Dagan organization for cattle management in the Ur III dynasty. ASJ 11 (1989), S. 69-111.

Maekawa, Kazuya: The Development of the É-Mí in Lagash during Early Dynastic III. Mesopotamia VIII (1973), S. 77-144.

- $\quad$ The Management of Fatted Sheep. ASJ 5 (1983) S. 81-111.

- The Agricultural Texts of Ur III Lagash of the British Museum (V). ASJ 9 (1987), S. 89-129.

- $\quad$ The Agricultural Texts of Ur III Lagash of the British Museum (IX). ASJ 15 (1993), S. 107-129.

Magid, Glenn: Micromanagement in the é-mi/dBa-ú: Notes on the Organization of Labor at Early Dynastic Lagash. In: T. Abusch, P.-A. Beaulieu, J. Huehnergard, P. Machinist, P. Steinkeller (Hg.): Historiography in the Cuneiform World. Proceedings of the XLV Rencontre Assyriologique Internationale Part I, Harvard University, Bethesda MD 2001, S. 313328.

Mander, Pietro: The Function of the Maliktum as Based on the Documentation of the Administrative Texts of Ebla. In: H. Waetzoldt (Hg.): Wirtschaft und Gesellschaft von Ebla, HSAO 2, Heidelberg 1988, S. 261-266.

Marchesi, Gianni: Who was Buried in the Royal Tombs of Ur? The Epigraphic and Textual Data. OrNS 73 (2004), S. 153-197.

Matthews, Donald/Eidem, Jasper: Tell Brak and Nagar. Iraq 55 (1993), S. 201207.

Maul, Stefan M.: kurgarrû und assinnu und ihr Stand in der babylonischen Gesellschaft. In: V. Haas (Hg.): Außenseiter und Randgruppen. Beiträge zu einer Sozialgeschichte des Alten Orients. Xenia, 32 (1992), S. 164-165.

- Der assyrische König - Hüter der Weltordnung. In: K. Watanabe (Hg.): Priests and Officials in the Ancient Near East. Papers of the Second Colloquium on the Ancient Near East - The City and its Life, held at the Middle Eastern Culture Center in Japan (Mitaka/Tokyo) March 22- 
24 1996, Heidelberg 1999, S. 201-214.

Mayr, Rudi: The Depiction of Ordinary Men and Women on the Seals of the Ur III Kingdom. In: Simo Parpola, R.M.Whiting (Hg.): Sex and Gender in the Ancient Near East. Proceedings of the XLVIIe Rencontre Assyriologique Internationale, Helsinki 2002, S. 359-366.

Melville, Sarah C.: Royal Women and the Exercise of Power in the Ancient Near East. In: D. C. Snell (Hg.): A Companion to the Ancient Near East. Malden, MA u.a. 2005.

Michalowski, Piotr: The Bride of Simanum. JAOS 95 (1975), S. 716-719.

- Royal Women of the Ur III Period. Part I: The Wife of Šulgi, JCS 28 (1976), S. 169-172.

- $\quad$ The Death of Šulgi. OrNS 46 (1977), S. 220-225.

- Dūrum and Uruk during the Ur III Period. Mesopotamia 12 (1977), S. 83-96.

- $\quad$ The Neo-Sumerian Silver Ring Texts. SMS 2/3 (1978), S. 43-58.

- $\quad$ Foreign Tribute to Sumer during the Ur III Period. ZA 68 (1978), S. 34-49.

- Royal Women of the Ur III Period. Part II: Geme-Ninlila. JCS 31 (1979), S. 171-176.

- $\quad$ Tudanapšum, Naram-Sin and Nippur. RA 75 (1981) S. 173-176.

- $\quad$ Royal Women of the Ur III Period - Part III. ASJ 4 (1982), S. 129139.

- Carisma and Control. In: M. Gibson, R. D. Biggs (Hg.): The Organization of Power. Aspects of Bureaucracy in the Ancient Near East. SAOC 46 (1987), S. 55-68.

- $\quad$ The Drinking Gods. In: L. Milano (Hg.): Drinking in Ancient Societies. History and Culture of Drinks in the Ancient Near East. Papers of a Symposium held in Rome, May 17-19, 1990 (History of the Ancient Near East/Studies VI), Padova 1994, S. 27-44.

- The Men from Mari. In: K. van Lerberghe, A. Schoors (Hg.): Immigration and Emigration within the Ancient Near East. Festschrift E. Lipinski, OLA 65 (1995), S. 181-188.

- The Ideological Foundation of the Ur III State. In: J.-W. Meyer, W. Sommerfeld (Hg.): 2000 v. Chr. Politische, wirtschaftliche und kulturelle Entwicklung im Zeichen einer Jahrtausendwende. 3. Internationales Colloquium der Deutschen Orient-Gesellschaft 4.-7. April 2000 in Frankfurt/Main und Marburg/Lahn. Saarbrücken 2004, S. 219-235.

- Iddin-Dagan and his Family. ZA 95 (2005), S. 65-76.

Mieroop, Marc Van de: Gold Offerings of Šulgi. OrNS 55 (1986), S. 131-151.

- Women in the Economy of Sumer. In: B. S. Lesko (Hg.): Women's 
Earliest Records from Ancient Egypt and Western Asia. Proceedings of the Conference on Women in the Ancient Near East, Brown University, Providence, Rhode Island November 5-7, 1987. Brown Judaic Studies 166, Atlanta, GA 1989, S. 53-66.

- $\quad$ Reed in the Old Babylonian Texts from Ur. BSA 6 (1992), S. 147-154.

- Rezension zu: W. Sallaberger, Der kultische Kalender der Ur III-Zeit, Berlin 1993, BiOr 52 (1995), S. 716-718.

- Cuneiform Texts and the Writing of History. London und New York, NY 1999.

- An Accountant's Nightmare: the Drafting of a Year's Summary, AfO 46-47 (1999/2000), S. 111-129.

Milano, Lucio: Cibo e società nel regno di Ebla. Una valutazione d'insieme. In: A. Archi (Hg.) ARET IX. Testi Amministrativi: Assegnazioni di Prodotti Alimentari (Archivio L. 2712 - Parte I), Roma 1990, S. 323343.

- Ébla: Gestion des terres et gestion des ressources alimentaires. In: J.M. Durand (Hg.): Amurru I. Mari, Ébla et les Hourrites. Dix ans de travaux, Paris 1996, S. 135-171.

Moran, William L.: A Note on igi-kár "provisions, supplies“. ASJ 5 (1983), S. 175-177.

Nagel, Wolfram/Strommenger, Eva: Reichsakkadische Glyptik und Plastik im Rahmen der mesopotamisch-elamischen Geschichte, BJVF 8 (1968), S. 137-206.

Neumann, Hans: Handwerk in Mesopotamien. Untersuchungen zu seiner Organisation in der Zeit der III. Dynastie von Ur. Berlin 19932.

- Goldverzierte Schuhe für die Königin. In: T. Richter, D. Prechel, J. Klinger (Hg.): Kulturgeschichten. Altorientalistische Studien für Volkert Haas zum 65. Geburtstag, Saarbrücken 2001, S. 285-289.

Neumann, Hans/Hruška, Blahoslav: Die Ur III-Texte aus der Sammlung des Altorientalischen Seminars der Karlsuniversität Prag. ArOr 62 (1994), S. 227-249.

Nöldeke, Arnold/Haller, Arndt von/Lenzen, Heinz/Heinrich, Ernst: Achter vorläufiger Bericht über die von der Deutschen Forschungsgemeinschaft in Uruk-Warka unternommenen Ausgrabungen. Aus den Abhandlungen der Preussischen Akademie der Wissenschaften Jahrgang 1936. Phil.-Hist. Klasse. Nr. 13, Berlin 1937.

Oppenheim, Adolf Leo: Catalogue of the Cuneiform Tablets of the Wilberforce Eames Babylonian Collection in The New York Public Library. Tablets of the Time of the Third Dynasty of Ur. AOS 32 (1948).

Orthmann, Winfried: Der alte Orient. Propyläen Kunstgeschichte Band 18, Berlin 1985. 
Owen, Dawid I.: A Thirteen Month Summary Account from Ur. In: M. A. Powell jr., R. H. Sack (Hg.): Studies in Honor of Tom B. Jones. AOAT 203, Neukirchen-Vluyn 1979, S. 57-70.

- Ur III Geographical and Prosopographical Notes. In: G. D. Young, M. W. Chavalas, R. E. Averbeck (Hg.): Crossing Boundaries and Linking Horizons. Studies in Honour of Michael C. Astour on His 80th Birthday, Bethesda, MD 1997, S. 367-398.

- $\quad$ More on Riṣ-ilum. NABU 1998/135.

- $\quad$ On the Patronymy of Šu-Suen. NABU 2001/17. ${ }^{1274}$

Parr, P. A.: Ninhilia: Wife of Ayakala, Governor of Umma. JCS 26 (1974), S. 90-111.

Payne, S.: siehe Postgate, JSS 20 (1975).

Pettinato, Giovanni: Semiramis. Herrin über Assur und Babylon. Zürich, München 1988.

- Il rituale per la successione al trono ad Ebla. Con Appendici di Franco D'Agostino e Paola Pisi. St. Sem. NS 9 (1992).

Pettinato, Giovanni/Waetzoldt, Hartmut: Dagān in Ebla und Mesopotamien nach den Texten aus dem 3. Jahrtausend. OrNS 54 (1985), S. 234-256.

Pohl, Alfred: Rechts- und Verwaltungsurkunden der III. Dynastie von Ur. Autographiert und mit Inventarverzeichnis und Namenlisten versehen. TMH NF 1/2, Leipzig 1937.

- $\quad$ Eine neusumerische Achatperle. OrNS 16 (1947), S. 464-465.

Pomponio, Francesco: Ebrium e il matrimonio dell'En di Ebla. AfO 40/41 (1993/94), S. 39-45.

Postgate, John Nicholas, with a contribution by S. Payne: Some Old Babylonian Shepherds and their Flocks. JSS 20 (1975), S. 1-21.

Potts, Timothy: Mesopotamia and the East. An Archaeological and Historical Study of Foreign Relations 3400-2000 BC. Oxford 1994.

Powell, Marvin A.: A Contribution to the History of Money in Mesopotamia prior to the Invention of Coinage. In: B. Hrouška, G. Komoróczy (Hg.): Festschrift Lubor Matouš II, Budapest 1978, S. 211-243.

- $\quad$ Geme-Ninlila, Beloved of Šulgi. RA 75 (1981), S. 93-94.

Prechel, Doris: Die Göttin Išhara. Ein Beitrag zur altorientalischen Religionsgeschichte. Abhandlungen zur Literatur Alt-Syrien-Palästinas und Mesopotamiens Band 11, Münster 1996.

Reiter, Karin: Die Metalle im Alten Orient unter besonderer Berücksichtigung altbabylonischer Quellen. AOAT 249, Münster 1997.

Renger, Johannes: Untersuchungen zum Priestertum in altbabylonischer Zeit.

1274 Der Beitrag wurde ohne Anmerkungen bereits in NABU 2000/82 publiziert. 
Teil 1, ZA 58 (NF 24) (1967), S. 110-188.

Richter, Thomas: Untersuchungen zu den lokalen Panthea Süd- und Mittelbabyloniens in altbabylonischer Zeit. AOAT 257, Münster 1999.

Röllig, Wolfgang: Artikel „Heirat“. RlA 4 (1972-75), S. 282-287.

- Politische Heiraten im Alten Orient. Saeculum 25 (1974), S. 11-23.

Roth, Silke: Bemerkungen zur Rolle der Königsmütter von der Frühzeit bis zum Ende der 12. Dynastie. In: R. Gundlach, W. Seipel (Hg.): Das frühe ägyptische Königtum. Akten des 2. Symposiums zur ägyptischen Königsideologie in Wien 24.-26.9. 1997, ÄAT 36, 2, (1999) S. $111-123$.

Sallaberger, Walther: Rezension zu Fatma Yıldız, Tohru Gomi, Die PuzrišDagan-Texte der Istanbuler Archäologischen Museen. Teil II: Nr. 7261379 (FAOS 16), Wiesbaden 1988, ZA 82 (1992), S. 131-137.

- $\quad$ Der kultische Kalender der Ur III-Zeit. Berlin 1993.

- $\quad$ Keilschrifttexte einer Privatsammlung. AfO 40/41 (1993/94), S. 52-63.

- Rezension zu Daniel Snell, Carl H. Lager, Economic Texts from Sumer (= Yale Oriental Series, Babylonian Texts 18). ZA 84 (1994) S. 305308.

- $\quad$ Eine reiche Bestattung im neusumerischen Ur. JCS 47 (1995), S. 1521.

- $\quad$ Nippur als religiöses Zentrum Mesopotamiens. In: G. Wilhelm (Hg.): Die orientalische Stadt: Kontinuität, Wandel, Bruch. 1. Internationales Kolloquium der Deutschen Orient-Gesellschaft 9.-10. Mai 1996 in Halle/Saale, Saarbrücken 1997, S. 147-168.

- Ur III-Zeit. In: W. Sallaberger, A. Westenholz, Mesopotamien, Akkade-Zeit und Ur III- Zeit, Annäherungen 3. Herausgegeben von P. Attinger u. M. Wäfler, OBO 160/3, Fribourg, Göttingen 1999, S. 119414.

- $\quad$ Königtum und Kult in der Hauptstadt Ur unter den Herrschern ihrer III. Dynastie (21.Jh.). In: W. Seipel, A. Wieczorek (Hg.): Von Babylon bis Jerusalem. Die Welt der altorientalischen Königsstädte, Bd. 2, Mannheim, Wien 1999, S. 255-260.

- Nachrichten aus dem Palast von Ebla. Eine Deutung von níĝ-mul-(an). In: P. Marrassini (Hg.): Semitic and Assyriological Studies Presented to Pelio Fronzaroli by Pupils and Colleagues. Wiesbaden 2003, S. 600625.

- "bringen“ im Sumerischen. Lesung und Bedeutung von de ${ }_{6}$ (DU) und tum $_{2}$ (DU). In: Rollinger, R. (Hg.): Von Sumer bis Homer. Festschrift für Manfred Schretter zum 60. Geburtstag am 25. Februar 2004. AOAT 325, Münster 2004, S. 557-576.

Salonen, Armas: Agricultura Mesopotamica nach sumerisch-akkadischen 
Quellen. Eine lexikalische und kulturgeschichtliche Untersuchung. Helsinki 1968.

— Die Namen für „Vogler“ im Alten Mesopotamien. BagMit 7 (1974) S. 167-172.

Schuller, Wolfgang: Frauen in der griechischen Geschichte. Konstanz 1985.

Sefati, Yitschak: Love Songs in Sumerian Literature. Bar-Ilan Studies in NearEastern Languages and Culture, Ramat-Yan 1998.

Selz, Gebhard J.: lú-su-a versus LU $_{2}$.SU.A: Eine Nachbemerkung. NABU 1989, 94.

- Untersuchungen zur Götterwelt des altsumerischen Stadtstaates von Lagaš. OPSNKF 13, Philadelphia, PA 1995.

- Five Divine Ladies: Thoughts on Inanna(k), Ištar, In(n)in(a), Annunītum, and Anat, and the Origin of the Title "Queen of Heaven". NIN 1 (2000), S. 29-61.

Sharlach, Tonia: Beyond Chronology: The Šakkanakkus of Mari and the Kings of Ur. In: W. W. Hallo, I. J. Winter (Hg.): Seals and Seal Impressions. Proceedings of the $\mathrm{XLV}^{\mathrm{e}}$ Rencontre Assyriologique Internationale Part II, Yale University, Bethesda, MD 2001, S. 59-70.

- Foreign Influences on the Religion of the Ur III Court. In: D. I. Owen, G. Wilhelm (Hg.): Studies on the Civilization and Cultures of Nuzi and the Hurrians 12, Bethesda, MD 2002, S. 91-114.

- Provincial Taxation and the Ur III State. CM 26, Leiden, Boston 2004.

Sigrist, René Marcel: Le sattukku dans l'Ešumeša durant la période d'Isin et Larsa. BiMes 11, Malibu, CA 1984.

- $\quad$ Kubatum. RA 80 (1986), S. 185.

- $\quad$ Le deuil pour Šu-Sin. In: H. Behrens, D. Loding, M. T. Roth (Hg.): DUMU-É-DUB-BA-A. Studies in Honor of Åke Sjöberg. OPSNKF 11, Philadelphia, PA 1989, S. 499-505.

- Drehem. Bethesda, MD 1992.

- Livraisons et dépenses royales durant la troisième Dynastie d'Ur. In: R. Chazan, W. W. Hallo, L. H. Schiffman (Hg.): Ki Baruch Hu. Ancient Near Eastern, Biblical, and Judaic Studies in Honor of Baruch A. Levine, Winona Lake, IN 1999, S. 111-149.

- Sumerian Archival Texts II. Texts from the Yale Babylonian Collections Part I, Bethesda, MD 2000.

- Sumerian Archival Texts III. Texts from the Yale Babylonian Collections Part II, Bethesda, MD 2000.

- Neo-Sumerian Archival Texts in the Nies Babylonian Collection. U. Kasten (Hg.): Catalogue of the Babylonian Collections at Yale 3, Bethesda, MD 2001.

Sigrist, Marcel/Butz, Kilian: Wirtschaftliche Beziehungen zwischen der 
Susiana und Südmesopotamien in der Ur-III-Zeit. AMI 19 (1986), S. 27-31.

Sigrist, Marcel/Figulla, Hugo H./Walker, Christopher B. F.: Catalogue of the Babylonian Tablets in the British Museum, Volume II. London 1996.

Sigrist, Marcel/Zadok, Ran/Walker, Christopher B. F.: Catalogue of the Babylonian Tablets in the British Museum, Volume III. London 2006.

Sigrist, Marcel/Gomi, Tohru: The Comprehensive Catalogue of Published Ur III Tablets. Bethesda, MD 1991.

Sjöberg, Aake. W.: in-nin šá-gur ${ }_{4}$-ra. A Hymn to the Goddess Inanna by the enPriestess Enheduanna. ZA 65 (1975/76) S. 161-253.

Sjöberg, Aake W./Bergmann, Eugen: The Collection of the Sumerian Temple Hymns. TCS III, Locoust Valley, NY 1969.

Sollberger, Edmond: Sur la chronologie des rois d'Ur et quelques problèmes connexes. AfO 17 (1954-56), S. 10-48.

- $\quad$ Ladies of the Ur-III Empire. RA 61 (1967), S. 69-70.

- $\quad$ Artikel „Kubatum“. RlA 6 (1980-83), S. 265.

Sommerfeld, Walter: Die Texte der Akkad-Zeit 1. Das Dijala-Gebiet: Tutub. IMGULA 3/1, Münster 1999.

Spar, Ira: Cuneiform Texts in the Metropolitan Museum of Art I. Tablets, Cones, and Bricks of the Third and Second Millenia B.C., New York, NY 1988.

Steible, Horst: Die Neusumerischen Bau- und Weihinschriften Teil 2; Kommentar zu den Gudea-Statuen, Inschriften der III. Dynastie von Ur, Inschriften der IV. und „V.“ Dynastie von Uruk, Varia. FAOS 9/2, Stuttgart 1991.

Steinkeller, Piotr: Notes on Two Sumerian Votive Inscriptions. RA 73 (1979), S. $189-190$.

- Mattresses and Felt in Early Mesopotamia. OrAn 19 (1980), S. 79-100.

- $\quad$ More on Ur III Royal Wives. ASJ 3 (1981), S. 77-92.

- $\quad$ On the Reading and Meaning of igi-kár and gúrum (IGI.GAR). ASJ 4 (1982), S. 149-151.

- The Question of Marhaši: A Contribution to the Historical Geography of Iran in the Third Millenium B.C.. ZA 72 (1982) S. 237-265.

- The Administrative and Economic Organization of the Ur III State: The Core and the Periphery. In: M. Gibson, R. D. Biggs (Hg.): The Organization of Power. Aspects of Bureaucracy in the Ancient Near East. SAOC 46 (1987), S. 19-41.

- $\quad$ Sale Documents of the Ur III-Period. FAOS 17, Stuttgart 1989.

- $\quad$ Sheep and goat terminology in Ur III sources from Drehem. BSA 8 (1995) S. 49-70.

- $\quad$ On Rulers, Priests and Sacred Marriage. In: K. Watanabe (Hg.): Priests 
and Officials in the Ancient Near East. Papers of the Second Colloquium on the Ancient Near East - The City and its Life, held at the Middle Eastern Culture Center in Japan (Mitaka/Tokyo) March 2224 1996, Heidelberg 1999, S. 103-136.

Stol, Marten: Artikel „Nanaja“. RlA 9 (1998) S. 146-151.

- Birth in Babylonia and the Bible. Its Mediterranean Setting. CM 14, Groningen 2000.

Stolper, Matthew W.: On the Dynasty of Šimaški and the Early Sukkalmahs. ZA 72 (1982), S. 42-67.

Such-Gutiérrez, Marcos: Die Prinzessin Meištarān. AuOr 19 (2001), S. 87-108.

- Beiträge zum Pantheon von Nippur im 3. Jahrtausend. Materiali per il Vocabolario Sumerico 9. Roma 2003.

Tohru, Ozaki/Yildiz, Fatma: Neue Ur-III Texte in den Nippur- und PuzrišDagan-Sammlungen der Archäologischen Museen zu Istanbul. JCS 54 (2002) S. 1-23.

Thureau-Dangin, François: Encore la Dynastie d'Agadé. RA 9 (1912), S. 8183.

Tonietti, Maria Vittoria: Le liste delle dam en: Cronologia interna. Criteri ed elementi per una datazione relativa dei testi economici di Ebla. QdS 16 (1989), S. 79-115.

Troy, Lana: Patterns of Queenship in ancient Egyptian myth and history. BOREAS 14, Uppsala 1986.

Uchitel, Alexander: Erín-èš-didli (II): Patterns of Conscription and Work Assignment during the Years AS 8 - S̆S 1. ASJ 18 (1996), S. 217-228.

Vermaak, P. Stafanus: Abi-Simti: A Semitic Matriarch in Sumer. JNSL 21 (1995), S. 105-122.

Visicato, Giuseppe/Westenholz, Aage: Some Unpublished Sale Contracts from Fara. In: S. Graziani (Hg.): Studi sul Vicino Oriente Antico dedicati alla memoria di Luigi Cagni, Napoli 2000, S. 1107-1133.

Volk, Konrad: Inanna und Šukaleduta. Zur historisch-politischen Deutung eines sumerischen Literaturwerkes. SANTAG 3, Wiesbaden 1995.

Waetzoldt, Hartmut: Zwei unveröffentlichte Ur III-Texte über die Herstellung von Tongefäßen. WO 6 (1970-1971), S. 7-41.

- $\quad$ Untersuchungen zur neusumerischen Textilindustrie. Roma 1972.

- $\quad$ Frauen (dam) in Ebla. In: L. Cagni (Hg.): Ebla 1975-1985. Napoli 1987, S. 365-377.

- Die Situation der Frauen und Kinder anhand ihrer Einkommensverhältnisse zur Zeit der III. Dynastie von Ur. AoF 15 (1988), S. 3044.

- Rezension zu McGuire Gibson, Robert D. Biggs (Hg.): The Organization of Power. Aspects of Bureaucracy in the Ancient Near 
East. SAOC 46 (1987). JAOS 111 (1991), S. 637-641.

- Die Berufsbezeichnung tibira. NABU 1997/96.

- Wirtschafts- und Verwaltungstexte aus Ebla. Archiv L. 2769. MEE 12, Roma 2001.

- $\quad \mathrm{Zu}$ den Siegeln der Vorsteher der Opferschauer Nannazišaĝal und Enlilzišaĝal. ZA 96 (2006), S. 178-184.

Waetzoldt, Hartmut/Pettinato, Giovanni: Dagān in Ebla und Mesopotamien nach den Texten aus dem 3. Jahrtausend. OrNS 54 (1985), S. 234-256.

Weadock Penelope N.: The Giparu at Ur. Iraq 37 (1975), S. 101-128.

Weiher, Egbert von: Der babylonische Gott Nergal. AOAT 11, NeukirchenVluyn 1971.

Westenholz, Aage: The Old Akkadian Empire in Contemporary Opinion. In: M. T. Larsen (Hg.): Power and Propaganda. A Symposium on Ancient Empires. Mesopotamia 7, Copenhagen 1979, S. 107-124.

- Old Sumerian and Old Akkadian Texts in Philadelphia. Part Two: The "Akkadian" Texts, the Enlilemaba Texts, and the Onion Texts. CNI Publications 3, Copenhagen 1987.

- The World View of Sargonic Officials. Differences in Mentality between Sumerians and Akkadians. In: M. Liverani (Hg.): Akkad. The First World Empire, HANES 5, Padova 1993, S. 157-169.

- The Old Akkadian Period. History and Culture. In: W. Sallaberger, A. Westenholz, Mesopotamien, Akkade-Zeit und Ur III- Zeit, Annäherungen 3. Herausgegeben von P. Attinger u. M. Wäfler, OBO 160/3, Fribourg, Göttingen 1999, S. 17-117.

Westenholz, Aage/Oelsner, Joachim: Zu den Weihplattenfragmenten der Hilprechts-Sammlung Jena. AoF 10 (1983), S. 209-216.

Westenholz, Aage und Joan Goodnick: Die Prinzessin Tutanapsum. AoF 10 (1983), S. 387-388.

Westenholz, Joan Goodnick: Enheduanna, En-Priestess, Hen of Nanna, Spouse of Nanna. In: H. Behrens, D. Loding, M.T. Roth (Hg.): DUMU-E ${ }_{2}$ DUB-BA-A. Studies in Honor of Âke Sjöberg. OPSNKF 11, Philadalphia, PA 1989, S. 539-556.

- The Clergy of Nippur: The Priestess of Enlil. In: M. De Jong Ellis (Hg.): Nippur at the Centennial. Papers Read at the $35^{\mathrm{e}}$ Rencontre Assyriologique Internationale, Philadelphia, 1988. OPSNKF 14, Philadalphia, PA 1992, S. 297-310.

Whiting, Robert M.: Tiš-atal of Niniveh and Babati, Uncle of Šu-Sin. JCS 28 (1976), S. 173-182.

Wilcke, Claus: Eine Schicksalsentscheidung für den toten Urnammu. In: A. Finet (Hg.): Actes de la XVIIe Rencontre Assyriologique Internationale, Université Libre de Bruxelles, 30 juin-4 juillet 1969, 
Ham-sur-Heure 1970, S. 81-92.

- Der aktuelle Bezug der Sammllung der sumerischen Tempelhymnen und ein Fragment eines Klageliedes. ZA 62 (1972), S, 35-61.

- Die Keilschrift-Texte der Sammlung Böllinger. AfO 25 (1974/1977), S. 84-94.

- $\quad$ Zum Königtum in der Ur III-Zeit. In: P. Garelli (Hg.), Le Palais et la Royauté (Archéologie et Civilisation), CRAI XIX, Paris 1974, S. 177232.

- Familiengründung im Alten Babylonien. In: E. W. Müller (Hg.): Geschlechtsreife und Legitimation zur Zeugung, München 1985.

- A Note on Ti'amat-bāštī and the Goddess ŠA(W)UŠ (K)A of Niniveh. DV 5 (1988), S. 21-26 + engl. summary S. 225-227.

- É-saĝ-da-na Nibru ${ }^{\mathrm{ki}}$ : An Early Administrative Center of the Ur III Empire. In: M. de Jong Ellis (Hg.): Nippur at the Centennial. Papers Read at the $35^{\mathrm{e}}$ Rencontre Assyriologique Internationale, Philadelphia, 1988. OPSNKF 14 (1992), S. 311-324.

- Ti'āmat-bāštī. NABU 1993, 36.

- Politik im Spiegel der Literatur, Literatur als Mittel der Politik im älteren Babylonien. In: K. Raaflaub (Hg.): Anfänge politischen Denkens in der Antike. Die nahöstlichen Kulturen und die Griechen. Schriften des Historischen Kollegs, Kolloquien 24, München 1993, S. 29-75.

- $\quad$ Aritkel „Ninsun“. RlA 9 (2001) S. 501-504.

Winter, Irene J.: Women in Public: The Disk of Enheduanna, the Beginning of the Office of En-Priestess, and the Weight of Visual Evidence. In: J.M. Durand (Hg.): La Femme dans la Proche Orient Antique, CRAI XXXIII 1986, Paris 1987, S. 189-201.

- The Body of the Able Ruler: Towards an Understanding of the Statues of Gudea. In: H. Behrens, D. Loding, M. T. Roth (Hg.): DUMU-E ${ }_{2}-$ DUB-BA-A. Studies in Honor of Âke Sjöberg. OPSNKF 11, Philadalphia, PA 1989, S. 573-583.

- Art in Empire: The Royal Image and the Visual Dimensions of Assyrian Ideology. In: S. Parpola, R. M. Whiting (Hg.), Assyria 1995. Proceedings of the 10th Anniversary Symposium of the Neo-Assyrian Text Corpus Project, Helsinki, September 7-11, 1995, Helsinki 1997, S. 359-381.

Yang Zhi: Sargonic Inscriptions from Adab. Changchun, 1989.

Zettler, Richard L.: The Ur III Temple of Inanna at Nippur. The Operation and Organization of Urban Religious Institutions in Mesopotamia in the Late Third Millennium B.C., BBVO Band 11, Berlin 1992. 
Zgoll, Annette: Der Rechtsfall der En-hyedu-Ana im Lied nin-me-šara. AOAT 246, Münster 1997.

- $\quad$ Ebeh und andere Gebirge in der politischen Landschaft der Akkadezeit. In: L. Milano et al. (Hg.): Landscapes. Territories, Frontiers and Horizons in the Ancient Near East. Papers presented to the XLIV Rencontre Assyriologique Internationale, Venezia, 7-11 July 1997, HANE/M III/2. Padova 2000, S. 83-90.

Ziegler, Nele: Le Harem de Zimrî-Lîm. Florilegium Marianum IV, Mémoires de N.A.B.U. 5, Paris 1999.

- $\quad$ Le Harem du vaincu. RA 93 (1999), S. 1-26. 


\section{Indizes}

Die nur in Anhang 1 (Tabelle 18) vorkommenden Personennamen wurden nicht in den Index aufgenommen.

Alle Quellen werden nach Möglichkeit nach einer neuen Edition zitiert. So werden die ursprünglich in AnOr 7 publizierten Texte nach MVN 18 zitiert, die Texte aus CT 32 nach NISABA 8, Inschriften der Akkade- und Ur III-Zeit nach der Edition in RIME.

\section{Götter}

Abzu 125

Adabal von Amadu 150

Adamma 192,246

Allagula $48,50,57,91$

Allašaniša 178

Allatum $47,50,57,72,73,82,88$, $125,131,144,146$

Amarazu 144,147

An 48,70

Annunītum... 34, 47, 68, 73, 82, 83, 91, $143,146,177,180$

BAD-mi 150

Barama 190

Bēlat-Deraban ... 32, 34, 36, 47, 57, 58, $69,72,76,83,91,106,120,181$

Bēlat-Nagar . .82

Bēlat-Šuhnir .... 32, 34, 36, 47, 57, 58, $69,72,76,83,91,106,120,181$

Dada .55

Dagān $106,132,181$

Damgalnunna 54,147

Damu 144,146

diĝir-ne ....74

Dumuzi $131,138,146$

en-á-nun ....54

Enki 36,37

Enlil 37, 47, 49, 57, 91, 128, 147, 156, $158,167,220,258$

Enlil-Ninlil. 211

Eštar-Dallatum 177

Flußordalgott 55,57

Gansura 137,167

Geštinanna $26,131,132,177$

Geštinanna-ama-lugal 27,177

Geštinanna-lugal
Geštinanna-SI.A-tum $26,27,82$ Gula .. 36, 37, 125, 126, 144, 147, 157, 167,240

Gunura 144,146

Haburītum $106,132,181$

Idabal von Luban.... 246,275

${ }^{\mathrm{d}} \mathrm{I}_{7}$-lú-ru-gú 89

Inanna.....26, 37, 47, 51, 55, 57, 60, 82, $88,91,106,120,133,135,147$, $154,156,157,167,168,177$, $180,181,207,249,252$

Inanna da-bàd-da . 60

Inanna von Nippur 60 Inanna von Ur 60

Inanna von Zabalam........135, 138, 180 Inanna-Haburītum ............135, 136, 146 Išar 138,146 Išhara.....48, 73, 82, 106, 132, 181, 230

Išḩara von MaNE 192

Išhara von Zuramu 192

Iškur $57,71,86$

Ištar von Akkade 253

Ištarān $143,146,156$

Kilili 177

Kura $190,191,246,275$

Lugalbanda $27,48,228$

Martu 177

Melamtaea. .73

Mišar 138,146

Muš-a-igi-gál 65,91

Nanaja ....... 48, 57, 71, 72, 82, 91, 143, $146,167,168,180$

Nanna ...37, 47, 55, 57, 58, 70, 92, 120, $128,147,252$

Nidakul 191 
Nidakul von Arukatu

192

Nidakul von Lubal

Niĝar $144,157,240$

${ }^{d}$ Nin-anše-lá .86

Ninazu 107

Nin-é-gal $72,93,131,147$

Nin-é-kù 179

Ninĝagia $50,57,91,93$

Ningal

Nin-GIŠ-KÉŠ́-a $48,55,125,135,147,242$

Nin-Gublaga 147

Nin-Gublaga von Asuggišdua .........255

Ninhursaĝ $51,144,146,154$

Ninigizibarra. 65,91

Nininsina 144,146

Ninkar 150

Ninkununna $125,144,147$

Ninlil $37,47,49,57,85,91,128$, $147,156,158,167,179,220$

Nin-niĝar $55,133,147$

Ninšubur $55,138,146$
Ninsun......27, 48, 57, 71, 88, 120, 131, $147,167,178,228$

Nintinuga $54,131,147$

Nintu 54

Nin-Tummala ..................................... 54

Ninurta $51,52,54,93,97,167$

Nungal $85,125,131$

Nuska $51,52,93$

Rasap 191,195

Rasap von Adani 246

Rasap von Duneb .............................. 150

Ša(w)uška ......................................... 226

Šagiš .................................................. 190

Šamaš 135

Šara 130,211

Šulpae 156

Šumah 144,146

Ulmašītum $34,48,69,73,83,91$

\section{Personen}

Aba-Enlilgin $98,115,163$

Aba-Enlilgin, Tochter des .......... 98, 99 Abbasaga ..... 45, 110, 122, 123, 126 ,

Abiati .216

Abilaša 115

Abili .215

Abī-simtī..... 26, 34, 45, 60, 82, 83, 95, 105-150, 159, 160, 166, 170, $176,180,231,235,236,261,272$

Abūbu

Adada

152

Adagaldi 114

Adalal, Schwester des 103

Adda-kalla ... 127

Addu-dûrî 272

Ahima 39

Ahūni 158

Ahušuni 149

Ahu-Wer 123,126
Ajakalla $127,139,174$ Ajazimu

Akalta 279

Alih 175

Ama-bara 36

Amaga $188,247,248$

Aman-Aštar ....................................... 257

Ama-ninĝa ........................................ 84

Amar-Suen..... 29, 105, 133, 154, 230, 236

Amar-Suen, Tochter des 223

Amur-ilam 170

Amur-ilī 231

Apilatum $38,56,94$

Apilia $38,56,103$

Apil-kīn von Mari 29

Arašuta 179

Aribatal 263

Arragum 152

Arzi 195

Asqudum 273 


\begin{tabular}{|c|c|}
\hline ................131 & Entemena .... \\
\hline Babati..... 47, 106, 108, 134, 170, 185, & En-uburzi-ana ........ \\
\hline 261 & 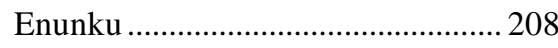 \\
\hline Bagum.............. & En-unu $_{6}$-gal-an-na ..... \\
\hline 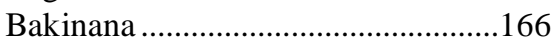 & 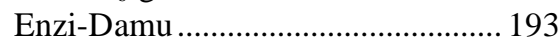 \\
\hline 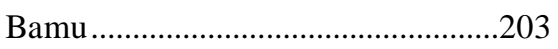 & 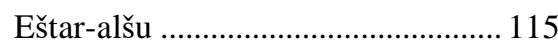 \\
\hline Banilum, Frau des ..............................101 & 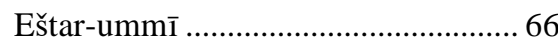 \\
\hline 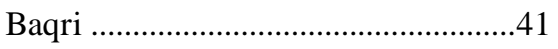 & 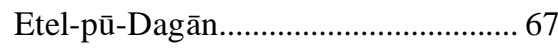 \\
\hline Baranamtara ............................... 272, 275 & Etel-pū-Dagān, Frau des ................... 101 \\
\hline Barbarlia .................................... 40, 45 & Ețib-Mêr...................................197, 198 \\
\hline 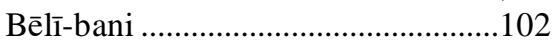 & Geme-Eanna ............................118, 265 \\
\hline 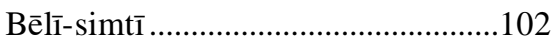 & Geme-Enlila (Königin) ....60, 120, 137, \\
\hline Bēlī-țāb ............................ 36, 38, 40, 56 & $153,164-170,176,179$ \\
\hline Bin-kali-šarrī .......................... 197, 198 & Geme-Enlila (Lukur des Ninurta) .. 165 \\
\hline 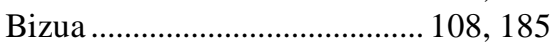 & Geme-Enlila (Prinzessin)..... 156, 165, \\
\hline 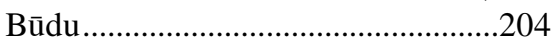 & 238 \\
\hline 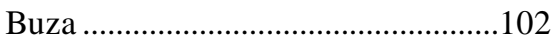 & Geme-Nanna.................117, 204, 231 \\
\hline 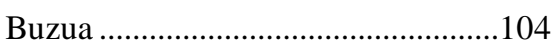 & Geme-Ninlila .... 66, 81, 116, 202-206, \\
\hline 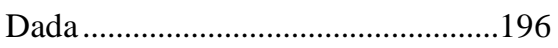 & $209,213,229$ \\
\hline 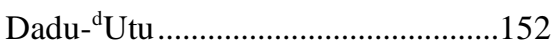 & Geme-Suen ...30-31, 36, 108, 234, 239 \\
\hline Dajati.................. & 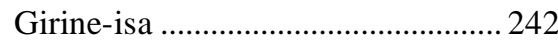 \\
\hline 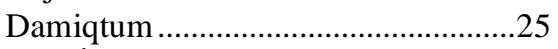 & GIRINI von Umma ............................. 44 \\
\hline Dati- $^{\mathrm{d}}$ TU ................................... 151, 267 & 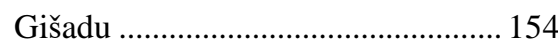 \\
\hline 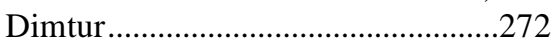 & Gudea von Lagaš............................... 265 \\
\hline 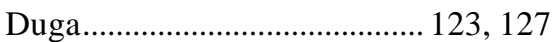 & Gutarla, Frau des ............................ 102 \\
\hline Dukra, Frau des ..................................91 & Haba ............................................. 188 \\
\hline Dusigu.... 150-153, 182, 186, 190, 268, & Habru...................... \\
\hline 271 & Halhalla...... \\
\hline Dusigu (Prinzessin) ................. 246, 274 & Halili................... \\
\hline Ea-niša ..... 98, 99, 171, 204, 206-211, & 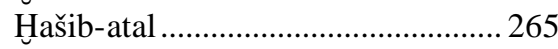 \\
\hline $213,229,239$ & 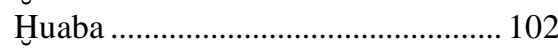 \\
\hline 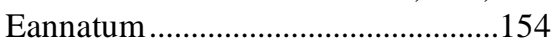 & 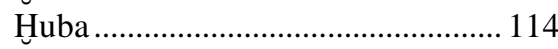 \\
\hline 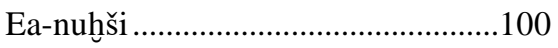 & Ibbi-Malik ....................................... 152 \\
\hline 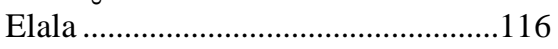 & Ibbi-Suen................ 120, 137, 164, 232 \\
\hline 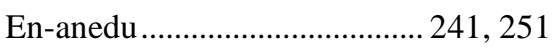 & Ibbi-Zikir.................................. 189, 266 \\
\hline 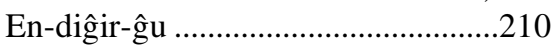 & Ibrium........................................ 245, 249 \\
\hline En-hedu-ana ...... 18, 20, 241, 249-255, & 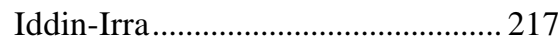 \\
\hline 257,259 & 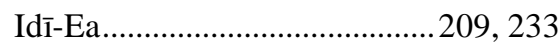 \\
\hline Enlila ...................................... 163, 225 & 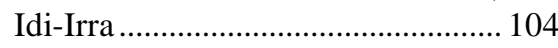 \\
\hline 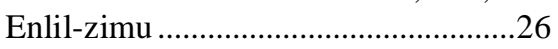 & 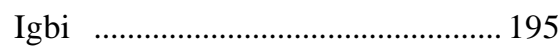 \\
\hline En-mahgal-ana ......................... 116, 243 & 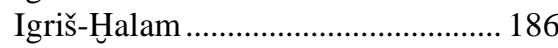 \\
\hline En-men-ana .............................250, 255 & Ili-napišti ......................................... 171 \\
\hline 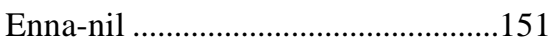 & 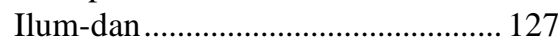 \\
\hline Enna-Utu................................. 194, 246 & 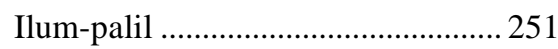 \\
\hline 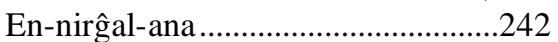 & 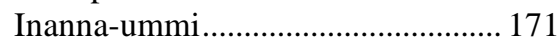 \\
\hline En-nirzi-ana .............................. 242, 243 & 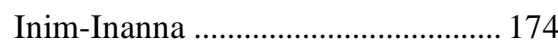 \\
\hline
\end{tabular}




\begin{tabular}{|c|c|}
\hline 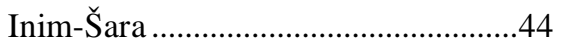 & Lugal-maniša .... \\
\hline 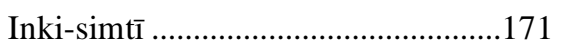 & Lugal-mušhuš .... \\
\hline 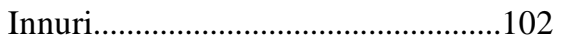 & Lugal-nirĝal ....... \\
\hline Intaea............. 110, 122, 127, 166, 227 & Lugal-sisa..... \\
\hline 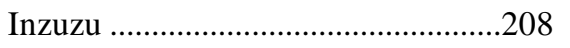 & Lugalzagesi....... \\
\hline 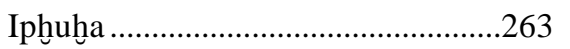 & Lu-melam.................... \\
\hline Ir'ag-Damu ................................. 187, 266 & Lu-Namma.................... \\
\hline Irĝu & Lu-Nanna .................................114, 163 \\
\hline Irĝ̣u dumu Lugal-pirigtur...................174 & Lu-Nanna, Frau des................211, 265 \\
\hline Irĝ̀u, Bruder der Ninkalla .................225 & Lu-Narua......................114, 207, 208 \\
\hline 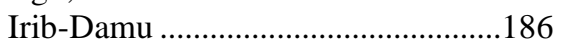 & Lu-Ninšubur ...................................... 174 \\
\hline 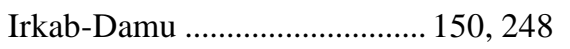 & 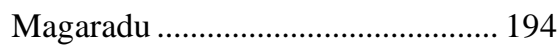 \\
\hline 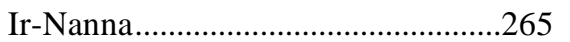 & Mama-kešda .................................. 215 \\
\hline Išar-Damu ...... 150, 186, 189, 246, 248, & Mama-kešda, Tochter des............... 215 \\
\hline 267,272 & 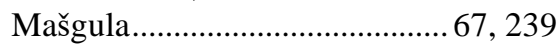 \\
\hline Iškun-Dagān ............................... 197, 199 & ME-Ulmaš .... \\
\hline 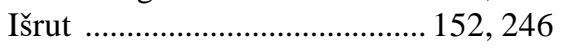 & 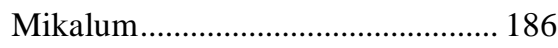 \\
\hline 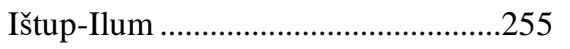 & Minari..................... \\
\hline 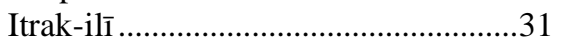 & 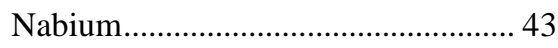 \\
\hline 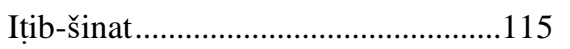 & 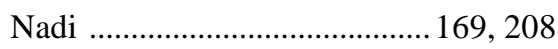 \\
\hline 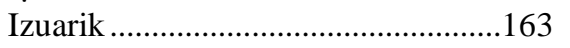 & Nalu ........................................ 45, 130 \\
\hline Izuarik, Frau des................. & 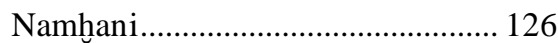 \\
\hline Kalam-henagi .................................. 40, 74 & Nanna-kiaĝ . \\
\hline Kešdut (Königin) ....186, 190, 195, 248 & Nanna-maba...................122, 127, 166 \\
\hline Kešdut (Prinzessin) ......... 192, 246, 267 & Narām-ilī....................39, 45, 203, 215 \\
\hline 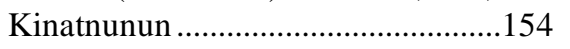 & Narām-ilī, Frau des ........................... 214 \\
\hline 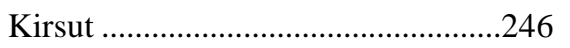 & Narām-Suen .............................. 198, 255 \\
\hline Kubātum .91, 109, 117, 131, 144, 153- & 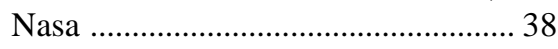 \\
\hline $164,170,182,235,236,272$ & NEtibudu................ 186, 188, 190, 195 \\
\hline 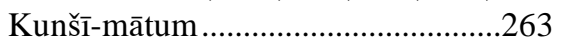 & 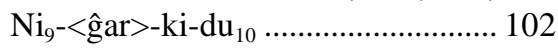 \\
\hline Laram-Ea .........................................179 & Niĝar-kidu.................. \\
\hline 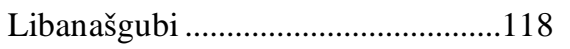 & 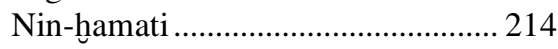 \\
\hline Libanukšabaš, Ensi von Marhaši ....118 & Ninhedu...................... \\
\hline 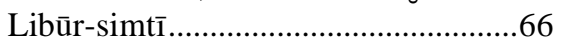 & 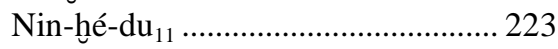 \\
\hline Liwwir-mitț̣̦ašu ...................................262 & 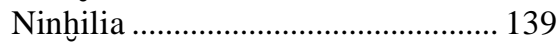 \\
\hline 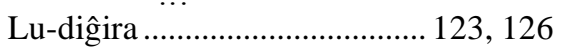 & 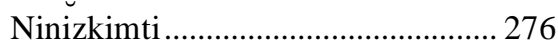 \\
\hline 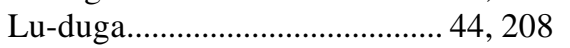 & Ninkalla...... $100,171,209,211-226$, \\
\hline 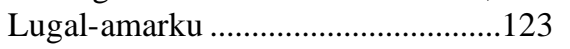 & $229,235,236$ \\
\hline 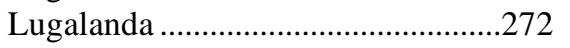 & Ninkalla, Tochter des Lú-giri ${ }_{17}-z a l \ldots$ \\
\hline 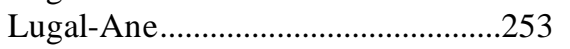 & \\
\hline 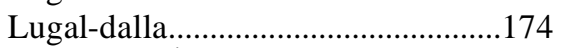 & 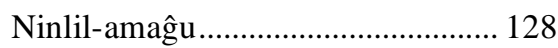 \\
\hline LUGAL-GÁNA-zi ................................197 & Ninliltum-imdi..........................43, 100 \\
\hline$\ldots \ldots \ldots \ldots \ldots \ldots \ldots \ldots \ldots \ldots \ldots \ldots . . . .175$ & Ninmelam .......... \\
\hline Lugal-kuzu........................25, 126, 164 & Nir-idaĝal..................... \\
\hline Lugal-magurre................114, 169, 176 & Nūh-ilum.............................116, 184 \\
\hline Lugal-magurre, Frau des ........ 234, 265 & Nuida, Frau des .......... \\
\hline
\end{tabular}




\begin{tabular}{|c|c|}
\hline Nūr-Adad.. & Šeškalla .... \\
\hline Nūr-Eštar ....... & Šîibtu ............ \\
\hline Nūr-Suen..................................... 127, 166 & Šu-Eštar.......... \\
\hline 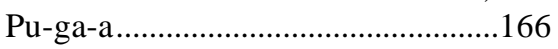 & Šu-Kūbum.......................30, 35, 38, 40 \\
\hline 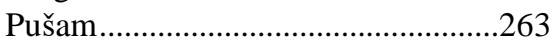 & Šulgi .................... 105, 167, 228, 234 \\
\hline $\mathrm{Puzur}_{4}-$ ú-ša ... & Šulgi-ajaĝu..... \\
\hline 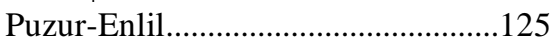 & Šulgi-bāni............................208, 227 \\
\hline Puzur-Eštar ...............43, 110, 174, 175 & Šulgi-ilī ..................38, 115, 130, 169 \\
\hline Puzur-Eštar (Akkade) ........................199 & Šulgi-ilī, Frau des ................................91 \\
\hline Puzur-Šamaš.... & Šulgi-simtī..26, 30-115, 120, 129-130, \\
\hline 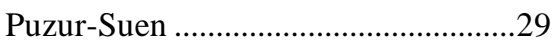 & $133,159,168,171,179,202$, \\
\hline Qudāšum............................................104 & $207,209,229,235-237,239,261$ \\
\hline 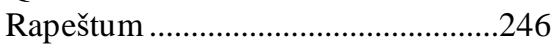 & Šulgi-simtī (Prinzessin)....66, 217, 274 \\
\hline 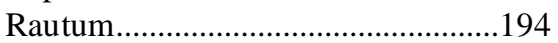 & 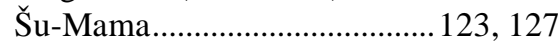 \\
\hline 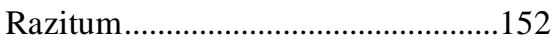 & Šu-Mama, Frau des .......................... 144 \\
\hline Rīm-ilī............ & 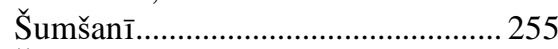 \\
\hline Rīṣsilum ............................. 126, 169, 184 & Šu-Ninšubur.............................. 122, 126 \\
\hline 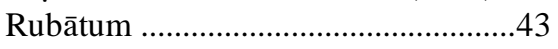 & 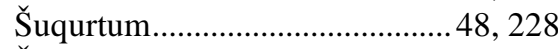 \\
\hline 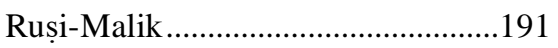 & Šuruš-kēn .................................... 43, 44 \\
\hline Sargon ...................................... 241, 252 & Šu-Suen ...... 106, 129, 133, 167, 231, \\
\hline SI.A.A & 236 \\
\hline SI.A-tum ...... 25-29, 66, 100, 108, 132, & Tabur-Damu............. 186 \\
\hline $180,182,235$ & Tabūr-ḩațtum ... \\
\hline 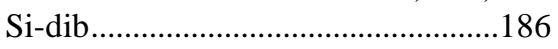 & Taddin-Eštar .......98, 99, 149, 209, 229 \\
\hline Simat-Ea ..............171, 209, 213, 229 & 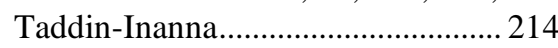 \\
\hline 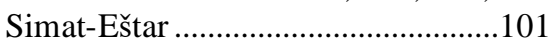 & Taddin-KI.ZA ....................................... 216 \\
\hline Simat-Ištarān ..................131, 161, 182 & 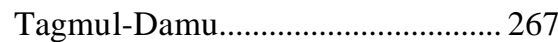 \\
\hline Simat-Nisaba ......................... 178, 232 & Tagriš-Damu ..........................266, 275 \\
\hline 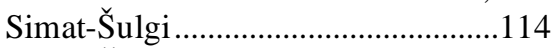 & Takūn-mātum .........................2231, 240 \\
\hline 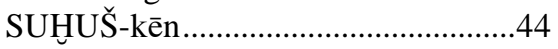 & 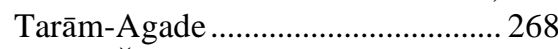 \\
\hline Sukkalmah, Frau des................ 66, 100 & Tarām-Šulgi _.................................... 263 \\
\hline SumPEŠdu ................................ 188, 189 & Tarām-Uram ..... 29-30, 106, 108, 133, \\
\hline 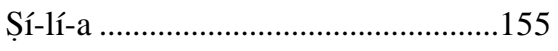 & 261 \\
\hline Șilluš-Dagān .................... 100, 115, 130 & Tarib-Damu ...............................153, 248 \\
\hline 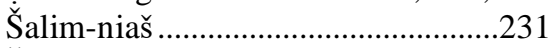 & TašLULtum ...................................... 196 \\
\hline 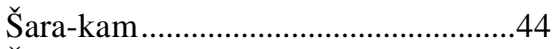 & Teșīn-Mama...........36, 43, 45, 100, 101 \\
\hline Šara-kam, Frau des .............................44 & Tešma-Damu ...................................... 194 \\
\hline 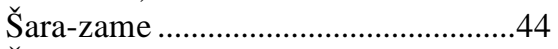 & Ti'amat-bāštī .. 117, 162, 226,-228, 261 \\
\hline Šar-kali-šarrī.............................. 196, 198 & Tinib-Dulum .....................188, 247, 248 \\
\hline Šarrum-bāni .....................172, 210, 213 & Tirin-Damu ....................................... 248 \\
\hline Šarrum-bāni, Frau des.............. 172, 265 & Tiša-Lim.........................191, 193, 267 \\
\hline Šarrum-ilī................43, 100, 172, 174 & 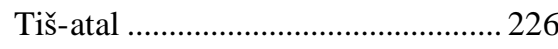 \\
\hline Šarrum-ilī, Frau des .................. 91, 100 & 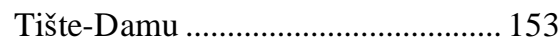 \\
\hline 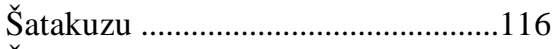 & Tukīn-ḩatți-migrīša .................. 168, 264 \\
\hline 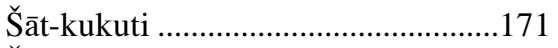 & Tūlid-Šamšī ..............................171, 211 \\
\hline 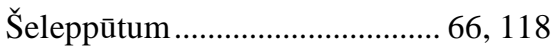 & 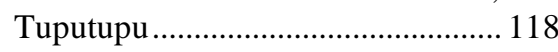 \\
\hline
\end{tabular}


Tūta-napšum

Tūta-šar-libbiš

198, 250, 256

196, 199

Ubartum

139

Udat-șenat

230,240

Ulaniš 127

Unabatal

.227

Ur-ab-ba-diĝir-ra

.208

Ur-Ba'u $109,114,127,174,216$

Ur-Enlil

31,237

Ur-èš-bar-ra

.208

Ur-Guenna

169

Ur-Igalim

$116,184,205$

Ur-Iškur

.264

Ur-ki-gu-la

149

Urkununna

..45

Ur-Lisi

.219

Ur-Lugal-edenka

38,56

Urmes

215,223

Ur-Namma
Orte und geographische

Bezeichnungen

Adab .275

Ägypten .277

Anšan .262

Arraphum .265

Badtibira 138

Burman .267

Dagga .215

Dēr 143

Deraban .261

Dijala-Gebiet .........................................32

Dilmun ...................................................2276

Dusigu $^{\mathrm{ki}}$ 152

Ebla $\quad$.....34, 118, 150, 154, 182, 186, 245,266

É-ga-ba. .97

Elam .276

Emar 192,267

Eridu . .68

Ešnunna $32,81,106,238,261$

Ga'eš 97,244
Ur-niĝar......43, 44, 100, 114, 169, 176, 237

Ur-niĝar, Frau des . .43

Ur-nighar, Tocher des .......................... 43

Ur-Ninšubur....................................... 208

Ur-Suen..........................216, 225, 233

Ur-Suen (Prinz) ................................. 216

Ur-Šulpae ........................................... 179

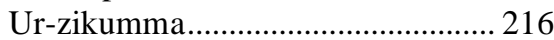

Ušaja .......................................100, 171

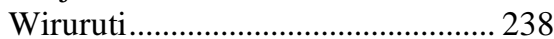

Za'aše ...................................... 192, 266

Za-ga-an-bi ........................................ 230

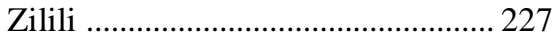

Zimini-barku..........................192, 267

Zimrî-Lîm ................................ 271, 273

Zubaga ................................... 123, 127

Zugalum .................................. 192, 267

Zuhutum, Frau des ........................... 144

Girsu...... 73, 112, 148, 163, 172, 198, 222

Griechenland..................................... 277

Gublu................................................. 195

Hamazi .............................................. 264

Harran ............................................... 267

Harši .................................................... 118

Karzida....................................... 59, 97

Kiš ……....................................... 267

Kisurra .................................................... 97

Lagaš .............................................. 271

Luban ................................................ 248

Lumnan ............................152, 192, 267

Marhaši ................................... 118, 262

Mari ..................29, 106, 118, 261, 271

Martum................................................ 191

Nagar..................................................... 266

Nenaš............................................... 190

Ninive.....................................226, 261

Nippur ....49, 56, 62, 97, 129, 143, 198, $218,220,257$ 
Pašime................................................263

Puzriš-Dagān ... 73, 112, 113, 133, 172, 213

Simānum

$118,262,263$

Šimaški 204, 209

Sippar .135

Suhnir .261

Tummal $54,62,85,211$

Ú.URUxA ${ }^{\mathrm{ki}}$ .223

Ú.URUxGUki .223

Udagga .215

Uguaš 151

Umma ..44, 88, 97, 112, 138, 172, 175, $176,197,218$
Ur $\quad . . \quad 51,56,58,112,124,149,172$, 244

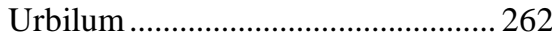

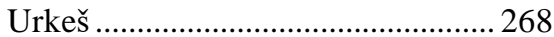

Uruk .....40, 51, 56, 60, 62, 74, 97, 167, 173

Urum 244

Urusagrig ..........................97, 99, 173

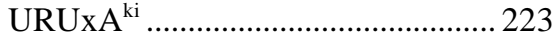

Zabalam ................................... 135, 138

Zabšali.....................................262, 264

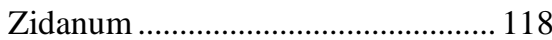

Zimudar......................................47, 117

Sachindex

Abgaben 163

Abum . 84,92

Abzu 147

Akiti-Fest. $76,80,92,97$

Akiti-Fest zur Aussaat .....58, 144, 167, $169,203,219,220,230,244$

Akiti-Fest zur Ernte $59,219,244$

Alum-Schaf 112

Amme 154,189

Amme des Königs Išar-Damu ..........154

Amtsname $242,251,256$

Amtstitel .240

Amtswechsel 35,90

Arbeitskräfte 138,140

Aufstand des Lugal-Ane. .253

Baden Nannas . .59

Baderiten 120,166

bala-Abgaben ....................................2224

Beamten der Šulgi-simtī ......................37

Begrüßungsgeschenk ..........................97

Bett 170

Beute 204, 209

Bierausschenken...... 69, 70, 71, 72, 73, $78,98,115,118,131,158,161$, $168,172,184,209,219,220,273$

Biertrinken .172
Brautgabe ........................................... 118

Brennmaterial ................................... 112

Bruder der Ninkalla.......................... 216

Butterschmalz ................................... 171

Datenformel...102, 117, 152, 187, 191, $243,245,250,255,256,257$, $262,263,264,267$

Datteln 70,259

dynastische Beziehung..................... 118

dynastische Ehe ..... 106, 119, 226, 260 , 275

e $\mathrm{SU}_{7} \cdot \mathrm{SU}_{7}$-Fest................................... 88

Edelmetalle .......................................... 138

Eheschließung.........................172, 191

Eheschließung, politisch ................. 118

Ehrengeschenk 115, 157, 184, 209, 214

Einkleiden Nannas

59

Einzugsfest $69,71,76,85,180$

Elūnum ...49, 69, 70, 77, 78, 79, 81, 91,

135,205

Emblem des Enlil 131

En der Inanna $136,171,241$

En des Enki 171,241

En des Enlil..... 256

En des Nanna 171

En des Nanna von Ga' eš .................. 241

En des Nanna von Ur ......116, 241, 275 
Ensi von Nippur ............................... 158

Ensi von Umma....................... 139, 174

Ensi von Zabšali.................................168

Ensi, Frau des ....................................114

Enten .....................................................42

Entu des Šamaš .................................255

Erhebt-Euch-Tag .................................65

Erkrankung .......................................145

Ernte.................................................97

Erntefest.............................................97

ér-sù-a-Fest ............................................98

erubbatum .............................................92

Ezem-mah..................59, 159, 219, 244

Ferkel .................................................42

Fest der Kette .......................................85

Fest des Himmelsbootes ..... 62, 66, 73, 93, 180, 206

Festmahl

.96

Festmahl für Inanna ............................63

Fettschwanzschaf ..................... 41, 112

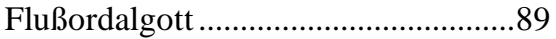

Frauenfest ........................................144

Frühgeburten .....................................157

ga-ma-ga-mu-è-Fest..........................86

gan-gan-è-Fest.......................................86

Gartenpersonal ...................................170

Gazelle .................................... 41, 112

Geburt ..... 90, 100, 156, 157, 188, 189,

192

Geburt des Viehs .................................73

Geflügel ..............................................95

Gesandte ...........................................118

Geschenk ...... 101, 102, 116, 117, 136, 140, 161, 162, 189, 195, 227,

232,273

Geschenke, Austausch von.................98

Geschwister der Abī-simtī................108

Geschwisterehe ....................................165

Gewänder............................................138

Giparu ...................................................251

Gold .................................................140

Götterreise ...........................................59

Grabbeigaben …...............................245

gu $_{4}$-gana ${ }_{2}$-Fest ...................................54

gudu $_{4}$-Priester .......................................81

Gusisu-Fest.................................. 54, 167
Güteraustausch .................................. 214

Handwerker ....................................... 169

Harfe der Inanna...................................... 65

Haus des Statuenortes ........................ 66

Haushalt der En .................................. 242

Haushalt der Geme-Enlila ............... 165

Haushalt der Königin .......45, 96, 112, $140,149,169,184$

Haushalt der Kubātum ..................... 163

Hebamme ............................................ 189

Herden der Abī-simtī ....................... 148

Herrscherkult ......................66, 85, 125

Hirsch ............................................... 112

Hochzeit ................................... 100, 204

Hochzeitsritual von Ebla................... 190

Holz ................................................... 172

Inthronisation einer En............251, 258

Kaufleute........................................... 276

Kettbaum............................................ 277

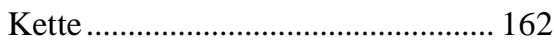

Kind der Königin.............................. 156

Klagefest Nannas .................................. 60

Klagen ............................52, 59, 61, 77

Klageumzug in Uruk........................ 64

Kult von Nippur ................................ 157

Landbesitz der Königin............ 193, 197

Ländereien ......................223, 247, 258

Lastboote

Lebensmittel .. 102, 112, 113, 138, 139, $165,166,172,176$

Lebenswelt, männlich/weiblich ..... 47, $55,159,183,184,220,277$

Lederarbeiter.................................... 114

Lukur des Ninurta ............................. 156

lulubäisches Schaf ............................ 112

lú-mah-Priesters ................................ 130

Maststall........................................... 163

Metallzuweisungen ........................... 150

Milchkinder ........................................ 154

Milchkindschaft................................. 155

Milchtrinken ...................................... 155

Mitgift ............................247, 268, 275

Möbel ............................................... 171

monatliche Feiertage .................... 50, 64

monatl. Feiertage bei Šulgi-simtī ..... 56

Monatsbeginn, Riten ........................ 181 


\begin{tabular}{|c|c|}
\hline $\begin{array}{r}\text { mu-DU-Lieferungen ...... } 41,110,203, \\
227,241\end{array}$ & $\begin{array}{l}\text { Schatzarchiv ...................136, 144, } 170 \\
\text { Schatzhaus der Königin .................. } 171\end{array}$ \\
\hline Mutter der Dusigu .................................152 & Schmuck...... 102, 116, 117, 161, 171, \\
\hline Mutter der Königin ............ & $192,202,231$ \\
\hline Mutter der Kubātum............................155 & Schreibgewohnheiten ..........................56 \\
\hline Mutter des Ibbi-Suen .........................157 & Schuharchiv ...........................170, 214 \\
\hline Mutter des Königs....28, 109, 126, 134, & 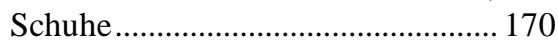 \\
\hline $145,150,187,272$ & 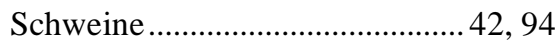 \\
\hline Nabrium ..............49, 69, 77, 78, 82, 93 & Schwester der Dusigu ...................... 152 \\
\hline Nagabtum …....................................... 42 & Schwester der Königin ........................ 32 \\
\hline Namen & Schwiegertochter...... 29, 44, 182, 192, \\
\hline NE.NE-ĝar-Fest................. 77, 85, 131 & $204,263,265,266$ \\
\hline Neulicht ......56, 57, 120, 125, 147, 157 & Schwurgötter... \\
\hline 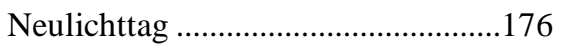 & šeršerrum \\
\hline 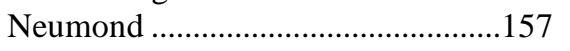 & Siegel.................. 117, 162, 195, 207 \\
\hline Neumondtag .............95, 120, 166, 176 & Silber .......................................... 162 \\
\hline offizieller Kult ............................. 48, 69 & Silberringe...................102, 116, 136 \\
\hline 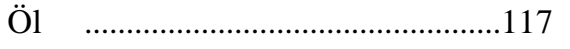 & Šimaški-Schafe ..................................... 41 \\
\hline Opfer zum 7. und 15. Tag...................57 & siskur $_{2}$-Riten im Garten......67, 78, 133, \\
\hline 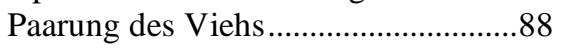 & 147 \\
\hline Palast der Königin ..............................124 & siskur $_{2}$-Riten im Palast ........................ 62 \\
\hline Perle & spontanes Opfer .................86, 129, 131 \\
\hline $\begin{array}{r}\text { Personal ...... 21, 44, 94, 103, 113, 151, } \\
169,188,208,216,268\end{array}$ & 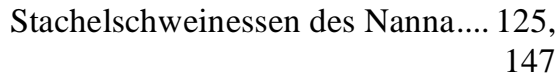 \\
\hline Personal der Dusigu ..............................151 & 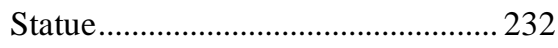 \\
\hline persönliche Gottheit....... 168, 181, 225, & Statue der Königin...........160, 183, 190 \\
\hline 229,232 & Statue der Kubatum.......................... 160 \\
\hline 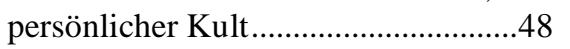 & Statue des Königs ...... $54,71,85,91$, \\
\hline persönliches Opfer ..132, 138, 157, 205 & 190,208 \\
\hline Prachtentfaltung am Hof...................162 & Statue des Šulgi ....... \\
\hline Priester der Bēlat-Šuhnir .....................80 & Stiefel ......................................... 214, 230 \\
\hline 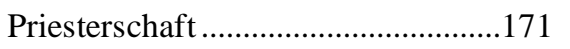 & Straußentempel ................................. 227 \\
\hline Proviant...................100, 115, 140, 192 & Šulgi-simtī-Archiv.............33, 175, 184 \\
\hline Reinigungsriten ...................... 121, 153 & Tafel der Königin ..................34, 60, 94 \\
\hline Reise der Dusigu ...............................152 & Tafel des Königs.........................59, 97 \\
\hline Reise der Königin ......58, 61, 135, 138, & Tauben........................................ 42, 60 \\
\hline $139,167,184,192,198,267$ & Tempelplattform .............................. 147 \\
\hline 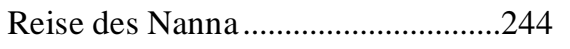 & Textilien ..............................117, 140 \\
\hline 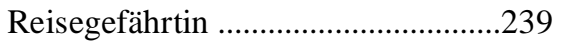 & Textilproduktion ...... 34, 103, 104, 149, \\
\hline Riten zum 7. Tag .............................131 & 194,273 \\
\hline Rohr .......................................... 164, 172 & Thron .............................................. 170 \\
\hline Rückerstattung von Vieh ......................38 & Thron der Königin............................ 170 \\
\hline Šabra der Königin ................................114 & Thron des Enlil ......................... 131, 147 \\
\hline 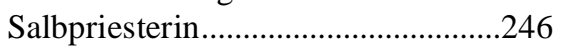 & Thron des Šulgi .................................. 116 \\
\hline 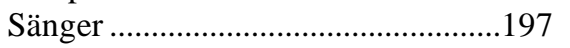 & Thron des Ur-Namma .....125, 126, 147 \\
\hline Schafstall .................88, 140, 163, 227 & Thronfolge .............. 90, 185, 187, 189 \\
\hline
\end{tabular}


Thronwechsel

Titulatur 234, 277

Titulatur, Wechsel .238

Tochter der Kubātum .155

Tod der Dusigu .152

Tor der Inanna .146

Tor des Gipar...... 57, 63, 143, 146, 168 Tor des Heiligtums......57, 63, 168, 180 Totenkult...... 27, 29, 84, 92, 108, 131,

Totenopfer ..... 27, 34, 68, 85, 107, 152, 190, 195, 202, 229, 231, 240

tragend Tieren als Opfer . .90

Transportarbeiten 140

Tribut 117

Tummalfest $54,69,85,158,159$, $210,220,244$

Tür .170

Übergangsriten . .63 unblutige Opfer 46,70

Unglückstag..... 120

Unterwelt 125

Unterweltsgötter 90,126

Vater des Ur-Namma. . .25 Vergöttlichung.... 27, 28, 199, 234, 238

\section{Wörter und Ausdrücke}

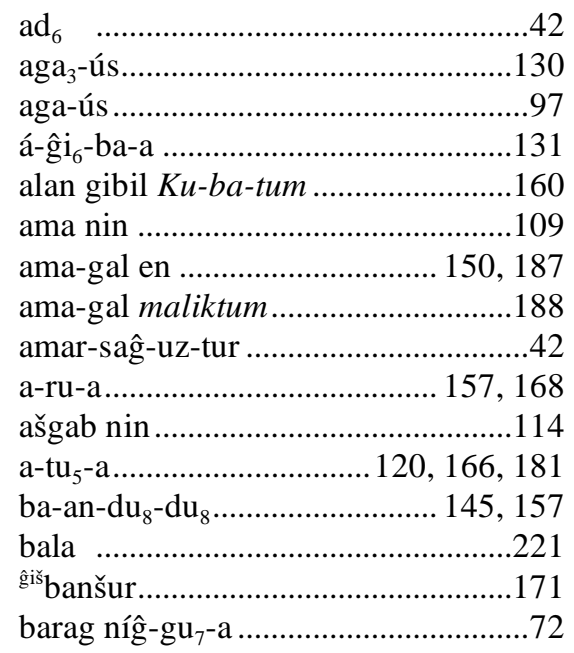

Verwaltung der Königin .................... 45

Verwaltung, Umstrukturierung ...... 113

Viehbesitz .......................162, 226, 232

Viehhaltung, Riten .. 88

Viehzucht. 140,222

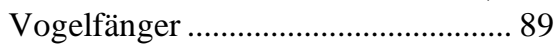

Vogelhaus ............................................. 89

Vollmondtag .................................... 182

Vorabendfeiern .................................. 131

Wachen des Königs.............................. 97

Waffen ............................................... 116

Wagen ..............................140, 151, 195

Walker................................................ 103

Weben …………………………….... 149

Weberinnen.............. 103, 149, 164, 194

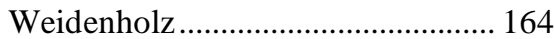

Weihgaben ....... 144, 146, 157, 168, 232

Weinberge .......................................... 194

Wildschaf .......................................... 112

Wildtiere ....................................41, 112

Wolle..... 89, 104, 148, 166, 195, 204,

Zeit des Lammens ................................ 88

Zeugbaum ....................................... 277

Zwiebelarchiv ....................................259 


\begin{tabular}{|c|c|}
\hline é-gal-la ba-an- $\mathrm{ku}_{4} \ldots \ldots$. & ĝiri $_{3}$ nin Šulgi-simtī .... \\
\hline 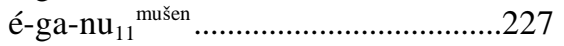 & gir-ni... \\
\hline e-ge ZAR .................................... 65,94 & ĝ̀iš-gi-na ........ \\
\hline é-gi & ĝiš-saĝ-du..... \\
\hline é-gi-na-ab-tum gibil nin-ke ${ }_{4} \ldots \ldots \ldots \ldots . . .171$ & 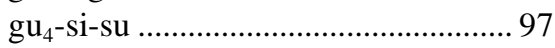 \\
\hline é ki-alan ....... & gukkal.......... \\
\hline é Ku-ba-tum............... & gú-un ....... \\
\hline é kurušda............ & 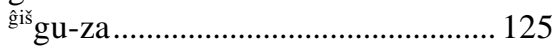 \\
\hline 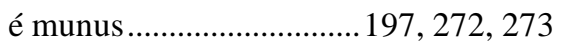 & haluppu............. \\
\hline e $\mathrm{SU}_{7} \cdot \mathrm{SU}_{7} \ldots \ldots \ldots \ldots \ldots \ldots \ldots$ & $\ldots 145$ \\
\hline 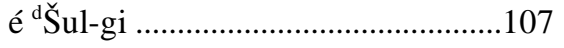 & 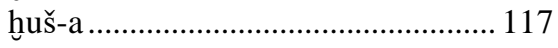 \\
\hline 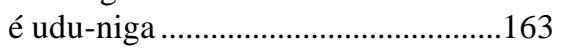 & igi-kár.....100, 115, 140, 157, 166, 179, \\
\hline 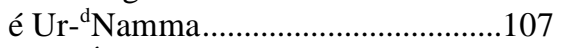 & $184,209,214$ \\
\hline 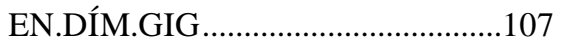 & ì-ĝiš bára-ak ................. \\
\hline é-ni, & in-da-ĝál.. \\
\hline 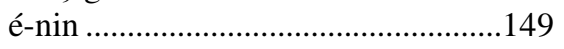 & $\mathrm{ir}_{7}{ }^{\text {mušen }} \ldots . .$. \\
\hline ér niĝin ${ }_{2}$-na .................................. 64, 92 & ká èš .................... \\
\hline ér niĝ̀in ${ }_{2}$-na ká gi gi $_{6}-$ par $_{4}$-ra ..................91 & 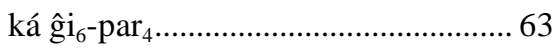 \\
\hline 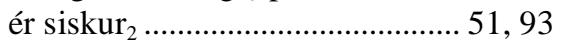 & ka-gur \\
\hline 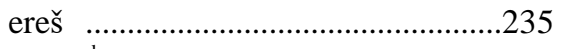 & $\mathrm{kaš}_{4} \quad \ldots \ldots \ldots . . .$. \\
\hline ér-sù d Nanna-áš ..................................60 & kaš-dé-a ...............69, $92,98,115,158$ \\
\hline 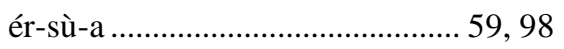 & ki-a-naĝ ...... 32, 68, 84, 107, 125, 202, \\
\hline erubbatum.. & 231 \\
\hline 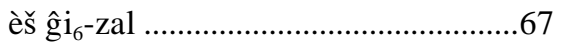 & ki-lugal ...... \\
\hline 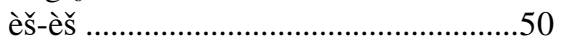 & ki-nin ............................................ 172 \\
\hline 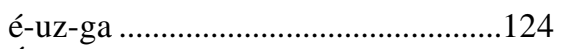 & 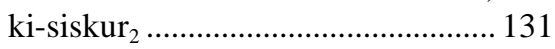 \\
\hline ÉxPAP ..... & kišib ama-nin-ĝá-ka.......................... 84 \\
\hline ezem diĝir- $\mathrm{ku}_{4}-\mathrm{ku}_{4} \ldots \ldots \ldots \ldots \ldots . . . . . .69,79,92$ & kišib d Šul-gi-sí-im-tum....................... 39 \\
\hline ezem diĝ̀ir-ku-ku ..................................77 & kurušda............................. 49, 116, 283 \\
\hline ezem gu $_{4}$-gana & kù-sal............................................ 192 \\
\hline 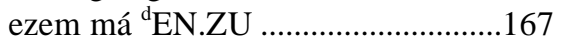 & $\mathrm{kuš}_{7} 39,148,163$ \\
\hline ezem má-an-na ....................................92 & lá-ì su-ga ........................................ 38 \\
\hline ezem-mah ................................ 59, 93 & 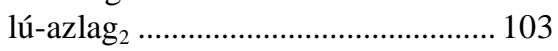 \\
\hline 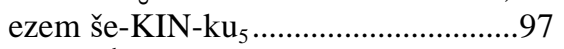 & lugal $\mathrm{ku}_{4}$-ra.............................131, 137 \\
\hline 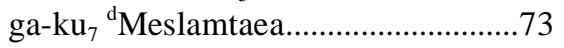 & lugal-ra gaba ri-a ................................97 \\
\hline ga-ma-am-mu-ut-tum................ 86, 93 & lukur ........................... 26, 230, 234, 237 \\
\hline ga-ma-ga-mu-è .......................... 86, 93 & 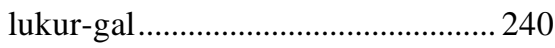 \\
\hline 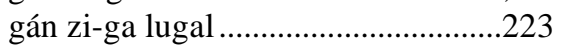 & lukur-kaskal ...........................207, 238 \\
\hline 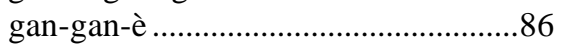 & 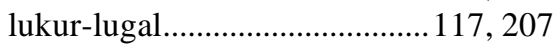 \\
\hline ĝá-udu ................. & má-an-na ..........................66, 180, 206 \\
\hline ga-zi-gu ${ }_{7}-\mathrm{a}$ & má-lah $_{5}$ \\
\hline ga-zi-gu ${ }_{7}-\mathrm{a}^{\mathrm{d}}$ Nin-hur-sag ....................154 & 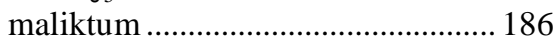 \\
\hline 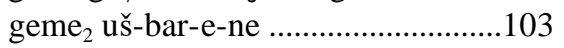 & ma-sá-ab....................................... 157 \\
\hline gerrānum .......................................... 61 & 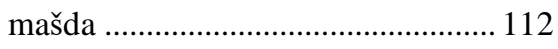 \\
\hline ğiri $_{3} A$-bí-sí-im-ti ...................... 131, 145 & máš-da-re-a ......................165, 175, 218 \\
\hline ĝiri $_{3}$ nin-ĝá ........................ 50, 64, 74 & máš-da-re-a lugal................................ 244 \\
\hline
\end{tabular}




\begin{tabular}{|c|c|}
\hline maškim... & sá-du ${ }_{11}$ nin-e-ne. \\
\hline mu-DU.. & sagi \\
\hline mu-DU A-bí-sí-im-ti.........................111 & siki udu $A$-bí-sí-im-ti ... \\
\hline mu-DU d Šulgi-simtī ................... 34, 36 & 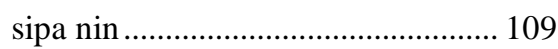 \\
\hline mu-DU Ku-ba-tum................................161 & $\operatorname{siskur}_{2} \ldots$ \\
\hline mu-DU-lugal .............................203, 214 & siskur $_{2}$ gu-la ...........................137, 146 \\
\hline MUNUS.NUNUZ.ZI ${ }^{\mathrm{d}}$ nanna............250 & 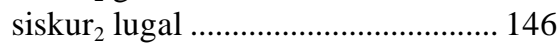 \\
\hline mušen-dù ............. & siskur $_{2}$ šà é-gal......... \\
\hline$\ldots \ldots \ldots \ldots \ldots \ldots . .238$ & siskur $_{2}$ šà-ga gu-ru-a.......................... 86 \\
\hline na-gada....................................... 114, 169 & siskur $_{2}$ šà-gi-gur $-\mathrm{g}_{7}{ }^{\mathrm{d}}$ Inanna Zabalam ${ }^{\mathrm{ki}}$ \\
\hline 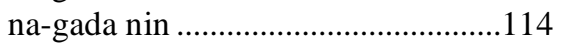 & .... 139 \\
\hline 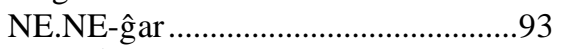 & ${ }^{\text {kušs }}$ suhub $_{2} \mathrm{du}_{8}$-ši-a é-ba-an ........214, 230 \\
\hline nesaĝ d En-líl-lá-šè ...................... & 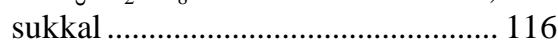 \\
\hline níĝ-dab ${ }_{5}$ šah-zé-da d Nanna................125 & 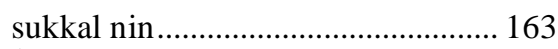 \\
\hline 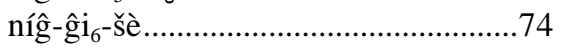 & 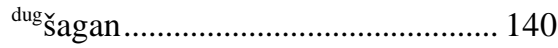 \\
\hline 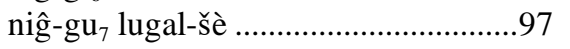 & 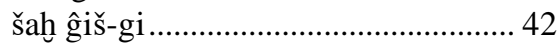 \\
\hline níĝ-gu & šah iri..................... \\
\hline 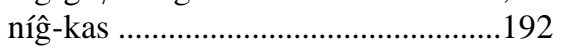 & $\check{s} \bar{a} k$ ultum ${ }^{\mathrm{d}}$ Inanna. \\
\hline 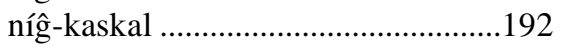 & šeg \\
\hline níĝ-ki-zàh...... & še-kin-kin .. \\
\hline níĝ́-ki-zàh šà gá-udu-ka ........................88 & 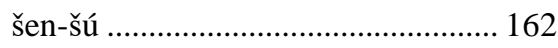 \\
\hline níĝ́-ki-zàh u u & 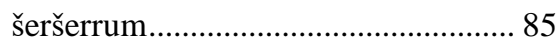 \\
\hline 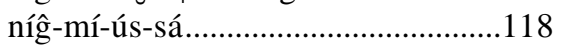 & šeš nin ................ \\
\hline 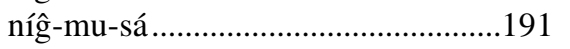 & 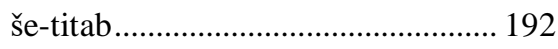 \\
\hline $\operatorname{nin} \quad \ldots \ldots \ldots \ldots \ldots \ldots \ldots . . .26,196,234,235$ & šu-bal-aka.... \\
\hline 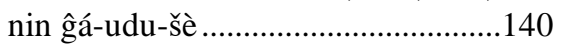 & 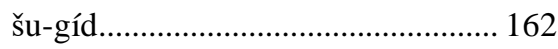 \\
\hline 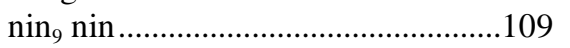 & šu-gur kù-sigg ${ }_{17}$-huš-a....................... 117 \\
\hline 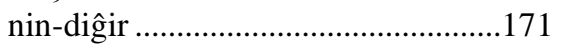 & 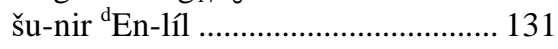 \\
\hline nin-e-ne ..........................108, 164, 235 & šùš $\quad$ ….......................................... 39 \\
\hline 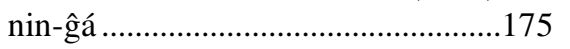 & tag A-bí-sí-im-ti nin ........................... 149 \\
\hline 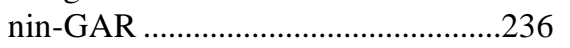 & 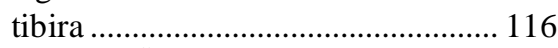 \\
\hline 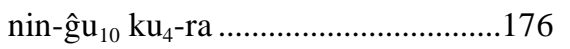 & tu-gur ${ }_{4}$ mušen \\
\hline 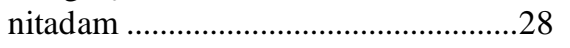 & tu-ti-da kù-sig ${ }_{17}$ huš-a..................... 171 \\
\hline 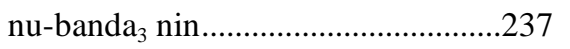 & $\mathrm{u}_{4} \mathrm{dab}_{5}$-ba níĝ̀-gu $\mathrm{u}_{7}$ nin-ĝá-šè .............. 95 \\
\hline 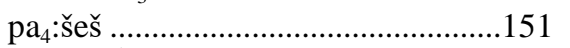 & 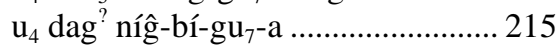 \\
\hline 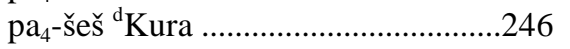 & 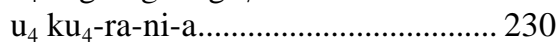 \\
\hline 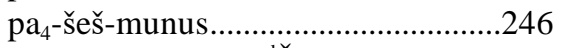 & $\mathrm{u}_{4}$ má è-a ............... \\
\hline 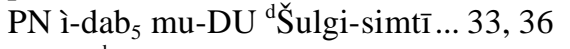 & $\mathrm{u}_{4}$-nú-a.................................. 95, 177 \\
\hline $\mathrm{PN} \mathrm{u}_{4}{ }^{\mathrm{d}} \mathrm{Ištarān}$ (KA.DI) in-da-a .......144 & $\mathrm{u}_{4}$ zi-ga-zé-na...... \\
\hline rá-gaba …........................................169 & $\mathrm{u}_{4}$ zi-ša-še-na..................................... 65 \\
\hline 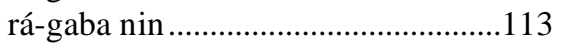 & 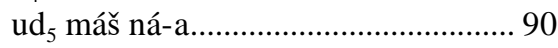 \\
\hline 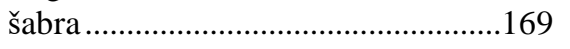 & udu-a-lum...................................... 112 \\
\hline 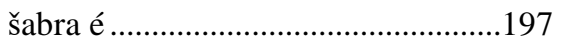 & udu-lú-ùlu-um................................. 112 \\
\hline šabra nin....................................... 176, 237 & 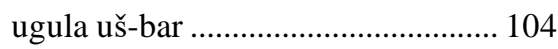 \\
\hline sá-du ${ }_{11} \ldots 81,84,97,111,164,202,227$ & um-me-da lugal .... \\
\hline 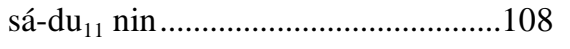 & um-mi-a.............. \\
\hline
\end{tabular}




\begin{tabular}{|c|c|}
\hline 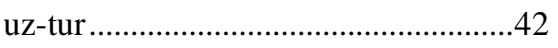 & zara $_{6}$ \\
\hline 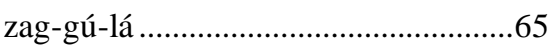 & 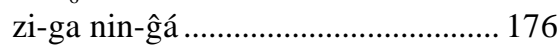 \\
\hline
\end{tabular}

Texte

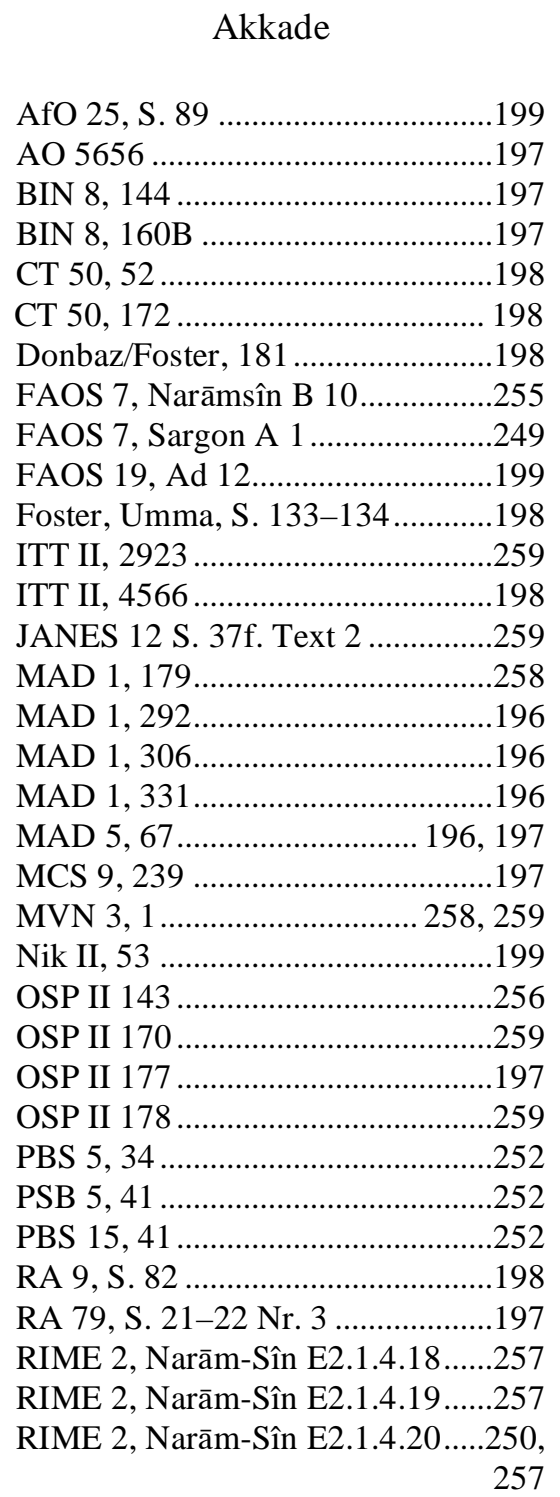

RIME 2, Narām-Sîn E2.1.4.33 .... 250, 255

RIME 2, Narām-Sîn E2.1.4.34 ..... 255

RIME 2, Narām-Sîn E2.1.4.51 ..... 255

RIME 2, Narām-Sîn E2.1.4.52 ..... 256

RIME 2, Narām-Sîn E2.1.4.2017.256

RIME 2, Narām-Sîn E2.1.4.2018. 255

RIME 2, Naram-Sîn E2.1.4.2019. 255

RIME 2, Narām-Sîn E2.1.4.2020. 255

RIME 2, Sagron E2.1.1.16 ........... 249

RIME 2, Sargon E2.1.1.2001 ....... 196

RIME 2, Sargon E2.1.1.2003 ....... 251

RIME 2, Sargon E2.1.1.2003-2005

RIME 2, Sargon E2.1.1.2005 ........251 249
RIME 2, Šar-kali-šarrī E2.1.5.2001

.............................................. 197

RIME 2, Šar-kali-šarrī E2.1.5.20012003 ..................................... 196

RTC 133 .......................................... 197

RTC 133b....................................... 258

RTC 134b....................................... 198

RTC 135b........................................ 198

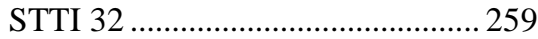

Tutub, Nr. 32 .................................. 196

Tutub, Nr. 63 ........................ 196, 197

Yang, Adab A 1034 ....................... 95

Ebla

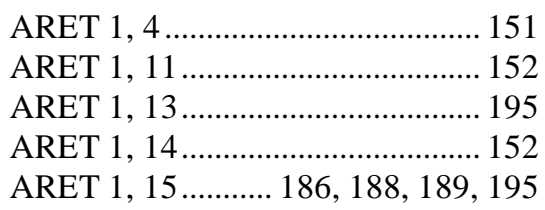




ARET 1, 16

MEE 5, 22 ..................................... 246

MEE 7, 24 ....................152, 190, 195

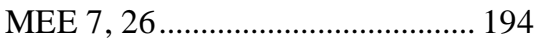

MEE 7, 27 ................................... 152

MEE 7, 34 ...................151, 191, 195

MEE 7, 44 ...................................... 191

MEE 7, 47 ..................................... 150

MEE 10, 5.................................. 152

MEE 10, 20..................150, 192, 246

MEE 10, 29........................... 186, 192

MEE 10, 41 ..................247, 248, 249

MEE 10, 44 .................................... 152

MEE 12, 5 .................................... 192

MEE 12, 26.................................. 192

MEE 12, 35 ........................ 152, 192

MEE 12, 41 .................................... 192

TM.75.G.1335 ….............................. 190

TM.75.G.1464 .................................. 193

TM.75.G.1743 _.................................. 194

TM.75.G.1770 .................................. 190

TM.75.G.1793 _................................. 246

TM.75.G.1890 ….............................. 246

TM.75.G.1896 ................................. 189

TM.75.G.2304 .................................. 193

TM.75.G.2328 ................................. 246

TM.75.G.2331 ................................... 194

TM.75.G.2340 _............................... 193

TM.75.G.2417 ………...................... 186

TM.75.G.2507 ................................. 189

TM.75.G.2551 ................................. 248

TM.75.G.2646+_.................... 193, 194

TM.75.G.10074 _................................ 193

TM.75.G.10088+ 10182 ............... 153

TM.75.G.10127 …............................ 193

TM.75.G.10150 .............................. 246

TM.75.G.12448+................. 193, 194

\section{Ur III}

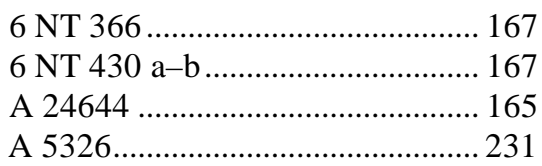


AAICAB I/1, Pl. 139 Ashm. 1971346. 207

AAICAB I/1, Pl. 40 Ashm. 1911-230 211

AAICAB I/1, Pl. 78 Ashm. 19241706 65

AAICAB I/2, Pl. 96 Ashm. 1935-554 293

AAICAB I/2, Pl. 97 Ashm. 1935-561 291

AAICAB I/2, Pl. 106 Ashm. 1937-70 148

AAICAB I/2, Pl. 114 Ashm. 1937635 104

AAICAB I/2, Pl. 118 Ashm. 1954208 244

AAICAB I/2, Pl. 121 Ashm. 19671497 112,114

AAICAB I/2, Pl. 139; Ashm 1971346 239

AAICAB I/2, Pl. 140 Ashm. 1971351 209,233

AAS 152 176,178

AfO 40/41, S. 52 Nr.1. .291

Akkadica 78, S. 13 155

Amherst 28 .222

AnOr 1, 1 .279

AnOr 1, 2 $98,99,290$

AnOr 1, 24 .282

AnOr 1, 234 148

ArOr 25, S. 562 Nr. 23 . 66,92

ArOr 62, S. 240, I 870 25,26

ARRIM 2, S. 3 231,240

ASJ 2, S. 31 Nr. 87 .222

ASJ 3, S. 86 107

ASJ 3, S. 91 $155,162,235$

ASJ 3, S. 92 .165

ASJ 4, S. 64 Nr. 1 . .77

ASJ 4, S. 65 Nr. 5 .42

ASJ 4, S. 133-134 Nr. 3 ...... 204, 209, 213,229

ASJ 4, S. 140 Nr. 1 $131,148,161$ ASJ 4, S. 141 Nr. 5 .210 ASJ 4, S. 141 Nr. 6 230 ASJ 4, S. 142 Nr. 7 ASJ 4, S. 142 Nr. 8 160,163 .170
ASJ 7, S. 123 Nr. 19 127

ASJ 9, S. 126 Nr. 57.....223, 224, 236

ASJ 9, S. 126, 57 265

ASJ 9, S. 270 Nr. 77 109

ASJ 9, S. 316 Nr. 6 ............................ 50

ASJ 9, S. 318 Nr. 12 ..................... 287

ASJ 11, S. 129 Nr. 59 ...222, 224, 236

ASJ 17, S. 317 104

ASJ 18, S. 223 107

ASJ 18, S. 228 107

ASJ 19, S. 20723 227

AUCT I, 32 161

AUCT I, 65 204

AUCT I, 79 163,210

AUCT I, 89 286, 289

AUCT I, 110 118,119

AUCT I, 159 163

AUCT I, 162 163,210

AUCT I, 265 173,174

AUCT I, 287 213, 217

AUCT I, 312 181

AUCT I, 380 223

AUCT I, 399 112

AUCT I, 407 163

AUCT I, 431 203

AUCT I, 479

AUCT I, 537 144, 147

AUCT I, 695 216

AUCT I, 881 295

AUCT I, 952 41, 280, 283, 288

AUCT I, 960

AUCT I, 967 72

AUCT II, 82 104

AUCT II, 97 181

AUCT II, 99 26,27

AUCT II, 114 $111,115,126$

AUCT II, 118 115

AUCT II, 152 218

AUCT II, 170

AUCT II, 238

AUCT III, 99

AUCT III, 208

AUCT III, 294

AUCT III, 321

AUCT III, 322

AUCT III, 326 $107,110,111,112$ .121, 128 133 144 166 263 208 208 244 


\begin{tabular}{|c|c|}
\hline AUCT III, 412 ......................... 207, 208 & BIN III, 382 ............... \\
\hline AUCT III, 428 ................. & BIN III, 403 ............. \\
\hline AUCT III, 489 ..................... 217, 274 & 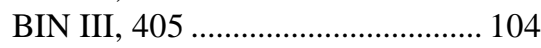 \\
\hline 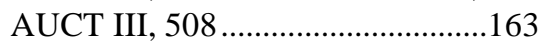 & BIN III, 409 ........ 203, 280, 282, 287 \\
\hline Bab 7, Pl. XIX Nr. 2 _................ 54, 91 & 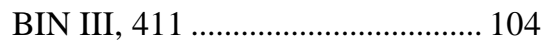 \\
\hline Bab 7, Pl. XIX Nr. 4 ...50, 51, 52, 53, & 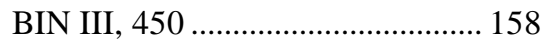 \\
\hline $89,93,294$ & BIN III, 484 ......... \\
\hline Bab 8, Pl. X HG 8 ........ & 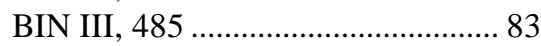 \\
\hline Bab 8, Pl. X Nr. 7 ...........................61 & BIN III, $486 \ldots \ldots \ldots \ldots \ldots . . . . . . . . . . .284,286,288$ \\
\hline Bab 8, Pupil 17....281, 282, 283, 284, & 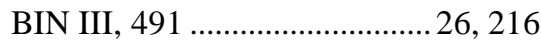 \\
\hline 285 & BIN III, $516 \ldots \ldots \ldots \ldots \ldots . . . . .116,203,205$ \\
\hline Bab 8, Pupil 30.......... & 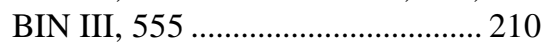 \\
\hline Barton HLC I Pl 3, HLb 17. 212, 222, & BIN III, $558 \ldots \ldots \ldots \ldots \ldots . . . . . . .143,163,227$ \\
\hline 224 & BIN III, $559 \ldots$. \\
\hline Barton HLC II Pl 82, HLb 82........148 & BIN III, $571 \ldots \ldots \ldots \ldots \ldots . . . . . . .155,156,216$ \\
\hline Barton HLC III, Pl 104, HLb 175.107 & 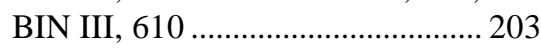 \\
\hline 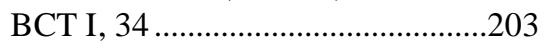 & BIN V, 4............. 219, 220, 221, 224 \\
\hline 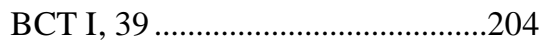 & 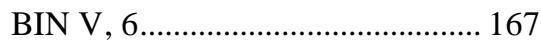 \\
\hline 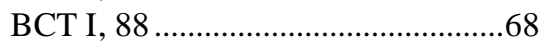 & BIN V $, 11 \ldots \ldots . .43,44,279,280,288$ \\
\hline 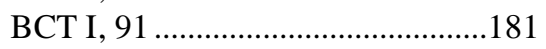 & 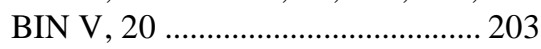 \\
\hline 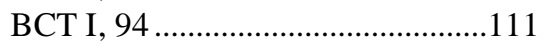 & BIN V, $31 \ldots \ldots \ldots \ldots \ldots . . . . . . . . . . . .139,141,236$ \\
\hline 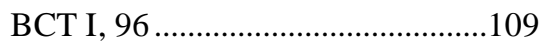 & BIN V, 55 .............................. 177, 179 \\
\hline 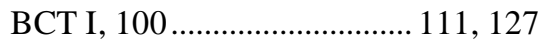 & BIN V, 57 .......................... 176, 178 \\
\hline 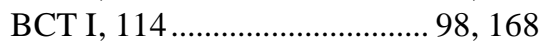 & 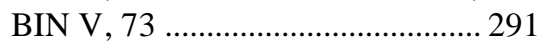 \\
\hline BCT I, $126 \ldots \ldots \ldots \ldots \ldots \ldots . . . . . . . . .108,109,185$ & 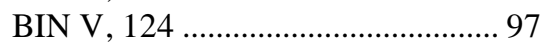 \\
\hline 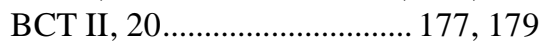 & BIN V, 127 ............................ 177, 179 \\
\hline BCT II, $246 \ldots \ldots \ldots . . .41,280,285,289$ & 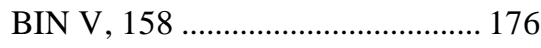 \\
\hline 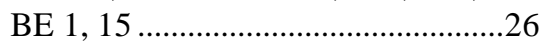 & BiOr 9, S. $173 \ldots \ldots \ldots \ldots \ldots \ldots . . . . . . . . . . . . .160,183$ \\
\hline 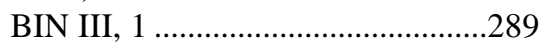 & BJRL 64, 111 Nr. $66 \ldots \ldots \ldots \ldots \ldots \ldots \ldots . . . . . . . . . . .63$ \\
\hline 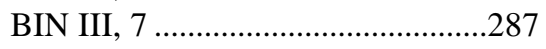 & 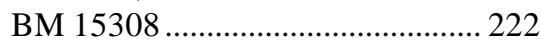 \\
\hline 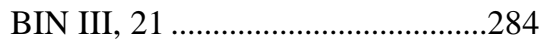 & 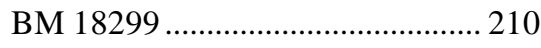 \\
\hline BIN III, $81 \ldots \ldots \ldots \ldots . . .112,115,124,126$ & 210 \\
\hline BIN III, $134 \ldots \ldots \ldots \ldots \ldots \ldots \ldots . . . . . . . . . . . . . . .230,240$ & BM $22874 \ldots \ldots \ldots \ldots \ldots \ldots \ldots \ldots . . . . . . .14,149,169$ \\
\hline 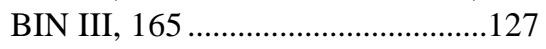 & BM $24954 \ldots \ldots \ldots . .$. \\
\hline 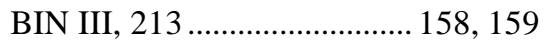 & 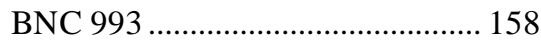 \\
\hline BIN III, $215 \ldots \ldots \ldots \ldots \ldots . . . . . .137,138,146$ & 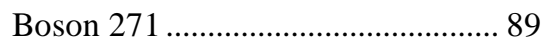 \\
\hline 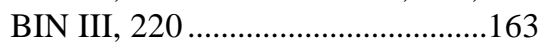 & Boson $328 \ldots \ldots \ldots \ldots \ldots \ldots . . . . .216,225,233$ \\
\hline 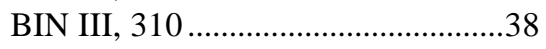 & 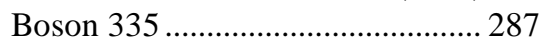 \\
\hline BIN III, $335 \ldots \ldots \ldots . .284,285,286,288$ & Boson 337 .......................................... 71 \\
\hline 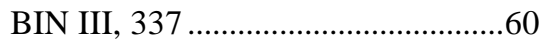 & Boson $358 \ldots \ldots \ldots \ldots . . . .41,43,279,288$ \\
\hline 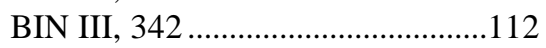 & 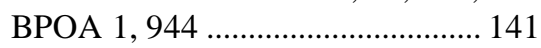 \\
\hline BIN III, 347 ............67, 98, 279, 281 & 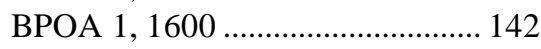 \\
\hline 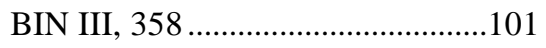 & 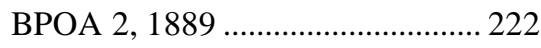 \\
\hline BIN III, $360 \ldots \ldots \ldots . . .36,280,283,284$ & Buccellati, Amorites, Pl. X, Nr 21118 \\
\hline 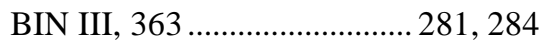 & Contenau, Umma 70 ..................... 212 \\
\hline BIN III, $366 \ldots \ldots \ldots \ldots \ldots \ldots . . . . . . . . . . .50,89,293$ & Cornell 98-12-009............... 161, 183 \\
\hline
\end{tabular}




\begin{tabular}{|c|c|}
\hline Cornell 99-14-036 .............. 161, 183 & DCS $53 \ldots$ \\
\hline Cornell 99-15-143:2 . & DPOA E1, 27. \\
\hline CST 41 ............................. 71, 92 & DPOA E1, $37 \ldots \ldots$. \\
\hline CST $42 \ldots \ldots . .33,38,43,279,281,288$ & DPOA E1, $81 \ldots \ldots$ \\
\hline 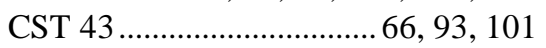 & Fales, Prima dell'alf., 17. \\
\hline 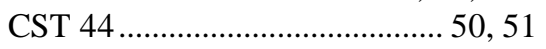 & 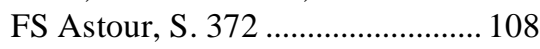 \\
\hline CST $45 \ldots .$. & FS Jones, S. 69 . \\
\hline CST $46 \ldots \ldots \ldots \ldots \ldots . . .281,282,283,284$ & FS Levine, S. 132-138 ................... 8 \\
\hline 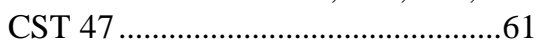 & 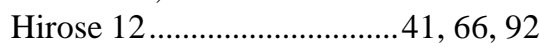 \\
\hline CST 48 & Hirose $13 \ldots$ \\
\hline 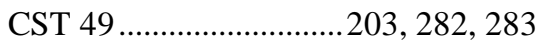 & Hirose $14 \ldots \ldots \ldots$. \\
\hline 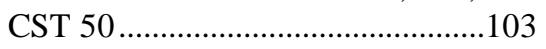 & Hirose $15 \ldots \ldots$. \\
\hline 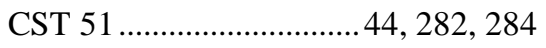 & Hirose $16 \ldots$ \\
\hline 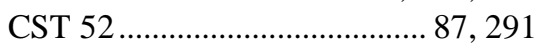 & Hirose $17 \ldots \ldots \ldots \ldots$ \\
\hline CST $115 \ldots \ldots \ldots \ldots \ldots \ldots \ldots \ldots . . . . . . . . . . .116,184,202$ & Hirose $18 \ldots \ldots$ \\
\hline 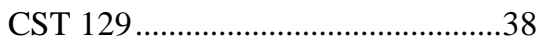 & 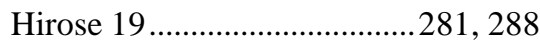 \\
\hline 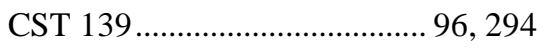 & Hirose $22 \ldots \ldots \ldots \ldots . . . . . .$. \\
\hline CST $157 \ldots \ldots \ldots . . .$. & Hirose $179 \ldots$. \\
\hline 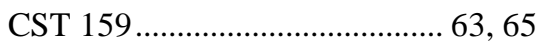 & 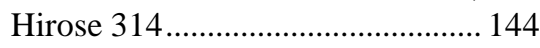 \\
\hline 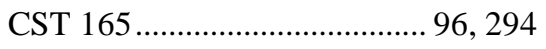 & Hirose $331 \ldots \ldots . .$. \\
\hline 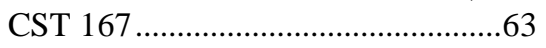 & ITT II, $628 \ldots \ldots \ldots \ldots \ldots . . . . . . . . . . . . .148,169,23$ \\
\hline 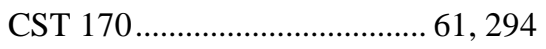 & 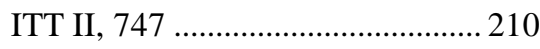 \\
\hline 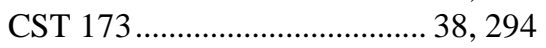 & ITT II, $752 \ldots \ldots \ldots \ldots . . . .$. \\
\hline 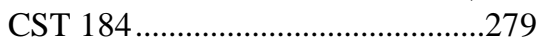 & 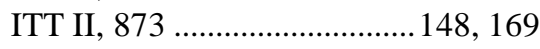 \\
\hline 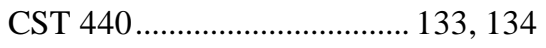 & ITT II, $896 .$. \\
\hline 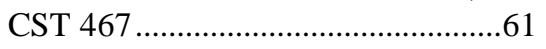 & 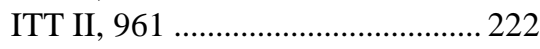 \\
\hline 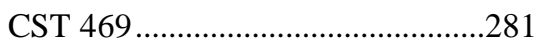 & 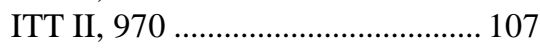 \\
\hline 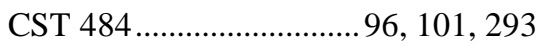 & ITT II, $3802 \ldots \ldots$ \\
\hline 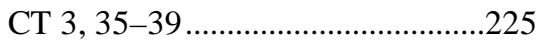 & 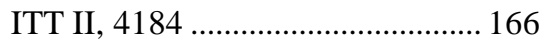 \\
\hline 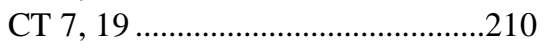 & 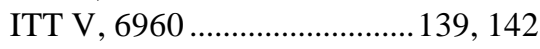 \\
\hline 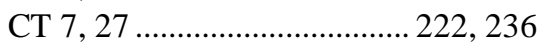 & ITT V, $9193 \ldots \ldots \ldots \ldots \ldots . . . . . . . . . .148,149,16$ \\
\hline 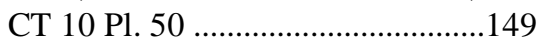 & 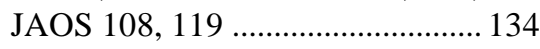 \\
\hline 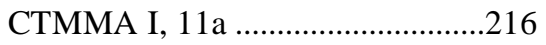 & JCS 10, S. 22 Nr. $11 \ldots \ldots \ldots \ldots . . .116,18$ \\
\hline CTMМА I, $17 \ldots . . .114,117,172,223$, & JCS 10, S. 30 Nr. 10 ....................... 11 \\
\hline $229,234,265$ & JCS 17, S. 32 ................................. 13 \\
\hline 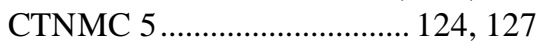 & JCS 28, S. $171 \ldots \ldots \ldots \ldots$ \\
\hline CTNMC 9............61, 64, 65, 86, 92 & JCS 29, S. 117 Nr. 144, 283, 285, 28 \\
\hline 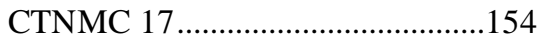 & JCS 31, S. 133 .................................. 3 \\
\hline 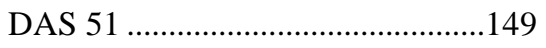 & JCS 31, S. 172 C............116, 184, 20 \\
\hline DCEPHE $259 \ldots \ldots \ldots \ldots \ldots \ldots . . . . .112,127$ & JCS 31, S. 175 G ..................205, 20 \\
\hline 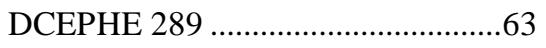 & 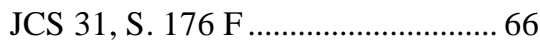 \\
\hline DCEPHE 293 ..................................50 & JCS 35, S. 183 Nr. $1 \ldots \ldots .80,87,89,9$ \\
\hline DCEPHE $299 \ldots \ldots \ldots \ldots . . . . .48,88,97,295$ & JCS 40, S. 244 Nr. $8 \ldots \ldots \ldots \ldots \ldots . . .67,28$ \\
\hline DCEPHE $302 \ldots \ldots \ldots \ldots . . . .282,284,285$ & JCS 52, S. 39 Nr. $35 \ldots \ldots \ldots \ldots \ldots \ldots \ldots . . . . . . . . . . . . .11$ \\
\hline 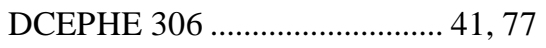 & JCS 52, S. 42 Nr. $45 \ldots \ldots$. \\
\hline DCEPHE 313 ................................... 87 & JCS 52, S. 47 Nr. $69 \ldots$ \\
\hline
\end{tabular}




\begin{tabular}{|c|c|}
\hline JCS 52, S. $128 \ldots \ldots \ldots \ldots \ldots . .81,206,291$ & MVN 8, $113 \ldots \ldots$ \\
\hline JCS 54, S. 7-9 Nr. 52 .. 114, 117, 162, & MVN 8, 115. \\
\hline 231,240 & MVN 8, $133 \ldots \ldots \ldots$ \\
\hline JEOL 26, S. 51 Nr. 13. & MVN 9, 165.112, 148, 149, 155, 163, \\
\hline JEOL 33 S. 118 Nr. 7 ....................160 & 236 \\
\hline JEOL 34, S. 28 Nr. $2 \ldots \ldots \ldots \ldots \ldots \ldots \ldots \ldots . . . .127$ & MVN $10,142 .$. \\
\hline JSOR 13, S. 179 Nr. 48 ................210 & MVN 10, $172 \ldots \ldots \ldots \ldots \ldots \ldots . . . . . . . . . .107,164$ \\
\hline 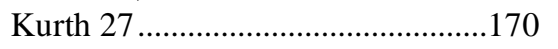 & 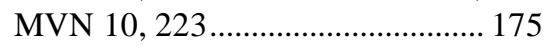 \\
\hline MTBM $257 \ldots \ldots \ldots \ldots \ldots . . .148,149,163$ & MVN 11, 146.............118, 119, 126 \\
\hline MTBM 336 ...................................169 & MVN 11, 154 ............................... 117 \\
\hline 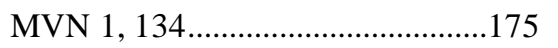 & MVN $11,183 \ldots \ldots \ldots \ldots \ldots \ldots \ldots . . . . . . . .113,238$ \\
\hline MVN 1, 135..................... 177, 179 & 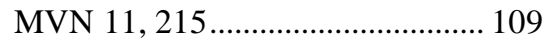 \\
\hline MVN 1, 143..................... 177, 179 & 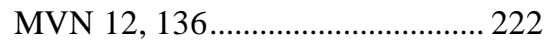 \\
\hline MVN 1, 240........................ 140, 141 & MVN $12,414 \ldots \ldots \ldots \ldots \ldots 113,173,174$ \\
\hline 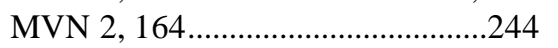 & MVN $13,98 \ldots \ldots$ \\
\hline MVN 2, $165 \ldots \ldots \ldots \ldots \ldots \ldots \ldots \ldots . . . . . . . . . . .63,80,88$ & 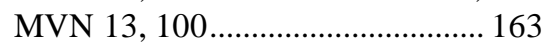 \\
\hline MVN 2, 167.. 115, 279, 283, 284, 287 & 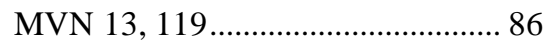 \\
\hline 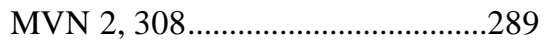 & 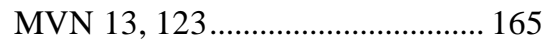 \\
\hline 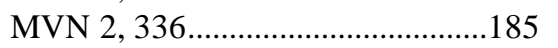 & MVN 13, $273 \ldots \ldots \ldots \ldots \ldots . . . .89,288,289$ \\
\hline MVN 3, 117............................ 36, 281 & 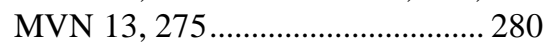 \\
\hline MVN 3, 130.......................... 31, 237 & 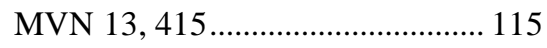 \\
\hline MVN 3, 136...............280, 282, 288 & MVN 13, 550.................... 125, 147 \\
\hline 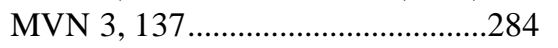 & 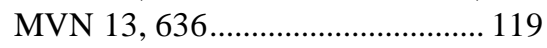 \\
\hline MVN 3, 143 ...................... 279, 285 & MVN 13, 639..................... 154, 157 \\
\hline 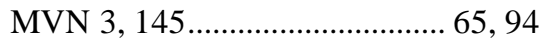 & 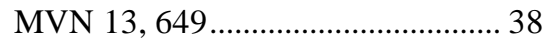 \\
\hline 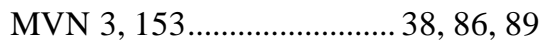 & 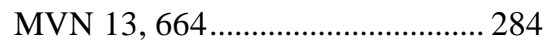 \\
\hline 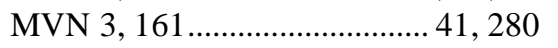 & MVN $13,675 \ldots$. \\
\hline 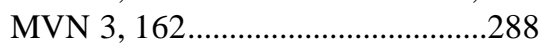 & 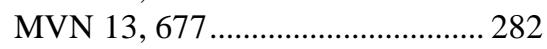 \\
\hline MVN 3, 178_...............50, 59, 93, 98 & 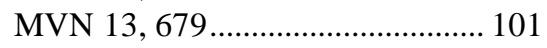 \\
\hline MVN 3, 179...............97, 279, 282 & MVN 13, 715 .........61, 87, 101, 293 \\
\hline 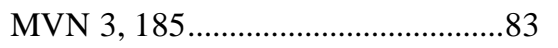 & MVN $13,794 \ldots \ldots \ldots \ldots . . .279,281,288$ \\
\hline MVN 3, 200...............280, 282, 286 & MVN 13, 820............................... 292 \\
\hline 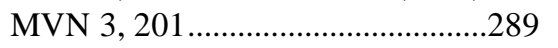 & MVN 13, 849................................. 115 \\
\hline 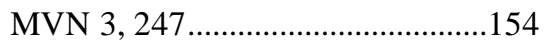 & MVN 13, 873 .............................. 281 \\
\hline 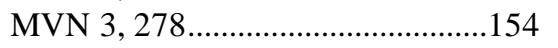 & MVN 14, 399................................. 164 \\
\hline 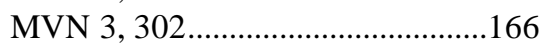 & MVN 14, 538..................... 140, 142 \\
\hline 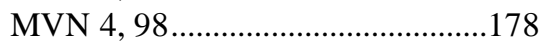 & 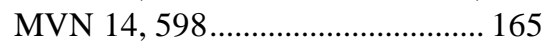 \\
\hline MVN 4, 99....................... 177, 179 & 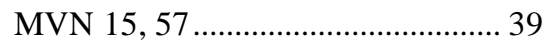 \\
\hline 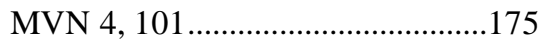 & MVN $15,91 \ldots . . \quad 219,220,224,235$ \\
\hline 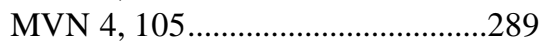 & 236 \\
\hline 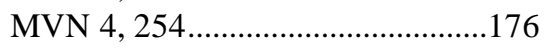 & MVN 15, 118...... 212, 213, 217, 224 \\
\hline 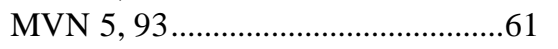 & MVN $15,162 \ldots$ \\
\hline MVN 5, 113....................................... & MVN $15,197 \ldots \ldots \ldots$. \\
\hline MVN 5, 125.........133, 134, 135, 147 & 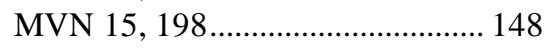 \\
\hline 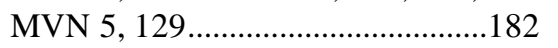 & 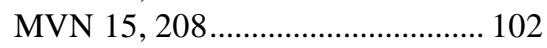 \\
\hline MVN 8, 97 ......................35, 237, 290 & MVN $15,216 \ldots$. \\
\hline
\end{tabular}




\begin{tabular}{|c|c|}
\hline MVN 15, $287 \ldots \ldots \ldots \ldots . . . .163,207,210$ & MVN 18, $63 \ldots \ldots \ldots .69,79,85,91,92$ \\
\hline MVN $15,306 \ldots \ldots$. & MVN $18,64 \ldots .$. \\
\hline MVN 15, $309 \ldots \ldots \ldots \ldots \ldots \ldots$ & MVN $18,65 \ldots$ \\
\hline MVN 15, $324 \ldots \ldots \ldots \ldots \ldots \ldots \ldots . . . . . . . . . . . .115,286$ & 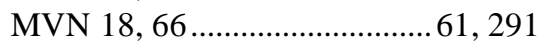 \\
\hline 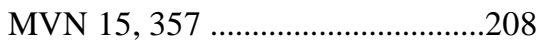 & MVN 18, $67 \ldots \ldots . .79,81,91,206,291$ \\
\hline MVN $16,713 \ldots \ldots .113,140,142,170$ & MVN 18, $68 \ldots \ldots \ldots \ldots \ldots . . . .50,51,98,99$ \\
\hline MVN 16, $796 \ldots \ldots \ldots \ldots . . .140,141,142$ & 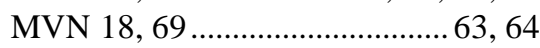 \\
\hline MVN 16, 837 ....................... 140, 142 & 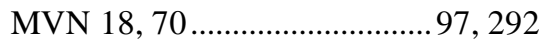 \\
\hline MVN 16, $916 \ldots \ldots \ldots \ldots . . . .139,141,165$ & 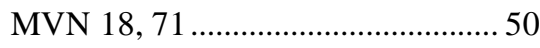 \\
\hline MVN $16,960 \ldots \ldots .91,113,140,141$ & MVN 18, $72 \ldots \ldots \ldots .38,61,62,87,293$ \\
\hline $155,157,170,236$ & MVN $18,73 \ldots . .48,59,60,80,87,93$ \\
\hline MVN $16,1012 \ldots \ldots \ldots \ldots \ldots \ldots . . . . . . . . . .154,164$ & 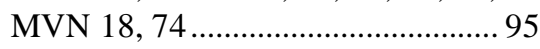 \\
\hline MVN 16, $1042 \ldots \ldots \ldots \ldots \ldots \ldots . . . . . . . . .112,164$ & MVN 18, $75 \ldots \ldots \ldots \ldots \ldots \ldots . . . . . . . . . . . .61,62,294$ \\
\hline MVN 16, $1092 \ldots \ldots .113,139,141,174$ & MVN 18, $76 \ldots \ldots \ldots \ldots \ldots \ldots . . . . . . . . . . . . .53,93$ \\
\hline MVN 16, $1268 \ldots \ldots \ldots \ldots \ldots \ldots . . . . . . . . . .154,164$ & MVN 18, $77 \ldots \ldots \ldots .51,80,87,93,294$ \\
\hline MVN $16,1330 \ldots \ldots \ldots \ldots . .140,142,170$ & MVN $18,78 \ldots \ldots \ldots \ldots$ \\
\hline MVN 16, $1370 \ldots \ldots \ldots \ldots \ldots \ldots . . . . . . . . . .112,164$ & 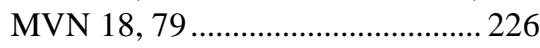 \\
\hline 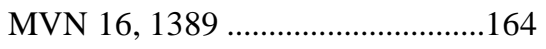 & MVN $18,80 \ldots \ldots \ldots . .$. \\
\hline MVN 16, $1428 \ldots \ldots \ldots \ldots \ldots \ldots . . . . . . . . . .108,163$ & 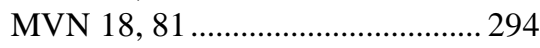 \\
\hline 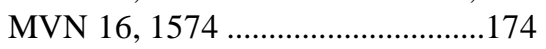 & 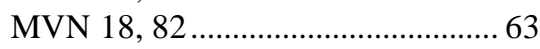 \\
\hline 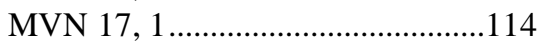 & MVN 18, $83 \ldots \ldots \ldots . .58,70,80,89,92$ \\
\hline 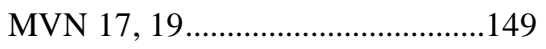 & MVN 18, $84 \ldots \ldots \ldots \ldots \ldots . . . . . .59,80,97,98$ \\
\hline MVN $18,2 \ldots \ldots .43,97,214,230,280$ & MVN $18,85 \ldots$ \\
\hline $282,283,284,285,288,289$ & 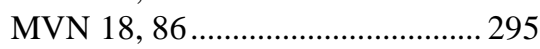 \\
\hline MVN $18,3 \ldots .279,283,284,285,288$ & 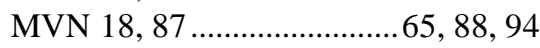 \\
\hline MVN $18,7 \ldots \ldots \ldots \ldots$ & MVN $18,88 \ldots$ \\
\hline 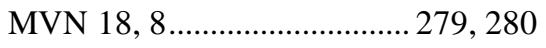 & MVN 18, $90 \ldots \ldots \ldots \ldots \ldots \ldots \ldots . . . . . . \ldots 1,63,65$ \\
\hline 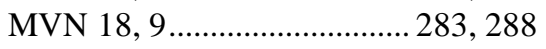 & 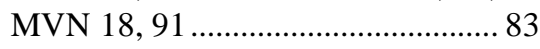 \\
\hline MVN $18,11 \ldots .43,279,282,285,286$ & MVN 18, $108 \ldots \ldots \ldots \ldots \ldots \ldots \ldots . . . . . . . . . .137,147$ \\
\hline 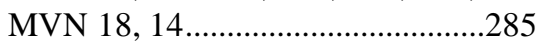 & 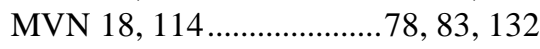 \\
\hline MVN 18, 15.....................279, 283 & 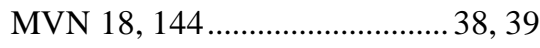 \\
\hline 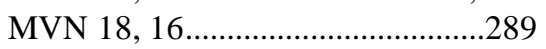 & MVN 18, $147 \ldots \ldots .279,281,282,28$ \\
\hline MVN 18, 40.........286, 287, 288, 289 & 28 \\
\hline MVN 18, 42...........39, 282, 283, 287 & MVN 18, $153 \ldots \ldots \ldots \ldots . . . .281,282,287$ \\
\hline MVN 18, 52..............26, 66, 68, 93 & MVN $18,155 \ldots \ldots \ldots$. \\
\hline MVN $18,53 \ldots .60,72,74,77,83,85$ & 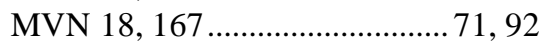 \\
\hline 93,132 & MVN 18, $235 \ldots \ldots \ldots \ldots \ldots \ldots \ldots . . . . . . . . . . . . .140,14$ \\
\hline MVN $18,55 \ldots \ldots \ldots . .$. & MVN 18, $241 \ldots \ldots \ldots \ldots \ldots \ldots . . . . . . . . . . .139,142$ \\
\hline 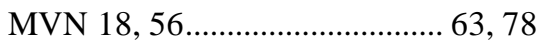 & 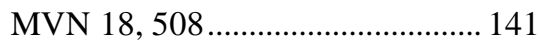 \\
\hline MVN $18,57 \ldots \ldots \ldots \ldots \ldots \ldots . . . . . . . .60,83,132$ & MVN $20,31 \ldots 82,134,135,136,14$ \\
\hline MVN 18, 58........................ 65, 91 & 168,20 \\
\hline MVN $18,59 \ldots \ldots \ldots \ldots \ldots \ldots \ldots . . . . . . . . . . . .60,61,73$ & MVN 22, $108 \ldots \ldots \ldots \ldots . . . .222,224,23$ \\
\hline MVN $18,60 \ldots . .72,73,75,83,87,93$ & 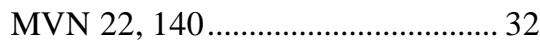 \\
\hline 132 & 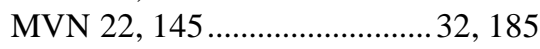 \\
\hline $61 \ldots \ldots \ldots . . . .48,7$ & NABU 1997/99.............................. 4 \\
\hline MVN $18,62 \ldots \ldots \ldots \ldots \ldots . . . .60,66,67,92$ & Nakahara 8 ............ \\
\hline
\end{tabular}




\begin{tabular}{|c|c|}
\hline Nakahara $28 \ldots$ & OIP $115,30 \ldots$ \\
\hline Nakahara $46 . . .$. & OIP $115,31 \ldots \ldots \ldots \ldots$ \\
\hline NATN 5 ............ & OIP $115,32 \ldots \ldots$ \\
\hline 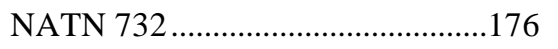 & 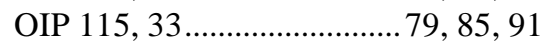 \\
\hline 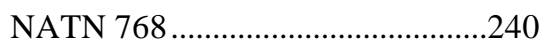 & OIP $115,34 \ldots \ldots \ldots \ldots \ldots \ldots \ldots \ldots \ldots \ldots \ldots, 59,79,92$ \\
\hline 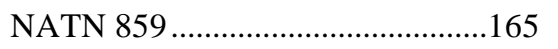 & 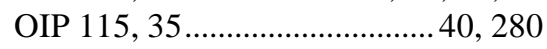 \\
\hline 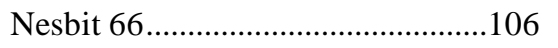 & 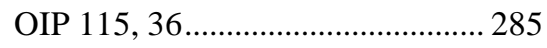 \\
\hline Newell 1600 .................................264 & OIP $115,37 \ldots \ldots \ldots \ldots \ldots \ldots \ldots . . .280,288$ \\
\hline Nik. 250 & OIP $115,38 \ldots \ldots \ldots \ldots . .41,280,282,283$ \\
\hline 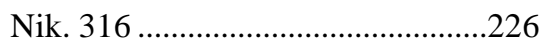 & 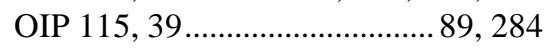 \\
\hline Nik. 484 ................................. 230, 240 & OIP $115,40 \ldots \ldots \ldots \ldots . . . .$. \\
\hline Nik. $488 \ldots \ldots \ldots \ldots \ldots . . .111,112,116,205$ & OIP $115,41 \ldots .$. \\
\hline 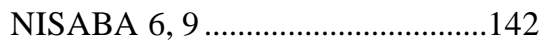 & OIP $115,42 \ldots .$. \\
\hline 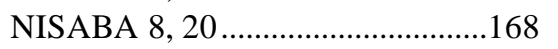 & 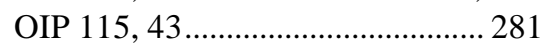 \\
\hline NISABA $8,26 \ldots \ldots \ldots \ldots \ldots \ldots . . . . . . . . . . . .120,126$ & OIP $115,44 \ldots \ldots$. \\
\hline NISABA 8, $27 \ldots \ldots \ldots \ldots \ldots \ldots . . . . . . . . . . . . . .208,226$ & 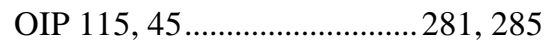 \\
\hline NISABA $8,30 \ldots \ldots \ldots \ldots \ldots \ldots \ldots . . .156,165$ & OIP $115,46 \ldots .$. \\
\hline NISABA $8,36 \ldots \ldots \ldots \ldots . . .120,124,126$ & 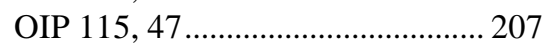 \\
\hline 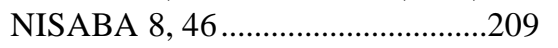 & 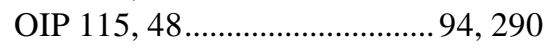 \\
\hline NISABA $8,70 \ldots \ldots \ldots \ldots . . .112,120,127$ & 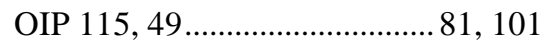 \\
\hline 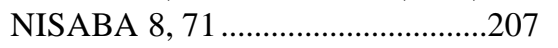 & 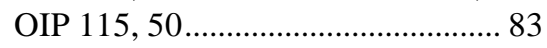 \\
\hline 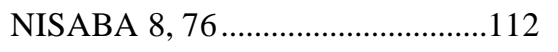 & 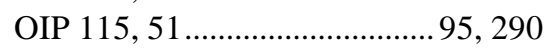 \\
\hline 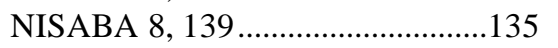 & 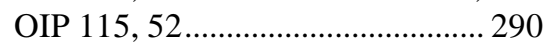 \\
\hline 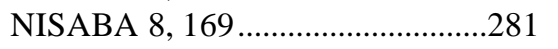 & 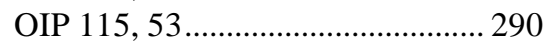 \\
\hline 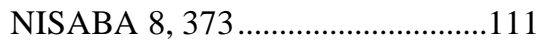 & OIP $115,54 \ldots$ \\
\hline NISABA 8, 374_................... 87, 293 & 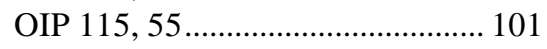 \\
\hline 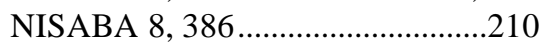 & OIP $115,56 \ldots \ldots \ldots \ldots \ldots . . . .95,98,99,290$ \\
\hline 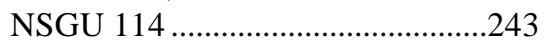 & 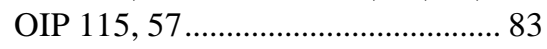 \\
\hline OIP $115,6 \ldots \ldots \ldots \ldots \ldots \ldots \ldots \ldots \ldots \ldots \ldots \ldots \ldots \ldots . . .203$ & OIP $115,58 \ldots \ldots . .95,98,99,209,291$ \\
\hline OIP $115,10 \ldots \ldots \ldots \ldots \ldots . . . . . . .116,204,205$ & 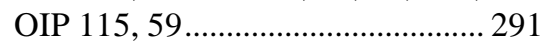 \\
\hline 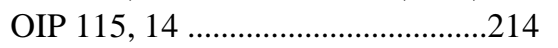 & OIP $115,60 \ldots \ldots \ldots \ldots \ldots \ldots . . . .101,214,291$ \\
\hline OIP $115,16 \ldots .36,67,229,230,281$ & 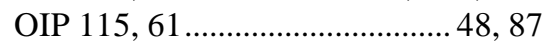 \\
\hline $283,285,288,289$ & OIP $115,62 \ldots \ldots \ldots \ldots . . .61,66,67,87,93$ \\
\hline OIP $115,17 \ldots \ldots \ldots . . .36,279,281,283$ & 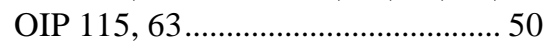 \\
\hline 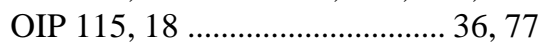 & 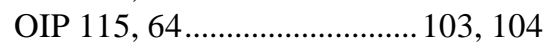 \\
\hline 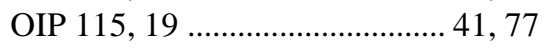 & OIP $115,65 \ldots \ldots .38,72,73,75,79,93$ \\
\hline OIP $115,20 \ldots \ldots \ldots \ldots \ldots \ldots \ldots \ldots \ldots \ldots \ldots . . .77$ & 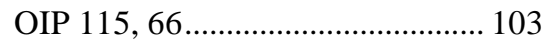 \\
\hline OIP $115,21 \ldots \ldots \ldots \ldots \ldots . . . . . .283,287,288$ & OIP $115,67 \ldots \ldots \ldots \ldots$ \\
\hline 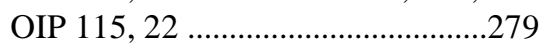 & 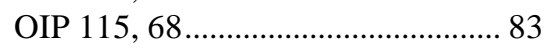 \\
\hline 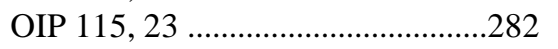 & OIP $115,69 \ldots \ldots \ldots$ \\
\hline OIP $115,24 \ldots \ldots \ldots \ldots \ldots . . . .280,282,287$ & OIP $115,70 \ldots \ldots \ldots$. \\
\hline 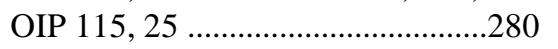 & OIP $115,71 \ldots \ldots \ldots \ldots$ \\
\hline 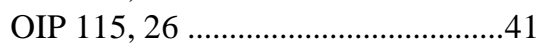 & 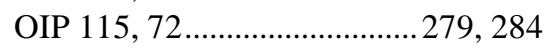 \\
\hline 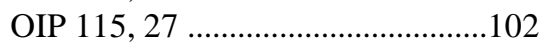 & OIP $115,74 \ldots \ldots \ldots \ldots \ldots \ldots . . . . . .44,286,289$ \\
\hline 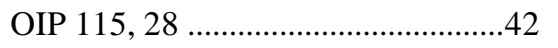 & 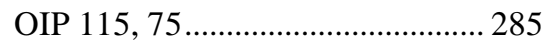 \\
\hline 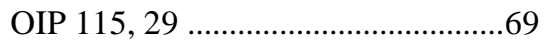 & OIP $115,76 \ldots \ldots \ldots \ldots \ldots . . .282,285,289$ \\
\hline
\end{tabular}


Indizes

\begin{tabular}{|c|c|}
\hline 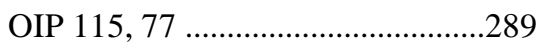 & 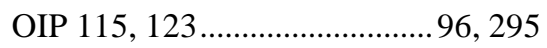 \\
\hline OIP $115,78 \ldots$ & OIP $115,125 .$. \\
\hline 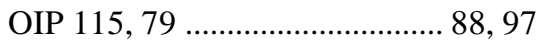 & 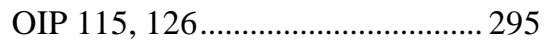 \\
\hline OIP $115,80 \ldots \ldots \ldots \ldots \ldots .61,86,93,292$ & OIP $115,127 \ldots \ldots \ldots \ldots \ldots \ldots \ldots \ldots \ldots, 83,88$ \\
\hline 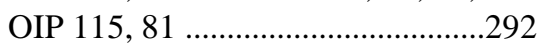 & OIP $115,128 \ldots \ldots \ldots \ldots$ \\
\hline OIP $115,82 \ldots \ldots \ldots \ldots \ldots . . .61,62,97,292$ & 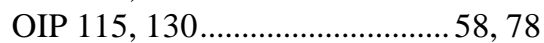 \\
\hline 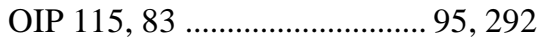 & OIP $115,131 \ldots \ldots \ldots \ldots \ldots \ldots \ldots$ \\
\hline 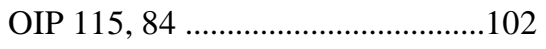 & 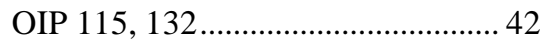 \\
\hline 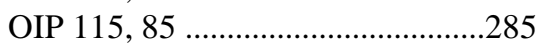 & 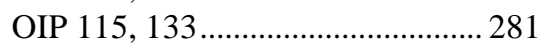 \\
\hline 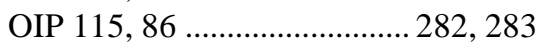 & 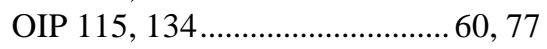 \\
\hline 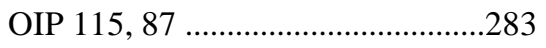 & 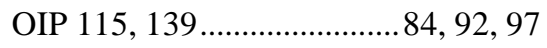 \\
\hline 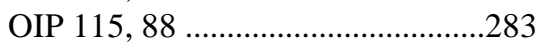 & OIP $115,199 \ldots \ldots \ldots \ldots \ldots . . . . .185,209,233$ \\
\hline OIP $115,89.115,281,285,287,288$ & 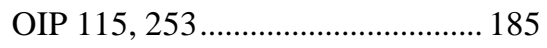 \\
\hline OIP $115,90 \ldots \ldots \ldots . .280,283,284,286$ & 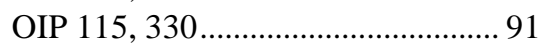 \\
\hline 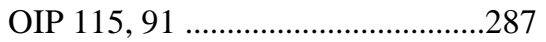 & OIP $115,367 \ldots \ldots \ldots \ldots \ldots \ldots \ldots . . . . . . . . . . . . .104,105$ \\
\hline 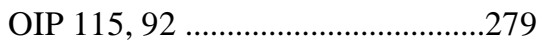 & OIP 115, 368 \\
\hline 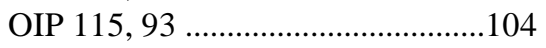 & 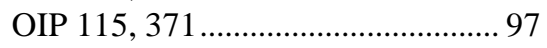 \\
\hline 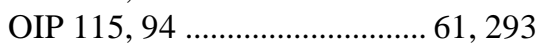 & 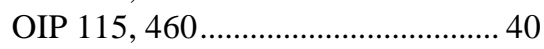 \\
\hline 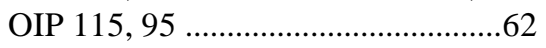 & OIP $121,9 \ldots \ldots \ldots \ldots . .112,118,119,265$ \\
\hline 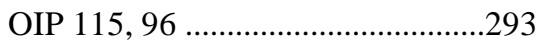 & OIP $121,11 \ldots \ldots \ldots \ldots \ldots \ldots \ldots \ldots \ldots \ldots \ldots 11,116,184$ \\
\hline OIP $115,97 \ldots \ldots \ldots \ldots \ldots \ldots \ldots \ldots \ldots \ldots . . .293$ & 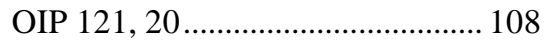 \\
\hline 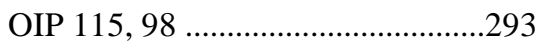 & 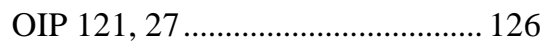 \\
\hline 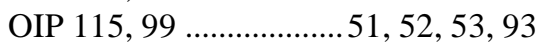 & 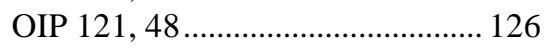 \\
\hline OIP $115,100 \ldots \ldots \ldots \ldots \ldots \ldots . . . . . . .61,87,293$ & OIP $121,164 \ldots \ldots \ldots \ldots \ldots . . . . .108,117,185$ \\
\hline OIP $115,101 \ldots \ldots \ldots \ldots \ldots . . . .80,89,293$ & OIP $121,271 \ldots$ \\
\hline OIP $115,102 \ldots \ldots \ldots \ldots \ldots \ldots \ldots \ldots . . . .89,293$ & 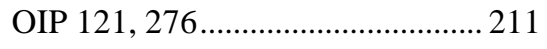 \\
\hline 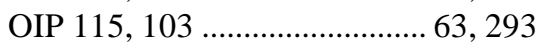 & OIP $121,283 \ldots \ldots \ldots \ldots \ldots . . .111,115,130$ \\
\hline OIP $115,104 \ldots$. & OIP $121,432 \ldots$ \\
\hline 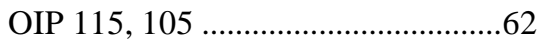 & 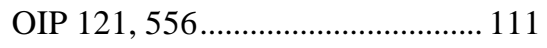 \\
\hline 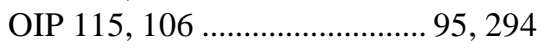 & 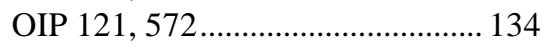 \\
\hline 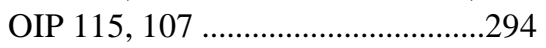 & 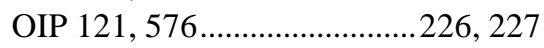 \\
\hline 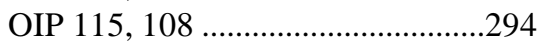 & 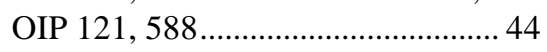 \\
\hline 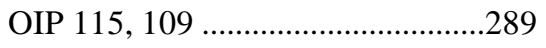 & OLP 8,7 Nr. $2 \ldots \ldots \ldots \ldots . .285,287,289$ \\
\hline 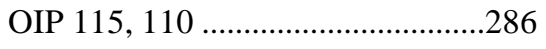 & 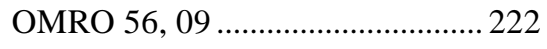 \\
\hline 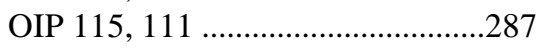 & OrAn 11, S. 273 Nr. $2 \ldots \ldots \ldots \ldots . . .61,62$ \\
\hline 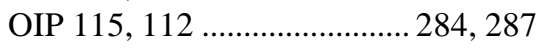 & OrAn 22, S. 203 …........................... 162 \\
\hline 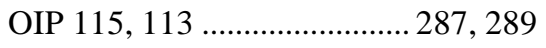 & Orient $16,3 \ldots \ldots \ldots \ldots \ldots \ldots \ldots . . .280,281$ \\
\hline OIP $115,114 \ldots \ldots \ldots \ldots \ldots \ldots \ldots \ldots \ldots \ldots \ldots \ldots \ldots \ldots \ldots \ldots \ldots \ldots \ldots . . .284$ & Orient $16,6 \ldots \ldots \ldots \ldots \ldots \ldots \ldots \ldots \ldots . . .44,285$ \\
\hline 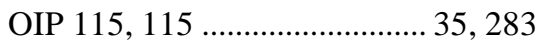 & 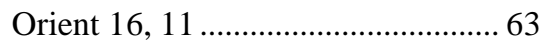 \\
\hline 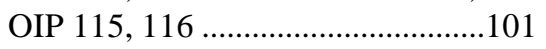 & Orient $16,16 \ldots \ldots .115,279,280,282$, \\
\hline OIP $115,117 \ldots \ldots \ldots . . . .97,98,101,294$ & $284,285,286,287$ \\
\hline 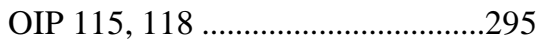 & Orient $16,28 \ldots \ldots \ldots \ldots \ldots . . . . .111,124,126$ \\
\hline 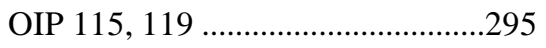 & 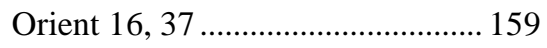 \\
\hline 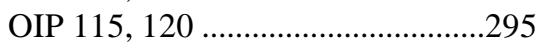 & 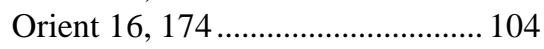 \\
\hline 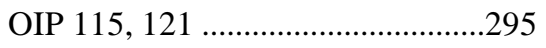 & OrNS 55, S. 134 Text $4 \ldots \ldots \ldots \ldots \ldots . . . . . . . .219$ \\
\hline OIP $115,122 \ldots \ldots \ldots \ldots \ldots . . .63,96,295$ & OrNS 55, S. 136 Text 5......... \\
\hline
\end{tabular}




\begin{tabular}{|c|c|}
\hline 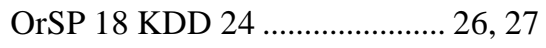 & PDT I, $610 \ldots \ldots .$. \\
\hline OrSP $18,1 \ldots \ldots \ldots \ldots \ldots \ldots . . .69,70,77,92$ & PDT I, $645 \ldots . . .48,50,55,61,89,293$ \\
\hline OrSP $18,6 \ldots \ldots \ldots . .283,285,288,289$ & 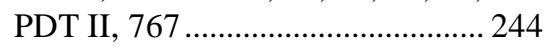 \\
\hline OrSP 18,17 .. & PDT II, $911 \ldots \ldots .$. \\
\hline 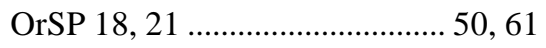 & 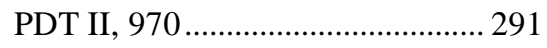 \\
\hline 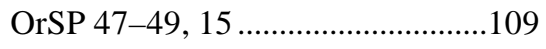 & PDT II, $973 \ldots \ldots$. \\
\hline OrSP $47-49,115 \ldots \ldots \ldots \ldots \ldots \ldots . . . . .110,116$ & PDT II, $980 \ldots \ldots \ldots \ldots \ldots \ldots \ldots$ \\
\hline PDT I, $56 \ldots \ldots \ldots \ldots \ldots . . . . . . . . . . . . .282,284,286$ & 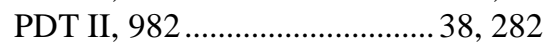 \\
\hline 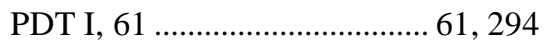 & 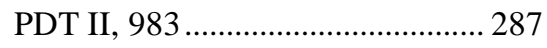 \\
\hline 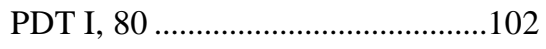 & PDT II, $993 \ldots \ldots \ldots . . . \ldots . . . . . . . . . .286,289$ \\
\hline 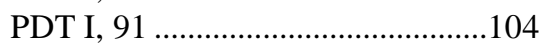 & 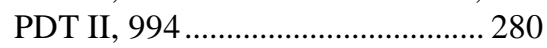 \\
\hline PDT I, 99 & PDT II, $998 \ldots \ldots .$. \\
\hline 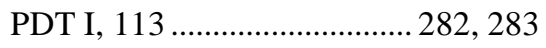 & 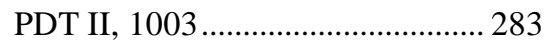 \\
\hline 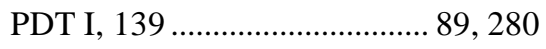 & PDT II, $1006 \ldots \ldots . .$. \\
\hline PDT I, $157 \ldots \ldots$. & PDT II, $1013 \ldots \ldots \ldots .115,285,286,289$ \\
\hline 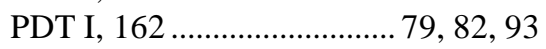 & PDT II, $1017 \ldots \ldots \ldots \ldots \ldots \ldots . . . .60,71,101$ \\
\hline 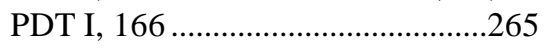 & 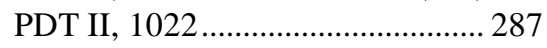 \\
\hline 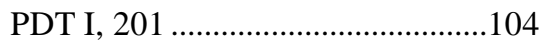 & 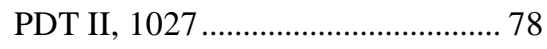 \\
\hline PDT I, $244 \ldots \ldots$. & PDT II, $1030 \ldots .$. \\
\hline PDT I, $269 \ldots \ldots$. & PDT II, $1035 \ldots \ldots$ \\
\hline PDT I, $294 \ldots \ldots \ldots \ldots \ldots \ldots \ldots \ldots . . . . . . . . . . . . . . . . .158,159$ & 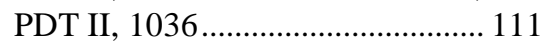 \\
\hline 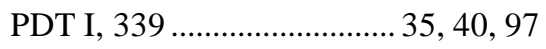 & PDT II, $1056 \ldots \ldots \ldots \ldots \ldots . . . . . .165,166,238$ \\
\hline 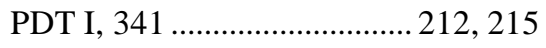 & 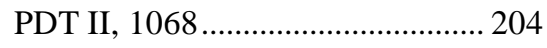 \\
\hline 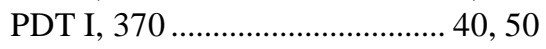 & 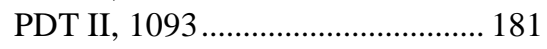 \\
\hline PDT I, $414 \ldots \ldots \ldots \ldots \ldots . . . .48,61,62,294$ & 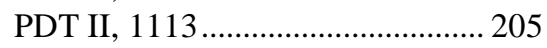 \\
\hline PDT I, $430 \ldots \ldots \ldots \ldots \ldots \ldots . . . . . . . . . . . . . . . .69,92$ & 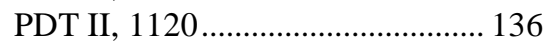 \\
\hline 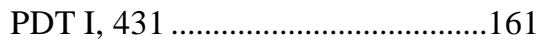 & 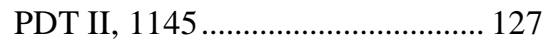 \\
\hline PDT I, $434 \ldots \ldots \ldots \ldots \ldots . . . . . . . . . . . . . . .212,214$ & 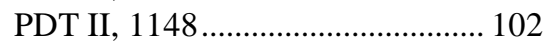 \\
\hline 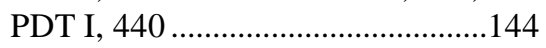 & 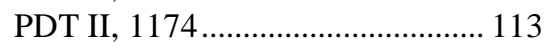 \\
\hline 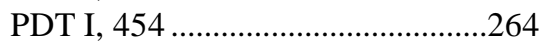 & 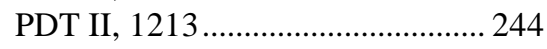 \\
\hline PDT I, $459 \ldots \ldots \ldots \ldots \ldots \ldots . . . . . . . . . . .66,67,93$ & PDT II, $1215 \ldots \ldots \ldots \ldots \ldots \ldots . . . . . . . . . . . . . . . . . .138,130$ \\
\hline 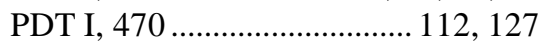 & PDT II, $1219 \ldots \ldots \ldots \ldots \ldots \ldots \ldots . . . . . . . . . . . . . .129,147$ \\
\hline PDT I, $475 \ldots \ldots \ldots \ldots . .280,281,282,287$ & 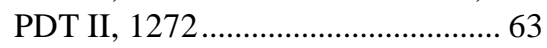 \\
\hline 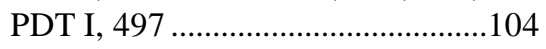 & 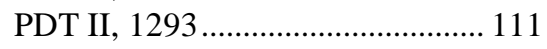 \\
\hline 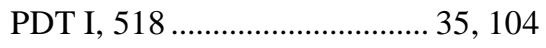 & PDT II, $1314 \ldots \ldots \ldots \ldots \ldots . . . . . . . . . . . . . . .36,37,77$ \\
\hline 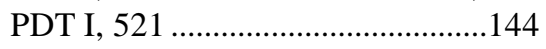 & 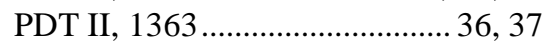 \\
\hline 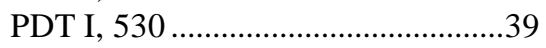 & 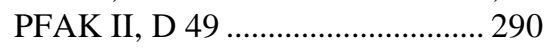 \\
\hline 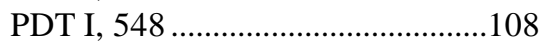 & Philips 13 ....... 32, 171, 210, 213, 229 \\
\hline 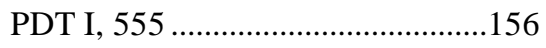 & 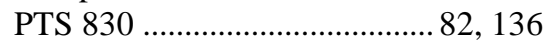 \\
\hline PDT I, $563 \ldots \ldots \ldots \ldots \ldots . . .137,164,167$ & RA 17, S. $212 \ldots \ldots \ldots \ldots \ldots \ldots . . .202,214$ \\
\hline 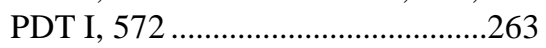 & RA 19,192 Nr. $4 \ldots \ldots \ldots . .41,78,81,91$ \\
\hline 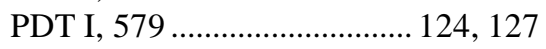 & RA 19,192 Nr. $7 \ldots . .44,285,287,288$ \\
\hline 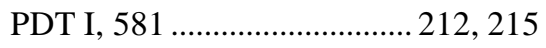 & 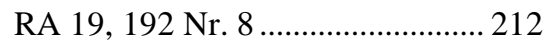 \\
\hline PDT I, $582 \ldots \ldots \ldots \ldots . . .72,74,76,93,97$ & RA 49, 86 Nr. 4 ..................283, 285 \\
\hline 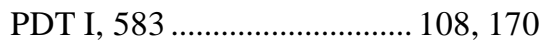 & 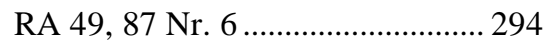 \\
\hline 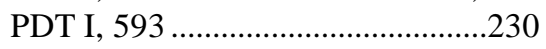 & RA 49,88 Nr. $12 \ldots$. \\
\hline
\end{tabular}


RA 73, 26 Nr. $1 \ldots . .280,282,284,285$

RA 74, 47 Nr. 116.........................204

RA 75, 94......................116, 203, 205

RA 79, 27 Nr. 22 ..........................295

RIME 3/2.1.1.51…............................25

RIME 3/2.1.1.52 .................... 29, 261

RIME 3/2.1.1.53............................29

RIME 3/2.1.1.54_............................242

RIME 3/2.1.2.62 ..............................27

RIME 3/2.1.2.66..................... 26, 180

RIME 3/2.1.2.67..................... 38, 234

RIME 3/2.1.2.68...................... 30, 31

RIME 3/2.1.2.69.................... 67, 239

RIME 3/2.1.2.70..............................39

RIME 3/2.1.2.71................................39

RIME 3/2.1.2.72 ...............................207

RIME 3/2.1.2.73 .............................208

RIME 3/2.1.2.74 ..............................208

RIME 3/2.1.2.75................... 207, 239

RIME 3/2.1.2.76_...........................208

RIME 3/2.1.2.77..............................208

RIME 3/2.1.2.78............................208

RIME 3/2.1.2.79.............................208

RIME 3/2.1.2.80 .............................208

RIME 3/2.1.2.81................... 208, 239

RIME 3/2.1.2.82 .................... 202, 203

RIME 3/2.1.2.83_................. 217, 220

RIME 3/2.1.2.84................... 218, 220

RIME 3/2.1.2.85.................... 48, 228

RIME 3/2.1.2.87.............................243

RIME 3/2.1.2.92 ............................171

RIME 3/2.1.2.93 .............................171

RIME 3/2.1.3.19...........................243

RIME 3/2.1.4.1................................264

RIME 3/2.1.4.28................... 162, 237

RIME 3/2.1.4.29................. 162, 228

RIME 3/2.1.4.32....47, 106, 108, 185, 261

RIME 3/2.1.4.33.................... 47, 108

RO 11, 96 Nr. 1...105, 279, 282, 284, $285,286,287,288,289$

Rochester 7 ........................... 137, 147

Rochester 11 .................101, 171, 291

Rochester 13 .......................................63

Rochester 22 …................... 50, 89, 97

RS 332
$50,89,97$

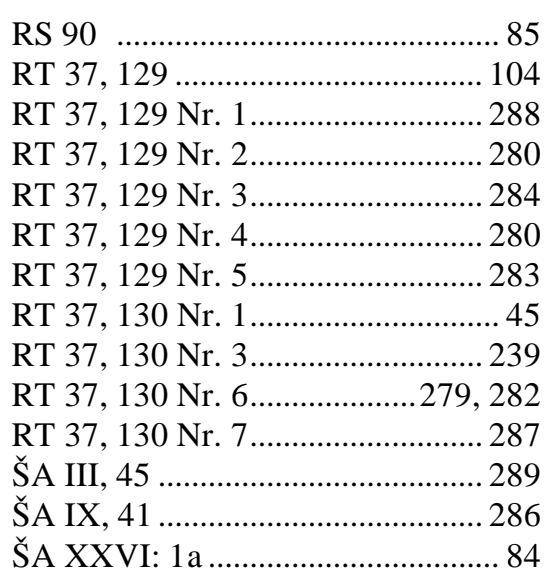

ŠA XXXIII: 1 ....................26, 61, 101

ŠA XLII: 5 ...................................... 115

ŠA LVIII: 35 ................................... 263

SACT I, 8.....................116, 184, 204

SACT I, 55 ............................ 45, 288

SACT I, 56 ................................... 289

SACT I, 57 ..................279, 282, 285

SACT I, 59................................... 279

SACT I, 60.................................... 288

SACT I, 131 ................................... 208

SACT I, 132 ..................................... 63

SACT I, 133 ..............................50, 291

SACT I, 172 ................................... 226

SACT I, 180 ..................................... 83

SACT II, 257 ................176, 177, 178

SACT II, 258 .................27, 177, 179

Santag 6, 344 ........................ 177, 178

Santag 6, 349 ....................... 177, 178

SAT I, 66 ............................112, 175

SAT I, 118 ........................... 164, 235

SAT I, 404 ............................ 173, 174

SAT II, 45 .................................... 240

SAT II, 47 ................................ 77, 90

SAT II, 48 ......................................... 240

SAT II, 55 ....................................... 240

SAT II, 69 ........................................ 240

SAT II, 107 ...................................... 102

SAT II, 153 ........................................ 50

SAT II, 226 ........................... 95, 290

SAT II, 234 ....................................... 208

SAT II, 294 .............................. 89, 280

SAT II, 309 ..................................... 216 


\begin{tabular}{|c|c|}
\hline SAT II, 312.. & SET 73 . \\
\hline 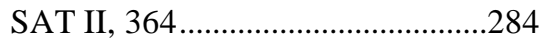 & SET 66 \\
\hline 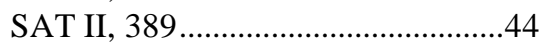 & 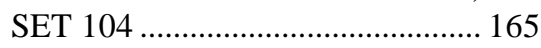 \\
\hline 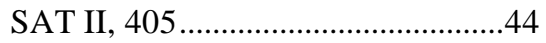 & SET $198 \ldots \ldots \ldots . . .$. \\
\hline 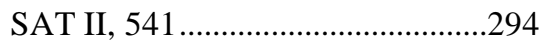 & 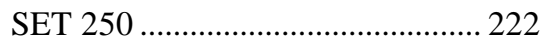 \\
\hline SAT II, $557 \ldots \ldots \ldots \ldots \ldots \ldots \ldots \ldots . . .63,80,88$ & SET $288 \ldots \ldots \ldots \ldots . . .140,141,146,236$ \\
\hline 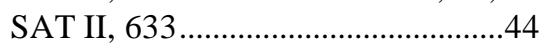 & 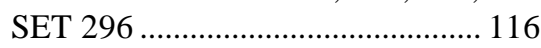 \\
\hline 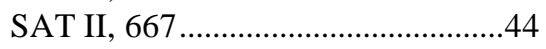 & 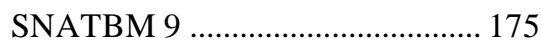 \\
\hline SAT II, $693 \ldots \ldots \ldots \ldots \ldots \ldots \ldots \ldots . . . . . . . . . . . . . . .43,146$ & SNATBM $271 \ldots \ldots \ldots \ldots \ldots \ldots . . . . . . . . . . . . . .151,157$ \\
\hline 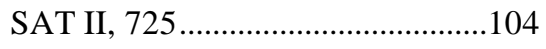 & SNATBM $422 \ldots \ldots \ldots \ldots \ldots . . . . . . . . . . . . .139,141$ \\
\hline 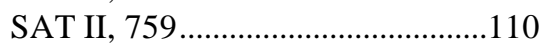 & SNATBM $436 \ldots \ldots \ldots \ldots \ldots \ldots . . . . . . . . .139,141$ \\
\hline 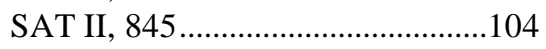 & SNATBM $481 \ldots \ldots \ldots \ldots . . . .113,139,142$ \\
\hline 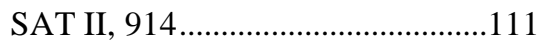 & SNATBM 499 ................................. 222 \\
\hline SAT II, $1089 \ldots \ldots \ldots \ldots \ldots . . . .111,124,127$ & SRD 5 \\
\hline SAT II, 1098 .................................... & SRD $10 \ldots \ldots \ldots \ldots \ldots \ldots \ldots \ldots \ldots \ldots \ldots \ldots \ldots \ldots \ldots \ldots . . .51,61,93$ \\
\hline SAT II, $1277 \ldots \ldots \ldots \ldots \ldots \ldots \ldots \ldots \ldots . . . . . . . . . . . . .154,155$ & 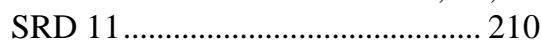 \\
\hline 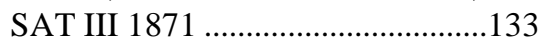 & 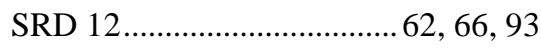 \\
\hline 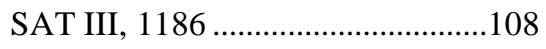 & 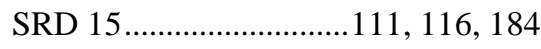 \\
\hline SAT III, $1277 \ldots \ldots .144,146,157,168$ & SRD $18 \ldots \ldots$. \\
\hline 240 & SRD $19 \ldots .$. \\
\hline 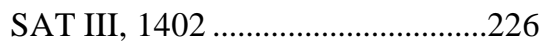 & 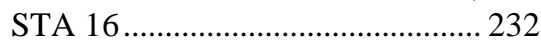 \\
\hline SAT III, 1507 ......................... 212, 222 & 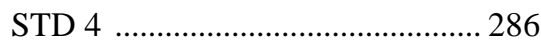 \\
\hline SAT III, $1568 \ldots \ldots \ldots \ldots \ldots \ldots \ldots . . . . . . . . . . . . . .140,142$ & StOr $9,22 \ldots \ldots \ldots \ldots . .284,285,287,289$ \\
\hline 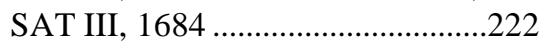 & …................ 143, 146 \\
\hline 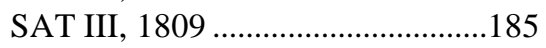 & $. .111,115,124,126$ \\
\hline 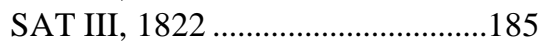 & TAD $64 \ldots \ldots \ldots \ldots \ldots . . . . . .111,115,124,126$ \\
\hline SAT III, $1861 \ldots \ldots \ldots \ldots \ldots \ldots \ldots . . . . . . . . . . . . . .160,163$ & TCL 2, 4682 ................................. 182 \\
\hline 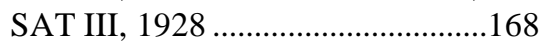 & TCL 2, 5484.................108, 117, 185 \\
\hline SAT III, $2025 \ldots \ldots \ldots \ldots . . . .164,165,166$ & 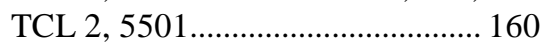 \\
\hline 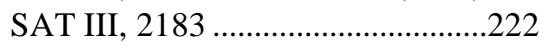 & 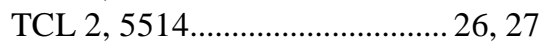 \\
\hline 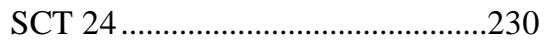 & TCL 2, 5547.................................. 162 \\
\hline 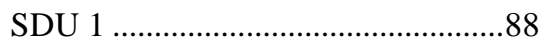 & TCL $2,5552 \ldots$. \\
\hline SDU 9 & 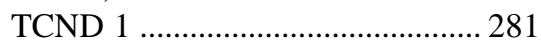 \\
\hline 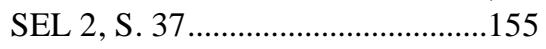 & 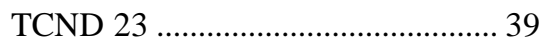 \\
\hline 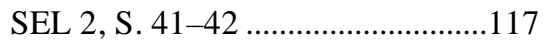 & TCND $24 \ldots \ldots \ldots \ldots . . . . .38,286,287,288$ \\
\hline SET 5 & TCND 26 \\
\hline 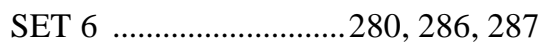 & 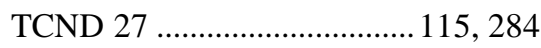 \\
\hline SET $7 \ldots \ldots \ldots \ldots \ldots . . . . . . . . . . . . .280,281,283$ & 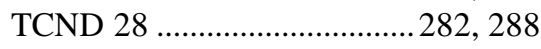 \\
\hline SET $8 \ldots \ldots \ldots \ldots \ldots . . . . . . . . . . . . . . .284, ~ 288,289$ & TCND $29 \ldots .$. \\
\hline SET $41 \ldots \ldots \ldots \ldots \ldots \ldots \ldots \ldots . . . .60,61,73,94$ & 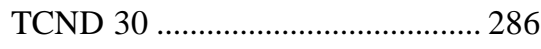 \\
\hline 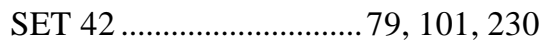 & 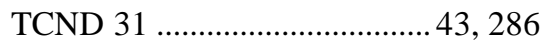 \\
\hline 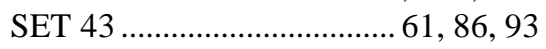 & TCND $32 \ldots \ldots \ldots \ldots \ldots . . . . . .41,67,281,285$ \\
\hline SET $44 \ldots \ldots \ldots . . .69,79,81,91,92,206$ & 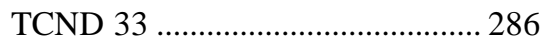 \\
\hline 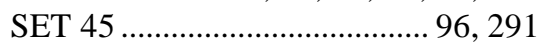 & TCND 34 ...................... \\
\hline 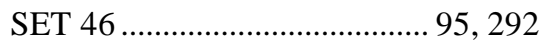 & 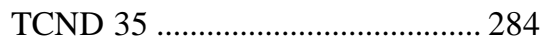 \\
\hline SET 53 .................................. 35, 295 & TCND $36 \ldots \ldots \ldots \ldots . . . .$. \\
\hline
\end{tabular}


Indizes

\begin{tabular}{|c|c|}
\hline TCND $37 \ldots .$. & TCNY $48 \ldots \ldots \ldots . . .58,59,80,92,97,98$ \\
\hline 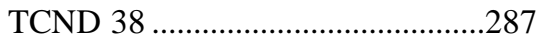 & TCNY 79.... \\
\hline TCND $39 \ldots$. & 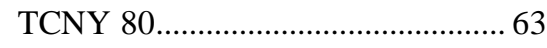 \\
\hline TCND $40 \ldots \ldots$ & 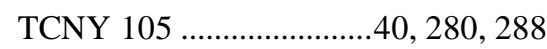 \\
\hline TCND $41 \ldots \ldots \ldots \ldots \ldots \ldots \ldots \ldots \ldots$ & TCNY $120 \ldots \ldots \ldots \ldots . . . .$. \\
\hline 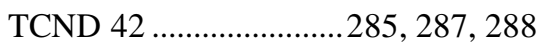 & TCNY 133 \\
\hline TCND 43 & 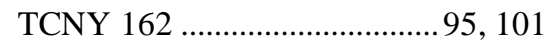 \\
\hline 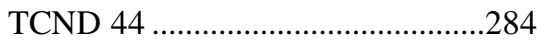 & TCNY 163 ....................................... 40 \\
\hline TCND $45 \ldots \ldots \ldots \ldots \ldots \ldots . . . . . . . . . . . .279,283,285$ & 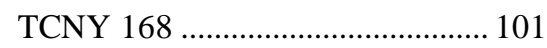 \\
\hline TCND 46 & TCNY $235 \ldots \ldots \ldots \ldots \ldots . . . . . . . . . . . . . . .1,280,288$ \\
\hline 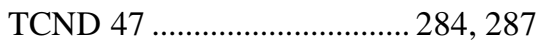 & TCNY $244 \ldots \ldots \ldots \ldots \ldots \ldots \ldots \ldots . . . . . . . . . . . . . . .144,146$ \\
\hline TCND 48 & TCNY $253 \ldots \ldots \ldots \ldots \ldots . . . . . . . . . . . . . .115,279$ \\
\hline 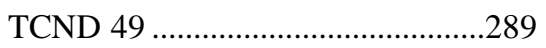 & TCNY $357 \ldots \ldots \ldots \ldots \ldots \ldots . . . .137,143,146$ \\
\hline 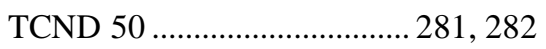 & 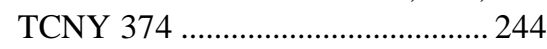 \\
\hline 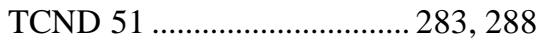 & TCS 1,4 \\
\hline 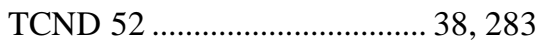 & 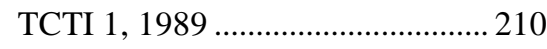 \\
\hline 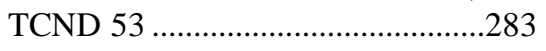 & 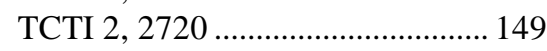 \\
\hline TCND $55 \ldots \ldots \ldots \ldots \ldots \ldots . . . . . . . . . . . . .216,225,233$ & TCTI $2,3716 \ldots$. \\
\hline 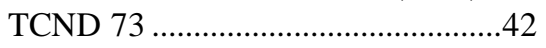 & 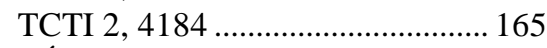 \\
\hline TCND $176 \ldots \ldots$. & 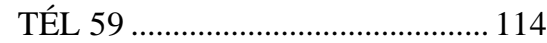 \\
\hline 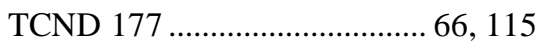 & Tel Aviv I, 56 .....................50, 54, 85 \\
\hline 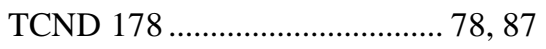 & TENS $324 \ldots \ldots \ldots \ldots \ldots \ldots . . . . . . . . . . . .102,172,173$ \\
\hline 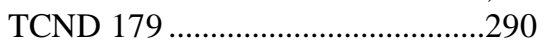 & TENS $360 \ldots \ldots \ldots \ldots \ldots$ \\
\hline 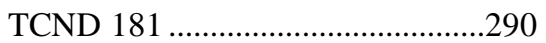 & 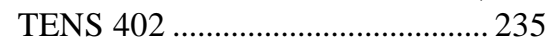 \\
\hline TCND $182 \ldots \ldots$. & TENS $443 \ldots$ \\
\hline TCND $183 \ldots \ldots$ & 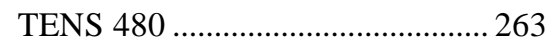 \\
\hline 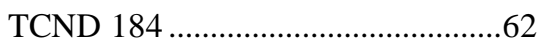 & 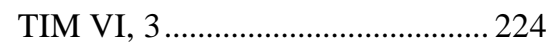 \\
\hline 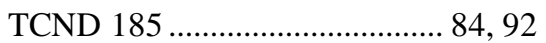 & TIM VI, $8 \ldots \ldots \ldots \ldots \ldots \ldots$ \\
\hline 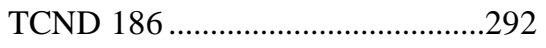 & 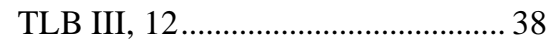 \\
\hline 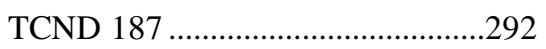 & 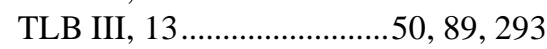 \\
\hline 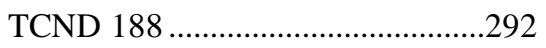 & 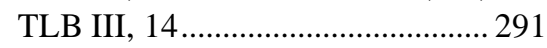 \\
\hline 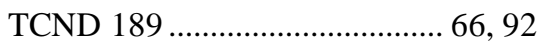 & 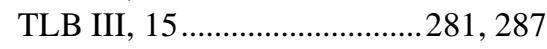 \\
\hline 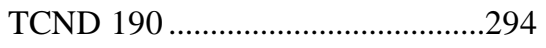 & 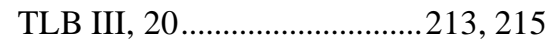 \\
\hline 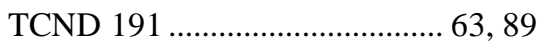 & 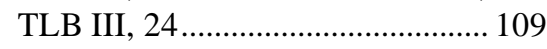 \\
\hline 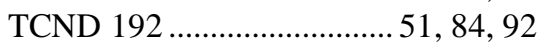 & 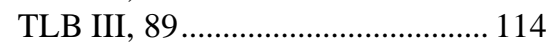 \\
\hline 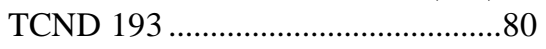 & 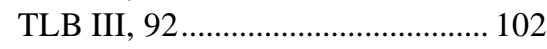 \\
\hline 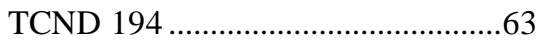 & 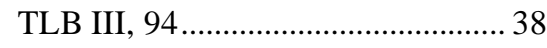 \\
\hline 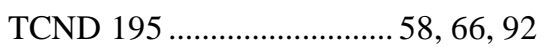 & 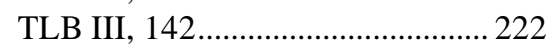 \\
\hline 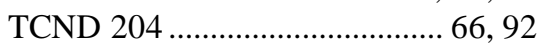 & TMH NF $1 / 2,183 \ldots \ldots \ldots \ldots \ldots . . . .212,218$ \\
\hline 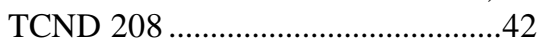 & TMH NF $1 / 2,184 \ldots \ldots \ldots \ldots \ldots . . . . .212,218$ \\
\hline 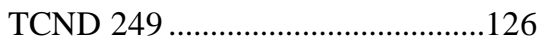 & TMH NF $1 / 2,186 \ldots \ldots \ldots \ldots \ldots . . . .212,218$ \\
\hline TCND $259 \ldots \ldots \ldots \ldots \ldots . . . . . . . . .111,116,184$ & TMH NF $1 / 2,188 \ldots \ldots \ldots \ldots \ldots . . . . .212,218$ \\
\hline 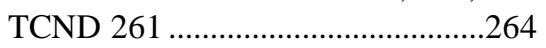 & 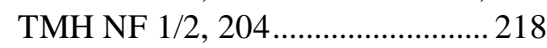 \\
\hline 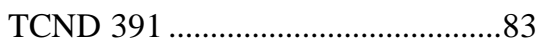 & TMH NF $1 / 2,219 \ldots \ldots \ldots \ldots \ldots . . . . .149,170$ \\
\hline 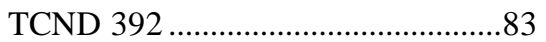 & TMH NF 1/2, 239....................... 218 \\
\hline 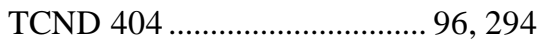 & TMH NF 1/2, Siegel $100 \ldots \ldots \ldots \ldots . . . .218$ \\
\hline
\end{tabular}




\begin{tabular}{|c|c|}
\hline Toronto 3 & TRU $77 \ldots \ldots$. \\
\hline Toronto $10 \ldots \ldots \ldots . . .103,279,281,289$ & TRU 78 . \\
\hline 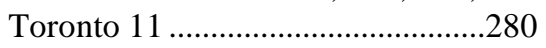 & TRU $110 \ldots$ \\
\hline Toronto $12 \ldots \ldots \ldots \ldots \ldots . . . . . .283,284,288$ & TRU $126 \ldots \ldots \ldots \ldots \ldots \ldots . . . . . . . . . . . . . .116,205,22$ \\
\hline 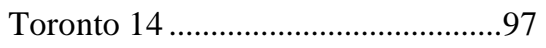 & TRU $272 \ldots . .72,74,78,82,83,87,9$ \\
\hline 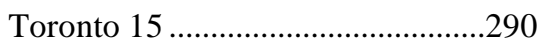 & .......... $70,79,87,9$ \\
\hline 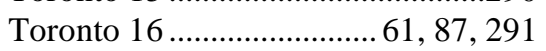 & TRU 274 \\
\hline Toronto 17 .............................. 101, 291 & 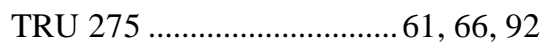 \\
\hline 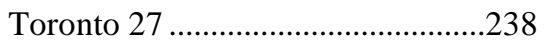 & TRU $278 \ldots \ldots \ldots \ldots \ldots \ldots \ldots . . . . . . . . . \ldots 16,184,20$ \\
\hline Toronto $48 \ldots \ldots \ldots \ldots \ldots \ldots \ldots \ldots . . . .118,119$ & TRU 280 . \\
\hline 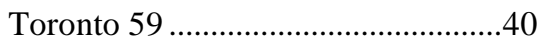 & 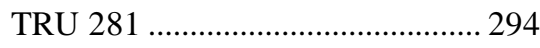 \\
\hline Toronto $75 \ldots \ldots \ldots \ldots \ldots \ldots . . . . . . . . .112,120,127$ & TRU $282 \ldots \ldots \ldots \ldots . . . .80,82,83,93,13$ \\
\hline 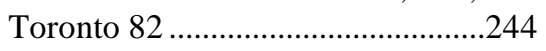 & TRU $284 \ldots \ldots . .61,62,97,98,99,29$ \\
\hline Toronto $160 \ldots \ldots \ldots \ldots \ldots \ldots \ldots . . . . . . . . . . . . . . . .133,134$ & TRU $286 \ldots \ldots \ldots . .$. \\
\hline Toronto $164 \ldots \ldots \ldots \ldots \ldots . . . . . .66,217,274$ & TRU 287 .. \\
\hline Toronto $592 \ldots \ldots$. & TRU $288 \ldots$ \\
\hline 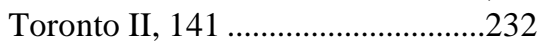 & 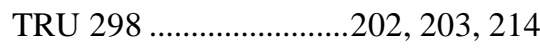 \\
\hline 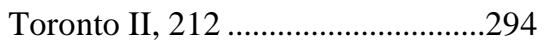 & 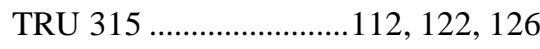 \\
\hline Toronto II, 407 ..................................114 & TUT $155 \ldots \ldots \ldots$. \\
\hline TPTS $7 \ldots \ldots \ldots \ldots \ldots \ldots \ldots \ldots . . . . . . . . . . . . .280,281,284$ & TUT $200 \ldots \ldots \ldots . . . .$. \\
\hline TPTS 8 & UCP 9/2/2, 37 . \\
\hline TPTS 9 & UCP 9/2/2, $70 \ldots \ldots \ldots \ldots \ldots \ldots . . . . . . . . . . . . . . . .280,28$ \\
\hline 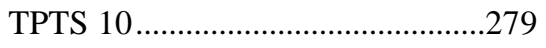 & $\ldots \ldots .44,114,23$ \\
\hline 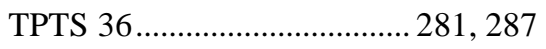 & UDT $41 \ldots \ldots \ldots \ldots . . . .$. \\
\hline 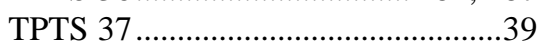 & UDT $95 \ldots \ldots \ldots \ldots \ldots \ldots \ldots \ldots \ldots . . . . . . . . . . . . . .121,124,12$ \\
\hline 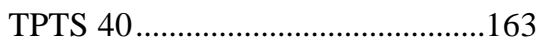 & UDT $116 \ldots \ldots \ldots . . .$. \\
\hline 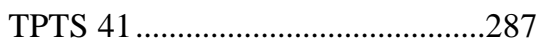 & UDT $129 \ldots \ldots \ldots \ldots$ \\
\hline 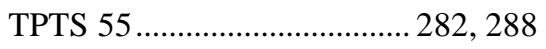 & UET $1,57 \ldots$ \\
\hline 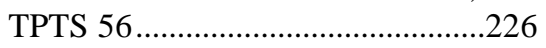 & UET $3,21 \ldots \ldots$. \\
\hline 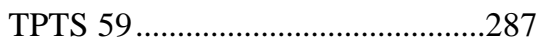 & UET $3,45 \ldots \ldots \ldots \ldots . . .$. \\
\hline TPTS $81 \ldots \ldots \ldots \ldots . . .111,115,124,126$ & UET $3,70 \ldots \ldots \ldots \ldots \ldots \ldots \ldots \ldots . . .136,17$ \\
\hline TPTS 95 & UET $3,96 \ldots \ldots \ldots \ldots \ldots \ldots \ldots . . . . . . . . .173,174,17$ \\
\hline 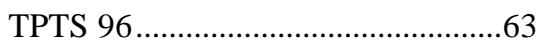 & 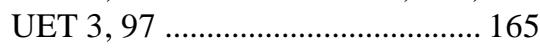 \\
\hline 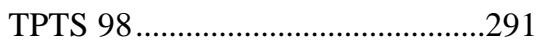 & UET 3, $99 \ldots \ldots \ldots \ldots \ldots \ldots \ldots . . . . . . . . . .173,174,17$ \\
\hline 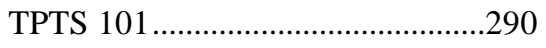 & UET $3,100 \ldots \ldots \ldots \ldots \ldots . . .173,174,17$ \\
\hline 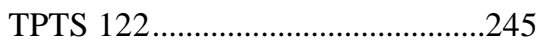 & UET $3,116 \ldots .$. \\
\hline 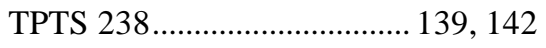 & 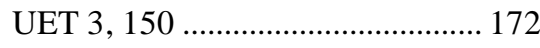 \\
\hline 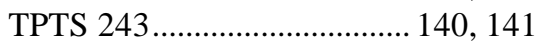 & UET $3,190 \ldots$. \\
\hline TrD 2 & UET $3,272 \ldots \ldots \ldots$ \\
\hline 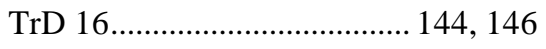 & UET 3, $289 \ldots \ldots$. \\
\hline 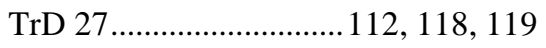 & UET $3,329 \ldots .$. \\
\hline 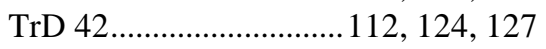 & UET $3,335 \ldots \ldots$. \\
\hline 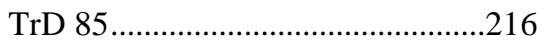 & 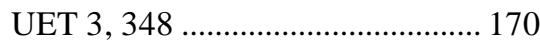 \\
\hline 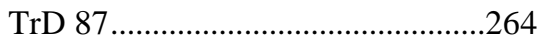 & UET $3,376 \ldots \ldots \ldots \ldots \ldots \ldots \ldots \ldots . . .165,16$ \\
\hline 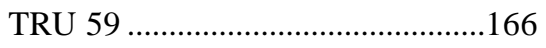 & 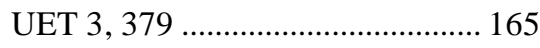 \\
\hline 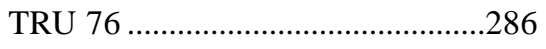 & 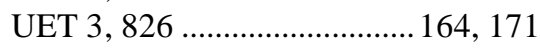 \\
\hline
\end{tabular}


Indizes

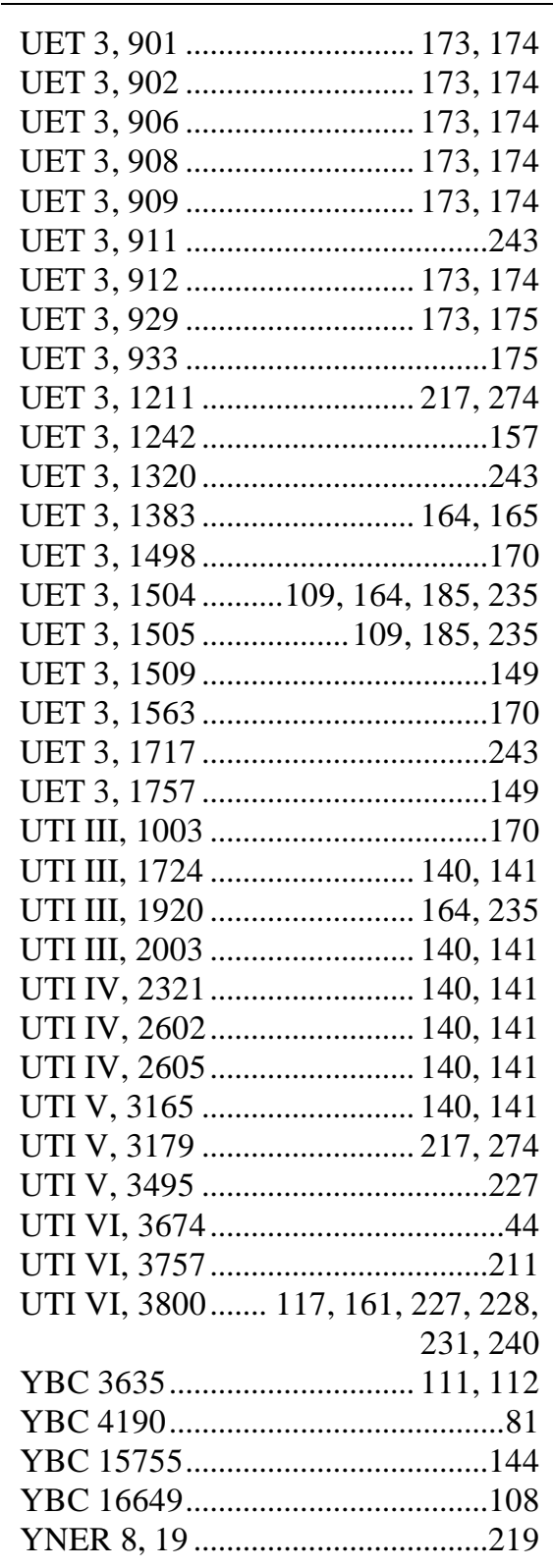

YOS 4, 79

279, 280, 284, 289

YOS 4, $240 \ldots \ldots \ldots \ldots \ldots \ldots . . . . . . . . . . .1,205,206$

YOS 18, 4 .. 81

YOS 18, 5 286

YOS 18, 6

44, 288

YOS 18, 20

112,128

YOS 18, 45

177, 179

YOS 18, 46 142

YOS 18, 47

173, 174

YOS 18, 49

177, 179

YOS 18, 50

177,179

YOS 18, 51

173

ZA 68, S. 38

117

ZA 80, S. 32

66

ZA 93, S. 58 Nr. 10 .................33, 294

ZVO 25, 134, 1 204

ZVO 25, 134, 2..... 32, 107, 130, 202,

229,275 243 149 70

UTI III, 1003 140,141

Sonstige

ARM 26.1 Nr. 13............................ 273

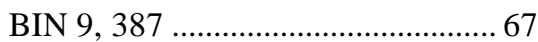

Enki und Inanna................................ 68

Gesetze von Ešnunna ..................... 172

Inanna und Ebeh............................. 250

in-nin šà-gur ${ }_{4}$-ra.............249, 250, 252

nin-me-šara ... 249, 250, 252, 253, 254

RIME 4, Rīm-Sîn I E4.2.14.20.... 245,

252

SRT 23

28,277

Šulgi B

27

Šulgi D ............................................. 155

Sumerische Tempelhymnen .......... 250

UET 1, 292 243

Ur-Nammas Tod 28,234 
$\mathrm{D}$ ie Könige der III. Dynastie von Ur (2112-2004 v.Chr.) waren stets mit mehreren Frauen gleichzeitig verheiratet, von denen jedoch nur eine Frau die Position einer Königin einnahm. Unter der großen Zahl von Wirtschaftsdokumenten dieser Zeit, die einen detaillierten Einblick in die staatliche Wirtschaft und Verwaltung geben, beziehen sich über 1000 Texte auf Transaktionen, die den Tätigkeitsfeldern der königlichen Gemahlinnen zugeordnet werden können. Alle Frauen der Herrscher von Ur waren in der Wirtschaft und Verwaltung tätig, sie waren zu verschiedenen Anlässen am Kult beteiligt und in die komplexen Strukturen des höfischen Lebens eingebunden.

In dieser Arbeit wird unter anderem den Fragen nachgegangen, in welchen Funktionen und bei welchen Tätigkeiten sich die königlichen Frauen in den Quellen nachweisen lassen und in welcher Weise sich das Aufgabenspektrum einer Königin von Ur von jenem einer Nebenfrau unterschied.

Vergleichend zur Situation der königlichen Frauen der Ur III-Zeit werden die Frauen der Herrscherhäuser im frühdynastischen Ebla und in der Akkadezeit in vier Exkursen betrachtet.

$\mathrm{D}$ ie Reihe "Göttinger Beiträge zun Alten Orient" setzt die erfolgreichen "Göttinger Arbeitshefte zur Altorientalischen Literatur" fort. Die Reihe wird vom Seminar für Altorientalistik der Georg-August-Universität Göttingen herausgegeben und behandelt die Erschließung und Deutung der reichhaltigen Schriftdenkmäler in akkadischer oder sumerischer Sprache aus der Zeit von ca. $3100-500$ v. Chr. 